\title{
WATER-RESOURCES DATA FOR THE FORT BERTHOLD INDIAN RESERVATIC N, WEST-CENTRAL NORTH DAKOTA
}

By James D. Wald and Steven W. Cates

U.S. GEOLOGICAL SURVEY

Open-File Report 95-304

Prepared in cooperation with the THREE AFFILIATED TRIBES 


\title{
U.S. DEPARTMENT OF THE INTERIOR \\ BRUCE BABBITT, Secretary
}

\author{
U.S. GEOLOGICAL SURVEY \\ GORDON P. EATON, Director
}

Any use of trade, product, or firm names is for descriptive purposes only and does not imply endorsement by the U.S. Government.

For additional information write to:

District Chief

U.S. Geological Survey Water Resources Division 821 East Interstate Avenue Bismarck, ND 58501-1199
Copies of this report can be purchased from:

U.S. Geological Survey Earth Science Information Center Open-File Reports Section Box 25286, MS 517 Denver Federal Center Denver, CO 80225 


\section{CONTENTS}

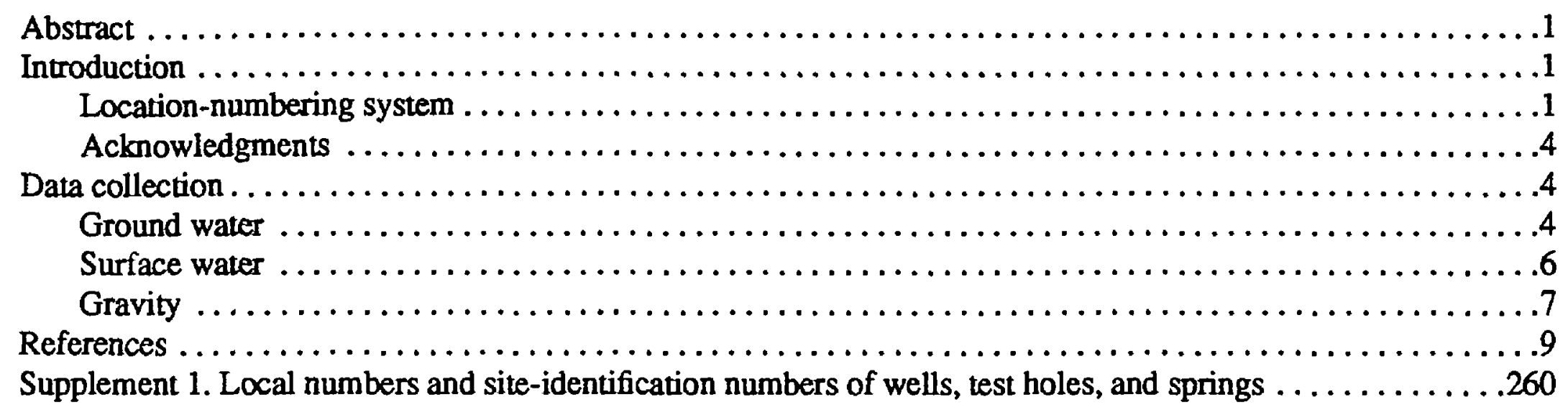

\section{PLATES}

1. Map showing locations of wells, test holes, and springs in the Fort Berthold Indian

Reservation, west-central North Dakota (in pocket)

\section{FIGURES}

1. Map showing location of the Fort Berthold Indian Reservation in west-central North Dakota ...........................2

2. Diagram showing system of numbering wells, test holes, and springs using township, range, and section and latitude and longitude

3. Map showing locations of water-level observation wells and streamflow-gaging stations..................................5

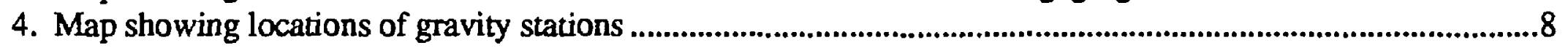

\section{TABLES}

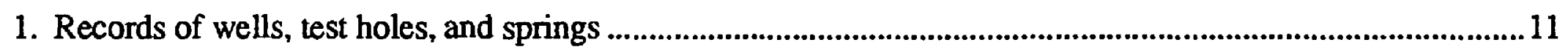

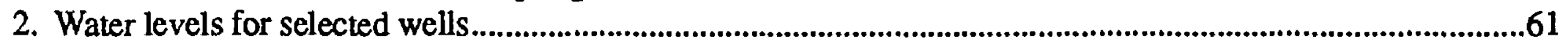

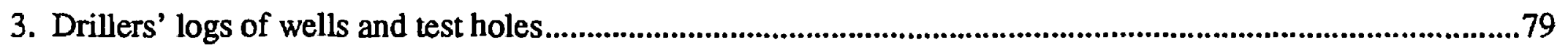

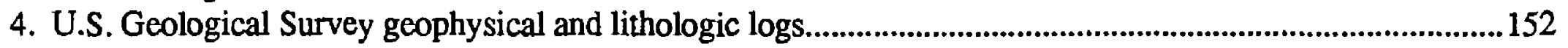

5. Physical properties and major-ion concentrations in water from wells .............................................................194

6. Trace-element concentrations in water from wells .............................................................................................213

7. Physical properties and major-ion concentrations in water from springs.........................................................222

8. Latitude, longitude, altitude, Bouguer gravity, and residual gravity values .........................................................225 


\begin{tabular}{rcl}
\hline Multlpiy & By & To obtain \\
\hline acre & 4,047 & hectare \\
cubic foot $\left(\mathrm{ft}^{3}\right)$ & 0.02832 & cubic meter \\
degree Celsius $\left({ }^{\circ} \mathrm{C}\right)$ & $(1)$ & degree Fahrenheit \\
foot $(\mathrm{ft})$ & 0.3048 & meter \\
inch $(\mathrm{in})$. & 25.4 & millimeter \\
liter $(\mathrm{L})$ & 0.2642 & gallon \\
meter $(\mathrm{m})$ & 3.281 & foot \\
micrometer $(/ \mathrm{m})$ & 0.00003937 & inch \\
milliliter $(\mathrm{mL})$ & 0.03381 & ounce \\
square mile $\left(\mathrm{mi}{ }^{2}\right)$ & 259.0 & hectare \\
\hline
\end{tabular}

${ }^{1}$ Temp ${ }^{\circ} \mathrm{F}=1.8$ temp ${ }^{\circ} \mathrm{C}+32$.

Sea level: In this report, "sea level" refers to the National Geodetic Vertical Datum of 1929 (NGVD of 1929)--a geodetic datum derived from a general adjustment of the first-order level nets of both the United States and Canada, formerly called Sea Level Datum of 1929.

Micrograms per liter $(\mu \mathrm{g} / \mathrm{L})$ is a unit expressing the concentration of a chemical constituent in solution as weight (micrograms) of solute per unit volume (liter) of water.

Microsiemens per centimeter at $25^{\circ} \mathrm{C}(\mu \mathrm{S} / \mathrm{cm})$ replaces micromhos per centimeter at $25^{\circ} \mathrm{C}$ used for specific conductance in older reports. The two units are equivalent.

Milligrams per liter $(\mathrm{mg} / \mathrm{L})$ is a unit expressing the concentration of a chemical constituent in solution as weight (milligrams) of solute per unit volume (liter) of water, $1 \mathrm{mg} / \mathrm{L}$ equals $1,000 \mu \mathrm{g} / \mathrm{L}$.

The numerical value of the acceleration of gravity at the Earth's surface is $980 \mathrm{~cm} / \mathrm{s}^{2}$ (centimeters per square second). The gal $\left(1 \mathrm{~cm} / \mathrm{s}^{2}\right)$ is the unit of acceleration of gravity and the milligal (mgal) is $1 / 1,000$ of a gal. 


\title{
WATER-RESOURCES DATA FOR THE FORT BERTHOLD INDIAN RESERVATION, WEST-CENTRAL NORTH DAKOTA
}

\author{
By James D. Wald and Steven W. Cates
}

\begin{abstract}
A study of the water resources of the Fort Berthold Indian Reservation was undertaken ti characterize the quality and quantity of ground-water and surface-water resources. The purpose of this report is to document the data-collection procedures used during the study and to present the data collected in tabular and graphical form.
\end{abstract}

Ground-water data were collected during May 1990 through November 1992. The data presented in this report include records of 1,325 wells, test holes, and springs; water-levels fcr 40 observation wells; drillers' logs for 211 wells and test holes; gamma-ray and resistivity logs for 21 test holes drilled in June 1992; water-quality data for 293 water samples from wells ant springs; and trace-element data for 225 water samples from wells.

Surface-water data were collected on Bear Den Creek, East Fork Shell Creek, Deepwater Creek, Moccasin Creek, and Squaw Creek from April 1990 through September 1992. Initially; five miscellaneous measurement sites were established so that discharge data, selected physical properties of water, and water samples for water-quality analysis could be collected.

Gravity data were collected over parts of the Fort Berthold Indian Reservation. As part of the gravity survey, positional data were acquired using global positioning satellite technology.

\section{INTRODUCTION}

In 1990, the U.S. Geological Survey, in cooperation with the Three Affiliated Tribes, began a study of the water resources of the Fort Berthold Indian Reservation (fig. 1). The purpose of this study is to us: existing data and additional data obtained during the study to characterize the quantity and quality of the ground- and surface-water resources of the Fort Berthold Indian Reservation. This study provides the basis for a water-management plan for the Reservation. The purpose of this report is to document the data collection procedures used during the study, the geologic and hydrologic data collected during the study, and selected data from previous investigations (Dingman and Gordon, 1954; Pettyjohn, 1968; Armstrong, 1969; Croft, 1970, 1985; Klausing, 1971, 1976).

\section{Location-Numbering System}

The township-range location number (fig. 2) used to identify wells, test holes, and springs in this report is based on the Federal system of rectangular surveys of the public lands. The first number dentes the township north of a base line, the second number denotes the range west of the fifth principal merician, 


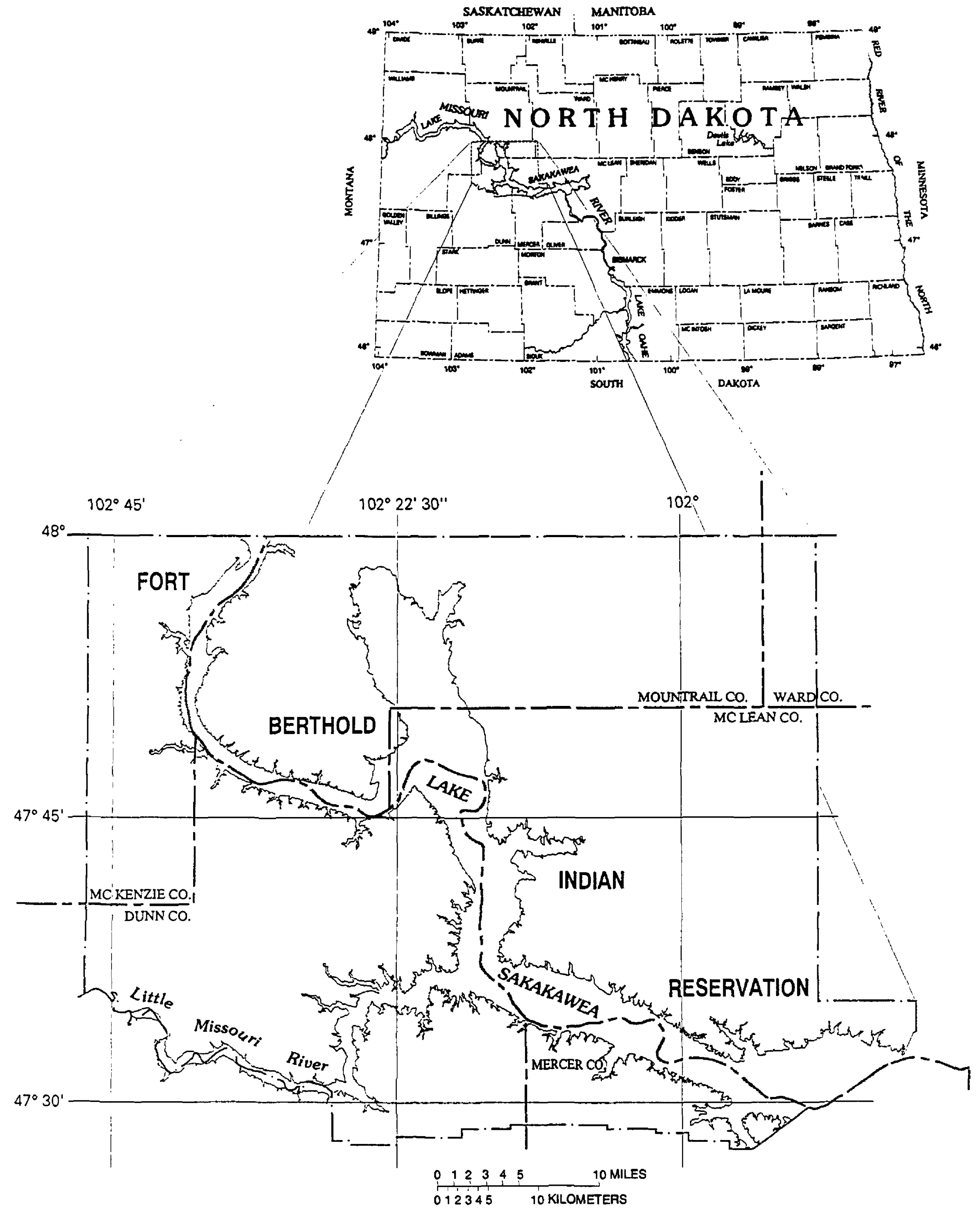

Figure 1. Location of the Fort Berthold Indian Reservation in west-central North Dakota. 


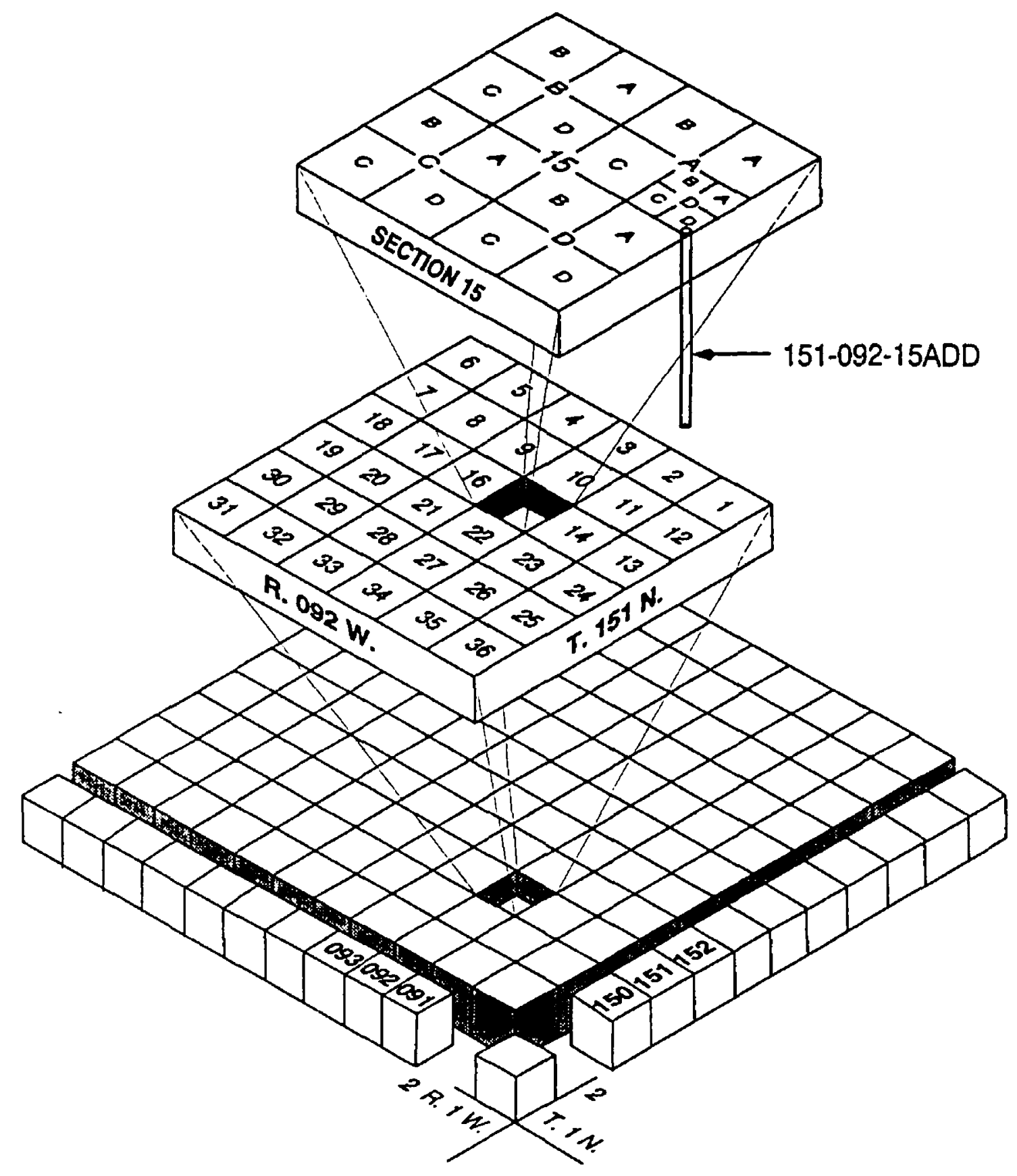

TOWNSHIP AND RANGE

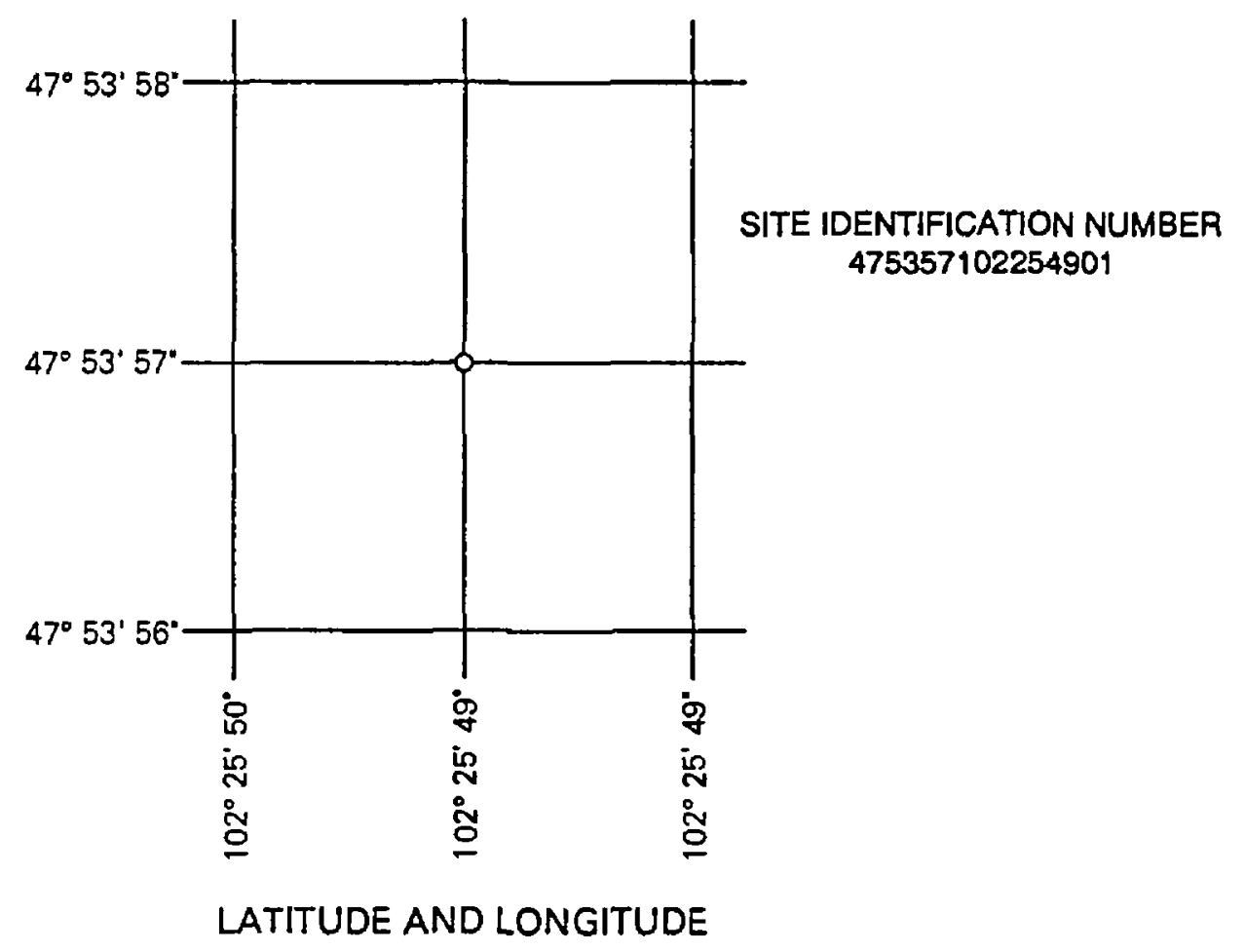

Figure 2. System of numbering wells, test holes, and springs using township, range, and section and latitude and longitude. 
and the third number denotes the section in which the well, test hole, or spring is located. The litters A, B, $C$, and D designate, respectively, the northeast, northwest, southwest, and southeast quarter section, quarter-quarter section, and quarter-quarter-quarter section (10-acre tract); thus, well 151-092-15ADD would be located in $\mathrm{SE}^{1 / 4} \mathrm{SE}^{1 / 4} \mathrm{NE}^{1 / 4}$ sec. $15, \mathrm{~T} .151 \mathrm{~N}$., $\mathrm{R}$. $92 \mathrm{~W}$. Sequence numbers are added to indicate the order of inventory if more than one well, test hole, or spring is located within a 10-acre tract. The township-range location number is referred to as the local number in this report.

The site-identification number used to identify wells, test holes, or springs is a unique 15-digit number based on the latitude-longitude location-numbering system. Although the site-identification number is formed from the latitude and longitude of a point believed to represent the location of the site, the number is an identifier and not a locator. The local numbers and the corresponding site-identification n'mbers are listed in supplement 1.

The numbering system used by the U.S. Geological Survey to identify surface-water staticns is an eight-digit downstream order number. The number is assigned in a downstream direction along the mainstem. All stations on a tributary entering upstream from a mainstream station are assigned a number before that station. A station on a tributary that enters between two mainstream stations is assi mped a number between them.

\section{Acknowledgments}

The collection of data for this report was made possible by the cooperation of residents and officials of the Fort Berthold Indian Reservation, who provided important information regarding wells, springs, and

streams. Permission from the residents of the Reservation to measure water levels, collect water samples, and have private property access was invaluable to the success of this study.

\section{DATA COLLECTION}

\section{Ground Water}

Initial ground-water reconnaissance was done in May 1990 with the inventory of 214 existing wells drilled between 1979 and 1990. These wells were located using well drillers' reports from State of North Dakota Board of Water Well Contractors. The data collected for the 214 inventoried wells and data available for an additional 1,111 wells, test holes, and springs are presented in table 1 . The data include the local number, depth of well, top of open interval, water level, specific conductance, $\mathrm{pH}$, temperature, and altitude of the land surface at the site. Well depth is the depth of casing for open-bottom wells or the base of the deepest well screen for screened wells. Locations of the wells, test holes, and springs listed in table 1 are shown on plate 1 (in pocket).

A network of 40 water-level observation wells (fig. 3) was established for documentation of short- and long-term water-level changes. Many of the observation wells in the network were constructed and measured during previous ground-water studies. Additional observation wells were established from those inventoried during May 1990 and from wells drilled in June 1992. Water levels for the observation wells are given in table 2.

Gravity and subsurface geology data and data from 211 drillers' logs were used to select lo ations for 27 test holes drilled in June 1992. These test holes ranged in depth from 40 to $390 \mathrm{ft}$ and wells completed 


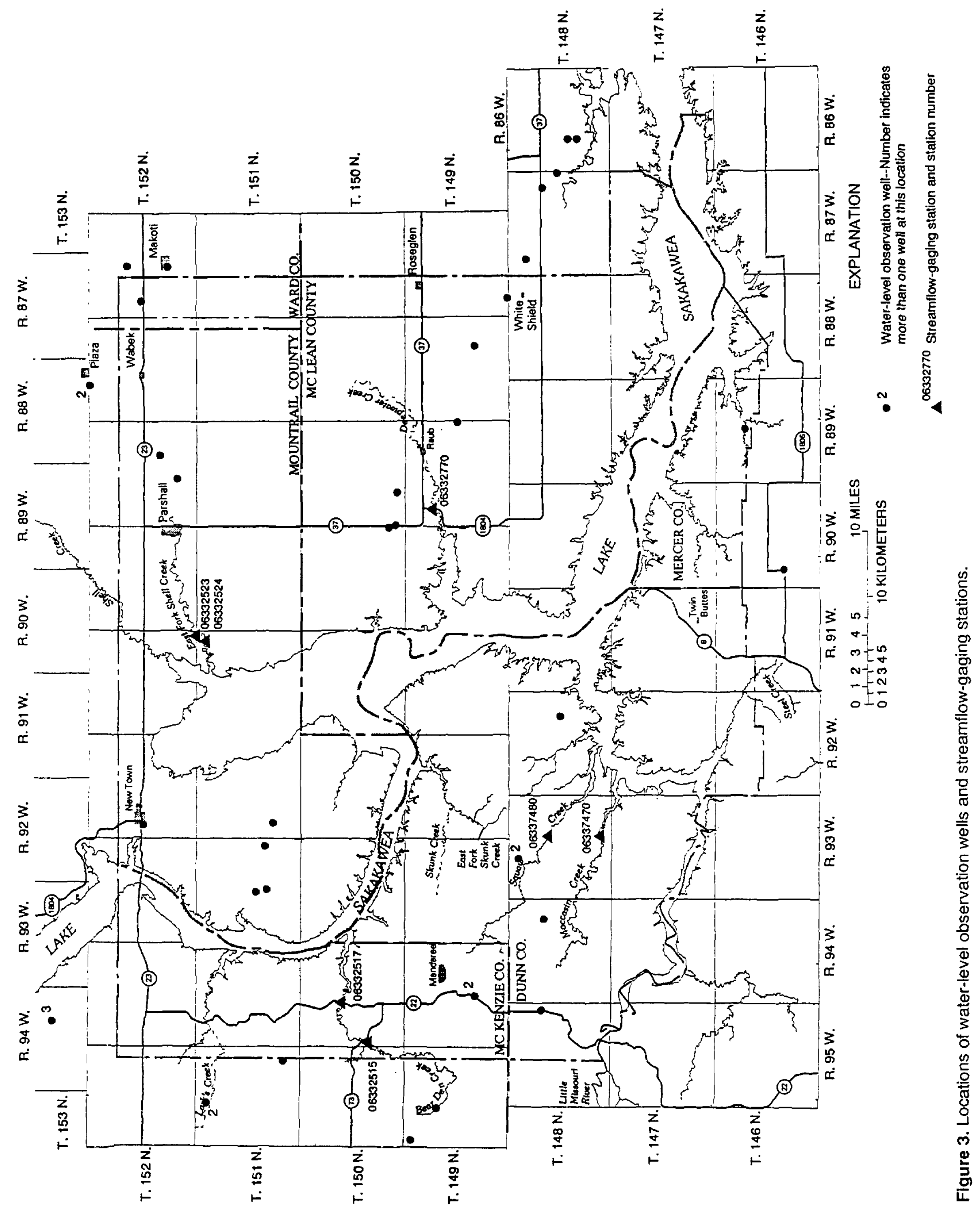


in selected test holes ranged in depth from 51 to $300 \mathrm{ft}$. Resistivity, gamma-ray, and lithology logs were made for each test hole. Logs obtained from drillers and other sources and resistivity and gamma-ray logs of 21 test holes drilled as part of this study are presented in tables 3 and 4.

Eleven of the test holes drilled in June 1992 were developed as wells by installing 2-in.-diameter polyvinyl-chloride casing and either 5 or $10 \mathrm{ft}$ of 10 - or 12-slot $(0.010$ - or 0.012 -in. slot size) p)lyvinylchloride screen. Casing joints were glued with solvent glue. A tremmie pipe was used to fill the annular space around the screen with graded silica sand to ensure placement of the sand opposite the screen. A slurry of bentonite grout was then pumped through the trimmie pipe to seal the screened zone from the upper hole. The remainder of the hole was filled with drill cuttings. Airlift methods were used to develop the wells. The wells were pumped a sufficient length of time to allow for the removal of any residual drilling fluid from the aquifer and for the specific conductance and $\mathrm{pH}$ of the water from the well to stabilize.

Water samples were collected from the observation wells and from selected private wells for waterquality analysis. A gas-squeeze pump was used to extract three well volumes of water from the observation wells before water samples were collected. Three well volumes of water were flushed through the plumbing systems of private wells before water samples were collected.

Field determinations of specific conductance, $\mathrm{pH}$, and water temperature were made when the water samples were collected. A $250-\mathrm{mL}$ sample was collected in a field-rinsed polyethylene bottle for laboratory analysis of specific conductance, $\mathrm{pH}$, and alkalinity. A $250-\mathrm{mL}$ sample was filtered through a $0.45-\mu \mathrm{m}$ pore size Millipore filter into an acid-rinsed polyethylene bottle and acidified to a pH of less than 2 with 2-mL of nitric acid for analysis of major cations (calcium, magnesium, sodium, and potassium). A 250-mL sample was filtered into a sample-rinsed polyethylene bottle for analysis of major anions (sulfate, chloride, fluoride, and silica). A 250 -mL sample was filtered into a sample-rinsed brown polyethylene bottle and preserved with mercuric chloride for analysis of nutrients (nitrogen and phosphorus species). A 500 -mL sample was filtered into an acid-rinsed polyethylene bottle and preserved with nitric acid for analysis of trace elements.

All samples were shipped in coolers filled with ice to the U.S. Geological Survey National Water Quality Laboratory in Arvada, Colo., for analysis. Samples were received at the laboratory within 4 days of collection. Analyses of nutrient samples were completed within 10 days of collection. The remaining analyses were completed within 100 days of collection. Constituents were analyzed using methods described by Fishman and Friedman (1989).

Physical properties and major-ion concentrations for 260 water samples from wells are list $? \mathrm{~d}$ in table 5, and trace-element concentrations for 225 water samples from wells are listed in table 6 Analyses dated from 1990 through 1992 were done as part of this study. Physical properties and major-ion concentrations for 33 water samples collected from 32 springs are listed in table 7 . Nine analyses dated 1992 were done as part of this study.

\section{Surface Water}

Surface-water data were collected for five selected streams on the Fort Berthold Indian Reservation. Miscellaneous discharge measurement sites were established on Bear Den Creek above mouth near Mandaree, N. Dak. (06332517), East Fork Shell Creek near mouth below Parshall, N. Dak. (06332524), Deepwater Creek at mouth near Raub, N. Dak. (06332770), Moccasin Creek at mouth near Mandaree, N. Dak. (06337470), and Squaw Creek above mouth near Mandaree, N. Dak. (06337480) in April 1990 (fig. 3). In September 1990, Bear Den Creek above mouth near Mandaree, N. Dak. (06332517. was 
discontinued, and data for Bear Den Creek was collected at an existing continuous-recording gaging station, Bear Den Creek near Mandaree, N. Dak. (06332515). In June 1991, East Fork Shell Creek near mouth below Parshall, N. Dak. (06332524) was moved a few miles upstream and was converted to a continuous-recording gaging station, East Fork Shell Creek near Parshall, N. Dak. (06332523). Also in June 1991, Deepwater Creek at mouth near Raub, N. Dak. (06332770) was converted from a miscellaneous discharge measurement site to a continuous-recording gaging station.

Discharge measurements were made following the procedures described by Rantz and others (19??). These procedures include the use of a pygmy meter or AA current meter and top-setting rod, a modified 3-in. flume, and a $1-\mathrm{ft}^{3}$ bucket. Mean daily discharges for the continuous-recording gaging stations were computed by using stage-discharge ratings and corresponding water-level stages (Rantz and others, 1082).

Selected physical properties of water, such as specific conductance, $\mathrm{pH}$, and dissolved-oxygen, and air and water temperature measurements were made at the time of each discharge measurement and watesamples were collected periodically for water-quality analysis. Procedures that were followed for onsite measurements and for collecting, treating, and shipping samples are given in publications on "Techniaues of Water Resources Investigations (Barnett and Mallory, 1971; Wershaw and others, eds., 1987; Fishn an and Friedman, 1989).

All surface-water data collected during this study are published in the U.S. Geological Survey Water Resources data reports (Harkness and others, 1991-93).

\section{Gravlty}

A gravity survey was conducted over about $800 \mathrm{mi}^{2}$ of the Fort Berthold Indian Reservation north of Lake Sakakawea (fig. 4) to locate low density zones (indicative of high porosity material) within or adjacent to buried-valley aquifers. Global Positioning System (GPS) technology was used to position nearly 1,800 gravity stations.

Gravity stations consisted of a numbered wooden stake driven into the ground to serve as a temporary monument. The GPS receiver antenna was placed on the monument and leveled, and 90 seconds of GrS data was recorded using 16-channel dual-frequency receivers operated in the "STOP AND GO" kinem atic mode. After several gravity readings were taken, the crew moved to the next station and the process vas repeated. Vertical and horizontal error was consistently less than 4 in., based on comparison of GPS reoccupation of 10 percent of the gravity stations. The latitude, longitude, and altitude values that we ve determined using GPS and the related Bouguer and residual gravity values are presented in table 8 . 


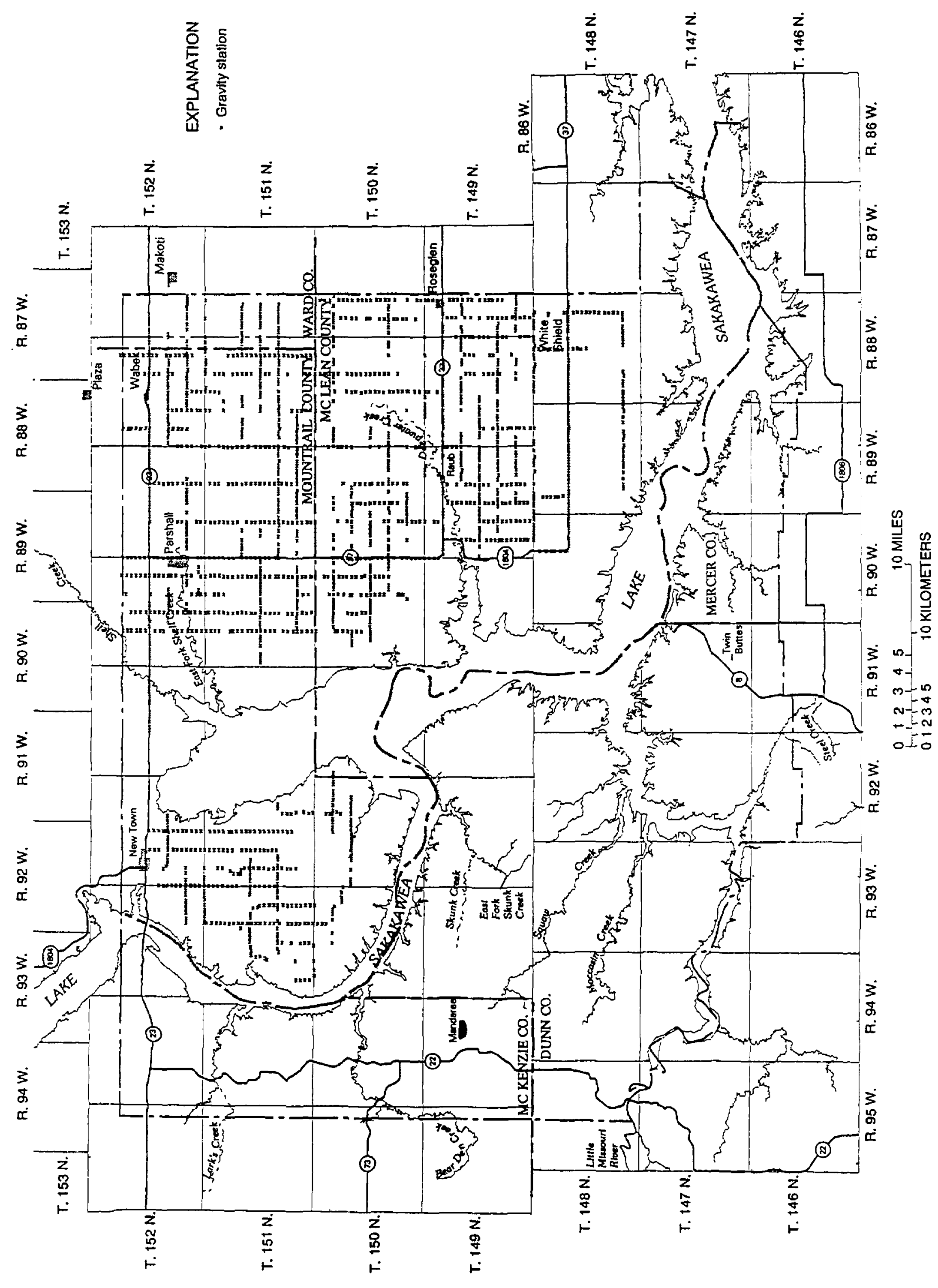

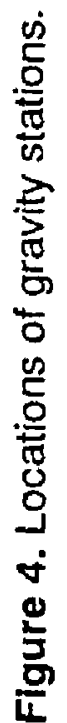




\section{REFERENCES}

Armstrong, C.A., 1969, Geology and ground water resources of Burke and Mountrail Counties; pt II, Ground vater basic data: North Dakota Geological Survey Bulletin 55 and North Dakota State Water Commission Count:' Ground Water Studies 14, 282 p.

Barnett, P.R., and Mallory, E.C., Jr., 1971, Determination of minor elements in water by emission spectroscopy: U.S. Geological Survey Techniques of Water-Resources Investigations, book 5, chap. A2, 31 p.

Croft, M.G., 1970, Ground water basic data, Mercer and Oliver Counties, North Dakota: North Dakota Geological Survey Bulletin 56, pt. II, and North Dakota State Water Commission County Ground Water Studies 15, pt. II, $268 \mathrm{p}$.

1985, Ground-water data for McKenzie County, North Dakota: North Dakota Geological Survey Bulletin 8?, pt. II, and North Dakota State Water Commission County Ground-Water Studies 37, pt. II, 455 p.

Dingman, R.J., and Gordon, E.D., 1954, Geology and ground-water resources of the Fort Berthold Indian Reservation, North Dakota: U.S. Geological Survey Water-Supply Paper 1259, 115 p.

Fishman, M.J., and Friedman, L.C., 1989, Methods for determination of inorganic substances in water and fluvial sediments: U.S. Geological Survey Techniques of Water-Resources Investigations, book 5, chap. AI, 545 p

Harkness, R.E., Haffield, N.D, and Berkas, W.R., 1991, Water resources data, North Dakota, water year 1990: U.S. Geological Survey Water-Data Report ND-90-1, 351 p.

Harkness, R.E., Haffield, N.D., Berkas, W.R., and Norbeck, S.W., 1992, Water resources data, North Dakota, water year 1991: U.S. Geological Survey Water-Data Report ND-91-1, 350 p.

1993, Water resources data, North Dakota, water year 1992: U.S. Geological Survey Water-Data Report ND-92-1, 434 p.

Klausing, R.L., 1971, Ground-water basic data, McLean County, North Dakota: North Dakota Geological Survey Bulletin 60, pt. II, and North Dakota State Water Commission County Ground Water Studies 19, pt. II, 468 p.

1976, Ground-water basic data for Dunn County, North Dakota: North Dakota Geological Survey Bulletin 68, pt. II, and North Dakota State Water Commission County Ground-Water Studies 25, pt. II, 501 p.

Pettyjohn, W.A., 1968, Geology and ground water resources of Renville and Ward Counties, North Dakota; pt 2, Ground water basic data: North Dakota Geological Survey Bulletin 50, pt. II, and North Dakota State Water Commission County Ground Water Studies 11, 302 p.

Rantz, S.E., 1982, Measurement and computation of streamflow: Volume 1. Measurement of stage and dischar 3 : U.S. Geological Survey Water-Supply Paper 2175, 284 p.

Wershaw, R.L., Fishman, M.J., Grabbe, R.R., and Lowe, L.E., eds., 1987, Methods for the determination of organic substances in water and fluvial sediments: U.S. Geological Survey Techniques of Water-Resources

Investigations, book 5, chap. A3, $80 \mathrm{p}$. 
Rimere ${ }^{7 a a^{2}}$ 


\section{Owner}

NDGS, North Dakota Geological Survey

NDSPS, North Dakota State Park Service

NDSWC, North Dakota State Water Commission

USAF, U.S. Air Force

USBIA, U.S. Bureau of Indian Affairs

USBM, U.S. Bureau of Mines

USGS, U.S. Geological Survey

\section{Water level}

Water levels are in feet below or (+) above land surface.

\section{Aquiler code}

Holocene

111ALVM Alluvium

Pleistocene

112BDVL Buried valley deposits

112BGFV Buried glaciofluvial deposits

112HDLK Hidden Lake aquifer

112NWTN New Town aquifer

112OTSH Outwash deposits

112SANISH Sanish aquifer

112SLCK Shell Creek aquifer system

112TLL Till deposits

112VANG Vang aquifer

112WSLD White Shield aquifer

Paleocene

125CBLD Cannonball-Ludlow Members of Fort Union Formation

125FRUN Fort Union Formation

125SNLB Sentinel Butte Member of Fort Union Formation

125TGRV Tongue River Member of Fort Union Formation

Cretaceous

211FXHL Fox Hills Sandstone

211HCFH Hell Creek Formation-Fox Hills Sandstone

Water-quality properties

Values shown are the field specific conductance, $\mathrm{pH}$, and temperature measured at the time of inventcry.

\section{Aitltude of land surface}

Altitude is in feet above sea level.

\section{Abbrevlatlons and symbols}

$\mu \mathrm{S} / \mathrm{cm}$, microsiemens per centimeter at 25 degrees Celsius

-- , no data 


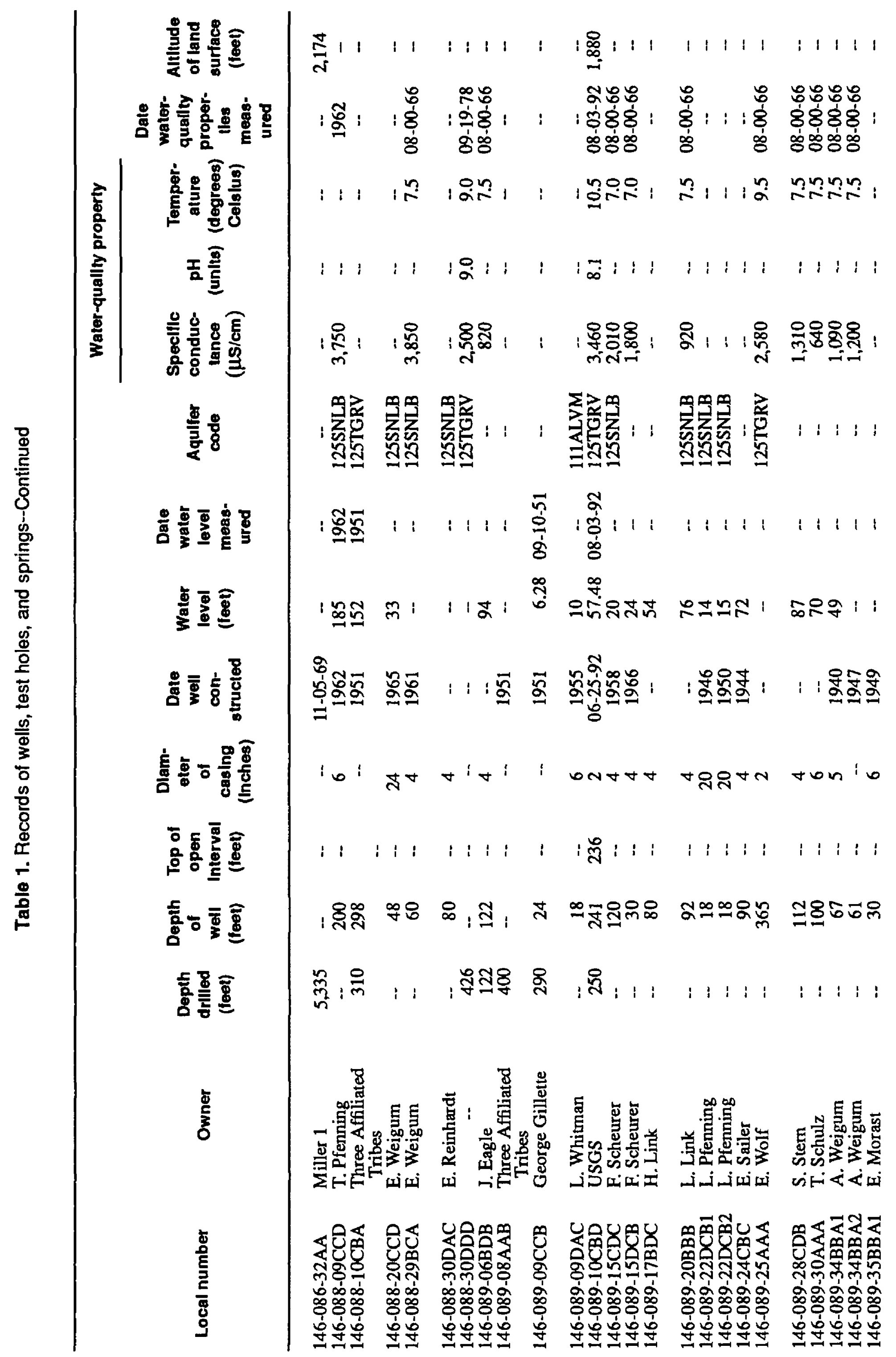




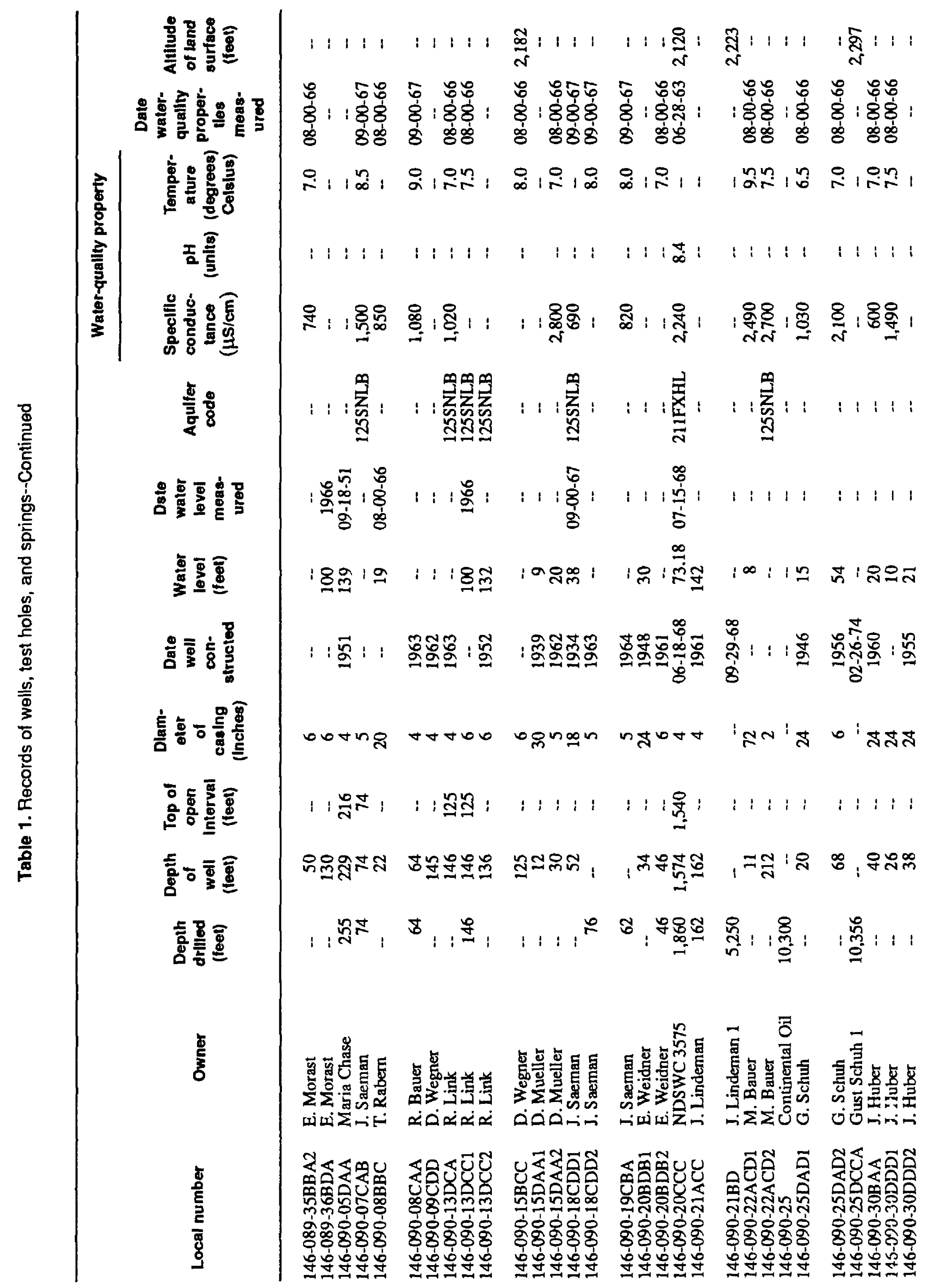




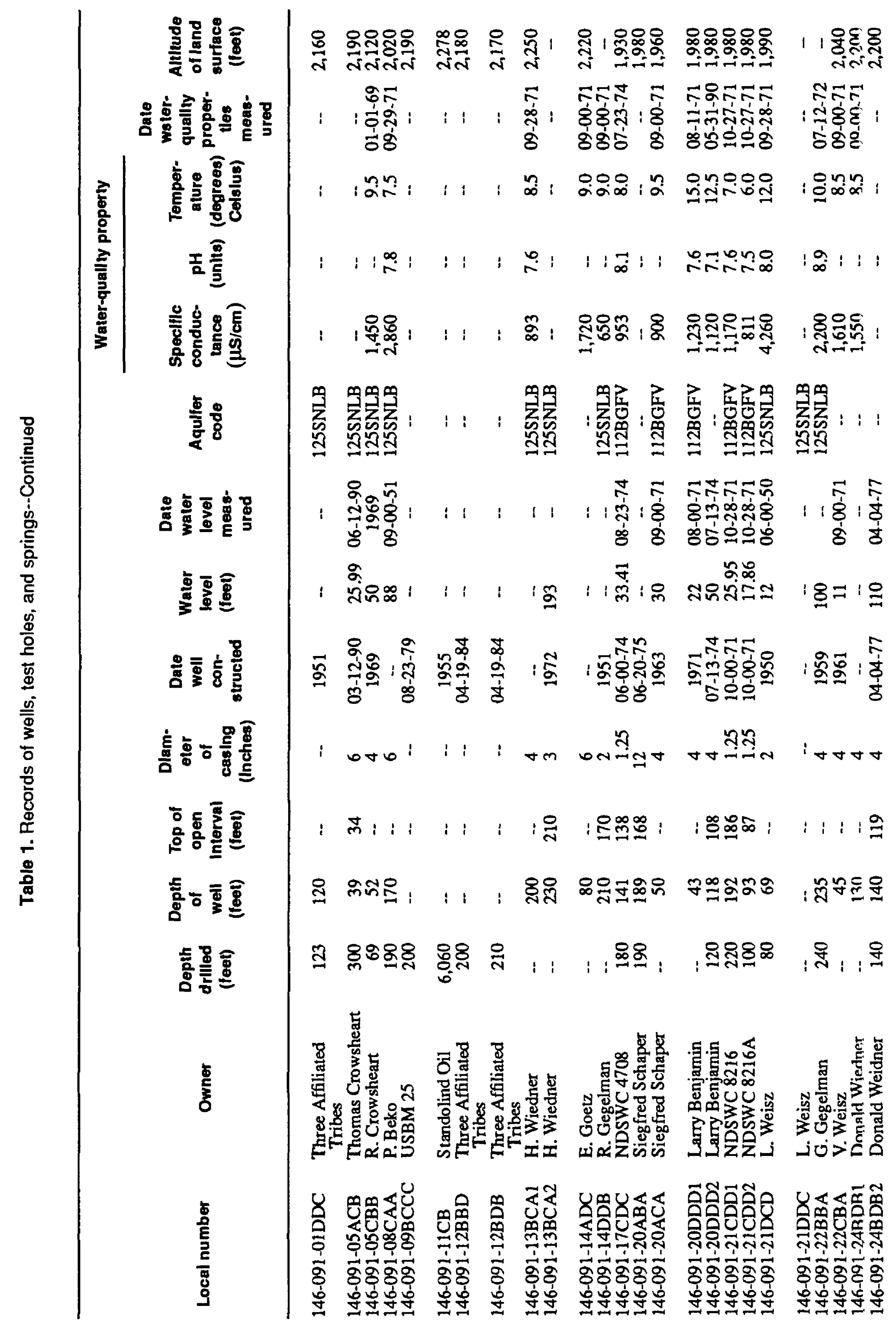




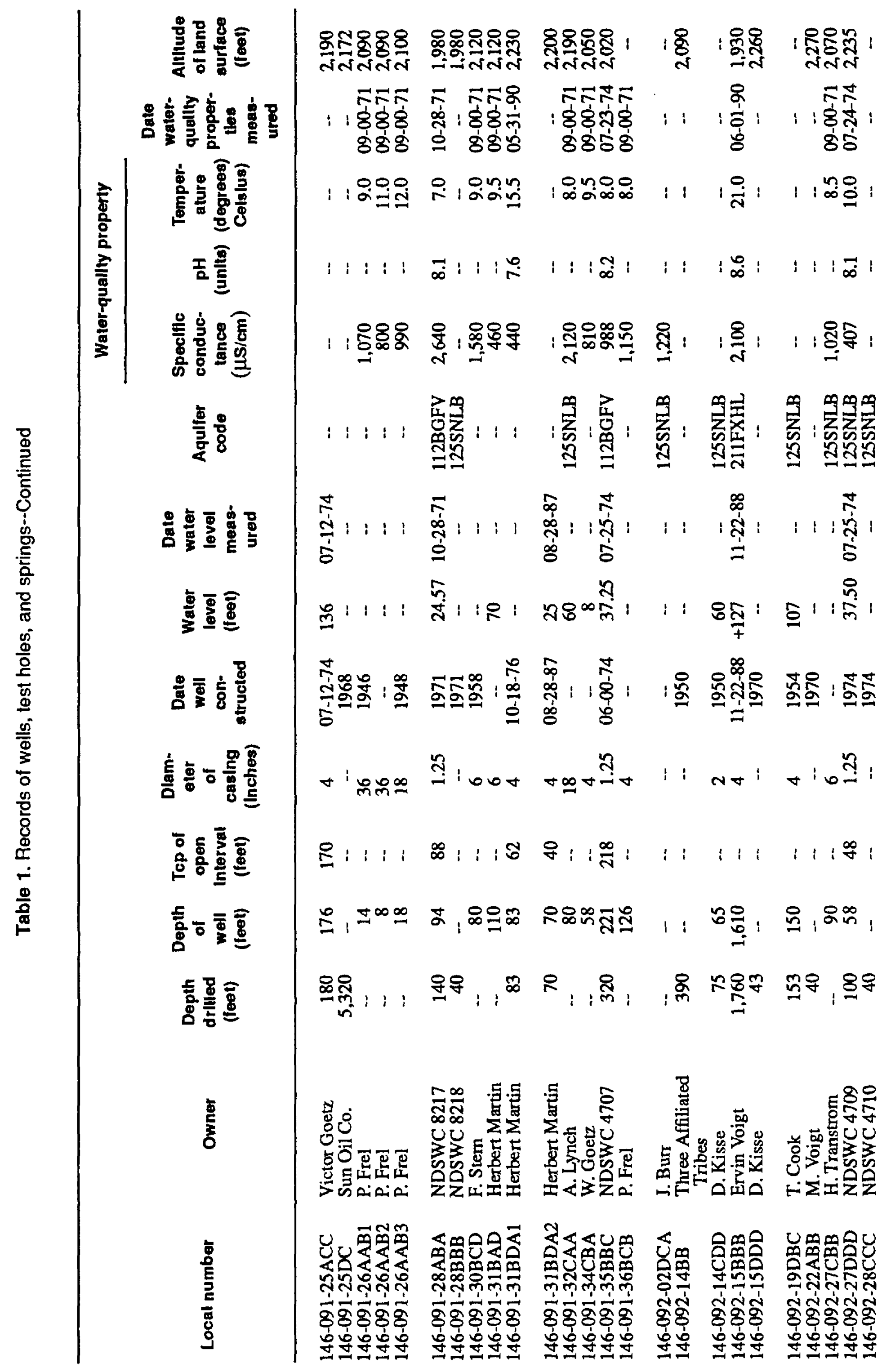




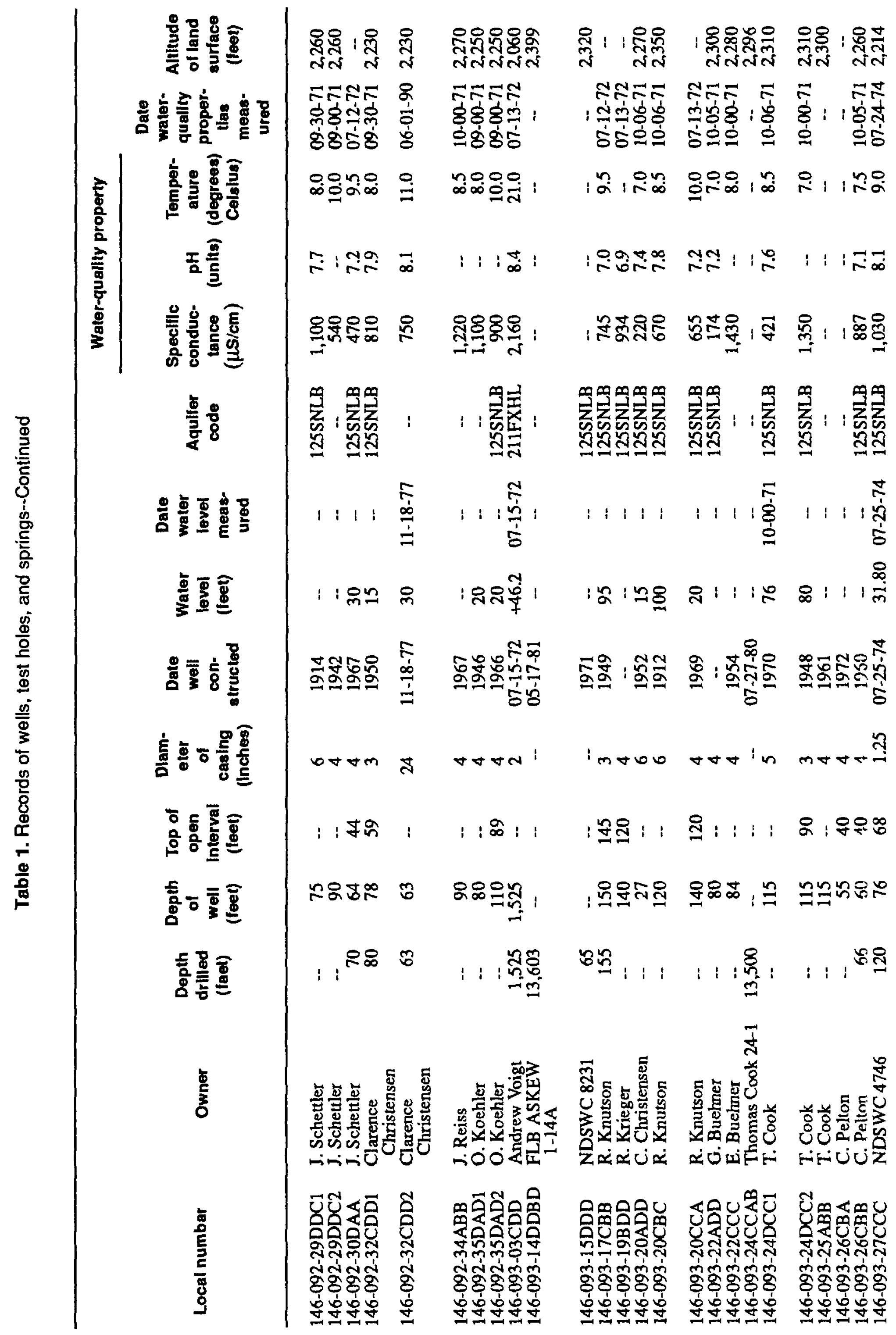




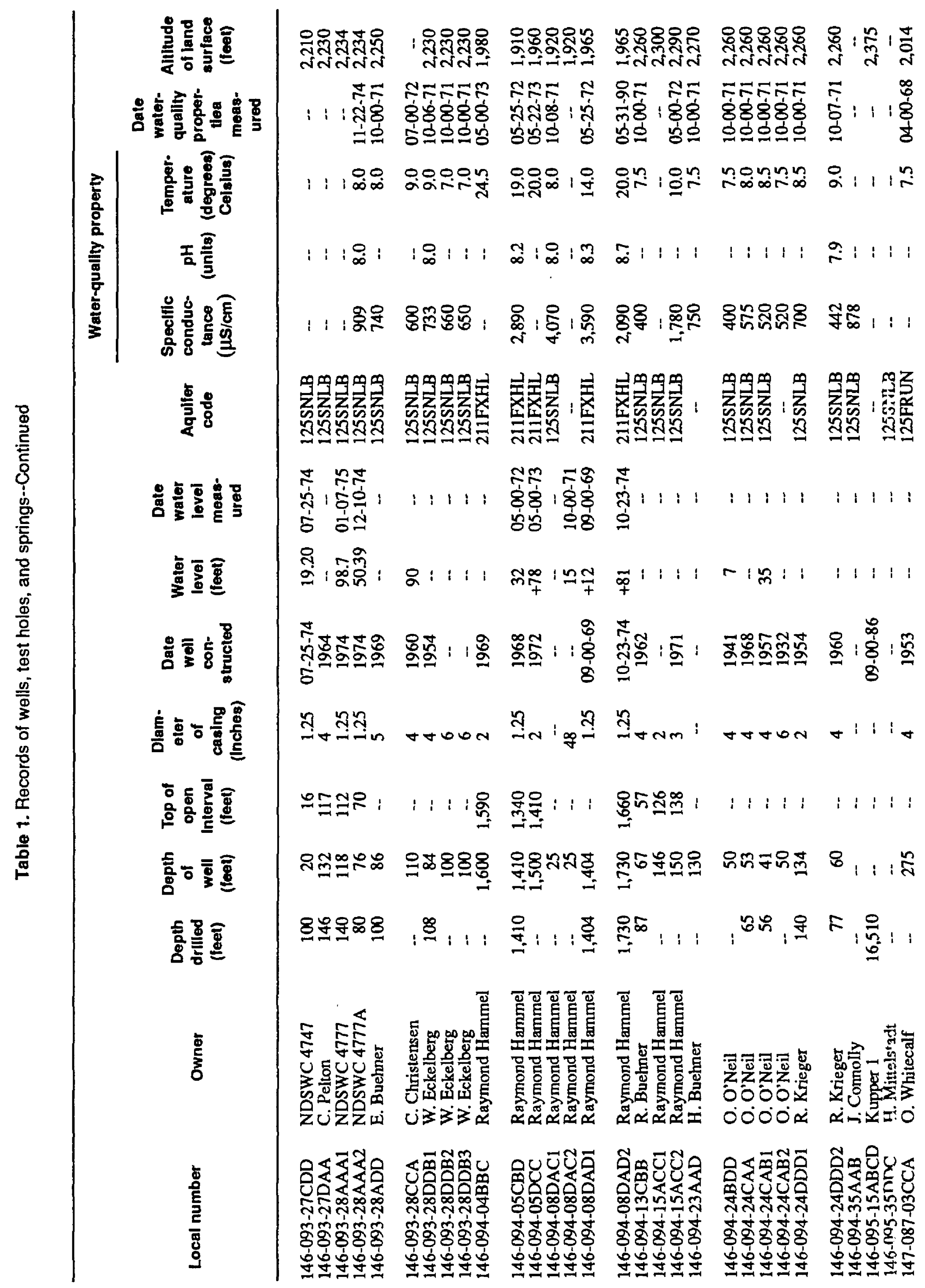




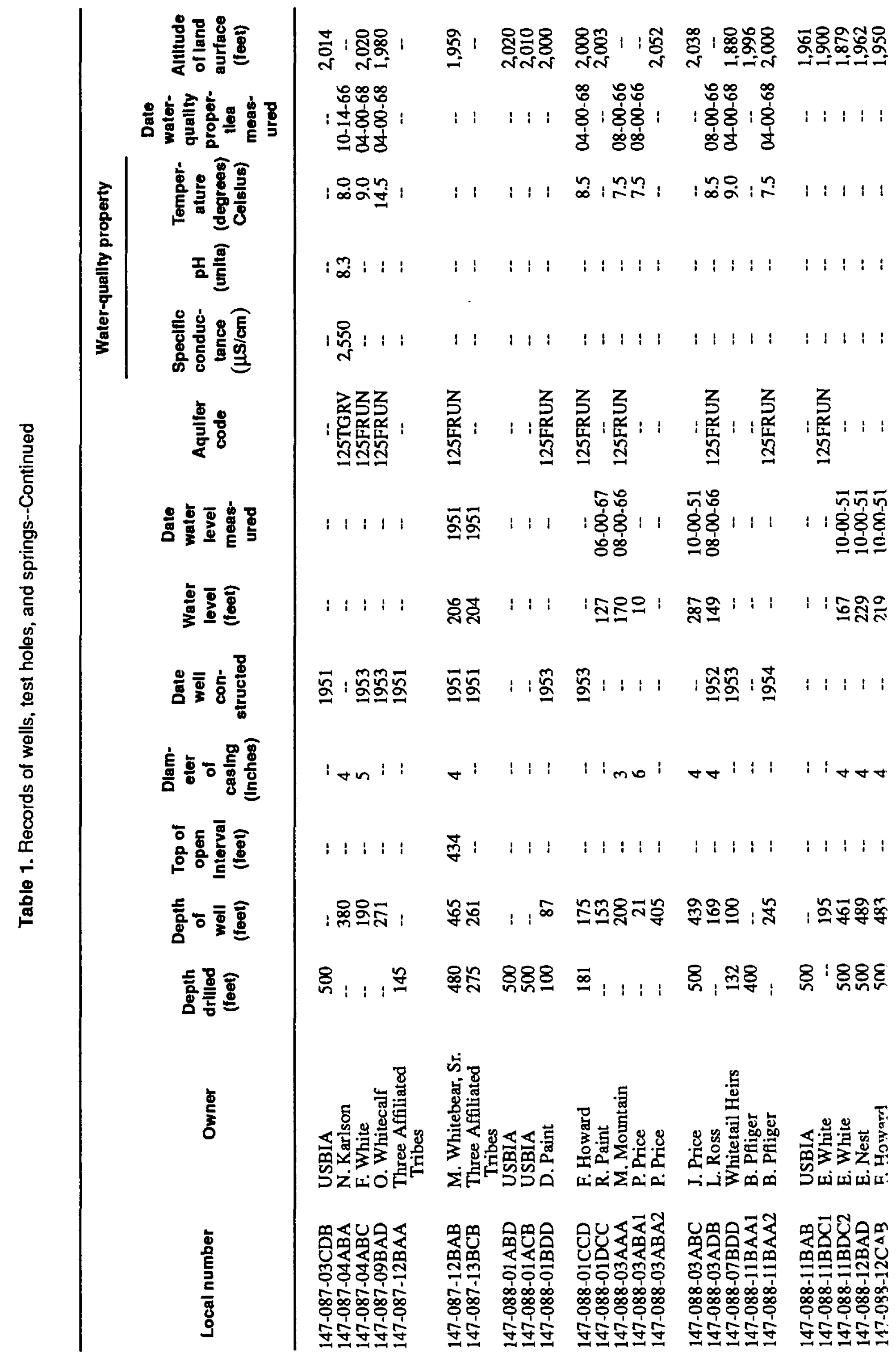




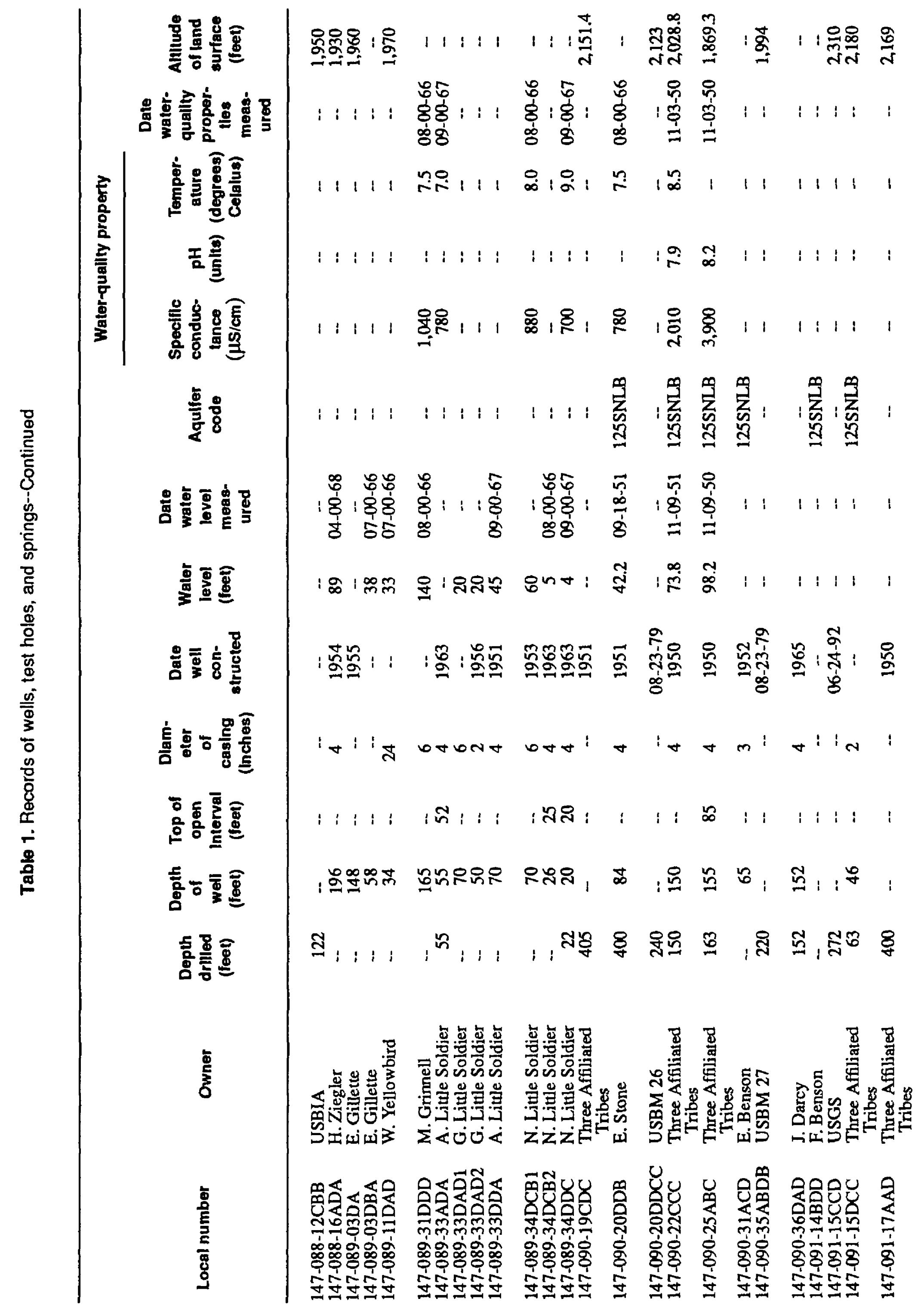




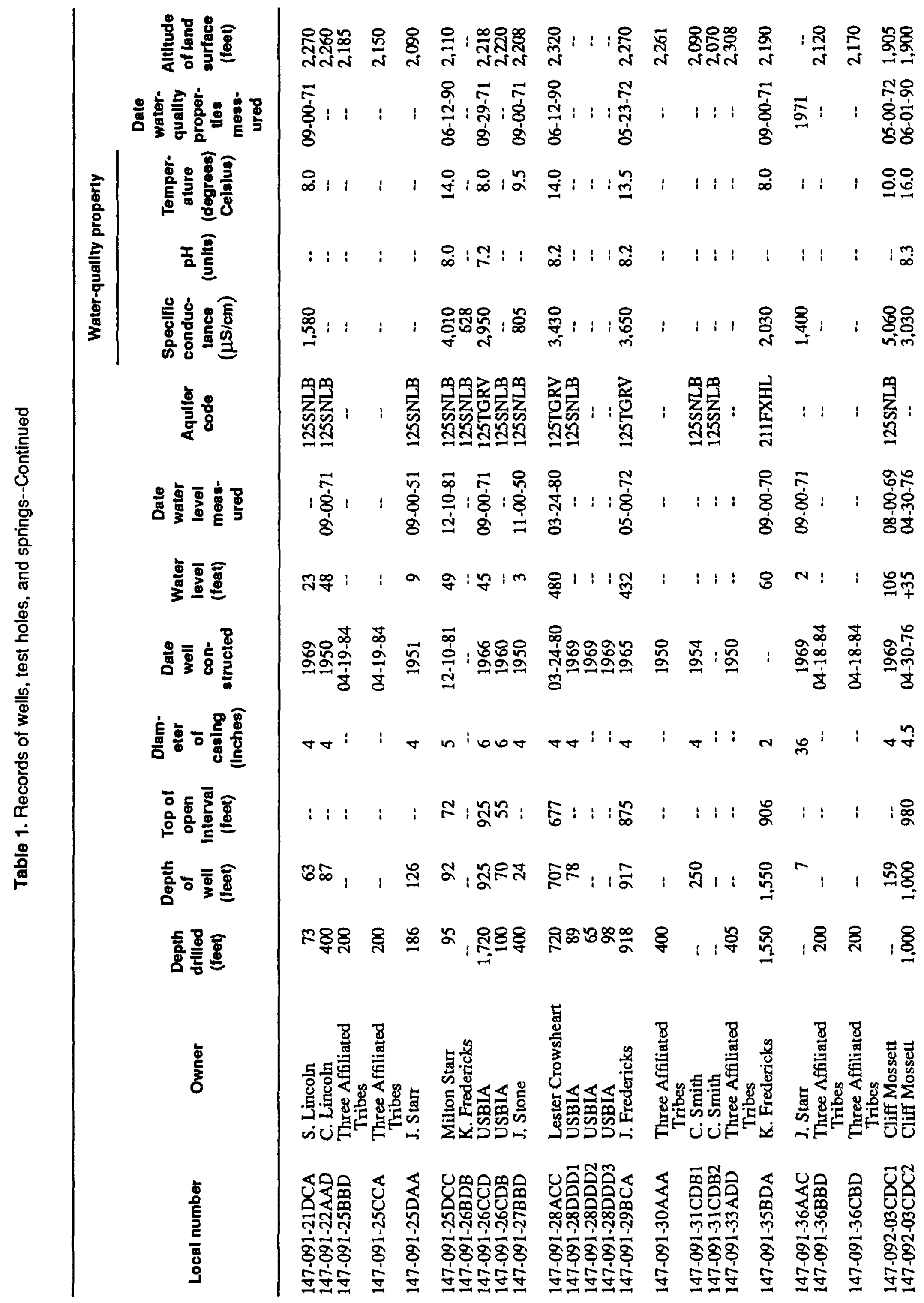




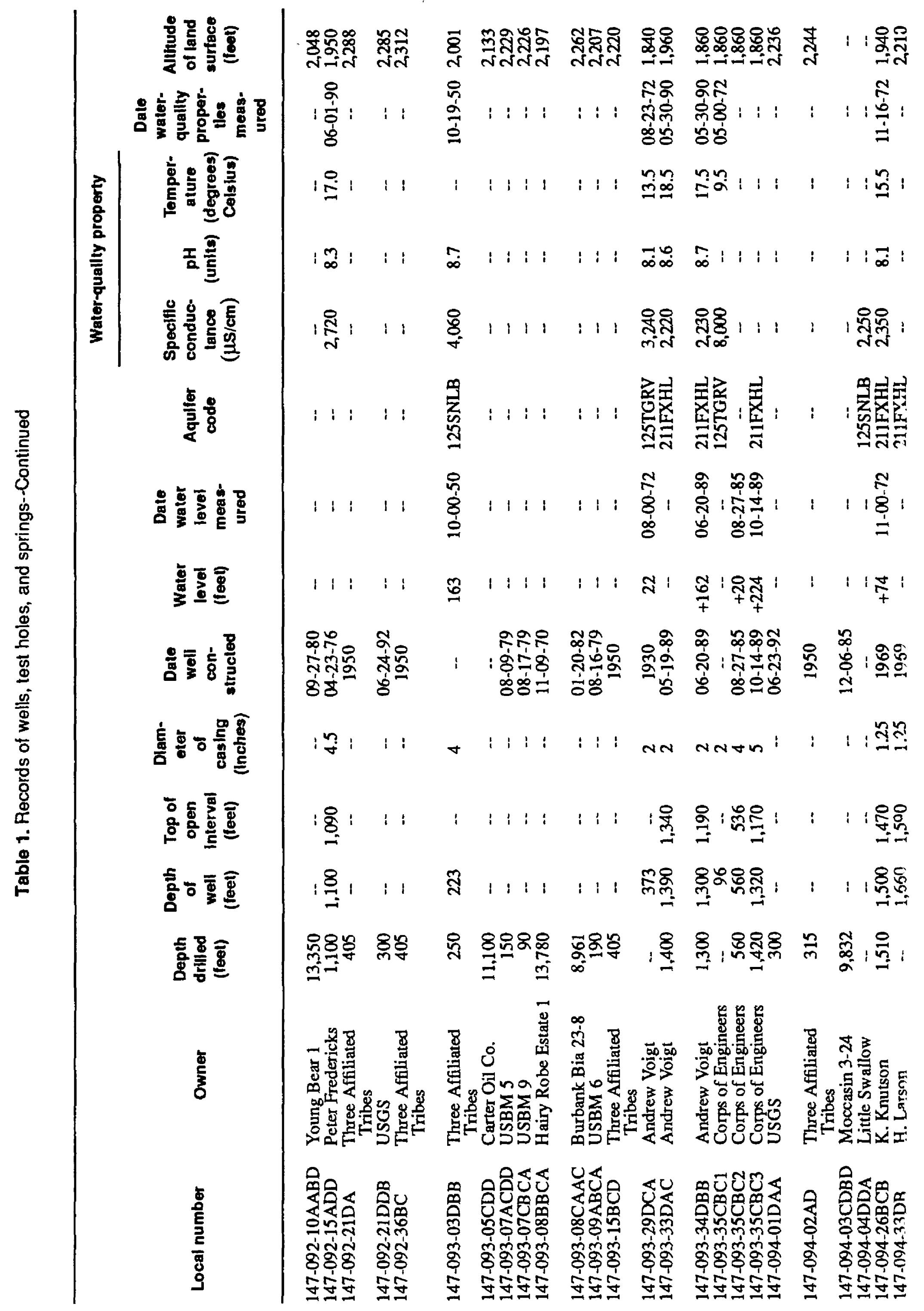









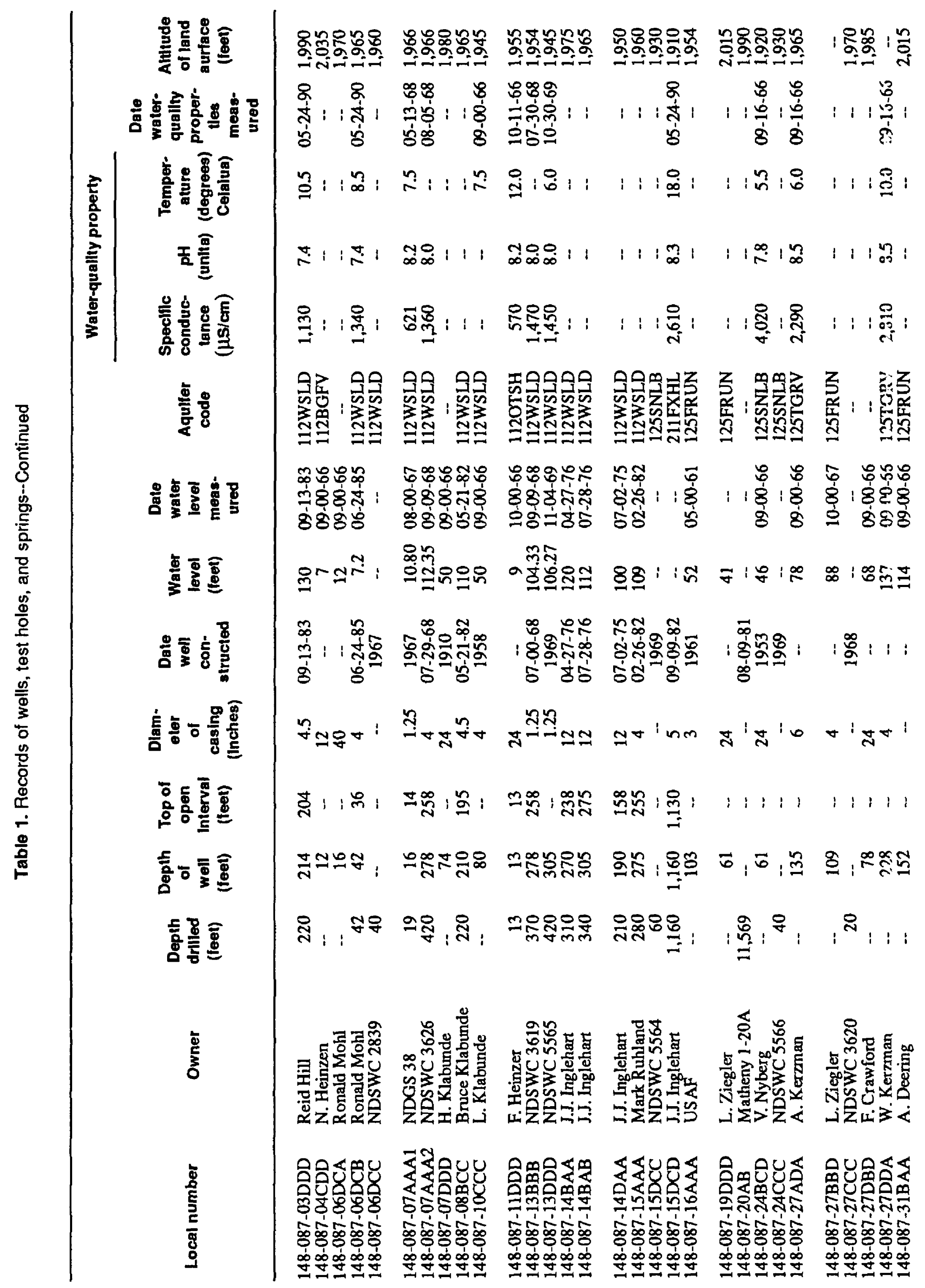




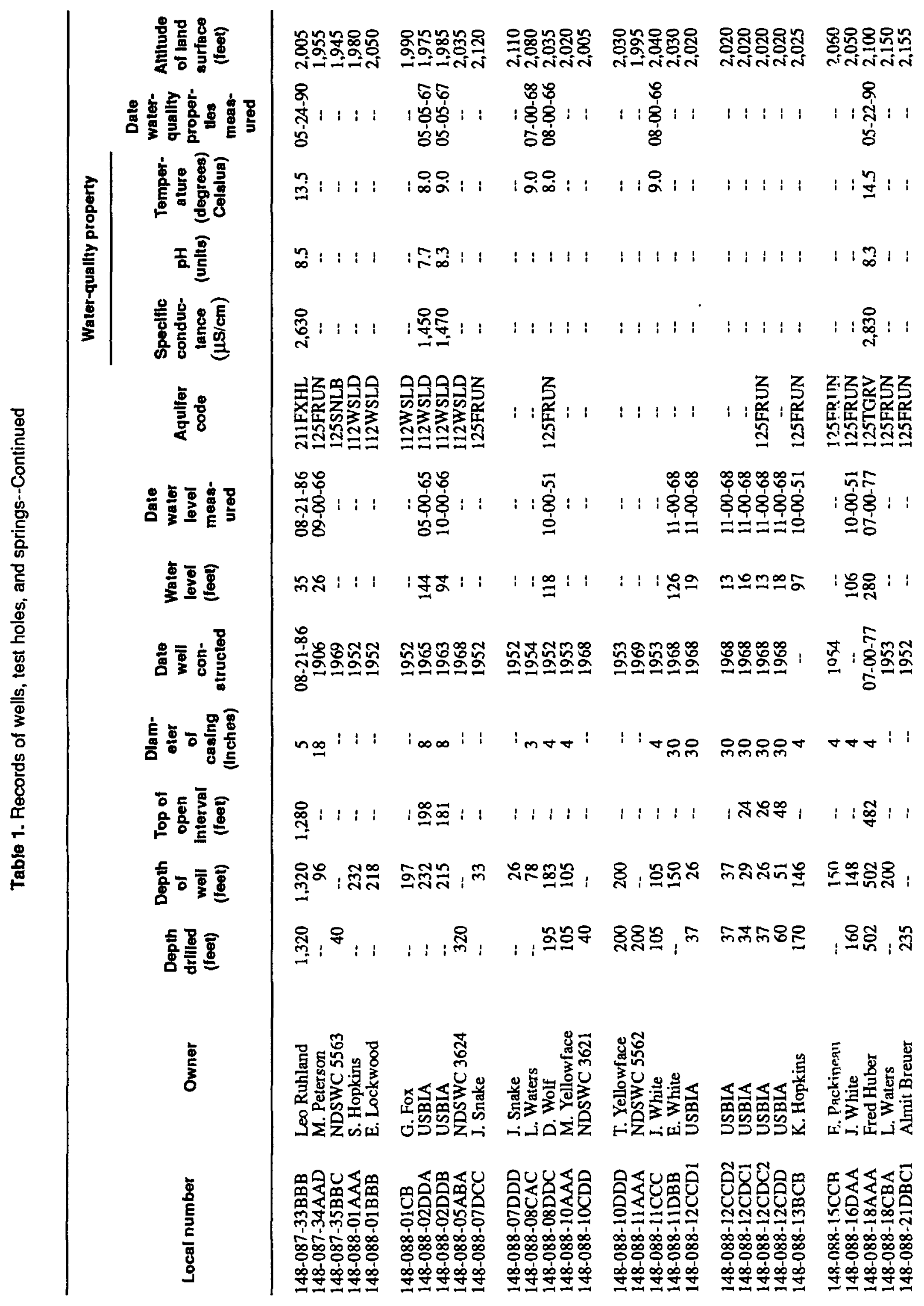




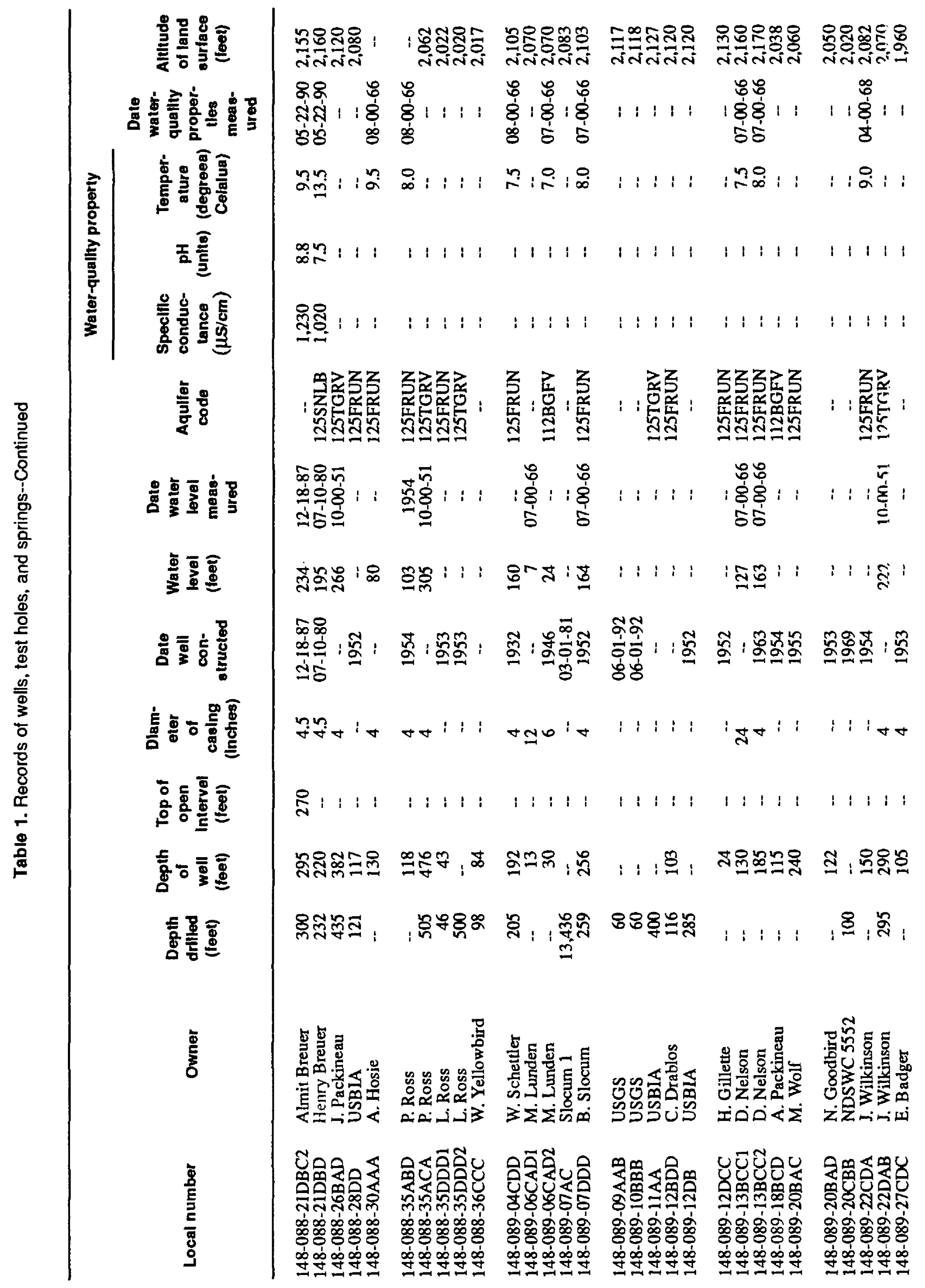




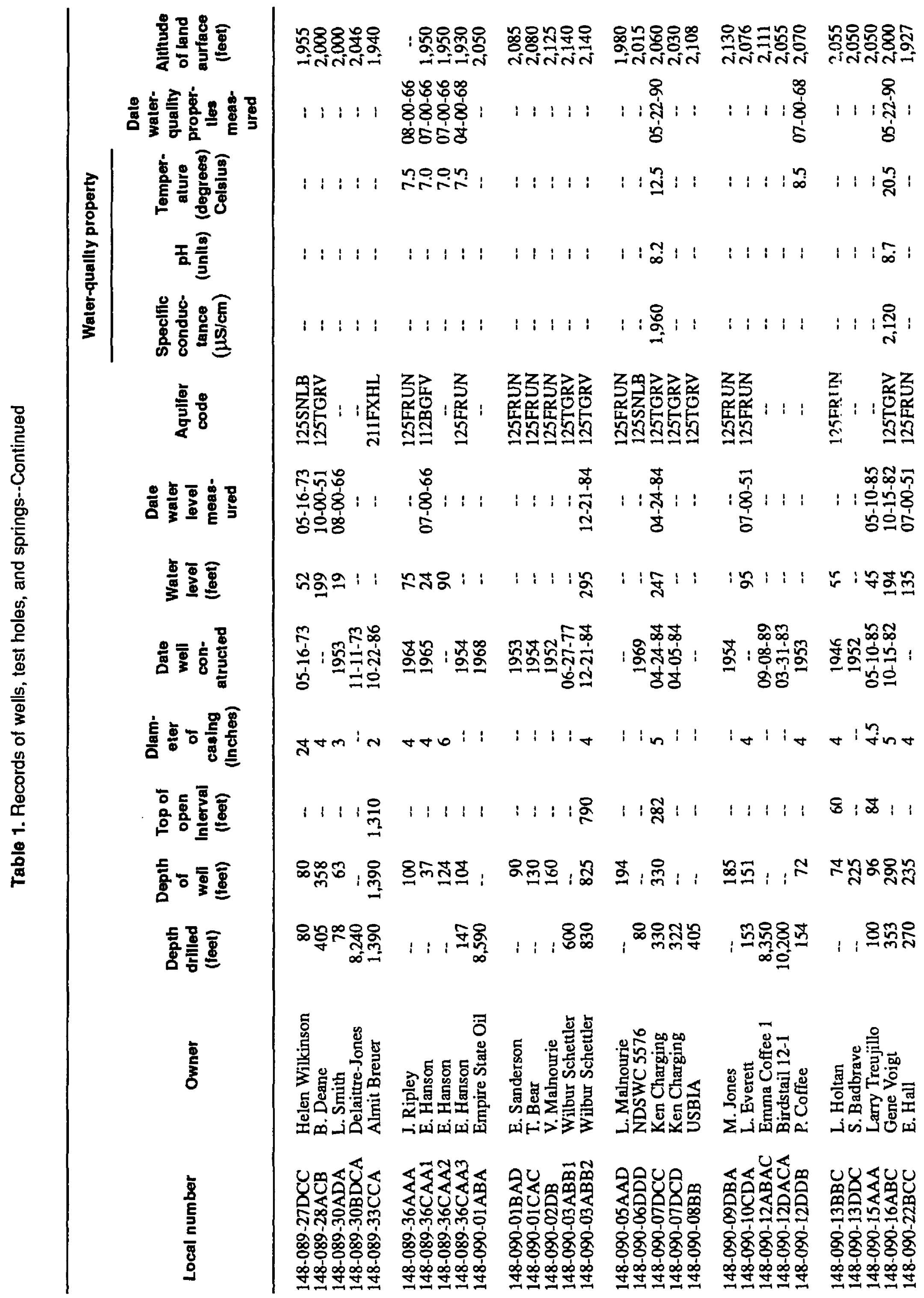




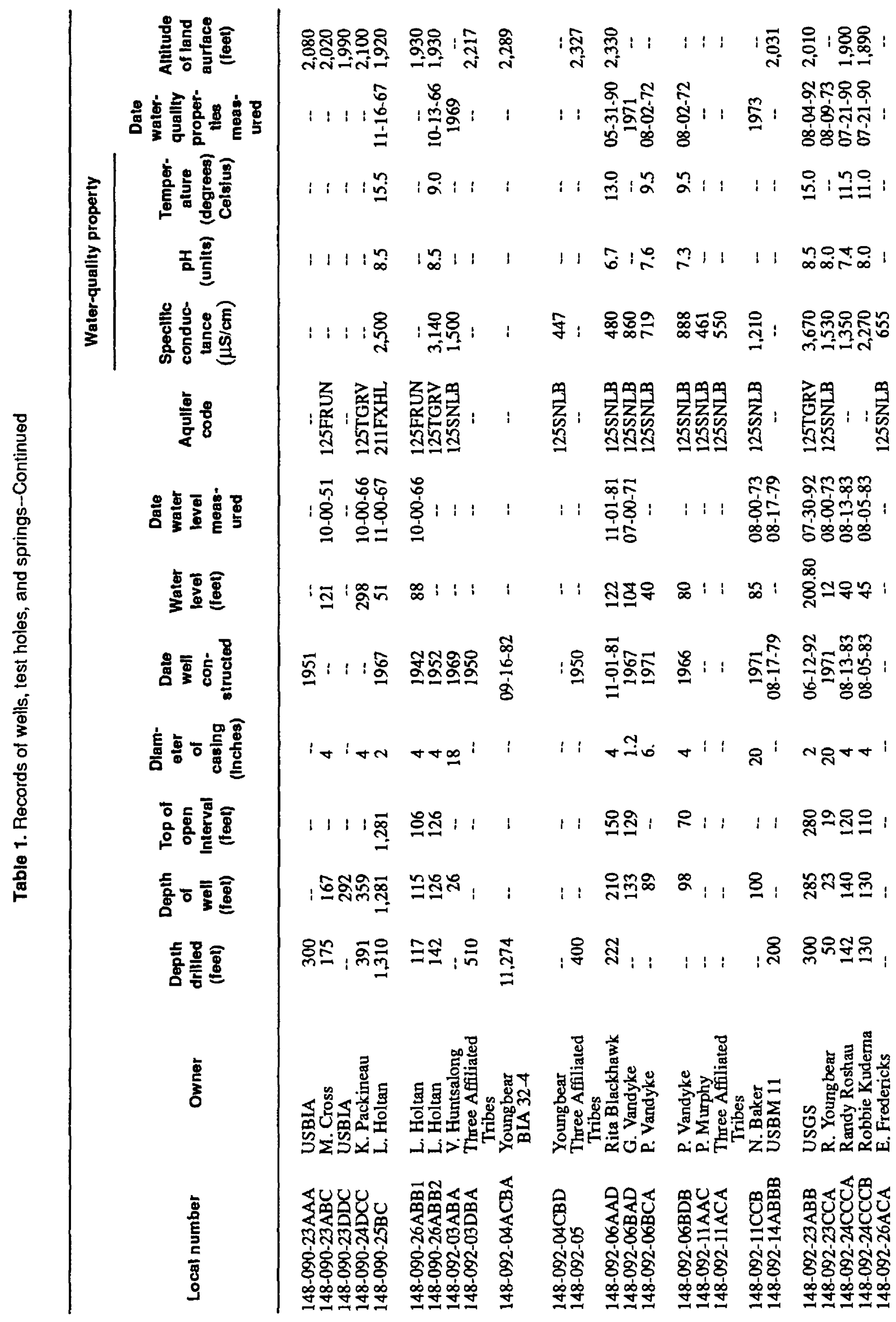




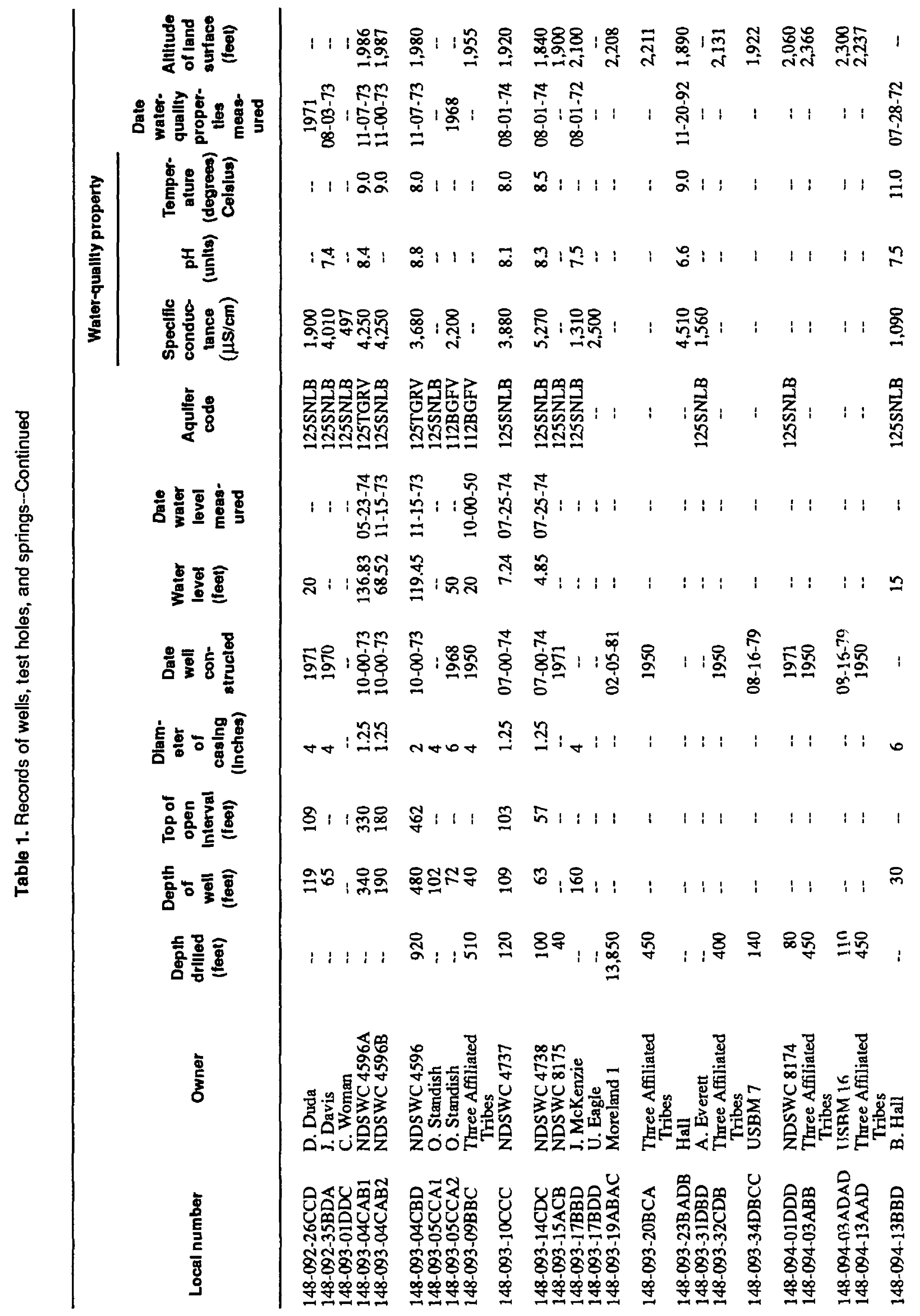




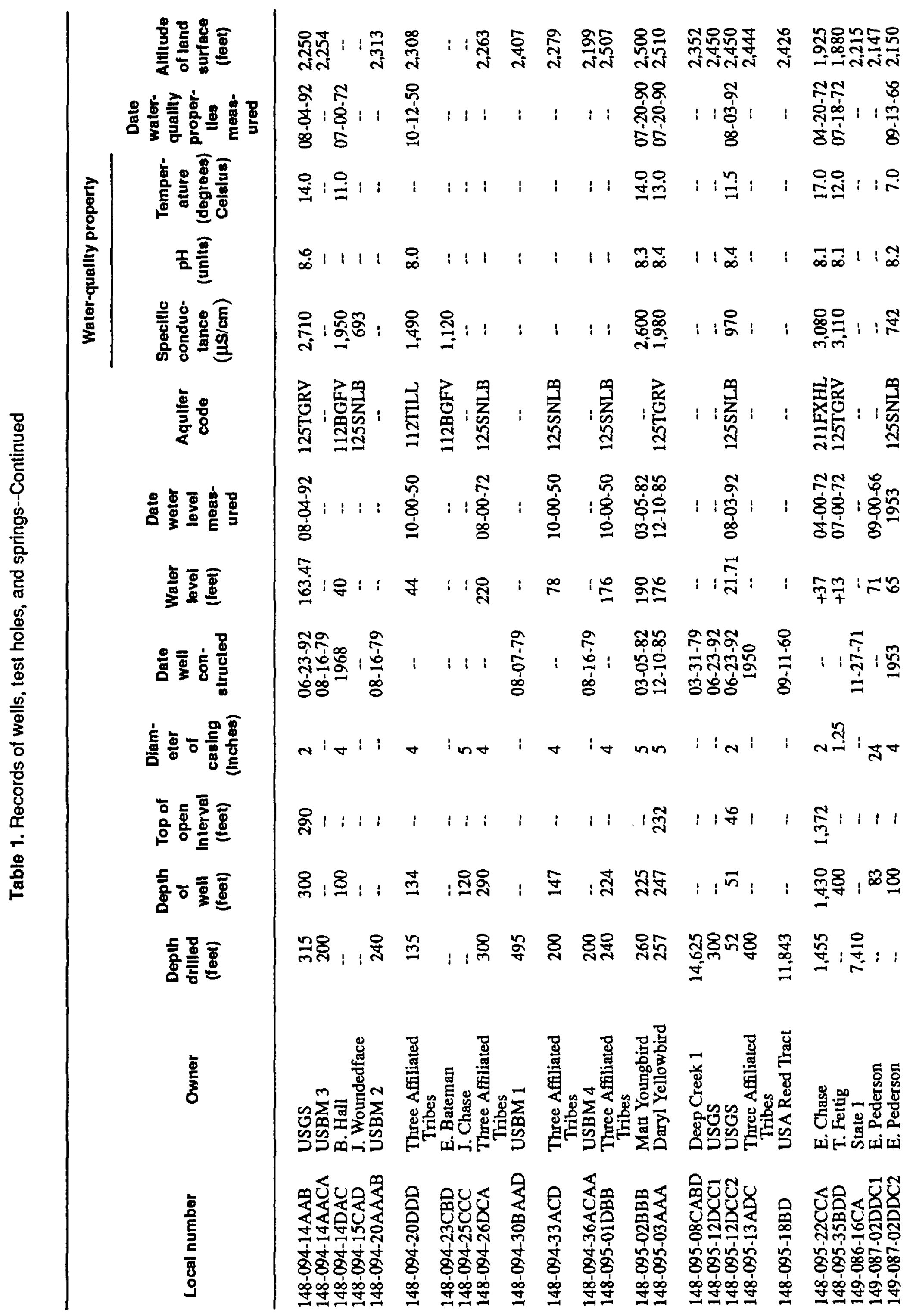




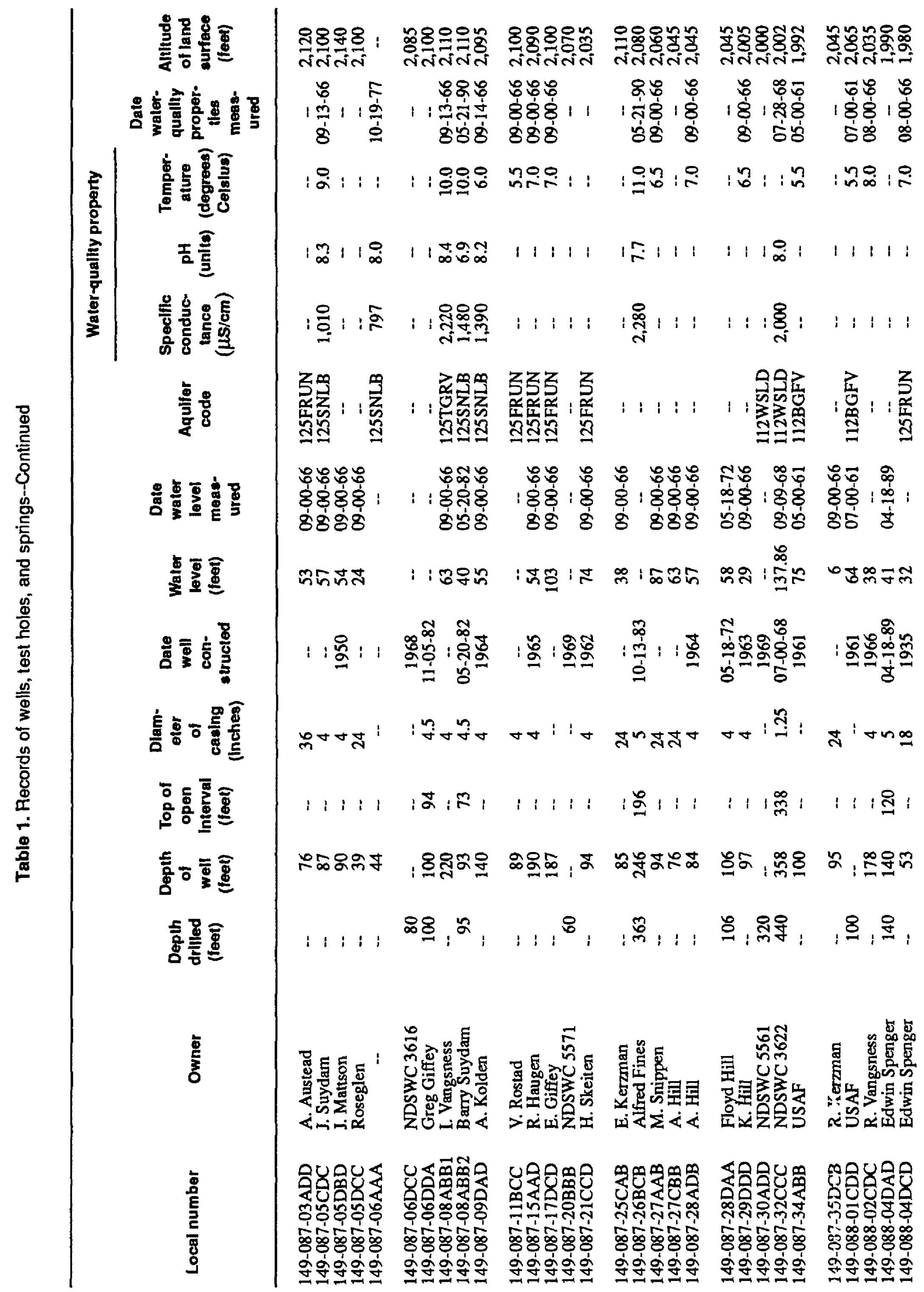









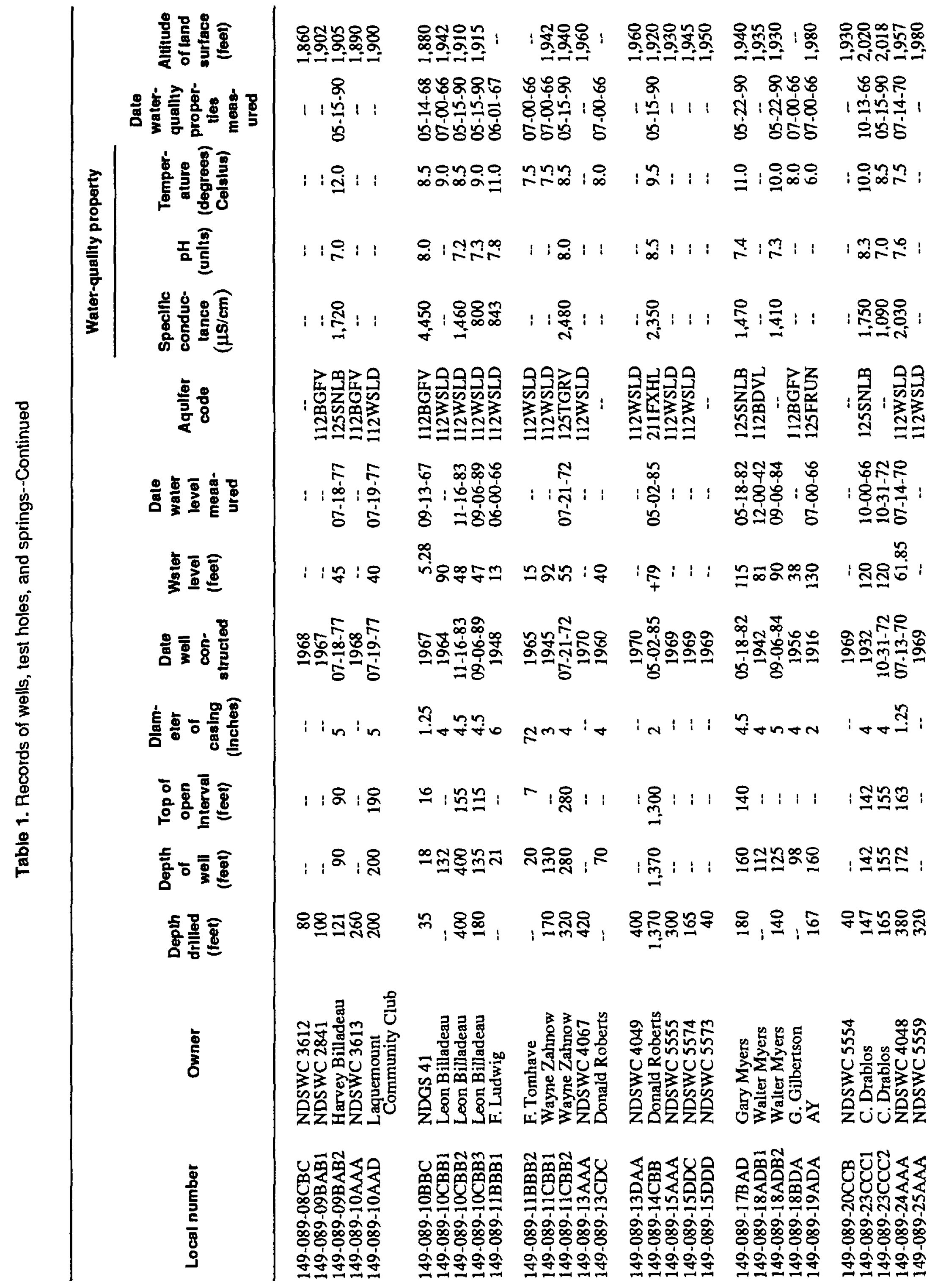




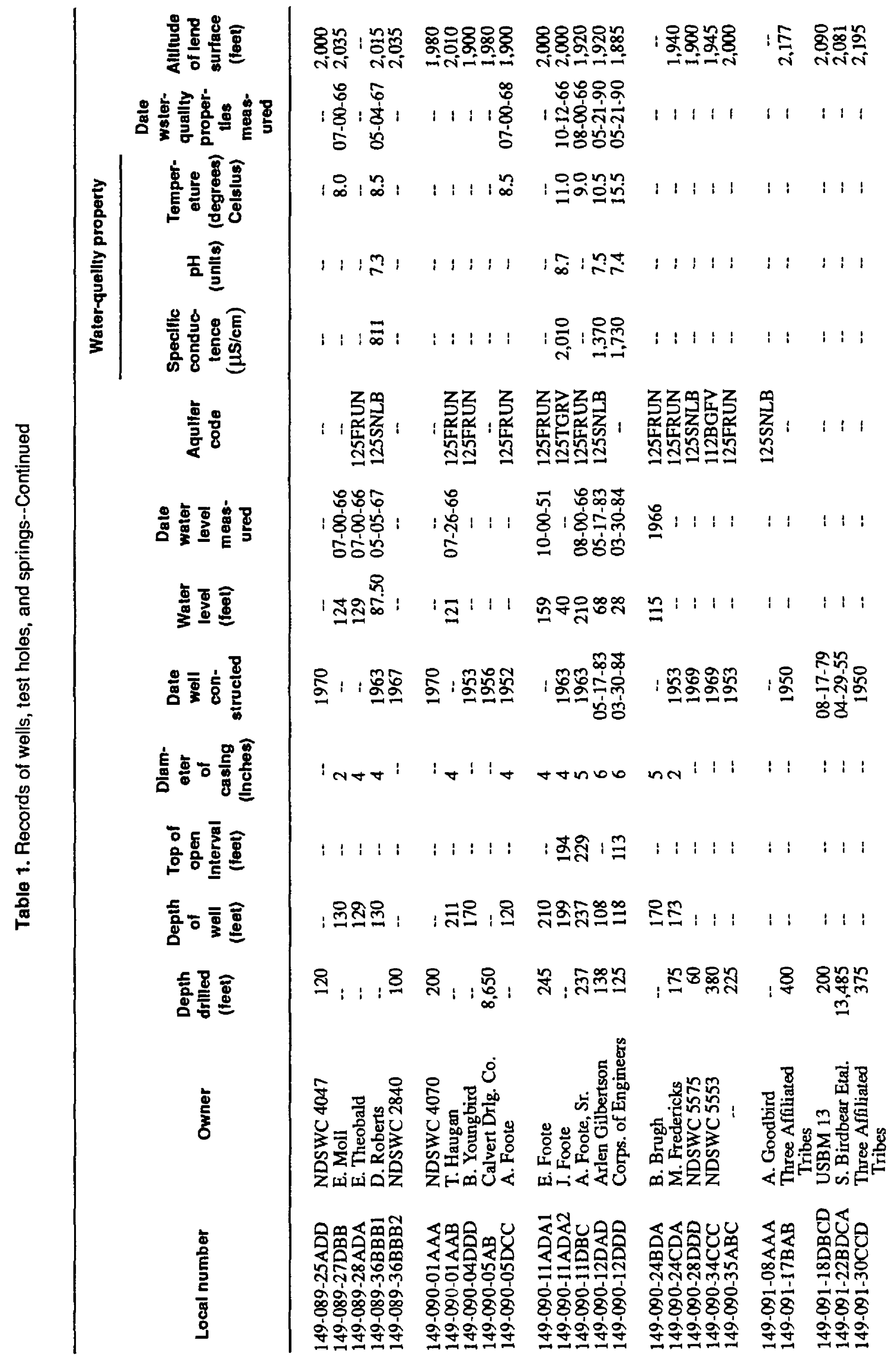




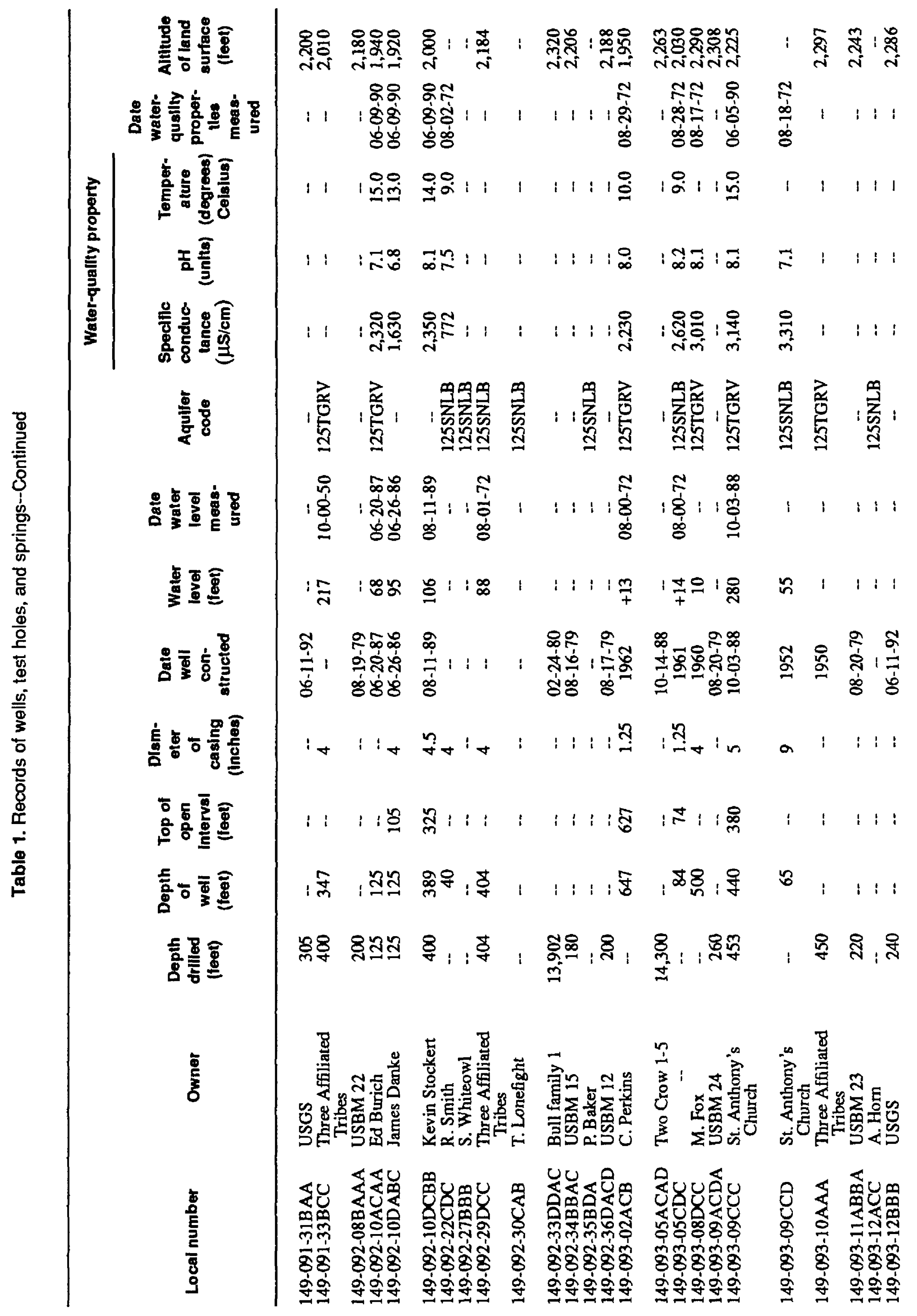




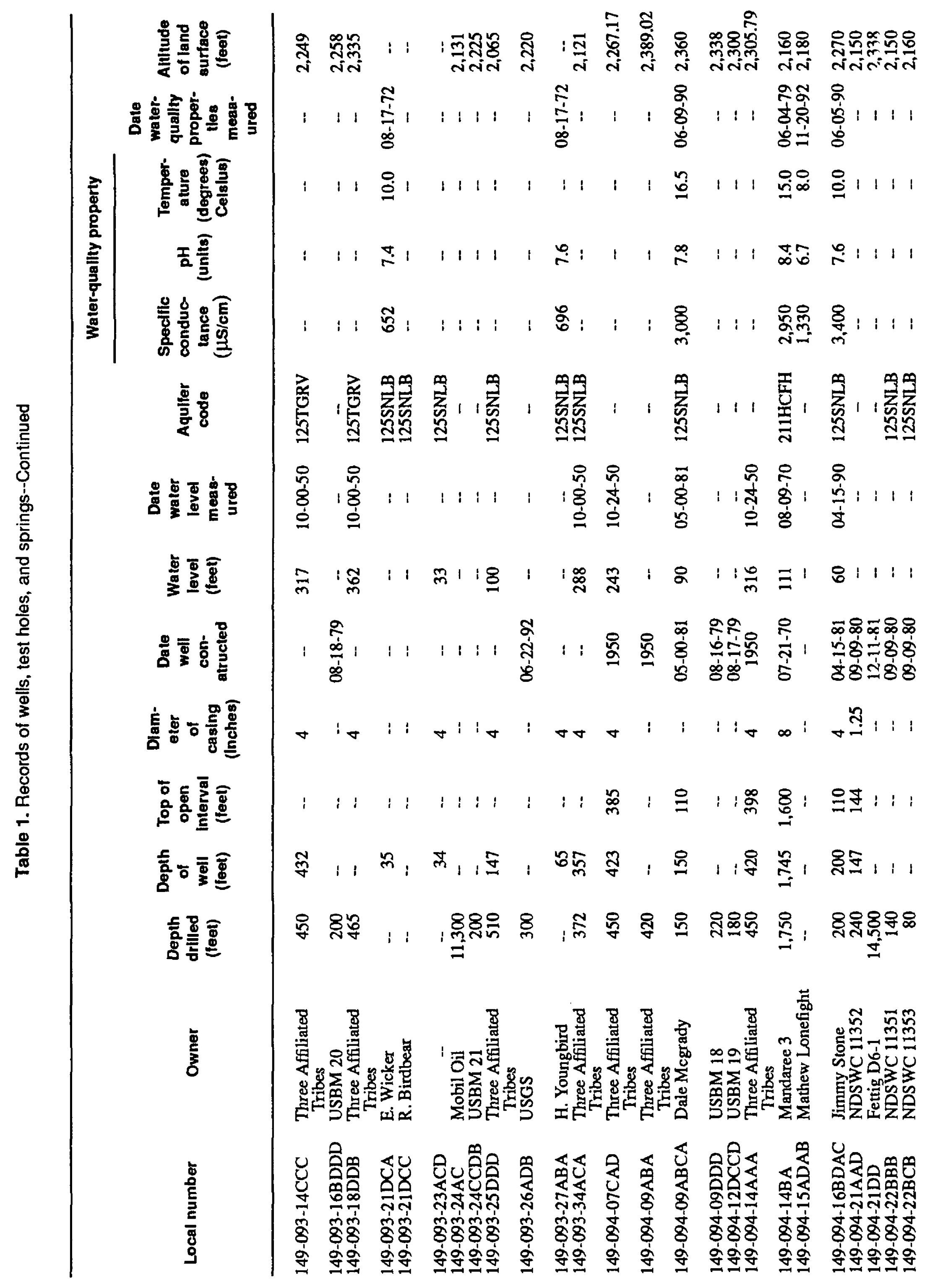




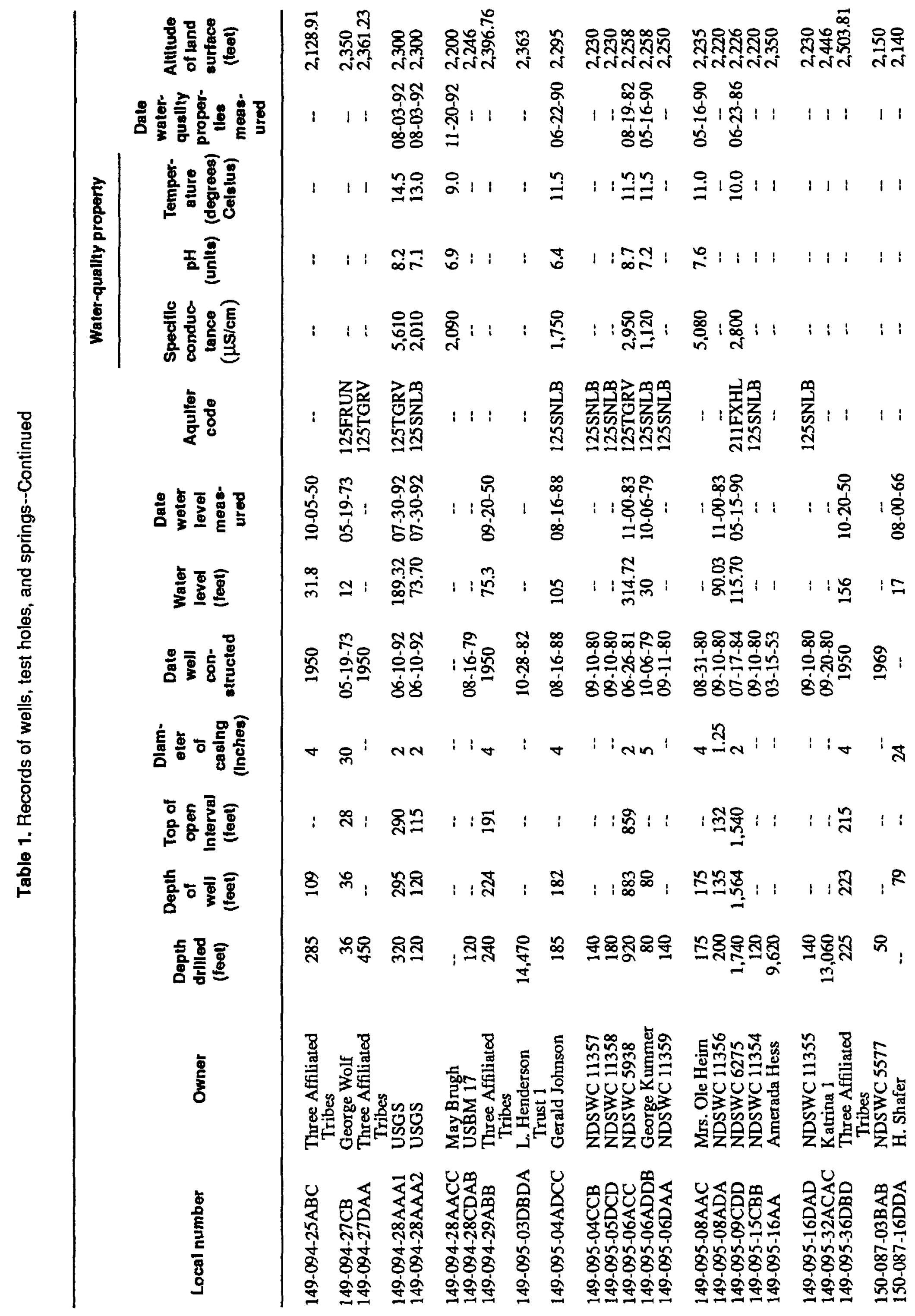




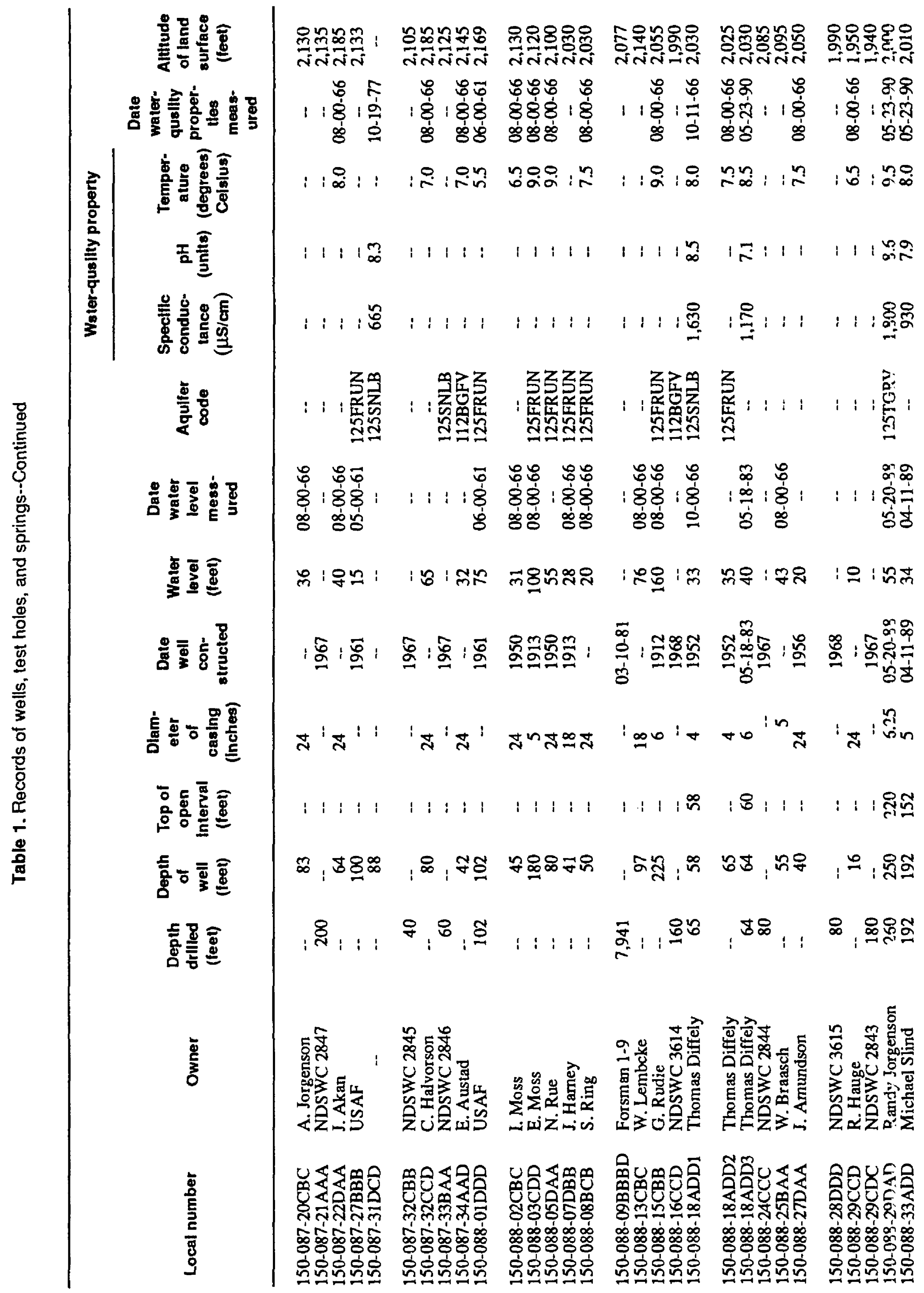




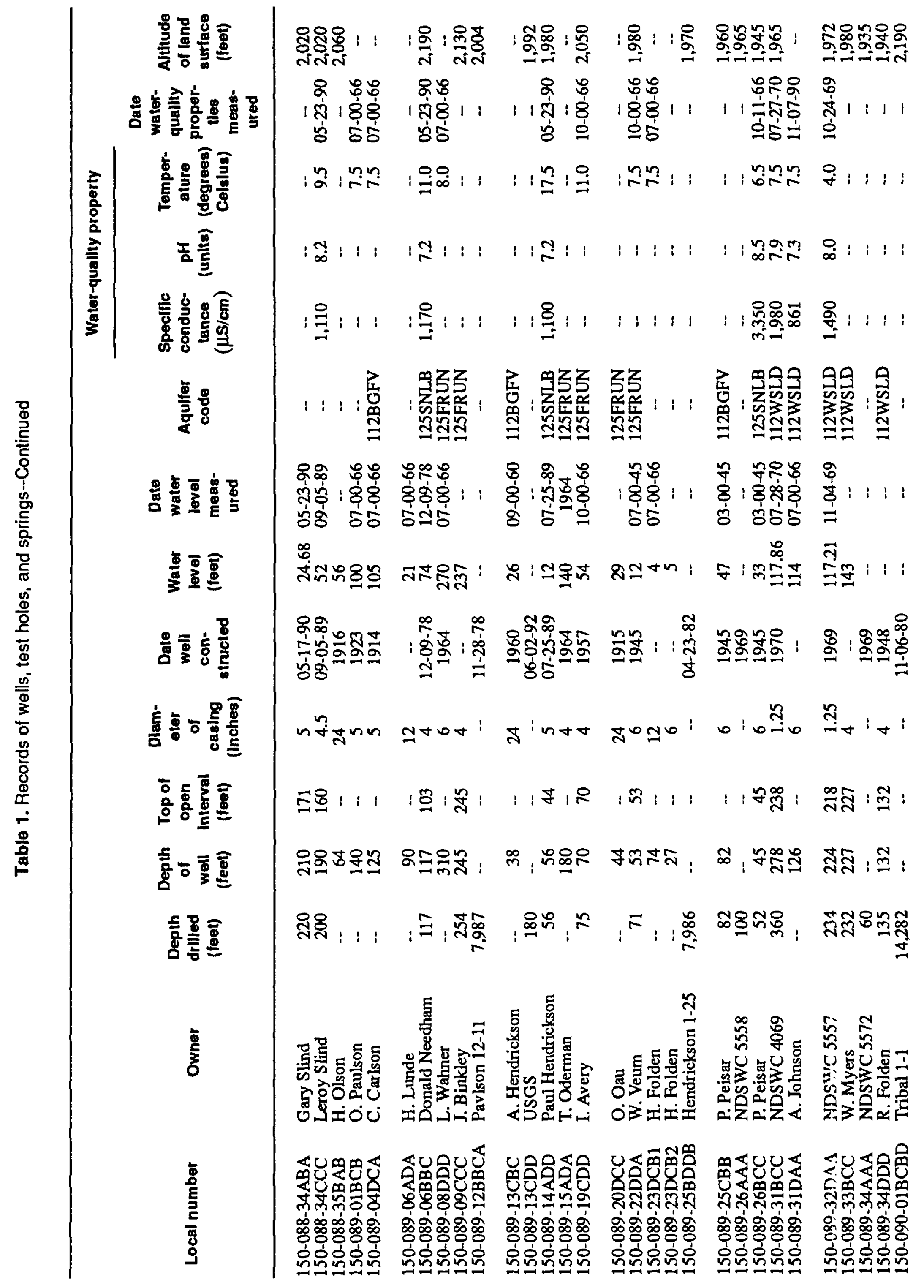




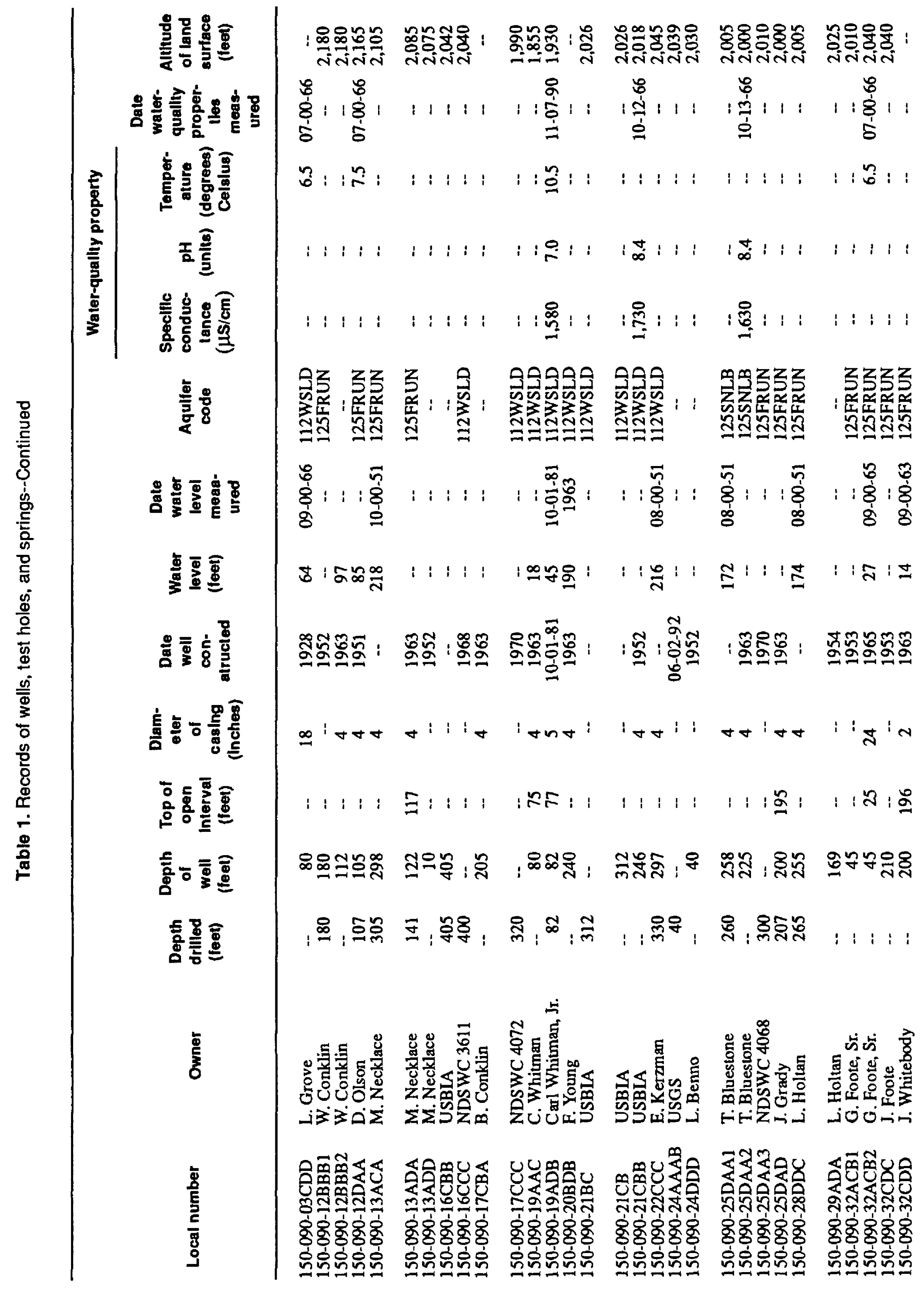




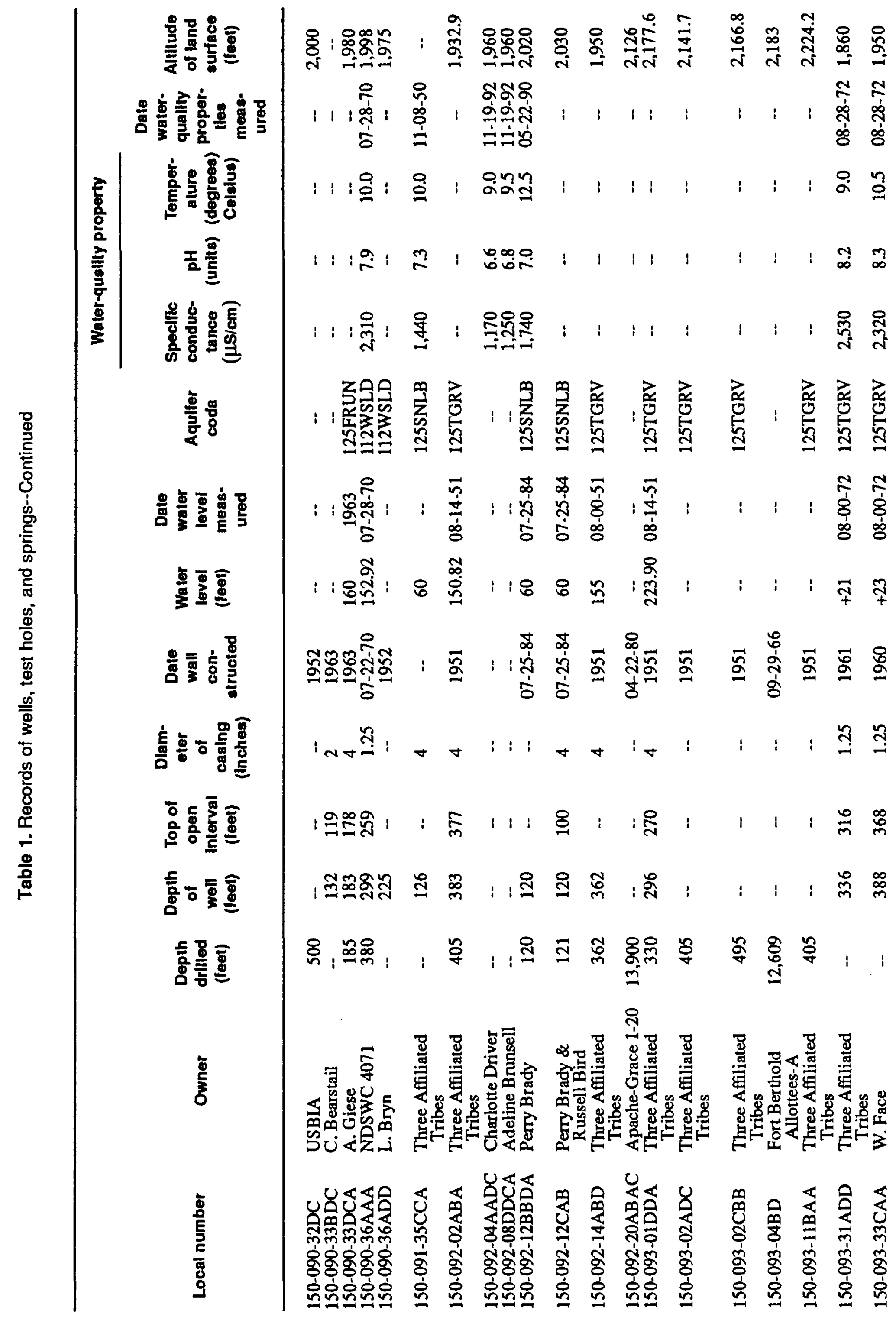




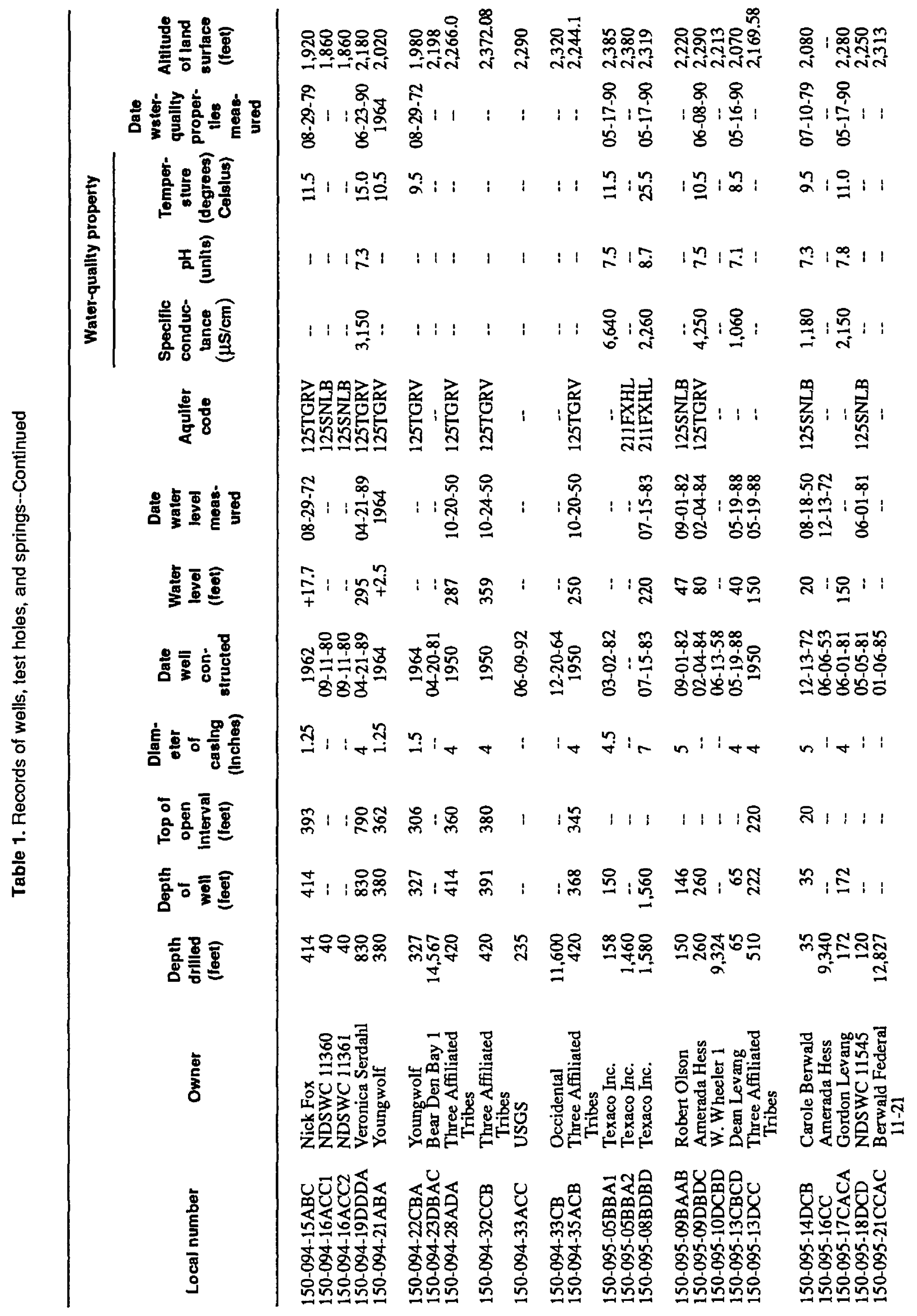




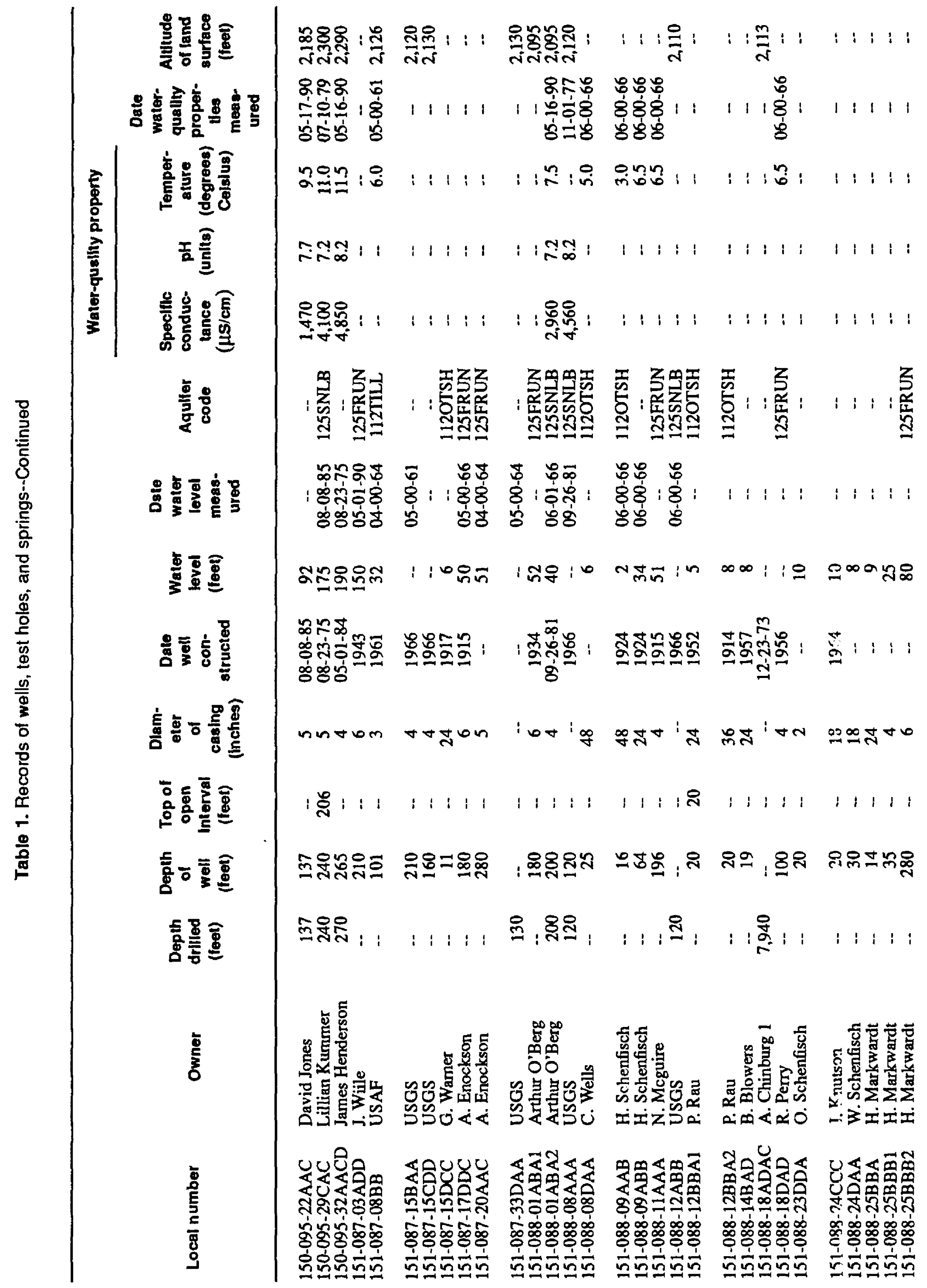




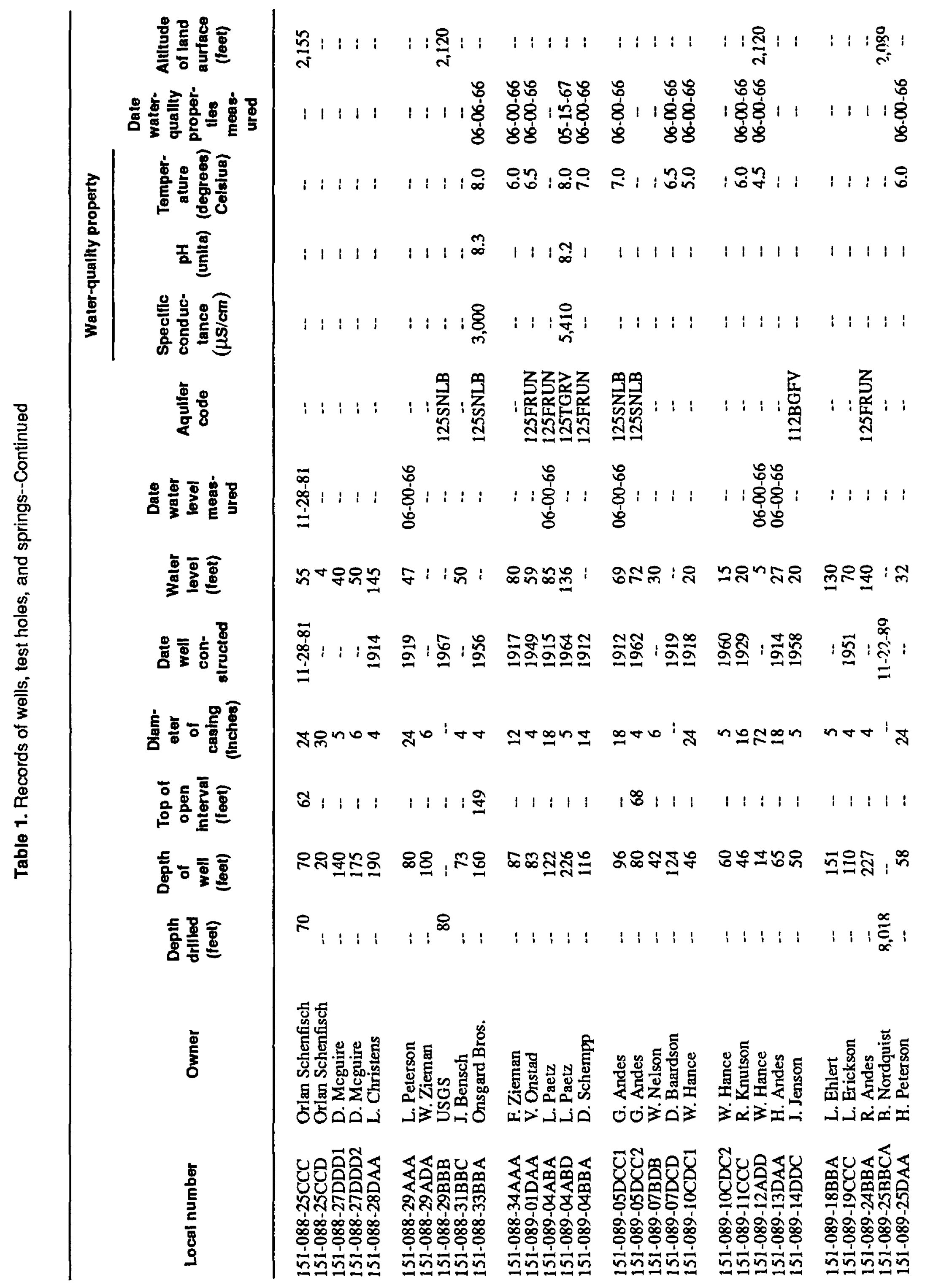









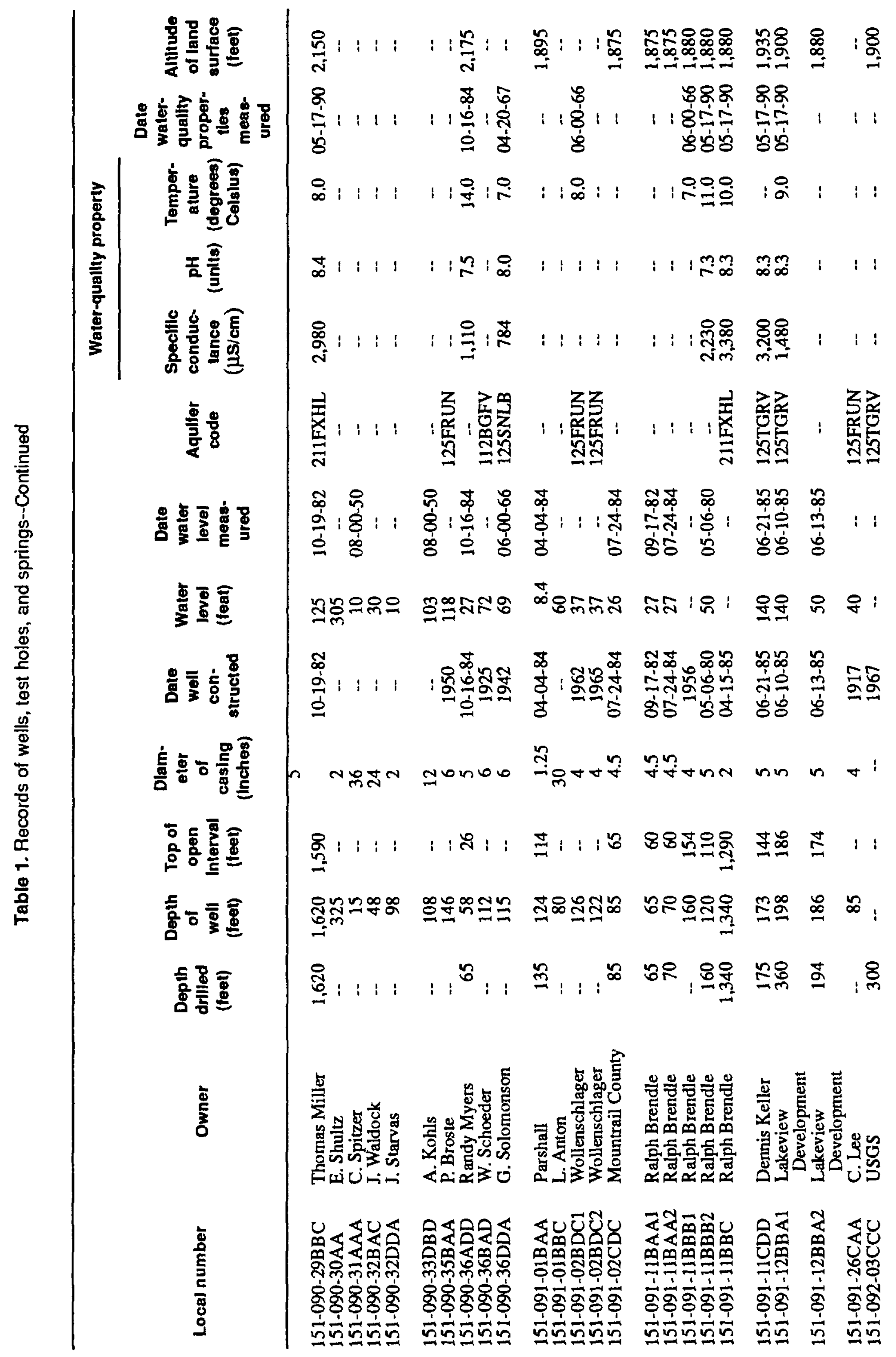




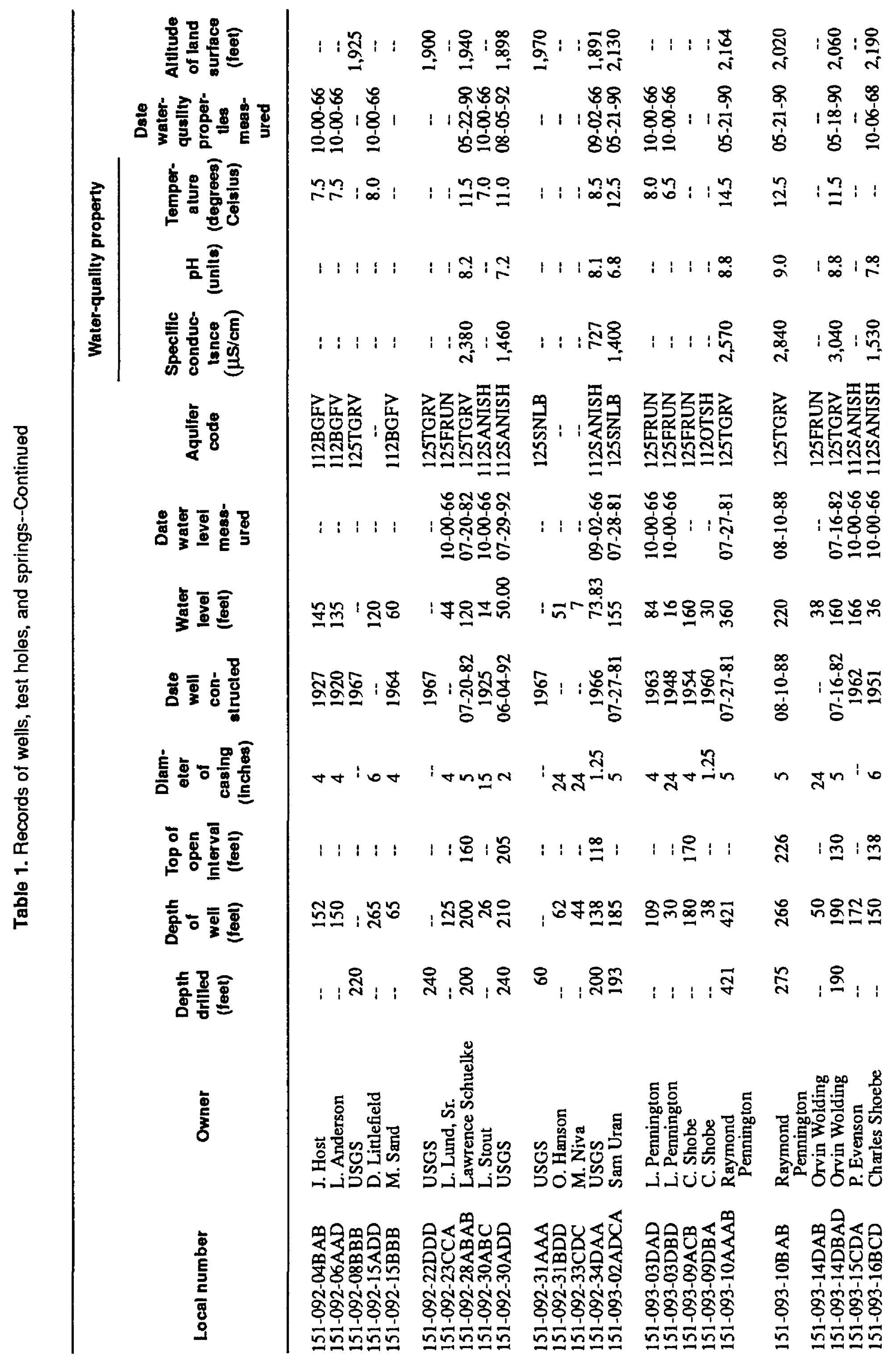









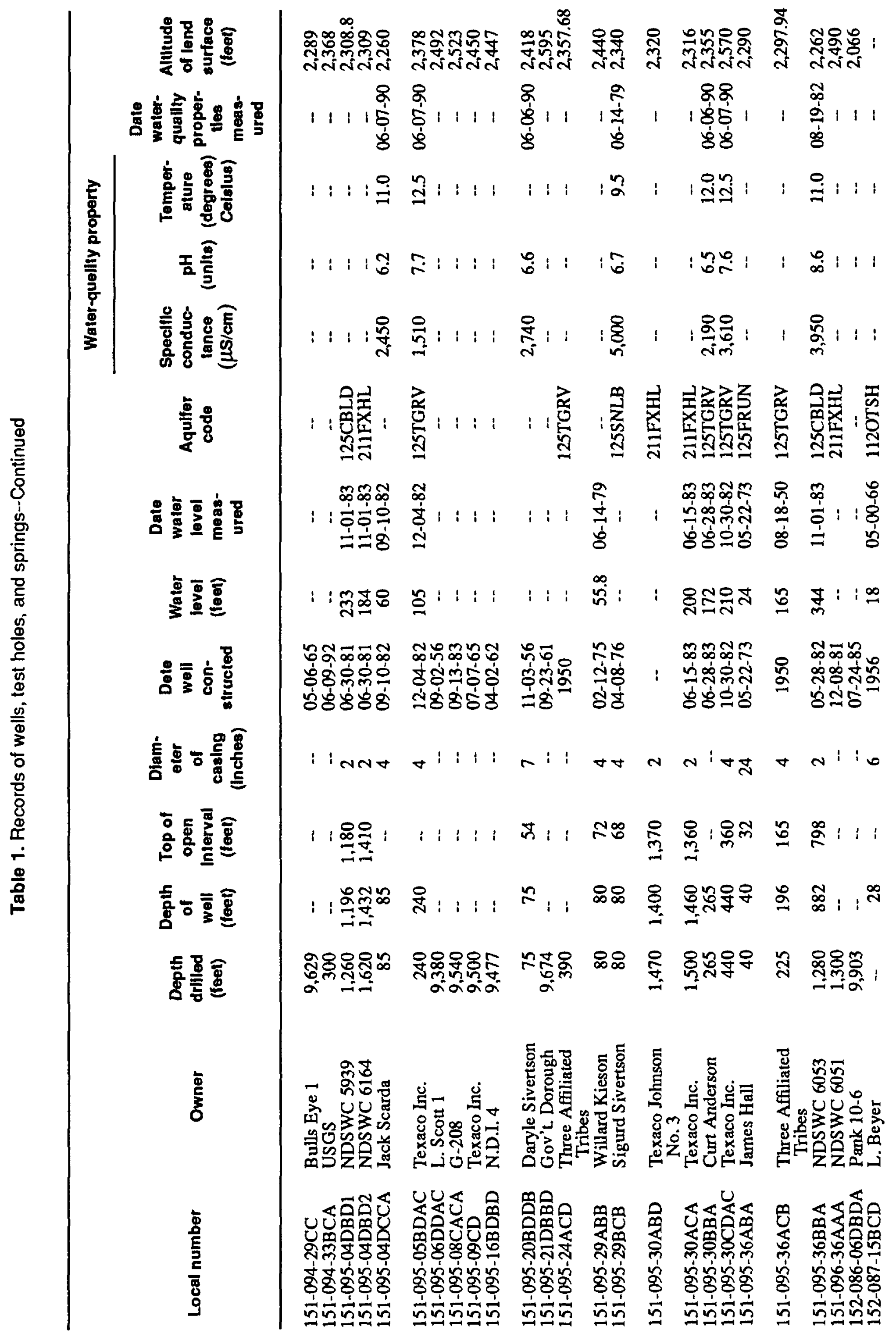




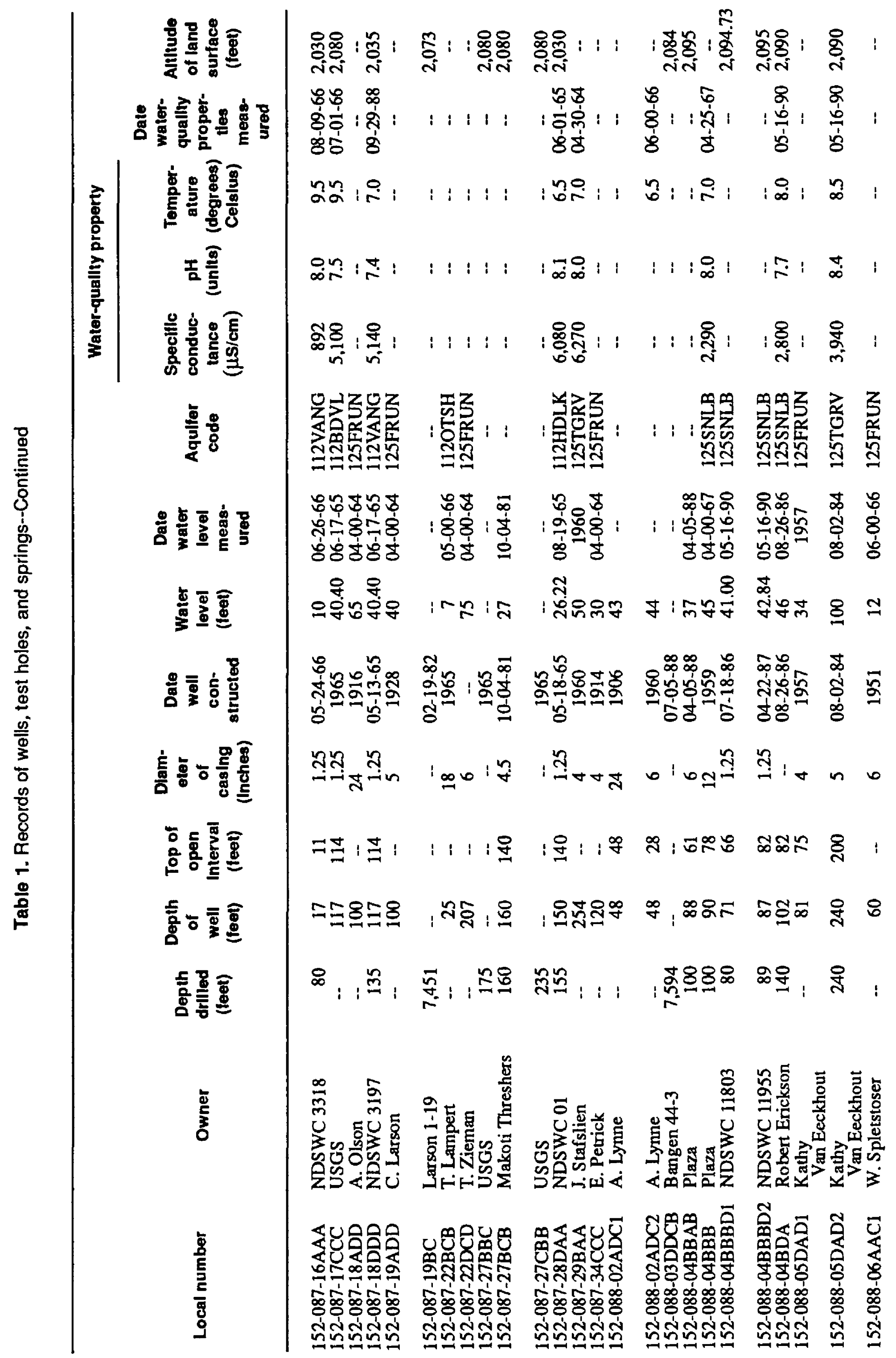




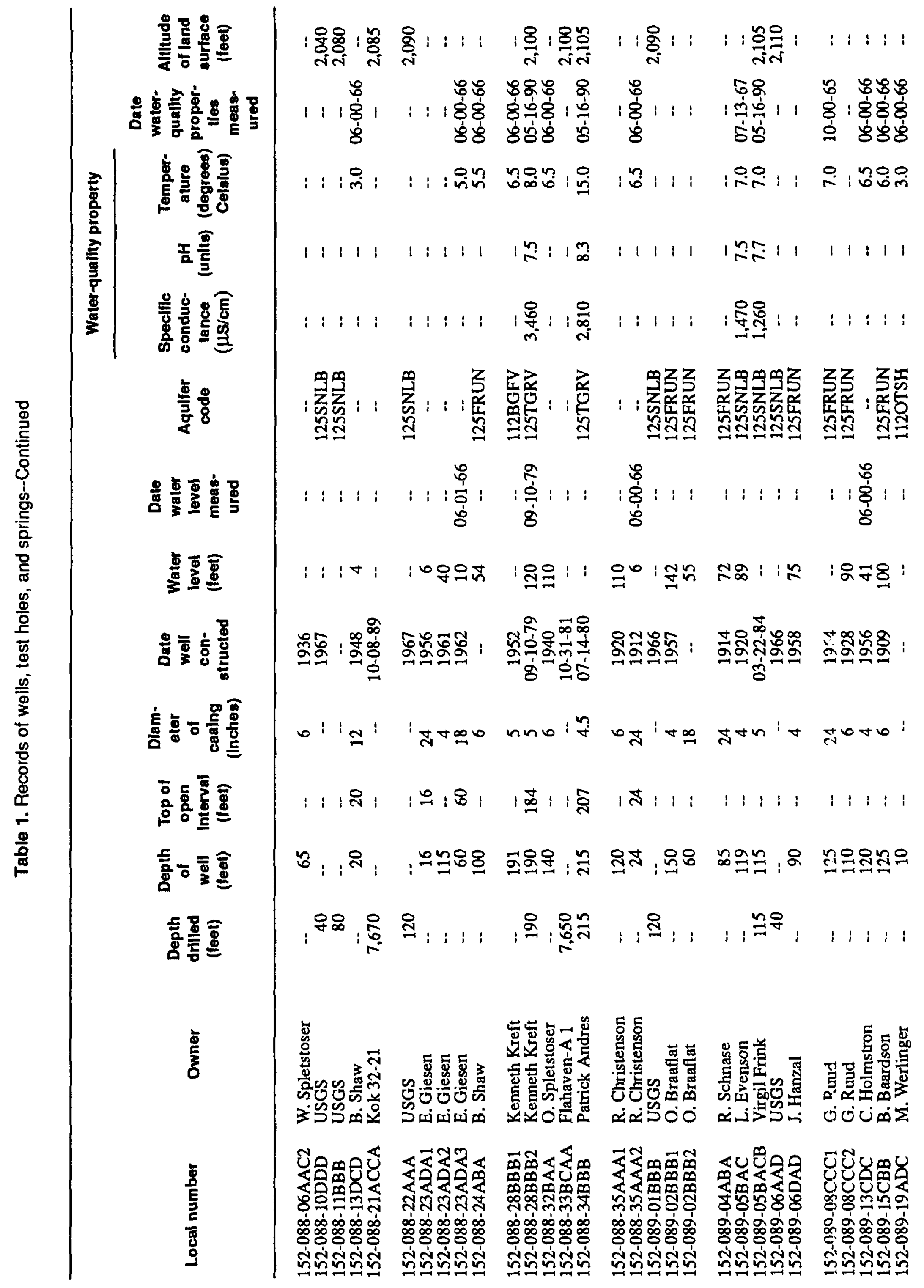




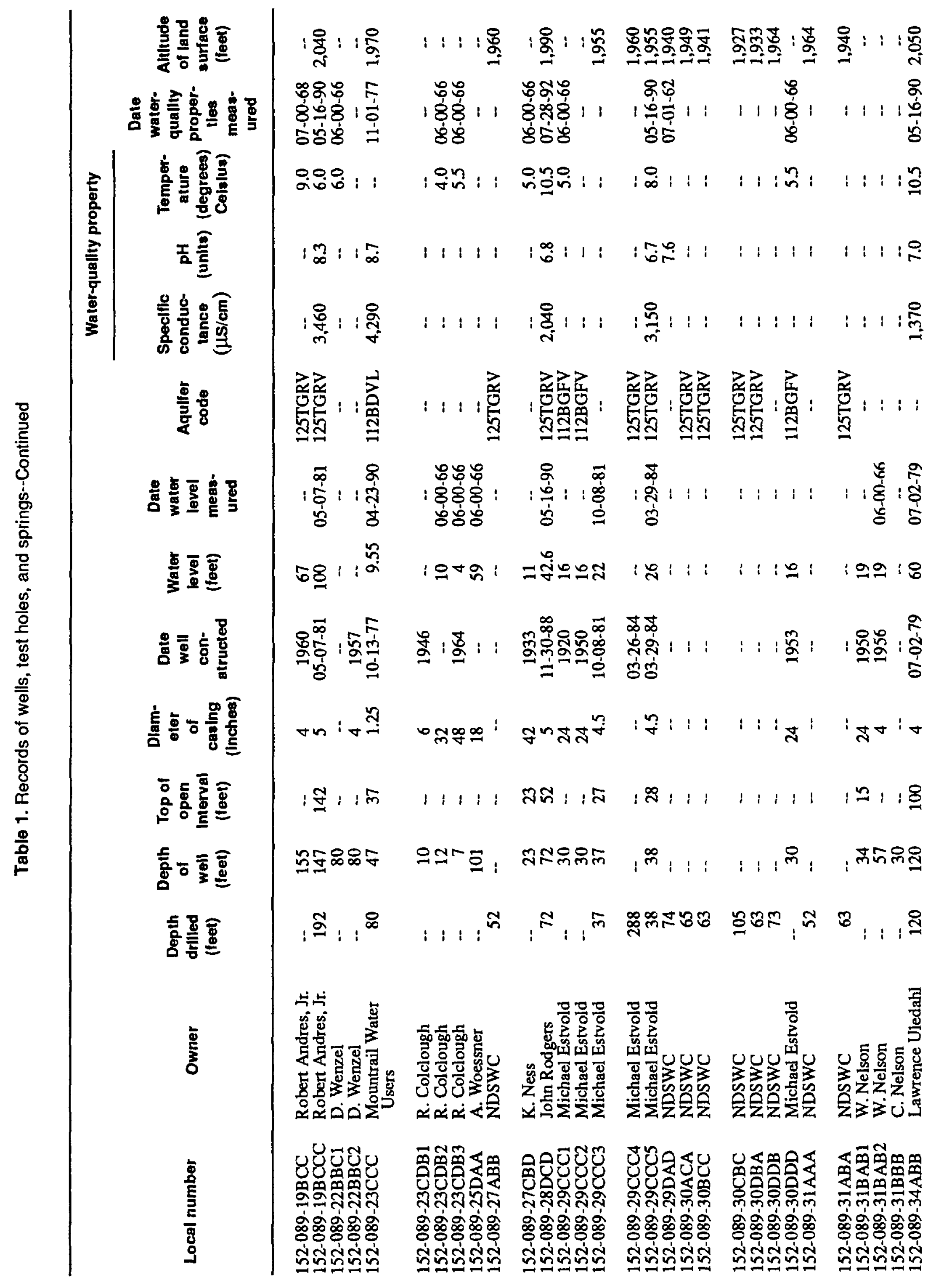




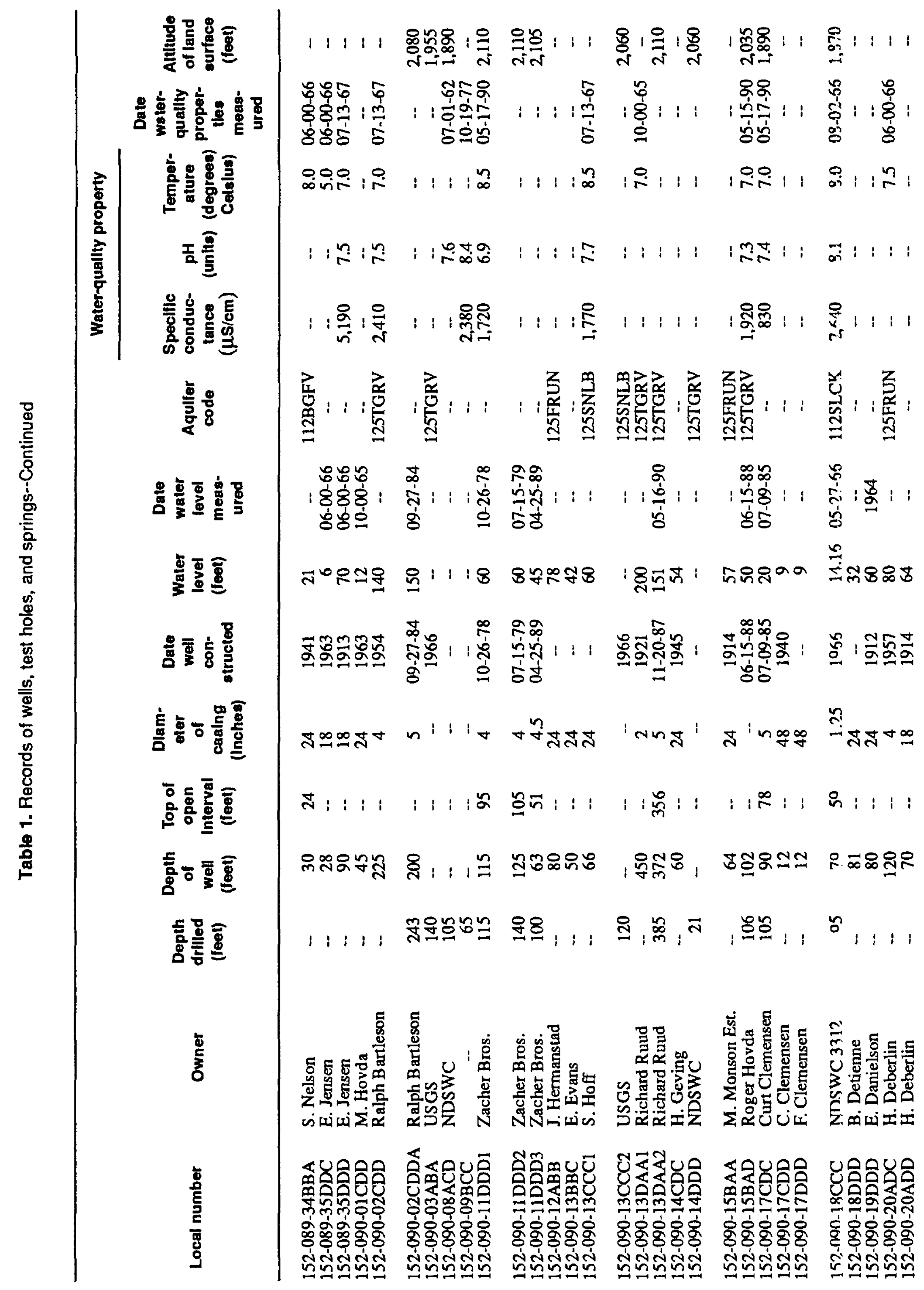




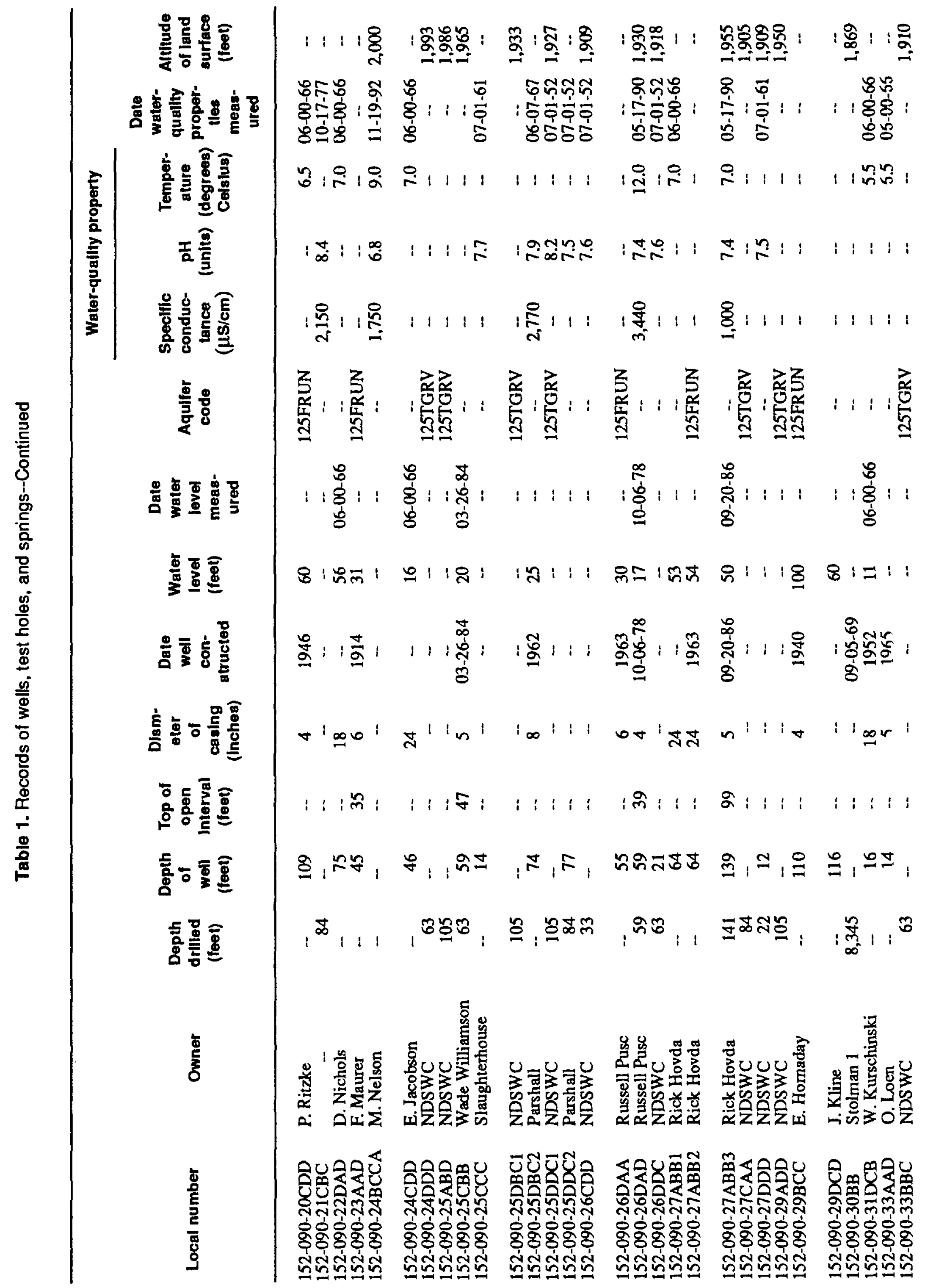




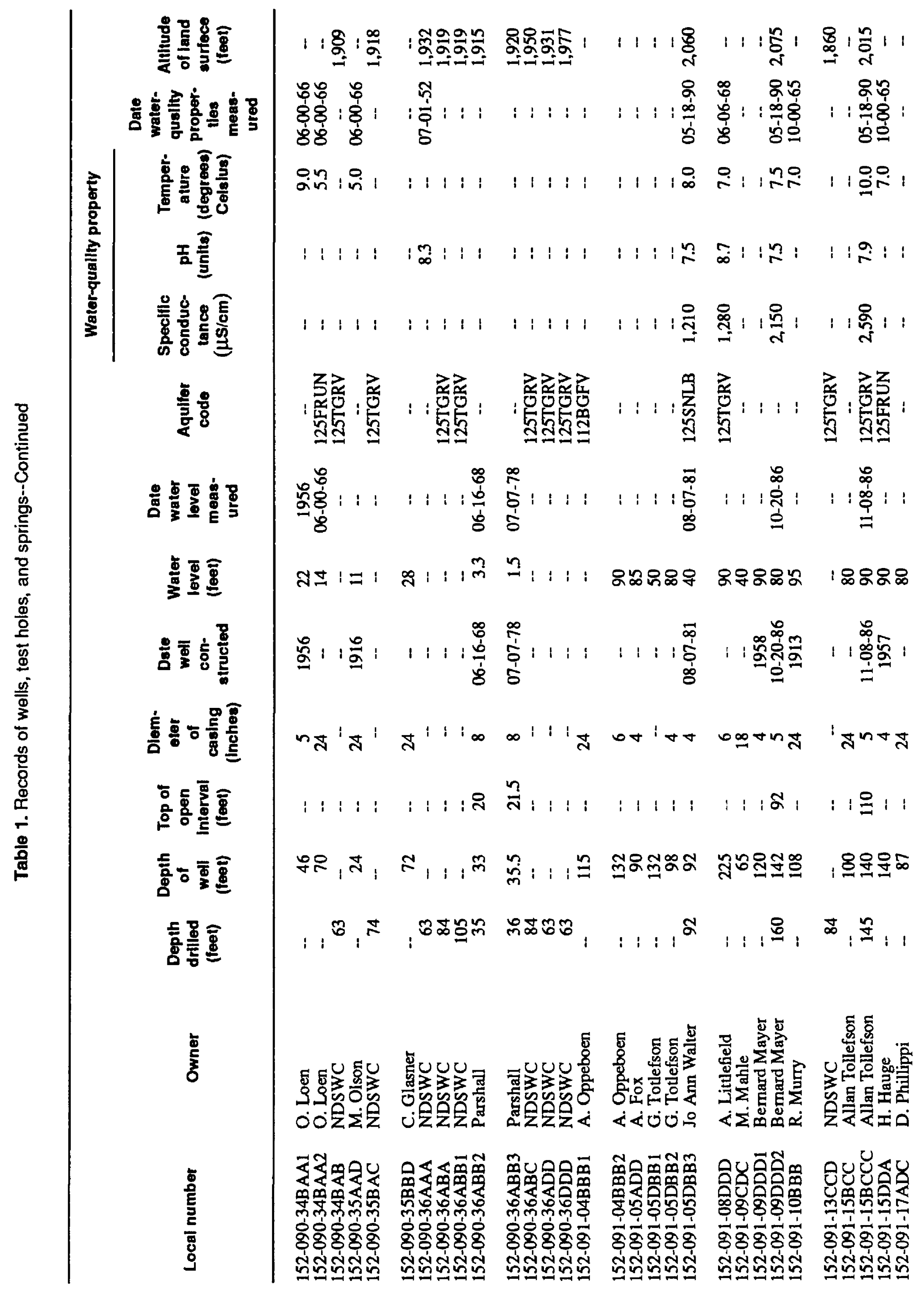









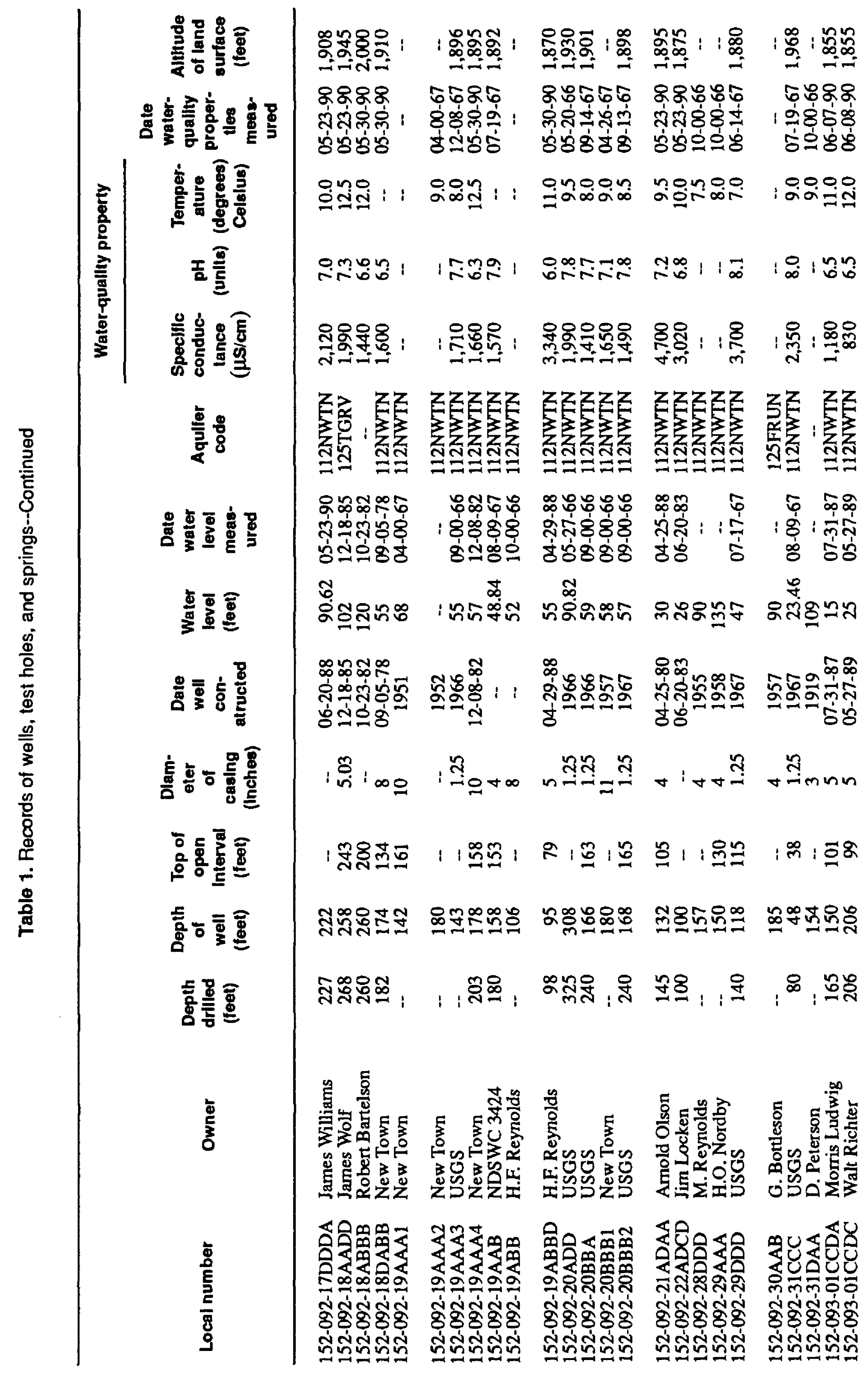




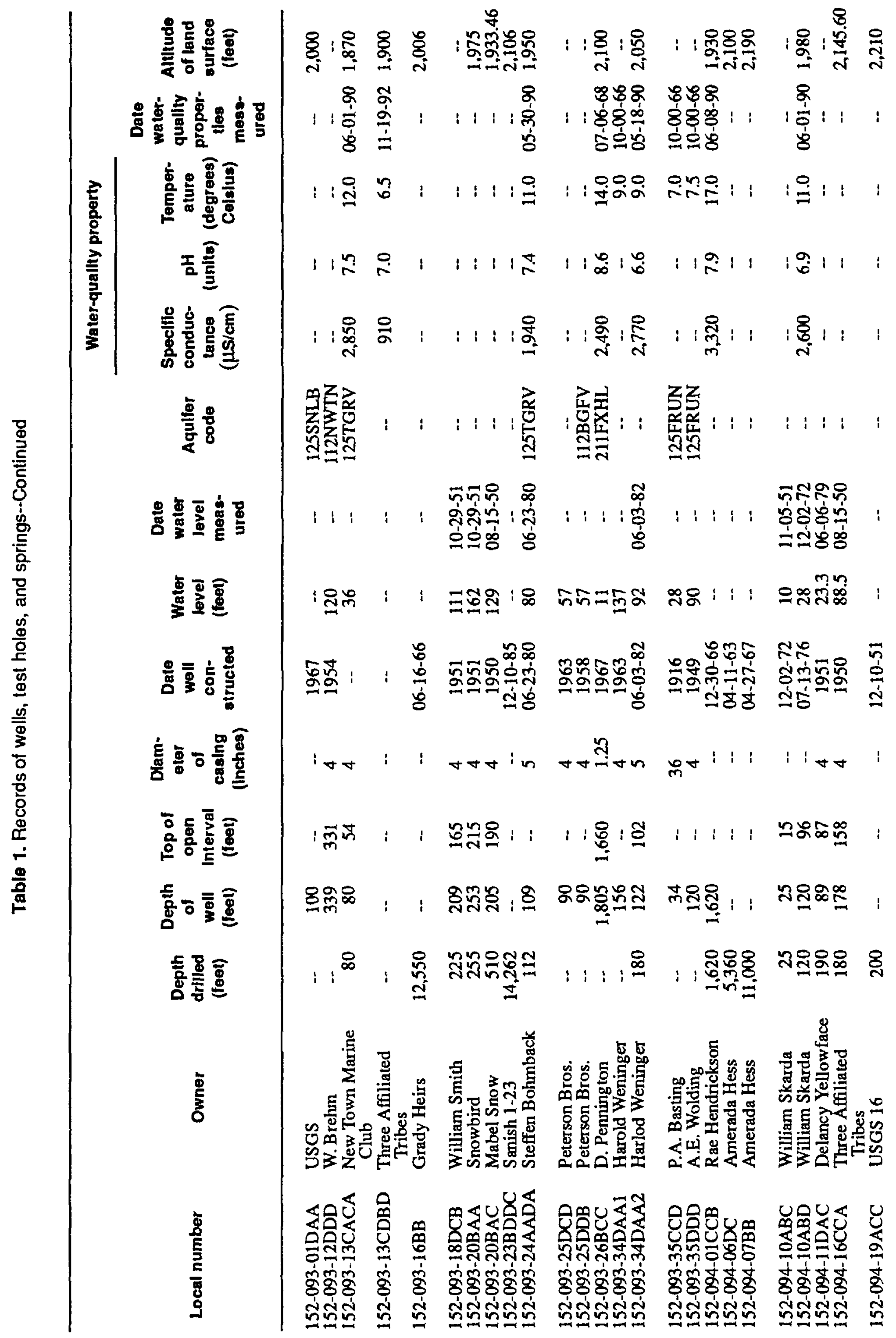









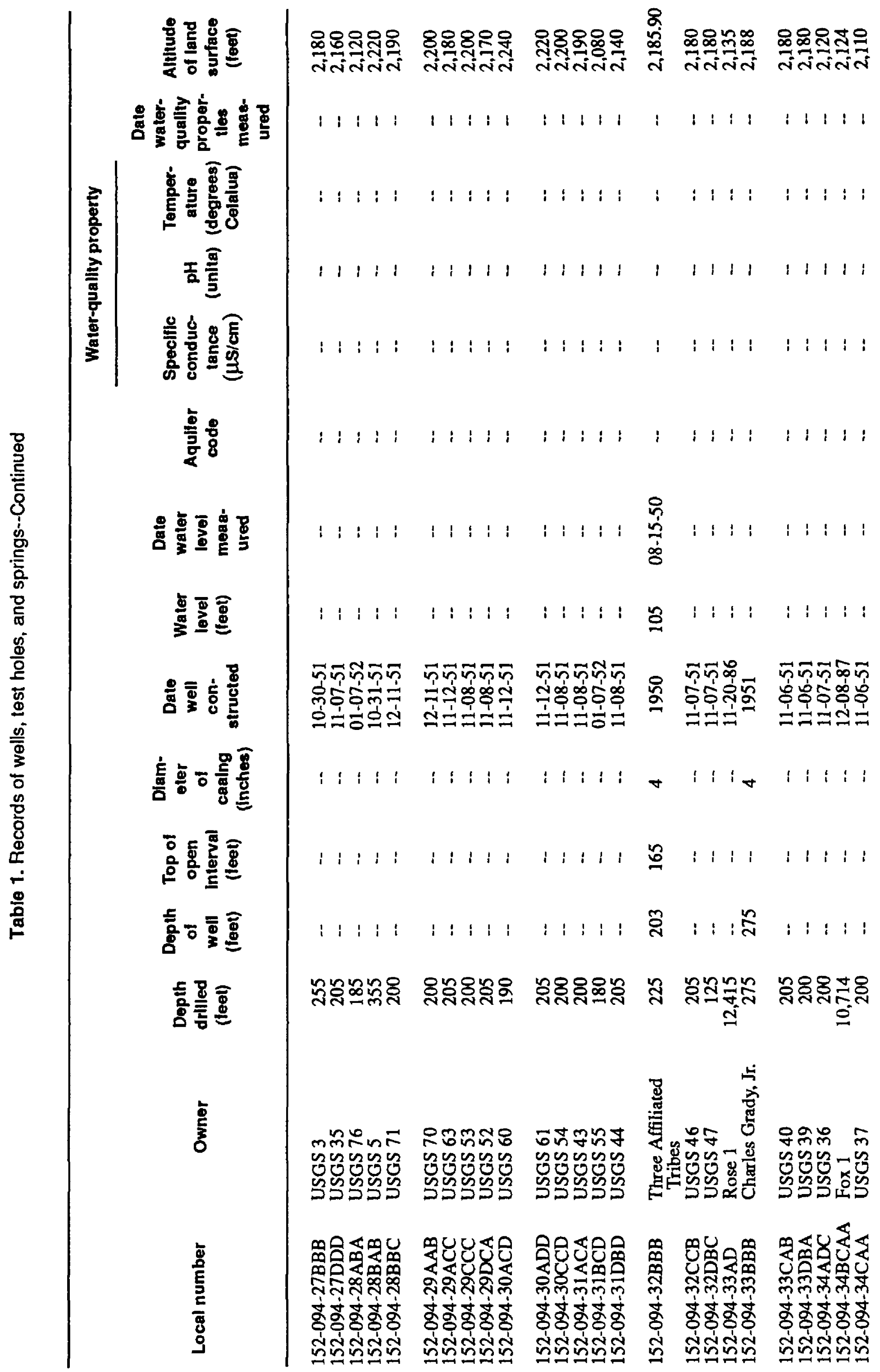




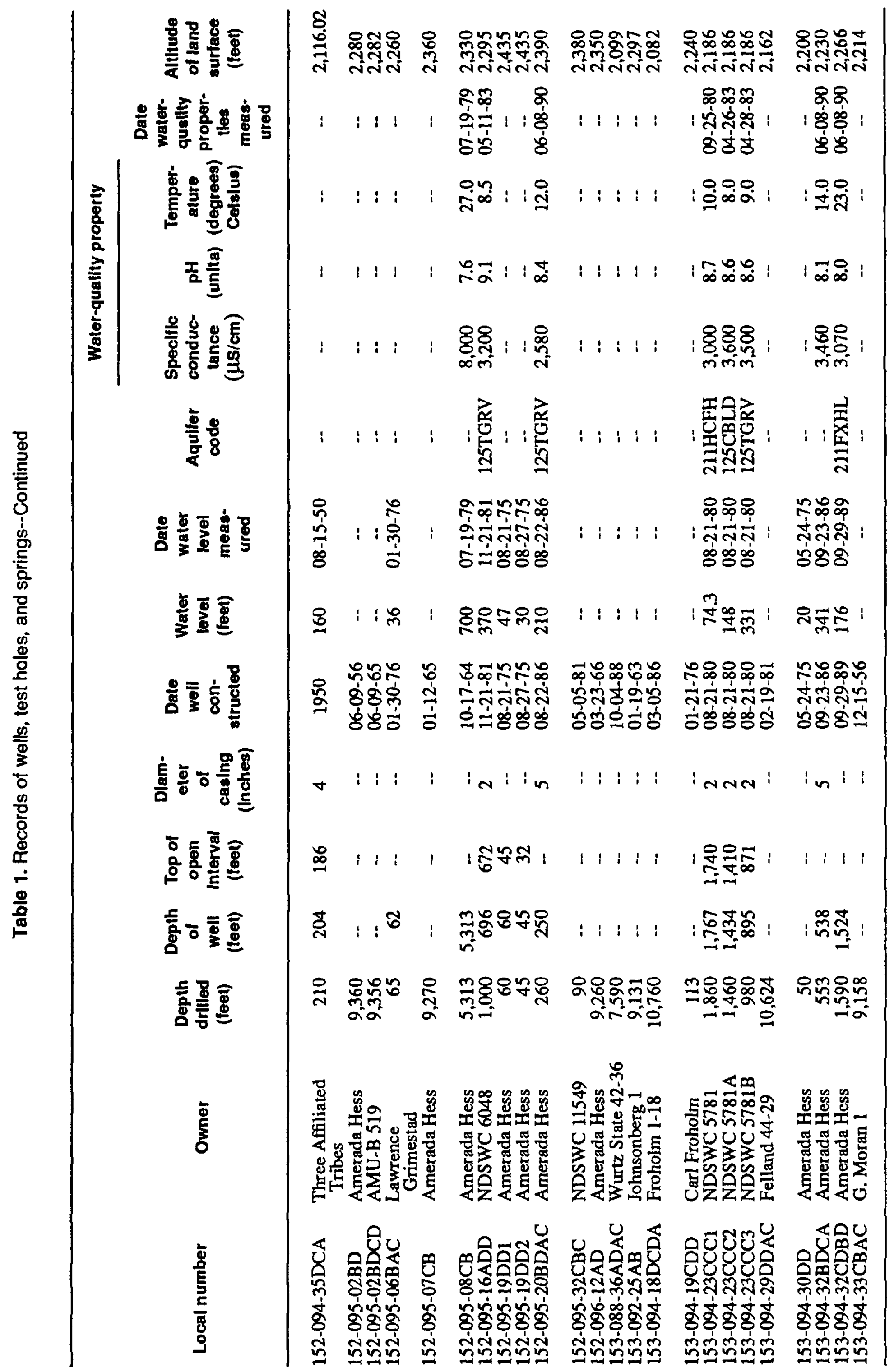


Table 2. Water levels for selected wells

\section{Owner}

NDSWC 3575, North Dakota State Water Commission, well number 3575

USGS, U.S. Geological Survey

\section{Aquifer code}

Pleistocene

112BDVL Buried valley deposits

112HDLK Hidden Lake aquifer

112NWTN New Town aquifer

112SANISH Sanish aquifer

112VANG Vang aquifer

112WSLD White Shield aquifer

Paleocene

$125 C B L D$

125SNLB

Cannonball-Ludlow Members of Fort Union Formation

125TGRV

Sentinel Butte Member of Fort Union Formation

Tongue River Member of Fort Union Formation

Cretaceous

211FXHL

Fox Hills Sandstone

$211 \mathrm{HCFH}$

Hell Creek Formation-Fox Hills Sandstone

Abbrevlations and symbois

- , no data 
Table 2. Water levels for selected wells-Continued

Owner: USGS

146-089-10CBD

Aquifor code: 125TGRV

Date drillisd: 06-25-92 Aititude: 1,880 foet

Well depth: 241 feet

\begin{tabular}{|c|c|c|c|c|c|c|c|}
\hline Date measured & $\begin{array}{l}\text { Water } \\
\text { level } \\
\text { (foet) }\end{array}$ & Date measured & $\begin{array}{l}\text { Water } \\
\text { lovel } \\
\text { (foet) }\end{array}$ & Date measured & $\begin{array}{l}\text { Water } \\
\text { level } \\
\text { (foet) }\end{array}$ & Date mesauret & $\begin{array}{l}\text { Water } \\
\text { level } \\
\text { (foet) }\end{array}$ \\
\hline $\begin{array}{l}\text { Aug. } 3,1992 \ldots \ldots \\
\text { Aug. } 28 \ldots \ldots \ldots\end{array}$ & $\begin{array}{l}57.48 \\
55.25\end{array}$ & Oct. $2,1992 \ldots \ldots$ & 55.78 & \multicolumn{2}{|c|}{$\begin{array}{l}\text { Highest water level: } \\
\text { Aug. 28, } 1992 \ldots \ldots \ldots 55.25\end{array}$} & \multicolumn{2}{|c|}{$\begin{array}{l}\text { Lowest water level: } \\
\text { Aug. } 3,1992 \ldots \ldots \ldots .57 .48\end{array}$} \\
\hline
\end{tabular}

Owner: NDSWC 3575

Aquifer code: $211 \mathrm{FXHL}$ Altitude: 2,120 foet

\begin{tabular}{|c|c|}
\hline Date measured & $\begin{array}{l}\text { Weter } \\
\text { level } \\
\text { (foet) }\end{array}$ \\
\hline $\begin{array}{l}\text { July } 15,1968 \ldots \ldots \ldots \\
\text { Aug. } 9 \ldots \ldots \\
\text { Sept } 4 \ldots \ldots \\
\text { Oct. } 2 \ldots \ldots \\
\text { Nov. } 5 \ldots \ldots \\
\text { Dec. } 4 \ldots \ldots \\
\text { Jan. } 17,1969 \ldots \ldots \\
\text { Feb. } 11 \ldots \ldots \\
\text { Mar. } 18 \ldots \ldots \\
\text { Ap. } 16 \ldots \ldots \\
\text { May } 21 \ldots \ldots \\
\text { June } 11 \ldots \ldots \\
\text { July } 16 \ldots \ldots \\
\text { July } 23 \ldots \ldots \\
\text { Aug. } 7 \ldots \ldots \\
\text { Sept } 8 \ldots \ldots \\
\text { Oct. } 28 \ldots \ldots \\
\text { Nov. } 20 \ldots \ldots \\
\text { Dec. } 16 \ldots \ldots \\
\text { Nov. } 30,1970 \ldots \ldots \\
\text { Dec. } 1,1971 \ldots \ldots \\
\text { June } 23,1972 \ldots \ldots \\
\text { Sept. } 19 \ldots \ldots \\
\text { Dec. } 5 \ldots \ldots \\
\text { Apt. } 3,1973 \ldots \ldots \\
\text { June } 22 \ldots \ldots \\
\text { Sept } 18 \ldots \ldots \\
\text { Dec. } 6 . \ldots \ldots \\
\text { Mar. } 21,1974 \ldots \ldots \\
\text { June } 26 \ldots \ldots \\
\text { Sept. } 18 \ldots \ldots \\
\text { Dec. } 4 \ldots \ldots \\
\text { Mar. } 20,1975 \ldots \ldots \\
\text { June } 12 \ldots \ldots \\
\ldots\end{array} \ldots \ldots$ & $\begin{array}{l}73.18 \\
73.25 \\
72.35 \\
72.36 \\
72.37 \\
72.13 \\
72.10 \\
72.16 \\
71.92 \\
72.15 \\
72.21 \\
71.93 \\
76.40 \\
75.23 \\
74.77 \\
74.83 \\
74.82 \\
74.55 \\
74.55 \\
73.52 \\
73.72 \\
73.71 \\
73.61 \\
74.30 \\
73.90 \\
73.75 \\
73.93 \\
73.94 \\
73.83 \\
74.10 \\
74.39 \\
74.38 \\
74.35 \\
74.08\end{array}$ \\
\hline
\end{tabular}

$146-090-20 \mathrm{CCC}$

Date drillind: 06-18-68 Well dept' 1,574 feet

\begin{tabular}{|c|c|c|c|c|c|}
\hline Date measured & $\begin{array}{l}\text { Water } \\
\text { level } \\
\text { (feet) }\end{array}$ & Dete measured & $\begin{array}{l}\text { Water } \\
\text { level } \\
\text { (feet) }\end{array}$ & Dete messured & $\begin{array}{l}\text { Water } \\
\text { level } \\
\text { (feet) }\end{array}$ \\
\hline 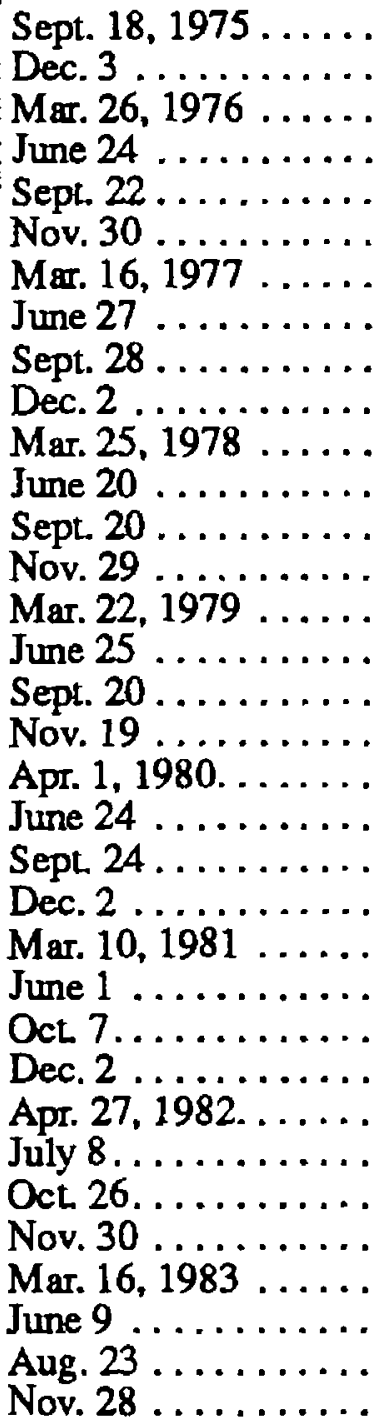 & $\begin{array}{l}74.44 \\
73.91 \\
74.54 \\
74.57 \\
73.55 \\
73.74 \\
73.79 \\
73.85 \\
74.14 \\
74.19 \\
74.39 \\
74.60 \\
75.00 \\
74.79 \\
75.14 \\
75.39 \\
75.79 \\
75.49 \\
76.19 \\
76.19 \\
76.54 \\
76.58 \\
76.88 \\
76.91 \\
77.29 \\
77.30 \\
77.88 \\
77.91 \\
77.95 \\
77.77 \\
78.38 \\
78.37 \\
78.76 \\
79.17\end{array}$ & 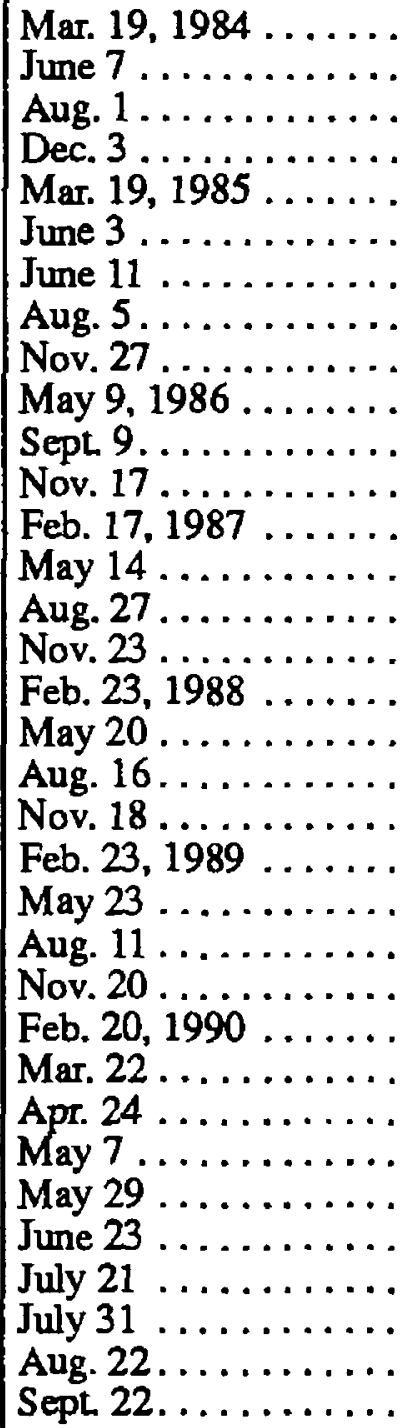 & $\begin{array}{l}79.10 \\
78.87 \\
79.50 \\
79.95 \\
79.82 \\
80.02 \\
80.12 \\
80.24 \\
80.09 \\
80.17 \\
80.82 \\
80.89 \\
81.11 \\
81.55 \\
81.85 \\
82.19 \\
83.29 \\
83.38 \\
83.59 \\
83.92 \\
83.94 \\
84.07 \\
84.62 \\
85.05 \\
84.99 \\
85.20 \\
84.85 \\
84.80 \\
85.04 \\
85.14 \\
85.45 \\
85.29 \\
85.39 \\
85.69\end{array}$ & 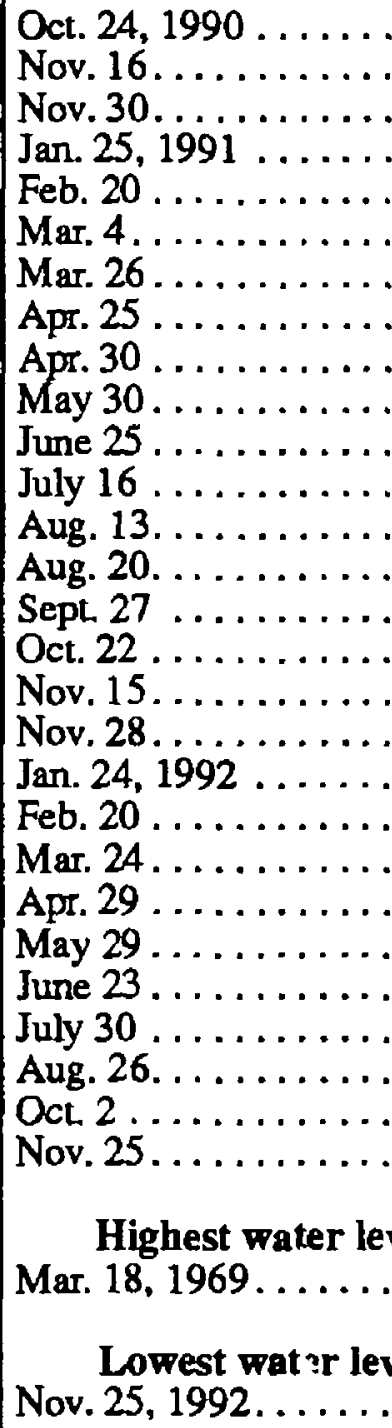 & 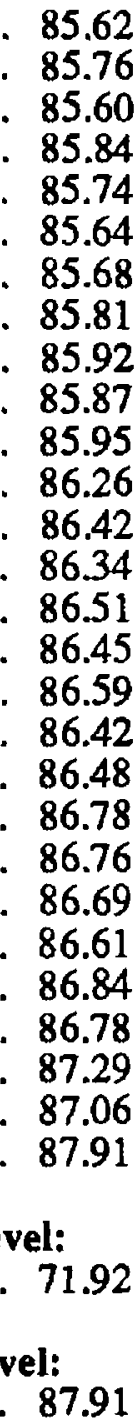 \\
\hline
\end{tabular}


Table 2 Water levels for selected wells-Continued

Owner: NDSWC 4043

148-086-20DAA

Aquiter code: 112WSLD

Date drilled: 1970 Altitude: 1,917 feet

Well depth: 208 feet

\begin{tabular}{|c|c|c|c|}
\hline $\begin{array}{l}\text { Water } \\
\text { level } \\
\text { (feet) }\end{array}$ & $\begin{array}{l}\text { Water } \\
\text { levet } \\
\text { (feet) }\end{array}$ & $\begin{array}{l}\text { Watar } \\
\text { level } \\
\text { (foat) }\end{array}$ & $\begin{array}{l}\text { Water } \\
\text { level } \\
\text { ('Aot) }\end{array}$ \\
\hline 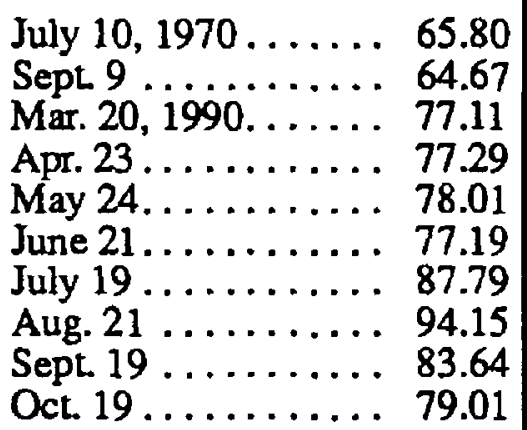 & 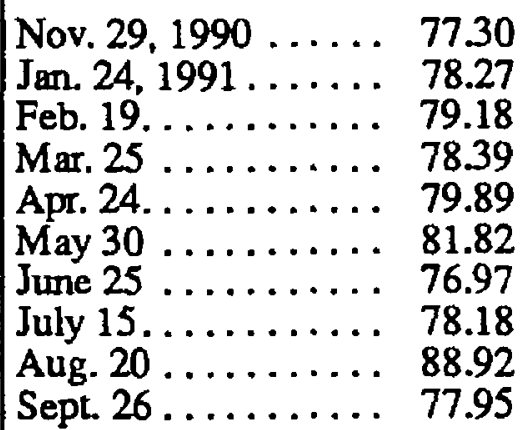 & 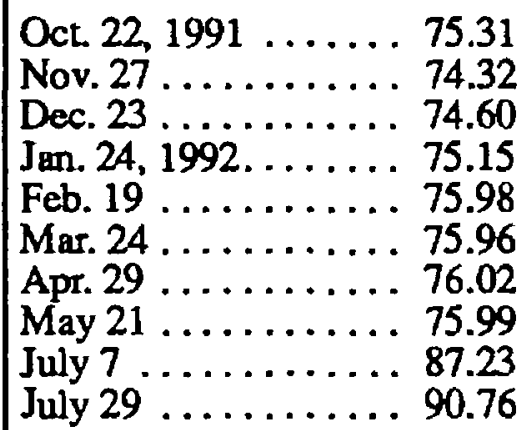 & $\begin{array}{l}\text { Aug. } 27,1992 \ldots \ldots \ldots .84 .05 \\
\text { Oct. } 1 \ldots \ldots .79 .25 \\
\text { Highest water leve'; } \\
\text { Sept. } 9,1970 \ldots \ldots .64 .67 \\
\text { Lowest water leve': } \\
\text { Aug. } 21,1990 \ldots \ldots . .94 .15\end{array}$ \\
\hline
\end{tabular}

Owner: NDSWC 4044

148-086-29AAA2

Aquifer code: 112WSLD

Date drilled: 07-00-70 Altitude: 1,902 feet

Well depth: 138 feet

\begin{tabular}{|c|c|c|c|c|c|c|}
\hline Date measured & $\begin{array}{l}\text { Water } \\
\text { level } \\
\text { (feet) }\end{array}$ & Date meaaured & $\begin{array}{l}\text { Water } \\
\text { level } \\
\text { (feet) }\end{array}$ & Date measured & $\begin{array}{l}\text { Water } \\
\text { lovel } \\
\text { (feet) }\end{array}$ & $\begin{array}{l}\text { V'ater } \\
\text { fovel } \\
\text { (inat) }\end{array}$ \\
\hline $\begin{array}{l}\text { July } 14,1970 \ldots \ldots \\
\text { Sept. } 9 \ldots \ldots \ldots \ldots \\
\text { Dec. } 1 \ldots \ldots \ldots \\
\text { Dec. } 2,1971 \ldots \ldots \ldots \\
\text { Mar. } 1,1972 \ldots \ldots \ldots \\
\text { May } 25 \ldots \ldots \ldots \ldots \\
\text { Aug. } 22 \ldots \ldots \ldots \\
\text { Dec. } 4 \ldots \ldots \\
\text { June } 29,1973 \ldots \ldots \ldots \\
\text { Sept } 26 \ldots \ldots \ldots \\
\text { Dec. } 5 . \ldots \ldots \ldots \\
\text { Feb. } 27,1974 \ldots \ldots \\
\text { May } 22 \ldots \ldots \\
\text { Aug. } 22 \ldots \ldots \ldots \\
\text { Dec. } 5 . \ldots \ldots \ldots \\
\text { Apr. } 7,1975 \ldots \ldots \ldots \\
\text { Dec. } 4 . \ldots \ldots \ldots \ldots \\
\text { Nov. } 30,1976 \ldots \ldots\end{array}$ & $\begin{array}{l}47.23 \\
46.59 \\
47.66 \\
46.73 \\
49.07 \\
46.15 \\
47.64 \\
45.20 \\
46.90 \\
49.35 \\
47.12 \\
49.05 \\
48.88 \\
48.21 \\
46.50 \\
49.06 \\
45.23 \\
47.57\end{array}$ & $\begin{array}{l}\text { Nov. } 29,1977 \ldots \ldots \\
\text { Nov. } 24,1978 \ldots \ldots \\
\text { Nov. } 19,1979 \ldots \ldots \\
\text { Nov. } 25,1980 \ldots \ldots \\
\text { Dec. } 2,1981 \ldots \ldots \\
\text { Dec. } 1,1982 \ldots \ldots \\
\text { Dec. } 5,1984 \ldots \ldots \\
\text { Dec. } 17,1985 \ldots \ldots \\
\text { Nov. } 14,1986 \ldots \ldots \\
\text { Dec. } 5,1987 \ldots \ldots \\
\text { Dec. } 14,1988 \ldots \ldots \\
\text { July } 13,1989 \ldots \ldots \\
\text { Dec. } 9 . \ldots \ldots \\
\text { Dec. } 12 \ldots \ldots \ldots \\
\text { Mar. } 20,1990 \ldots \ldots \\
\text { Apr. } 23, \ldots \ldots \ldots \\
\text { May } 24 \ldots \ldots \ldots \\
\text { June } 21 \ldots \ldots \ldots \\
\end{array}$ & $\begin{array}{l}47.34 \\
47.79 \\
47.14 \\
51.45 \\
52.33 \\
45.97 \\
44.94 \\
48.20 \\
42.85 \\
45.88 \\
56.39 \\
66.64 \\
58.06 \\
58.15 \\
59.17 \\
59.44 \\
60.11 \\
59.24\end{array}$ & 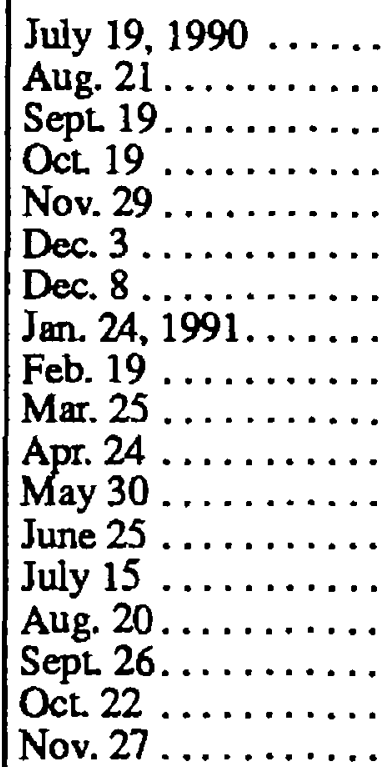 & $\begin{array}{r}69.64 \\
75.88 \\
65.59 \\
61.02 \\
59.38 \\
58.73 \\
59.43 \\
60.40 \\
61.30 \\
61.76 \\
62.14 \\
63.87 \\
58.97 \\
60.09 \\
70.79 \\
59.87 \\
57.32 \\
56.35\end{array}$ & 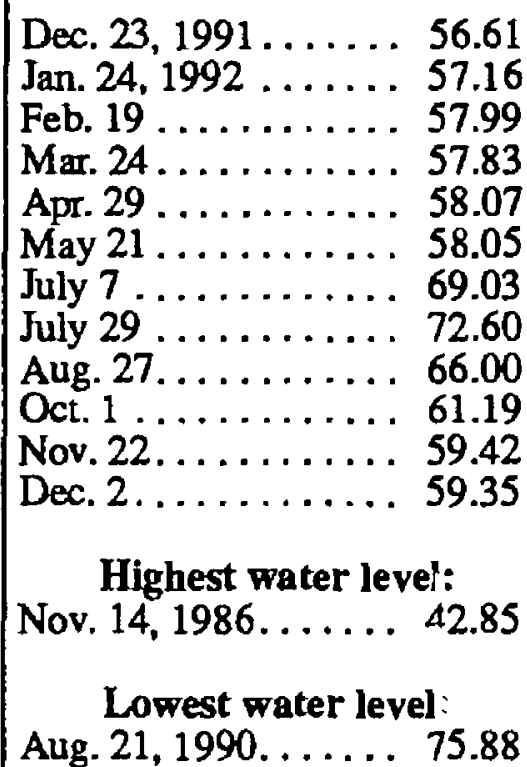 \\
\hline
\end{tabular}


Table 2. Water levels for selected wells-Continued

Owner: NDSWC 3626

148-087-07AAA2

Aquifer code: 112WSLD

Date drille d: $07-29-68$

Altitude: 1,966 foet

\begin{tabular}{|c|c|c|c|c|c|c|c|}
\hline Date measured & $\begin{array}{l}\text { Water } \\
\text { level } \\
\text { (feer) }\end{array}$ & Date mealured & $\begin{array}{l}\text { Water } \\
\text { level } \\
\text { (feet) }\end{array}$ & Date measured & $\begin{array}{l}\text { Water } \\
\text { lovel } \\
\text { (foet) }\end{array}$ & Dete measurert & $\begin{array}{l}\text { Water } \\
\text { level } \\
\text { (foet) }\end{array}$ \\
\hline 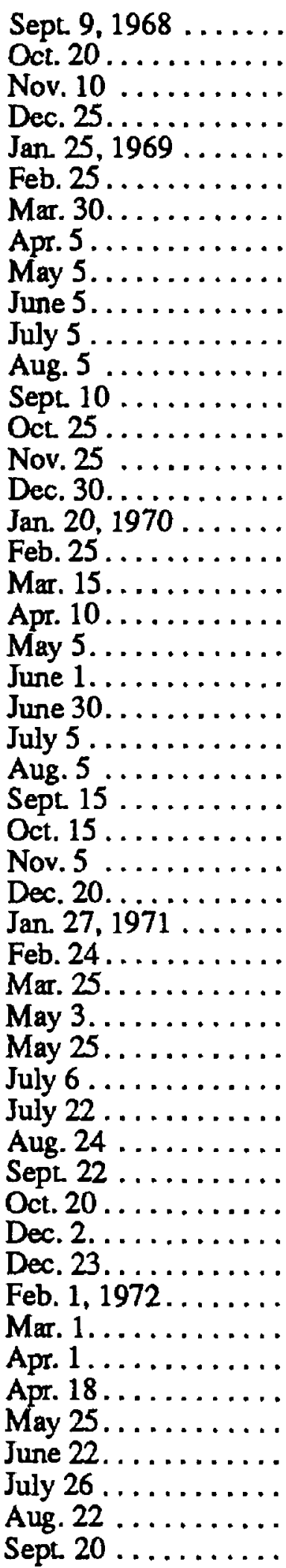 & $\begin{array}{l}112.35 \\
112.00 \\
112.10 \\
112.16 \\
112.32 \\
112.67 \\
113.17 \\
112.91 \\
112.17 \\
111.75 \\
110.91 \\
110.10 \\
110.11 \\
110.30 \\
110.43 \\
110.63 \\
111.06 \\
111.51 \\
111.61 \\
111.51 \\
111.61 \\
111.34 \\
110.47 \\
110.41 \\
109.29 \\
108.93 \\
108.93 \\
108.98 \\
109.11 \\
109.36 \\
109.47 \\
109.42 \\
108.85 \\
108.82 \\
108.14 \\
112.09 \\
109.63 \\
109.91 \\
109.21 \\
108.08 \\
108.12 \\
108.44 \\
108.45 \\
107.45 \\
107.06 \\
111.16 \\
109.12 \\
107.96 \\
111.96 \\
109.60\end{array}$ & 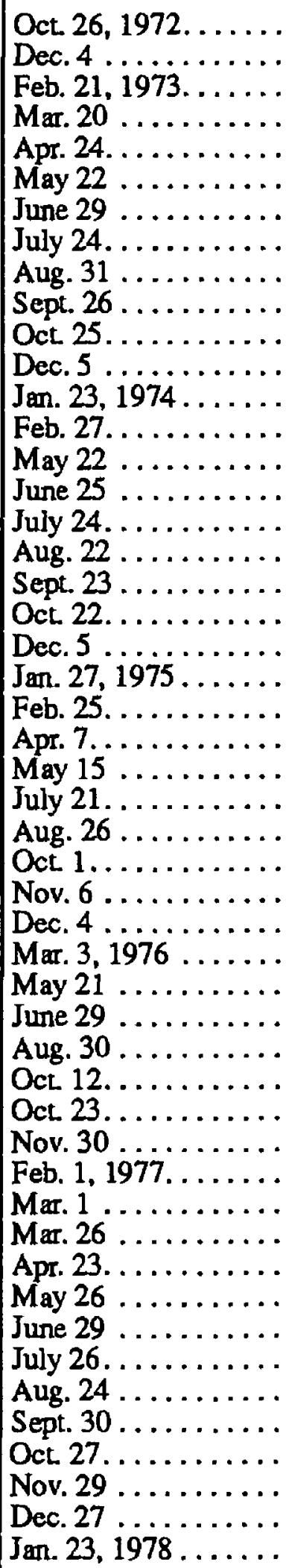 & $\begin{array}{l}106.75 \\
106.36 \\
106.76 \\
106.66 \\
106.71 \\
108.03 \\
113.13 \\
113.46 \\
114.92 \\
112.42 \\
111.56 \\
107.47 \\
107.35 \\
107.36 \\
107.25 \\
111.26 \\
113.60 \\
110.10 \\
108.31 \\
107.29 \\
106.14 \\
106.24 \\
107.25 \\
106.63 \\
105.99 \\
113.65 \\
109.57 \\
105.63 \\
104.74 \\
103.80 \\
105.29 \\
105.98 \\
107.33 \\
113.95 \\
112.88 \\
108.84 \\
106.48 \\
106.25 \\
106.43 \\
106.30 \\
106.65 \\
113.10 \\
119.09 \\
132.92 \\
124.60 \\
112.15 \\
110.55 \\
112.54 \\
109.51 \\
109.69\end{array}$ & 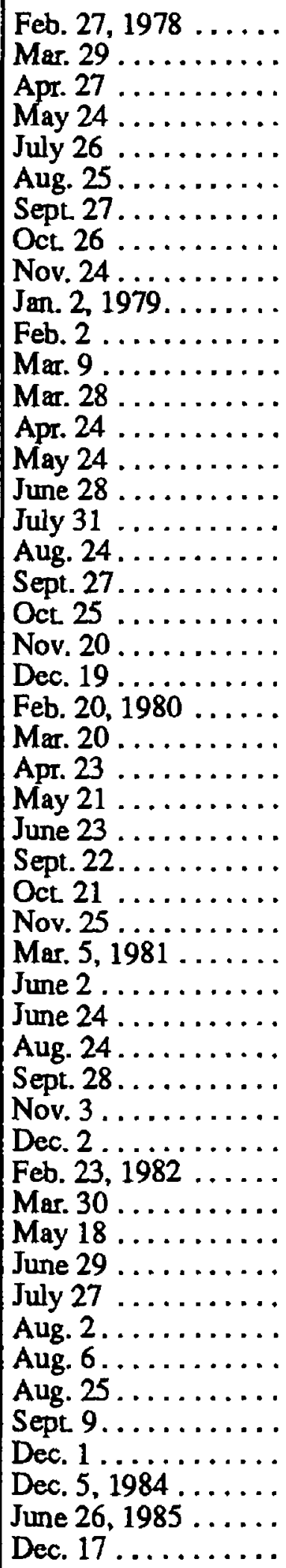 & $\begin{array}{l}.110 .06 \\
.110 .17 \\
.108 .72 \\
.107 .70 \\
.111 .40 \\
.121 .35 \\
.109 .01 \\
.110 .08 \\
.108 .77 \\
.108 .33 \\
.106 .13 \\
.110 .96 \\
.106 .25 \\
.105 .32 \\
.106 .47 \\
.106 .87 \\
.120 .34 \\
.119 .15 \\
.112 .60 \\
.107 .32 \\
.106 .37 \\
.105 .34 \\
.105 .39 \\
.105 .06 \\
.105 .11 \\
.125 .92 \\
.123 .01 \\
.116 .25 \\
.112 .04 \\
.112 .50 \\
.107 .70 \\
.108 .04 \\
.113 .14 \\
.117 .80 \\
.110 .19 \\
.108 .79 \\
.107 .86 \\
.107 .88 \\
.107 .37 \\
.106 .57 \\
.111 .84 \\
.119 .90 \\
.124 .25 \\
.121 .88 \\
.114 .19 \\
.110 .08 \\
.103 .02 \\
.102 .78 \\
.109 .06 \\
.103 .40\end{array}$ & 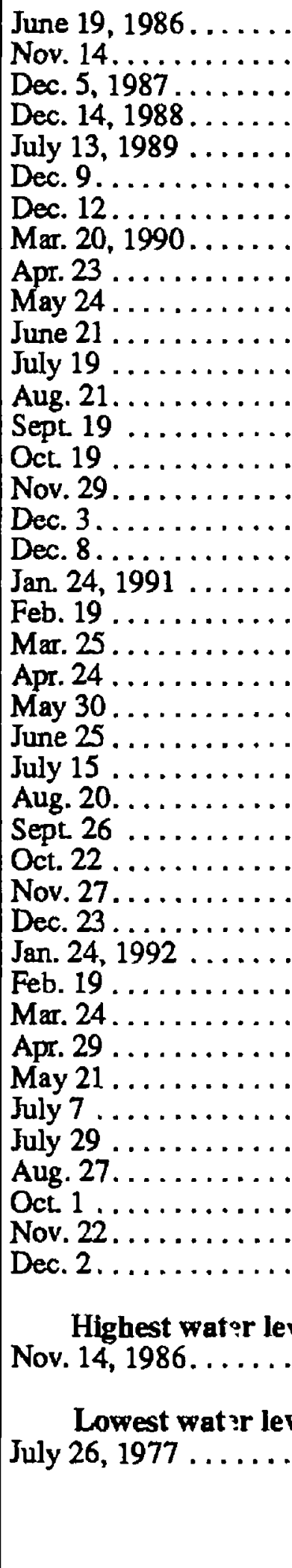 & $\begin{array}{l}109.30 \\
100.84 \\
101.44 \\
107.67 \\
119.13 \\
109.25 \\
109.24 \\
108.96 \\
108.82 \\
110.06 \\
109.15 \\
127.38 \\
126.71 \\
116.62 \\
112.20 \\
110.55 \\
110.50 \\
110.38 \\
110.16 \\
110.25 \\
110.39 \\
110.28 \\
113.33 \\
110.00 \\
115.44 \\
122.31 \\
112.55 \\
109.97 \\
108.86 \\
108.53 \\
108.20 \\
108.46 \\
108.39 \\
108.31 \\
108.22 \\
123.62 \\
126.94 \\
118.38 \\
111.68 \\
110.68 \\
110.57 \\
.101: \\
100.84 \\
\text { vel: } \\
132.92\end{array}$ \\
\hline
\end{tabular}


Table 2 Water levels for selected wells-Continued

Owner: NDSWC 3619

148-087-13BBB

Aquifer code: 112WSLD

Altitude: 1,954 feet

Well depth: 278 feet

\begin{tabular}{|c|c|c|c|c|c|c|c|}
\hline Date measured & $\begin{array}{l}\text { Water } \\
\text { level } \\
\text { (foet) }\end{array}$ & Date measured & $\begin{array}{l}\text { Wator } \\
\text { level } \\
\text { (foet) }\end{array}$ & Date meaaured & $\begin{array}{l}\text { Water } \\
\text { level } \\
\text { (foet) }\end{array}$ & Date measured & $\begin{array}{l}\text { V'ater } \\
\text { level } \\
\text { (feet) }\end{array}$ \\
\hline $\begin{array}{l}\text { Sept } 9,1968 \ldots \ldots \\
\text { Jan. } 15,1969 \ldots \ldots \\
\text { Apr. } 17 \ldots \ldots \ldots \\
\text { July } 16 \ldots \ldots \ldots \\
\text { Sept } 5 \ldots \ldots \ldots \\
\text { Nov. } 2 \ldots \ldots \ldots \\
\text { Dec. } 19 \ldots \ldots \ldots \\
\text { Jan. } 20,1970 \ldots \ldots \\
\text { Feb. } 19 \ldots \ldots \ldots \\
\text { Mar. } 2 \ldots \ldots \ldots \\
\text { Apr. } 22 \ldots \ldots \ldots \\
\text { June } 5 \ldots \ldots \ldots \\
\text { June } 30 \ldots \ldots \ldots \\
\end{array}$ & $\begin{array}{l}104.33 \\
104.59 \\
105.42 \\
102.19 \\
101.56 \\
101.90 \\
103.46 \\
104.28 \\
105.01 \\
105.18 \\
105.17 \\
104.74 \\
103.15\end{array}$ & $\begin{array}{l}\text { Sept } 9,1970 \ldots \ldots \\
\text { Dec. } 1, \ldots \ldots \\
\text { Mar. } 20,1990 \ldots \ldots \\
\text { Apt. } 23 \ldots \ldots \ldots \\
\text { May } 24 \ldots \ldots \ldots \\
\text { June } 21 \ldots \ldots \ldots \ldots \\
\text { July } 19 \ldots \ldots \ldots \ldots \\
\text { Aug. } 21 \ldots \ldots \ldots \ldots \\
\text { Sept } 19 \ldots \ldots \ldots \ldots \\
\text { Oct } 19 \ldots \ldots \ldots \ldots \\
\text { Nov. } 29 \ldots \ldots \ldots \ldots \\
\text { Jan. } 24,1991 \ldots \ldots \ldots \\
\text { Feb. } 19 \ldots \ldots \ldots \ldots\end{array}$ & $\begin{array}{l}101.16 \\
101.50 \\
108.35 \\
108.36 \\
110.46 \\
108.69 \\
126.01 \\
133.27 \\
116.75 \\
110.75 \\
109.32 \\
109.55 \\
110.03\end{array}$ & $\begin{array}{l}\text { Mar. } 25,1991 \ldots \ldots \\
\text { Apr. } 24 \ldots \ldots \ldots \\
\text { May } 30 \ldots \ldots \ldots \\
\text { June } 25 \ldots \ldots \ldots \\
\text { July } 15 \ldots \ldots \ldots \\
\text { Aug. } 20 \ldots \ldots \ldots \\
\text { Sept. } 26 \ldots \ldots \ldots \ldots \\
\text { Oct. } 22 \ldots \ldots \ldots \\
\text { Nov. } 27 \ldots \ldots \ldots \\
\text { Dec. } 23 \ldots \ldots \ldots \\
\text { Jan. } 24,1992 \ldots \ldots \ldots \\
\text { Feb. } 19 \ldots \ldots \ldots \\
\text { Mar. } 24 \ldots \ldots \ldots \ldots \\
\end{array}$ & $\begin{array}{l}.112 .25 \\
.110 .39 \\
.115 .22 \\
.109 .05 \\
.114 .55 \\
.126 .53 \\
.111 .13 \\
.108 .05 \\
.108 .08 \\
.106 .28 \\
.106 .80 \\
.107 .34 \\
.107 .35\end{array}$ & $\begin{array}{r}\text { Apr. } 29,1992 \ldots \ldots \\
\text { May } 21 \ldots \ldots \ldots \\
\text { July } 7 \ldots \ldots \ldots \\
\text { July } 29 \ldots \ldots \ldots \\
\text { Aug. } 27 \ldots \ldots \ldots \\
\text { Oct. } 1 \ldots \ldots \ldots \ldots \\
\text { Highest water } \\
\text { Sept. } 9,1970 \ldots \ldots \\
\\
\text { Lowest water } \\
\text { Aug. } 21,1990 \ldots \ldots\end{array}$ & $\begin{array}{l}.177 .38 \\
.177 .39 \\
.124 .17 \\
.130 .39 \\
119.05 \\
.111 .93 \\
\text { ve': } \\
.101 .16 \\
\text { ve!: } \\
.133 .27\end{array}$ \\
\hline
\end{tabular}

Owner: NDSWC 5565

Aquifer code: 112WSLD

Altitude: 1,945 feet

\begin{tabular}{|c|c|c|c|}
\hline Date measurod & $\begin{array}{l}\text { Water } \\
\text { level } \\
\text { (feet) }\end{array}$ & Date measured & $\begin{array}{l}\text { Water } \\
\text { level } \\
\text { (feet) }\end{array}$ \\
\hline $\begin{array}{l}\text { Nov. } 4,1969 \ldots \ldots \\
\text { Dec. } 9 . \ldots \ldots \ldots \\
\text { June } 5,1970 \ldots \ldots \\
\text { June } 25 \ldots \ldots \ldots \\
\text { Sept } 9 \ldots \ldots \ldots \\
\text { Apr. } 23,1990 \ldots \ldots \\
\text { May } 24 \ldots \ldots \ldots \ldots \\
\text { June } 21 \ldots \ldots \ldots \ldots \\
\text { July } 19 \ldots \ldots \ldots \ldots \\
\text { Aug. } 21 \ldots \ldots \ldots\end{array}$ & $\begin{array}{l}106.27 \\
107.51 \\
108.97 \\
107.59 \\
105.06 \\
114.47 \\
115.83 \\
114.74 \\
128.79 \\
135.89\end{array}$ & $\begin{array}{l}\text { Sept. } 19,1990 \ldots \\
\text { Oct. } 19 \ldots \ldots \ldots \\
\text { Nov. } 29 \ldots \ldots \ldots \\
\text { Feb. } 19,1991 \ldots \ldots \\
\text { Mar. } 25 \ldots \ldots \ldots \\
\text { Apr. } 24 \ldots \ldots \ldots \\
\text { May } 30 \ldots \ldots \ldots \\
\text { June } 25 \ldots \ldots \ldots \\
\text { July } 15 \ldots \ldots \ldots \ldots \\
\text { Aug. } 20 \ldots \ldots \ldots\end{array}$ & $\begin{array}{l}122.27 \\
117.03 \\
115.05 \\
116.23 \\
116.79 \\
116.78 \\
120.00 \\
114.78 \\
119.19 \\
129.90\end{array}$ \\
\hline
\end{tabular}

148-087-13DDD

Date drilled: 1969

Well depth: 305 feet

\begin{tabular}{|c|c|c|c|}
\hline Date measured & $\begin{array}{l}\text { Water } \\
\text { level } \\
\text { (feat) }\end{array}$ & Date measured & $\begin{array}{l}\text { Water } \\
\text { level } \\
\text { ("nat) }\end{array}$ \\
\hline $\begin{array}{l}\text { Sept. } 26,1991 \ldots \ldots \\
\text { Oet } 22 \ldots \ldots \ldots \ldots \\
\text { Nov. } 27 \ldots \ldots \ldots \ldots \\
\text { Dec. } 23 \ldots \ldots \ldots \\
\text { Jan. } 24,1992 \ldots \ldots \ldots \\
\text { Feb. } 19 \ldots \ldots \ldots \ldots \\
\text { Mar. } 24 \ldots \ldots \ldots \ldots \\
\text { Apr. } 29 \ldots \ldots \ldots \ldots \\
\text { May } 21 \ldots \ldots \ldots \ldots \\
\text { July } 7 \ldots \ldots \ldots \ldots\end{array}$ & $\begin{array}{l}.116 .37 \\
.113 .45 \\
.112 .45 \\
.112 .05 \\
.112 .70 \\
.113 .33 \\
.113 .25 \\
.113 .42 \\
.113 .43 \\
.127 .73\end{array}$ & 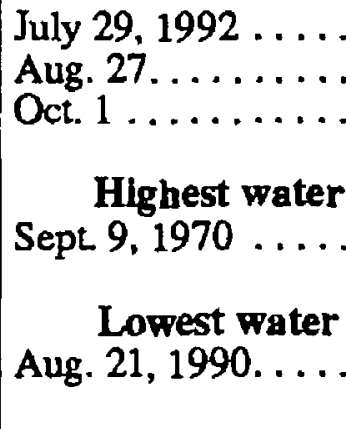 & $\begin{array}{l}132.72 \\
123.37 \\
116.33 \\
\text { ve?: } \\
105.06 \\
\text { vel: } \\
135.89\end{array}$ \\
\hline
\end{tabular}

Owner: USGS

Aquifer code: 125TGRV

Altitude: 2,010 feet

\begin{tabular}{|c|c|c|c|c|c|c|c|}
\hline Date measured & $\begin{array}{l}\text { Water } \\
\text { level } \\
\text { (feet) }\end{array}$ & Date measured & $\begin{array}{l}\text { Water } \\
\text { level } \\
\text { (feet) }\end{array}$ & Date measured & $\begin{array}{l}\text { Water } \\
\text { level } \\
\text { (feet) }\end{array}$ & Date measured & $\begin{array}{l}\text { W'ater } \\
\text { lisvel } \\
\text { (teet) }\end{array}$ \\
\hline July $30,1992 \ldots \ldots$ & 200.80 & Aug. $28,1992 \ldots$ & 200.41 & \multicolumn{2}{|c|}{$\begin{array}{c}\text { Highest water level: } \\
\text { Aug. 28, 1992 .....200.41 }\end{array}$} & \multicolumn{2}{|c|}{$\begin{array}{c}\text { Lowest water level: } \\
\text { July } 30,1992 \ldots \ldots \ldots 2 \text {. . . } 80\end{array}$} \\
\hline
\end{tabular}

Date drilled: 06-12-92 Well depth: 285 feet

148-092-23ABB 
Table 2. Water leveis for selected wells--Continued

Owner: NDSWC 4596A

148-093-04CAB1

Aquifer code: $125 T$ GRV

$148-093-04 C A B 1$

Altitude: 1,986 feet

\begin{tabular}{|c|c|c|c|c|c|c|c|}
\hline Date meaaured & $\begin{array}{l}\text { Water } \\
\text { lovel } \\
\text { (foot) }\end{array}$ & Date moesured & $\begin{array}{l}\text { Water } \\
\text { lovet } \\
\text { (foot) }\end{array}$ & Date moseurod & $\begin{array}{l}\text { Water } \\
\text { level } \\
\text { (foat) }\end{array}$ & Date measurod & $\begin{array}{l}\text { Water } \\
\text { lovol } \\
\text { (foot) }\end{array}$ \\
\hline $\begin{array}{l}\text { May } 23,1974 \ldots \ldots \\
\text { July } 25, \ldots \ldots \ldots \ldots \\
\text { Aug. } 23, \ldots \ldots \ldots \\
\text { Sept. } 26 \ldots \ldots \ldots \\
\text { Oct. } 29 \ldots \ldots \ldots \ldots \\
\text { Mar. } 22,1990 \ldots \ldots \\
\text { Apr. } 24 \ldots \ldots \ldots \ldots \\
\text { May } 25 \ldots \ldots \ldots \ldots \\
\text { June } 23 . \ldots \ldots \ldots \ldots \\
\text { July } 20,1990 \ldots \ldots \\
\text { Aug. } 22 \ldots \ldots \ldots \ldots \\
\end{array}$ & $\begin{array}{l}136.83 \\
137.15 \\
138.27 \\
137.87 \\
137.80 \\
131.25 \\
131.01 \\
130.90 \\
130.79 \\
130.88 \\
130.97\end{array}$ & $\begin{array}{l}\text { Sept. } 21,1990 \ldots \ldots \\
\text { Oct. } 23 \ldots \ldots \ldots \ldots \\
\text { Nov. } 29 \ldots \ldots \ldots \\
\text { Jan. } 24,1991 \ldots \ldots \\
\text { Feb. } 19 \ldots \ldots \ldots \ldots \\
\text { Mar. } 26 \ldots \ldots \ldots \ldots \\
\text { Apr. } 24 \ldots \ldots \ldots \ldots \\
\text { May } 30 \ldots \ldots \ldots \ldots \\
\text { June } 25 \ldots \ldots \ldots \ldots \\
\text { July } 16 \ldots \ldots \ldots \ldots \\
\text { Aug. } 20 \ldots \ldots \ldots \ldots \\
\end{array}$ & $\begin{array}{l}130.94 \\
130.88 \\
130.77 \\
130.79 \\
130.76 \\
130.63 \\
130.69 \\
130.63 \\
130.47 \\
130.58 \\
130.48\end{array}$ & 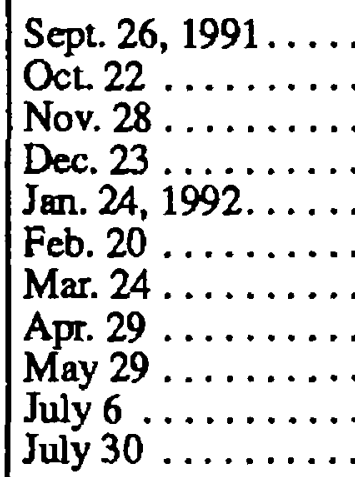 & $\begin{array}{l}.130 .47 \\
.130 .51 \\
.130 .57 \\
.130 .39 \\
.130 .53 \\
.130 .34 \\
.130 .22 \\
.130 .22 \\
.130 .30 \\
.130 .23 \\
.130 .40\end{array}$ & $\begin{array}{r}\text { Aug. } 28,1992 \ldots \ldots \\
\text { Oct. } 2 \ldots \ldots \ldots \ldots \\
\text { Highest water } \\
\text { Aug. } 28,1992 \ldots \ldots \\
\text { Lowest wate- } \\
\text { Aug. } 23,1974 \ldots \ldots\end{array}$ & $\begin{array}{l}.130 .16 \\
.130 .22 \\
\text { vel: } \\
.130 .16 \\
\text { vel: } \\
.138 .27\end{array}$ \\
\hline
\end{tabular}

Owner: NDSWC 4596B

148-093-04CAB2

Aqulfer code: 125 SNLB

Date drillert: $10-00-73$ Altitude: 1,987 feet

Well depth: 190 feet

\begin{tabular}{|c|c|c|c|c|c|c|c|}
\hline Date measured & $\begin{array}{l}\text { Water } \\
\text { level } \\
\text { (foot) }\end{array}$ & Date measured & $\begin{array}{l}\text { Water } \\
\text { level } \\
\text { (foet) }\end{array}$ & Date measured & $\begin{array}{l}\text { Water } \\
\text { level } \\
\text { (foet) }\end{array}$ & Date measured & $\begin{array}{l}\text { Water } \\
\text { level } \\
\text { (foot) }\end{array}$ \\
\hline $\begin{array}{l}\text { Nov. } 15,1973 \ldots \ldots \\
\text { Feb. } 14,1974 \ldots \ldots \\
\text { Apr. } 4 \ldots \ldots \ldots \ldots \\
\text { May } 23 \ldots \ldots \ldots \\
\text { July } 25 \ldots \ldots \ldots \\
\text { Aug. } 23 \ldots \ldots \ldots \\
\text { Sept } 26 \ldots \ldots \\
\text { Oct. } 29 \ldots \ldots \\
\text { Mar. } 22,1990 \ldots \ldots \\
\text { Apr. } 24 \ldots \ldots \\
\text { May } 25 \ldots \ldots \ldots \\
\end{array}$ & $\begin{array}{l}68.52 \\
68.38 \\
68.30 \\
68.06 \\
68.40 \\
68.33 \\
67.97 \\
68.06 \\
63.05 \\
62.94 \\
63.00\end{array}$ & $\begin{array}{l}\text { June } 23,1990 \ldots \ldots \\
\text { July } 20 \ldots \ldots \ldots \ldots \\
\text { Aug. } 22 \ldots \ldots \ldots \ldots \\
\text { Sept. } 21 \ldots \ldots \ldots \\
\text { Oct. } 24 \ldots \ldots \ldots \ldots \\
\text { Nov. } 29 \ldots \ldots \ldots \\
\text { Jan. } 24,1991 \ldots \ldots \ldots \\
\text { Feb. } 19 \ldots \ldots \ldots \ldots \\
\text { Mar. } 26 \ldots \ldots \ldots \ldots \\
\text { Apr. } 24 \ldots \ldots \ldots \ldots \\
\text { May } 30 \ldots \ldots \ldots \ldots \\
\end{array}$ & $\begin{array}{l}63.02 \\
63.15 \\
63.19 \\
63.28 \\
63.33 \\
63.28 \\
63.44 \\
63.36 \\
63.34 \\
63.38 \\
63.44\end{array}$ & $\begin{array}{l}\text { June } 25,1991 \ldots \ldots \\
\text { July } 16 \ldots \ldots \ldots \\
\text { Aug. } 20 \ldots \ldots \ldots \\
\text { Sept. } 26 \ldots \ldots \ldots \\
\text { Oct. } 22 \ldots \ldots \ldots \\
\text { Nov. } 28 \ldots \ldots \\
\text { Dec. } 23 \ldots \ldots \\
\text { Jan. } 24,1992 \ldots \ldots \\
\text { Feb. } 20 \ldots \ldots \\
\text { Mar. } 24 \ldots \ldots \ldots \\
\text { Apr. } 29 \ldots \ldots \\
\end{array}$ & $\begin{array}{l}63.43 \\
63.59 \\
63.66 \\
63.64 \\
63.61 \\
63.57 \\
63.68 \\
63.62 \\
63.62 \\
63.76 \\
63.74\end{array}$ & $\begin{array}{l}\text { May } 29,1992 \ldots \ldots \\
\text { July } 6 \ldots \ldots \ldots \\
\text { July } 30 \ldots \ldots \ldots \\
\text { Aug. } 28 \ldots \ldots \ldots \ldots \\
\text { Oct. } 2 \ldots \ldots \ldots \ldots \\
\text { Highest water } \\
\text { Apr. } 24,1990 \ldots \ldots \\
\\
\text { Lowest water } \\
\text { Nov. } 15,1973 \ldots \ldots\end{array}$ & $\begin{array}{l}63.88 \\
63.78 \\
64.05 \\
63.96 \\
64.03 \\
\\
\text { vel: } \\
62.94 \\
\text { vel: } 6 \\
68.52\end{array}$ \\
\hline
\end{tabular}

Owner: USGS

148-094-14AAB

Aquifer code: 125TGRV

Date drillert: $06-23-92$

Altitude: 2,250 feet

Well depth: 300 feet

\begin{tabular}{|c|c|c|c|c|c|c|c|}
\hline Date measured & $\begin{array}{l}\text { Wator } \\
\text { level } \\
\text { (foot) }\end{array}$ & Date meaaured & $\begin{array}{l}\text { Water } \\
\text { level } \\
\text { (foot) }\end{array}$ & Date moasured & $\begin{array}{l}\text { Water } \\
\text { level } \\
\text { (feot) }\end{array}$ & Date measured' & $\begin{array}{l}\text { Water } \\
\text { lovel } \\
\text { (feet) }\end{array}$ \\
\hline $\begin{array}{l}\text { Aug. } 4,1992 \ldots \ldots \\
\text { Aug. } 28 \ldots \ldots \ldots\end{array}$ & $\begin{array}{l}163.47 \\
163.28\end{array}$ & Oct. 2, 1992. & 163.30 & \multicolumn{2}{|c|}{$\begin{array}{c}\text { Highest water level: } \\
\text { Aug. } 28,1992 \ldots \ldots \ldots 163.28\end{array}$} & \multicolumn{2}{|c|}{$\begin{array}{c}\text { Lowest water level: } \\
\text { Aug. } 4,1992 \ldots \ldots \ldots 163.47\end{array}$} \\
\hline
\end{tabular}


Table 2 Water levels for selected wells-Continued

Owner: USGS

148-095-12DCC2

Aqulfer code: 125SNLB

Date drilied: 06-23-92 Altitude: 2,450 feet

\begin{tabular}{|c|c|c|c|c|c|c|c|}
\hline Date measured & $\begin{array}{l}\text { Water } \\
\text { level } \\
\text { (feet) }\end{array}$ & Date meaaured & $\begin{array}{l}\text { Water } \\
\text { level } \\
\text { (feet) }\end{array}$ & Date measured & $\begin{array}{l}\text { Water } \\
\text { level } \\
\text { (feet) }\end{array}$ & Date measured & $\begin{array}{l}\text { Water } \\
\text { level } \\
\text { (aet) }\end{array}$ \\
\hline $\begin{array}{l}\text { July } 30,1992 \ldots \ldots \\
\text { Aug. } 28 \ldots \ldots\end{array}$ & $\begin{array}{l}21.69 \\
21.61\end{array}$ & Oct. $1,1992 \ldots \ldots$ & 21.52 & $\begin{array}{r}\text { Highest wate } \\
\text { Oct } 1,1992 \ldots .\end{array}$ & $\begin{array}{l}\text { vel: } \\
21.52\end{array}$ & \multicolumn{2}{|c|}{$\begin{array}{l}\text { Lowest water level: } \\
\text { July } 30,1992 \ldots \ldots \ldots 21.69\end{array}$} \\
\hline
\end{tabular}

Owner: NDSWC 3622

Aquifer code: 112WSLD

Altitude: 2,002 feet

\begin{tabular}{|c|c|}
\hline Date messured & $\begin{array}{c}\text { Water } \\
\text { level } \\
\text { (feet) }\end{array}$ \\
\hline 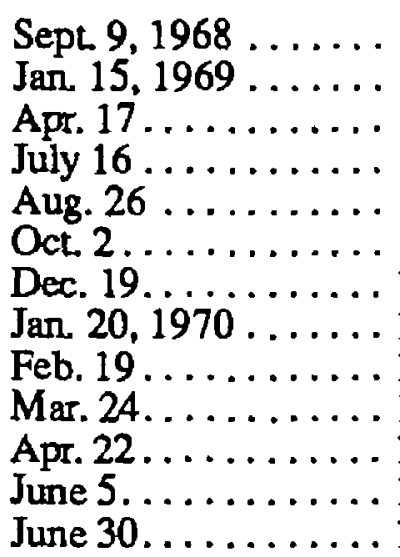 & $\begin{array}{l}137.86 \\
137.57 \\
137.91 \\
136.18 \\
135.55 \\
135.37 \\
135.94 \\
136.13 \\
136.45 \\
136.40 \\
136.44 \\
136.35 \\
135.70\end{array}$ \\
\hline
\end{tabular}

149-087-32CCC

Date drilled: $07-00-68$ Well depth: 358 feet

\begin{tabular}{|c|c|c|c|c|c|}
\hline Date measured & $\begin{array}{l}\text { Water } \\
\text { level } \\
\text { (feet) }\end{array}$ & Date measured & $\begin{array}{l}\text { Water } \\
\text { level } \\
\text { (feet) }\end{array}$ & Date meaaured & $\begin{array}{l}\text { U'inter } \\
\text { Invel } \\
\text { ('net) }\end{array}$ \\
\hline 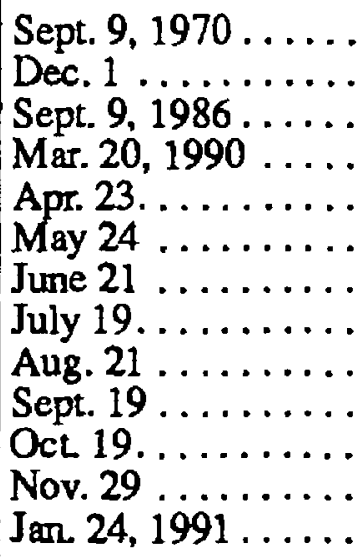 & $\begin{array}{l}134.28 \\
133.96 \\
137.86 \\
132.44 \\
132.25 \\
133.02 \\
132.64 \\
146.40 \\
147.14 \\
139.59 \\
135.75 \\
134.17 \\
133.64\end{array}$ & $\begin{array}{l}\text { Feb. } 19,1991 \ldots \ldots \\
\text { Mar. } 25 \ldots \ldots \ldots \ldots \\
\text { Apr. } 24 \ldots \ldots \ldots \ldots \\
\text { May } 30 \ldots \ldots \ldots \\
\text { June } 25 \ldots \ldots \ldots \ldots \\
\text { July } 15 \ldots \ldots \ldots \ldots \\
\text { Aug. } 20 \ldots \ldots \ldots \ldots \\
\text { Sept. } 26 \ldots \ldots \ldots \\
\text { Oct. } 22 \ldots \ldots \ldots \ldots \\
\text { Nov. } 27,1991 \ldots \ldots \\
\text { Dec. } 23 \ldots \ldots \ldots \\
\text { Jan. } 24,1992 \ldots \ldots \ldots \\
\text { Feb. } 19 \ldots \ldots \ldots \ldots\end{array}$ & $\begin{array}{l}.133 .64 \\
.133 .79 \\
.133 .65 \\
.135 .56 \\
.133 .48 \\
.136 .69 \\
.143 .46 \\
.136 .05 \\
.133 .74 \\
.132 .78 \\
.132 .38 \\
.131 .99 \\
.132 .14\end{array}$ & \multicolumn{2}{|c|}{ 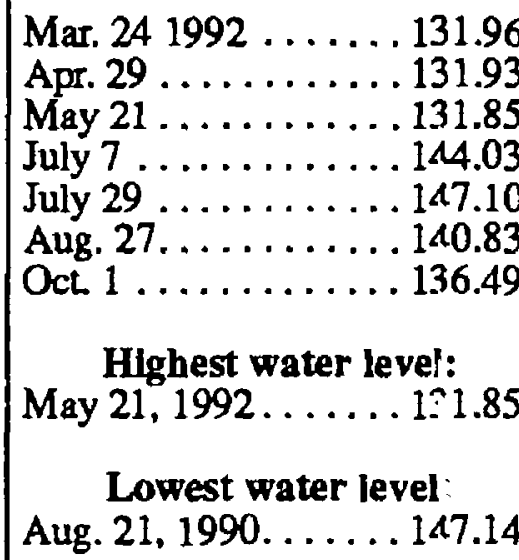 } \\
\hline
\end{tabular}

Owner: USGS

149-088-26BAB

Aquifer code: 112WSLD

Date drilled: 06-01-92 Altitude: 1,988 feet Well depth: 260 feet

\begin{tabular}{|c|c|c|c|c|c|c|c|}
\hline Date measured & $\begin{array}{l}\text { Water } \\
\text { level } \\
\text { (feet) }\end{array}$ & Date measured & $\begin{array}{l}\text { Water } \\
\text { level } \\
\text { (feet) }\end{array}$ & Date measured & $\begin{array}{l}\text { Water } \\
\text { level } \\
\text { (feet) }\end{array}$ & Date measured & $\begin{array}{l}\text { Water } \\
\text { lovel } \\
\text { (fret) }\end{array}$ \\
\hline $\begin{array}{l}\text { July } 29,1992 \ldots \ldots \\
\text { Aug. } 27 \ldots \ldots \ldots\end{array}$ & $\begin{array}{l}130.39 \\
129.30\end{array}$ & \multicolumn{2}{|c|}{ Oct $1,1992 \ldots \ldots \ldots 127.18$} & \multicolumn{2}{|c|}{$\begin{array}{c}\text { Highest water level: } \\
\text { Oct. } 1,1992 \ldots \ldots \ldots 127.18\end{array}$} & \multicolumn{2}{|c|}{$\begin{array}{c}\text { Lowest water level: } \\
\text { July } 29,1992 \ldots \ldots \text {. . } 1 \geq 0.39\end{array}$} \\
\hline
\end{tabular}


Table 2. Water levels for selected wells--Continued

OWner: NDSWC 4048

149-089-24AAA

Aquifer code: 112WSLD

Altitude: 1,957 foet

\begin{tabular}{|c|c|c|c|}
\hline Date measured & $\begin{array}{l}\text { Water } \\
\text { level } \\
\text { (feot) }\end{array}$ & Date meaaured & $\begin{array}{l}\text { Water } \\
\text { level } \\
\text { (feet) }\end{array}$ \\
\hline 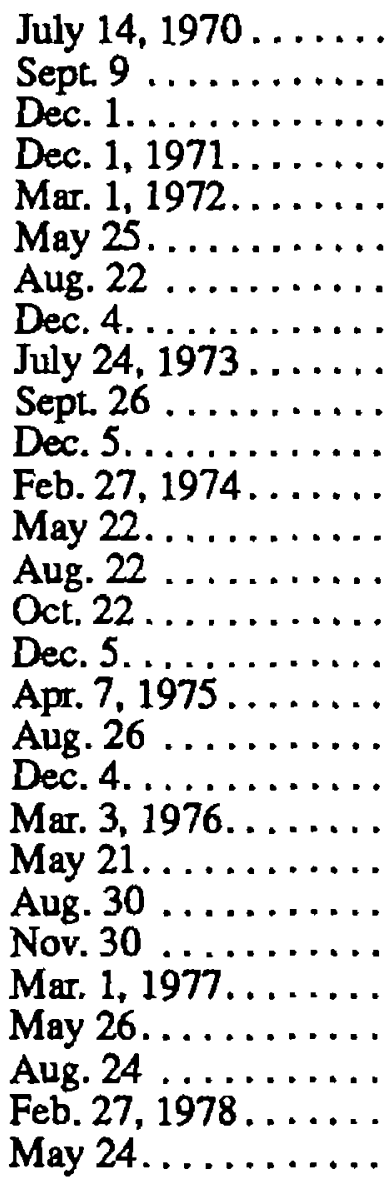 & $\begin{array}{l}61.85 \\
61.65 \\
61.20 \\
60.73 \\
59.49 \\
60.14 \\
60.18 \\
60.07 \\
59.69 \\
59.67 \\
59.52 \\
59.15 \\
59.05 \\
59.26 \\
59.22 \\
58.85 \\
58.40 \\
58.29 \\
58.75 \\
57.75 \\
57.66 \\
57.61 \\
57.42 \\
57.29 \\
57.04 \\
57.21 \\
56.82 \\
56.80\end{array}$ & 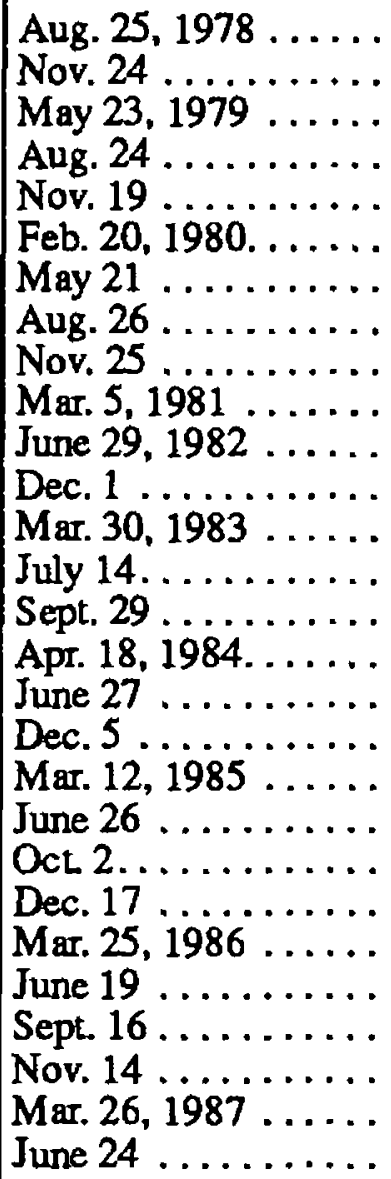 & $\begin{array}{l}56.80 \\
56.47 \\
56.90 \\
56.40 \\
55.80 \\
55.55 \\
55.55 \\
55.96 \\
55.80 \\
54.25 \\
55.11 \\
54.65 \\
54.50 \\
54.35 \\
54.55 \\
53.97 \\
53.76 \\
53.83 \\
53.44 \\
53.25 \\
53.20 \\
53.16 \\
53.10 \\
53.05 \\
52.77 \\
52.48 \\
52.02 \\
52.15\end{array}$ \\
\hline
\end{tabular}

\begin{tabular}{|c|c|}
\hline Date measured & $\begin{array}{l}\text { Water } \\
\text { level } \\
\text { (feet) }\end{array}$ \\
\hline 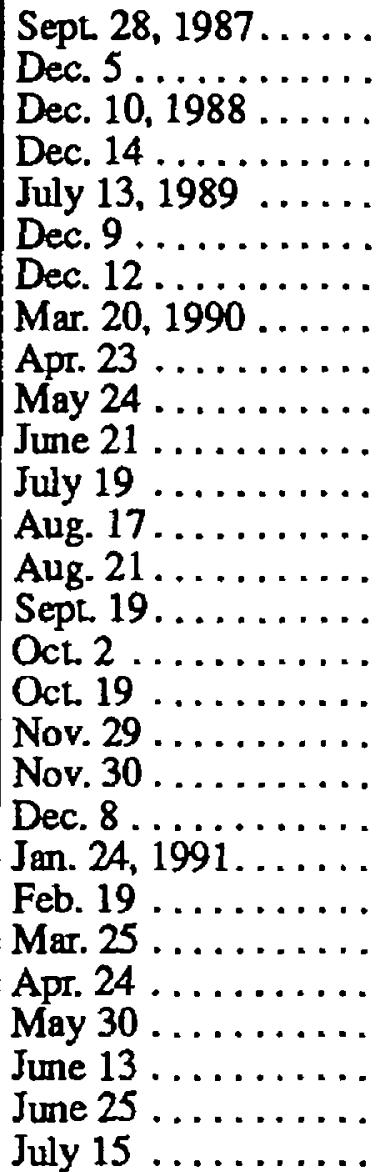 & $\begin{array}{l}52.05 \\
51.90 \\
52.34 \\
52.19 \\
52.24 \\
52.27 \\
52.25 \\
52.75 \\
52.54 \\
52.64 \\
52.75 \\
52.91 \\
52.35 \\
53.01 \\
53.06 \\
52.40 \\
53.04 \\
53.01 \\
52.45 \\
52.60 \\
52.99 \\
52.96 \\
53.00 \\
52.98 \\
52.86 \\
52.35 \\
52.80 \\
52.89\end{array}$ \\
\hline
\end{tabular}

Date dril ad: 07-13-70 Well depth: 172 feet

\begin{tabular}{|c|c|}
\hline Date measurid & $\begin{array}{l}\text { Water } \\
\text { level } \\
\text { (feet) }\end{array}$ \\
\hline 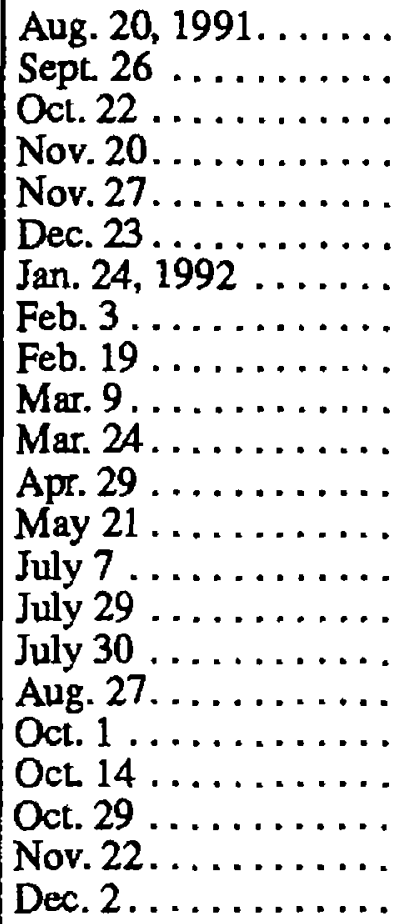 & $\begin{array}{l}53.02 \\
52.97 \\
52.77 \\
52.39 \\
52.97 \\
52.99 \\
53.00 \\
52.42 \\
52.92 \\
52.45 \\
52.84 \\
52.84 \\
52.75 \\
52.70 \\
51.23 \\
52.43 \\
53.04 \\
53.08 \\
52.62 \\
52.57 \\
52.44 \\
52.53\end{array}$ \\
\hline
\end{tabular}

Highest wa ter level: July $29,1992 \ldots \ldots \ldots 51.23$

Lowest wa+er level: July $14,1970 \ldots \ldots 61.85$

Owner: USGS

149-094-28AAA1

Aqulfer code: 125TGRV

Date drilled: 06-10-92 Altitude: 2,300 feet

Well dep`h: 295 feet

\begin{tabular}{|c|c|c|c|c|c|c|c|}
\hline Date measured & $\begin{array}{l}\text { Water } \\
\text { level } \\
\text { (feet) }\end{array}$ & Date meaaured & $\begin{array}{l}\text { Water } \\
\text { level } \\
\text { (feet) }\end{array}$ & Date meaaured & $\begin{array}{l}\text { Water } \\
\text { level } \\
\text { (feet) }\end{array}$ & Date measurnd & $\begin{array}{l}\text { Water } \\
\text { level } \\
\text { (feet) }\end{array}$ \\
\hline \multicolumn{2}{|c|}{$\begin{array}{l}\text { July } 30,1992 \ldots \ldots \ldots 189.32 \\
\text { Aug. } 28 \ldots \ldots \ldots \ldots 1.04\end{array}$} & \multicolumn{2}{|c|}{ OCL $1,1992 \ldots \ldots 191.05$} & \multicolumn{2}{|c|}{$\begin{array}{c}\text { Highest water level: } \\
\text { July } 30,1992 \ldots \ldots \ldots 189.32\end{array}$} & \multicolumn{2}{|c|}{$\begin{array}{c}\text { Lowest wa+er level: } \\
\text { Oct. } 1,1992 \ldots \ldots \ldots 191.05\end{array}$} \\
\hline
\end{tabular}

Owner: USGS

Aqulfer code: 125SNLB

Altitude: 2,300 feet

\begin{tabular}{|c|c|c|c|c|c|c|c|}
\hline Date measured & $\begin{array}{l}\text { Water } \\
\text { level } \\
\text { (feet) }\end{array}$ & Date measured & $\begin{array}{l}\text { Water } \\
\text { level } \\
\text { (feet) }\end{array}$ & Date measured & $\begin{array}{l}\text { Water } \\
\text { tevel } \\
\text { (feot) }\end{array}$ & Date meaaured & $\begin{array}{l}\text { Water } \\
\text { level } \\
\text { (feet) }\end{array}$ \\
\hline $\begin{array}{l}\text { July } 30,1992 \ldots \ldots \\
\text { Aug. } 28 \ldots \ldots\end{array}$ & $\begin{array}{l}73.70 \\
73.84\end{array}$ & Oct $1,1992 \ldots \ldots$ & 73.95 & \multicolumn{2}{|c|}{$\begin{array}{c}\text { Highest water level: } \\
\text { July } 30,1992 \ldots \ldots \ldots 73.70\end{array}$} & \multicolumn{2}{|c|}{$\begin{array}{c}\text { Lowest wa'er level: } \\
\text { Oct. } 1,1992 \ldots \ldots \ldots .73 .95\end{array}$} \\
\hline
\end{tabular}

149-094-28AAA2 Date drilled: $6-10-92$
Well depth: 120 feet 
Table 2 Water levels for selected wells-Continued

Owmer: NDSWC 5938

149-095-06ACC

Aquifer code: 125TGRV

Date drilled: $06-26-81$ Altitude: 2,258 foet

Well depth: 883 feet

\begin{tabular}{|c|c|c|c|c|c|c|c|}
\hline Date measured & $\begin{array}{l}\text { Water } \\
\text { level } \\
\text { (foet) }\end{array}$ & Date measured & $\begin{array}{l}\text { Water } \\
\text { lovel } \\
\text { (feot) }\end{array}$ & Date moasured & $\begin{array}{l}\text { Water } \\
\text { lovel } \\
\text { (feet) }\end{array}$ & Date moasured & $\begin{array}{l}\text { Wiater } \\
\text { Invel } \\
\text { (feet) }\end{array}$ \\
\hline $\begin{array}{l}\text { Nov. } 1,1983 \ldots \ldots \\
\text { Apt. } 23,1990 \ldots \ldots \\
\text { May } 24 \ldots \ldots \ldots \ldots \\
\text { June } 21 \ldots \ldots \ldots \ldots \\
\text { July } 20 \ldots \ldots \ldots \ldots \\
\text { Aug. } 22 \ldots \ldots \ldots \ldots \\
\text { Sept } 21 \ldots \ldots \ldots \ldots \\
\text { Oct. } 22 \ldots \ldots \ldots \ldots \\
\text { Nov. } 29 \ldots \ldots \ldots \ldots\end{array}$ & $\begin{array}{l}314.72 \\
314.25 \\
314.60 \\
314.39 \\
314.84 \\
314.42 \\
314.48 \\
314.57 \\
314.30\end{array}$ & $\begin{array}{l}\text { Jan. } 24,1991 \ldots \ldots \\
\text { Feb. } 19 \ldots \ldots \ldots \ldots \\
\text { Mar. } 26 \ldots \ldots \ldots \ldots \\
\text { Apr. } 24 \ldots \ldots \ldots \ldots \\
\text { May } 30 \ldots \ldots \ldots \ldots \\
\text { June } 25 \ldots \ldots \ldots \ldots \\
\text { July } 16 \ldots \ldots \ldots \ldots \\
\text { Aug. } 20 \ldots \ldots \ldots \ldots \\
\text { Sept. } 26 \ldots \ldots \ldots \ldots\end{array}$ & $\begin{array}{l}314.45 \\
314.60 \\
314.50 \\
314.10 \\
313.80 \\
313.85 \\
313.95 \\
314.00 \\
313.95\end{array}$ & $\begin{array}{l}\text { Oct. } 22,1991 \ldots \ldots \\
\text { Nov. } 28 \ldots \ldots \ldots \ldots \\
\text { Dec. } 23 \ldots \ldots \ldots \\
\text { Jan. } 24,1992 \ldots \ldots \\
\text { Feb. } 20 \ldots \ldots \ldots \ldots \\
\text { Mar. } 24 \ldots \ldots \ldots \ldots \\
\text { Apr. } 29 \ldots \ldots \ldots \ldots \\
\text { May } 29 \ldots \ldots \ldots \ldots \\
\text { July } 7 \ldots \ldots \ldots \ldots\end{array}$ & $\begin{array}{l}.314 .29 \\
.314 .05 \\
.314 .34 \\
.314 .23 \\
.314 .32 \\
.314 .38 \\
.314 .23 \\
.314 .34 \\
.314 .27\end{array}$ & \multicolumn{2}{|c|}{$\begin{array}{l}\text { July } 30,1992 \ldots \ldots \ldots 314.42 \\
\text { Aug. } 28 \ldots \ldots \ldots \ldots .314 .36 \\
\text { Oct. } 1 \ldots \ldots \ldots \ldots .314 .45 \\
\quad \text { Highest water level: } \\
\text { May } 30,1991 \ldots \ldots \ldots 313.80 \\
\text { Lowest water level }: \\
\text { July } 20,1990 \ldots \ldots .314 .84\end{array}$} \\
\hline
\end{tabular}

Owner: NDSWC 6275

Aquifer code: $211 \mathrm{FXHL}$

Altitude: 2,226 feet

\begin{tabular}{|c|c|}
\hline Date measured & $\begin{array}{l}\text { Water } \\
\text { level } \\
\text { (feet) }\end{array}$ \\
\hline $\begin{array}{l}\text { May } 15,1990 \ldots \ldots \\
\text { June } 22 \ldots \ldots \ldots \\
\text { July } 20 \ldots \ldots \\
\text { Aug. } 22 \ldots \ldots \\
\text { Sept } 22 \ldots \ldots \\
\text { Oct. } 22 \ldots \ldots \\
\text { Nov. } 29 \ldots \ldots \\
\text { Jan. } 24,1991 \ldots \\
\text { Feb. } 19 \ldots \ldots \\
\end{array}$ & $\begin{array}{l}115.70 \\
116.05 \\
116.29 \\
116.28 \\
116.49 \\
116.72 \\
116.61 \\
116.91 \\
116.75\end{array}$ \\
\hline
\end{tabular}

\section{9-095-09CDD}

Date drilied: $07-17-84$

Well depth: 1,561 feet

\begin{tabular}{|c|c|c|c|c|c|}
\hline Date measured & $\begin{array}{l}\text { Water } \\
\text { lovel } \\
\text { (foat) }\end{array}$ & Date measured & $\begin{array}{l}\text { Water } \\
\text { lovel } \\
\text { (feot) }\end{array}$ & Date measured & $\begin{array}{l}\text { Waiter } \\
\text { level } \\
\text { (f Pat) }\end{array}$ \\
\hline $\begin{array}{l}\text { Mar. } 26,1991 \ldots \ldots \\
\text { Apr. } 24 \ldots \ldots \ldots \ldots \\
\text { May } 30 \ldots \ldots \ldots \ldots \\
\text { June } 25 \ldots \ldots \ldots \\
\text { July } 16 \ldots \ldots \ldots \\
\text { Aug. } 20 \ldots \ldots \ldots \\
\text { Sept. } 26 \ldots \ldots \ldots \\
\text { Oct } 22 \ldots \ldots \ldots \\
\text { Nov. } 28 \ldots \ldots \ldots \ldots \\
\end{array}$ & $\begin{array}{l}116.83 \\
116.87 \\
116.91 \\
117.06 \\
117.30 \\
117.39 \\
117.51 \\
117.53 \\
117.63\end{array}$ & $\begin{array}{l}\text { Dec. } 23,1991 \ldots \ldots \\
\text { Jan. } 24,1992 \ldots \ldots \ldots \\
\text { Feb. } 20 \ldots \ldots \ldots \ldots \\
\text { Mar. } 24 \ldots \ldots \ldots \ldots \\
\text { Apr. } 29 \ldots \ldots \ldots \ldots \\
\text { July } 7 \ldots \ldots \ldots \ldots \\
\text { July } 30 \ldots \ldots \ldots \ldots \\
\text { Aug. } 28 \ldots \ldots \ldots \ldots \\
\text { Oct. } 1 \ldots \ldots \ldots \ldots\end{array}$ & $\begin{array}{l}.117 .81 \\
.117 .92 \\
.117 .98 \\
.118 .04 \\
.117 .93 \\
.118 .25 \\
.118 .61 \\
.118 .49 \\
.118 .61\end{array}$ & \multicolumn{2}{|c|}{$\begin{array}{c}\begin{array}{c}\text { Highest water level } \\
\text { May } 15,1990 \ldots \ldots \ldots 115.70 \\
\text { Lowest water level }\end{array} \\
\text { July } 30,1992 \ldots \ldots \ldots 118.61 \\
\text { Oct. } 1,1992 \ldots \ldots \ldots 118.61\end{array}$} \\
\hline
\end{tabular}

Owner: NDSWC 4069

Aquifer code: 112WSLD Altitude: 1,965 fe日t

\begin{tabular}{|c|c|}
\hline Date measured & $\begin{array}{l}\text { Water } \\
\text { level } \\
\text { (feel) }\end{array}$ \\
\hline $\begin{array}{l}\text { July } 28,1970 \ldots \ldots \\
\text { Sept. } 9 \ldots \ldots \ldots \\
\text { Dec. } 1 \ldots \ldots \ldots \ldots \\
\text { Mar. } 20,1990 \ldots \ldots \\
\text { Apr. } 23 \ldots \ldots \ldots \ldots \\
\text { May } 24 \ldots \ldots \ldots \\
\text { June } 21 \ldots \ldots \ldots \\
\text { July } 19 \ldots \ldots \ldots \ldots \\
\text { Aug. } 21 \ldots \ldots \ldots \\
\text { Sept. } 19 \ldots \ldots \ldots\end{array}$ & $\begin{array}{l}117.86 \\
117.74 \\
117.10 \\
108.10 \\
107.56 \\
107.95 \\
108.19 \\
108.22 \\
108.27 \\
108.13\end{array}$ \\
\hline
\end{tabular}

150-089-31BCC

Date drilled: 197 ?

Well depth: 278 feet

\begin{tabular}{|c|c|}
\hline Date measured & $\begin{array}{l}\text { Water } \\
\text { level } \\
\text { (feet) }\end{array}$ \\
\hline 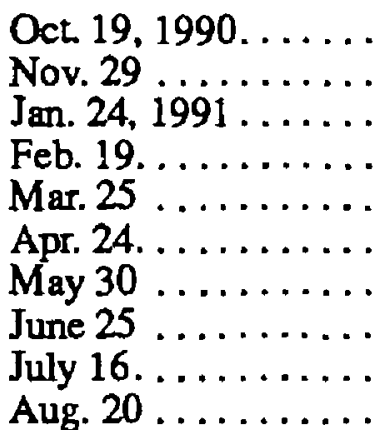 & $\begin{array}{l}108.14 \\
108.12 \\
108.29 \\
108.20 \\
110.82 \\
109.84 \\
108.10 \\
108.22 \\
108.35 \\
108.17\end{array}$ \\
\hline
\end{tabular}

\begin{tabular}{|c|c|}
\hline Date measured & $\begin{array}{l}\text { Water } \\
\text { level } \\
\text { (foet) }\end{array}$ \\
\hline $\begin{array}{l}\text { Sept. } 26,1991 \ldots \ldots \\
\text { Oct. } 22 \ldots \ldots \ldots \\
\text { Nov. } 27 \ldots \ldots \ldots \\
\text { Dec. } 23 \ldots \ldots \ldots \\
\text { Jan. } 24,1992 \ldots \ldots \\
\text { Feb. } 19 \ldots \ldots \ldots \\
\text { Mar. } 24 \ldots \ldots \ldots \\
\text { Apr. } 29 \ldots \ldots \ldots \\
\text { May } 21 \ldots \ldots \ldots \\
\text { July } 7 \ldots \ldots \ldots\end{array}$ & $\begin{array}{l}.108 .24 \\
.107 .77 \\
.108 .20 \\
.108 .29 \\
.107 .96 \\
.108 .19 \\
.108 .10 \\
.108 .19 \\
.108 .22 \\
.108 .09\end{array}$ \\
\hline
\end{tabular}

$\begin{array}{ll}\text { Date measured } & \begin{array}{c}\text { Weter } \\ \text { level } \\ \text { (fivet) }\end{array}\end{array}$

July $29,1992 \ldots \ldots \ldots 10^{2}, 31$

Oct. $1 \ldots \ldots \ldots \ldots . . . .108 .19$

Highest water level: Apr. 23, $1990 \ldots \ldots .107 .56$

Lowest water level: July $28,1970 \ldots \ldots . .117 .86$
Aug. $27 \ldots \ldots \ldots \ldots 108.57$ 
Table 2. Water levels for selected wells-Continued

Owner: NDSWC 5557

150-089-32DAA

Aquifer code: 112WSLD

Date drill ra: 1969 Altltude: 1,972 feet

Well depth: 224 feet

\begin{tabular}{|c|c|c|c|c|c|c|c|}
\hline Date measured & $\begin{array}{l}\text { Water } \\
\text { level } \\
\text { (foet) }\end{array}$ & Date meseured & $\begin{array}{l}\text { Water } \\
\text { lovel } \\
\text { (foet) }\end{array}$ & Date mossured & $\begin{array}{l}\text { Water } \\
\text { level } \\
\text { (feet) }\end{array}$ & Date measured & $\begin{array}{l}\text { Water } \\
\text { level } \\
\text { (feet) }\end{array}$ \\
\hline $\begin{array}{l}\text { Nov. } 4,1969 \ldots \ldots \\
\text { Dec. } 19 \ldots \ldots \ldots \ldots \\
\text { Jan } 20,1970 \ldots \ldots \\
\text { Feb. } 19 \ldots \ldots \ldots \ldots \\
\text { Mar. } 24 \ldots \ldots \ldots \ldots \\
\text { Apr. } 22 \ldots \ldots \ldots \ldots \\
\text { June } 5 \ldots \ldots \ldots \ldots \\
\text { June } 30 \ldots \ldots \ldots \ldots \\
\text { Sept. } 9 \ldots \ldots \ldots \ldots \\
\text { Dec. } 1, \ldots \ldots \ldots \ldots \\
\text { Apr. } 23,1990 \ldots \ldots \\
\text { May } 24 \ldots \ldots \ldots \ldots\end{array}$ & $\begin{array}{l}117.21 \\
117.58 \\
117.38 \\
117.35 \\
116.80 \\
118.86 \\
117.08 \\
116.72 \\
116.42 \\
115.79 \\
105.98 \\
106.34\end{array}$ & $\begin{array}{l}\text { June } 21,1990 \ldots \ldots \\
\text { July } 19 \ldots \ldots \ldots \ldots \\
\text { Aug. } 21 \ldots \ldots \ldots \ldots \\
\text { Sept. } 19 \ldots \ldots \ldots \ldots \\
\text { Oct. } 19 \ldots \ldots \ldots \ldots \\
\text { Nov. } 29 \ldots \ldots \ldots \ldots \\
\text { Jan. } 24,1991 \ldots \ldots \ldots \\
\text { Feb. } 19 \ldots \ldots \ldots \ldots \\
\text { Mar. } 25 \ldots \ldots \ldots \ldots \\
\text { Apr. } 24 \ldots \ldots \ldots \ldots \\
\text { May } 30 \ldots \ldots \ldots \ldots \\
\text { June } 25 \ldots \ldots \ldots \ldots\end{array}$ & $\begin{array}{l}106.49 \\
106.64 \\
106.64 \\
106.57 \\
106.50 \\
106.53 \\
106.60 \\
106.57 \\
106.54 \\
106.55 \\
106.53 \\
106.63\end{array}$ & $\begin{array}{l}\text { July } 15,1991 \ldots \ldots \\
\text { Aug. } 20 \ldots \ldots \ldots \ldots \\
\text { Sept. } 26 \ldots \ldots \ldots \ldots \\
\text { Oct. } 22 \ldots \ldots \ldots \ldots \\
\text { Nov. } 27 \ldots \ldots \ldots \ldots \\
\text { Dec. } 23 \ldots \ldots \ldots \\
\text { Jan. } 24,1992 \ldots \ldots \ldots \\
\text { Feb. } 19 \ldots \ldots \ldots \ldots \\
\text { Mar. } 24 \ldots \ldots \ldots \ldots \\
\text { Apr. } 29 \ldots \ldots \ldots \ldots \\
\text { May } 21 \ldots \ldots \ldots \ldots \\
\text { July } 7 \ldots \ldots \ldots \ldots\end{array}$ & $\begin{array}{l}.106 .69 \\
.106 .61 \\
.106 .64 \\
.106 .17 \\
.106 .46 \\
.106 .38 \\
.106 .25 \\
.106 .23 \\
.106 .40 \\
.106 .45 \\
.106 .51 \\
.106 .44\end{array}$ & $\begin{array}{r}\text { July } 29,1992 \ldots \ldots \\
\text { Aug. } 27 \ldots \ldots \ldots \\
\text { Oct. } 1 \ldots \ldots \ldots \\
\text { Highest water } \\
\text { Apr. } 23,1990 \ldots \ldots \\
\\
\text { Lowest water } \\
\text { Apr. } 22,1970 \ldots \ldots\end{array}$ & $\begin{array}{l}.106 .69 \\
.106 .60 \\
.106 .68 \\
\text { evel: } \\
.105 .98 \\
\text { evel: } \\
.118 .86\end{array}$ \\
\hline
\end{tabular}

Owner: NDSWC 4071

150-090-36AAA

Aquifer code: 112WSLD

Altitude: 1,998 feet

\begin{tabular}{|c|c|c|c|}
\hline Date measurod & $\begin{array}{l}\text { Water } \\
\text { level } \\
\text { (feet) }\end{array}$ & Date measured & $\begin{array}{l}\text { Water } \\
\text { level } \\
\text { (feet) }\end{array}$ \\
\hline $\begin{array}{l}\text { July } 28,1970 \ldots \ldots \\
\text { Sept } 9 \ldots \ldots \ldots \\
\text { Dec. } 1 \ldots \ldots \ldots \\
\text { Dec. } 4,1972 \ldots \ldots \ldots \\
\text { Dec. } 5,1973 \ldots \ldots \\
\text { Dec. } 5,1974 \ldots \ldots \\
\text { Dec. } 4,1975 \ldots \ldots \\
\text { Nov. } 30,1976 \ldots \ldots \\
\text { Nov. } 29,1977 \ldots \ldots \\
\text { Nov. } 22,1978 \ldots \ldots \\
\text { Nov. } 19,1979 \ldots \ldots \\
\text { Nov. } 25,1980 \ldots \ldots \\
\text { Dec. } 1,1981 \ldots \ldots \\
\text { Dec. } 1,1982 \ldots \ldots \\
\text { Dec. } 5,1984 \ldots \ldots\end{array}$ & $\begin{array}{l}152.92 \\
152.82 \\
152.21 \\
150.60 \\
150.05 \\
148.99 \\
147.69 \\
147.55 \\
147.09 \\
146.97 \\
145.85 \\
147.28 \\
145.10 \\
144.25 \\
143.75\end{array}$ & $\begin{array}{l}\text { Dec. } 17,1985 \ldots \ldots \\
\text { Nov. } 14,1986 \ldots \ldots \\
\text { Dec. } 5,1987 \ldots \ldots \\
\text { Dec. } 14,1988 \ldots \ldots \\
\text { July } 13,1989 \ldots \ldots \\
\text { Dec. } 9 \ldots \ldots \ldots \\
\text { Mar. } 20,1990 \ldots \ldots \\
\text { Apr. } 23 \ldots \ldots \ldots \\
\text { May } 24 \ldots \ldots \ldots \ldots \\
\text { June } 21 \ldots \ldots \ldots \ldots \\
\text { July } 19 \ldots \ldots \ldots \ldots \\
\text { Aug. } 21 \ldots \ldots \ldots \ldots \\
\text { Sept. } 19 \ldots \ldots \ldots \ldots \\
\text { Oct. } 19 \ldots \ldots \ldots \ldots \\
\text { Nov. } 29 \ldots \ldots \ldots \ldots \\
\end{array}$ & $\begin{array}{l}143.41 \\
142.39 \\
141.75 \\
142.56 \\
143.00 \\
142.78 \\
143.05 \\
142.51 \\
142.92 \\
143.10 \\
143.24 \\
142.71 \\
143.12 \\
143.11 \\
143.06\end{array}$ \\
\hline
\end{tabular}

Date drilled: $07-22-70$ Well depth: 299 feet

\begin{tabular}{|c|c|}
\hline Date measured & $\begin{array}{l}\text { Water } \\
\text { leval } \\
\text { (feet) }\end{array}$ \\
\hline $\begin{array}{l}\text { Nov. } 30,1990 \ldots \ldots \\
\text { Dec. } 8, \ldots \ldots \ldots \\
\text { Jan. } 24,1991 \ldots \ldots \\
\text { Feb. } 19 \ldots \ldots \ldots \\
\text { Mar. } 25 \ldots \ldots \ldots \\
\text { Apr. } 24 \ldots \ldots \ldots \\
\text { May } 30 \ldots \ldots \ldots \\
\text { June } 25 \ldots \ldots \ldots \\
\text { July } 16 \ldots \ldots \ldots \\
\text { Aug. } 20 \ldots \ldots \ldots \\
\text { Sept. } 26 \ldots \ldots \ldots \\
\text { Oct. } 22 \ldots \ldots \ldots \\
\text { Nov. } 27 \ldots \ldots \ldots \\
\text { Dec. } 23 \ldots \ldots \ldots \\
\text { Jan. } 24,1992 \ldots \ldots \\
\end{array}$ & $\begin{array}{l}.143 .05 \\
.143 .12 \\
.143 .26 \\
.143 .18 \\
.143 .09 \\
.143 .09 \\
.143 .09 \\
.143 .21 \\
.143 .34 \\
.143 .14 \\
.143 .21 \\
.142 .74 \\
.143 .07 \\
.143 .19 \\
.142 .87\end{array}$ \\
\hline
\end{tabular}

\begin{tabular}{|c|c|}
\hline Date messured & $\begin{array}{c}\text { Water } \\
\text { level } \\
\text { (feet) }\end{array}$ \\
\hline $\begin{array}{l}\text { Feb. } 19,1992 \ldots \ldots \\
\text { Mar. } 24 \ldots \ldots \ldots \\
\text { Apt. } 29 \ldots \ldots \ldots \\
\text { May } 21 \ldots \ldots \ldots \ldots \\
\text { July } 7 \ldots \ldots \ldots \ldots \\
\text { July } 29 \ldots \ldots \ldots \ldots \\
\text { Aug. } 27 \ldots \ldots \ldots \ldots \\
\text { Oct. } 1 \ldots \ldots \ldots \ldots \\
\text { Nov. } 22 \ldots \ldots \ldots \ldots\end{array}$ & $\begin{array}{l}143.09 \\
.143 .06 \\
.143 .10 \\
.143 .14 \\
.143 .06 \\
.143 .29 \\
.143 .49 \\
.143 .25 \\
.143 .03\end{array}$ \\
\hline
\end{tabular}

Highest wa ter level:

Dec. 5, 1987 . . . . . . 141.75

Lowest wa $+9, \mathrm{r}$ level: July $28,1970 \ldots \ldots 152.92$
Aquifer code: 112SANISH Altitude: 1,898 feet
Owner: USGS

151-092-30ADD

Date drilled: 06-04-92 Well depth: 210 feet

\begin{tabular}{|c|c|c|c|c|c|c|c|}
\hline Date measured & $\begin{array}{l}\text { Water } \\
\text { level } \\
\text { (feet) }\end{array}$ & Date measured & $\begin{array}{l}\text { Water } \\
\text { level } \\
\text { (feet) }\end{array}$ & Date messured & $\begin{array}{l}\text { Water } \\
\text { level } \\
\text { (feet) }\end{array}$ & Data messuriad & $\begin{array}{l}\text { Water } \\
\text { level } \\
\text { (teat) }\end{array}$ \\
\hline $\begin{array}{l}\text { July } 29,1992 \ldots \ldots \\
\text { Aug. } 27 \ldots \ldots \ldots\end{array}$ & $\begin{array}{l}50.00 \\
49.98\end{array}$ & Oct. $1,1992 . \ldots \ldots$ & 49.93 & $\begin{array}{l}\text { Highest water } \\
\text { Oct. 1, } 1992 \ldots . . .\end{array}$ & $\begin{array}{l}\text { vel: } \\
.49 .93\end{array}$ & $\begin{array}{l}\text { Lowest water } \\
\text { July } 29,1992 \ldots \ldots\end{array}$ & $\begin{array}{l}\text { vel: } \\
.50 .00\end{array}$ \\
\hline
\end{tabular}


Table 2. Water levels for selected wells--Continued

Owner: USGS

151-093-21ADD

Aquifer code: 112SANISH

Altitude: 1,995 foet

\begin{tabular}{|c|c|c|c|c|c|c|c|}
\hline Date measured & $\begin{array}{l}\text { Water } \\
\text { Jevel } \\
\text { (feot) }\end{array}$ & Date measured & $\begin{array}{l}\text { Water } \\
\text { level } \\
\text { (feot) }\end{array}$ & Date measured & $\begin{array}{l}\text { Water } \\
\text { lovel } \\
\text { (feet) }\end{array}$ & Date measured & $\begin{array}{l}\text { Water } \\
\text { level } \\
\text { (finet) }\end{array}$ \\
\hline $\begin{array}{l}\text { Aug. } 5,1992 \ldots \ldots \\
\text { Aug. } 27 \ldots \ldots\end{array}$ & $\begin{array}{l}154.95 \\
152.69\end{array}$ & Oct. $1,1992 \ldots$ & 152.38 & \multicolumn{2}{|c|}{$\begin{array}{c}\text { Highest water level: } \\
\text { Oct. } 1,1992 \ldots \ldots \ldots .152 .38\end{array}$} & \multicolumn{2}{|c|}{$\begin{array}{l}\text { Lowrest water level: } \\
\text { Aug. } 5,1992 \ldots \ldots \ldots 1 \approx 4.95\end{array}$} \\
\hline
\end{tabular}

Owner: USGS

151-093-24DCC

Aqulfer code: 112SANISH

Altitude: 1,925 feet

Date drilled: 06-03-92

Well depth: 145 feet

\begin{tabular}{|c|c|c|c|c|c|c|c|}
\hline Date measured & $\begin{array}{l}\text { Water } \\
\text { level } \\
\text { (feel) }\end{array}$ & Date measured & $\begin{array}{l}\text { Water } \\
\text { level } \\
\text { (feet) }\end{array}$ & Dato measured & $\begin{array}{l}\text { Water } \\
\text { level } \\
\text { (feot) }\end{array}$ & Date meaaured & $\begin{array}{l}\text { Water } \\
\text { level } \\
\text { (f rat) }\end{array}$ \\
\hline $\begin{array}{l}\text { July } 29,1992 \ldots \ldots \\
\text { Aug. } 27 \ldots \ldots\end{array}$ & $\begin{array}{l}79.65 \\
79.50\end{array}$ & Oct. $1,1992 \ldots \ldots$ & 79.80 & $\begin{array}{r}\text { Highest water } \\
\text { Aug. } 27,1992 \ldots \ldots\end{array}$ & vel: 79.50 & $\begin{array}{r}\text { Lowest wate } \\
\text { Oct. } 1,1992 \ldots .\end{array}$ & vel: 79.80 \\
\hline
\end{tabular}

Owner: USGS

$151-093-27 B B B$

Aquifer codo: 112SANISH

Altitude: 1,985 feet

Date drilled: 06-04-92

\begin{tabular}{|c|c|c|c|c|c|c|c|}
\hline Date meaaured & $\begin{array}{l}\text { Water } \\
\text { level } \\
\text { (feet) }\end{array}$ & Date measured & $\begin{array}{l}\text { Water } \\
\text { level } \\
\text { (feot) }\end{array}$ & Date measured & $\begin{array}{l}\text { Water } \\
\text { level } \\
\text { (feet) }\end{array}$ & Dafe measured & $\begin{array}{l}\text { Water } \\
\text { level } \\
\text { (f vat) }\end{array}$ \\
\hline $\begin{array}{l}\text { July } 27,1992 \ldots \ldots \\
\text { Aug. } 27 \ldots \ldots \ldots\end{array}$ & $\begin{array}{l}142.80 \\
141.70\end{array}$ & Oct. $1,1992 \ldots$ & 142.76 & \multicolumn{2}{|c|}{$\begin{array}{c}\text { Highest water level: } \\
\text { Aug. } 27,1992 \ldots \ldots .141 .70\end{array}$} & \multicolumn{2}{|c|}{$\begin{array}{l}\text { Lowest water level: } \\
\text { July } 27,1992 \ldots \ldots \ldots 142.80\end{array}$} \\
\hline
\end{tabular}

Owner: NDSWC 5939

Aquifer code: 125CBLD

Altitude: $2,308.8$ feet

\begin{tabular}{|c|c|c|c|}
\hline Date measurod & $\begin{array}{l}\text { Water } \\
\text { level } \\
\text { (feet) }\end{array}$ & Date measured & $\begin{array}{l}\text { Water } \\
\text { level } \\
\text { (feet) }\end{array}$ \\
\hline $\begin{array}{l}\text { Nov. } 1,1983 \ldots \ldots \\
\text { Apr. } 23,1990 \ldots \ldots \\
\text { May } 24 \ldots \ldots \ldots \\
\text { June } 22 \ldots \ldots \ldots \ldots \\
\text { July } 20 \ldots \ldots \ldots \ldots \\
\text { Aug. } 22 \ldots \ldots \ldots \ldots \\
\text { Sept. } 21 \ldots \ldots \ldots \ldots \\
\text { Oct. } 22 \ldots \ldots \ldots \ldots \\
\text { Nov. } 29 \ldots \ldots \ldots\end{array}$ & $\begin{array}{l}233.28 \\
231.70 \\
231.85 \\
231.75 \\
231.70 \\
231.72 \\
231.46 \\
231.46 \\
231.49\end{array}$ & \multicolumn{2}{|c|}{ 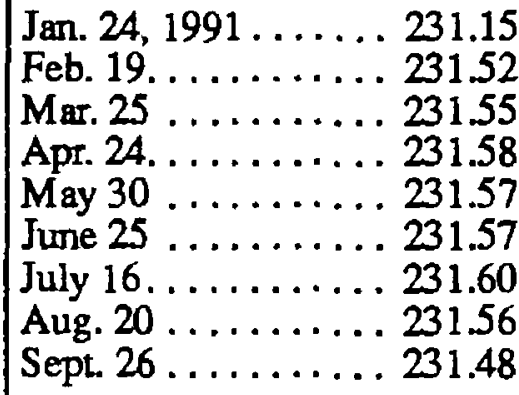 } \\
\hline
\end{tabular}

\section{1-095-04DBD1}

Date drilled: $06-70-81$ Well depth: 1,196 feet

\begin{tabular}{|c|c|}
\hline Date measured & $\begin{array}{l}\text { Water } \\
\text { level } \\
\text { (feet) }\end{array}$ \\
\hline $\begin{array}{l}\text { Oct. } 22,1991 \ldots \\
\text { Nov. } 28 \ldots \ldots \\
\text { Dec. } 23 \ldots \ldots \\
\text { Jan. } 24,1992 \ldots \ldots \\
\text { Feb. } 20 \ldots \ldots \\
\text { Mar. } 24 \ldots \ldots \\
\text { Apr. } 29 \ldots \ldots \\
\text { May } 29 \ldots \ldots \\
\text { July } 7 \ldots \ldots \\
\end{array}$ & $\begin{array}{l}231.47 \\
231.46 \\
231.44 \\
231.45 \\
230.86 \\
231.38 \\
231.49 \\
230.34 \\
231.00\end{array}$ \\
\hline
\end{tabular}

Date measured $\begin{aligned} & \text { Water } \\ & \text { Ievel } \\ & \text { (firat) }\end{aligned}$

July $29,1992 \ldots \ldots .239 .98$

Aug. 27. . . . . . . . 237.99

Oct. $1 \ldots \ldots . . .237 .88$

Highest water level: May 29, 1992 . . . . . . 237.34

Lowest water level: Nov. $1,1983 \ldots \ldots .233 .28$ 
Table 2 Water levels for selected wells--Continued

Owner: NDSWC 6164

151-095-04DBD2

Aquifer code: $211 \mathrm{FXHL}$

Date drilled: $06-30-81$ Altitude: 2,309 feet

\begin{tabular}{|c|c|c|c|c|c|c|c|}
\hline Date measured & $\begin{array}{l}\text { Water } \\
\text { level } \\
\text { (feet) }\end{array}$ & Date measured & $\begin{array}{l}\text { Wrier } \\
\text { level } \\
\text { (foet) }\end{array}$ & Date measured & $\begin{array}{l}\text { Water } \\
\text { level } \\
\text { (foet) }\end{array}$ & Dste measured & $\begin{array}{l}\text { Water } \\
\text { lovel } \\
\text { (feet) }\end{array}$ \\
\hline $\begin{array}{l}\text { Nov. } 1,1983 \ldots \ldots \\
\text { Apr. } 23,1990 \ldots \ldots \\
\text { May } 24 \ldots \ldots \ldots \ldots \\
\text { June } 21 \ldots \ldots \ldots \ldots \\
\text { July } 20 \ldots \ldots \ldots \ldots \\
\text { Aug. } 22 \ldots \ldots \ldots \ldots \\
\text { Sept } 21 \ldots \ldots \ldots \ldots \\
\text { Oct. } 22 \ldots \ldots \ldots \ldots \\
\text { Nov. } 29 \ldots \ldots \ldots \ldots\end{array}$ & $\begin{array}{l}184.50 \\
193.22 \\
193.75 \\
193.69 \\
193.93 \\
193.98 \\
194.25 \\
194.48 \\
194.46\end{array}$ & $\begin{array}{l}\text { Jan. } 24,1991 \ldots \ldots \\
\text { Feb. } 19 . \ldots \ldots \ldots \\
\text { Mar. } 25 \ldots \ldots \ldots \ldots \\
\text { Apr. } 24 \ldots \ldots \ldots \ldots \\
\text { May } 30 \ldots \ldots \ldots \ldots \\
\text { June } 25 \ldots \ldots \ldots \ldots \\
\text { July } 16 \ldots \ldots \ldots \ldots \\
\text { Aug. } 20 \ldots \ldots \ldots \ldots \\
\text { Sept. } 26 \ldots \ldots \ldots \ldots\end{array}$ & $\begin{array}{l}194.86 \\
194.83 \\
194.92 \\
195.13 \\
195.36 \\
195.62 \\
195.94 \\
196.19 \\
196.53\end{array}$ & $\begin{array}{l}\text { Oct. } 22,1991 \ldots \ldots \\
\text { Nov. } 28 \ldots \ldots \ldots \ldots \\
\text { Dec. } 23 \ldots \ldots \ldots \ldots \\
\text { Jan. } 24,1992 \ldots \ldots \\
\text { Feb. } 20 \ldots \ldots \ldots \ldots \\
\text { Mar. } 24 \ldots \ldots \ldots \ldots \\
\text { Apr. } 29 \ldots \ldots \ldots \ldots \\
\text { May } 29 \ldots \ldots \ldots \ldots \\
\text { July } 7 \ldots \ldots \ldots \ldots\end{array}$ & $\begin{array}{l}.196 .63 \\
.196 .59 \\
.197 .00 \\
.197 .10 \\
.197 .48 \\
.196 .74 \\
.196 .82 \\
.197 .22 \\
.198 .37\end{array}$ & \multicolumn{2}{|c|}{$\begin{array}{c}\text { July } 29,1992 \ldots \ldots \ldots 198.70 \\
\text { Aug. } 27 \ldots \ldots \ldots \ldots 198.84 \\
\text { Oct. } 1 \ldots \ldots \ldots \ldots 199.14 \\
\text { Highest wa+er level: } \\
\text { Nov. } 1,1983 \ldots \ldots \ldots 184.50 \\
\text { Lopest water level: } \\
\text { Oct. } 1,1992 \ldots \ldots \ldots 199.14\end{array}$} \\
\hline
\end{tabular}

Owner: NDSWC 6053

151-095-36BBA

Aquifer code: $125 \mathrm{CBLD}$

Date drilled: $05-28-82$ Altitude: 2,262 feet

Well depth: 882 feet

\begin{tabular}{|c|c|c|c|c|c|c|c|}
\hline Date measured & $\begin{array}{l}\text { Water } \\
\text { level } \\
\text { (foet) }\end{array}$ & Date measured & $\begin{array}{l}\text { Water } \\
\text { leved } \\
\text { (foet) }\end{array}$ & Date measured & $\begin{array}{l}\text { Water } \\
\text { lovel } \\
\text { (feet) }\end{array}$ & Date messurct & $\begin{array}{l}\text { Water } \\
\text { level } \\
\text { (feet) }\end{array}$ \\
\hline $\begin{array}{l}\text { Nov. } 1,1983 \ldots \ldots \\
\text { July } 20,1990 \ldots \ldots \\
\text { Aug. } 22 \ldots \ldots \ldots \\
\text { Sept } 21 \ldots \ldots \ldots \\
\text { Oct. } 22 \ldots \ldots \ldots \\
\text { Nov. } 29 \ldots \ldots \ldots \\
\text { Jan. } 24,1991 \ldots \ldots \\
\text { Feb. } 19 \ldots \ldots \ldots \\
\text { Mar. } 26 \ldots \ldots \ldots\end{array}$ & $\begin{array}{l}344.22 \\
344.15 \\
344.08 \\
344.12 \\
344.28 \\
344.18 \\
343.60 \\
343.90 \\
343.98\end{array}$ & $\begin{array}{l}\text { Apt. } 24,1991 \ldots \ldots \\
\text { May } 30 \ldots \ldots \ldots \\
\text { June } 25 \ldots \ldots \ldots \\
\text { July } 16 \ldots \ldots \ldots \\
\text { Aug. } 20 \ldots \ldots \ldots \\
\text { Sept. } 26 \ldots \ldots \ldots \\
\text { Oct. } 22 \ldots \ldots \ldots \\
\text { Nov. } 28 \ldots \ldots \ldots \\
\text { Dec. } 23 \ldots \ldots \ldots\end{array}$ & $\begin{array}{l}343.74 \\
343.55 \\
343.49 \\
343.30 \\
344.06 \\
343.90 \\
344.10 \\
344.08 \\
344.12\end{array}$ & $\begin{array}{l}\text { Jan. } 24,1992 \ldots \ldots \\
\text { Feb. } 20 \ldots \ldots \ldots \\
\text { Mar. } 24 \ldots \ldots \ldots \\
\text { Apr. } 29 \ldots \ldots \ldots \\
\text { May } 29 \ldots \ldots \ldots \\
\text { July } 7 \ldots \ldots \ldots \\
\text { July } 30 \ldots \ldots \ldots \\
\text { Aug. } 28 \ldots \ldots \ldots \\
\text { Oct } 1 \ldots \ldots \ldots\end{array}$ & $\begin{array}{l}.344 .14 \\
.344 .13 \\
.344 .09 \\
.343 .99 \\
.344 .10 \\
.344 .05 \\
.344 .02 \\
.344 .08 \\
.344 .27\end{array}$ & \multicolumn{2}{|c|}{$\begin{array}{c}\text { Highest water level: } \\
\text { July } 16,1991 \ldots \ldots \ldots 343.30 \\
\text { Lowest water level: } \\
\text { Oct. 22, } 1990 \ldots \ldots \ldots 344.28\end{array}$} \\
\hline
\end{tabular}


Table 2. Water levels for selected wells-Continued

Owner: NDSWC 3318

152-087-16AAA

Aqulfer code: 112VANG Aititude: 2,030 feet

\begin{tabular}{|c|c|c|c|c|c|c|c|}
\hline Date measured & $\begin{array}{l}\text { ater } \\
\text { vel } \\
\text { eet) }\end{array}$ & Date measured & $\begin{array}{l}\text { Water } \\
\text { lovel } \\
\text { (feel) }\end{array}$ & Date measured & $\begin{array}{l}\text { Water } \\
\text { level } \\
\text { (feet) }\end{array}$ & Date measured & $\begin{array}{l}\text { Water } \\
\text { level } \\
\text { (feet) }\end{array}$ \\
\hline 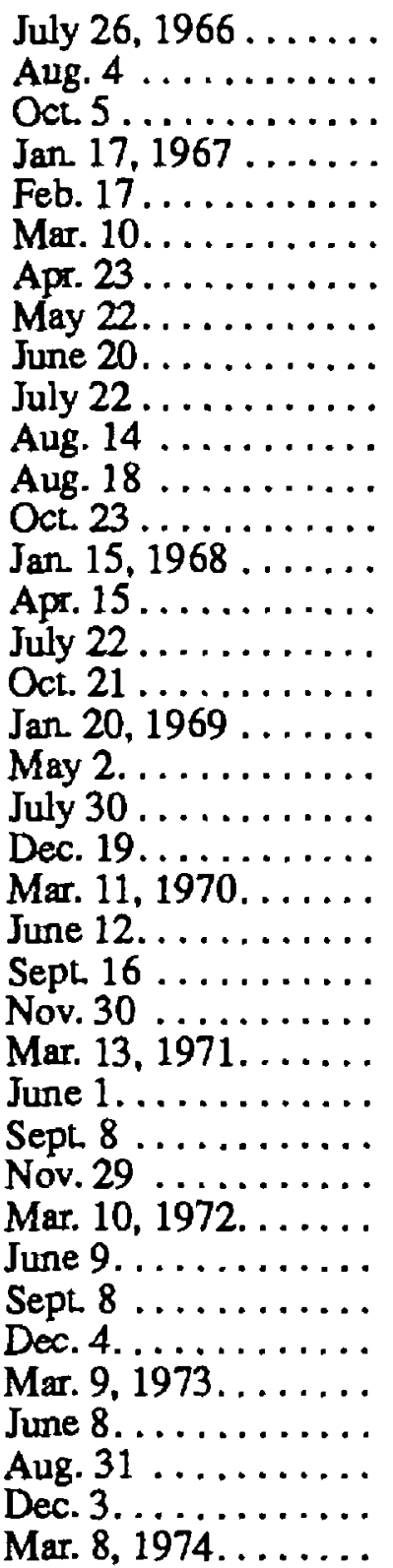 & $\begin{array}{r}9.06 \\
9.13 \\
10.00 \\
8.76 \\
8.92 \\
8.15 \\
8.15 \\
7.97 \\
8.06 \\
8.28 \\
8.47 \\
8.50 \\
8.94 \\
9.28 \\
8.91 \\
8.88 \\
8.49 \\
8.91 \\
7.79 \\
7.54 \\
8.35 \\
8.78 \\
6.11 \\
6.11 \\
6.78 \\
7.74 \\
7.50 \\
7.53 \\
7.93 \\
8.72 \\
7.71 \\
7.50 \\
8.03 \\
8.27 \\
8.09 \\
7.86 \\
7.85 \\
8.35\end{array}$ & $\begin{array}{l}\text { June } 10,1974 \ldots \ldots \\
\text { Sept. } 3 \ldots \ldots \ldots \\
\text { Dec. } 4 \ldots \ldots \ldots \\
\text { Mar. } 4,1975 \ldots \ldots \\
\text { June } 23 \ldots \ldots \\
\text { Sept. } 30 \ldots \ldots \\
\text { Dec. } 4 \ldots \ldots \\
\text { June } 12,1976 \ldots \ldots \\
\text { Sept. } 3 \ldots \ldots \\
\text { Dec. } 1 \ldots \ldots \\
\text { Feb. } 28,1977 \ldots \ldots \\
\text { June } 7 \ldots \ldots \\
\text { Sept. } 7 \ldots \ldots \\
\text { Sept. } 23 \ldots \ldots \\
\text { Dec. } 6 \ldots \ldots \\
\text { Mar. } 25,1978 \ldots \ldots \\
\text { June } 15 \ldots \ldots \\
\text { Sept. } 22 \ldots \ldots \\
\text { Nov. } 21 \ldots \ldots \\
\text { Mar. } 1,1979 \ldots \ldots \\
\text { June } 6 \ldots \ldots \\
\text { Sept. } 5 \ldots \ldots \\
\text { Dec. } 6 \ldots \ldots \\
\text { Mar. } 6,1980 \ldots \\
\text { June } 5 . \ldots \ldots \\
\text { Sept. } 5 \ldots \ldots \\
\text { Dec. } 4 \ldots \ldots \\
\text { Mar. } 6,1981 \ldots \ldots \\
\text { June } 10 \ldots \ldots \\
\text { Sept. } 4 \ldots \ldots \\
\text { Nov. } 30 \ldots \ldots \\
\text { Mar. } 22,1982 \ldots \\
\text { June } 15,1984 \ldots \ldots \\
\text { Sept. } 22 \ldots \ldots \\
\text { Dec. } 2 \ldots \ldots \\
\text { Dec. } 3 \ldots \ldots \\
\text { Mar. } 23,1985 \ldots \ldots \\
\text { Sept. } 28 \ldots \ldots \\
\end{array}$ & $\begin{array}{l}7.01 \\
7.52 \\
8.26 \\
7.79 \\
5.58 \\
6.64 \\
6.64 \\
6.37 \\
7.11 \\
8.12 \\
8.77 \\
8.76 \\
8.16 \\
9.05 \\
8.77 \\
8.96 \\
6.02 \\
7.35 \\
7.65 \\
8.50 \\
6.87 \\
7.65 \\
8.42 \\
8.98 \\
8.91 \\
9.30 \\
9.45 \\
9.61 \\
9.66 \\
9.60 \\
9.76 \\
9.95 \\
7.70 \\
8.35 \\
8.74 \\
8.74 \\
9.05 \\
8.43\end{array}$ & 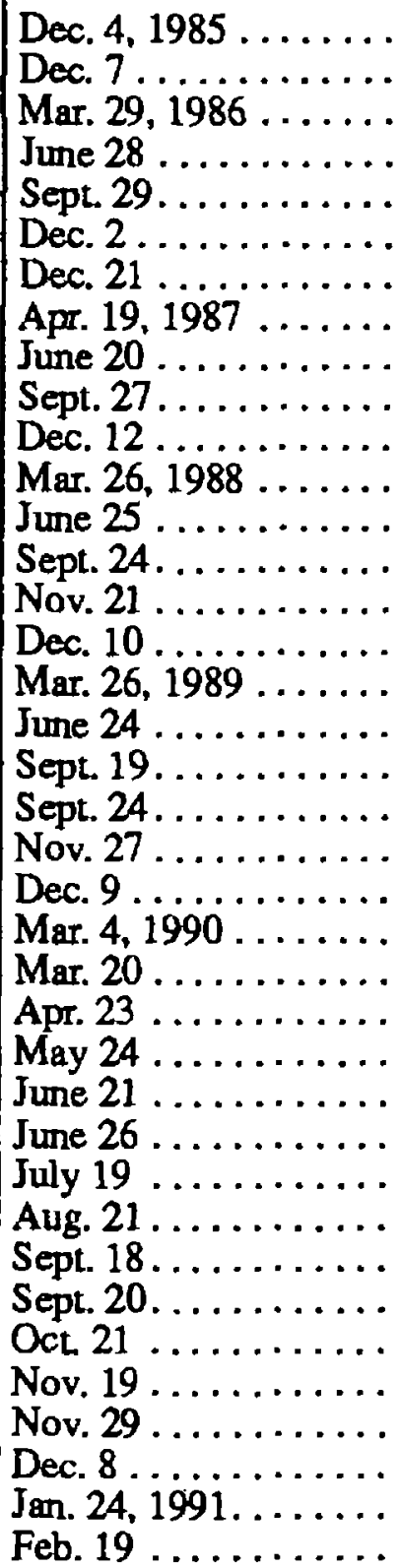 & $\begin{array}{r}8.53 \\
8.52 \\
8.39 \\
7.70 \\
8.07 \\
8.42 \\
8.54 \\
8.28 \\
8.53 \\
8.82 \\
9.21 \\
9.42 \\
9.47 \\
9.69 \\
9.80 \\
9.88 \\
9.57 \\
9.29 \\
9.58 \\
9.63 \\
9.82 \\
9.87 \\
10.17 \\
9.70 \\
9.95 \\
10.20 \\
10.09 \\
10.11 \\
9.93 \\
9.98 \\
10.05 \\
9.98 \\
10.15 \\
10.26 \\
9.67 \\
10.32 \\
10.08\end{array}$ & 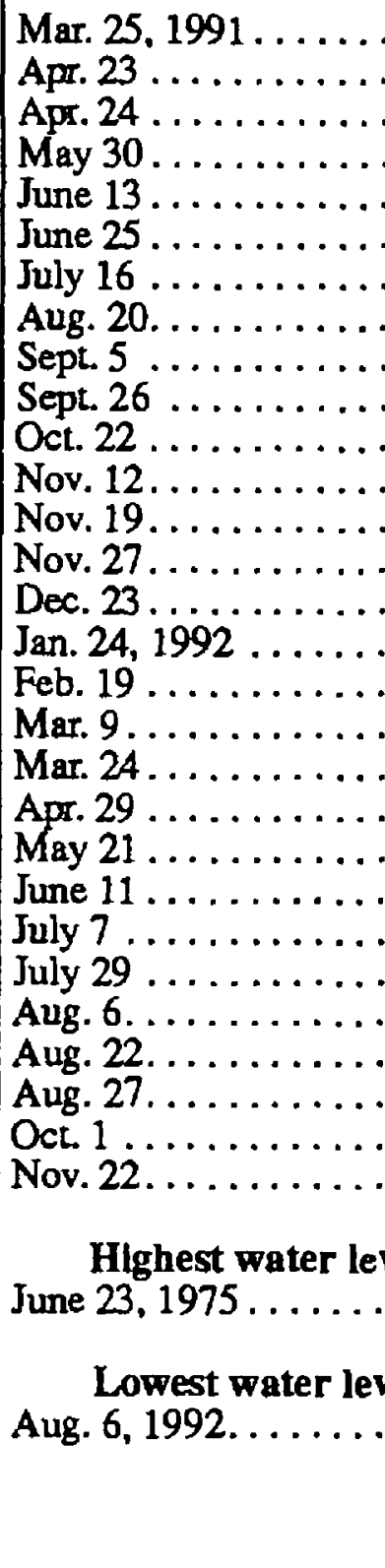 & 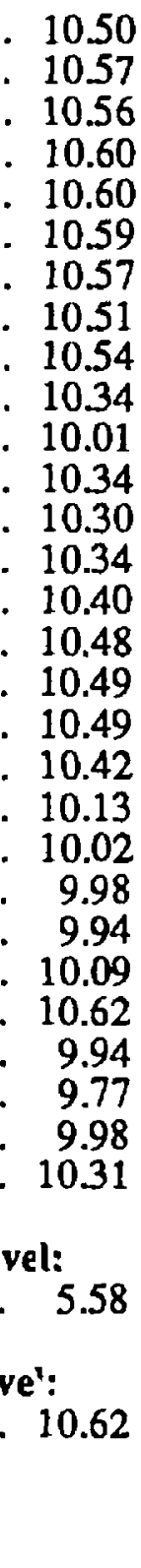 \\
\hline
\end{tabular}


Table 2. Water levels for selected Wells-Continued

Owner: NDSWC 3197

152-087-18DDD

Aquifer code: 112VANG

Date drillet: $05-13-65$ Altitude: 2,035 feet

Well deptr : 117 foet

\begin{tabular}{|c|c|c|c|c|c|c|c|}
\hline Date meeaured & $\begin{array}{l}\text { Water } \\
\text { level } \\
\text { (feet) }\end{array}$ & Data measured & $\begin{array}{l}\text { Water } \\
\text { level } \\
\text { (feet) }\end{array}$ & Date meaaured & $\begin{array}{l}\text { Water } \\
\text { level } \\
\text { (feet) }\end{array}$ & Date meesured & $\begin{array}{l}\text { Water } \\
\text { level } \\
\text { (feet) }\end{array}$ \\
\hline $\begin{array}{l}\text { June } 17,1965 \ldots \ldots \\
\text { Aug. } 19 \ldots \ldots \ldots \\
\text { Sept. } 13 \ldots \ldots \ldots \\
\text { Oct. } 23 \ldots \ldots \ldots \\
\text { Nov. } 23 \ldots \ldots \ldots \\
\text { Dec. } 30 \ldots \ldots \ldots \\
\text { Jan. } 31,1966 \ldots \ldots \\
\text { Mar. } 14 \ldots \ldots \ldots \\
\text { May } 11 \ldots \ldots \ldots \\
\text { June } 6 \ldots \ldots \ldots \\
\text { Aug. } 3 \ldots \ldots \\
\text { Aug. } 18,1967 \ldots \ldots \\
\text { July } 22,1968 \ldots \ldots \\
\text { July } 30,1969 \ldots \ldots \\
\text { Dec. } 19 . \ldots \ldots \\
\text { Nov. } 30,1970 \ldots \ldots \\
\text { Nov. } 29,1971 \ldots \ldots \\
\text { Dec. } 4,1972 \ldots \ldots \\
\text { Dec. } 3,1973 \ldots \ldots \\
\text { Dec. } 4,1974 \ldots \ldots \\
\text { Dec. } 4,1975 \ldots \ldots\end{array}$ & $\begin{array}{l}40.40 \\
37.12 \\
36.98 \\
36.68 \\
36.59 \\
36.73 \\
36.62 \\
36.76 \\
36.50 \\
36.39 \\
39.52 \\
37.05 \\
37.80 \\
36.74 \\
36.61 \\
34.14 \\
34.50 \\
34.37 \\
33.75 \\
34.07 \\
32.20\end{array}$ & $\begin{array}{l}\text { Nov. } 30,1976 \ldots \ldots \\
\text { Dec. } 6,1977 \ldots \ldots \\
\text { Nov. } 21,1978 \ldots \ldots \\
\text { Dec. } 6,1979 \ldots \ldots \\
\text { Dec. } 4,1980 \ldots \ldots \\
\text { Nov. } 30,1981 \ldots \ldots \\
\text { Dec. } 9,1982 \ldots \ldots \\
\text { Nov. } 29,1983 \ldots \ldots \\
\text { Dec. } 2,1984 \ldots \ldots \\
\text { Dec. } 3 . \ldots \\
\text { July } 9,1985 \ldots \ldots \ldots \\
\text { Dec. } 4 \ldots \ldots \ldots \\
\text { Dec. } 7 \ldots \ldots \ldots \\
\text { Dec. } 21,1986 \ldots \ldots \\
\text { Dec. } 12,1987 \ldots \ldots \\
\text { Nov. } 21,1988 \ldots \ldots \\
\text { Dec. } 10 \ldots \ldots \ldots \\
\text { Sept. } 19,1989 \ldots \ldots \\
\text { Nov. } 27 \ldots \ldots \\
\text { Dec. } 9 \ldots \ldots \\
\text { Mar. } 20,1990 \ldots \ldots\end{array}$ & $\begin{array}{l}32.84 \\
33.76 \\
33.36 \\
33.76 \\
34.85 \\
36.05 \\
34.73 \\
34.50 \\
34.52 \\
34.57 \\
34.50 \\
34.38 \\
34.30 \\
33.85 \\
34.56 \\
36.13 \\
36.20 \\
36.85 \\
36.67 \\
32.59 \\
37.25\end{array}$ & 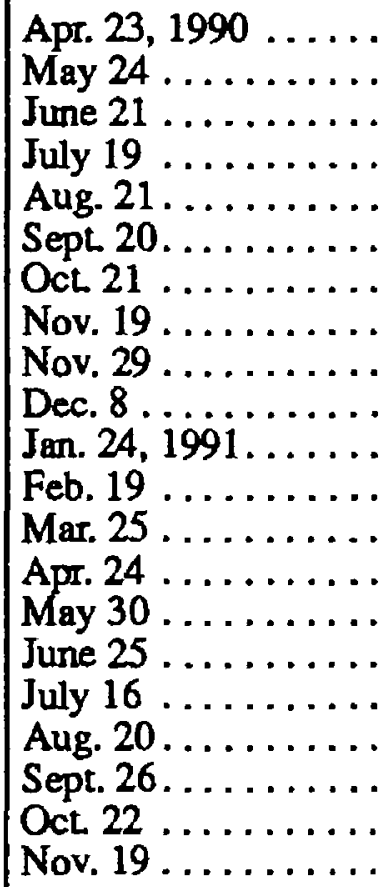 & $\begin{array}{r}37.33 \\
36.40 \\
37.31 \\
37.45 \\
37.58 \\
37.47 \\
37.71 \\
37.81 \\
.37 .03 \\
37.86 \\
37.83 \\
37.87 \\
.37 .99 \\
38.03 \\
37.93 \\
37.88 \\
38.09 \\
38.13 \\
38.10 \\
38.02 \\
38.01\end{array}$ & $\begin{array}{l}\text { Nov. } 27,1991 \ldots \ldots \\
\text { Dec. } 23 \ldots \ldots \ldots \\
\text { Jan. } 24,1992 \ldots \ldots \\
\text { Feb. } 19 \ldots \ldots \ldots \ldots \\
\text { Mar. } 24 \ldots \ldots \ldots \ldots \\
\text { Apr. } 29 \ldots \ldots \ldots \ldots \\
\text { May } 21 \ldots \ldots \ldots \ldots \\
\text { July } 7 \ldots \ldots \ldots \ldots \\
\text { July } 29 \ldots \ldots \ldots \ldots \\
\text { Aug. } 5 \ldots \ldots \ldots \ldots \\
\text { Aug. } 27 \ldots \ldots \ldots \\
\text { Oct. } 1 \ldots \ldots \ldots \ldots \\
\text { Nov. } 22 \ldots \ldots \ldots \ldots \\
\\
\text { Highest watt? } \\
\text { Dec. } 4,1975 \ldots \ldots \ldots \\
\\
\text { Lowest water } \\
\text { June } 17,1965 \ldots \ldots\end{array}$ & $\begin{array}{l}37.91 \\
38.02 \\
37.97 \\
38.05 \\
37.90 \\
37.97 \\
38.01 \\
37.98 \\
38.14 \\
38.25 \\
38.79 \\
\text {. } 38.32 \\
37.70 \\
\\
\text { vel: } \\
32.20 \\
\text { vel: } \\
\end{array}$ \\
\hline
\end{tabular}

Owner: NDSWC 01

152-087-28DAA

Aquifer code: 112HDLK

Date drille f: 05-18-65 Altitude: 2,030 feet

Well depth: 150 feet

\begin{tabular}{|c|c|c|c|c|c|c|c|}
\hline Date measured & $\begin{array}{l}\text { Water } \\
\text { level } \\
\text { (feet) }\end{array}$ & Date measurod & $\begin{array}{l}\text { Water } \\
\text { level } \\
\text { (feet) }\end{array}$ & Date measured & $\begin{array}{l}\text { Weter } \\
\text { level } \\
\text { (feet) }\end{array}$ & Date meaaurert & $\begin{array}{l}\text { Water } \\
\text { leval } \\
\text { (feet) }\end{array}$ \\
\hline 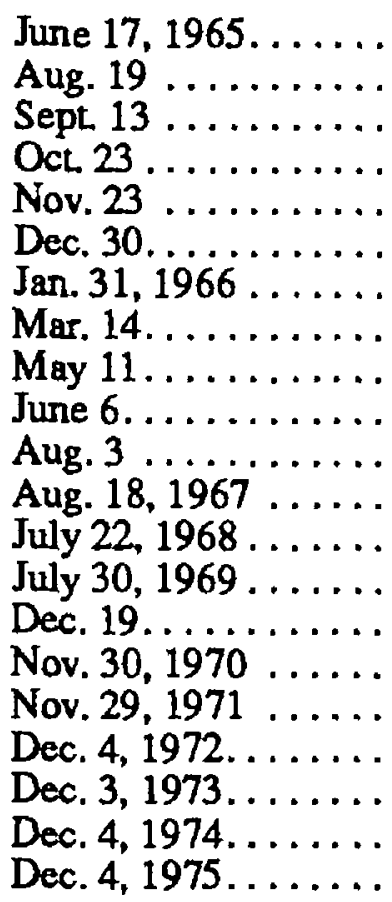 & $\begin{array}{l}29.02 \\
26.22 \\
26.10 \\
26.00 \\
25.75 \\
26.40 \\
25.66 \\
25.69 \\
25.40 \\
25.35 \\
26.57 \\
25.81 \\
26.14 \\
25.36 \\
25.32 \\
23.55 \\
23.60 \\
23.49 \\
23.20 \\
22.82 \\
21.79\end{array}$ & $\begin{array}{l}\text { Nov. } 30,1976 \ldots \ldots \\
\text { Dec. } 6,1977 \ldots \ldots \\
\text { Nov. } 21,1978 \ldots \ldots \\
\text { Dec. } 6,1979 \ldots \ldots \\
\text { Dec. } 4,1980 \ldots \ldots \\
\text { Nov. } 30,1981 \ldots \ldots \\
\text { Dec. } 9,1982 \ldots \ldots \\
\text { Nov. } 29,1983 \ldots \ldots \\
\text { Dec. } 2,1984 \ldots \ldots \\
\text { Dec. } 3 \ldots \ldots \\
\text { July } 9,1985 \ldots \ldots \ldots \\
\text { Dec. } 4 \ldots \ldots \ldots \\
\text { Dec. } 7 \ldots \ldots \ldots \\
\text { Dec. } 21,1986 \ldots \ldots \\
\text { Dec. } 12,1987 \ldots \ldots \\
\text { Nov. } 21,1988 \ldots \ldots \\
\text { Dec. } 10 \ldots \ldots \\
\text { Sept } 19,1989 \ldots \ldots \\
\text { Nov. } 27 \ldots \ldots \ldots \\
\text { Dec. } 9 \text {. } \ldots \ldots \ldots \\
\text { Mar. } 20,1990 \ldots \ldots \\
\end{array}$ & $\begin{array}{l}23.05 \\
22.49 \\
22.25 \\
22.44 \\
23.25 \\
24.08 \\
23.10 \\
23.00 \\
22.86 \\
22.92 \\
22.88 \\
22.90 \\
22.79 \\
23.10 \\
22.43 \\
23.88 \\
23.95 \\
24.52 \\
24.63 \\
24.61 \\
24.80\end{array}$ & 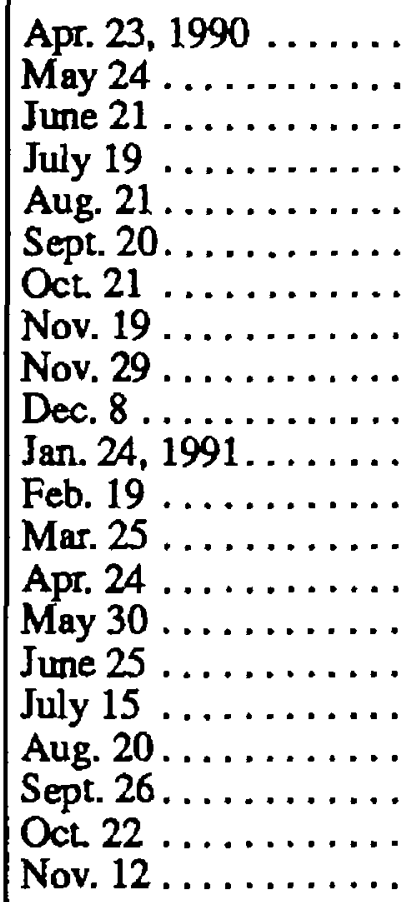 & $\begin{array}{l}25.15 \\
25.15 \\
25.05 \\
25.22 \\
25.34 \\
25.38 \\
25.39 \\
25.30 \\
25.33 \\
25.38 \\
25.40 \\
25.41 \\
25.66 \\
25.70 \\
25.49 \\
25.65 \\
25.80 \\
25.85 \\
25.63 \\
25.63 \\
.25 .44\end{array}$ & 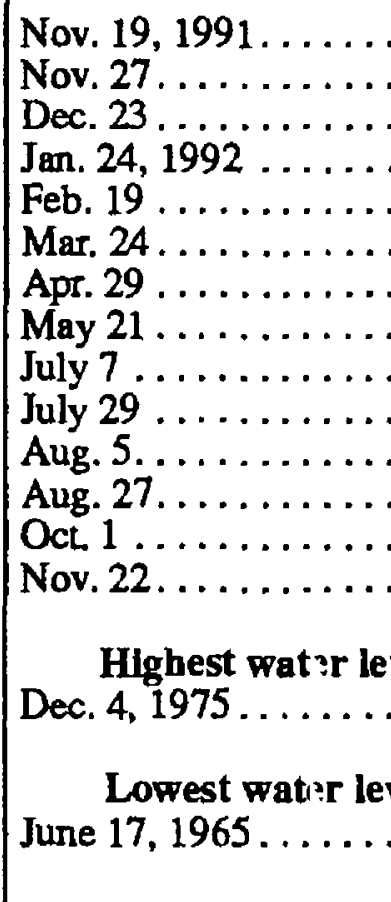 & $\begin{array}{r}25.51 \\
25.76 \\
25.75 \\
25.63 \\
25.85 \\
25.79 \\
25.85 \\
25.90 \\
25.79 \\
26.09 \\
25.91 \\
26.09 \\
26.15 \\
25.85 \\
\\
\text { vel: } \\
21.79 \\
\text { vel: } \\
29.02\end{array}$ \\
\hline
\end{tabular}


Table 2 Water levels for selected wells-Continued

Owner: NDSWC 11803

152-088-04BBBD1

Aquifer code: 125SNLB

Altitude: $2,094.73$ feet

\begin{tabular}{|c|c|c|c|c|c|}
\hline Date measured & $\begin{array}{l}\text { Water } \\
\text { Jevel } \\
\text { (feet) }\end{array}$ & Date measured & $\begin{array}{l}\text { Water } \\
\text { level } \\
\text { (foet) }\end{array}$ & $\begin{array}{l}\text { Water } \\
\text { Jevel } \\
\text { (feot) }\end{array}$ & $\begin{array}{l}\text { Water } \\
\text { level } \\
\text { ('ret) }\end{array}$ \\
\hline 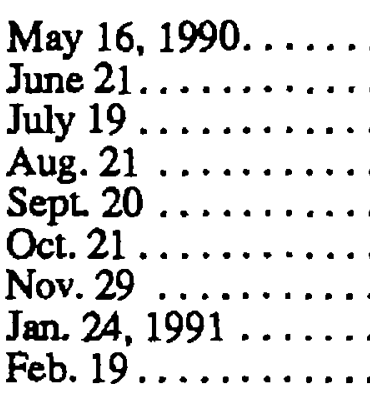 & $\begin{array}{l}41.00 \\
39.49 \\
40.77 \\
40.88 \\
39.88 \\
40.89 \\
38.23 \\
37.98 \\
41.74\end{array}$ & $\begin{array}{l}\text { Mar. } 25,1991 \ldots \ldots \\
\text { Apr. } 24 \ldots \ldots \\
\text { May } 30 \ldots \ldots \\
\text { June } 25 \ldots \ldots \\
\text { July } 16 \ldots \ldots \\
\text { Aug. } 20 \ldots \ldots \\
\text { Sept } 26 \ldots \ldots \\
\text { Oct } 22 \ldots \ldots \\
\text { Nov. } 27 \ldots \ldots \\
\text { No } \ldots \ldots \ldots \\
\ldots\end{array}$ & $\begin{array}{l}39.77 \\
42.62 \\
43.97 \\
39.10 \\
44.24 \\
43.14 \\
42.12 \\
41.70 \\
39.11\end{array}$ & 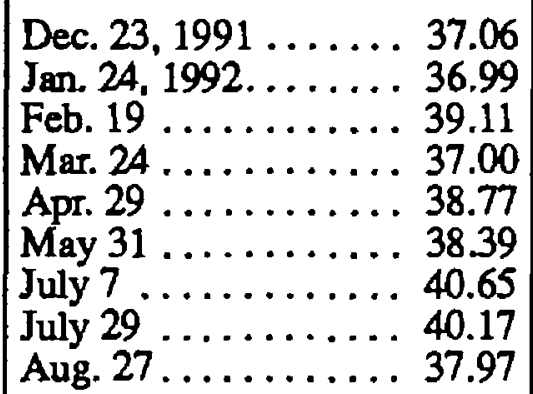 & 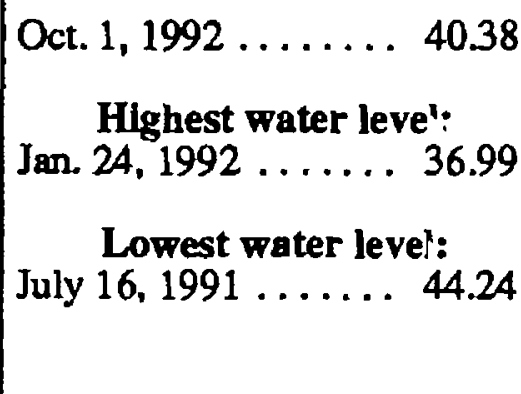 \\
\hline
\end{tabular}

Owner: NDSWC 11955

152-088-04BBBD2

Aqulfer code: 125 SNLB

Date drilled: $04-22-87$ Altitude: 2,095 feet

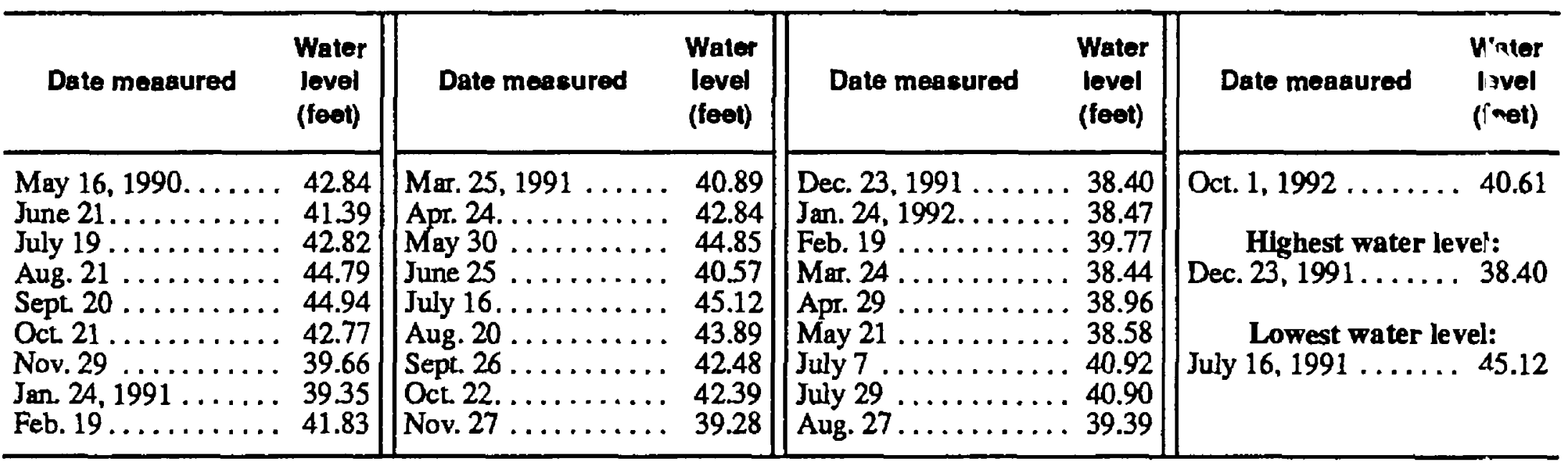

Owner: Mountrail Water Users

$152-089-23 C C C$

Aquifer code: $112 \mathrm{BDVL}$

Altitude: 1,970 feet

\begin{tabular}{|c|c|c|c|}
\hline Date measured & $\begin{array}{l}\text { Water } \\
\text { level } \\
\text { (feot) }\end{array}$ & Date measured & $\begin{array}{l}\text { Water } \\
\text { level } \\
\text { (feet) }\end{array}$ \\
\hline $\begin{array}{l}\text { Apr. } 23,1990 \ldots \ldots \\
\text { May } 24 \ldots \ldots \ldots \ldots \\
\text { June } 21 \ldots \ldots \ldots \ldots \\
\text { July } 19 \ldots \ldots \ldots \ldots \\
\text { Aug. } 21 \ldots \ldots \ldots \ldots \\
\text { Sept } 20 \ldots \ldots \ldots \ldots \\
\text { Oct. } 21 \ldots \ldots \ldots \ldots \\
\text { Nov. } 29 \ldots \ldots \\
\text { Jan. } 24,1991 \ldots \ldots \ldots \\
\end{array}$ & $\begin{array}{r}9.55 \\
9.70 \\
9.56 \\
9.89 \\
10.77 \\
10.82 \\
9.93 \\
9.97 \\
9.48\end{array}$ & $\begin{array}{l}\text { Feb. } 19,1991 \ldots \ldots \ldots \\
\text { Mar. } 25 \ldots \ldots \ldots \\
\text { Apr. } 24 \ldots \ldots \ldots \ldots \\
\text { May } 30 \ldots \ldots \\
\text { June } 25 \ldots \ldots \ldots \ldots \\
\text { July } 15 \ldots \ldots \ldots \ldots \\
\text { Aug. } 20 \ldots \ldots \ldots \ldots \\
\text { Sept. } 26 \ldots \ldots \ldots \ldots \\
\text { Oct. } 22 \ldots \ldots \ldots \ldots \ldots\end{array}$ & $\begin{array}{r}9.34 \\
9.14 \\
9.49 \\
9.65 \\
9.49 \\
9.86 \\
10.06 \\
9.59 \\
9.47\end{array}$ \\
\hline
\end{tabular}

Date drilled: $10-13-77$ Weli depth: 47 foet

\begin{tabular}{|c|c|c|}
\hline Date measured & $\begin{array}{l}\text { Water } \\
\text { level } \\
\text { (feet) }\end{array}$ & $\begin{array}{l}\text { Hater } \\
\text { hovel } \\
\text { (feet) }\end{array}$ \\
\hline $\begin{array}{l}\text { Nov. } 27,1991 \ldots \ldots \ldots \\
\text { Dec. } 23 \ldots \ldots \ldots \ldots \\
\text { Jan. } 24,1992 \ldots \ldots \ldots \\
\text { Feb. } 19 \ldots \ldots \ldots \\
\text { Mar. } 24 \ldots \ldots \ldots \ldots \\
\text { Apr. } 29 \ldots \ldots \ldots \ldots \\
\text { May } 21 \ldots \ldots \ldots \\
\text { July } 7 \ldots \ldots \ldots \\
\text { July } 29 \ldots \ldots \ldots \ldots \ldots\end{array}$ & $\begin{array}{l}9.10 \\
9.14 \\
8.86 \\
8.32 \\
8.82 \\
9.05 \\
5.49 \\
9.43 \\
9.99\end{array}$ & 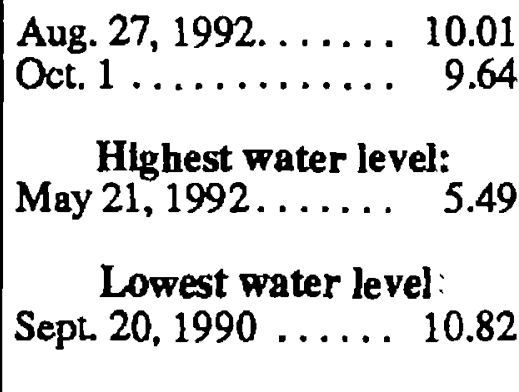 \\
\hline
\end{tabular}


Table 2 Water levels for selected wells-Continued

Owner: John Rodgers

152-089-28DCD

Aquifer code: 125TGRV

Date drillet: $11-30-88$ Altitude: 1,990 teet

\begin{tabular}{|c|c|c|c|c|c|c|c|}
\hline Date measured & $\begin{array}{l}\text { Water } \\
\text { level } \\
\text { (feet) }\end{array}$ & Date measured & $\begin{array}{l}\text { Water } \\
\text { level } \\
\text { (feet) }\end{array}$ & Date measured & $\begin{array}{l}\text { Water } \\
\text { level } \\
\text { (feat) }\end{array}$ & Date measurec & $\begin{array}{l}\text { Water } \\
\text { level } \\
\text { (feet) }\end{array}$ \\
\hline $\begin{array}{l}\text { May } 16,1990 \ldots \ldots \\
\text { June } 21 \ldots \ldots \ldots \ldots \\
\text { July } 19 \ldots \ldots \ldots \\
\text { Aug. } 21 \ldots \ldots \ldots \\
\text { Sept } 20 \ldots \ldots \ldots \\
\text { Oct. } 21 \ldots \ldots \ldots \\
\text { Nov. } 29 \ldots \ldots \ldots \\
\end{array}$ & $\begin{array}{l}42.64 \\
42.65 \\
42.74 \\
42.95 \\
43.12 \\
43.04 \\
42.91\end{array}$ & $\begin{array}{l}\text { Jan. } 24,1991 \ldots \ldots \ldots \\
\text { Feb. } 19 \ldots \ldots \ldots \ldots \\
\text { Mar. } 25 \ldots \ldots \ldots \ldots \\
\text { Apr. } 24 \ldots \ldots \ldots \ldots \\
\text { May } 30 \ldots \ldots \ldots \ldots \\
\text { June } 25 \ldots \ldots \ldots \ldots \\
\text { July } 16 \ldots \ldots \ldots\end{array}$ & $\begin{array}{l}42.93 \\
42.78 \\
42.70 \\
42.70 \\
42.68 \\
42.65 \\
42.74\end{array}$ & $\begin{array}{l}\text { Aug. } 20,1991 \ldots \ldots \\
\text { Sept. } 26 \ldots \ldots \ldots \ldots \\
\text { Oct. } 22 \ldots \ldots \ldots \ldots \\
\text { Nov. } 27 \ldots \ldots \ldots \ldots \\
\text { Dec. } 23 \ldots \ldots \ldots \ldots\end{array}$ & $\begin{array}{l}42.92 \\
42.87 \\
42.43 \\
42.90 \\
42.75\end{array}$ & \multicolumn{2}{|c|}{$\begin{array}{c}\text { Highest water level: } \\
\text { Oct. 22, } 1991 \ldots \ldots \ldots 42.43 \\
\text { Lowest water level: } \\
\text { Sept. 20, } 1990 \ldots \ldots .43 .12\end{array}$} \\
\hline
\end{tabular}

Owner: NDSWC 3424

Aquifer code: $112 \mathrm{NWTN}$ Altitude: 1,892 feet

\begin{tabular}{|c|c|c|c|}
\hline Date measured & $\begin{array}{l}\text { Watar } \\
\text { leval } \\
\text { (feot) }\end{array}$ & Date megaured & $\begin{array}{l}\text { Water } \\
\text { level } \\
\text { (feel) }\end{array}$ \\
\hline $\begin{array}{l}\text { Aug. } 9,1967 \ldots \ldots \\
\text { Sept } 13 \ldots \ldots \\
\text { Oct. } 10 \ldots \ldots \\
\text { Oct. } 26 \ldots \ldots \\
\text { Oct. } 31 \ldots \ldots \\
\text { Nov. } 5 \ldots \ldots \\
\text { Nov. } 10 \ldots \ldots \\
\text { Nov. } 15 \ldots \ldots \\
\text { Nov. } 20 \ldots \ldots \\
\text { Nov. } 25 \ldots \ldots \\
\text { Nov. } 30 \ldots \ldots \\
\text { Dec. } 4 \ldots \ldots \\
\text { Dec. } 5 \ldots \ldots \\
\text { Dec. } 7 \ldots \ldots \\
\text { Jan. } 9.1968 \ldots \ldots \\
\text { Jan. } 10 \ldots \ldots \\
\text { Jan. } 15 \ldots \ldots \\
\text { Jan. } 20 \ldots \ldots \\
\text { Jan. } 25 \ldots \ldots \\
\text { Jan } 31 \ldots \ldots \\
\text { Feb. } 5 \ldots \ldots \\
\text { Feb. } 10 \ldots \ldots \\
\text { Feb. } 15 \ldots \ldots \\
\text { Feb. } 25 \ldots \ldots \\
\text { Feb. } 28 \ldots \ldots \\
\text { Mar. } 5 \ldots \ldots \\
\text { Mar. } 10 \ldots \ldots \\
\text { Mar. } 13 \ldots \ldots \\
\text { Apr. } 10 \ldots \ldots \\
\text { May } 5 \ldots \ldots \\
\text { May } 13 \ldots \ldots \\
\text { June } 10 \ldots \ldots \\
\text { June } 15 \ldots \ldots \\
\text { June } 20 \ldots \ldots \\
\text { June } 25 \ldots \ldots \\
\text { June } 30 \ldots \ldots \\
\text { July } 5 \ldots \ldots \\
\text { July } 8 \ldots \ldots \\
\text { July } 10 \ldots \ldots \\
\ldots\end{array}$ & $\begin{array}{l}48.84 \\
50.50 \\
50.23 \\
50.73 \\
50.88 \\
51.28 \\
51.25 \\
51.45 \\
51.48 \\
51.50 \\
51.96 \\
52.38 \\
52.52 \\
52.99 \\
54.21 \\
54.17 \\
54.53 \\
54.92 \\
55.08 \\
55.35 \\
55.55 \\
55.67 \\
55.83 \\
56.47 \\
56.65 \\
56.55 \\
56.65 \\
56.36 \\
53.10 \\
54.20 \\
54.17 \\
55.83 \\
55.80 \\
53.97 \\
53.43 \\
51.87 \\
51.28 \\
52.13 \\
51.03\end{array}$ & $\begin{array}{l}\text { July } 15,1968 \ldots \ldots \\
\text { July } 20 \ldots \ldots \\
\text { July } 25 \ldots \ldots \\
\text { July } 31 \ldots \ldots \\
\text { Aug. } 5 \ldots \ldots \\
\text { Aug. } 10 \ldots \ldots \\
\text { Aug. } 15 \ldots \ldots \\
\text { Aug. } 20 \ldots \ldots \\
\text { Aug. } 25 \ldots \ldots \\
\text { Aug. } 31 \ldots \ldots \\
\text { Sept. } 5 \ldots \ldots \\
\text { Sept. } 10 \ldots \ldots \\
\text { Sept. } 15 \ldots \ldots \\
\text { Sept. } 20 \ldots \ldots \\
\text { Sept. } 25 \ldots \ldots \\
\text { Sept. } 30 \ldots \ldots \\
\text { Oct. } 2 \ldots \ldots \\
\text { Oct. } 5 \ldots \ldots \\
\text { Oct. } 10 \ldots \ldots \\
\text { Oct. } 15 \ldots \ldots \\
\text { Oct } 20 \ldots \ldots \\
\text { Oct. } 25 \ldots \ldots \\
\text { Oct } 31 \ldots \ldots \\
\text { Nov. } 5 \ldots \ldots \\
\text { Nov. } 10 \ldots \ldots \\
\text { Nov. } 15 \ldots \ldots \\
\text { Nov. } 20 \ldots \ldots \\
\text { Nov. } 25 \ldots \ldots \\
\text { Nov. } 30 \ldots \ldots \\
\text { Dec. } 5 \ldots \ldots \\
\text { Jan. } 2,1969 \ldots \ldots \\
\text { Feb. } 11 \ldots \ldots \\
\text { Mar. } 10 \ldots \ldots \\
\text { Apr. } 10 \ldots \ldots \\
\text { May } 5 \\
\text { June } 2 \ldots \ldots \\
\text { June } 30 \ldots \ldots \\
\text { July } 28 \ldots \ldots \\
\text { Aug. } 22 \ldots \ldots \\
\ldots\end{array}$ & $\begin{array}{l}50.68 \\
50.79 \\
49.83 \\
49.68 \\
50.01 \\
49.64 \\
49.13 \\
48.85 \\
48.45 \\
48.17 \\
48.00 \\
47.92 \\
47.72 \\
47.45 \\
47.60 \\
47.51 \\
47.79 \\
47.75 \\
48.05 \\
48.53 \\
48.54 \\
48.45 \\
48.95 \\
48.95 \\
49.00 \\
48.95 \\
49.00 \\
49.08 \\
49.94 \\
49.52 \\
50.75 \\
53.28 \\
55.04 \\
53.56 \\
51.27 \\
51.59 \\
47.91 \\
45.30 \\
47.22\end{array}$ \\
\hline
\end{tabular}

152-092-19AAB

Date drille-t: --

Well deptr : 158 feet

\begin{tabular}{|c|c|c|c|}
\hline Date measured & $\begin{array}{l}\text { Water } \\
\text { level } \\
\text { (foet) }\end{array}$ & Date meazured & $\begin{array}{l}\text { Water } \\
\text { level } \\
\text { (foet) }\end{array}$ \\
\hline 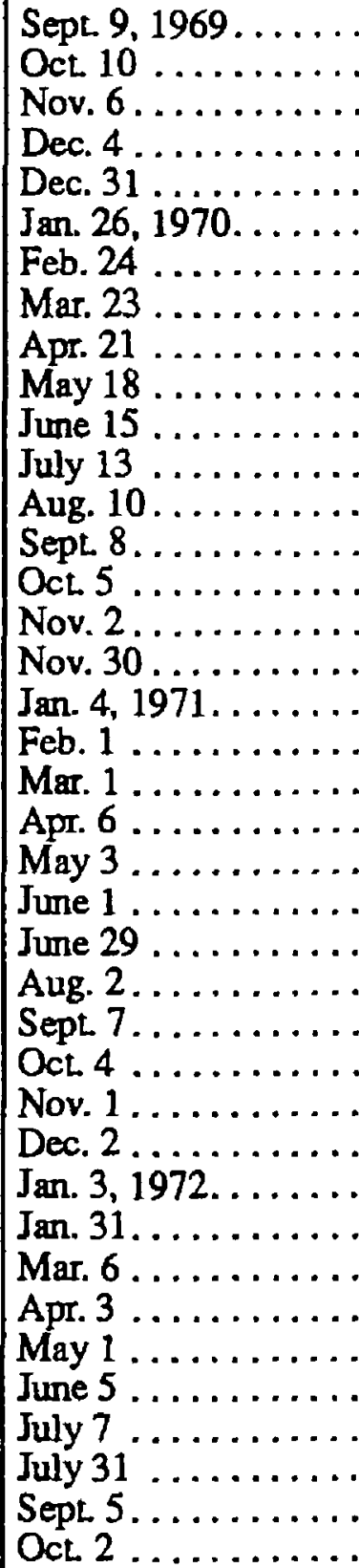 & $\begin{array}{l}48.37 \\
48.04 \\
49.12 \\
50.37 \\
51.76 \\
53.22 \\
55.27 \\
55.34 \\
55.24 \\
54.49 \\
52.00 \\
49.07 \\
47.92 \\
48.38 \\
47.24 \\
48.25 \\
48.85 \\
51.38 \\
52.50 \\
52.65 \\
50.35 \\
50.30 \\
50.45 \\
47.69 \\
48.49 \\
47.32 \\
47.24 \\
47.07 \\
47.97 \\
50.27 \\
51.07 \\
51.85 \\
47.01 \\
47.60 \\
48.22 \\
46.44 \\
46.13 \\
46.46 \\
45.89\end{array}$ & 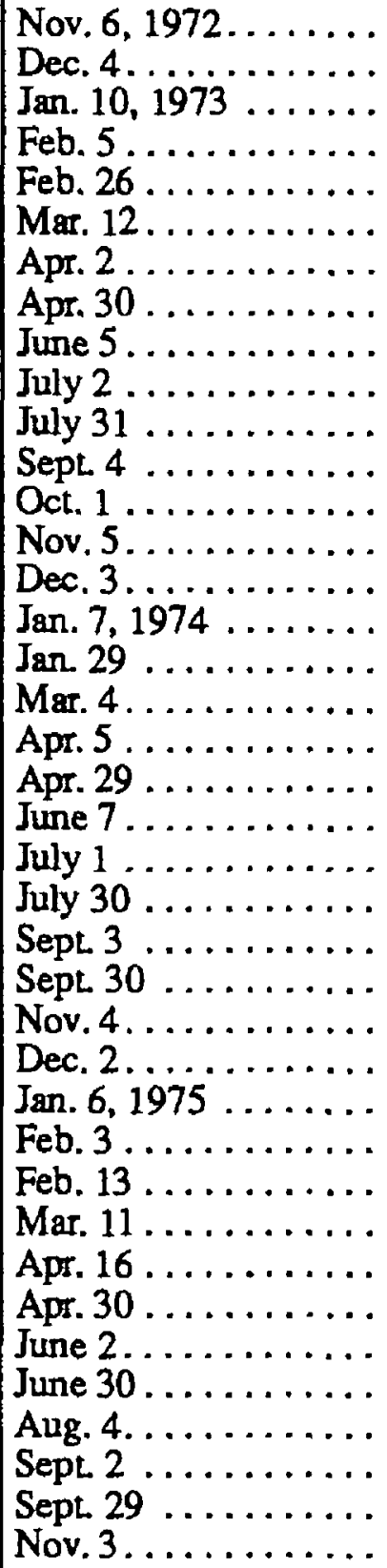 & $\begin{array}{l}46.25 \\
47.32 \\
48.00 \\
49.16 \\
49.76 \\
49.44 \\
49.42 \\
50.16 \\
48.39 \\
46.23 \\
46.95 \\
46.82 \\
46.79 \\
48.19 \\
49.05 \\
50.65 \\
51.81 \\
53.26 \\
53.64 \\
52.70 \\
52.23 \\
50.03 \\
46.98 \\
46.36 \\
47.21 \\
47.90 \\
48.76 \\
50.36 \\
51.45 \\
51.88 \\
52.87 \\
53.45 \\
51.44 \\
48.09 \\
45.08 \\
42.28 \\
43.25 \\
44.92 \\
46.79\end{array}$ \\
\hline
\end{tabular}


Table 2. Water levels for selected wells-Continued

Owner: NDSWC 3424

Aquifer code: 112NWTN Altitude: 1,892 feet

\begin{tabular}{|c|c|c|c|}
\hline Date measured & $\begin{array}{l}\text { Water } \\
\text { level } \\
\text { (foet) }\end{array}$ & Date measured & $\begin{array}{l}\text { Water } \\
\text { level } \\
\text { (feet) }\end{array}$ \\
\hline 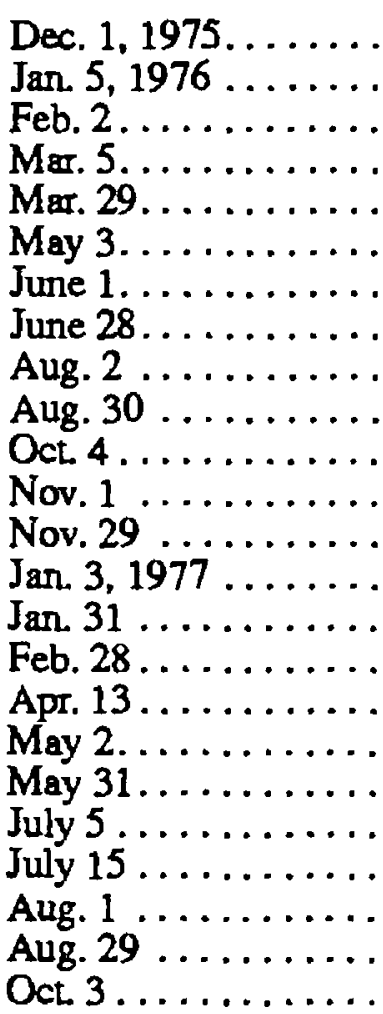 & $\begin{array}{l}48.00 \\
49.95 \\
51.03 \\
51.46 \\
50.30 \\
50.45 \\
50.85 \\
46.97 \\
47.45 \\
47.94 \\
48.42 \\
48.92 \\
50.23 \\
51.82 \\
53.88 \\
54.98 \\
56.20 \\
57.14 \\
56.01 \\
56.71 \\
55.80 \\
56.61 \\
56.38 \\
56.09\end{array}$ & $\begin{array}{l}\text { Oct. } 31,1977 \ldots \ldots \\
\text { Nov. } 28 \ldots \ldots \ldots \\
\text { Jan. } 3,1978 \ldots \ldots \\
\text { Mar. } 3 \ldots \ldots \ldots \\
\text { June } 5 \ldots \ldots \ldots \\
\text { Sept. } 5 \ldots \ldots \ldots \\
\text { Nov. } 27 \ldots \ldots \ldots \\
\text { Mar. } 8,1979 \ldots \ldots \\
\text { June } 6 \ldots \ldots \\
\text { Sept. } 7 \ldots \ldots \ldots \\
\text { Nov. } 26 \ldots \ldots \ldots \\
\text { Mar. } 17,1980 \ldots \ldots \\
\text { June } 2 \ldots \ldots \ldots \\
\text { Aug. } 27 \ldots \ldots \ldots \\
\text { Dec. } 1 \ldots \ldots \\
\text { Mar. } 16,1981 \ldots \ldots \\
\text { June } 5 \ldots \ldots \ldots \\
\text { Sept. } 3 \ldots \ldots \ldots \\
\text { Nov. } 30 \ldots \ldots \\
\text { May } 12,1982 \ldots \ldots \\
\text { July } 21 \ldots \ldots \ldots \\
\text { Dec. } 1 \ldots \ldots \\
\text { Dec. } 1,1983 \ldots \ldots \\
\text { Nov. } 29,1984 \ldots \ldots \\
\end{array}$ & $\begin{array}{l}56.22 \\
57.53 \\
57.62 \\
57.73 \\
51.86 \\
47.10 \\
50.56 \\
50.01 \\
48.85 \\
49.29 \\
48.76 \\
54.05 \\
55.57 \\
53.59 \\
55.84 \\
59.56 \\
60.53 \\
58.39 \\
57.39 \\
56.23 \\
51.93 \\
49.24 \\
49.22 \\
48.95\end{array}$ \\
\hline
\end{tabular}

152-092-19AAB-Continued

Date drilled:

Well depth: $15 E$ feet

\begin{tabular}{|c|c|c|c|}
\hline Date meaaured & $\begin{array}{l}\text { Water } \\
\text { level } \\
\text { (feet) }\end{array}$ & Date measured & $\begin{array}{l}\text { Yoter } \\
\text { level } \\
\text { (feet) }\end{array}$ \\
\hline $\begin{array}{l}\text { Jume } 4,1985 \ldots \ldots \\
\text { Dec. } 3 \ldots \ldots \ldots \ldots \\
\text { Nov. } 20,1986 \ldots \ldots \\
\text { Sept. } 23,1987 \ldots \ldots \\
\text { Nov. } 18 \ldots \ldots \ldots \\
\text { Nov. } 16,1988 \ldots \ldots \\
\text { Nov. } 27,1989 \ldots \ldots \\
\text { Mar. } 21,1990 \ldots \ldots \\
\text { Apr. } 23 \ldots \ldots \ldots \ldots \\
\text { May } 24 \ldots \ldots \ldots \ldots \\
\text { June } 21 \ldots \ldots \ldots \ldots \\
\text { July } 19 \ldots \ldots \ldots \ldots \\
\text { Aug. } 21 \ldots \ldots \ldots \ldots \\
\text { Sept. } 21 \ldots \ldots \ldots \ldots \\
\text { Oct. } 21 \ldots \ldots \ldots \ldots\end{array}$ & $\begin{array}{l}52.30 \\
53.69 \\
47.43 \\
51.51 \\
52.32 \\
63.68 \\
66.24 \\
68.36 \\
68.47 \\
69.80 \\
70.39 \\
68.26 \\
69.03 \\
69.23 \\
68.63\end{array}$ & $\begin{array}{l}\text { Aug. } 20,1991 \ldots \ldots \ldots \\
\text { Sept. } 26 \ldots \ldots \ldots \ldots \\
\text { Oct. } 22 \ldots \ldots \ldots \ldots \\
\text { Nov. } 6 \ldots \ldots \ldots \ldots \\
\text { Nov. } 28 \ldots \ldots \ldots \ldots \\
\text { Dec. } 23 \ldots \ldots \ldots \ldots \\
\text { Jan. } 24,1992 \ldots \ldots \ldots \\
\text { Feb. } 20 \ldots \ldots \ldots \ldots \\
\text { Mar. } 24 \ldots \ldots \ldots \ldots \\
\text { Apr. } 29 \ldots \ldots \ldots \ldots \\
\text { May } 21 \ldots \ldots \ldots \ldots \\
\text { July } 7 \ldots \ldots \ldots \ldots \\
\text { July } 29 \ldots \ldots \ldots \ldots \\
\text { Aug. } 28 \ldots \ldots \ldots \ldots \\
\text { Oct. } 1 \ldots \ldots \ldots \ldots \ldots\end{array}$ & $\begin{array}{l}65.95 \\
65.98 \\
65.16 \\
65.09 \\
64.57 \\
65.70 \\
66.65 \\
67.08 \\
66.86 \\
69.09 \\
69.66 \\
68.87 \\
69.59 \\
68.90 \\
69.65\end{array}$ \\
\hline
\end{tabular}

Highest water level: Nov $14 \ldots \ldots \ldots \ldots .67 .61$ Nov. $29 \ldots \ldots .6 .68 .29$ Jan. 24, $1991 \ldots \ldots .669 .06$ Feb. $19 \ldots \ldots \ldots \ldots 70.23$ Mar. $25 \ldots \ldots \ldots \ldots 771.29$

Apr. $24 \ldots \ldots \ldots \ldots 72.48$ May $30 \ldots \ldots \ldots .72 .92$ June $25 \ldots \ldots \ldots 6.69 .63$ July $16 \ldots \ldots \ldots \ldots 6.65$

Owner: NDSWC 5781

153-094-23CCC1

Aquifer code: $211 \mathrm{HCFH}$

Date drilled: 08-21-80 Altitude: 2,186 feet

Well depth: 1,767 feet

\begin{tabular}{|c|c|c|c|c|c|}
\hline Date measured & $\begin{array}{l}\text { Water } \\
\text { level } \\
\text { (feet) }\end{array}$ & Date measured & $\begin{array}{l}\text { Water } \\
\text { level } \\
\text { (feet) }\end{array}$ & $\begin{array}{l}\text { Water } \\
\text { level } \\
\text { (foat) }\end{array}$ & $\begin{array}{l}\text { V'ater } \\
\text { level } \\
\text { (feet) }\end{array}$ \\
\hline $\begin{array}{l}\text { Aug. } 21,1980 \ldots \ldots \\
\text { Apr. } 23,1990 \ldots \ldots \\
\text { May } 24 \ldots \ldots \\
\text { June } 21 \ldots \ldots \ldots \\
\text { July } 20 \ldots \ldots \ldots \\
\text { Aug. } 21 \ldots \ldots \\
\text { Sept } 21 \ldots \ldots \\
\text { Oct } 21 \ldots \ldots \\
\text { Nov. } 29 \ldots \ldots \\
\text { No } \ldots \ldots \ldots \\
\ldots\end{array}$ & $\begin{array}{l}74.27 \\
72.67 \\
73.35 \\
72.85 \\
73.06 \\
73.09 \\
73.45 \\
73.54 \\
73.77\end{array}$ & 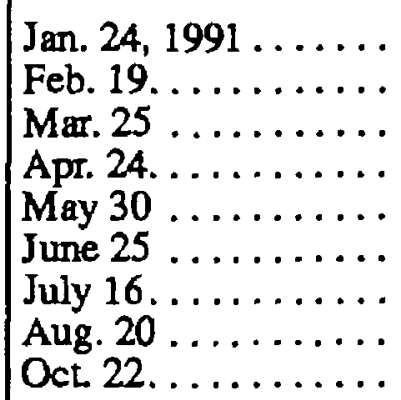 & $\begin{array}{l}74.13 \\
74.32 \\
74.50 \\
74.69 \\
74.89 \\
74.93 \\
75.04 \\
75.19 \\
75.47\end{array}$ & 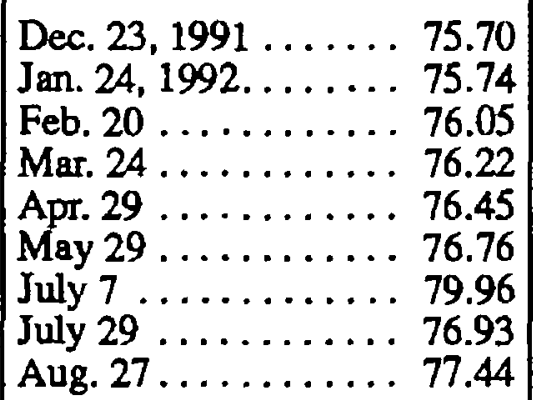 & 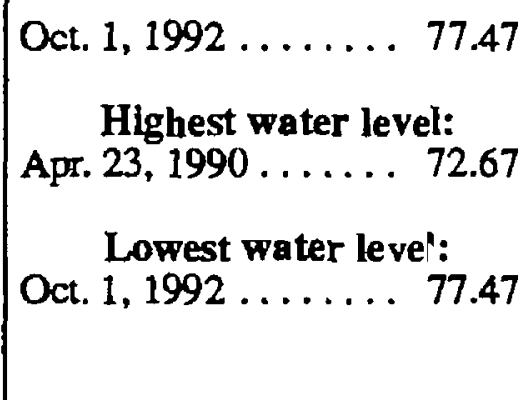 \\
\hline
\end{tabular}


Table 2. Water levels for selected wells-Continued

Owner: NDSWC 5781A

153-094-23ccC2

Aquifer code: 125CBLD Altitude: 2,186 feet

\begin{tabular}{|c|c|c|c|c|c|c|c|}
\hline Date measured & $\begin{array}{l}\text { Water } \\
\text { level } \\
\text { (feot) }\end{array}$ & Date meaaured & $\begin{array}{l}\text { Water } \\
\text { lovel } \\
\text { (feet) }\end{array}$ & Date measured & $\begin{array}{l}\text { Water } \\
\text { level } \\
\text { (feat) }\end{array}$ & Date measurird & $\begin{array}{l}\text { Water } \\
\text { lovel } \\
\text { (foet) }\end{array}$ \\
\hline $\begin{array}{l}\text { Aug. } 21,1980 \ldots \ldots \\
\text { Aps. } 23,1990 \ldots \ldots \\
\text { May } 24 \ldots \ldots \ldots \ldots \\
\text { June } 21 \ldots \ldots \ldots \ldots \\
\text { July } 20 \ldots \ldots \ldots \ldots \\
\text { Aug. } 21 \ldots \ldots \ldots \ldots \\
\text { Sept. } 21 \ldots \ldots \ldots \ldots \\
\text { Oct. } 21 \ldots \ldots \ldots \ldots \\
\text { Nov. } 29 \ldots \ldots \ldots \ldots\end{array}$ & $\begin{array}{l}148.12 \\
149.60 \\
149.85 \\
149.89 \\
149.96 \\
150.05 \\
150.19 \\
150.16 \\
150.19\end{array}$ & $\begin{array}{l}\text { Jan. } 24,1991 \ldots \ldots \\
\text { Feb. } 19 . \ldots \ldots \ldots \\
\text { Mar. } 25 \ldots \ldots \ldots \\
\text { Apr. } 24 \ldots \ldots \ldots \\
\text { May } 30 \ldots \ldots \ldots \\
\text { June } 25 \ldots \ldots \ldots \\
\text { July } 16 \ldots \ldots \ldots \\
\text { Aug. } 20 \ldots \ldots \ldots \\
\text { Sept. } 26 \ldots \ldots \ldots \\
\end{array}$ & $\begin{array}{l}150.48 \\
150.44 \\
150.44 \\
150.44 \\
150.47 \\
150.43 \\
150.52 \\
150.55 \\
150.63\end{array}$ & $\begin{array}{l}\text { Oct. } 22,1991 \ldots \ldots \\
\text { Nov. } 27 \ldots \ldots \ldots \\
\text { Dec. } 23 \ldots \ldots \ldots \\
\text { Jan. } 24,1992 \ldots \ldots \ldots \\
\text { Feb. } 20 \ldots \ldots \ldots \ldots \\
\text { Mar. } 24 \ldots \ldots \ldots \ldots \\
\text { Apr. } 29 \ldots \ldots \ldots \ldots \\
\text { May } 29 \ldots \ldots \ldots \ldots \\
\text { July } 7 \ldots \ldots \ldots \ldots\end{array}$ & $\begin{array}{l}.150 .58 \\
.150 .62 \\
.150 .60 \\
.150 .59 \\
.150 .82 \\
.150 .79 \\
.150 .72 \\
.150 .86 \\
.150 .82\end{array}$ & \multicolumn{2}{|c|}{ 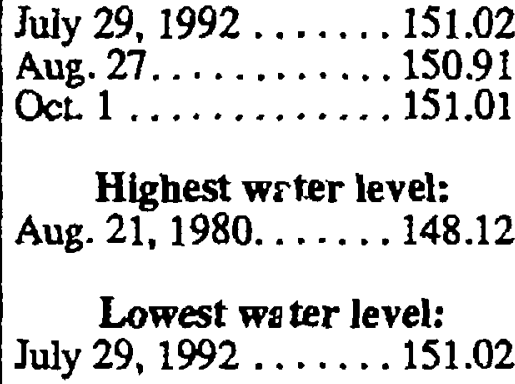 } \\
\hline
\end{tabular}

Owner: NDSWC 5781B

$153-094-23 \operatorname{ccc} 3$

Aqulfer code: 125TGRV

Date drilled: $08-21-80$ Altitude: 2,186 fe日t Well dep th: 895 feet

\begin{tabular}{|c|c|c|c|c|c|c|c|}
\hline Date measured & $\begin{array}{l}\text { Water } \\
\text { level } \\
\text { (foet) }\end{array}$ & Date measured & $\begin{array}{l}\text { Water } \\
\text { level } \\
\text { (feot) }\end{array}$ & Date measured & $\begin{array}{l}\text { Water } \\
\text { level } \\
\text { (foet) }\end{array}$ & Date measurad & $\begin{array}{l}\text { Water } \\
\text { lovel } \\
\text { (foet) }\end{array}$ \\
\hline $\begin{array}{l}\text { Aug. } 21,1980 \ldots \\
\text { Apt. } 23,1990 \ldots \ldots \\
\text { May } 24 \ldots \ldots \ldots \ldots \\
\text { June } 21 \ldots \ldots \ldots \ldots \\
\text { July } 20 \ldots \ldots \ldots \ldots \\
\text { Aug. } 21 \ldots \ldots \ldots \ldots \\
\text { Sept } 21 \ldots \ldots \ldots \\
\text { Oct } 21 \ldots \ldots \ldots \\
\text { Nov. } 29 \ldots \ldots \ldots\end{array}$ & $\begin{array}{l}330.83 \\
333.40 \\
333.70 \\
333.60 \\
333.44 \\
333.36 \\
333.48 \\
333.50 \\
333.90\end{array}$ & $\begin{array}{l}\text { Jan. } 24,1991 \ldots \ldots \\
\text { Feb. } 19 \ldots \ldots \ldots \\
\text { Mar. } 25 \ldots \ldots \ldots \\
\text { Apr. } 24 \ldots \ldots \ldots \\
\text { May } 30 \ldots \ldots \ldots \\
\text { June } 25 \ldots \ldots \ldots \\
\text { July } 16 \ldots \ldots \ldots \\
\text { Aug. } 20 \ldots \ldots \ldots \\
\text { Sept } 26 \ldots \ldots \ldots\end{array}$ & $\begin{array}{l}333.70 \\
334.00 \\
334.10 \\
334.19 \\
333.90 \\
334.10 \\
334.00 \\
334.16 \\
334.05\end{array}$ & $\begin{array}{l}\text { Oct. } 22,1991 \ldots \ldots \\
\text { Nov. } 27 \ldots \ldots \ldots \\
\text { Dec. } 23 \ldots \ldots \ldots \\
\text { Jan. } 24,1992 \ldots \ldots \\
\text { Feb. } 20 \ldots \ldots \ldots \\
\text { Mar. } 24 \ldots \ldots \ldots \ldots \\
\text { Apr. } 29 \ldots \ldots \ldots \ldots \\
\text { May } 29 \ldots \ldots \ldots \ldots \\
\text { July } 7 \ldots \ldots \ldots \ldots\end{array}$ & $\begin{array}{l}.334 .15 \\
.334 .14 \\
.334 .18 \\
.334 .18 \\
.334 .27 \\
.334 .21 \\
.334 .45 \\
.334 .52 \\
.334 .66\end{array}$ & $\begin{array}{r}\text { July } 29,1992 \ldots \ldots \\
\text { Aug. } 27 \ldots \ldots \ldots \\
\text { Oct. } 1 \ldots \ldots \ldots \\
\text { Highest water } \\
\text { Aug. } 21,1980 \ldots \ldots \\
\\
\text { Lowest water } \\
\text { Oct. } 1,1992 \ldots \ldots\end{array}$ & $\begin{array}{l}334.71 \\
334.68 \\
334.72 \\
\text { vel: } \\
330.83 \\
\text { vel: } \\
.334 .72\end{array}$ \\
\hline
\end{tabular}


Tabie 3. Drillers' logs of wells and test holes

146-088-10CBA

(Log from Dingman and Gordon, 1954)

Altitude: Not available

Date drilled: 1951

\begin{tabular}{|c|c|c|c|c|c|}
\hline Materlal & $\begin{array}{c}\text { Thlck- } \\
\text { ness } \\
\text { (foet) }\end{array}$ & $\begin{array}{l}\text { Depth } \\
\text { (feet) }\end{array}$ & Materlal & $\begin{array}{c}\text { Thlak- } \\
\text { ness } \\
\text { (feet) }\end{array}$ & $\begin{array}{l}\text { Denth } \\
\text { (fFat) }\end{array}$ \\
\hline 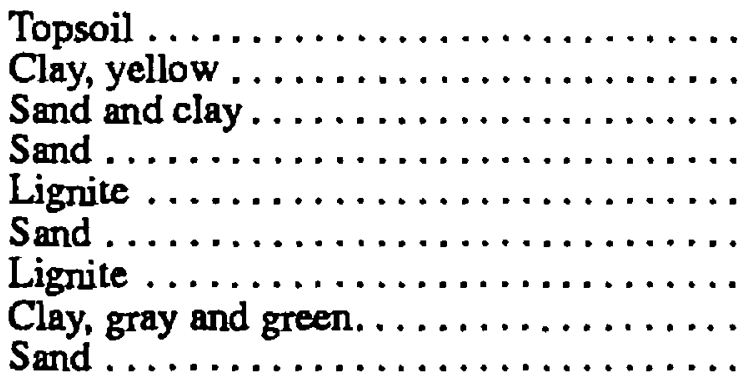 & $\begin{array}{r}5 \\
13 \\
20 \\
18 \\
7 \\
33 \\
6 \\
52 \\
34\end{array}$ & $\begin{array}{r}5 \\
18 \\
38 \\
56 \\
63 \\
96 \\
102 \\
154 \\
188\end{array}$ & 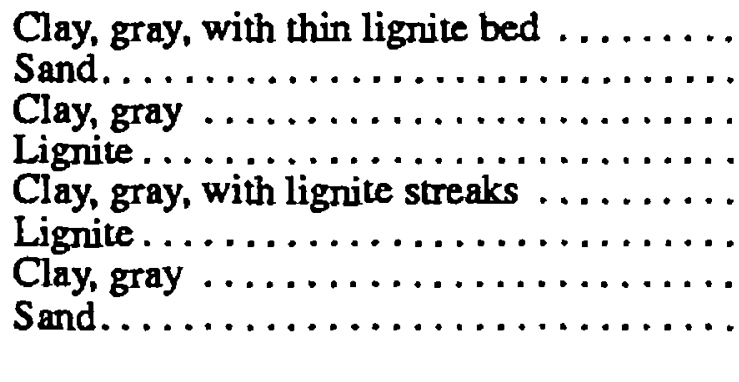 & $\begin{array}{r}38 \\
2 \\
14 \\
3 \\
10 \\
20 \\
33 \\
2\end{array}$ & $\begin{array}{l}226 \\
228 \\
212 \\
215 \\
2 \div 5 \\
275 \\
308 \\
310\end{array}$ \\
\hline
\end{tabular}

146-089-08AAB

(Log from Dingman and Gordon, 1954)

Altitude: Not avaliable

Date drilled: 1951

\begin{tabular}{|c|c|c|c|c|c|}
\hline Materlal & $\begin{array}{c}\text { Thlck- } \\
\text { ness } \\
\text { (feet) }\end{array}$ & $\begin{array}{l}\text { Depth } \\
\text { (feet) }\end{array}$ & Materlal & $\begin{array}{c}\text { Thick- } \\
\text { ness } \\
\text { (feat) }\end{array}$ & $\begin{array}{l}\text { Derth } \\
\text { (fe-t) }\end{array}$ \\
\hline 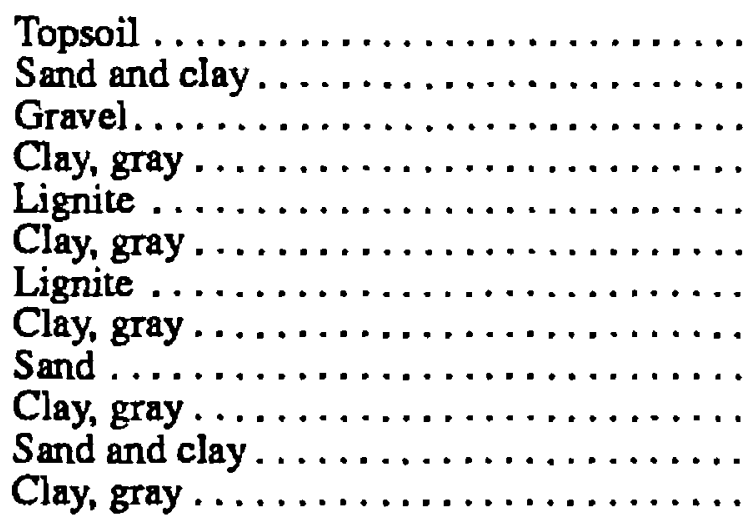 & $\begin{array}{r}5 \\
3 \\
5 \\
3 \\
5 \\
65 \\
2 \\
24 \\
1 \\
37 \\
13 \\
12\end{array}$ & $\begin{array}{r}5 \\
8 \\
13 \\
16 \\
21 \\
86 \\
88 \\
112 \\
113 \\
150 \\
163 \\
175\end{array}$ & 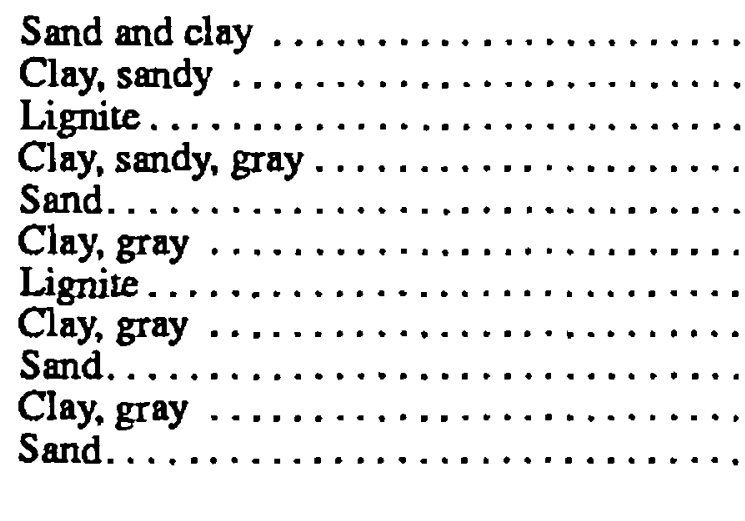 & $\begin{array}{r}10 \\
12 \\
7 \\
6 \\
2 \\
77 \\
6 \\
21 \\
15 \\
7 \\
64\end{array}$ & $\begin{array}{l}185 \\
197 \\
204 \\
210 \\
212 \\
289 \\
295 \\
316 \\
331 \\
338 \\
402\end{array}$ \\
\hline
\end{tabular}

146-089-09CCB

(Log from Dingman and Gordon, 1954)

Alttude: Not avallable

Date drilled: 1951

\begin{tabular}{|c|c|c|c|c|c|}
\hline Material & $\begin{array}{l}\text { Thick- } \\
\text { ness } \\
\text { (feot) }\end{array}$ & $\begin{array}{l}\text { Depth } \\
\text { (feet) }\end{array}$ & Matertal & $\begin{array}{c}\text { Thlck- } \\
\text { ness } \\
\text { (feet) }\end{array}$ & $\begin{array}{l}\text { Depth } \\
\text { (fert) }\end{array}$ \\
\hline 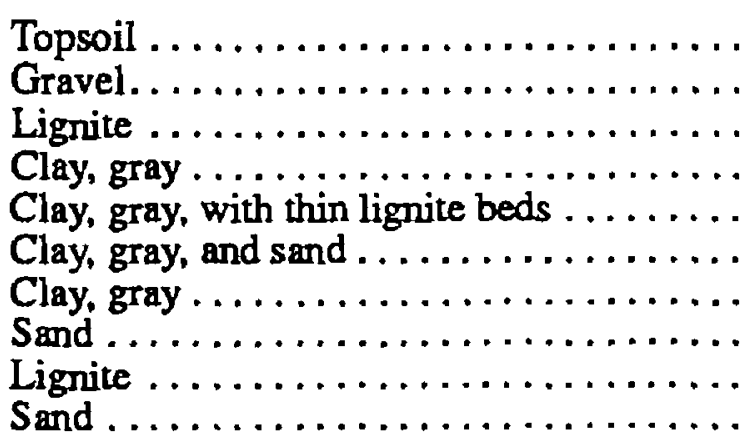 & $\begin{array}{r}5 \\
9 \\
2 \\
39 \\
28 \\
44 \\
7 \\
16 \\
5 \\
24\end{array}$ & $\begin{array}{r}5 \\
14 \\
16 \\
55 \\
83 \\
127 \\
134 \\
150 \\
155 \\
179\end{array}$ & 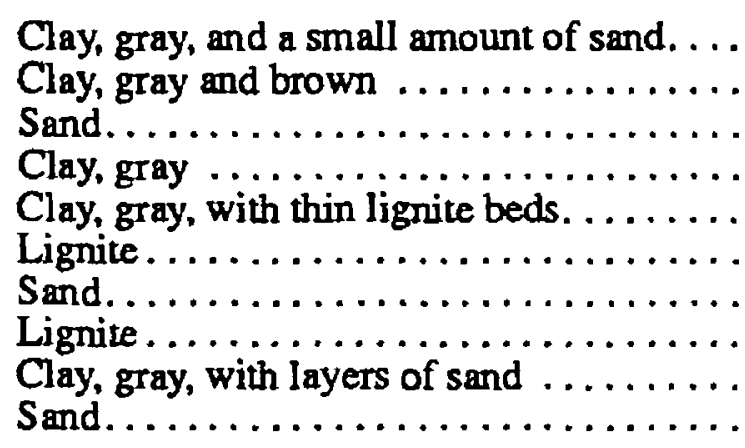 & $\begin{array}{r}16 \\
14 \\
2 \\
15 \\
16 \\
5 \\
2 \\
3 \\
17 \\
21\end{array}$ & $\begin{array}{l}195 \\
209 \\
211 \\
226 \\
242 \\
247 \\
249 \\
252 \\
269 \\
250\end{array}$ \\
\hline
\end{tabular}


Table 3. Drillers' logs of wells and test holes--Continued

146-090-05DAA

(Log trom Dingmen and Gordon, 1954)

Altitude: Not available

Date drilled: 1951

\begin{tabular}{|c|c|c|c|c|c|}
\hline Material & $\begin{array}{l}\text { Thick- } \\
\text { ness } \\
\text { (foet) }\end{array}$ & $\begin{array}{l}\text { Depth } \\
\text { (feet) }\end{array}$ & Material & $\begin{array}{l}\text { Thiok- } \\
\text { nes? } \\
\text { (feen) }\end{array}$ & $\begin{array}{l}\text { Depth } \\
\text { (feet) }\end{array}$ \\
\hline 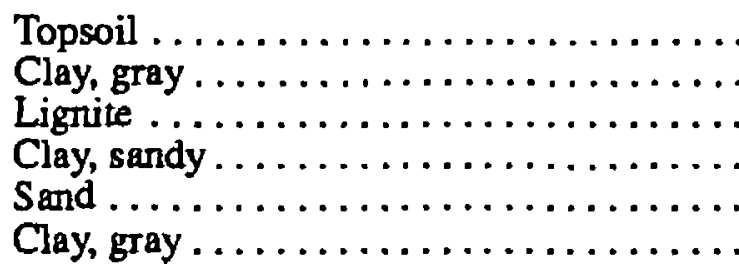 & $\begin{array}{r}4 \\
14 \\
\text {. } \\
\text {. } \\
\\
20 \\
\text {. }\end{array}$ & $\begin{array}{r}4 \\
18 \\
25 \\
30 \\
50 \\
54\end{array}$ & 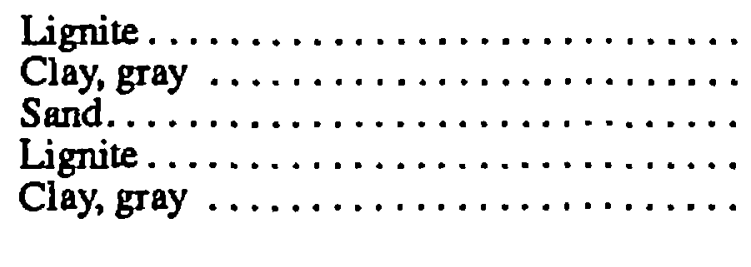 & $\begin{array}{r}6 \\
112 \\
4 \pi \\
3 \pi\end{array}$ & $\begin{array}{r}60 \\
172 \\
216 \\
218 \\
255\end{array}$ \\
\hline
\end{tabular}

146-091-05ACB

(Log modifled from Gregory Drilling, inc.)

Altitude: 2,190 feet

Date drille A: 03-12-90

\begin{tabular}{|c|c|c|c|c|c|}
\hline Materlal & $\begin{array}{l}\text { Thiok- } \\
\text { ness } \\
\text { (feot) }\end{array}$ & $\begin{array}{l}\text { Depth } \\
\text { (feel) }\end{array}$ & Materlal & $\begin{array}{c}\text { Thlet= } \\
\text { nes? } \\
\text { (feen) }\end{array}$ & $\begin{array}{l}\text { Depth } \\
\text { (feet) }\end{array}$ \\
\hline 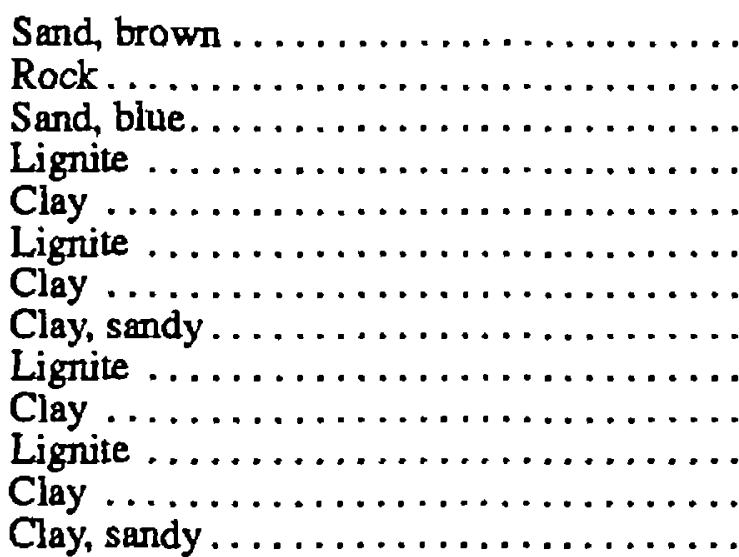 & $\begin{array}{r}27 \\
3 \\
4 \\
2 \\
34 \\
5 \\
10 \\
5 \\
3 \\
52 \\
5 \\
15 \\
10\end{array}$ & $\begin{array}{r}27 \\
30 \\
34 \\
36 \\
70 \\
75 \\
85 \\
90 \\
93 \\
145 \\
150 \\
165 \\
175\end{array}$ & 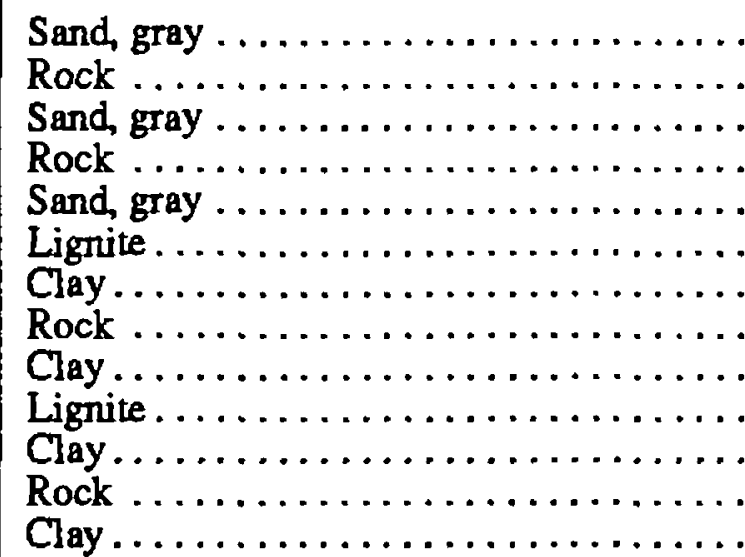 & $\begin{array}{r}19 \\
1 \\
4 \\
2 \\
6 \\
8 \\
16 \\
3 \\
12 \\
4 \\
39 \\
1 \\
10\end{array}$ & $\begin{array}{l}194 \\
195 \\
199 \\
201 \\
207 \\
215 \\
231 \\
234 \\
246 \\
250 \\
289 \\
290 \\
300\end{array}$ \\
\hline
\end{tabular}

146-091-20ABA

(Log modifled from Russell Drilling Co., inc.)

Altitude: 1,980 feet

Date drillert: $06-20-75$

\begin{tabular}{|c|c|c|c|c|c|}
\hline Material & $\begin{array}{l}\text { Thlck- } \\
\text { ness } \\
\text { (foet) }\end{array}$ & $\begin{array}{l}\text { Depth } \\
\text { (feet) }\end{array}$ & Material & $\begin{array}{l}\text { Thlot. } \\
\text { nes? } \\
\text { (fee) }\end{array}$ & $\begin{array}{l}\text { Depth } \\
\text { (feet) }\end{array}$ \\
\hline $\begin{array}{l}\text { Sand, silty } \ldots \ldots \ldots \ldots \ldots \ldots \ldots \ldots \ldots \ldots \ldots \ldots \ldots \ldots \\
\text { Clay, silty } \ldots \ldots \ldots \ldots \ldots \ldots \ldots \ldots \ldots \\
\text { Sand, fine } \ldots \ldots \ldots \ldots \ldots \ldots \ldots \ldots\end{array}$ & $\begin{array}{l}40 \\
37 \\
38\end{array}$ & $\begin{array}{r}40 \\
77 \\
115\end{array}$ & 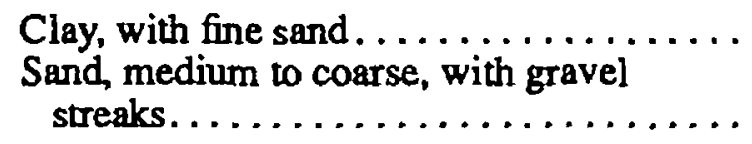 & $\begin{array}{l}49 \\
26\end{array}$ & $\begin{array}{l}164 \\
190\end{array}$ \\
\hline
\end{tabular}


Table 3. Drillers' logs of wells and test holes--Continued

146-091-20DDD2

(Log modtfled from Mann Drilling Co.)

Altitude: 1,980 feet

Date drilled: $07-13-74$

\begin{tabular}{|c|c|c|c|c|c|}
\hline Material & $\begin{array}{l}\text { Thlok- } \\
\text { noss } \\
\text { (feot) }\end{array}$ & $\begin{array}{l}\text { Depth } \\
\text { (feet) }\end{array}$ & Material & $\begin{array}{l}\text { Thick- } \\
\text { ness } \\
\text { (feet) }\end{array}$ & $\begin{array}{l}\text { Cepth } \\
\text { (frel) }\end{array}$ \\
\hline $\begin{array}{l}\text { Clay } \ldots \ldots \ldots \ldots \ldots \ldots \ldots \ldots \ldots \ldots \ldots \ldots \ldots \ldots \ldots \ldots \ldots \\
\text { Sand and gravel } \ldots \ldots \ldots \ldots \ldots \ldots \ldots\end{array}$ & $\begin{array}{l}37 \\
35\end{array}$ & $\begin{array}{l}37 \\
72\end{array}$ & 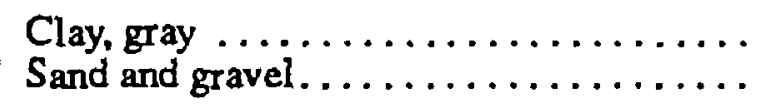 & $\begin{array}{r}7 \\
41\end{array}$ & $\begin{array}{r}79 \\
120\end{array}$ \\
\hline
\end{tabular}

146-091-24BDB2

(Log modified from Thompson Drilling)

Altitude: 2,200 feet

Date drilled: $04-04-77$

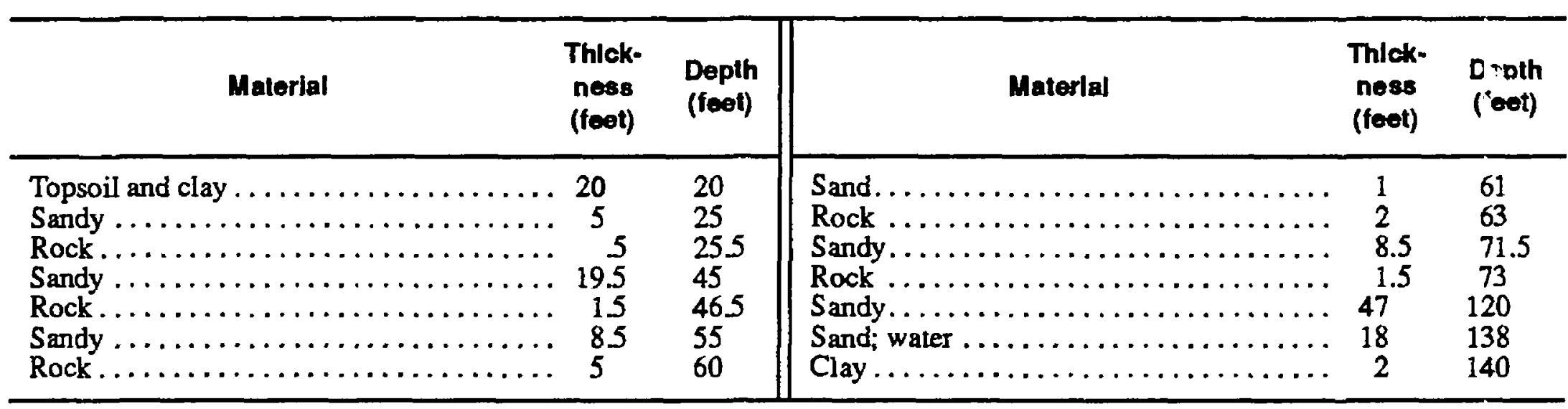

146-091-25ACC

(Log modifled from Mann Drilling Co.)

Altitude: 2,190 foet

Date drllied: $07-12-74$

\begin{tabular}{|c|c|c|c|c|c|}
\hline Materlal & $\begin{array}{l}\text { Thlck- } \\
\text { ness } \\
\text { (feet) }\end{array}$ & $\begin{array}{l}\text { Depth } \\
\text { (feet) }\end{array}$ & Materlal & $\begin{array}{l}\text { Thlek- } \\
\text { ness } \\
\text { (feet) }\end{array}$ & $\begin{array}{l}\text { Dinth } \\
\text { (feet) }\end{array}$ \\
\hline $\begin{array}{l}\text { Sand } \ldots \ldots \ldots \ldots \ldots \ldots \ldots \ldots \ldots \ldots \ldots \ldots \ldots \ldots \\
\text { Lignite } \ldots \ldots \ldots \ldots \ldots \ldots \ldots \ldots\end{array}$ & $\begin{array}{r}170 \\
6\end{array}$ & $\begin{array}{l}170 \\
176\end{array}$ & Clay $\ldots \ldots \ldots \ldots \ldots \ldots \ldots$ & 4 & 180 \\
\hline
\end{tabular}

146-091-31BDA1

(Log modifled from Thompson Drilling)

Altitude: 2,230 feet

Date drllled: $10-18-76$

\begin{tabular}{|c|c|c|c|c|c|}
\hline Materlal & $\begin{array}{l}\text { Thlek- } \\
\text { ness } \\
\text { (feet) }\end{array}$ & $\begin{array}{l}\text { Depth } \\
\text { (feet) }\end{array}$ & Material & $\begin{array}{l}\text { Thlek- } \\
\text { ness } \\
\text { (foet) }\end{array}$ & $\begin{array}{l}\text { Disth } \\
\text { (fret) }\end{array}$ \\
\hline $\begin{array}{l}\text { Topsoil and sand. } \ldots \ldots \ldots \ldots \ldots \ldots \ldots \ldots \ldots \ldots \ldots \ldots \ldots \\
\text { Rock } \ldots \ldots \ldots \ldots \ldots \ldots \ldots \ldots \ldots \\
\text { Sand, red. } \ldots \ldots \ldots \ldots \ldots \ldots \ldots\end{array}$ & $\begin{array}{r}11 \\
2 \\
52\end{array}$ & $\begin{array}{l}11 \\
13 \\
65\end{array}$ & $\begin{array}{l}\text { Sand, blue } \ldots \ldots \ldots \ldots \ldots \ldots \ldots \ldots \ldots \ldots \ldots \ldots \\
\text { Clay } \ldots \ldots \ldots \ldots \ldots \ldots \ldots\end{array}$ & $\begin{array}{r}15 \\
3\end{array}$ & $\begin{array}{l}80 \\
83\end{array}$ \\
\hline
\end{tabular}


Table 3. Drillers' logs of wells and test holes--Continued

146-091-31BDA2

(Log modifled from Opp Well Drilling)

Altitude: 2,200 feet

Date drille : $08-28-87$

\begin{tabular}{|c|c|c|c|c|c|}
\hline Materlal & $\begin{array}{l}\text { Thlok- } \\
\text { ness } \\
\text { (feet) }\end{array}$ & $\begin{array}{l}\text { Depth } \\
\text { (feot) }\end{array}$ & Materlal & $\begin{array}{l}\text { Thlok. } \\
\text { nest } \\
\text { (feet) }\end{array}$ & $\begin{array}{l}\text { Depth } \\
\text { (feet) }\end{array}$ \\
\hline 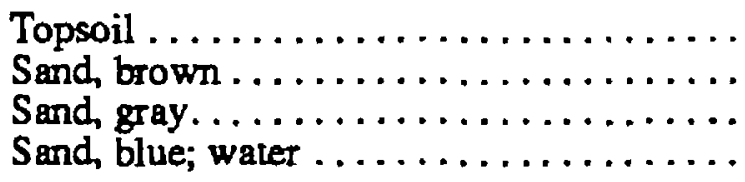 & $\begin{array}{r}3 \\
24 \\
8 \\
14\end{array}$ & $\begin{array}{r}3 \\
27 \\
35 \\
49\end{array}$ & $\begin{array}{l}\text { Lignite } \ldots \ldots \ldots \ldots \ldots \ldots \ldots \ldots \ldots \ldots \ldots \ldots \\
\text { Clay, blue. . . . } \ldots \ldots \ldots \ldots \ldots \ldots \ldots \ldots \ldots \ldots \\
\text { Clay, dark } \ldots \ldots \ldots \ldots \ldots \ldots \ldots \ldots \ldots \ldots\end{array}$ & $\begin{array}{r}1 \\
15 \\
5\end{array}$ & $\begin{array}{l}50 \\
65 \\
70\end{array}$ \\
\hline
\end{tabular}

146-092-15BBB

(Log modifled from Gregory Drilling, inc.)

Altitude: 1,930 feet

Date drlilieN: $11-22-88$

\begin{tabular}{|c|c|c|c|c|c|}
\hline Materlal & $\begin{array}{l}\text { Thlck- } \\
\text { ness } \\
\text { (feet) }\end{array}$ & $\begin{array}{l}\text { Depth } \\
\text { (feot) }\end{array}$ & Materlai & $\begin{array}{l}\text { Thlck- } \\
\text { ness } \\
\text { (foo') }\end{array}$ & $\begin{array}{l}\text { Depth } \\
\text { (feet) }\end{array}$ \\
\hline 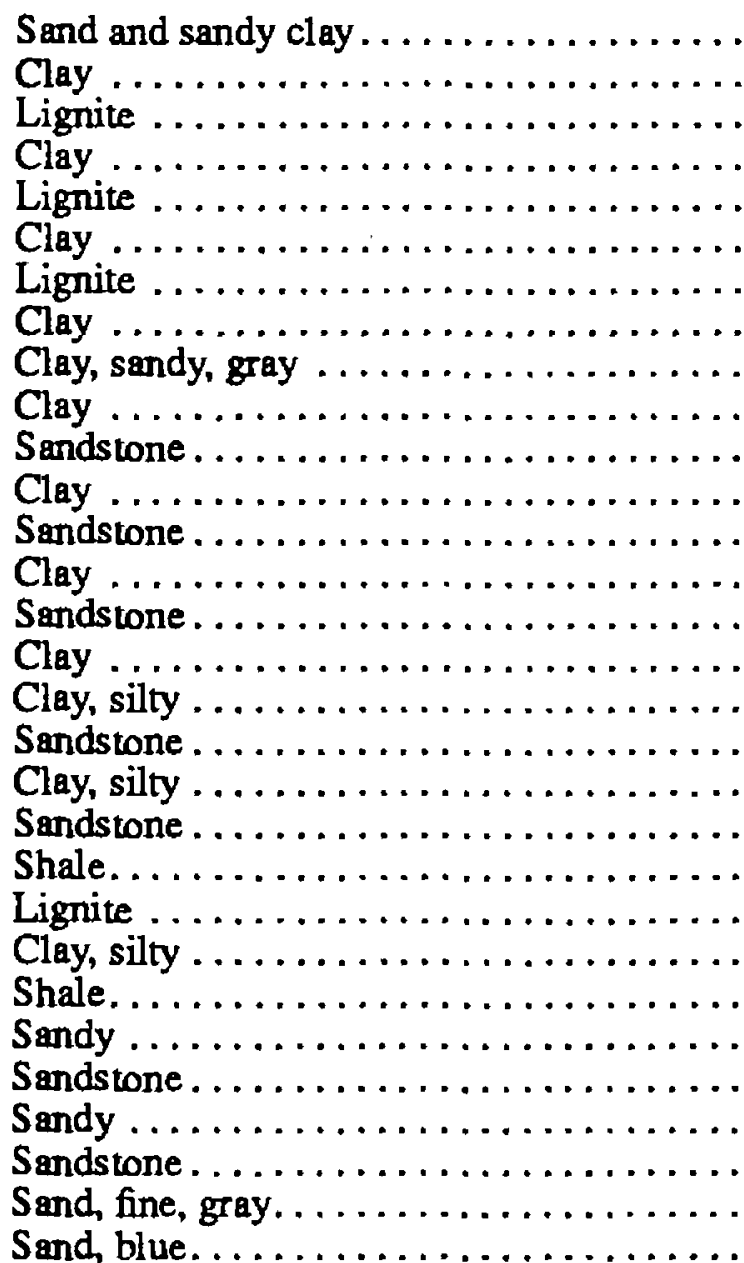 & $\begin{array}{r}22 \\
25 \\
3 \\
36 \\
9 \\
44 \\
6 \\
7 \\
23 \\
76 \\
4 \\
90 \\
2 \\
4 \\
1 \\
78 \\
32 \\
3 \\
24 \\
4 \\
9 \\
6 \\
18 \\
276 \\
30 \\
2 \\
43 \\
1 \\
42 \\
28\end{array}$ & $\begin{array}{r}22 \\
47 \\
50 \\
86 \\
95 \\
139 \\
145 \\
152 \\
175 \\
251 \\
255 \\
345 \\
347 \\
351 \\
352 \\
430 \\
462 \\
465 \\
489 \\
493 \\
502 \\
508 \\
526 \\
802 \\
832 \\
834 \\
877 \\
878 \\
920 \\
948\end{array}$ & 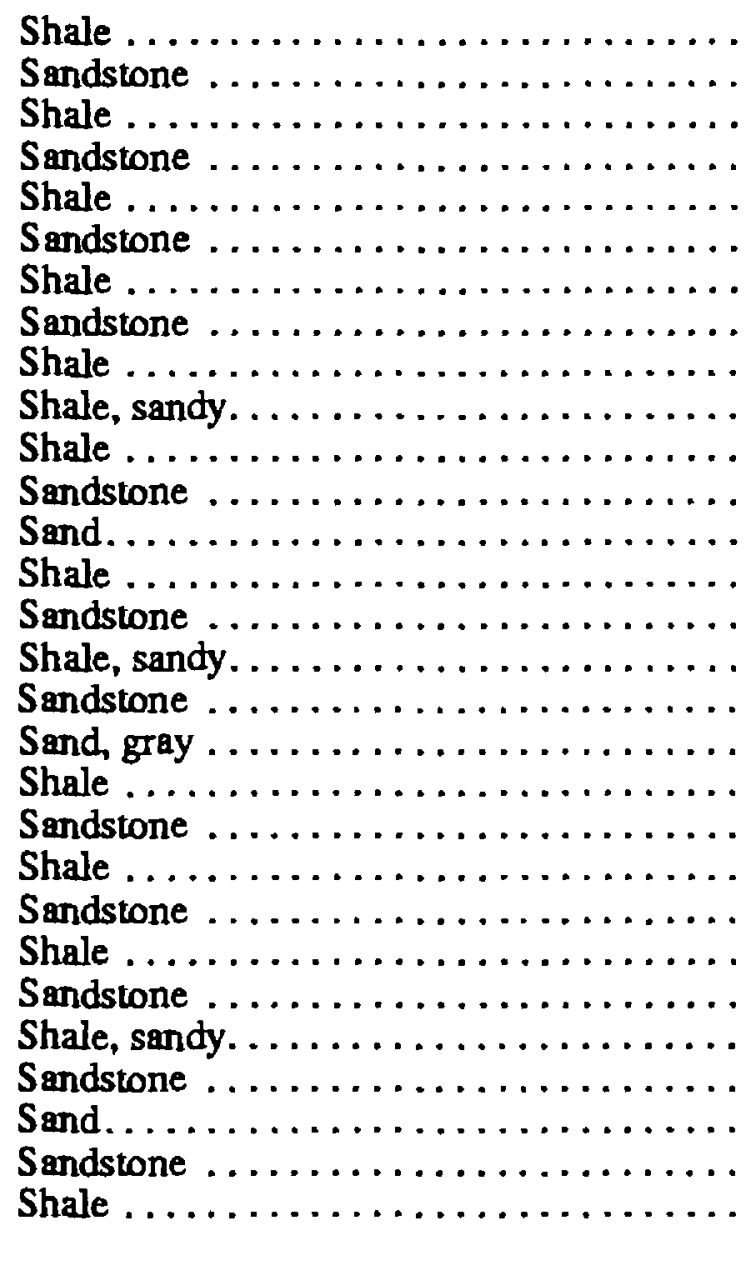 & $\begin{array}{r}65 \\
1 \\
91 \\
1 \\
24 \\
1 \\
55 \\
1 \\
25 \\
10 \\
18 \\
1 \\
16 \\
72 \\
2 \\
13 \\
2 \\
16 \\
24 \\
5 \\
195 \\
1 \\
23 \\
1 \\
96 \\
1 \\
14 \\
1 \\
34\end{array}$ & $\begin{array}{l}1,013 \\
1,014 \\
1,105 \\
1,106 \\
1,130 \\
1,131 \\
1,186 \\
1,187 \\
1,215 \\
1,225 \\
1,243 \\
1,244 \\
1,260 \\
1,332 \\
1,334 \\
1,347 \\
1,349 \\
1,365 \\
1,389 \\
1,394 \\
1,589 \\
1,590 \\
1,613 \\
1,614 \\
1,710 \\
1,711 \\
1,725 \\
1,726 \\
1,760\end{array}$ \\
\hline
\end{tabular}


Table 3. Drillers' logs of wells and test holes--Continued

146-092-32CDD2

(Log modifled from Opp Well Drilling)

\begin{tabular}{|c|c|c|c|c|c|}
\hline Materlal & $\begin{array}{l}\text { Thlek- } \\
\text { neas } \\
\text { (feel) }\end{array}$ & $\begin{array}{l}\text { Depth } \\
\text { (feet) }\end{array}$ & Material & $\begin{array}{l}\text { Thick. } \\
\text { neses } \\
\text { (feet) }\end{array}$ & $\begin{array}{l}\text { Dinth } \\
\text { (feet) }\end{array}$ \\
\hline 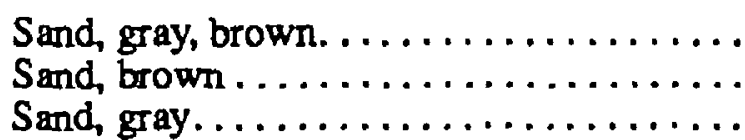 & $\begin{array}{r}2 \\
9 \\
19\end{array}$ & $\begin{array}{r}2 \\
11 \\
30\end{array}$ & $\begin{array}{l}\text { Sand, light-blue } \ldots \ldots \ldots \ldots \ldots \ldots \ldots \ldots \ldots \\
\text { Sand, blue } \ldots \ldots \ldots \ldots \ldots \ldots \ldots\end{array}$ & $\begin{array}{l}18 \\
15\end{array}$ & $\begin{array}{l}48 \\
63\end{array}$ \\
\hline
\end{tabular}

146-094-08DAD2

(Log modifled from Ralph Wold Well Drilling)

Altitude: 1,965 feet

Date drilled: $10-? 3-74$

\begin{tabular}{|c|c|c|c|c|c|}
\hline Material & $\begin{array}{l}\text { Thick- } \\
\text { neos } \\
\text { (feot) }\end{array}$ & $\begin{array}{l}\text { Depth } \\
\text { (feet) }\end{array}$ & Material & $\begin{array}{c}\text { Thlck- } \\
\text { ness } \\
\text { (feet) }\end{array}$ & $\begin{array}{l}\text { D.nth } \\
\text { (fret) }\end{array}$ \\
\hline $\begin{array}{l}\text { Clay, sandy } \ldots \ldots \ldots \ldots \ldots \ldots \ldots \ldots \ldots \\
\text { Shale. } \ldots \ldots \ldots \ldots \ldots \\
\text { Sand } \ldots \ldots \ldots \ldots \\
\text { Shale } \ldots \ldots \ldots \ldots \ldots \\
\text { Rock } \ldots \ldots \ldots \ldots\end{array}$ & $\begin{array}{r}30 \\
. \quad 37 \\
. \quad 18 \\
. \quad 35 \\
. \quad 4\end{array}$ & $\begin{array}{l}1,440 \\
1,477 \\
1,495 \\
1,530 \\
1,534\end{array}$ & $\begin{array}{l}\text { Shale } \ldots \ldots \ldots \ldots \ldots \ldots \ldots \ldots \ldots \ldots \ldots \ldots \ldots \ldots \\
\text { Sand } \ldots \ldots \ldots \ldots \ldots \ldots \ldots \ldots \ldots \ldots \ldots \ldots \ldots \ldots \ldots \ldots \\
\text { Rock } \ldots \ldots \ldots \ldots \ldots \ldots \ldots \ldots \ldots \ldots \ldots \\
\text { Sand } \ldots \ldots \ldots \ldots \ldots \ldots \ldots \ldots \ldots \ldots\end{array}$ & $\begin{array}{r}26 \\
144 \\
4 \\
22\end{array}$ & $\begin{array}{l}1.560 \\
1.704 \\
1.708 \\
1.730\end{array}$ \\
\hline
\end{tabular}

147-087-03CDB

(Log from Dingman and Gordon, 1954)

Altitude: 2,014 feet

Date drilied: 1951

\begin{tabular}{|c|c|c|c|c|c|}
\hline Materlal & $\begin{array}{c}\text { Thlck- } \\
\text { ness } \\
\text { (feot) }\end{array}$ & $\begin{array}{l}\text { Depth } \\
\text { (feet) }\end{array}$ & Materlel & $\begin{array}{l}\text { Thlck- } \\
\text { nese } \\
\text { (foet) }\end{array}$ & $\begin{array}{l}\text { Dinth } \\
\text { (f }>\text { at) }\end{array}$ \\
\hline 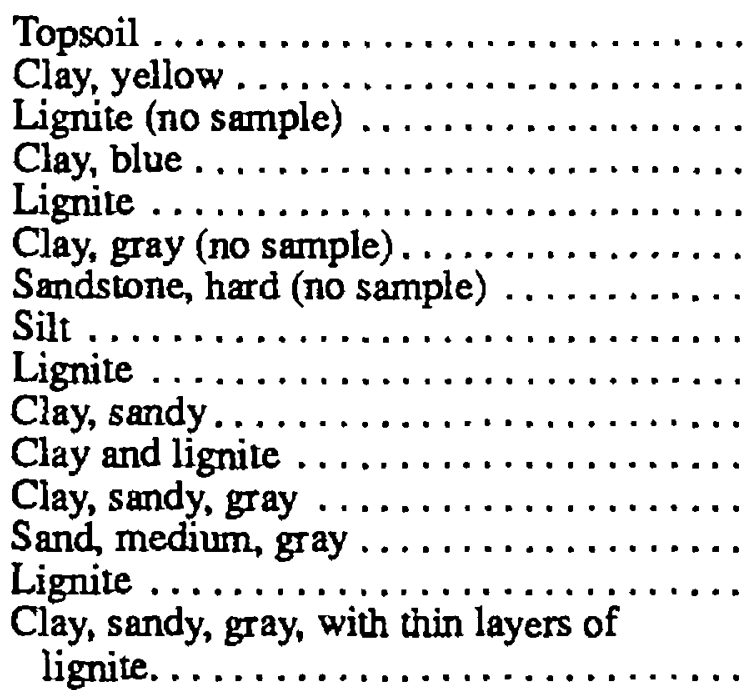 & $\begin{array}{r}2 \\
25 \\
1 \\
22 \\
2 \\
86 \\
4 \\
44 \\
7 \\
14 \\
6 \\
3 \\
22 \\
7\end{array}$ & $\begin{array}{r}2 \\
27 \\
28 \\
50 \\
52 \\
138 \\
142 \\
186 \\
193 \\
207 \\
213 \\
216 \\
238 \\
245 \\
278\end{array}$ & 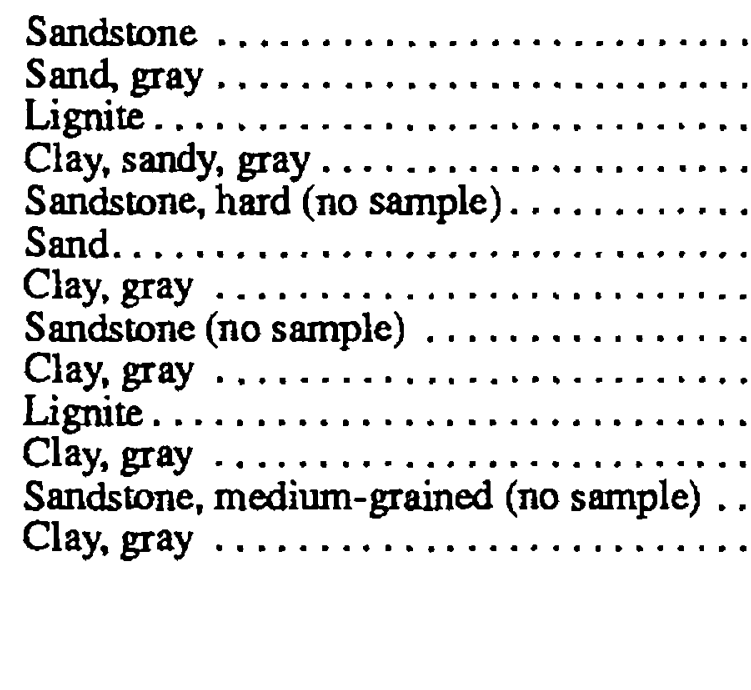 & $\begin{array}{r}2 \\
22 \\
6 \\
44 \\
4 \\
47 \\
19 \\
2 \\
13 \\
9 \\
21 \\
1 \\
32\end{array}$ & $\begin{array}{l}280 \\
\vdots 02 \\
208 \\
252 \\
\vdots 56 \\
403 \\
422 \\
424 \\
437 \\
446 \\
4.67 \\
468 \\
500\end{array}$ \\
\hline
\end{tabular}


Tabie 3. Drillers' logs of wells and test holes--Continued

147-087-12BAA

(Log from Dingman and Gordon, 1954)

Alttude: Not available

Date crilled: 1951

\begin{tabular}{|c|c|c|c|c|c|}
\hline Materlal & $\begin{array}{l}\text { Thick- } \\
\text { nesa } \\
\text { (foot) }\end{array}$ & $\begin{array}{l}\text { Depth } \\
\text { (feet) }\end{array}$ & Material & $\begin{array}{l}\text { Thlck- } \\
\text { nege } \\
\text { (feet) }\end{array}$ & $\begin{array}{l}\text { Depth } \\
\text { (feet) }\end{array}$ \\
\hline $\begin{array}{l}\text { Topsoil . . . . . . . . . . . . . . . . . . . } \\
\text { Clay and gravel, yellow . . . . . . . . . }\end{array}$ & $\begin{array}{r}2 \\
13\end{array}$ & $\begin{array}{r}2 \\
15\end{array}$ & (No sample) . . . . . . . . . . . . . . . & 130 & 145 \\
\hline
\end{tabular}

147-087-12BAB

(Log from Dingman and Gordon, 1954)

Alttude: 1,959 feet

Date d illed: 1951

\begin{tabular}{|c|c|c|c|c|c|}
\hline Material & $\begin{array}{l}\text { Thlok- } \\
\text { ness } \\
\text { (teot) }\end{array}$ & $\begin{array}{l}\text { Depth } \\
\text { (feet) }\end{array}$ & Meterlal & $\begin{array}{l}\text { Thlet. } \\
\text { nest } \\
\text { (feat) }\end{array}$ & $\begin{array}{l}\text { Depth } \\
\text { (feet) }\end{array}$ \\
\hline 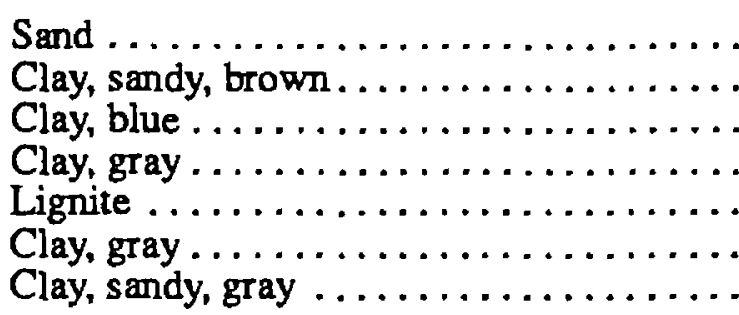 & $\begin{array}{r}23 \\
7 \\
51 \\
34 \\
5 \\
6 \\
34\end{array}$ & $\begin{array}{r}23 \\
30 \\
81 \\
115 \\
120 \\
126 \\
160\end{array}$ & 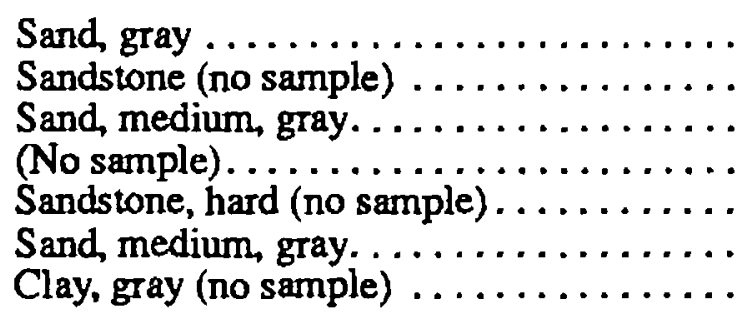 & $\begin{array}{r}89 \\
4 \\
3 \\
176 \\
2 \\
36 \\
10\end{array}$ & $\begin{array}{l}249 \\
253 \\
256 \\
432 \\
434 \\
470 \\
480\end{array}$ \\
\hline
\end{tabular}

147-087-13BCB

(Log from Dingman and Gordon, 1954)

Alttude: Not available

Date drilled: 1951

\begin{tabular}{|c|c|c|c|c|c|}
\hline Material & $\begin{array}{l}\text { Thick- } \\
\text { ness } \\
\text { (feet) }\end{array}$ & $\begin{array}{l}\text { Depth } \\
\text { (feet) }\end{array}$ & Material & $\begin{array}{l}\text { Thict. } \\
\text { ness } \\
\text { (feet) }\end{array}$ & $\begin{array}{l}\text { Depth } \\
\text { (feot) }\end{array}$ \\
\hline 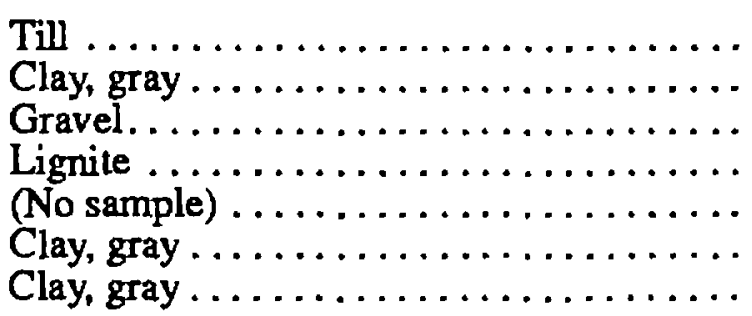 & $\begin{array}{r}30 \\
30 \\
44 \\
3 \\
7 \\
26 \\
2\end{array}$ & $\begin{array}{r}30 \\
60 \\
104 \\
107 \\
114 \\
140 \\
142\end{array}$ & 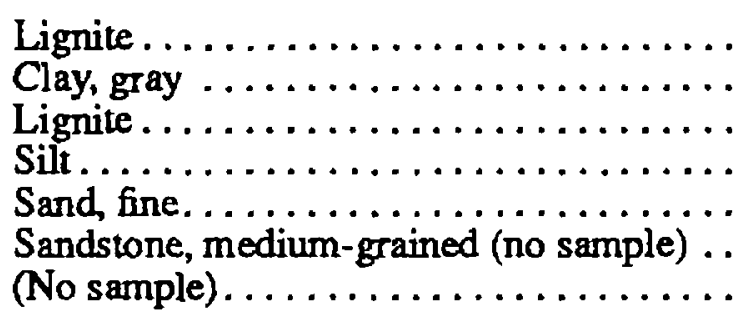 & $\begin{array}{r}6 \\
28 \\
9 \\
11 \\
12 \\
4 \\
63\end{array}$ & $\begin{array}{l}148 \\
176 \\
185 \\
196 \\
208 \\
212 \\
275\end{array}$ \\
\hline
\end{tabular}


Tabie 3. Drillers' logs of wells and test holes--Continued

147-090-19CDC

(Log from Dingman and Gordon, 1954)

Altitude: $2,151.4$ feet

Date drilled: 1951

\begin{tabular}{|c|c|c|c|c|}
\hline $\begin{array}{l}\text { Thick- } \\
\text { ness } \\
\text { (feet) }\end{array}$ & $\begin{array}{l}\text { Depth } \\
\text { (feet) }\end{array}$ & Materlal & $\begin{array}{l}\text { Thlek- } \\
\text { nese } \\
\text { (feet) }\end{array}$ & $\begin{array}{l}\text { Dinth } \\
\text { (foot) }\end{array}$ \\
\hline 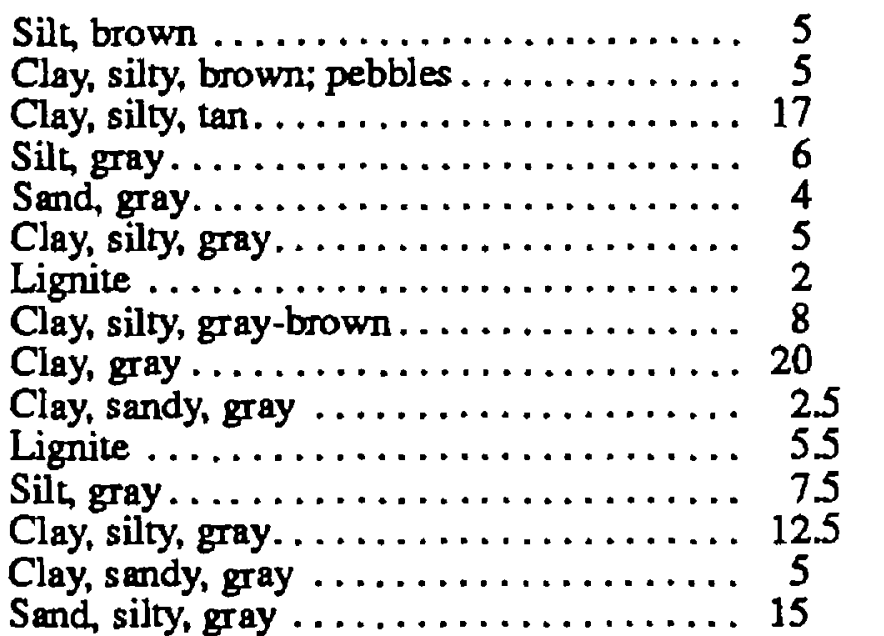 & $\begin{array}{l}5 \\
10 \\
27 \\
33 \\
37 \\
42 \\
44 \\
52 \\
72 \\
74.5 \\
80 \\
87.5 \\
100 \\
105 \\
120\end{array}$ & 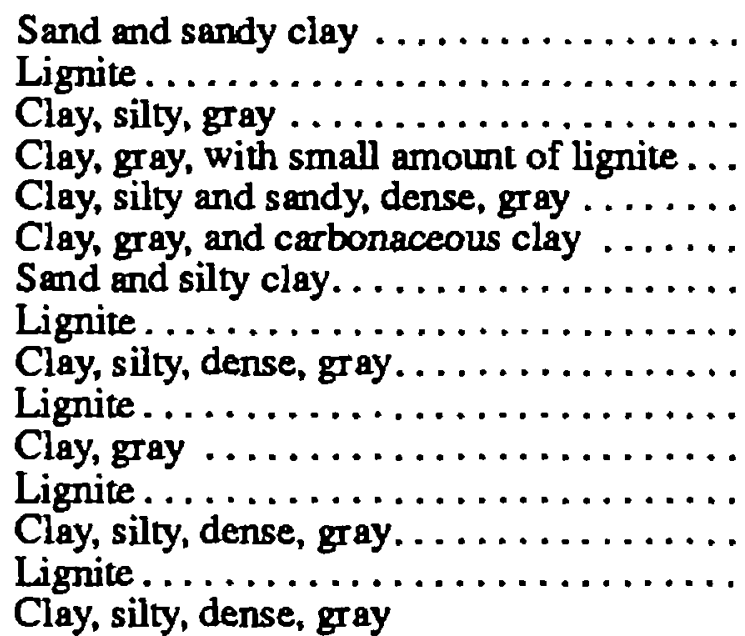 & $\begin{array}{r}12 \\
6 \\
7 \\
5 \\
118 \\
2 \\
6 \\
3 \\
26 \\
26.5 \\
3 \\
40 \\
4 \\
26\end{array}$ & $\begin{array}{l}132 \\
138 \\
145 \\
150 \\
2<9 \\
270 \\
276 \\
279 \\
305 \\
305.5 \\
332 \\
335 \\
375 \\
379 \\
405\end{array}$ \\
\hline
\end{tabular}

147-90-20DDB

(Log from Dingman and Gordon, 1954)

Altitude: Not available

Date drilled: 1951

\begin{tabular}{|c|c|c|c|c|c|}
\hline Material & $\begin{array}{l}\text { Thlck- } \\
\text { ness } \\
\text { (feer) }\end{array}$ & $\begin{array}{l}\text { Depth } \\
\text { (feet) }\end{array}$ & Materlal & $\begin{array}{l}\text { Thlak- } \\
\text { ness } \\
\text { (feet) }\end{array}$ & $\begin{array}{l}\text { Donth } \\
(f \circ g t)\end{array}$ \\
\hline 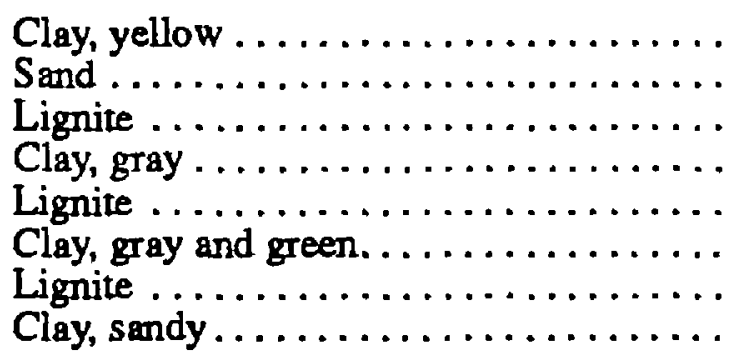 & $\begin{array}{r}16 \\
30 \\
4 \\
40 \\
3 \\
40 \\
3 \\
43\end{array}$ & $\begin{array}{r}16 \\
46 \\
50 \\
90 \\
93 \\
133 \\
136 \\
179\end{array}$ & 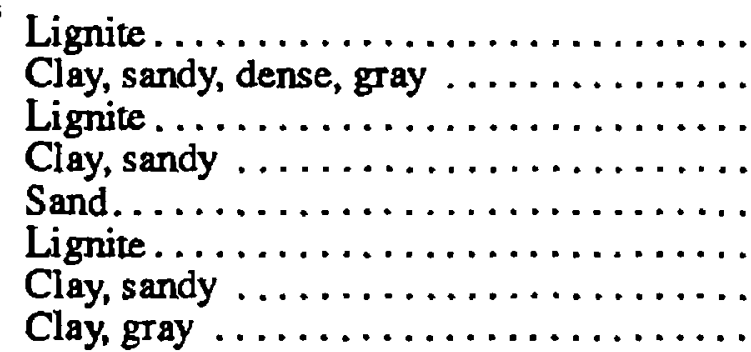 & $\begin{array}{r}3 \\
110 \\
5 \\
18 \\
41 \\
2 \\
12 \\
30\end{array}$ & $\begin{array}{l}182 \\
292 \\
297 \\
215 \\
356 \\
358 \\
370 \\
400\end{array}$ \\
\hline
\end{tabular}

147-090-22CcC

(Log from Dlngman and Gordon, 1954)

Altitude: $2,028.8$ feet

Date drilled: 1950

\begin{tabular}{|c|c|c|c|c|c|}
\hline Material & $\begin{array}{c}\text { Thlck- } \\
\text { ness } \\
\text { (feet) }\end{array}$ & $\begin{array}{l}\text { Depth } \\
\text { (feet) }\end{array}$ & Material & $\begin{array}{l}\text { Thick- } \\
\text { ness } \\
\text { (feet) }\end{array}$ & $\begin{array}{l}\text { Depth } \\
(f \circ 9 t)\end{array}$ \\
\hline $\begin{array}{l}\text { Soil, silty and clayey, brown . . . . . . . . } \\
\text { Clay, silty, brown ................. }\end{array}$ & $\begin{array}{r}5 \\
10\end{array}$ & $\begin{array}{r}5 \\
15\end{array}$ & $\begin{array}{l}\text { Sand. . . . . . . . . . . . . . . . . . . . } \\
\text { Clay, gray(?) (no sample) . . . . . . . }\end{array}$ & $\begin{array}{l}37 \\
98\end{array}$ & $\begin{array}{r}52 \\
150\end{array}$ \\
\hline
\end{tabular}


Table 3. Drillers' logs of wells and test holes--Continued

147-090-25ABC

(Log from Dingman and Gordon, 1954)

Date drilled: 1950

\begin{tabular}{|c|c|c|c|c|c|}
\hline Material & $\begin{array}{l}\text { Thlok- } \\
\text { ness } \\
\text { (feot) }\end{array}$ & $\begin{array}{l}\text { Depth } \\
\text { (feet) }\end{array}$ & Material & $\begin{array}{l}\text { Thlok. } \\
\text { nes? } \\
\text { (foet) }\end{array}$ & $\begin{array}{l}\text { Depth } \\
\text { (feet) }\end{array}$ \\
\hline 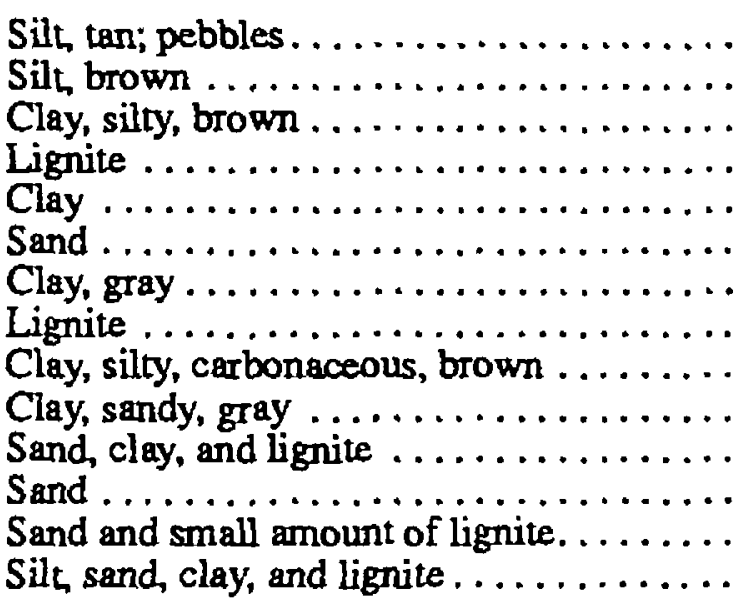 & $\begin{array}{r}10 \\
10 \\
4 \\
6 \\
5 \\
5 \\
11 \\
7.5 \\
1.5 \\
5 \\
5 \\
15 \\
9 \\
1\end{array}$ & $\begin{array}{l}10 \\
20 \\
24 \\
30 \\
35 \\
40 \\
51 \\
58.5 \\
60 \\
65 \\
70 \\
85 \\
94 \\
95\end{array}$ & 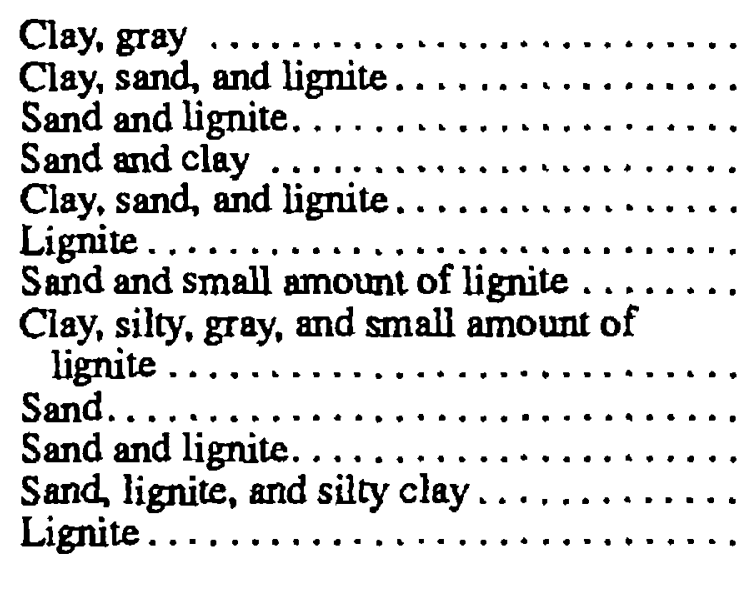 & $\begin{array}{r}5 \\
5 \\
10 \\
5 \\
2.5 \\
1 \\
6.5 \\
5 \\
10 \\
5 \\
10 \\
3\end{array}$ & $\begin{array}{l}100 \\
105 \\
115 \\
120 \\
122.5 \\
123.5 \\
130 \\
135 \\
145 \\
150 \\
160 \\
163\end{array}$ \\
\hline
\end{tabular}

147-091-25DCC

(Log modifled from Mohl Drilling, Inc.)

Altitude: 2,110 feet

Date drillet: $12-10-81$

\begin{tabular}{|c|c|c|c|c|c|}
\hline Material & $\begin{array}{l}\text { Thick- } \\
\text { ness } \\
\text { (feet) }\end{array}$ & $\begin{array}{l}\text { Depth } \\
\text { (feet) }\end{array}$ & Materlal & $\begin{array}{l}\text { Thick- } \\
\text { noss } \\
\text { (fent) }\end{array}$ & $\begin{array}{l}\text { Depth } \\
\text { (feet) }\end{array}$ \\
\hline 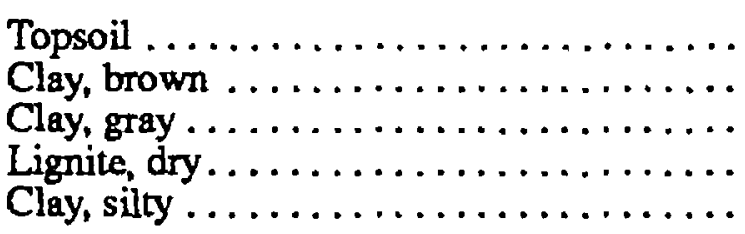 & $\begin{array}{r}2 \\
28 \\
16 \\
4 \\
20\end{array}$ & $\begin{array}{r}2 \\
30 \\
46 \\
50 \\
70\end{array}$ & $\begin{array}{l}\text { Sand, coarse. } \ldots \ldots \ldots \ldots \ldots \ldots \ldots \ldots \ldots \ldots \\
\text { Sandstone, hard } \ldots \ldots \ldots \ldots \ldots \ldots \ldots \ldots \ldots \\
\text { Sand, fine. } \ldots \ldots \ldots \ldots \ldots \ldots \ldots \ldots \ldots \ldots \\
\text { Clay, gray } \ldots \ldots \ldots \ldots \ldots \ldots \ldots \ldots \ldots\end{array}$ & $\begin{array}{r}7 \\
3 \\
12 \\
3\end{array}$ & $\begin{array}{l}77 \\
80 \\
92 \\
95\end{array}$ \\
\hline
\end{tabular}


Table 3. Drillers' logs of wells and test holes--Continued

147-091-28ACC

(Log modified from Gregory Drililng, Inc.)

Date drilied: $03-2,4-80$

\begin{tabular}{|c|c|c|c|c|c|}
\hline Material & $\begin{array}{l}\text { Thick- } \\
\text { nees } \\
\text { (foot) }\end{array}$ & $\begin{array}{l}\text { Depth } \\
\text { (feet) }\end{array}$ & Materlal & $\begin{array}{l}\text { Thick- } \\
\text { neas } \\
\text { (foet) }\end{array}$ & $\begin{array}{l}\text { Depth } \\
\text { (fent) }\end{array}$ \\
\hline 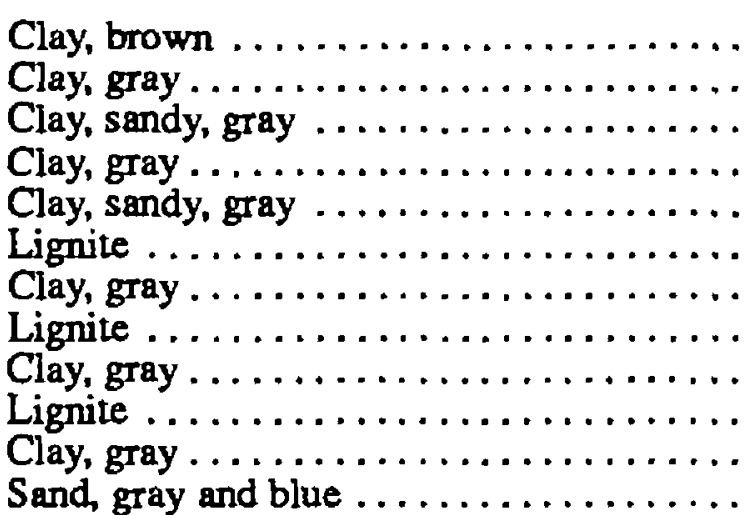 & $\begin{array}{r}5 \\
25 \\
5 \\
24 \\
9 \\
3 \\
37 \\
2 \\
25 \\
3 \\
122 \\
35\end{array}$ & $\begin{array}{r}5 \\
30 \\
35 \\
59 \\
68 \\
71 \\
108 \\
110 \\
135 \\
138 \\
260 \\
295\end{array}$ & 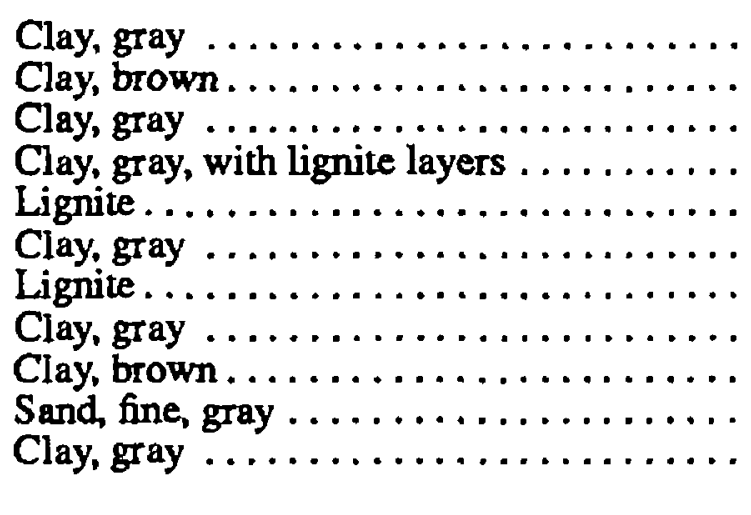 & $\begin{array}{r}25 \\
25 \\
55 \\
18 \\
6 \\
129 \\
4 \\
98 \\
22 \\
29 \\
14\end{array}$ & $\begin{array}{l}32.0 \\
345 \\
4 C 0 \\
418 \\
424 \\
553 \\
557 \\
655 \\
677 \\
7 C 6 \\
720\end{array}$ \\
\hline
\end{tabular}

147-092-03CDC2

(Log modified from Kieson Drilling)

Alttude: 1,900 foet

Date drilled: $04-30-76$

\begin{tabular}{|c|c|c|c|c|c|}
\hline Material & $\begin{array}{l}\text { Thick- } \\
\text { ness } \\
\text { (feat) }\end{array}$ & $\begin{array}{l}\text { Depth } \\
\text { (feet) }\end{array}$ & Material & $\begin{array}{l}\text { Thick- } \\
\text { neas } \\
\text { (feet) }\end{array}$ & $\begin{array}{l}\text { Depth } \\
\text { (fert) }\end{array}$ \\
\hline 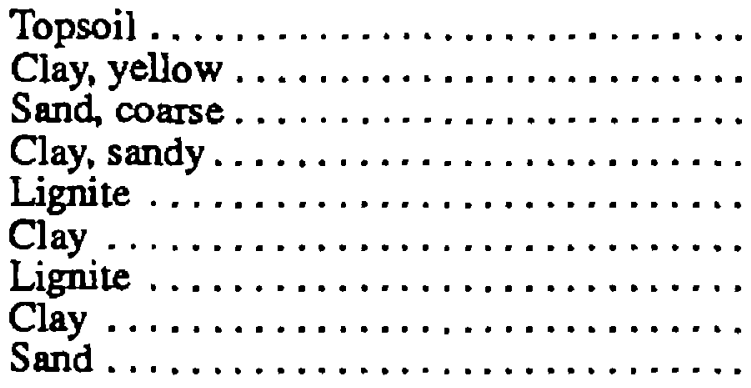 & $\begin{array}{r}3 \\
27 \\
70 \\
33 \\
2 \\
152 \\
3 \\
75 \\
175\end{array}$ & $\begin{array}{r}3 \\
30 \\
100 \\
133 \\
135 \\
287 \\
290 \\
365 \\
540\end{array}$ & 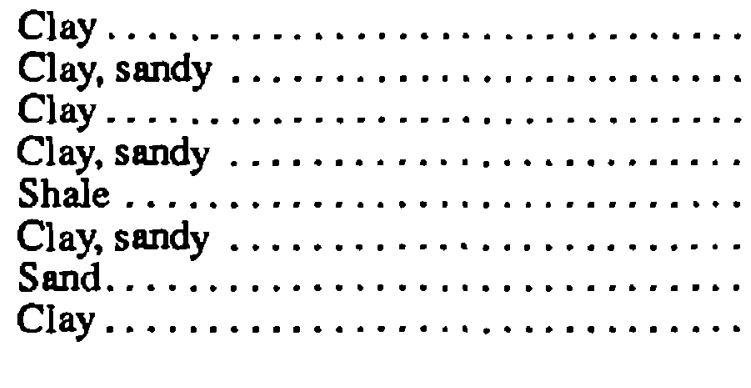 & $\begin{array}{r}225 \\
20 \\
160 \\
25 \\
15 \\
5 \\
10 \\
5\end{array}$ & $\begin{array}{r}7: 5 \\
7>5 \\
9 \div 5 \\
970 \\
9 ? 5 \\
9 ? 7 \\
1,0>7 \\
1,075\end{array}$ \\
\hline
\end{tabular}


Table 3. Drillers' logs of wells and test holes--Continued

147-092-15ADD

(Log modified from Kieson Driliing)

Altitude: 1,950 feet

Date drilled: $04-23-76$

\begin{tabular}{|c|c|c|c|c|c|}
\hline Materlal & $\begin{array}{l}\text { Thlok- } \\
\text { ness } \\
\text { (feet) }\end{array}$ & $\begin{array}{l}\text { Depth } \\
\text { (feet) }\end{array}$ & Materlal & $\begin{array}{l}\text { Thlal - } \\
\text { ness } \\
\text { (feet" }\end{array}$ & $\begin{array}{l}\text { Depth } \\
\text { (feet) }\end{array}$ \\
\hline 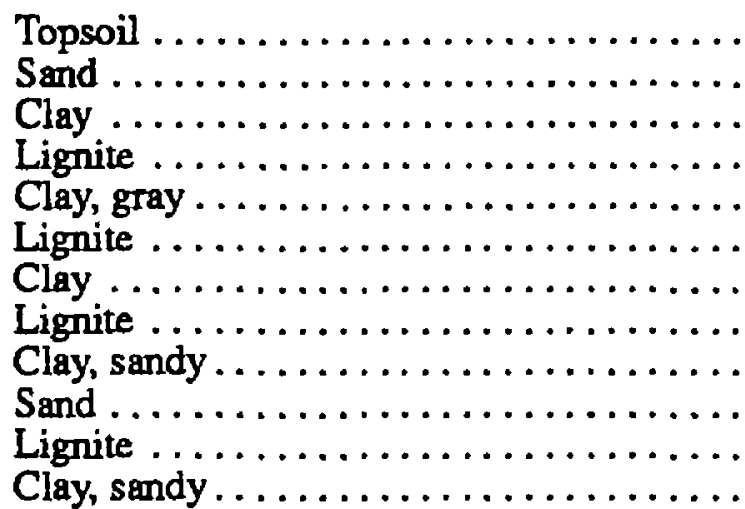 & $\begin{array}{r}2 \\
48 \\
15 \\
5 \\
88 \\
4 \\
26 \\
7 \\
125 \\
55 \\
9 \\
34\end{array}$ & $\begin{array}{r}2 \\
50 \\
65 \\
70 \\
158 \\
162 \\
188 \\
195 \\
320 \\
375 \\
384 \\
418\end{array}$ & 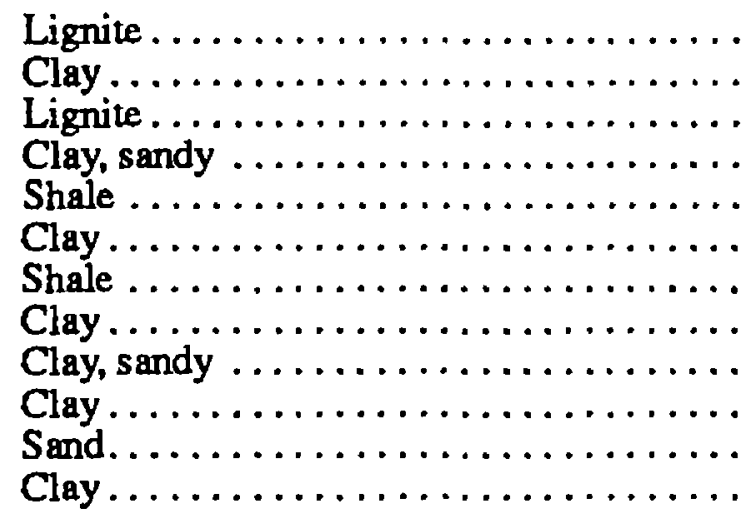 & $\begin{array}{r}4 \\
215 \\
5 \\
183 \\
30 \\
60 \\
15 \\
120 \\
30 \\
10 \\
8 \\
2\end{array}$ & $\begin{array}{r}422 \\
637 \\
642 \\
825 \\
855 \\
915 \\
930 \\
1,050 \\
1,080 \\
1,090 \\
1,098 \\
1,100\end{array}$ \\
\hline
\end{tabular}

147-093-33DAC

(Log modified from Mann-Stumvoll Driliing)

Altitude: 1,960 feet

Date drilled: $05-19-89$

\begin{tabular}{|c|c|c|c|c|c|}
\hline Meterfal & $\begin{array}{l}\text { Thlck- } \\
\text { ness } \\
\text { (feet) }\end{array}$ & $\begin{array}{l}\text { Depth } \\
\text { (feet) }\end{array}$ & Material & $\begin{array}{l}\text { Thlch- } \\
\text { ness } \\
\text { ffeet }\end{array}$ & $\begin{array}{l}\text { Depth } \\
\text { (feet) }\end{array}$ \\
\hline 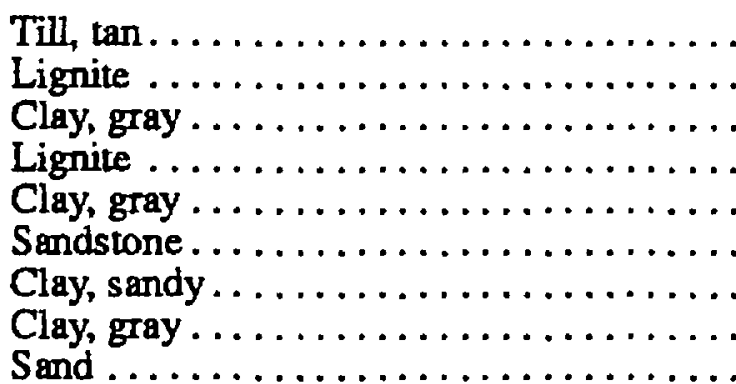 & $\begin{array}{r}61 \\
7 \\
178 \\
3 \\
27 \\
1 \\
63 \\
70 \\
\end{array}$ & $\begin{array}{r}61 \\
68 \\
246 \\
249 \\
276 \\
277 \\
340 \\
410 \\
460\end{array}$ & 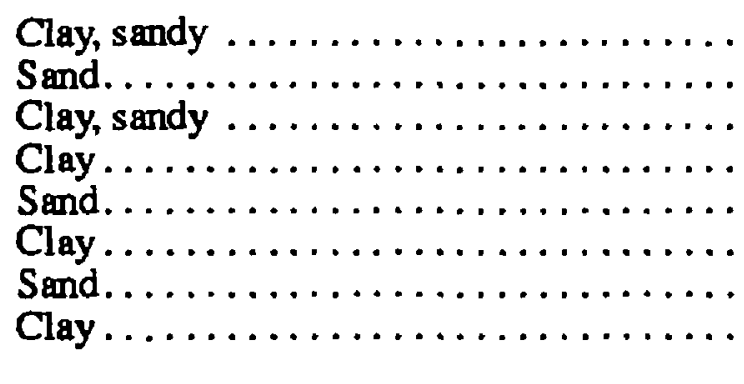 & $\begin{array}{r}20 \\
100 \\
80 \\
400 \\
15 \\
265 \\
50 \\
10\end{array}$ & $\begin{array}{r}480 \\
580 \\
660 \\
1,060 \\
1,075 \\
1,340 \\
1,390 \\
1,400\end{array}$ \\
\hline
\end{tabular}

147-093-34DBB

(Log modifled from Mann-Stumvoll Drilling)

Altitude: 1,860 fe日t

Date drilled: $\quad 06-20-89$

\begin{tabular}{|c|c|c|c|c|c|}
\hline Material & $\begin{array}{l}\text { Thlek- } \\
\text { nesa } \\
\text { (feet) }\end{array}$ & $\begin{array}{l}\text { Depth } \\
\text { (feot) }\end{array}$ & Materlal & $\begin{array}{l}\text { Thlct - } \\
\text { nese } \\
\text { ffeet' }\end{array}$ & $\begin{array}{l}\text { Depth } \\
\text { (feet) }\end{array}$ \\
\hline 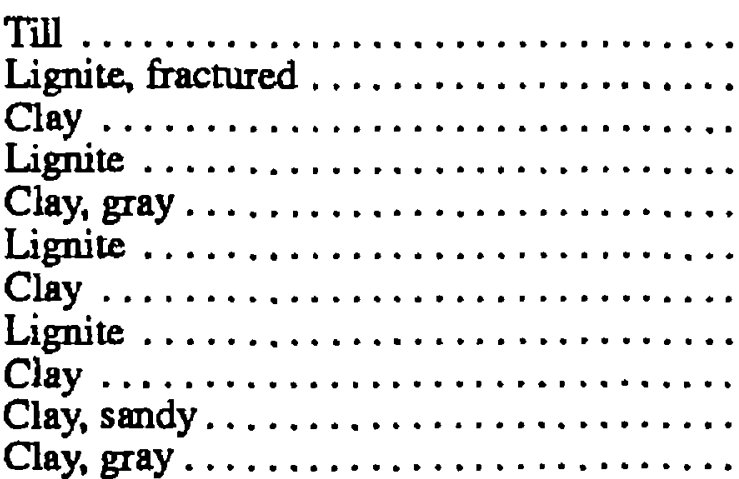 & $\begin{array}{r}28 \\
2 \\
5 \\
3 \\
117 \\
6 \\
2 \\
2 \\
15 \\
72 \\
43\end{array}$ & $\begin{array}{r}28 \\
30 \\
35 \\
38 \\
155 \\
161 \\
163 \\
165 \\
180 \\
252 \\
295\end{array}$ & 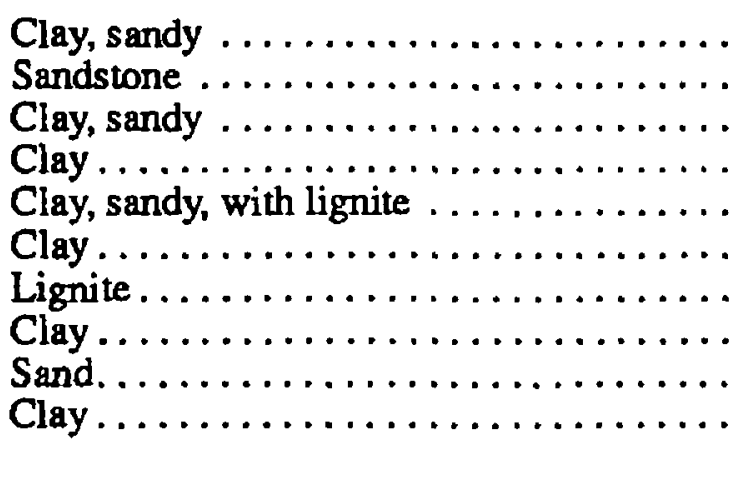 & $\begin{array}{r}13 \\
5 \\
35 \\
132 \\
240 \\
245 \\
13 \\
212 \\
60 \\
50\end{array}$ & $\begin{array}{r}308 \\
313 \\
348 \\
480 \\
720 \\
965 \\
978 \\
1,190 \\
1,250 \\
1,300\end{array}$ \\
\hline
\end{tabular}


Table 3. Drillers' logs of wells and test holes--Continued

147-093-35CBC2

(Log modified from Gregory Drilling, Inc.)

Date drllled: 08-27-85

\begin{tabular}{|c|c|c|c|c|c|}
\hline Materlal & $\begin{array}{l}\text { Thlok- } \\
\text { nese } \\
\text { (feat) }\end{array}$ & $\begin{array}{l}\text { Depth } \\
\text { (feot) }\end{array}$ & Materlal & $\begin{array}{l}\text { Thlck- } \\
\text { neses } \\
\text { (feet) }\end{array}$ & $\begin{array}{l}\text { Denth } \\
\text { (fent) }\end{array}$ \\
\hline 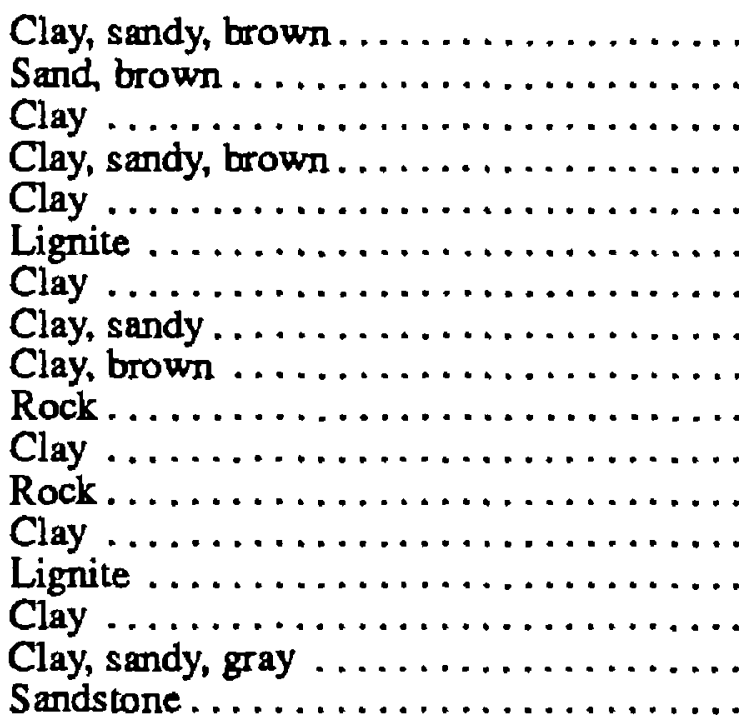 & 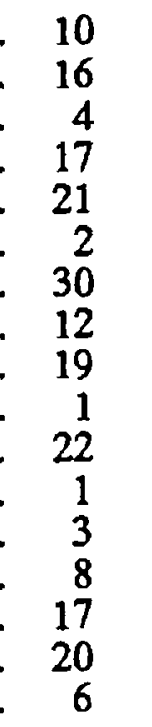 & $\begin{array}{r}10 \\
26 \\
30 \\
47 \\
68 \\
70 \\
100 \\
112 \\
131 \\
132 \\
154 \\
155 \\
158 \\
166 \\
183 \\
203 \\
209\end{array}$ & 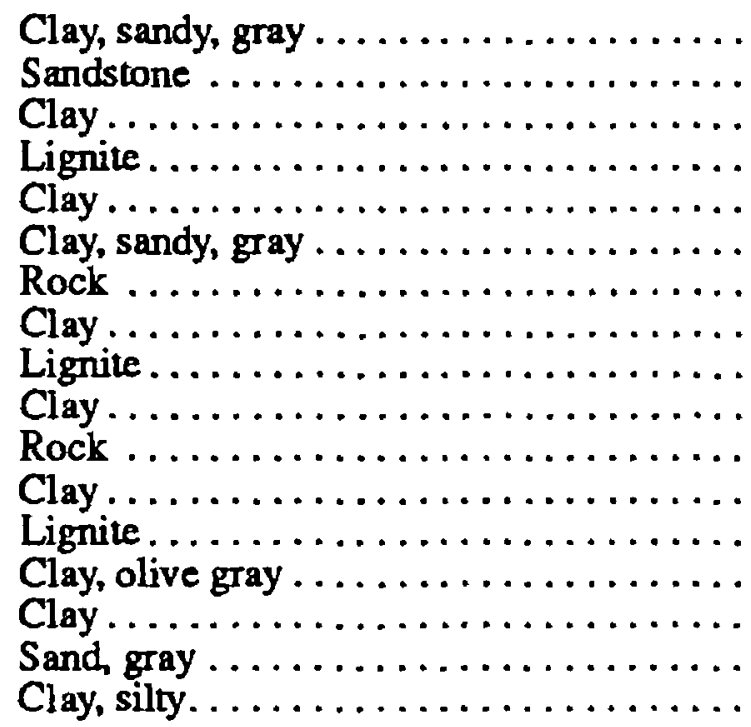 & $\begin{array}{r}41 \\
2 \\
32 \\
5 \\
26 \\
7 \\
1 \\
47 \\
5 \\
60 \\
1 \\
33 \\
4 \\
23 \\
37 \\
17 \\
10\end{array}$ & $\begin{array}{l}2 \div 7 \\
2 \div 2 \\
2 ? 7 \\
2 ? 9 \\
315 \\
322 \\
323 \\
370 \\
375 \\
435 \\
436 \\
469 \\
473 \\
496 \\
533 \\
5: 9 \\
560\end{array}$ \\
\hline
\end{tabular}

147-093-35CBC3

(Log modified from Himebaugh Drilling)

Alttude: 1,860 feet

Date drilled: $10-14-89$

\begin{tabular}{|c|c|c|c|c|c|}
\hline Material & $\begin{array}{l}\text { Thick- } \\
\text { nees } \\
\text { (feet) }\end{array}$ & $\begin{array}{l}\text { Depth } \\
\text { (feat) }\end{array}$ & Matorlal & $\begin{array}{l}\text { Thlck- } \\
\text { nese } \\
\text { (feet) }\end{array}$ & $\begin{array}{l}\text { Denth } \\
\text { (fent) }\end{array}$ \\
\hline 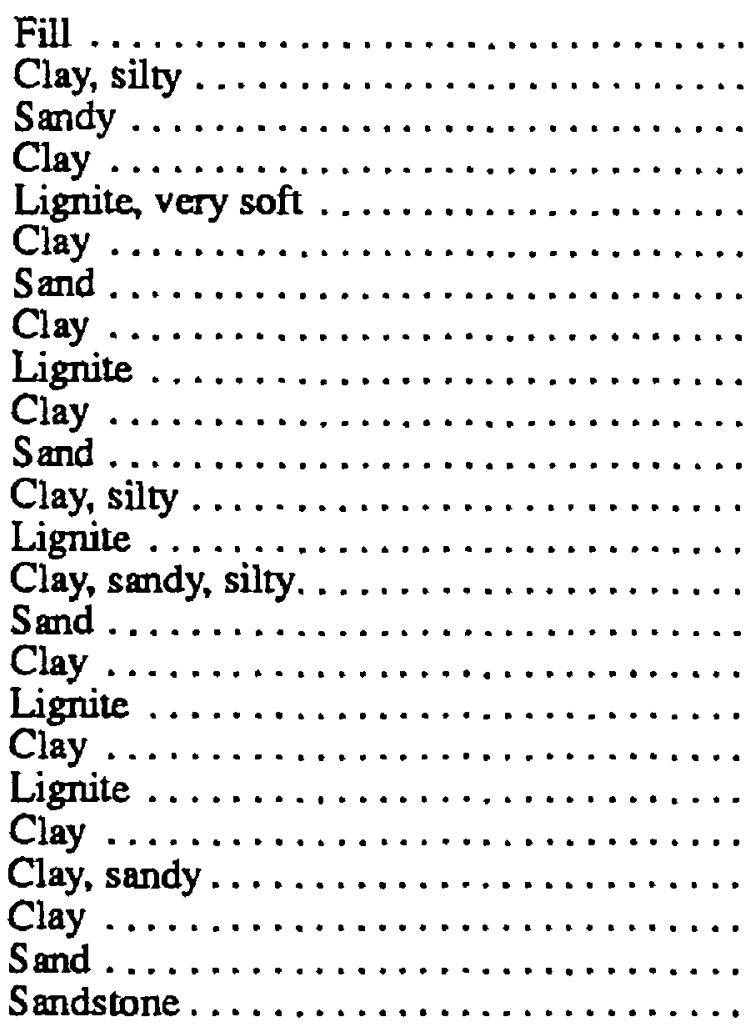 & $\begin{array}{r}2 \\
10 \\
6 \\
44 \\
5 \\
9 \\
33 \\
48 \\
9 \\
16 \\
71 \\
31 \\
3 \\
116 \\
31 \\
22 \\
21 \\
126 \\
4 \\
50 \\
48 \\
144 \\
11 \\
2\end{array}$ & $\begin{array}{r}2 \\
12 \\
18 \\
62 \\
67 \\
76 \\
109 \\
157 \\
166 \\
182 \\
253 \\
284 \\
287 \\
403 \\
434 \\
456 \\
477 \\
603 \\
607 \\
657 \\
705 \\
849 \\
860 \\
862\end{array}$ & 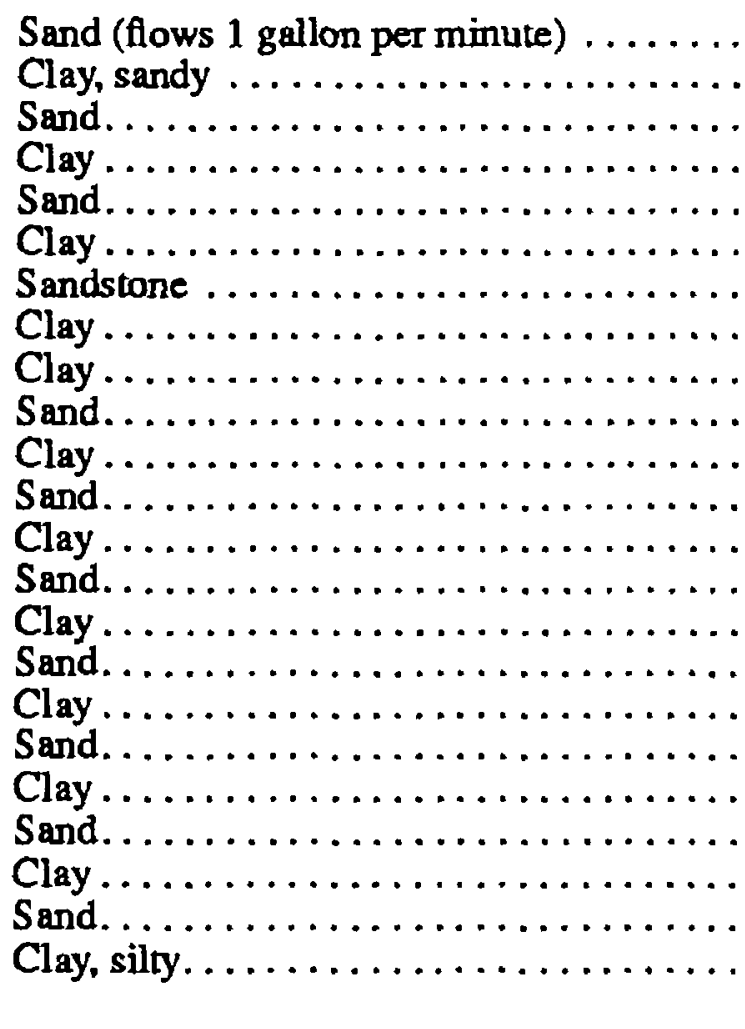 & $\begin{array}{r}3 \\
35 \\
7 \\
25 \\
28 \\
77 \\
1 \\
33 \\
15 \\
9 \\
64 \\
46 \\
27 \\
7 \\
24 \\
49 \\
4 \\
35 \\
10 \\
17 \\
3 \\
9 \\
35\end{array}$ & $\begin{array}{r}865 \\
900 \\
907 \\
932 \\
560 \\
1,037 \\
1,938 \\
1,071 \\
1,(866 \\
1,(995 \\
1,159 \\
1,205 \\
1,232 \\
1,239 \\
1,263 \\
1,312 \\
1,316 \\
1,351 \\
1,361 \\
1,378 \\
1,381 \\
1,390 \\
1,425\end{array}$ \\
\hline
\end{tabular}


Table 3. Driliers' logs of wells and test holes--Continued

147-094-35CAA

(Log modifled trom Raiph Wold Well Drilling)

Date drilled: $10-09-74$

\begin{tabular}{|c|c|c|c|c|c|}
\hline Material & $\begin{array}{l}\text { Thlek- } \\
\text { neas } \\
\text { (feat) }\end{array}$ & $\begin{array}{l}\text { Dopth } \\
\text { (feet) }\end{array}$ & Materlal & $\begin{array}{l}\text { Thlcte } \\
\text { near } \\
\text { (feet) }\end{array}$ & $\begin{array}{l}\text { Depth } \\
\text { (feet) }\end{array}$ \\
\hline 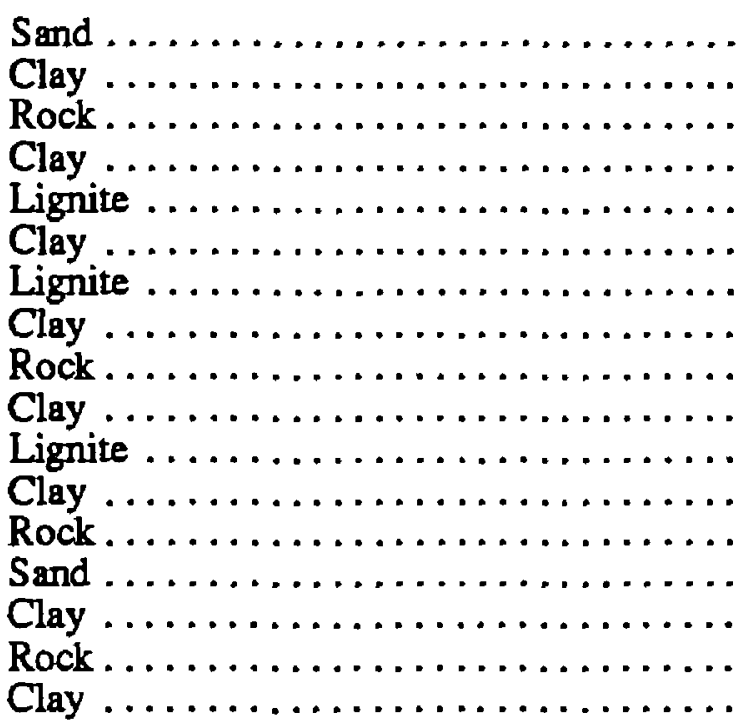 & $\begin{array}{r}15 \\
45 \\
1 \\
159 \\
5 \\
45 \\
10 \\
63 \\
2 \\
65 \\
5 \\
40 \\
5 \\
35 \\
185 \\
5 \\
220\end{array}$ & $\begin{array}{r}15 \\
60 \\
61 \\
220 \\
225 \\
270 \\
280 \\
343 \\
345 \\
410 \\
415 \\
455 \\
460 \\
495 \\
680 \\
685 \\
905\end{array}$ & 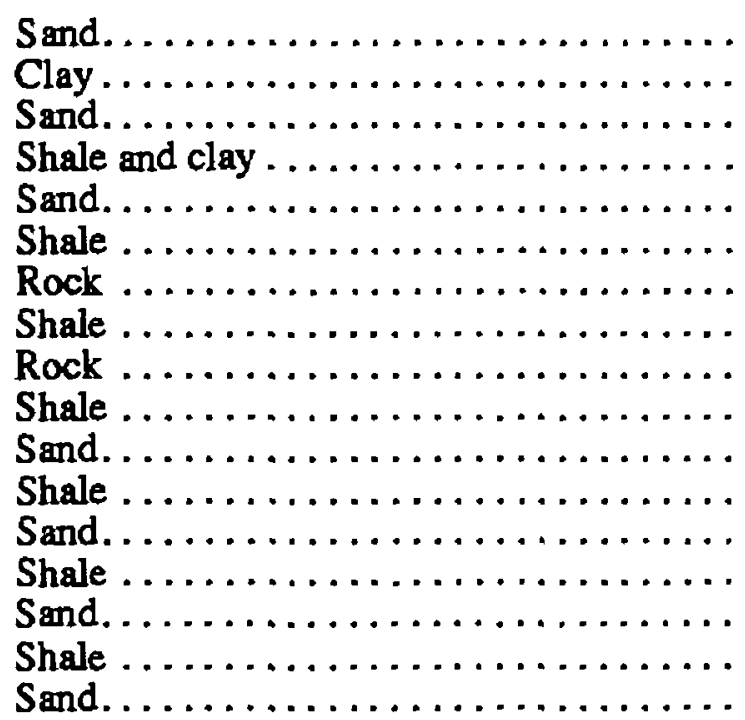 & $\begin{array}{r}10 \\
20 \\
20 \\
150 \\
15 \\
80 \\
2 \\
68 \\
6 \\
114 \\
20 \\
20 \\
5 \\
60 \\
10 \\
35 \\
70\end{array}$ & $\begin{array}{r}915 \\
935 \\
955 \\
1,105 \\
1,120 \\
1,200 \\
1,202 \\
1,270 \\
1,276 \\
1,390 \\
1,410 \\
1,430 \\
1,435 \\
1,495 \\
1,505 \\
1,540 \\
1,610\end{array}$ \\
\hline
\end{tabular}

147-094-35CBB

(Log moditled trom Mann-Stumvoll Drilling)

Altitude: 2,150 feet

\begin{tabular}{|c|c|c|c|c|c|}
\hline \multicolumn{3}{|l|}{ Altitude: 2,150 feet } & \multicolumn{3}{|c|}{ Date drilled: } \\
\hline Material & $\begin{array}{l}\text { Thick- } \\
\text { ness } \\
\text { (feet) }\end{array}$ & $\begin{array}{l}\text { Depth } \\
\text { (feet) }\end{array}$ & Materlal & $\begin{array}{l}\text { Thloten } \\
\text { ness } \\
\text { (feet) }\end{array}$ & $\begin{array}{l}\text { Depth } \\
\text { (feet) }\end{array}$ \\
\hline 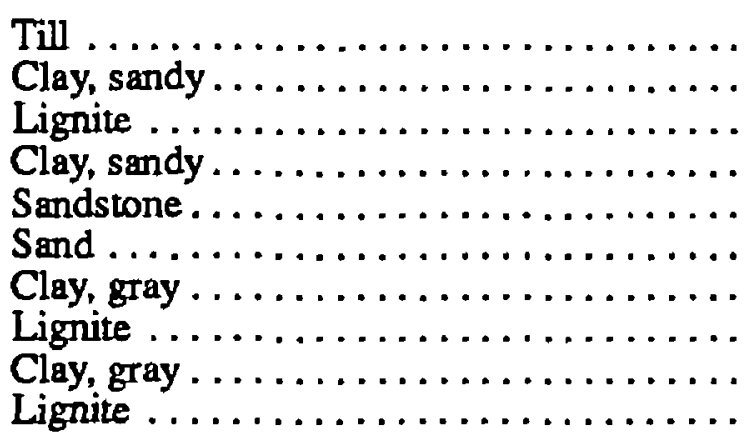 & $\begin{array}{r}20 \\
20 \\
3 \\
52 \\
4 \\
15 \\
6 \\
1 \\
112 \\
8\end{array}$ & $\begin{array}{r}20 \\
40 \\
43 \\
95 \\
99 \\
114 \\
120 \\
121 \\
233 \\
241\end{array}$ & 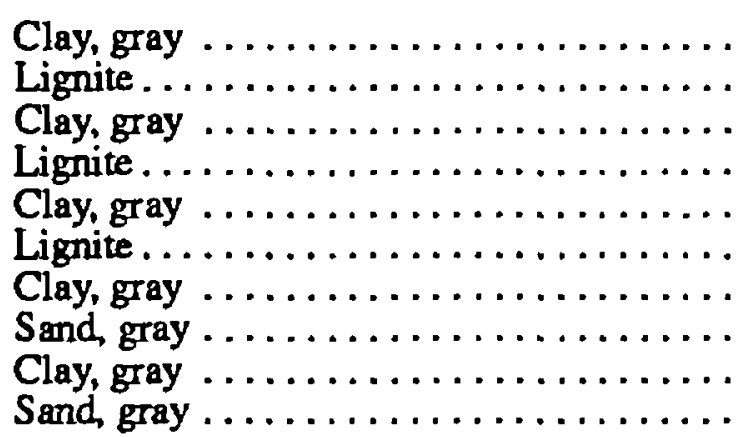 & $\begin{array}{r}137 \\
9 \\
64 \\
4 \\
163 \\
7 \\
225 \\
42 \\
603 \\
65\end{array}$ & $\begin{array}{r}378 \\
387 \\
451 \\
455 \\
618 \\
625 \\
850 \\
892 \\
1,495 \\
1,560\end{array}$ \\
\hline
\end{tabular}


Table 3. Drillers' logs of wells and test holes--Continued

147-094-36BAD

(Log modifled from Mann-Stumvoll Drilling)

Date drilled: $05 \cdot 27-89$

\begin{tabular}{|c|c|c|c|c|c|}
\hline Matorial & $\begin{array}{l}\text { Thlok- } \\
\text { ness } \\
\text { (feet) }\end{array}$ & $\begin{array}{l}\text { Depth } \\
\text { (feet) }\end{array}$ & Materlal & $\begin{array}{l}\text { Thlok- } \\
\text { ness } \\
\text { (foel) }\end{array}$ & $\begin{array}{l}\text { [nth } \\
\text { (feet) }\end{array}$ \\
\hline 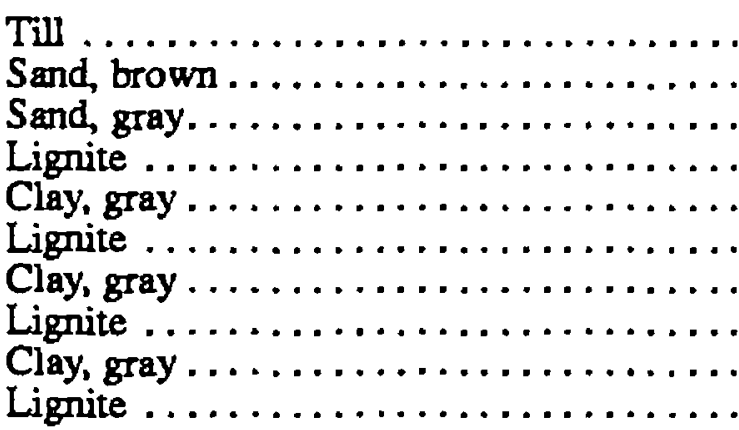 & $\begin{array}{r}28 \\
7 \\
15 \\
1 \\
62 \\
5 \\
51 \\
11 \\
128 \\
9\end{array}$ & $\begin{array}{r}28 \\
35 \\
50 \\
51 \\
113 \\
118 \\
169 \\
180 \\
308 \\
317\end{array}$ & 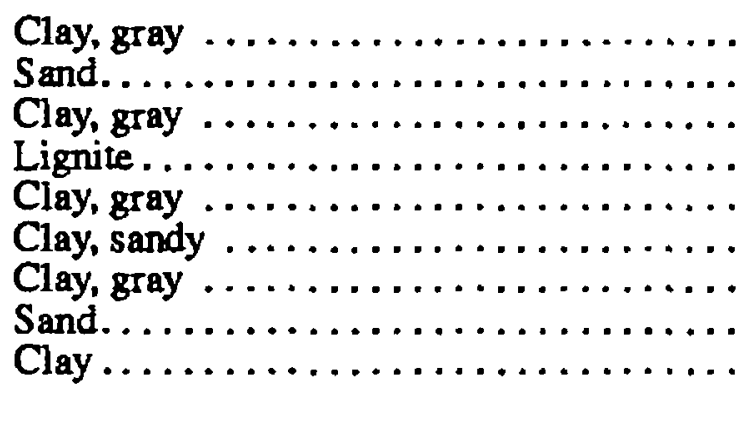 & $\begin{array}{r}145 \\
14 \\
156 \\
25 \\
53 \\
30 \\
650 \\
60 \\
10\end{array}$ & $\begin{array}{r}462 \\
476 \\
632 \\
657 \\
710 \\
740 \\
1,390 \\
1,450 \\
1,460\end{array}$ \\
\hline
\end{tabular}

147-095-13Ccc3

(Log modified from LTP Enterprises, inc.)

Aititude: 2,420 feet

Date drilled: $05 \cdot 22-79$

\begin{tabular}{|c|c|c|c|c|c|}
\hline Material & $\begin{array}{l}\text { Thlok- } \\
\text { ness } \\
\text { (foot) }\end{array}$ & $\begin{array}{l}\text { Deplh } \\
\text { (foet) }\end{array}$ & Material & $\begin{array}{l}\text { Thlok- } \\
\text { neas } \\
\text { (feet) }\end{array}$ & $\begin{array}{l}\text { Dopth } \\
\text { ('pel) }\end{array}$ \\
\hline 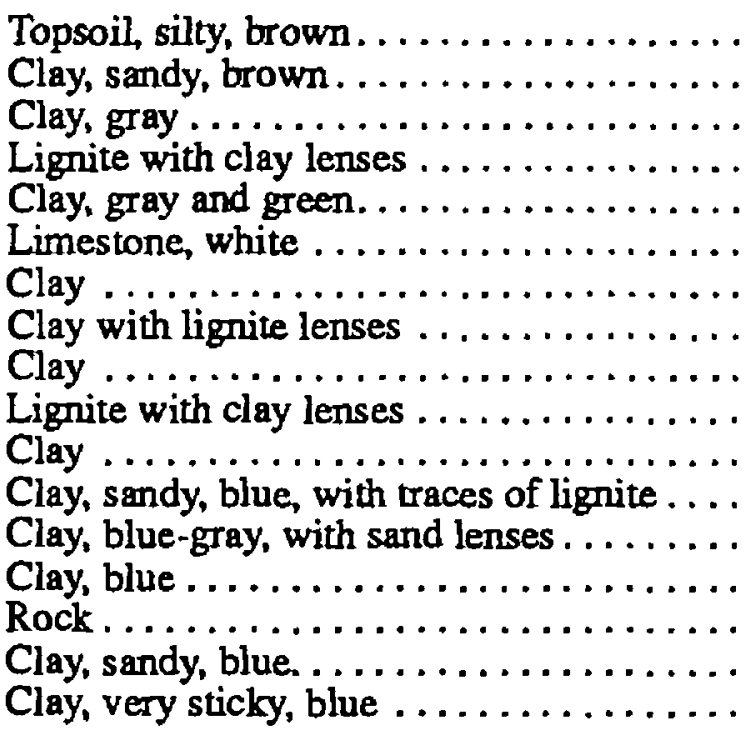 & $\begin{array}{r}2 \\
24 \\
29 \\
5 \\
53 \\
1 \\
91 \\
57 \\
288 \\
21 \\
430 \\
128 \\
10 \\
144 \\
4 \\
7 \\
8\end{array}$ & $\begin{array}{r}2 \\
26 \\
55 \\
60 \\
113 \\
114 \\
205 \\
262 \\
550 \\
571 \\
1,001 \\
1,129 \\
1,139 \\
1,283 \\
1,287 \\
1,294 \\
1,302\end{array}$ & 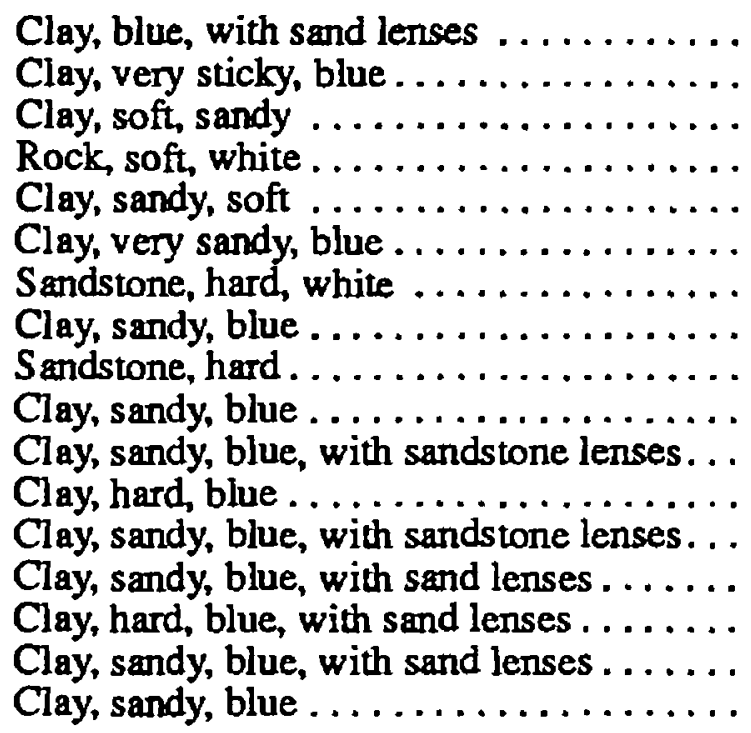 & $\begin{array}{r}102 \\
10 \\
25 \\
2 \\
209 \\
69 \\
4 \\
145 \\
4 \\
32 \\
15 \\
21 \\
84 \\
15 \\
45 \\
36 \\
10\end{array}$ & $\begin{array}{l}1.404 \\
1.414 \\
1.439 \\
1.441 \\
1.650 \\
1.719 \\
1.723 \\
1.868 \\
1.872 \\
1.904 \\
1.919 \\
1.940 \\
2.024 \\
2.039 \\
2,084 \\
2,120 \\
2.130\end{array}$ \\
\hline
\end{tabular}


Table 3. Drillers' logs of wells and test holes--Continued

147-095-18DDA

(Log modified from Ralph Wold Woll Driling)

Altitude: 2,560 feet

Date drille d: $12-28-74$

\begin{tabular}{|c|c|c|c|c|c|}
\hline Material & $\begin{array}{l}\text { Thloke } \\
\text { noss } \\
\text { (foet) }\end{array}$ & $\begin{array}{l}\text { Depth } \\
\text { (feet) }\end{array}$ & Materlal & $\begin{array}{l}\text { Thlat. } \\
\text { neat } \\
\text { (foet! }\end{array}$ & $\begin{array}{l}\text { Depth } \\
\text { (feet) }\end{array}$ \\
\hline 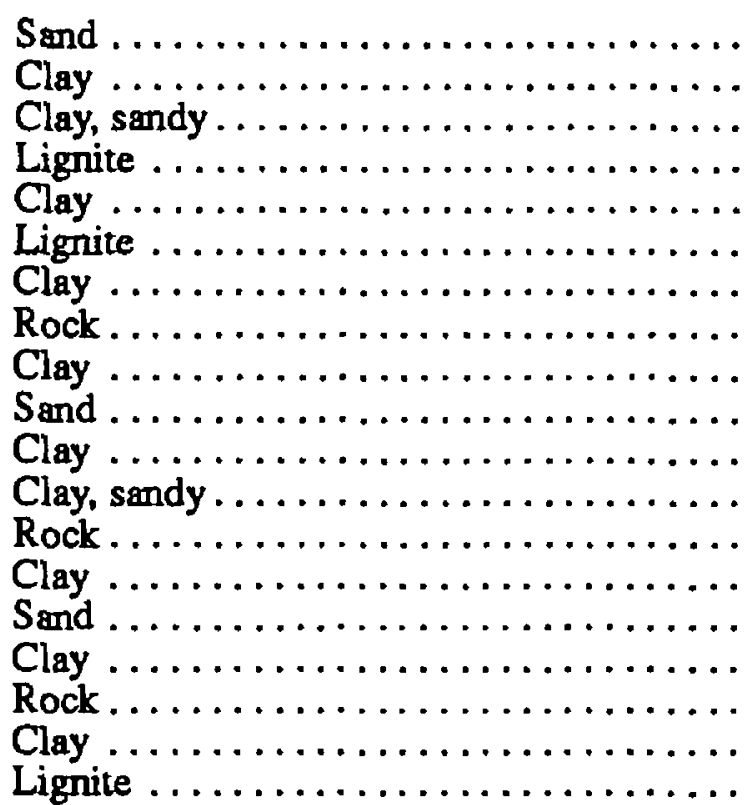 & 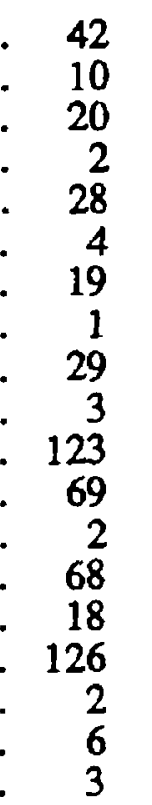 & $\begin{array}{r}42 \\
52 \\
72 \\
74 \\
102 \\
106 \\
125 \\
126 \\
155 \\
158 \\
281 \\
350 \\
352 \\
420 \\
438 \\
564 \\
566 \\
572 \\
575\end{array}$ & 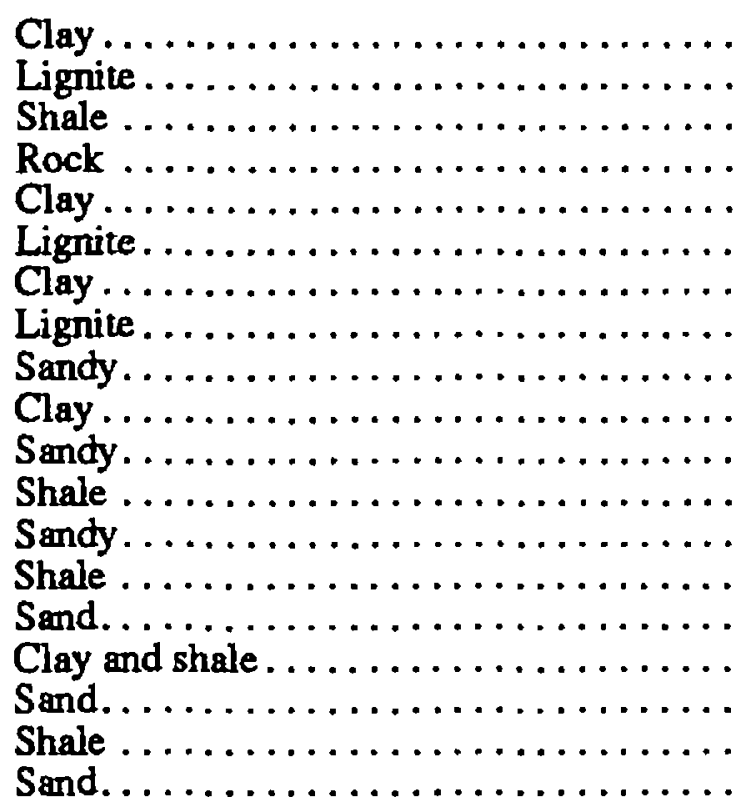 & $\begin{array}{r}98 \\
6 \\
66 \\
5 \\
190 \\
25 \\
121 \\
17 \\
92 \\
45 \\
30 \\
130 \\
30 \\
167 \\
33 \\
305 \\
25 \\
20 \\
72\end{array}$ & $\begin{array}{r}673 \\
679 \\
745 \\
750 \\
940 \\
965 \\
1,086 \\
1,103 \\
1,195 \\
1,240 \\
1,270 \\
1,400 \\
1,430 \\
1,597 \\
1,630 \\
1,935 \\
1,960 \\
1,980 \\
2,052\end{array}$ \\
\hline
\end{tabular}

147-095-22BBB

(Log modified from Gregory Drilling, Inc.)

Altitude: 2,430 feet

Date drille f: $11-18-78$

\begin{tabular}{|c|c|c|c|c|c|}
\hline Material & $\begin{array}{l}\text { Thick- } \\
\text { ness } \\
\text { (feot) }\end{array}$ & $\begin{array}{l}\text { Depth } \\
\text { (feet) }\end{array}$ & Materlal & $\begin{array}{l}\text { Thick- } \\
\text { nese } \\
\text { (foet) }\end{array}$ & $\begin{array}{l}\text { Depth } \\
\text { (feet) }\end{array}$ \\
\hline 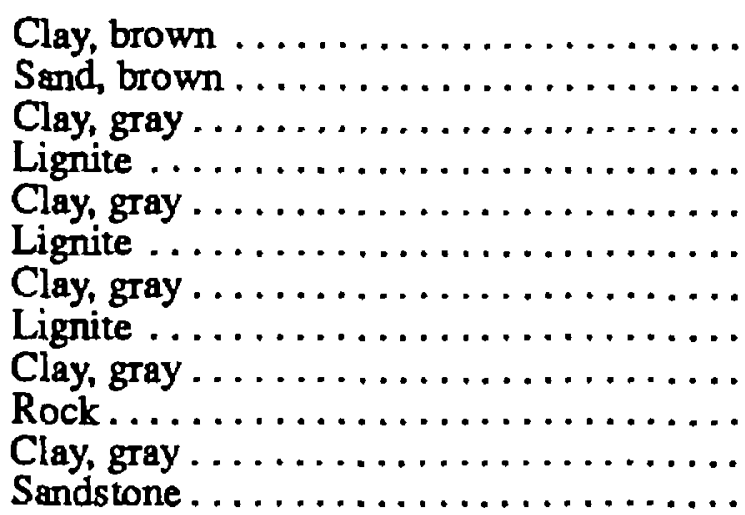 & $\begin{array}{r}15 \\
50 \\
75 \\
4 \\
116 \\
4 \\
46 \\
2 \\
107 \\
3 \\
246 \\
3\end{array}$ & $\begin{array}{r}15 \\
65 \\
140 \\
144 \\
260 \\
264 \\
310 \\
312 \\
419 \\
422 \\
668 \\
671\end{array}$ & 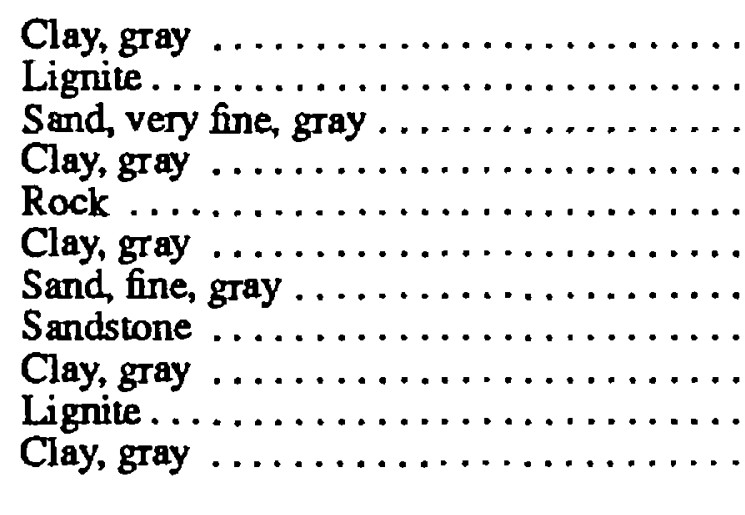 & $\begin{array}{r}74 \\
6 \\
8 \\
26 \\
5 \\
135 \\
40 \\
2 \\
18 \\
6 \\
9\end{array}$ & $\begin{array}{r}745 \\
751 \\
759 \\
785 \\
790 \\
925 \\
965 \\
967 \\
985 \\
991 \\
1,000\end{array}$ \\
\hline
\end{tabular}


Table 3. Drillers' logs of wells and test holes-Continued

148-087-02CDC

(Log modifled from Mann Driiling Co.)

Altitude: 2,000 feet

Date drilled: $10-21-80$

\begin{tabular}{|c|c|c|c|c|c|}
\hline Material & $\begin{array}{l}\text { Thick- } \\
\text { ness } \\
\text { (feet) }\end{array}$ & $\begin{array}{l}\text { Depth } \\
\text { (feot) }\end{array}$ & Material & $\begin{array}{l}\text { Thick- } \\
\text { ness } \\
\text { (feet) }\end{array}$ & $\begin{array}{l}D \cdot n \text {th } \\
\text { (foet) }\end{array}$ \\
\hline $\begin{array}{l}\text { Till, silty, tan. . . . . . . . } \\
\text { Till, gray........... }\end{array}$ & $\begin{array}{r}73 \\
105\end{array}$ & $\begin{array}{r}73 \\
178\end{array}$ & $\begin{array}{l}\text { Sand } \ldots \ldots \ldots \ldots \ldots \ldots \ldots \ldots \ldots \ldots \ldots \ldots \ldots \ldots \ldots \ldots \ldots \\
\text { Gravel } \ldots \ldots \ldots \ldots \ldots \ldots \ldots \ldots \ldots\end{array}$ & $\begin{array}{l}8 \\
9\end{array}$ & $\begin{array}{l}186 \\
195\end{array}$ \\
\hline
\end{tabular}

148-087-03DDD

(Log modifled from Mann Driliing Co.)

Aititude: 1,990 feet

Date drilied: $09-13-83$

\begin{tabular}{|c|c|c|c|c|c|}
\hline Material & $\begin{array}{l}\text { Thlok- } \\
\text { ness } \\
\text { (feet) }\end{array}$ & $\begin{array}{l}\text { Depth } \\
\text { (feot) }\end{array}$ & Materlal & $\begin{array}{l}\text { Thick- } \\
\text { neas } \\
\text { (feet) }\end{array}$ & $\begin{array}{l}\text { Dinth } \\
\text { (feet) }\end{array}$ \\
\hline $\begin{array}{l}\text { Till, } \tan \ldots \ldots \ldots \ldots \ldots \ldots \ldots \ldots \ldots \ldots \ldots \ldots \ldots \ldots \ldots \ldots \ldots \ldots \\
\text { Till, gray } \ldots \ldots \ldots \ldots \ldots \ldots \ldots \ldots\end{array}$ & $\begin{array}{r}43 \\
121\end{array}$ & $\begin{array}{r}43 \\
164\end{array}$ & $\begin{array}{l}\text { Sand, silty . . . . . . . . . . . . . . . . . . . . . . . . . . . } \\
\text { Gravel . }\end{array}$ & $\begin{array}{l}31 \\
25\end{array}$ & $\begin{array}{l}195 \\
220\end{array}$ \\
\hline
\end{tabular}

148-087-06DCB

(Log modified from Broneske Weil Drilling)

Altitude: 1,965 feet

Date drilied: $06-24-85$

\begin{tabular}{|c|c|c|c|c|c|}
\hline Materlal & $\begin{array}{l}\text { Thick- } \\
\text { ness } \\
\text { (feet) }\end{array}$ & $\begin{array}{l}\text { Depth } \\
\text { (feet) }\end{array}$ & Matortal & $\begin{array}{l}\text { Thick- } \\
\text { ness } \\
\text { (feet) }\end{array}$ & $\begin{array}{l}\text { Dinth } \\
\text { (inet) }\end{array}$ \\
\hline $\begin{array}{l}\text { Topsoil } \ldots \ldots \ldots \ldots \\
\text { Clay and silt . . . . . . . }\end{array}$ & $\begin{array}{r}2 \\
34\end{array}$ & $\begin{array}{r}2 \\
36\end{array}$ & 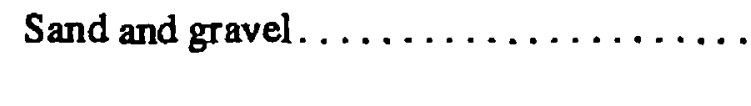 & 6 & 42 \\
\hline
\end{tabular}

148-087-08BCC

(Log modifled from Mann Drilling Co.)

Altitude: 1,965 feet

Date drilled: 05-?1-82

\begin{tabular}{|c|c|c|c|c|c|}
\hline Material & $\begin{array}{l}\text { Thlck- } \\
\text { ness } \\
\text { (feet) }\end{array}$ & $\begin{array}{l}\text { Depth } \\
\text { (feet) }\end{array}$ & Material & $\begin{array}{l}\text { Thick- } \\
\text { ness } \\
\text { (feet) }\end{array}$ & $\begin{array}{l}\text { Dinth } \\
(f \circ a t)\end{array}$ \\
\hline $\begin{array}{l}\text { Till, } \tan \ldots \ldots \ldots \ldots \ldots \\
\text { Till, gray . . . . . . . }\end{array}$ & $\begin{array}{r}44 \\
126\end{array}$ & $\begin{array}{r}44 \\
170\end{array}$ & $\begin{array}{l}\text { Sand, fine } \ldots \ldots \ldots \ldots \ldots \ldots \ldots \ldots \ldots \ldots \ldots \ldots \ldots \ldots \ldots \\
\text { Gravel } \ldots \ldots \ldots \ldots \ldots \ldots \ldots \ldots\end{array}$ & $\begin{array}{l}20 \\
30\end{array}$ & $\begin{array}{l}190 \\
220\end{array}$ \\
\hline
\end{tabular}


Table 3. Drillers' logs of wells and test holes--Continued

148-087-14BAA

(Log modffled from Mann Drilling Co.)

Altudude: 1,975 feet

Date drilled: 04-27-76

\begin{tabular}{|c|c|c|c|c|c|}
\hline Material & $\begin{array}{l}\text { Thick- } \\
\text { nese } \\
\text { (foet) }\end{array}$ & $\begin{array}{l}\text { Depth } \\
\text { (feet) }\end{array}$ & Materlel & $\begin{array}{l}\text { Thlck- } \\
\text { ness } \\
\text { (feot) }\end{array}$ & $\begin{array}{l}\text { Depth } \\
\text { (foet) }\end{array}$ \\
\hline $\begin{array}{l}\text { Till, } \tan \ldots \ldots \ldots \ldots \ldots \ldots \ldots \ldots \ldots \ldots \ldots \ldots \ldots \ldots \ldots \ldots \ldots \ldots \ldots \ldots \ldots \ldots \\
\text { Till } \ldots \ldots \ldots \ldots \ldots \ldots \ldots \ldots \ldots \ldots\end{array}$ & $\begin{array}{r}42 \\
30 \\
6\end{array}$ & $\begin{array}{l}42 \\
72 \\
78\end{array}$ & $\begin{array}{l}\text { Till } \ldots \ldots \ldots \ldots \ldots \ldots \ldots \ldots \ldots \ldots \ldots \ldots \ldots \ldots \\
\text { Gravel, coarse } \ldots \ldots \ldots \ldots \ldots \ldots \ldots \ldots \ldots \\
\text { Sand and medium gravel. } \ldots \ldots \ldots \ldots \ldots \ldots\end{array}$ & $\begin{array}{r}158 \\
14 \\
60\end{array}$ & $\begin{array}{l}236 \\
250 \\
310\end{array}$ \\
\hline
\end{tabular}

148-087-14BAB

(Log modifled from Mann Drilling Co.)

Altitude: 1,965 feet

Date drilled: $\quad 07-28-76$

\begin{tabular}{|c|c|c|c|c|c|}
\hline Msterlal & $\begin{array}{l}\text { Thick- } \\
\text { noss } \\
\text { (feet) }\end{array}$ & $\begin{array}{l}\text { Depth } \\
\text { (feet) }\end{array}$ & Msterisl & $\begin{array}{l}\text { Thlck- } \\
\text { ness } \\
\text { (feot) }\end{array}$ & $\begin{array}{l}\text { Depth } \\
\text { (feot) }\end{array}$ \\
\hline $\begin{array}{l}\text { Till, } \tan \ldots \ldots \ldots \ldots \ldots \ldots \ldots \ldots \ldots \ldots \ldots \ldots \ldots \\
\text { Till, gray } \ldots \ldots \ldots \ldots \ldots \ldots \ldots \ldots \ldots \ldots \ldots \\
\text { Sand } \ldots \ldots \ldots \ldots \ldots \ldots \ldots \ldots \ldots\end{array}$ & $\begin{array}{r}40 \\
160 \\
70\end{array}$ & $\begin{array}{r}40 \\
200 \\
270\end{array}$ & $\begin{array}{l}\text { Gravel, cogrse } \ldots \ldots \ldots \ldots \ldots \ldots \ldots \ldots \ldots \ldots \\
\text { Gravel with lignite chips . . . . . . . . . }\end{array}$ & $\begin{array}{l}35 \\
35\end{array}$ & $\begin{array}{l}305 \\
340\end{array}$ \\
\hline
\end{tabular}

148-087-14DAA

(Log modifled from Mann Drilling Co.)

Altitude: 1,950 feet

Date drilled: 07-02-75

\begin{tabular}{|c|c|c|c|c|c|}
\hline Materlal & $\begin{array}{l}\text { Thlck- } \\
\text { ness } \\
\text { (foet) }\end{array}$ & $\begin{array}{l}\text { Depth } \\
\text { (feet) }\end{array}$ & Materlal & $\begin{array}{l}\text { Thick- } \\
\text { ness } \\
\text { (foet) }\end{array}$ & $\begin{array}{l}\text { Depth } \\
\text { (feet) }\end{array}$ \\
\hline $\begin{array}{l}\text { Till } \ldots \ldots \ldots \ldots \ldots \ldots \ldots \ldots \ldots \ldots \ldots \ldots \ldots \ldots \ldots \\
\text { Gravel, coarse. } \ldots \ldots \ldots \ldots \ldots \ldots \ldots \ldots \ldots \ldots\end{array}$ & $\begin{array}{r}155 \\
35\end{array}$ & $\begin{array}{l}155 \\
190\end{array}$ & $\begin{array}{l}\text { Sand with lignite chips } \ldots \ldots \ldots \ldots \ldots \ldots \ldots \\
\text { Gravel } \ldots \ldots \ldots \ldots \ldots \ldots \ldots \ldots \ldots\end{array}$ & $\begin{array}{l}10 \\
10\end{array}$ & $\begin{array}{l}200 \\
210\end{array}$ \\
\hline
\end{tabular}

148-087-15AAA

(Log modifled from Traut Well Drilling)

Alttude: 1,960 feet

Date drilled: $02-26-82$

\begin{tabular}{|c|c|c|c|c|c|}
\hline Materlal & $\begin{array}{l}\text { Thick- } \\
\text { ness } \\
\text { (feet) }\end{array}$ & $\begin{array}{l}\text { Depth } \\
\text { (feet) }\end{array}$ & Materlel & $\begin{array}{l}\text { Thlok- } \\
\text { ness } \\
\text { (feot) }\end{array}$ & $\begin{array}{l}\text { Depth } \\
\text { (feot) }\end{array}$ \\
\hline 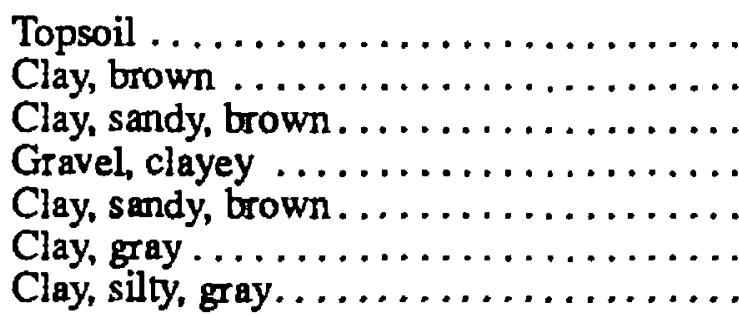 & $\begin{array}{r}1 \\
42 \\
7 \\
4 \\
13 \\
49 \\
52\end{array}$ & $\begin{array}{r}1 \\
43 \\
50 \\
54 \\
67 \\
116 \\
168\end{array}$ & 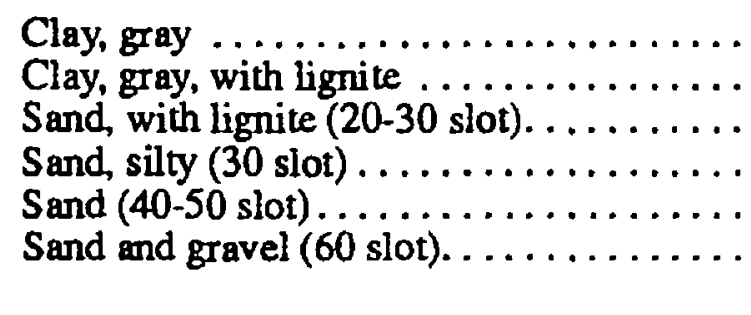 & $\begin{array}{l}29 \\
21 \\
20 \\
13 \\
14 \\
15\end{array}$ & $\begin{array}{l}197 \\
218 \\
238 \\
251 \\
265 \\
280\end{array}$ \\
\hline
\end{tabular}


Table 3. Drillers' logs of wells and test holes--Continued

148-087-15DCD

(Log modifled from Mann Drilling Co.)

Altitude: 1,910 feet

Date drilled: $09-09-82$

\begin{tabular}{|c|c|c|c|c|c|}
\hline Material & $\begin{array}{c}\text { Thlok- } \\
\text { nees } \\
\text { (feet) }\end{array}$ & $\begin{array}{l}\text { Depth } \\
\text { (feet) }\end{array}$ & Material & $\begin{array}{l}\text { Thick- } \\
\text { nese } \\
\text { (feet) }\end{array}$ & $\begin{array}{l}\text { Dapth } \\
\text { (fivt) }\end{array}$ \\
\hline 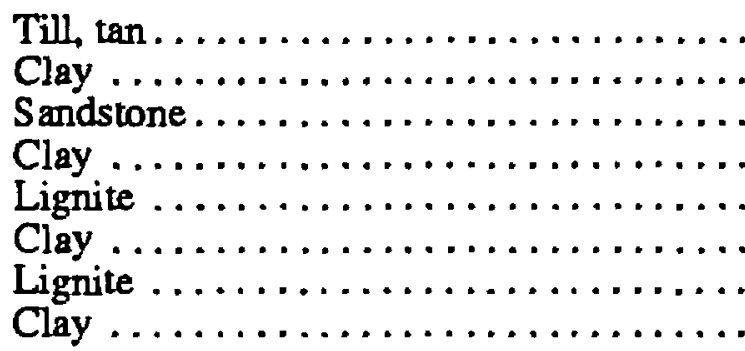 & $\begin{array}{r}24 \\
13 \\
3 \\
43 \\
\text {. } \quad 3 \\
96 \\
11 \\
\text {. } \\
155\end{array}$ & $\begin{array}{r}24 \\
37 \\
40 \\
83 \\
86 \\
182 \\
193 \\
348\end{array}$ & 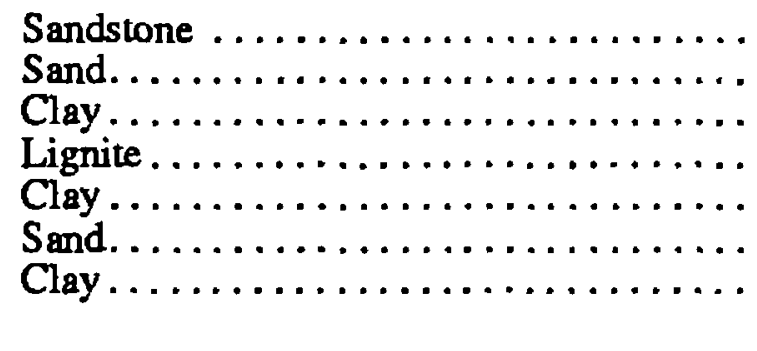 & $\begin{array}{r}5 \\
44 \\
543 \\
10 \\
167 \\
35 \\
8\end{array}$ & $\begin{array}{r}353 \\
397 \\
940 \\
950 \\
1,117 \\
1,152 \\
1,160\end{array}$ \\
\hline
\end{tabular}

148-087-33BBB

(Log modifled from Mann Driling Co.)

Altitude: 2,005 feet

Date drilled: $\quad 08-21-86$

\begin{tabular}{|c|c|c|c|c|c|}
\hline Material & $\begin{array}{l}\text { Thlek- } \\
\text { nese } \\
\text { (feet) }\end{array}$ & $\begin{array}{l}\text { Depth } \\
\text { (feet) }\end{array}$ & Material & $\begin{array}{l}\text { Thlak- } \\
\text { ness } \\
\text { (feet) }\end{array}$ & $\begin{array}{l}\text { Denth } \\
\text { (fnet) }\end{array}$ \\
\hline 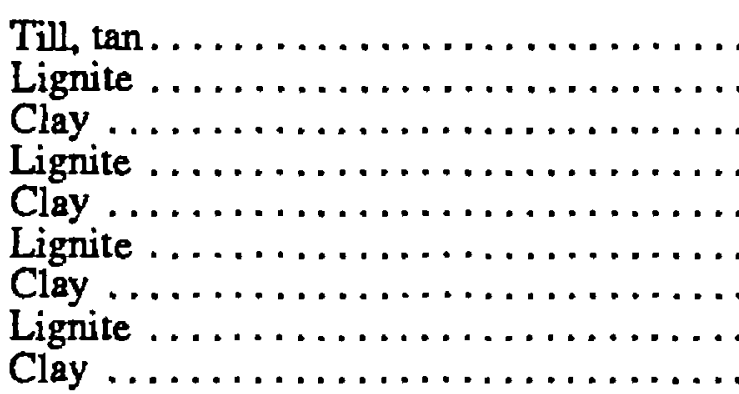 & $\begin{array}{r}20 \\
4 \\
\text {. } \\
38 \\
3 \\
\text {. } \\
75 \\
7 \\
23 \\
2 \\
\text {. } \\
\text {. }\end{array}$ & $\begin{array}{r}20 \\
24 \\
62 \\
65 \\
100 \\
107 \\
130 \\
132 \\
241\end{array}$ & 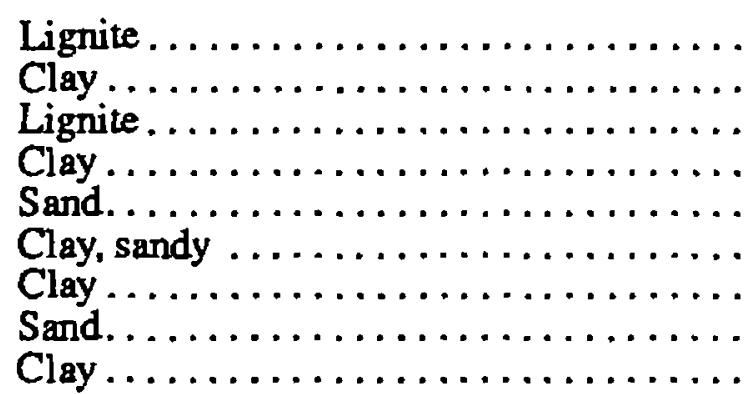 & $\begin{array}{r}3 \\
56 \\
14 \\
386 \\
10 \\
10 \\
553 \\
43 \\
4\end{array}$ & $\begin{array}{r}244 \\
300 \\
314 \\
700 \\
710 \\
720 \\
1,273 \\
1,316 \\
1,320\end{array}$ \\
\hline
\end{tabular}

148-088-18AAA

(Log modifled from Mann Driling Co.)

Altitude: 2,100 foet

Date drilled: $07-50-77$

Material


Table 3. Drillers' logs of wells and test holes--Continued

148-088-21DBC2

(Log modifled from Mann Drilling Co.)

Altitude: 2,155 feet

Date drilied: $12-18-87$

\begin{tabular}{|c|c|c|c|c|c|}
\hline Material & $\begin{array}{l}\text { Thlek- } \\
\text { ness } \\
\text { (feet) }\end{array}$ & $\begin{array}{l}\text { Depth } \\
\text { (feet) }\end{array}$ & Material & $\begin{array}{c}\text { Thlek. } \\
\text { nest } \\
\text { (fee') }\end{array}$ & $\begin{array}{l}\text { Depth } \\
\text { (feet) }\end{array}$ \\
\hline 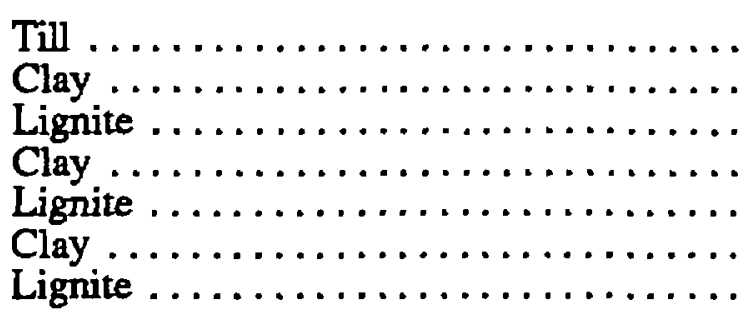 & $\begin{array}{r}18 \\
27 \\
8 \\
160 \\
6 \\
1 \\
12\end{array}$ & $\begin{array}{r}18 \\
45 \\
53 \\
213 \\
219 \\
220 \\
232\end{array}$ & 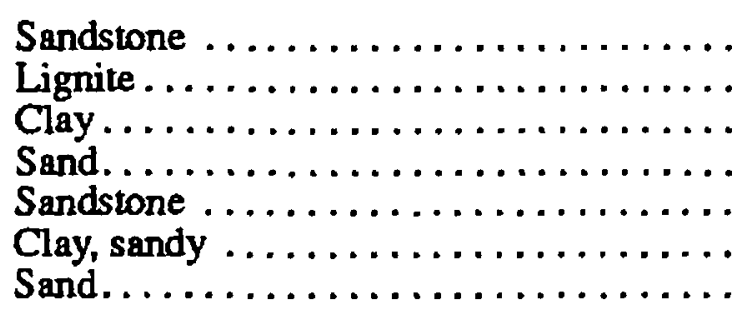 & $\begin{array}{r}4 \\
6 \\
14 \\
6 \\
6 \\
22 \\
10\end{array}$ & $\begin{array}{l}236 \\
242 \\
256 \\
262 \\
268 \\
290 \\
300\end{array}$ \\
\hline
\end{tabular}

148-088-21DBD

(Log modified from Mann Drilling Co.)

Aititude: 2,160 feet

Date drillet: $07-10-80$

\begin{tabular}{|c|c|c|c|c|c|}
\hline Material & $\begin{array}{l}\text { Thlck- } \\
\text { nees } \\
\text { (feet) }\end{array}$ & $\begin{array}{l}\text { Depth } \\
\text { (feet) }\end{array}$ & Materlal & $\begin{array}{l}\text { Thlok. } \\
\text { nees } \\
\text { (foe') }\end{array}$ & $\begin{array}{l}\text { Depth } \\
\text { (feet) }\end{array}$ \\
\hline $\begin{array}{l}\text { Clay, sandy, } \tan . \ldots \ldots \ldots \ldots \ldots \ldots \ldots \ldots \\
\text { Clay } \ldots \ldots \ldots \ldots \ldots \ldots \ldots \\
\text { Lignite } \ldots \ldots \ldots \ldots \ldots \ldots \ldots \ldots \ldots \ldots\end{array}$ & $\begin{array}{l}27 \\
21 \\
10\end{array}$ & $\begin{array}{l}27 \\
48 \\
58\end{array}$ & 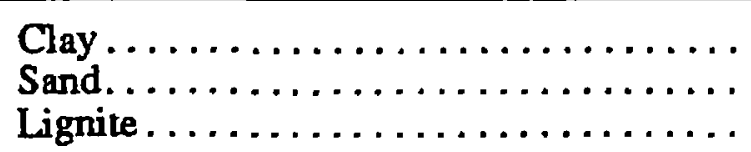 & $\begin{array}{r}162 . \\
5 \\
7\end{array}$ & $\begin{array}{l}220 \\
225 \\
232\end{array}$ \\
\hline
\end{tabular}

148-089-09AAB

(Log Modifled from Water Supply, inc.)

Altitude: 2,117 feet

Date drilied: $\quad 06-01-92$

\begin{tabular}{|c|c|c|c|c|c|}
\hline Materlal & $\begin{array}{l}\text { Thick- } \\
\text { ness } \\
\text { (feet) }\end{array}$ & $\begin{array}{l}\text { Depth } \\
\text { (feet) }\end{array}$ & Materlal & $\begin{array}{l}\text { Thlok- } \\
\text { nee? } \\
\text { (foe") }\end{array}$ & $\begin{array}{l}\text { Depth } \\
\text { (foet) }\end{array}$ \\
\hline 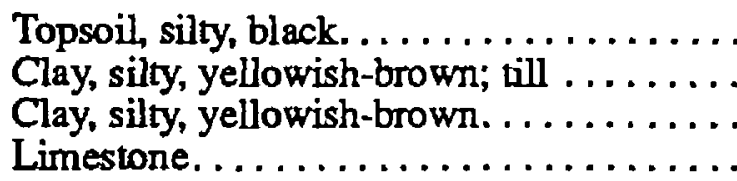 & $\begin{array}{r}1 \\
13 \\
3 \\
1\end{array}$ & $\begin{array}{r}1 \\
14 \\
17 \\
18\end{array}$ & $\begin{array}{l}\text { Clay, silty, yellowish; till. . . . . . . . . . . } \\
\text { Sand, silty, medium-gray. . . . . . . . . . } \\
\text { Clay, silty, yellowish-brown; bedrock. . . } \\
\text { Clay, silty, medium-gray . . . . . . . . }\end{array}$ & $\begin{array}{r}22 \\
5 \\
7 \\
8\end{array}$ & $\begin{array}{l}40 \\
45 \\
52 \\
60\end{array}$ \\
\hline
\end{tabular}


Table 3. Drillers' logs of wells and test holes--Continued

148-089-10BBB

(Log modified from Water Supply, Inc.)

\begin{tabular}{|c|c|c|c|c|c|}
\hline Material & $\begin{array}{l}\text { Thlck- } \\
\text { ness } \\
\text { (foet) }\end{array}$ & $\begin{array}{l}\text { Depth } \\
\text { (feel) }\end{array}$ & Materlal & $\begin{array}{l}\text { Thick- } \\
\text { ness } \\
\text { (foet) }\end{array}$ & $\begin{array}{l}\text { Dinth } \\
\text { (f }>\text { t) }\end{array}$ \\
\hline 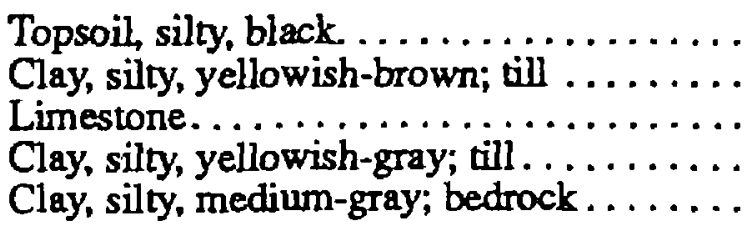 & $\begin{array}{r}1 \\
8 \\
1 \\
14 \\
10\end{array}$ & $\begin{array}{r}1 \\
9 \\
10 \\
24 \\
34\end{array}$ & 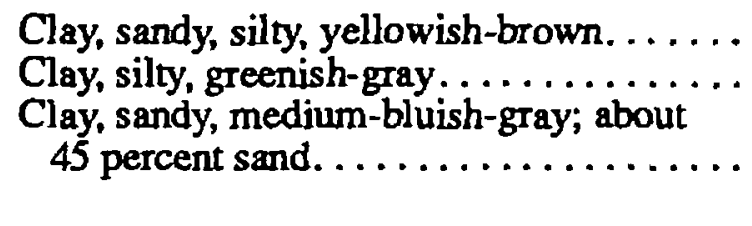 & $\begin{array}{r}14 \\
6 \\
6\end{array}$ & $\begin{array}{l}48 \\
54 \\
60\end{array}$ \\
\hline
\end{tabular}

148-089-27DCC

(Log modified from Aberle Well Co.)

Alttude: 1,955 feet

\begin{tabular}{|c|c|c|c|c|c|}
\hline Matorial & $\begin{array}{l}\text { Thick- } \\
\text { ness } \\
\text { (foet) }\end{array}$ & $\begin{array}{l}\text { Depth } \\
\text { (feet) }\end{array}$ & Materlal & $\begin{array}{l}\text { Thick- } \\
\text { ness } \\
\text { (feet) }\end{array}$ & $\begin{array}{l}\text { Depth } \\
(f-9 t)\end{array}$ \\
\hline $\begin{array}{l}\text { Sand, fine, yellow } \ldots \ldots \ldots \ldots \ldots \ldots \ldots \ldots \ldots \\
\text { Till, yellow } \ldots \ldots \ldots \ldots \ldots \ldots \ldots \ldots \ldots \ldots \\
\text { Clay, gray } \ldots \ldots \ldots \ldots \ldots \ldots \ldots\end{array}$ & $\begin{array}{r}2 \\
\cdot \quad 40 \\
14\end{array}$ & $\begin{array}{r}2 \\
42 \\
56\end{array}$ & 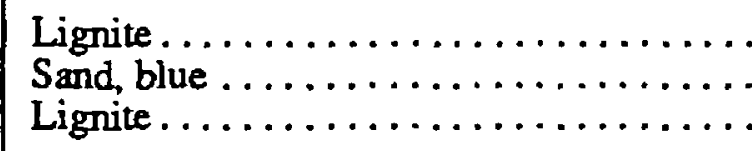 & $\begin{array}{r}3 \\
13 \\
8\end{array}$ & $\begin{array}{l}59 \\
72 \\
80\end{array}$ \\
\hline
\end{tabular}

148-089-33CCA

(Log modifled from Mann Drilling Co.)

Alttude: 1,940 feet

\begin{tabular}{|c|c|c|c|c|c|}
\hline Materiai & $\begin{array}{l}\text { Thick- } \\
\text { ness } \\
\text { (feet) }\end{array}$ & $\begin{array}{l}\text { Depth } \\
\text { (feet) }\end{array}$ & Material & $\begin{array}{l}\text { Thick- } \\
\text { ness } \\
\text { (feet) }\end{array}$ & $\begin{array}{l}\text { Depth } \\
\text { (fmet) }\end{array}$ \\
\hline 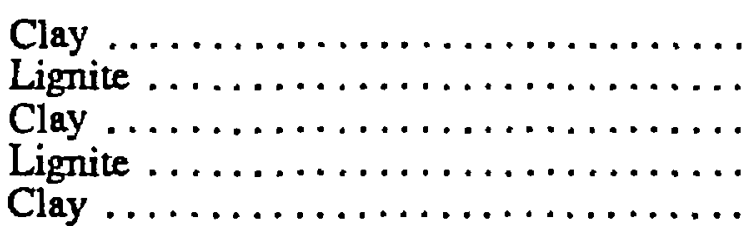 & $\begin{array}{r}7 \\
4 \\
21 \\
5 \\
463\end{array}$ & $\begin{array}{r}7 \\
11 \\
32 \\
37 \\
500\end{array}$ & 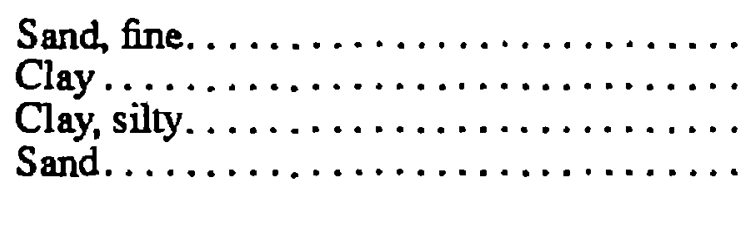 & $\begin{array}{r}27 \\
413 \\
375 \\
72\end{array}$ & $\begin{array}{r}527 \\
940 \\
1,315 \\
1,387\end{array}$ \\
\hline
\end{tabular}


Table 3. Drillers' logs of wells and test holes--Continued

\section{8-090-03ABB1 \\ (Log modifled from Mann Driling Co.)}

Altitude: 2,140 feet

Date drlllert: $06-27-77$

\begin{tabular}{|c|c|c|c|c|c|}
\hline Material & $\begin{array}{l}\text { Thlok- } \\
\text { ness } \\
\text { (foet) }\end{array}$ & $\begin{array}{l}\text { Depth } \\
\text { (feat) }\end{array}$ & Material & $\begin{array}{l}\text { Thlck. } \\
\text { neas } \\
\text { (teot) }\end{array}$ & $\begin{array}{l}\text { Depth } \\
\text { (feet) }\end{array}$ \\
\hline 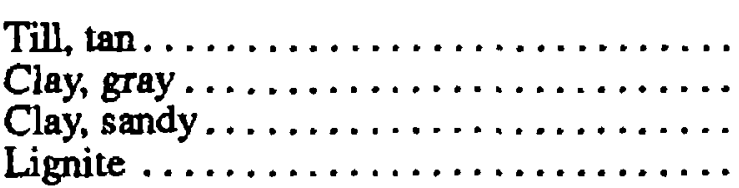 & $\begin{array}{r}30 \\
60 \\
30 \\
2\end{array}$ & $\begin{array}{l}30 \\
90 \\
120 \\
122\end{array}$ & 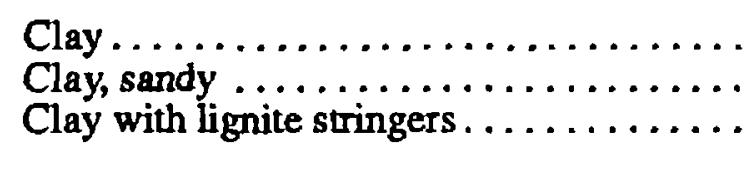 & $\begin{array}{r}53 \\
45 \\
380\end{array}$ & $\begin{array}{l}175 \\
220 \\
600\end{array}$ \\
\hline
\end{tabular}

148-090-07DCC

(Log modified from Water Suppiy, Inc.)

Altitude: 2,060 feet

Date drillet: $04-24-84$

\begin{tabular}{|c|c|c|c|c|c|}
\hline Material & $\begin{array}{l}\text { Thlok- } \\
\text { ness } \\
\text { (feet) }\end{array}$ & $\begin{array}{l}\text { Depth } \\
\text { (feet) }\end{array}$ & Materlal & $\begin{array}{c}\text { Thlak. } \\
\text { neas } \\
\text { (feot) }\end{array}$ & $\begin{array}{l}\text { Depth } \\
\text { (feet) }\end{array}$ \\
\hline 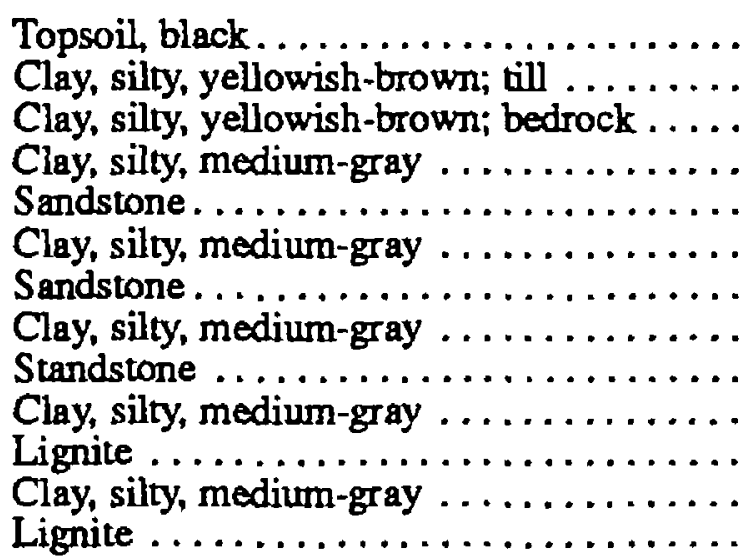 & $\begin{array}{r}1 \\
6 \\
10 \\
42 \\
1 \\
12 \\
1 \\
7 \\
3 \\
14 \\
2 \\
33 \\
2\end{array}$ & $\begin{array}{r}1 \\
7 \\
17 \\
59 \\
60 \\
72 \\
73 \\
80 \\
83 \\
97 \\
99 \\
132 \\
134\end{array}$ & 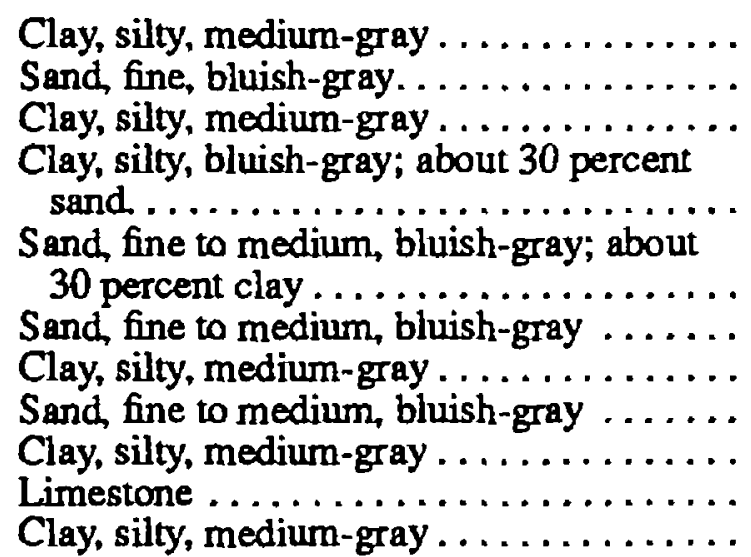 & $\begin{array}{r}18 \\
6 \\
24 \\
18 \\
80 \\
20 \\
17 \\
5 \\
3 \\
4 \\
1\end{array}$ & $\begin{array}{l}152 \\
158 \\
182 \\
200 \\
280 \\
300 \\
317 \\
322 \\
325 \\
329 \\
330\end{array}$ \\
\hline
\end{tabular}

148-090-07DCD

(Log modifled from Water Supply, Inc.)

Altitude: 2,030 feet

Date drilied: 04-05-84

\begin{tabular}{|c|c|c|c|c|c|}
\hline Materlal & $\begin{array}{l}\text { Thick- } \\
\text { ness } \\
\text { (feet) }\end{array}$ & $\begin{array}{l}\text { Depth } \\
\text { (feet) }\end{array}$ & Materlal & $\begin{array}{l}\text { Thlek- } \\
\text { ners } \\
\text { (feet) }\end{array}$ & $\begin{array}{l}\text { Depth } \\
\text { (feet) }\end{array}$ \\
\hline 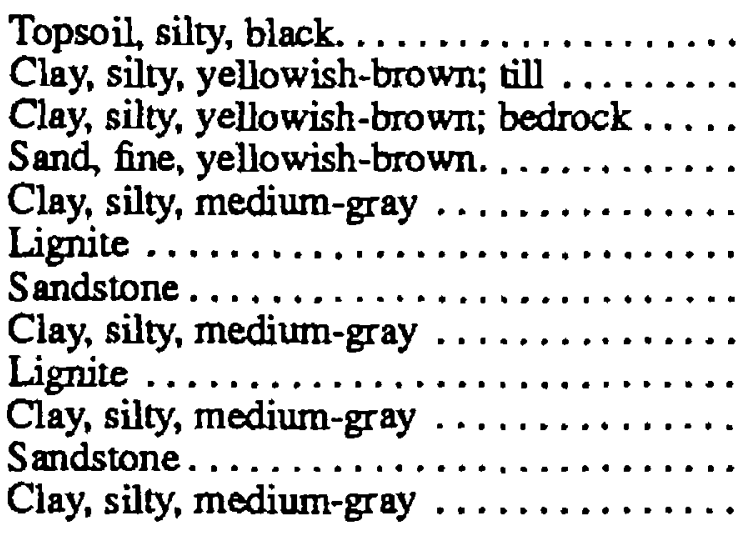 & $\begin{array}{r}1 \\
5 \\
17 \\
5 \\
33 \\
1 \\
1 \\
44 \\
2 \\
14 \\
12 \\
10\end{array}$ & $\begin{array}{r}1 \\
6 \\
23 \\
28 \\
61 \\
62 \\
63 \\
107 \\
109 \\
123 \\
135 \\
145\end{array}$ & 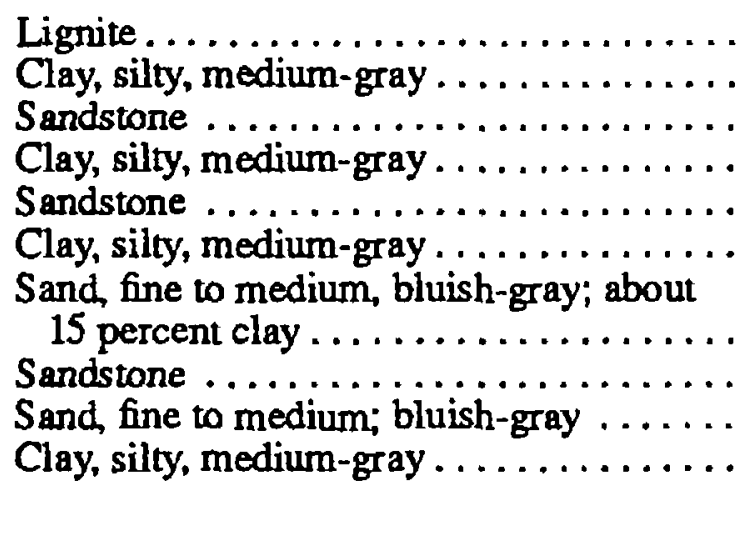 & $\begin{array}{c}1.5 \\
36.5 \\
2 \\
87 \\
3 \\
5 \\
\\
30 \\
1 \\
9 \\
2\end{array}$ & $\begin{array}{l}146.5 \\
183 \\
185 \\
272 \\
275 \\
280 \\
\\
310 \\
311 \\
320 \\
322\end{array}$ \\
\hline
\end{tabular}


Table 3. Drillers' logs of wells and test holes--Continued

148-090-16ABC

(Log modified from Woter Supply, Inc.)

\begin{tabular}{|c|c|c|c|c|c|}
\hline Materlal & $\begin{array}{l}\text { Thlck- } \\
\text { ness } \\
\text { (feel) }\end{array}$ & $\begin{array}{l}\text { Depth } \\
\text { (feet) }\end{array}$ & Material & $\begin{array}{l}\text { Thlck- } \\
\text { ness } \\
\text { (feet) }\end{array}$ & $\begin{array}{l}D \text {-nth } \\
\text { (ingt) }\end{array}$ \\
\hline 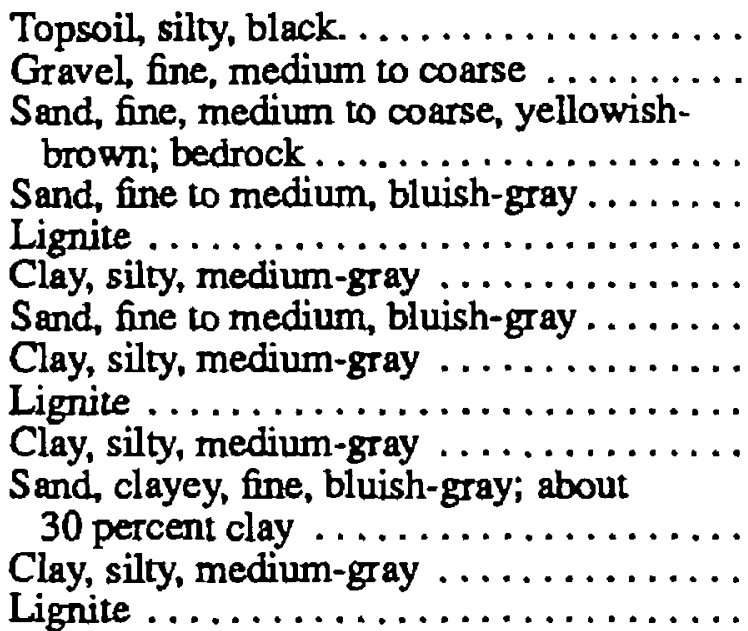 & $\begin{array}{r}36.5 \\
12 \\
6 \\
5 \\
1.5 \\
13 \\
34 \\
2 \\
34 \\
3 \\
2 \\
1\end{array}$ & $\begin{array}{l}37 \\
49 \\
55 \\
55.5 \\
57 \\
70 \\
104 \\
106 \\
140 \\
143 \\
145 \\
146\end{array}$ & 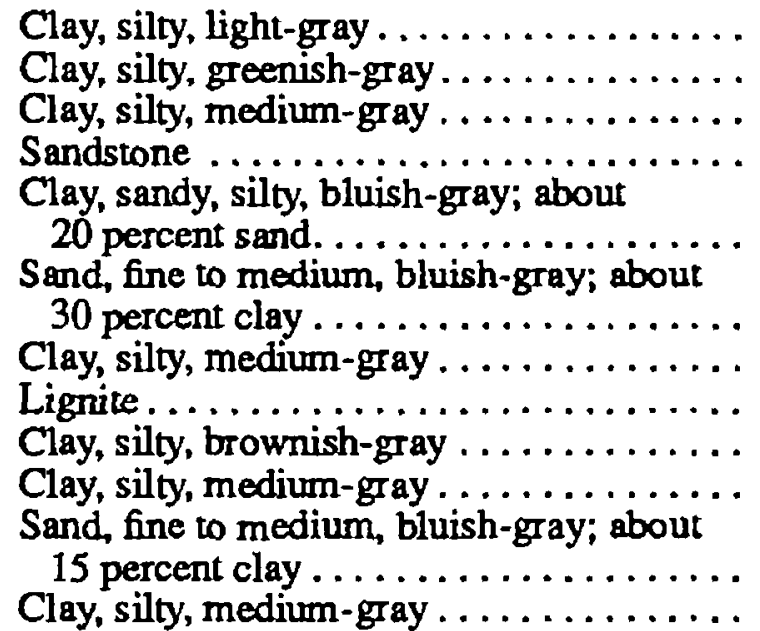 & $\begin{array}{r}3 \\
5 \\
23 \\
1 \\
3 \\
15 \\
9 \\
3 \\
9 \\
74 \\
61 \\
1\end{array}$ & $\begin{array}{l}149 \\
154 \\
177 \\
178 \\
181 \\
\\
196 \\
205 \\
208 \\
217 \\
291\end{array}$ \\
\hline
\end{tabular}

148-092-06AAD

(Log modifled from Sax Well Driliing)

Date drilled: $11-01-81$

\begin{tabular}{|c|c|c|c|c|c|}
\hline Materlal & $\begin{array}{l}\text { Thlek- } \\
\text { neess } \\
\text { (foet) }\end{array}$ & $\begin{array}{l}\text { Depth } \\
\text { (feet) }\end{array}$ & Material & $\begin{array}{c}\text { Thick- } \\
\text { nees } \\
\text { (feet) }\end{array}$ & $\begin{array}{l}\text { Dinth } \\
\text { (feet) }\end{array}$ \\
\hline 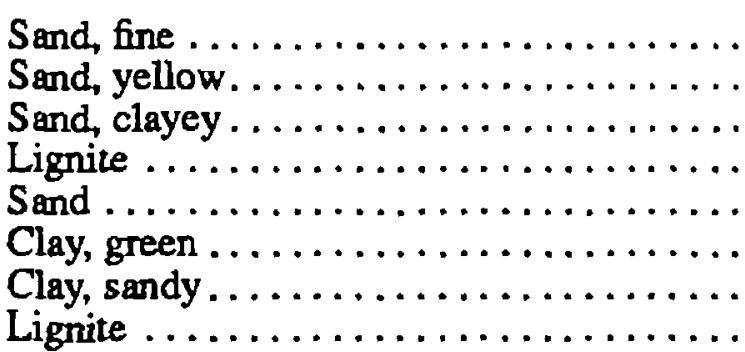 & $\begin{array}{r}30 \\
95 \\
7 \\
6 \\
1 \\
1 \\
1 \\
1\end{array}$ & $\begin{array}{r}30 \\
125 \\
132 \\
138 \\
139 \\
140 \\
141 \\
142\end{array}$ & 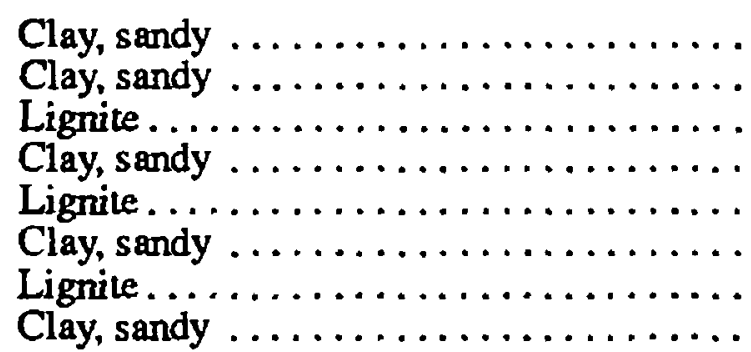 & $\begin{array}{r}18 \\
2 \\
1 \\
27 \\
2 \\
24 \\
3 \\
3\end{array}$ & $\begin{array}{l}160 \\
162 \\
163 \\
190 \\
192 \\
216 \\
219 \\
222\end{array}$ \\
\hline
\end{tabular}

148-092-24CCCA

(Log modifled from Smiley's Drilling)

Altitude: 1,900 feet

Date drilled: $08-13-83$

\begin{tabular}{|c|c|c|c|c|c|}
\hline Material & $\begin{array}{l}\text { Thlck- } \\
\text { ness } \\
\text { (feet) }\end{array}$ & $\begin{array}{l}\text { Depth } \\
\text { (feet) }\end{array}$ & Materlal & $\begin{array}{l}\text { Thick- } \\
\text { ness } \\
\text { (feet) }\end{array}$ & $\begin{array}{l}\text { Dinth } \\
\text { (fret) }\end{array}$ \\
\hline $\begin{array}{l}\text { Dirt, black. . . . . . . . } \\
\text { Clay, brown . . . . . . } \\
\text { Clay, blue .... }\end{array}$ & $\begin{array}{l}10 \\
20 \\
30\end{array}$ & $\begin{array}{l}10 \\
30 \\
60\end{array}$ & $\begin{array}{l}\text { Clay, sandy, blue } \ldots \ldots \ldots \ldots \ldots \ldots \ldots \ldots \ldots \ldots \ldots \ldots \\
\text { Shale } \ldots \ldots \ldots \ldots \ldots \ldots \ldots \ldots \ldots \\
\text { Sand, blue } \ldots \ldots \ldots \ldots \ldots \ldots \ldots\end{array}$ & $\begin{array}{r}20 \\
5 \\
57\end{array}$ & $\begin{array}{r}80 \\
85 \\
142\end{array}$ \\
\hline
\end{tabular}


Table 3. Drillers' logs of wells and test holes--Continued

148-092-24CCCB

(Log modified from Smliey's Drilling)

Altude: 1,890 feet

Date drilled: $08-05-83$

\begin{tabular}{ccc||ccc}
\hline Matertal & $\begin{array}{c}\text { Thick- } \\
\text { ness } \\
\text { (feet) }\end{array}$ & $\begin{array}{l}\text { Depth } \\
\text { (feet) }\end{array}$
\end{tabular}

148-095-02BBB

(Log modifled from Mohl Drilling, Inc.)

Altitude: 2,500 feet

Date drille t: 03-05-82

\begin{tabular}{|c|c|c|c|c|c|}
\hline Materlal & $\begin{array}{l}\text { Thick- } \\
\text { ness } \\
\text { (feet) }\end{array}$ & $\begin{array}{l}\text { Depth } \\
\text { (feet) }\end{array}$ & Material & $\begin{array}{l}\text { Thlck- } \\
\text { nes? } \\
\text { (fee") }\end{array}$ & $\begin{array}{l}\text { Depth } \\
\text { (feot) }\end{array}$ \\
\hline 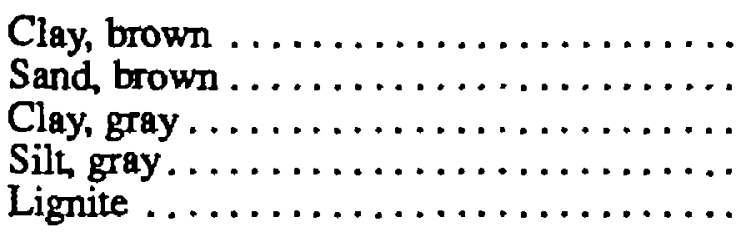 & $\begin{array}{r}35 \\
55 \\
30 \\
43 \\
2\end{array}$ & $\begin{array}{r}35 \\
90 \\
120 \\
163 \\
165\end{array}$ & 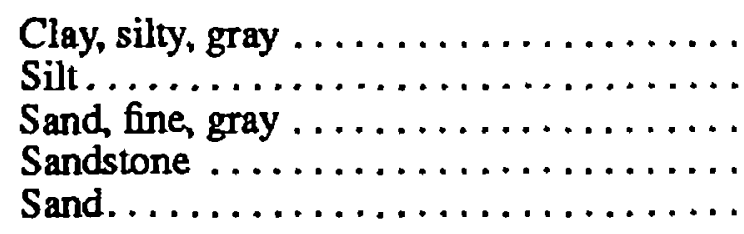 & $\begin{array}{r}35 \\
20 \\
5 \\
13 \\
22\end{array}$ & $\begin{array}{l}200 \\
220 \\
225 \\
238 \\
260\end{array}$ \\
\hline
\end{tabular}

148-095-03AAA

(Log modified from LTP Enterprises, Inc.)

Altitude: 2,510 feet

Date drilled: $12-10-85$

\begin{tabular}{|c|c|c|c|c|c|}
\hline Material & $\begin{array}{l}\text { Thick- } \\
\text { ness } \\
\text { (feot) }\end{array}$ & $\begin{array}{l}\text { Depth } \\
\text { (feet) }\end{array}$ & Meterial & $\begin{array}{l}\text { Thicl. } \\
\text { nes: } \\
\text { (foer) }\end{array}$ & $\begin{array}{l}\text { Depth } \\
\text { (feet) }\end{array}$ \\
\hline 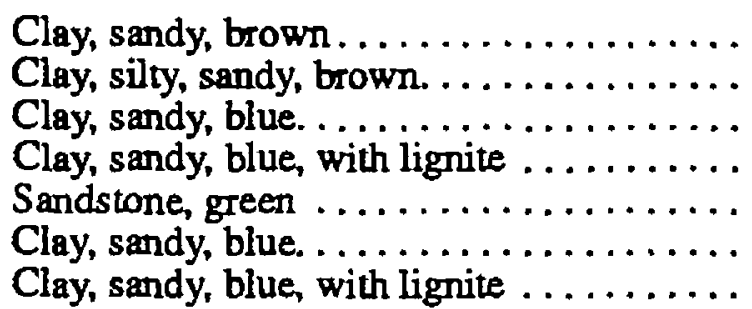 & $\begin{array}{r}18 \\
29 \\
17 \\
33 \\
5 \\
40 \\
5\end{array}$ & $\begin{array}{r}18 \\
47 \\
64 \\
97 \\
102 \\
142 \\
147\end{array}$ & 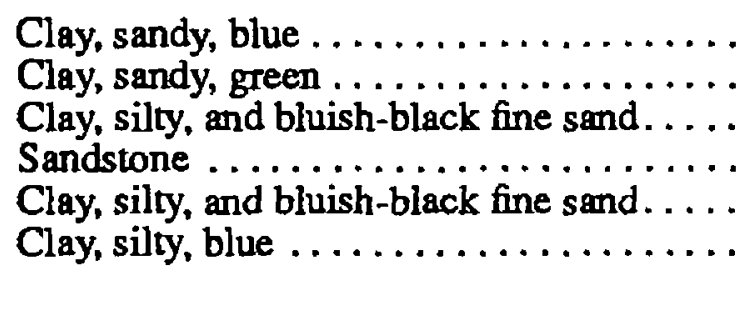 & $\begin{array}{l}5 \\
45 \\
16 \\
2.5 \\
31.5 \\
10\end{array}$ & $\begin{array}{l}152 \\
197 \\
213 \\
215.5 \\
247 \\
257\end{array}$ \\
\hline
\end{tabular}


Table 3. Drillers' logs of wells and test holes--Continued

148-095-12DCC2

(Log modifled from Water Supply, tnc.)

Altitude: 2,450 feet

Date drilled: $0 €-23-92$

\begin{tabular}{|c|c|c|c|c|c|}
\hline Material & $\begin{array}{l}\text { Thlck- } \\
\text { ness: } \\
\text { (feat) }\end{array}$ & $\begin{array}{l}\text { Depth } \\
\text { (feat) }\end{array}$ & Material & $\begin{array}{l}\text { Thlck- } \\
\text { neas } \\
\text { (foet) }\end{array}$ & $\begin{array}{l}\text { Depth } \\
\text { (feet) }\end{array}$ \\
\hline $\begin{array}{l}\text { Topsoil, silty, black. .................. } \\
\text { Clay, silty, yellowish-brown, bedrock .... } \\
\text { Sand, fine, yellowish-brown; about } \\
10 \text { percent clay . . . . . . . . . . . . }\end{array}$ & $\begin{array}{r}1 \\
9 \\
22\end{array}$ & $\begin{array}{r}1 \\
10 \\
32\end{array}$ & $\begin{array}{l}\text { Sand, fine, bluish-gray; about } \\
10 \text { percent clay } . . . \ldots \ldots \ldots \ldots\end{array}$ & 20 & 52 \\
\hline
\end{tabular}

149-087-06DDA

(Log modifled from Mann Driliing Co.)

Altitude: 2,100 feet

Date drilled: $11-05-82$

\begin{tabular}{|c|c|c|c|c|c|}
\hline Material & $\begin{array}{l}\text { Thick- } \\
\text { ness } \\
\text { (feet) }\end{array}$ & $\begin{array}{l}\text { Depth } \\
\text { (feat) }\end{array}$ & Matorial & $\begin{array}{l}\text { Thick- } \\
\text { ness } \\
\text { (feet) }\end{array}$ & $\begin{array}{l}\text { raoth } \\
\text { (foet) }\end{array}$ \\
\hline $\begin{array}{l}\text { Till, silty, } \tan \ldots \ldots \ldots \ldots \ldots \ldots \ldots \ldots \ldots \ldots \\
\text { Clay, gray } \ldots \ldots \ldots \ldots \ldots \ldots \ldots \ldots \ldots \ldots \ldots \\
\text { Lignite } \ldots \ldots \ldots \ldots \ldots \ldots \ldots \ldots\end{array}$ & $\begin{array}{r}34 \\
11 \\
1\end{array}$ & $\begin{array}{l}34 \\
45 \\
46\end{array}$ & $\begin{array}{l}\text { Clay, gray } \ldots \ldots \ldots \ldots \ldots \ldots \ldots \ldots \ldots \ldots \ldots \ldots \ldots \ldots \ldots \\
\text { Lignite } \ldots \ldots \ldots \ldots \ldots \ldots \ldots\end{array}$ & $\begin{array}{r}48 \\
6\end{array}$ & $\begin{array}{r}94 \\
100\end{array}$ \\
\hline
\end{tabular}

149-087-08ABB2

(Log modified from Mann Driiiing Co.)

Altitude: 2,110 feet

Date drilled: $05 \cdot ? 0-82$

\begin{tabular}{|c|c|c|c|c|c|}
\hline Material & $\begin{array}{l}\text { Thlck- } \\
\text { ness } \\
\text { (foet) }\end{array}$ & $\begin{array}{l}\text { Depth } \\
\text { (feet) }\end{array}$ & Materlal & $\begin{array}{l}\text { Thlck- } \\
\text { ness } \\
\text { (foet) }\end{array}$ & $\begin{array}{l}\text { Innth } \\
\text { (feet) }\end{array}$ \\
\hline $\begin{array}{l}\text { Till, } \tan \ldots \ldots \ldots \ldots \ldots \\
\text { Till, gray............ }\end{array}$ & $\begin{array}{l}32 \\
41\end{array}$ & $\begin{array}{l}32 \\
73\end{array}$ & $\begin{array}{l}\text { Sand. } \ldots \ldots \ldots \ldots \ldots \ldots \ldots \ldots \ldots \ldots \ldots \ldots \ldots \ldots \ldots \ldots \\
\text { Sand, fine. } \ldots \ldots \ldots \ldots \ldots \ldots \ldots\end{array}$ & $\begin{array}{r}7 \\
15\end{array}$ & $\begin{array}{l}80 \\
95\end{array}$ \\
\hline
\end{tabular}

149-087-26BCB

(Log modifled from Mann Drlliing Co.)

Altitude: 2,080 feet

Date drilled: $10 \cdot 13-83$

\begin{tabular}{|c|c|c|c|c|c|}
\hline Material & $\begin{array}{l}\text { Thick- } \\
\text { neas } \\
\text { (feet) }\end{array}$ & $\begin{array}{l}\text { Depth } \\
\text { (feet) }\end{array}$ & Material & $\begin{array}{l}\text { Thick- } \\
\text { nass } \\
\text { (feot) }\end{array}$ & $\begin{array}{l}\text { Cepth } \\
\text { (feet) }\end{array}$ \\
\hline 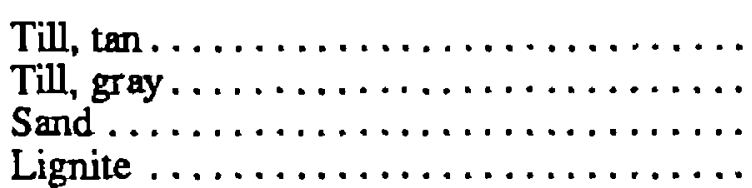 & $\begin{array}{r}56 \\
62 \\
37 \\
4\end{array}$ & $\begin{array}{r}56 \\
118 \\
155 \\
159\end{array}$ & 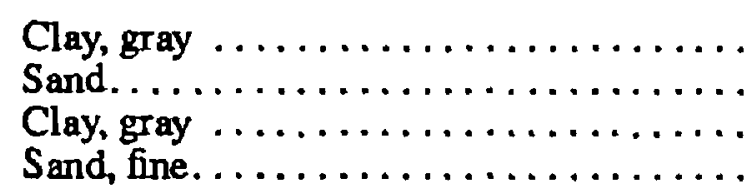 & $\begin{array}{r}77 \\
10 \\
9 \\
108\end{array}$ & $\begin{array}{l}236 \\
246 \\
255 \\
363\end{array}$ \\
\hline
\end{tabular}


Table 3. Drillers' logs of wells and test holes--Continued

149-087-28DAA

(Log modifled from Broneske Woll Drilling)

Altitude: 2,045 feet

Date drilled: $\quad 05-18-72$

\begin{tabular}{|c|c|c|c|c|c|}
\hline Materlal & $\begin{array}{l}\text { Thlck- } \\
\text { neese } \\
\text { (feat) }\end{array}$ & $\begin{array}{l}\text { Depth } \\
\text { (feot) }\end{array}$ & Materlal & $\begin{array}{l}\text { Thlisk- } \\
\text { nere } \\
\text { (fent) }\end{array}$ & $\begin{array}{l}\text { Depth } \\
\text { (feet) }\end{array}$ \\
\hline 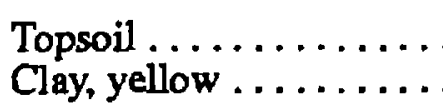 & $\begin{array}{r}2 \\
16\end{array}$ & $\begin{array}{r}2 \\
18\end{array}$ & $\begin{array}{l}\text { Clay, sandy, yellow . . . . . . . . . . . } \\
\text { Sand, blue . . . . . . . . . . . . . . }\end{array}$ & $\begin{array}{l}74 \\
14\end{array}$ & $\begin{array}{r}92 \\
106\end{array}$ \\
\hline
\end{tabular}

149-088-04DAD

(Log modifled from Mann-Stumvoll Drilling)

Altitude: 1,990 feet

Date drllle d: $\quad 04-18-89$

\begin{tabular}{|c|c|c|c|c|c|}
\hline Materlal & $\begin{array}{c}\text { Thlck- } \\
\text { ness } \\
\text { (feet) }\end{array}$ & $\begin{array}{l}\text { Depth } \\
\text { (feet) }\end{array}$ & Meterlal & $\begin{array}{l}\text { Thlck- } \\
\text { ners } \\
\text { (fent) }\end{array}$ & $\begin{array}{l}\text { Depth } \\
\text { (feet) }\end{array}$ \\
\hline $\begin{array}{l}\text { Till, } \tan , \ldots \ldots \ldots \ldots \ldots \ldots \\
\text { Clay } \ldots \ldots \ldots \ldots \ldots \ldots\end{array}$ & $\begin{array}{l}46 \\
36\end{array}$ & $\begin{array}{l}46 \\
82\end{array}$ & $\begin{array}{l}\text { Sand } \tan \ldots \ldots \ldots \ldots \ldots \ldots \ldots \ldots \ldots \ldots \ldots \ldots \\
\text { Sand } \operatorname{gray} \ldots \ldots \ldots \ldots \ldots \ldots \ldots \ldots\end{array}$ & $\begin{array}{l}38 \\
20\end{array}$ & $\begin{array}{l}120 \\
140\end{array}$ \\
\hline
\end{tabular}

149-088-11DAA2

(Log modifled from Mann-Stumvoll Drilling)

Altitude: 2,035 feet

Date drillin: $08-21-89$

\begin{tabular}{|c|c|c|c|c|c|}
\hline Meterlal & $\begin{array}{l}\text { Thick- } \\
\text { ness } \\
\text { (foet) }\end{array}$ & $\begin{array}{l}\text { Depth } \\
\text { (feet) }\end{array}$ & Msterial & $\begin{array}{l}\text { Thlck- } \\
\text { ness } \\
\text { (fent) }\end{array}$ & $\begin{array}{l}\text { Depth } \\
\text { (feet) }\end{array}$ \\
\hline 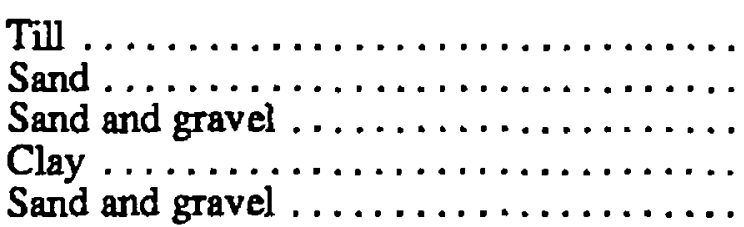 & $\begin{array}{r}62 \\
21 \\
4 \\
15 \\
15\end{array}$ & $\begin{array}{r}62 \\
83 \\
87 \\
102 \\
117\end{array}$ & 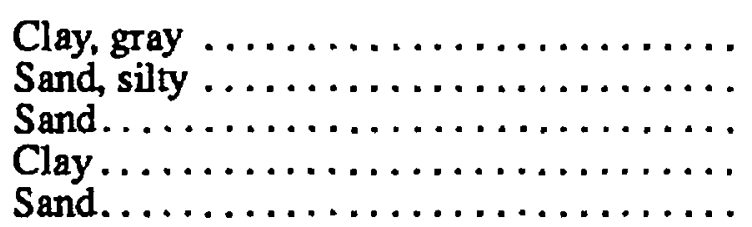 & $\begin{array}{l}2 \pi \\
2 \pi \\
21 \\
21\end{array}$ & $\begin{array}{l}140 \\
156 \\
179 \\
181 \\
202\end{array}$ \\
\hline
\end{tabular}

149-088-12BAB

(Log modifled from Mann Drilling Co.)

Altitude: 2,060 feet

Date drillet: $01-31-76$

\begin{tabular}{|c|c|c|c|c|c|}
\hline MaterlsI & $\begin{array}{l}\text { Thlck- } \\
\text { ness } \\
\text { (feet) }\end{array}$ & $\begin{array}{l}\text { Depth } \\
\text { (feet) }\end{array}$ & Materlal & $\begin{array}{l}\text { Thlrk- } \\
\text { ners } \\
\text { (fert) }\end{array}$ & $\begin{array}{l}\text { Dopth } \\
\text { (feet) }\end{array}$ \\
\hline 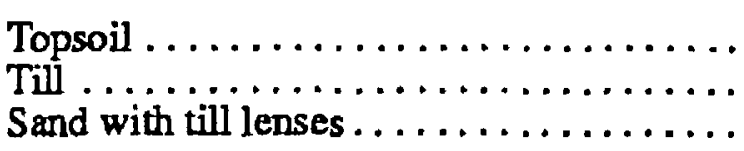 & $\begin{array}{r}2 \\
68 \\
13\end{array}$ & $\begin{array}{r}2 \\
70 \\
83\end{array}$ & 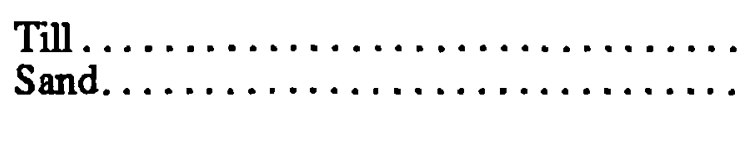 & $\begin{array}{l}75 \\
22\end{array}$ & $\begin{array}{l}158 \\
180\end{array}$ \\
\hline
\end{tabular}


Table 3. Drillers' logs of wells and test holes--Continued

149-088-23DAA

(Log modifled from Mann-Stumvoll Drilling)

Altitude: 1,985 feet

Date drilled: $04-19-89$

\begin{tabular}{|c|c|c|c|c|c|}
\hline Material & $\begin{array}{l}\text { Thlck- } \\
\text { ness } \\
\text { (feet) }\end{array}$ & $\begin{array}{l}\text { Depth } \\
\text { (feet) }\end{array}$ & Materlal & $\begin{array}{c}\text { Thlck- } \\
\text { neses } \\
\text { (feet) }\end{array}$ & $\begin{array}{l}\text { Depth } \\
\text { (feot) }\end{array}$ \\
\hline $\begin{array}{l}\text { Topsoil } \ldots \ldots \ldots \ldots \ldots \ldots \ldots \ldots \ldots \ldots \ldots \ldots \ldots \ldots \ldots \\
\text { Sand, } \tan . \ldots \ldots \ldots \ldots \ldots \ldots \ldots\end{array}$ & $\begin{array}{r}3 \\
29\end{array}$ & $\begin{array}{r}3 \\
32\end{array}$ & $\begin{array}{l}\text { Clay, sandy } \ldots \ldots \ldots \ldots \ldots \ldots \ldots \ldots \ldots \ldots \\
\text { Sand, very fine, gray } \ldots \ldots \ldots \ldots \ldots \ldots\end{array}$ & $\begin{array}{l}28 \\
10\end{array}$ & $\begin{array}{l}60 \\
70\end{array}$ \\
\hline
\end{tabular}

149-089-01BDA

(Log modifled from Mann Drilling Co.)

Altitude: 1,915 feet

Date drilled: $05-15-79$

\begin{tabular}{|c|c|c|c|c|c|}
\hline Materlal & $\begin{array}{l}\text { Thick- } \\
\text { ness } \\
\text { (feet) }\end{array}$ & $\begin{array}{l}\text { Depth } \\
\text { (feet) }\end{array}$ & Maferlal & $\begin{array}{l}\text { Thick- } \\
\text { ness } \\
\text { (feet) }\end{array}$ & $\begin{array}{l}\text { Depth } \\
\text { (feet) }\end{array}$ \\
\hline 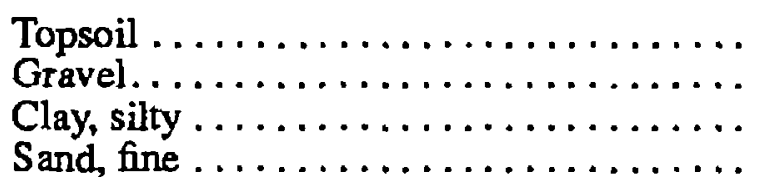 & $\begin{array}{r}2 \\
5 \\
56 \\
12\end{array}$ & $\begin{array}{r}2 \\
7 \\
63 \\
75\end{array}$ & 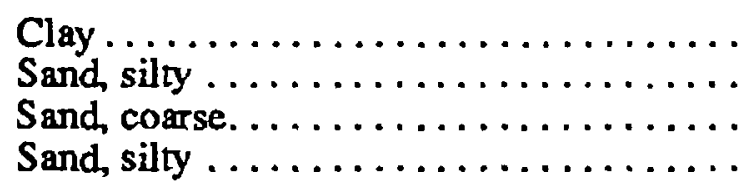 & $\begin{array}{l}62 \\
83 \\
80 \\
40\end{array}$ & $\begin{array}{l}137 \\
220 \\
300 \\
340\end{array}$ \\
\hline
\end{tabular}

149-089-03BBD

(Log modifled from Mann Drilling Co.)

Altitude: 1,950 feet

Date drilled: $11-26-82$

\begin{tabular}{|c|c|c|c|c|c|}
\hline Materlal & $\begin{array}{l}\text { Thick- } \\
\text { nees } \\
\text { (feet) }\end{array}$ & $\begin{array}{l}\text { Depth } \\
\text { (feet) }\end{array}$ & Materlal & $\begin{array}{l}\text { Thick- } \\
\text { ness } \\
\text { (feot) }\end{array}$ & $\begin{array}{l}\text { Depth } \\
\text { (feet) }\end{array}$ \\
\hline $\begin{array}{l}\text { Till, tan } \ldots \ldots \ldots \ldots \ldots \ldots \ldots \ldots \ldots \ldots \ldots \ldots \\
\text { Till, gravelly } \ldots \ldots \ldots \ldots \ldots \ldots \ldots \ldots \ldots \\
\text { Till, gray. } \ldots \ldots \ldots \ldots \ldots \ldots \ldots\end{array}$ & $\begin{array}{l}87 \\
35 \\
43\end{array}$ & $\begin{array}{r}87 \\
122 \\
165\end{array}$ & $\begin{array}{l}\text { Sand, silty } \ldots \ldots \ldots \ldots \ldots \ldots \ldots \ldots \ldots \ldots \ldots \ldots \ldots \ldots \ldots \ldots \ldots \ldots \ldots \\
\text { Gravel } \ldots \ldots \ldots \ldots \ldots \ldots \ldots \ldots \ldots \\
\text { Sand. } \ldots \ldots \ldots \ldots \ldots \ldots \ldots\end{array}$ & $\begin{array}{r}41 \\
27 \\
7\end{array}$ & $\begin{array}{l}206 \\
233 \\
240\end{array}$ \\
\hline
\end{tabular}

149-089-03DAA

(Log modffled from Mann Drilling Co.)

Altitude: 1,935 fe日t

Date drilled: 12-03-73

\begin{tabular}{|c|c|c|c|c|c|}
\hline Material & $\begin{array}{l}\text { Thlck- } \\
\text { ness } \\
\text { (feet) }\end{array}$ & $\begin{array}{l}\text { Depth } \\
\text { (feet) }\end{array}$ & Materlal & $\begin{array}{c}\text { Thick- } \\
\text { ness } \\
\text { (feet) }\end{array}$ & $\begin{array}{l}\text { Depth } \\
\text { (feet) }\end{array}$ \\
\hline 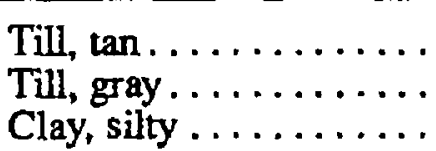 & $\begin{array}{r}28 \\
42 \\
112\end{array}$ & $\begin{array}{r}28 \\
70 \\
182\end{array}$ & 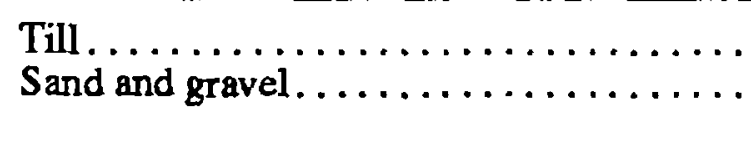 & $\begin{array}{l}19 \\
19\end{array}$ & $\begin{array}{l}201 \\
220\end{array}$ \\
\hline
\end{tabular}


Table 3. Drillers' logs of wells and test holes--Continued

149-089-09BAB2

(Log modifled from Mann Drilling Co.)

Date drilled: $07-18-77$

\begin{tabular}{|c|c|c|c|c|c|}
\hline Materlal & $\begin{array}{l}\text { Thlok- } \\
\text { nese } \\
\text { (feet) }\end{array}$ & $\begin{array}{l}\text { Depth } \\
\text { (feet) }\end{array}$ & Materlal & $\begin{array}{c}\text { Thl ik- } \\
\text { nevs } \\
\text { (feri) }\end{array}$ & $\begin{array}{l}\text { Depth } \\
\text { (feet) }\end{array}$ \\
\hline 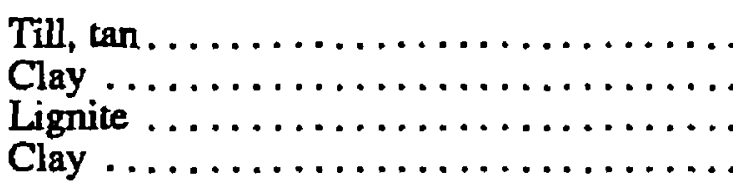 & $\begin{array}{r}32 \\
12 \\
1 \\
16\end{array}$ & $\begin{array}{l}32 \\
44 \\
45 \\
61\end{array}$ & 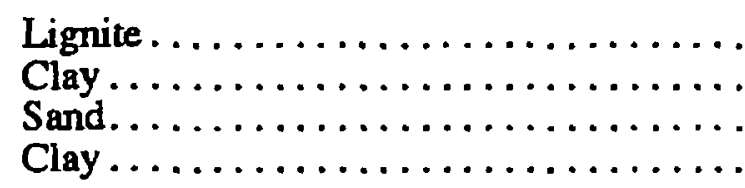 & $\begin{array}{r}2 \\
24 \\
33 \\
1\end{array}$ & $\begin{array}{r}63 \\
87 \\
120 \\
121\end{array}$ \\
\hline
\end{tabular}

149-089-10AAD

( Log modifled trom Mann Drilling Co.)

Altitude: 1,900 feet

Date drill יd: 07-19-77

\begin{tabular}{|c|c|c|c|c|c|}
\hline Material & $\begin{array}{l}\text { Thlck- } \\
\text { ness } \\
\text { (feef) }\end{array}$ & $\begin{array}{l}\text { Depth } \\
\text { (feet) }\end{array}$ & Materlal & $\begin{array}{l}\text { Thlisk- } \\
\text { nerse } \\
\text { (fent) }\end{array}$ & $\begin{array}{l}\text { Depth } \\
\text { (foet) }\end{array}$ \\
\hline $\begin{array}{l}\text { Topsoil .............. } \\
\text { Sand and gravel ....... } \\
\text { Clay .............. }\end{array}$ & $\begin{array}{r}2 \\
9 \\
129\end{array}$ & $\begin{array}{r}2 \\
11 \\
140\end{array}$ & $\begin{array}{l}\text { Till } \ldots \ldots \ldots \ldots \ldots \ldots \ldots \ldots \ldots \ldots \ldots \ldots \ldots \\
\text { Gravel } \ldots \ldots \ldots \ldots \ldots \ldots \ldots \ldots\end{array}$ & $\begin{array}{l}48 \\
12\end{array}$ & $\begin{array}{l}188 \\
200\end{array}$ \\
\hline
\end{tabular}

149-089-10CBB2

( Log moditled from Mann Drilling Co.)

Altitude: 1,910 feet

Date drilled: $14-16-83$

\begin{tabular}{|c|c|c|c|c|c|}
\hline Material & $\begin{array}{l}\text { Thick- } \\
\text { ness } \\
\text { (feet) }\end{array}$ & $\begin{array}{l}\text { Depth } \\
\text { (feet) }\end{array}$ & Materlal & $\begin{array}{l}\text { Think- } \\
\text { ners } \\
\text { (fert) }\end{array}$ & $\begin{array}{l}\text { Depth } \\
\text { (feet) }\end{array}$ \\
\hline 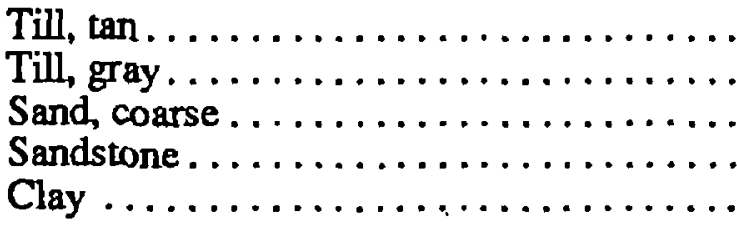 & $\begin{array}{r}37 \\
116 \\
22 \\
2 \\
7\end{array}$ & $\begin{array}{r}37 \\
153 \\
175 \\
177 \\
184\end{array}$ & 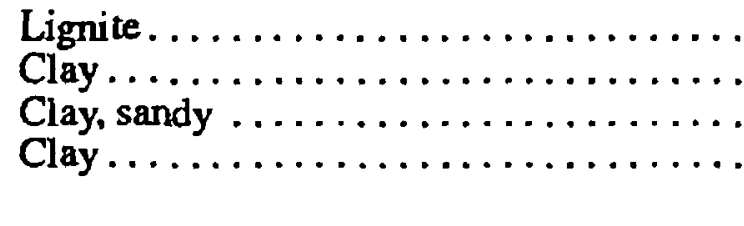 & $\begin{array}{r}5 \\
25 \\
72 \\
114\end{array}$ & $\begin{array}{l}189 \\
214 \\
286 \\
400\end{array}$ \\
\hline
\end{tabular}


Table 3. Drillers' logs of wells and test holes-Continued

149-089-10CBB3

(Log modifled from Mann-Stumvoll Drillng)

Altitude: 1,915 feet

Date drilled: $09 \quad 06-89$

\begin{tabular}{|c|c|c|c|c|c|}
\hline Material & $\begin{array}{l}\text { Thlck- } \\
\text { ness } \\
\text { (feet) }\end{array}$ & $\begin{array}{l}\text { Depth } \\
\text { (feet) }\end{array}$ & Material & $\begin{array}{l}\text { Thlck- } \\
\text { ness } \\
\text { (feet) }\end{array}$ & $\begin{array}{l}\text { Cepth } \\
\text { (feet) }\end{array}$ \\
\hline 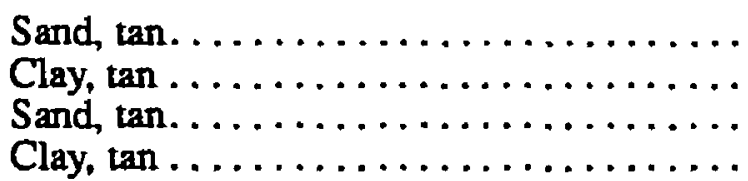 & $\begin{array}{r}14 \\
42 \\
6 \\
53\end{array}$ & $\begin{array}{r}14 \\
56 \\
62 \\
115\end{array}$ & $\begin{array}{l}\text { Sand and gravel } \ldots \ldots \ldots \ldots \ldots \ldots \ldots \ldots \ldots \ldots \ldots \ldots \ldots \\
\text { Till, gray } \ldots \ldots \ldots \ldots \ldots \ldots \ldots \ldots \ldots \\
\text { Clay, gray } \ldots \ldots \ldots \ldots \ldots \ldots\end{array}$ & $\begin{array}{l}20 \\
30 \\
15\end{array}$ & $\begin{array}{l}135 \\
165 \\
180\end{array}$ \\
\hline
\end{tabular}

149-089-11CBB2

(Log modifled from Mann Drilling Co.)

Altitude: 1,940 feet

Date drllled: $07-21-72$

\begin{tabular}{|c|c|c|c|c|c|}
\hline Matorial & $\begin{array}{l}\text { Thlck- } \\
\text { ness } \\
\text { (feet) }\end{array}$ & $\begin{array}{l}\text { Depth } \\
\text { (feet) }\end{array}$ & Material & $\begin{array}{l}\text { Thlck- } \\
\text { ness } \\
\text { (feet) }\end{array}$ & $\begin{array}{l}D \text { spth } \\
\text { ('not) }\end{array}$ \\
\hline 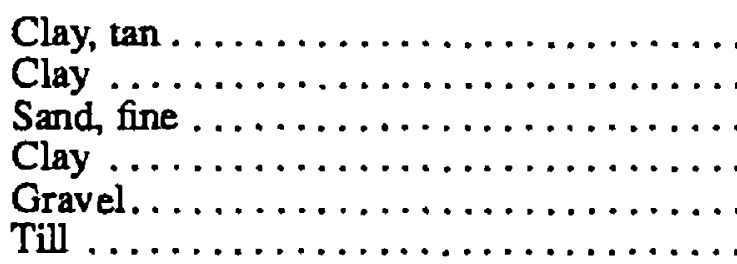 & $\begin{array}{r}29 \\
26 \\
7 \\
\\
108 \\
. \quad 6 \\
\end{array}$ & $\begin{array}{r}29 \\
55 \\
62 \\
170 \\
176 \\
268\end{array}$ & 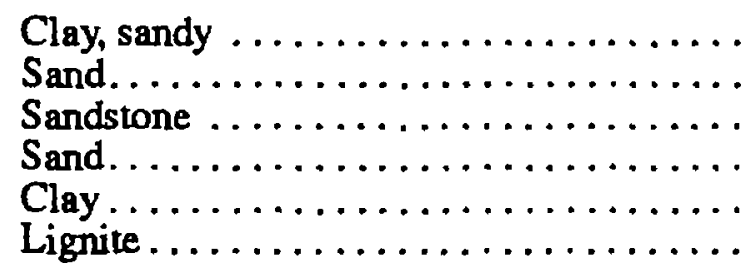 & $\begin{array}{r}12 \\
14 \\
5 \\
6 \\
6 \\
9\end{array}$ & $\begin{array}{l}280 \\
294 \\
299 \\
305 \\
311 \\
320\end{array}$ \\
\hline
\end{tabular}

149-089-14CBB

(Log modifled from Mann Driliing Co.)

Altitude: 1,920 feet

Date drilled: $\quad 05-02-85$

\begin{tabular}{|c|c|c|c|c|c|}
\hline Matorial & $\begin{array}{l}\text { Thick- } \\
\text { nesa } \\
\text { (feet) }\end{array}$ & $\begin{array}{l}\text { Depth } \\
\text { (feel) }\end{array}$ & Material & $\begin{array}{l}\text { Thick- } \\
\text { ness } \\
\text { (feet) }\end{array}$ & $\begin{array}{l}\text { Dinth } \\
\text { (int) }\end{array}$ \\
\hline 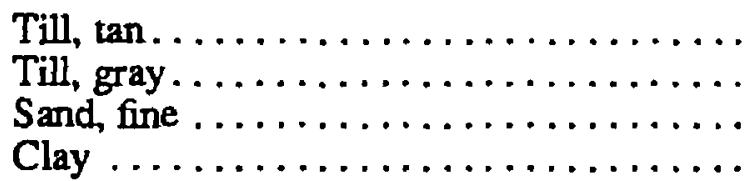 & $\begin{array}{r}25 \\
175 \\
120 \\
20\end{array}$ & $\begin{array}{r}25 \\
200 \\
320 \\
340\end{array}$ & 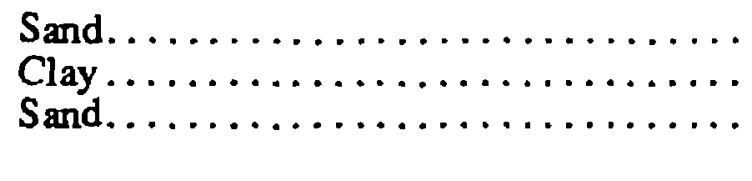 & $\begin{array}{r}15 \\
950 \\
65\end{array}$ & $\begin{array}{r}355 \\
1.305 \\
1.370\end{array}$ \\
\hline
\end{tabular}


Table 3. Drillers' logs of wells and test holes--Continued

149-089-17BAD

(Log modifled from Mann Drilling Co.)

Altitude: 1,940 foet

Date drilled: $05-18-82$

\begin{tabular}{|c|c|c|c|c|c|}
\hline Matorlal & $\begin{array}{l}\text { Thlck- } \\
\text { ness } \\
\text { (feet) }\end{array}$ & $\begin{array}{l}\text { Depth } \\
\text { (feot) }\end{array}$ & Materlal & $\begin{array}{l}\text { Thlck- } \\
\text { ners } \\
\text { (feet) }\end{array}$ & $\begin{array}{l}\text { Depth } \\
\text { (feet) }\end{array}$ \\
\hline 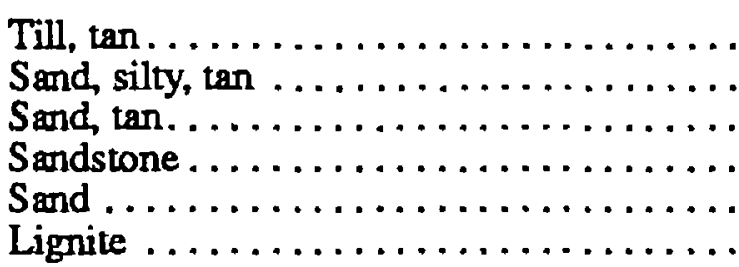 & $\begin{array}{r}13 \\
59 \\
28 \\
5 \\
65 \\
1\end{array}$ & $\begin{array}{r}13 \\
72 \\
100 \\
105 \\
170 \\
171\end{array}$ & 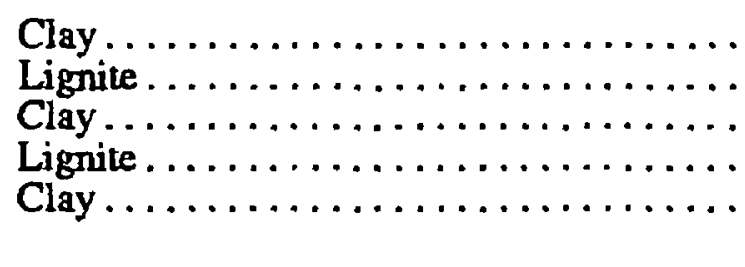 & $\begin{array}{l}4 \\
1 \\
2 \\
1 \\
1\end{array}$ & $\begin{array}{l}175 \\
176 \\
178 \\
179 \\
180\end{array}$ \\
\hline
\end{tabular}

149-089-18ADB2

(Log modifled from Mann Drilling Co.)

Altitude: 1,930 feet

Date driller: $09-06-84$

\begin{tabular}{|c|c|c|c|c|c|}
\hline Material & $\begin{array}{l}\text { Thlck- } \\
\text { nese } \\
\text { (feet) }\end{array}$ & $\begin{array}{l}\text { Depth } \\
\text { (foet) }\end{array}$ & Material & $\begin{array}{l}\text { Thirk- } \\
\text { nors } \\
\text { (fert) }\end{array}$ & $\begin{array}{l}\text { Depth } \\
\text { (feet) }\end{array}$ \\
\hline $\begin{array}{l}\text { Till } \ldots \ldots \ldots \ldots \ldots \ldots \ldots \ldots \ldots \ldots \ldots \ldots \ldots \ldots \ldots \\
\text { Clay, silty } \ldots \ldots \ldots \ldots \ldots \ldots \ldots \ldots \ldots \ldots \ldots \ldots \\
\text { Sand, silty } \ldots \ldots \ldots \ldots \ldots \ldots \ldots \ldots \ldots \ldots \ldots\end{array}$ & $\begin{array}{l}64 \\
36 \\
23\end{array}$ & $\begin{array}{r}64 \\
100 \\
123\end{array}$ & $\begin{array}{l}\text { Sandstone } \ldots \ldots \ldots \ldots \ldots \ldots \ldots \ldots \ldots \ldots \ldots \\
\text { Sand } \ldots \ldots \ldots \ldots \ldots \ldots \ldots \ldots \ldots \ldots \ldots\end{array}$ & $\underset{1}{2}$ & $\begin{array}{l}125 \\
140\end{array}$ \\
\hline
\end{tabular}

149-089-23CcC2

(Log modifled from Mann Drilling Co.)

Altitude: 2,018 feet

Date drille $4: \quad 10-31-72$

\begin{tabular}{|c|c|c|c|c|c|}
\hline Material & $\begin{array}{l}\text { Thlck- } \\
\text { neea } \\
\text { (feet) }\end{array}$ & $\begin{array}{l}\text { Depth } \\
\text { (feet) }\end{array}$ & Materlal & $\begin{array}{l}\text { Thick- } \\
\text { ness } \\
\text { (fent) }\end{array}$ & $\begin{array}{l}\text { Depth } \\
\text { (feet) }\end{array}$ \\
\hline 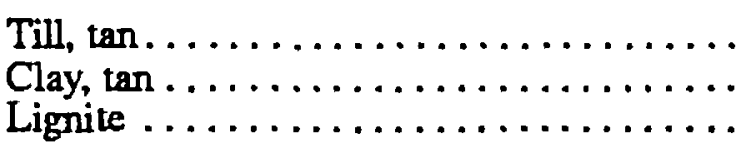 & $\begin{array}{r}19 \\
17 \\
4\end{array}$ & $\begin{array}{l}19 \\
36 \\
40\end{array}$ & $\begin{array}{l}\text { Clay, gray } \ldots \ldots \ldots \ldots \ldots \ldots \ldots \ldots \ldots \ldots \ldots \ldots \ldots \ldots \\
\text { Sand, dry } \ldots \ldots \ldots \ldots \ldots \ldots \ldots \ldots \ldots \\
\text { Sand, water } \ldots \ldots \ldots \ldots \ldots \ldots \ldots \ldots\end{array}$ & $\begin{array}{l}22 \\
78 \\
25\end{array}$ & $\begin{array}{r}62 \\
140 \\
165\end{array}$ \\
\hline
\end{tabular}

149-090-12DAD

(Log modifled from Mann Drilling Co.)

Altitude: 1,920 feet

Date drilled: $05-17-83$

\begin{tabular}{|c|c|c|c|c|c|}
\hline Materla| & $\begin{array}{l}\text { Thlcke } \\
\text { ness } \\
\text { (feet) }\end{array}$ & $\begin{array}{l}\text { Depth } \\
\text { (teat) }\end{array}$ & Materlal & $\begin{array}{l}\text { Thlek- } \\
\text { nors } \\
\text { (fort) }\end{array}$ & $\begin{array}{l}\text { Depth } \\
\text { (feet) }\end{array}$ \\
\hline $\begin{array}{l}\text { Clay, silty, tan } \ldots \ldots \ldots \ldots \ldots \ldots \ldots \ldots \ldots \ldots \ldots \\
\text { Sand } \ldots \ldots \ldots \ldots \ldots \ldots \ldots \ldots \ldots \ldots \\
\text { Sandstone } \ldots \ldots \ldots \ldots \ldots \ldots \ldots \ldots \ldots \ldots\end{array}$ & $\begin{array}{r}30 \\
78 \\
2\end{array}$ & $\begin{array}{r}30 \\
108 \\
110\end{array}$ & 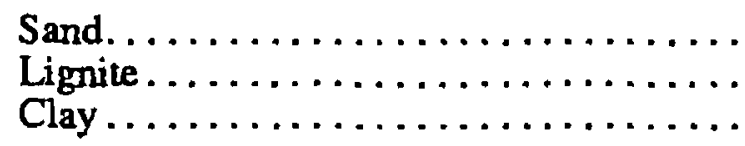 & $\begin{array}{r}25 \\
2 \\
1\end{array}$ & $\begin{array}{l}135 \\
137 \\
138\end{array}$ \\
\hline
\end{tabular}


Table 3. Drillers' logs of wells and test holes--Continued

149-90-12DDD

(Log modifled from Mann Drllling Co.)

Altitude: 1,885 feet

Date drilled: $0330-84$

\begin{tabular}{|c|c|c|c|c|c|}
\hline Materlal & $\begin{array}{l}\text { Thick- } \\
\text { nese } \\
\text { (feet) }\end{array}$ & $\begin{array}{l}\text { Depth } \\
\text { (feet) }\end{array}$ & Material & $\begin{array}{l}\text { Thlck- } \\
\text { nese } \\
\text { (feet) }\end{array}$ & $\begin{array}{l}\text { Dipth } \\
\text { (renet) }\end{array}$ \\
\hline 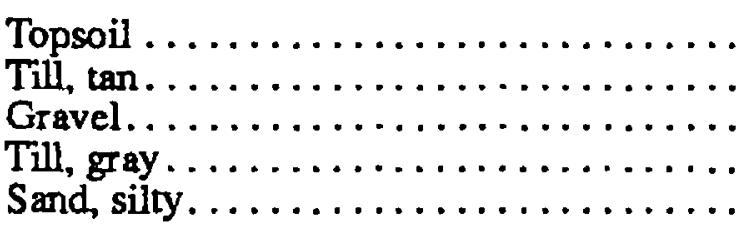 & $\begin{array}{r}1 \\
33 \\
2 \\
28 \\
26\end{array}$ & $\begin{array}{r}1 \\
34 \\
36 \\
64 \\
90\end{array}$ & $\begin{array}{l}\text { Sand. } \ldots \ldots \ldots \ldots \ldots \ldots \ldots \ldots \ldots \\
\text { Sand and fine gravel } \ldots \ldots \ldots \ldots \ldots \ldots \ldots \ldots \\
\text { Boulders } \ldots \ldots \ldots \ldots \ldots \ldots \ldots \ldots \ldots \ldots \ldots \\
\text { Clay, gray } \ldots \ldots \ldots \ldots \ldots \ldots \ldots \ldots \ldots \ldots\end{array}$ & $\begin{array}{r}20 \\
8 \\
2 \\
5\end{array}$ & $\begin{array}{l}110 \\
118 \\
120 \\
125\end{array}$ \\
\hline
\end{tabular}

149-092-10ACAA

(Log modifled from Smiley's Drilling)

Altitude: 1,940 feot

Date drilled: $\quad 06-20-87$

\begin{tabular}{|c|c|c|c|c|c|}
\hline Materlai & $\begin{array}{l}\text { Thlck- } \\
\text { neses } \\
\text { (teet) }\end{array}$ & $\begin{array}{l}\text { Depth } \\
\text { (feel) }\end{array}$ & Material & $\begin{array}{l}\text { Thick- } \\
\text { nese } \\
\text { (feet) }\end{array}$ & $\begin{array}{l}\text { Dinth } \\
\text { ("eet) }\end{array}$ \\
\hline 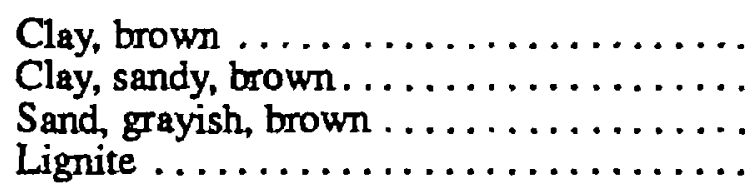 & $\begin{array}{r}44 \\
44 \\
17 \\
3\end{array}$ & $\begin{array}{r}44 \\
88 \\
105 \\
108\end{array}$ & $\begin{array}{l}\text { Sand, gray } \ldots \ldots \ldots \ldots \ldots \ldots \ldots \ldots \ldots \ldots \ldots \ldots \ldots \\
\text { Sandstone } \ldots \ldots \ldots \ldots \ldots \ldots \ldots \ldots \ldots \\
\text { Sand, gray } \ldots \ldots \ldots \ldots \ldots \ldots\end{array}$ & $\begin{array}{l}7 \\
2 \\
8\end{array}$ & $\begin{array}{l}115 \\
117 \\
125\end{array}$ \\
\hline
\end{tabular}

149-092-10DABC

(Log modifled from Smiley's Drilling)

Altitude: 1,920 feet

Date drilled: $06-26-86$

\begin{tabular}{|c|c|c|c|c|c|}
\hline Materlal & $\begin{array}{l}\text { Thick- } \\
\text { ness } \\
\text { (feet) }\end{array}$ & $\begin{array}{l}\text { Depth } \\
\text { (feet) }\end{array}$ & Materlal & $\begin{array}{l}\text { Thlck- } \\
\text { ness } \\
\text { (feet) }\end{array}$ & $\begin{array}{l}\text { Dinth } \\
\text { (f } \rightarrow t)\end{array}$ \\
\hline $\begin{array}{l}\text { Clay ................. } \\
\text { Sandstone } \ldots \ldots \ldots \ldots \\
\text { Clay, brown . . . . . }\end{array}$ & $\begin{array}{r}32 \\
5 \\
51\end{array}$ & $\begin{array}{l}32 \\
37 \\
88\end{array}$ & $\begin{array}{l}\text { Clay, sandy, brown } \ldots \ldots \ldots \ldots \ldots \ldots \ldots \ldots \\
\text { Sand, clayey, gray } \ldots \ldots \ldots \ldots \ldots \ldots\end{array}$ & $\begin{array}{r}7 \\
30\end{array}$ & $\begin{array}{r}95 \\
125\end{array}$ \\
\hline
\end{tabular}


Table 3. Drillers' logs of wells and test holes--Continued

149-092-10DCBB

(Log modifled from Gregory Drilling, Inc.)

Alttude: 2,000 feet

Date drilled: $08-11-89$

\begin{tabular}{|c|c|c|c|c|c|}
\hline Material & $\begin{array}{l}\text { Thiak- } \\
\text { ness } \\
\text { (feel) }\end{array}$ & $\begin{array}{l}\text { Depth } \\
\text { (feet) }\end{array}$ & Material & $\begin{array}{l}\text { Thlik- } \\
\text { neres } \\
\text { (fert) }\end{array}$ & $\begin{array}{l}\text { Depth } \\
\text { (feet) }\end{array}$ \\
\hline 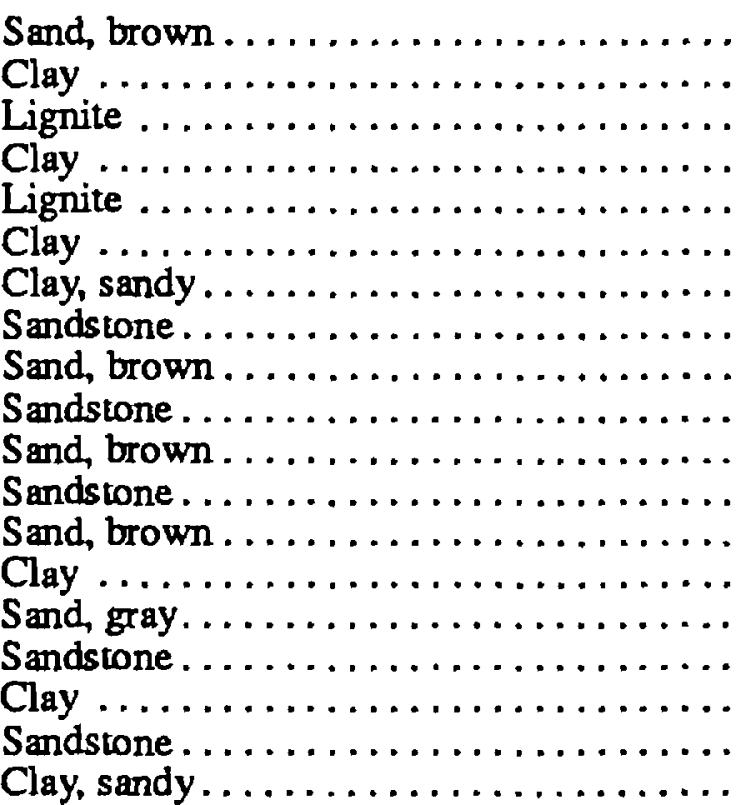 & $\begin{array}{r}10 \\
20 \\
2 \\
36 \\
2 \\
15 \\
16 \\
2 \\
14 \\
3 \\
6 \\
2 \\
18 \\
3 \\
3 \\
1 \\
17 \\
1 \\
10\end{array}$ & $\begin{array}{r}10 \\
30 \\
32 \\
68 \\
70 \\
85 \\
101 \\
103 \\
117 \\
120 \\
126 \\
128 \\
146 \\
149 \\
152 \\
153 \\
170 \\
171 \\
181\end{array}$ & 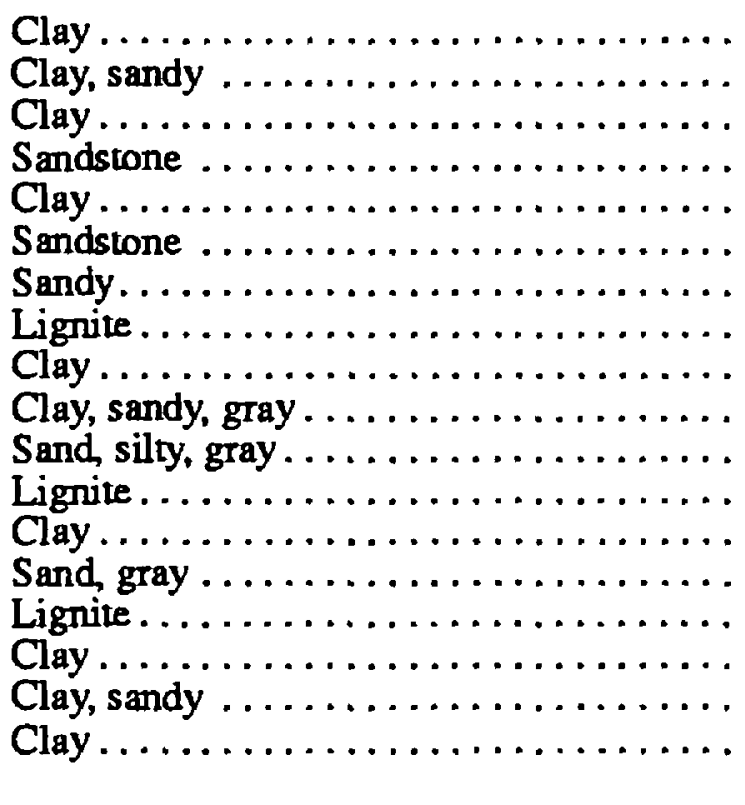 & $\begin{array}{r}10 \\
10 \\
8 \\
1 \\
33 \\
1 \\
9 \\
1 \\
7 \\
9 \\
11 \\
5 \\
24 \\
10 \\
3 \\
3 \\
5 \\
5\end{array}$ & $\begin{array}{l}191 \\
201 \\
209 \\
210 \\
243 \\
244 \\
253 \\
254 \\
325 \\
334 \\
345 \\
350 \\
374 \\
384 \\
387 \\
390 \\
395 \\
400\end{array}$ \\
\hline
\end{tabular}

149-093-09CCC

(Log modifled from Dennis Water Well Drilling)

Altitude: 2,225 feet

Date drille d: $\quad 10-03-88$

\begin{tabular}{|c|c|c|c|c|c|}
\hline Materlal & $\begin{array}{l}\text { Thick- } \\
\text { ness } \\
\text { (feet) }\end{array}$ & $\begin{array}{l}\text { Depth } \\
\text { (feet) }\end{array}$ & Msterlal & $\begin{array}{l}\text { Thirk- } \\
\text { nore } \\
\text { (ferli) }\end{array}$ & $\begin{array}{l}\text { Depth } \\
\text { (feet) }\end{array}$ \\
\hline 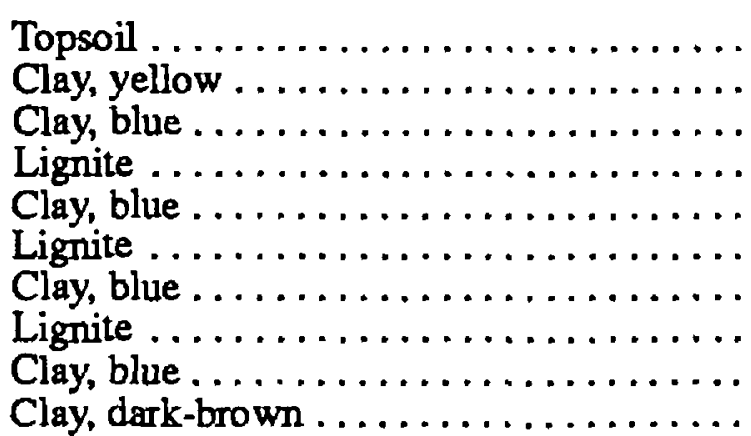 & $\begin{array}{r}1 \\
29 \\
35 \\
3 \\
2 \\
3 \\
38 \\
3 \\
18 \\
5.5\end{array}$ & $\begin{array}{l}1 \\
30 \\
65 \\
68 \\
70 \\
73 \\
111 \\
114 \\
132 \\
137.5\end{array}$ & 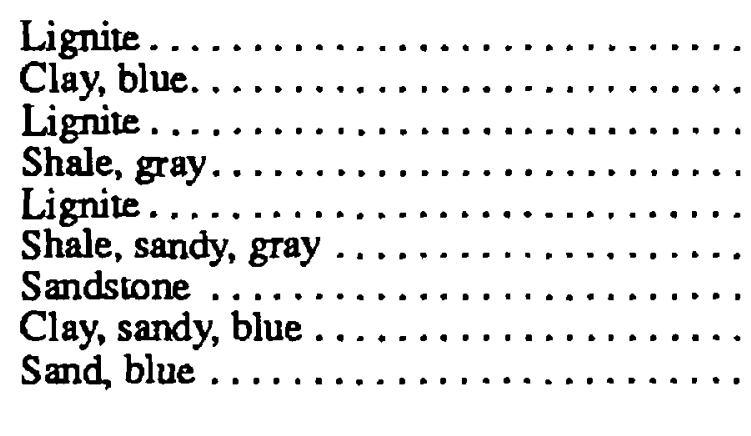 & $\begin{array}{r}7.5 \\
42 \\
4 \\
83 \\
4 \\
89 \\
6 \\
7 \\
73\end{array}$ & $\begin{array}{l}145 \\
187 \\
191 \\
274 \\
278 \\
367 \\
373 \\
380 \\
453\end{array}$ \\
\hline
\end{tabular}


Table 3. Drillers' logs of wells and test holes--Continued

149-094-07CAD

(Log from Dingman and Gordon, 1954)

Altitude: $2,267.17$ feet

Date drliled: 1950

\begin{tabular}{|c|c|c|c|c|}
\hline $\begin{array}{l}\text { Thick- } \\
\text { neess } \\
\text { (feet) }\end{array}$ & $\begin{array}{l}\text { Depth } \\
\text { (feet) }\end{array}$ & Material & $\begin{array}{l}\text { Thlck- } \\
\text { nese } \\
\text { (feet) }\end{array}$ & $\begin{array}{l}\text { c roth } \\
\text { (foet) }\end{array}$ \\
\hline 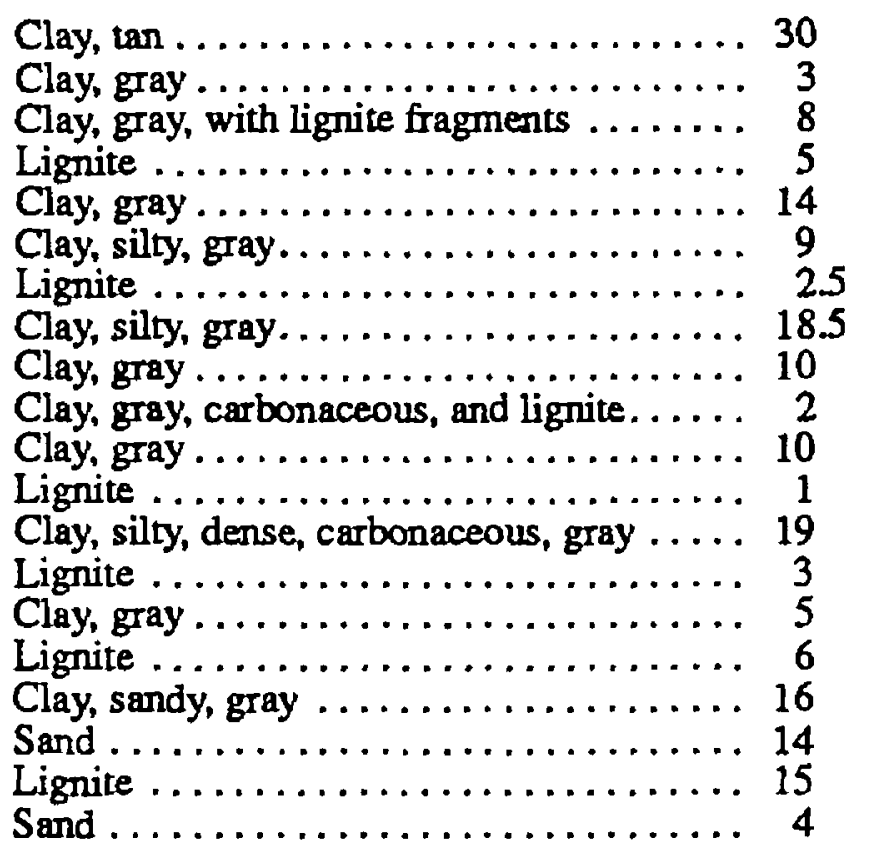 & $\begin{array}{l}30 \\
33 \\
41 \\
46 \\
60 \\
69 \\
71.5 \\
90 \\
100 \\
102 \\
112 \\
113 \\
132 \\
135 \\
140 \\
146 \\
162 \\
176 \\
191 \\
195\end{array}$ & 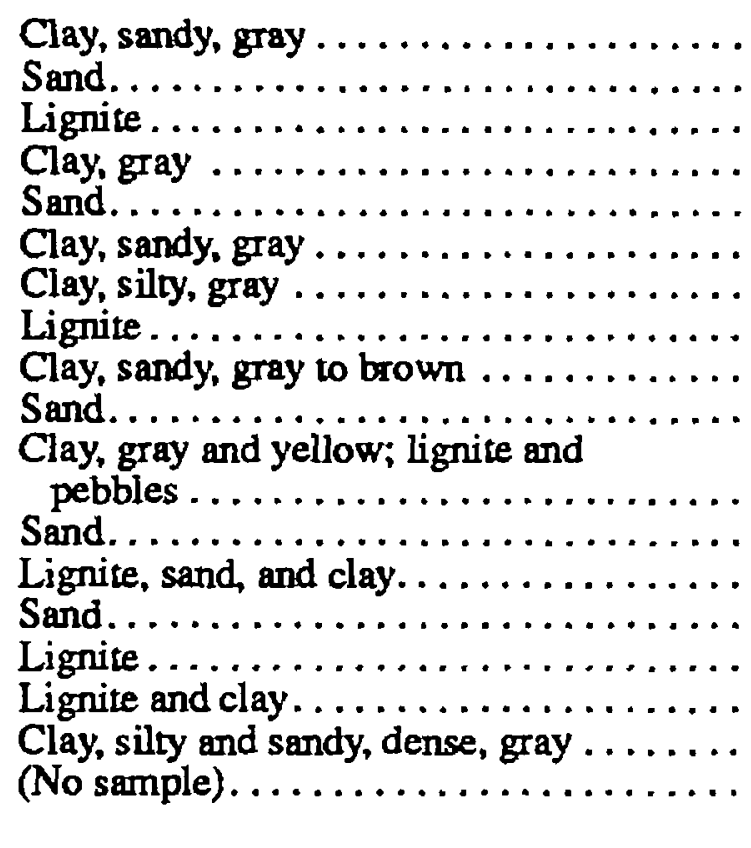 & $\begin{array}{r}5 \\
5 \\
7 \\
3 \\
5 \\
5 \\
5 \\
3 \\
7 \\
37 \\
3 \\
67 \\
1 \\
2 \\
10 \\
25 \\
50 \\
15\end{array}$ & $\begin{array}{l}200 \\
205 \\
212 \\
215 \\
220 \\
225 \\
230 \\
233 \\
240 \\
277 \\
\\
280 \\
347 \\
348 \\
350 \\
360 \\
385 \\
435 \\
450\end{array}$ \\
\hline
\end{tabular}

149-094-09ABA

(Log from Dingman and Gordon, 1954)

Altitude: $2,389.02$ feet

Date drilled: 1950

\begin{tabular}{|c|c|c|c|c|c|}
\hline Material & $\begin{array}{l}\text { Thick- } \\
\text { nees } \\
\text { (feel) }\end{array}$ & $\begin{array}{l}\text { Depth } \\
\text { (foot) }\end{array}$ & Material & $\begin{array}{l}\text { Thick- } \\
\text { ness } \\
\text { (feet) }\end{array}$ & $\begin{array}{l}\text { Dinth } \\
\text { (nnt) }\end{array}$ \\
\hline 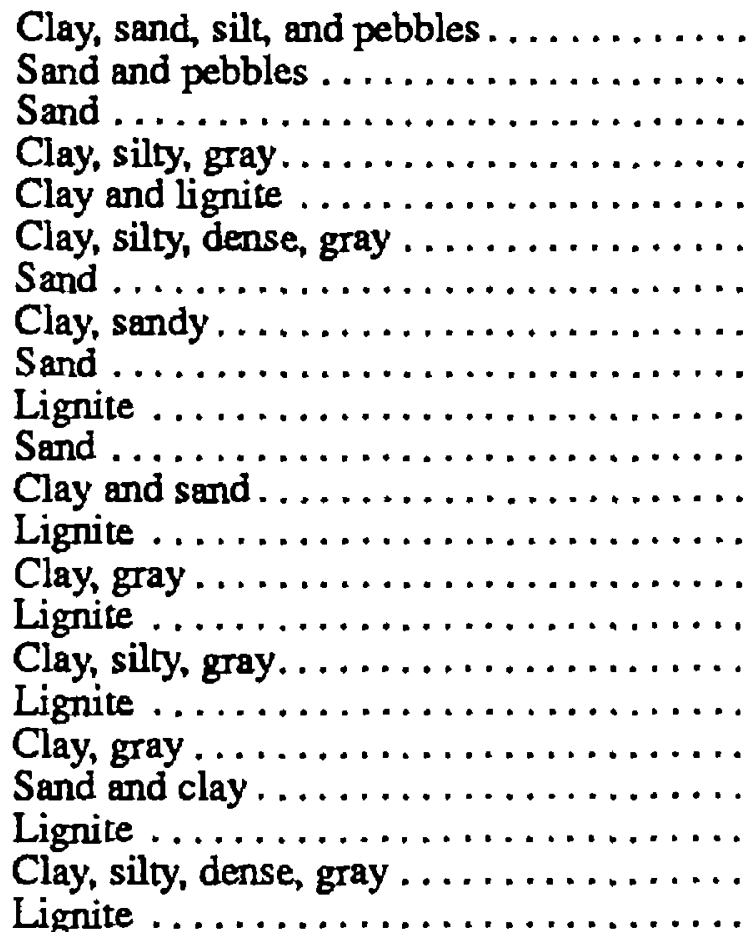 & $\begin{array}{r}10 \\
5 \\
5 \\
5 \\
5 \\
72 \\
8 \\
5 \\
4 \\
1 \\
5 \\
5 \\
5 \\
15 \\
5 \\
14 \\
1.5 \\
14.5 \\
10 \\
5 \\
20 \\
7\end{array}$ & $\begin{array}{l}10 \\
15 \\
20 \\
25 \\
30 \\
102 \\
110 \\
115 \\
119 \\
120 \\
125 \\
130 \\
135 \\
150 \\
155 \\
169 \\
170.5 \\
185 \\
195 \\
200 \\
220 \\
227\end{array}$ & 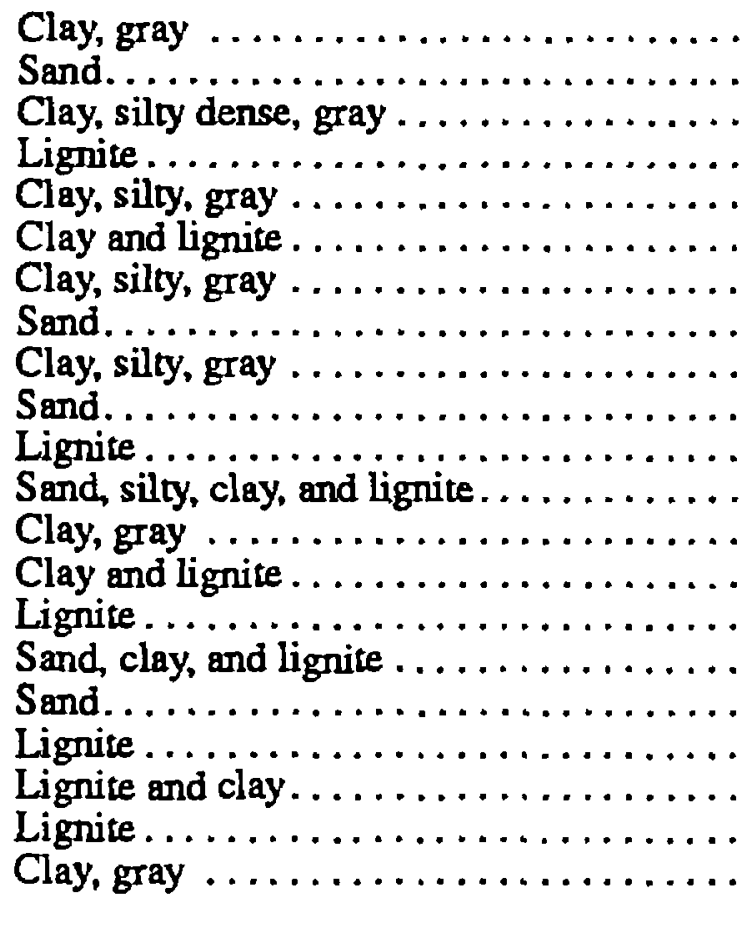 & $\begin{array}{c}13 \\
5 \\
30 \\
10 \\
9 \\
2 \\
4 \\
15 \\
7.5 \\
13.5 \\
10 \\
4 \\
5 \\
10 \\
2 \\
3 \\
30 \\
5 \\
5 \\
4 \\
6\end{array}$ & $\begin{array}{l}210 \\
215 \\
275 \\
2 ? 5 \\
2 ? 4 \\
276 \\
377 \\
315 \\
322.5 \\
336 \\
316 \\
357 \\
3 \div 5 \\
355 \\
357 \\
370 \\
470 \\
475 \\
410 \\
414 \\
4 \geqslant 0\end{array}$ \\
\hline
\end{tabular}


Table 3. Drillers' logs of wells and test holes--Continued

149-094-09ABCA

(Log modifled from Sax Well Drilling)

\begin{tabular}{|c|c|c|c|c|c|}
\hline Materlal & $\begin{array}{l}\text { Thick- } \\
\text { ness } \\
\text { (feet) }\end{array}$ & $\begin{array}{l}\text { Depth } \\
\text { (feet) }\end{array}$ & Matorlal & $\begin{array}{l}\text { Thisk- } \\
\text { neses } \\
\text { (fret) }\end{array}$ & $\begin{array}{l}\text { Depth } \\
\text { (foot) }\end{array}$ \\
\hline 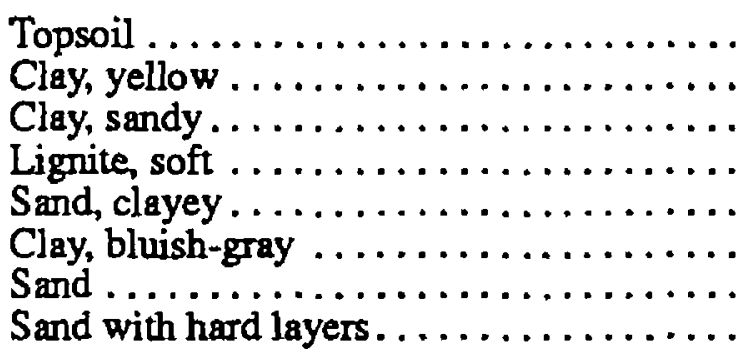 & $\begin{array}{r}2 \\
2 \\
8 \\
2 \\
18 \\
3 \\
20 \\
6\end{array}$ & $\begin{array}{r}2 \\
4 \\
12 \\
14 \\
32 \\
35 \\
55 \\
61\end{array}$ & 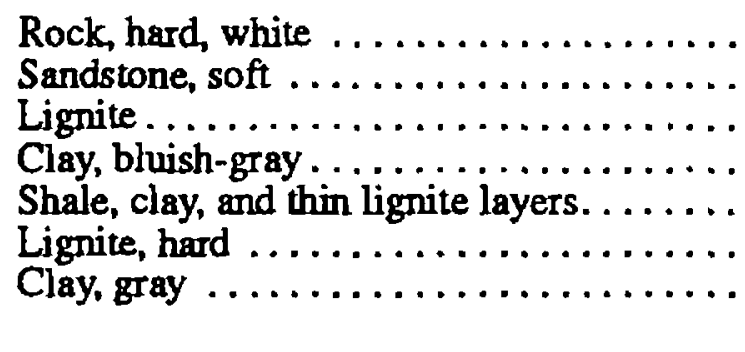 & $\begin{array}{r}2 \\
13 \\
1 \\
3 \\
50 \\
5 \\
15\end{array}$ & $\begin{array}{r}63 \\
76 \\
77 \\
80 \\
130 \\
135 \\
150\end{array}$ \\
\hline
\end{tabular}

149-094-14AAA

(Log from Dingman and Gordon, 1954)

Altitude: $2,305.79$ feet

Date drilled: 1950

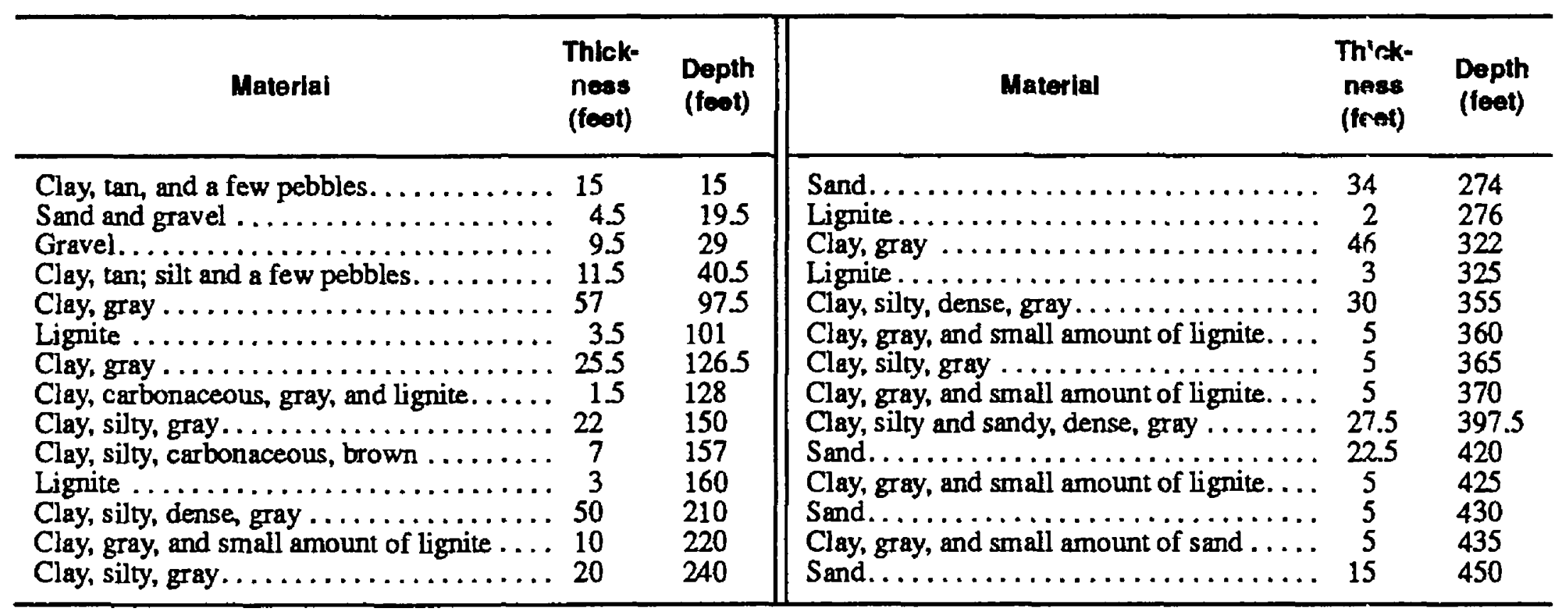

149-094-16BDAC

(Log modifled from Sax Well Drilling)

Albitude: 2,270 feet

Date drilled: $04-15-81$

\begin{tabular}{|c|c|c|c|c|c|}
\hline Materlal & $\begin{array}{l}\text { Thlek- } \\
\text { nees } \\
\text { (feet) }\end{array}$ & $\begin{array}{l}\text { Depth } \\
\text { (foot) }\end{array}$ & Material & $\begin{array}{l}\text { Thick- } \\
\text { nese } \\
\text { (feat) }\end{array}$ & $\begin{array}{l}\text { Depth } \\
\text { (feet) }\end{array}$ \\
\hline 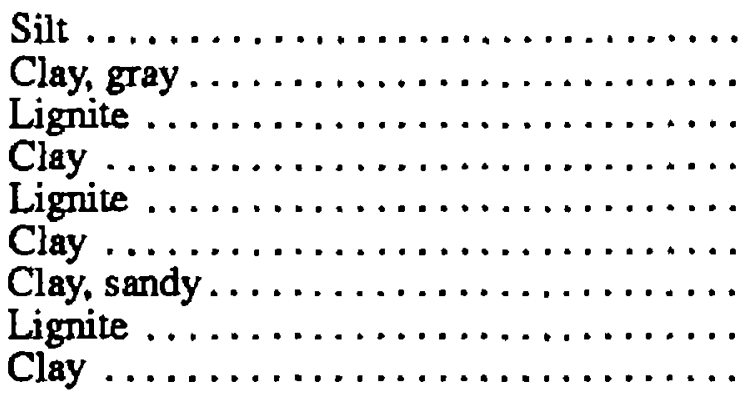 & $\begin{array}{r}3 \\
9 \\
3 \\
7 \\
2 \\
16 \\
8 \\
3 \\
5\end{array}$ & $\begin{array}{l}3 \\
12 \\
15 \\
22 \\
24 \\
40 \\
48 \\
51 \\
56\end{array}$ & 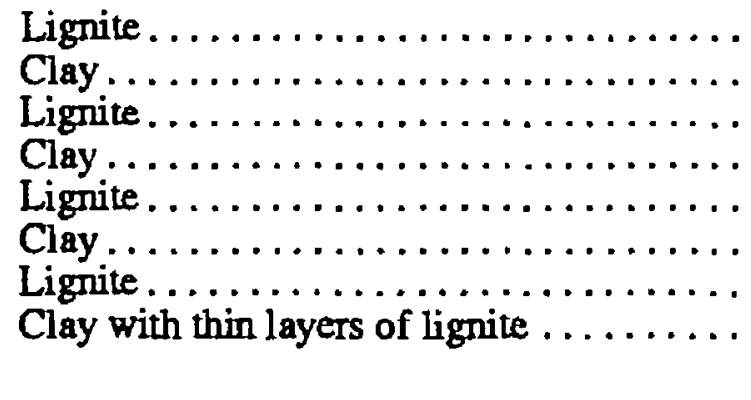 & $\begin{array}{r}3 \\
2 \\
3 \\
5 n \\
1 \\
22 \\
2 \\
61\end{array}$ & $\begin{array}{r}59 \\
61 \\
64 \\
114 \\
115 \\
137 \\
139 \\
200\end{array}$ \\
\hline
\end{tabular}


Table 3. Drillers' logs of wells and test holes--Continued

149-094-25ABC

(Log from Dingman and Gordon, 1954)

Altitude: $2,128.91$ feet

Date drilled: 1950

\begin{tabular}{|c|c|c|c|c|c|}
\hline Material & $\begin{array}{l}\text { Thick- } \\
\text { ness } \\
\text { (feet) }\end{array}$ & $\begin{array}{l}\text { Depth } \\
\text { (feet) }\end{array}$ & Materlal & $\begin{array}{l}\text { Thlok- } \\
\text { ness } \\
\text { (feet) }\end{array}$ & $\begin{array}{l}\text { Dinth } \\
\text { (fret) }\end{array}$ \\
\hline 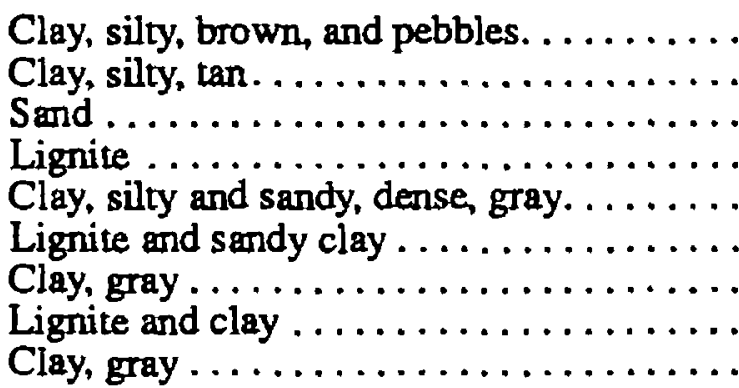 & $\begin{array}{r}25 \\
20 \\
\text {. } \\
\text {. } \\
\text {. } \\
\text {. } \\
\text {. } \\
33 \\
\text {. } \\
2 \\
10\end{array}$ & $\begin{array}{r}25 \\
45 \\
52 \\
56 \\
110 \\
115 \\
148 \\
150 \\
160\end{array}$ & 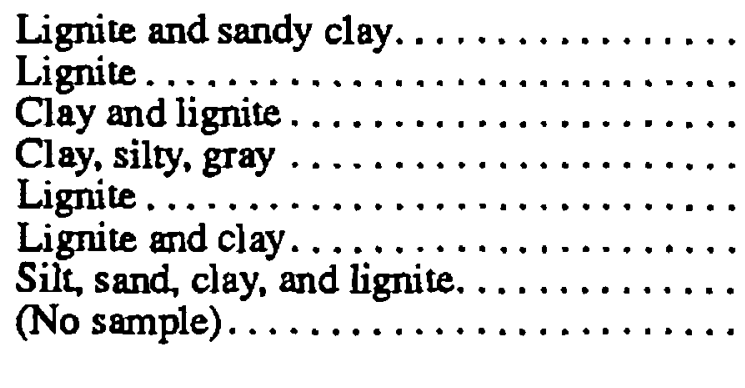 & $\begin{array}{r}5 \\
15 \\
5 \\
15 \\
10 \\
5 \\
10 \\
60\end{array}$ & $\begin{array}{l}165 \\
180 \\
185 \\
200 \\
210 \\
215 \\
225 \\
285\end{array}$ \\
\hline
\end{tabular}

149-094-27DAA

(Log from Dingman and Gordon, 1954)

Altitude: $2,361.23$ fe日t

Date drilled: 1950

\begin{tabular}{|c|c|c|c|c|c|}
\hline Material & $\begin{array}{l}\text { Thlok- } \\
\text { ness } \\
\text { (feet) }\end{array}$ & $\begin{array}{l}\text { Depth } \\
\text { (feet) }\end{array}$ & Materlal & $\begin{array}{l}\text { Thlck- } \\
\text { ness } \\
\text { (feet) }\end{array}$ & $\begin{array}{l}\text { Dorth } \\
\text { (f ret) }\end{array}$ \\
\hline 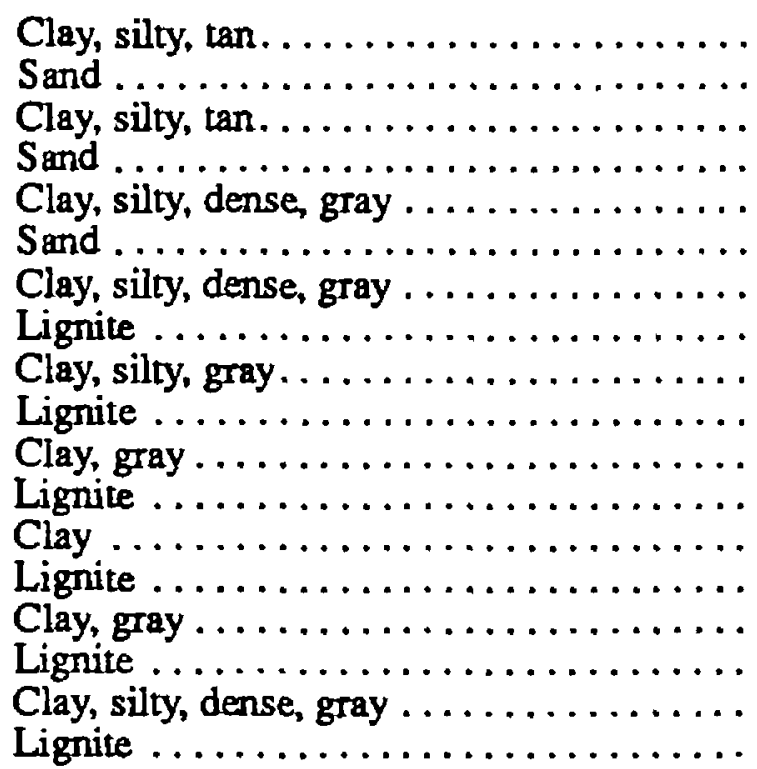 & $\begin{array}{r}5 \\
10 \\
19 \\
4 \\
47 \\
5 \\
13 \\
2 \\
50 \\
7 \\
7 \\
3 \\
5 \\
3 \\
13 \\
7 \\
43 \\
3\end{array}$ & $\begin{array}{r}5 \\
15 \\
34 \\
38 \\
85 \\
90 \\
103 \\
105 \\
155 \\
162 \\
169 \\
172 \\
177 \\
180 \\
193 \\
200 \\
243 \\
246\end{array}$ & 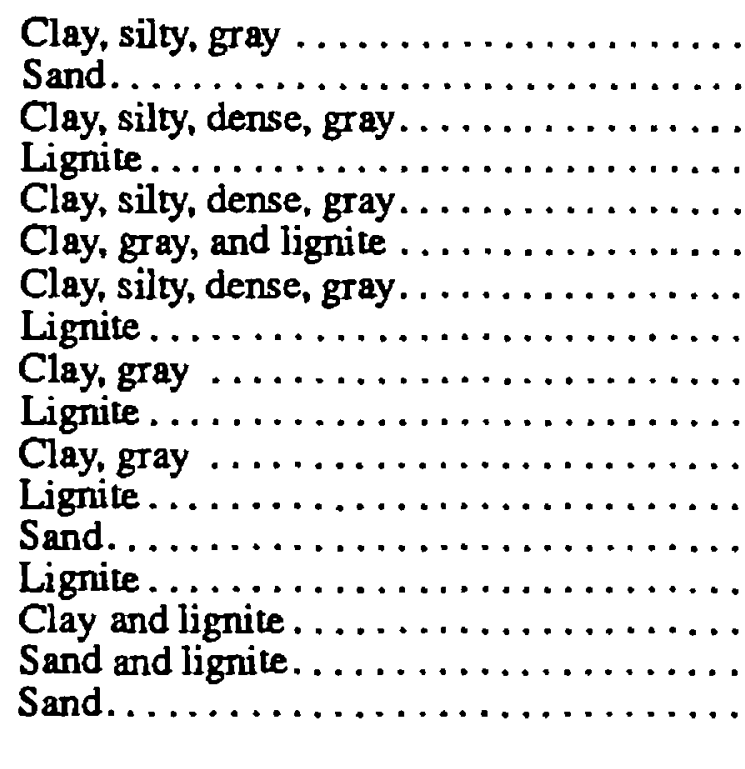 & $\begin{array}{r}4 \\
12 \\
31 \\
2 \\
20 \\
4 \\
15 \\
2 \\
9 \\
4 \\
26 \\
2 \\
13 \\
9 \\
8 \\
7 \\
36\end{array}$ & $\begin{array}{l}250 \\
262 \\
293 \\
295 \\
\vdots 15 \\
219 \\
234 \\
236 \\
245 \\
249 \\
275 \\
277 \\
390 \\
299 \\
407 \\
414 \\
450\end{array}$ \\
\hline
\end{tabular}


Table 3. Drillers' logs of wells and test holes--Continued

149-094-28AAA2

(Log modifled from Water Supply, Inc.)

\begin{tabular}{|c|c|c|c|c|c|}
\hline Material & $\begin{array}{l}\text { Thlek- } \\
\text { neese } \\
\text { (teot) }\end{array}$ & $\begin{array}{l}\text { Depth } \\
\text { (feat) }\end{array}$ & Material & $\begin{array}{l}\text { Thlat- } \\
\text { nert } \\
\text { (foet) }\end{array}$ & $\begin{array}{l}\text { Depth } \\
\text { (feet) }\end{array}$ \\
\hline $\begin{array}{l}\text { Topsoil, silty, black. . . . . . . . . . . . . . . } \\
\text { Clay, silty, yellowish-brown. . . . . . . . . . } \\
\text { Sand, fine to medium, yellowish-brown . . } \\
\text { Clay, silty, yellowish-brown. . . . . . . . . } \\
\text { Sand, fine, yellowish-brown, with clay } \\
\text { layers . . . . . . . . . . . . . . . . . . . . . } \\
\text { Clay, silty, yellowish-brown. . . . . . . . } \\
\text { Clay, silty, yellowish-brown; bedrock . . . } \\
\text { Clay, silty, blackish-gray . . . . . . . . . . . . }\end{array}$ & $\begin{array}{r}1 \\
12 \\
3 \\
4 \\
8 \\
22 \\
8 \\
2\end{array}$ & $\begin{array}{l}1 \\
13 \\
16 \\
20 \\
28 \\
50 \\
58 \\
60\end{array}$ & 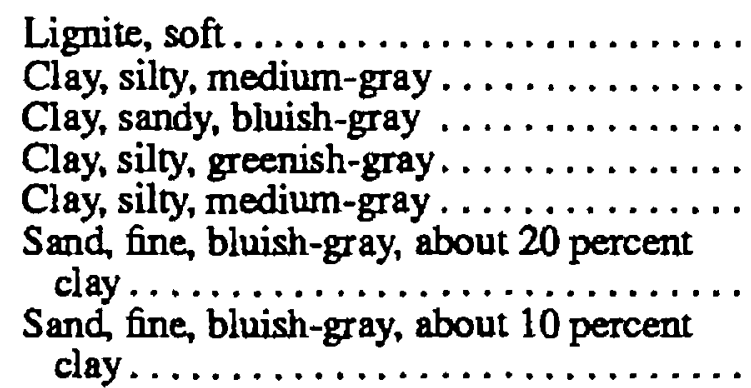 & $\begin{array}{r}4 \\
6 \\
4 \\
7 \\
13 \\
2 \\
24\end{array}$ & $\begin{array}{r}64 \\
70 \\
74 \\
81 \\
94 \\
96 \\
\\
120\end{array}$ \\
\hline
\end{tabular}

149-094-29ABB

(Log from Dingman and Gordon, 1954)

Altitude: $2,396.76$ feet

Date crilied: 1950

\begin{tabular}{|c|c|c|c|c|c|}
\hline Material & $\begin{array}{l}\text { Thick- } \\
\text { noss } \\
\text { (feot) }\end{array}$ & $\begin{array}{l}\text { Depth } \\
\text { (feet) }\end{array}$ & Material & $\begin{array}{l}\text { Thick. } \\
\text { ness } \\
\text { (feet) }\end{array}$ & $\begin{array}{l}\text { Depth } \\
\text { (feet) }\end{array}$ \\
\hline 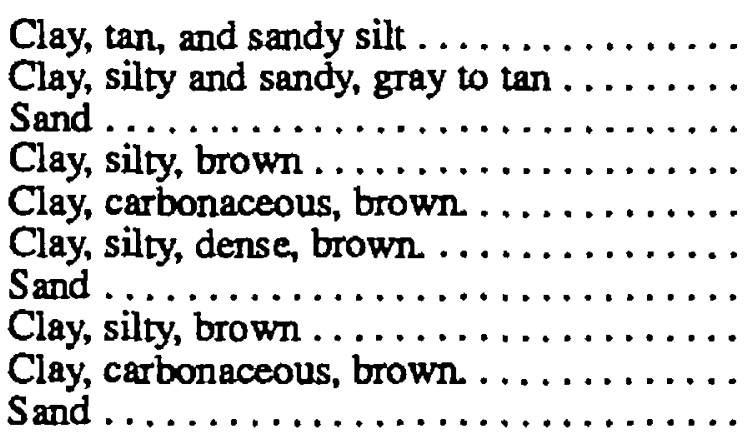 & $\begin{array}{r}11 \\
14 \\
5 \\
6 \\
4 \\
10 \\
5 \\
7 \\
13 \\
21\end{array}$ & $\begin{array}{l}11 \\
25 \\
30 \\
36 \\
40 \\
50 \\
55 \\
62 \\
75 \\
96\end{array}$ & 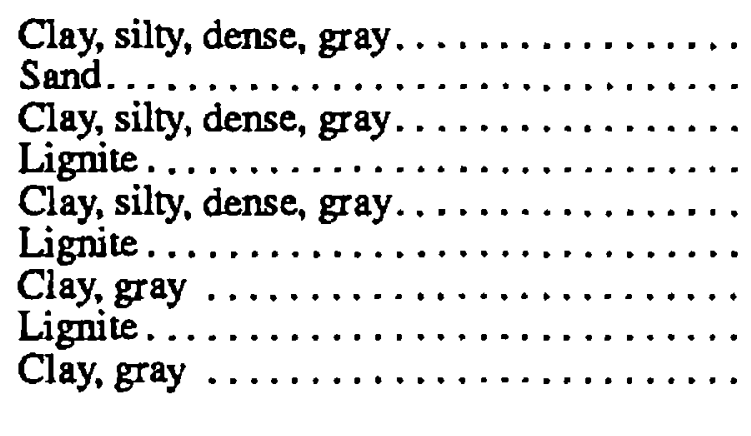 & $\begin{array}{r}39 \\
5 \\
15 \\
2 \\
34 \\
7 \\
27.5 \\
7.5 \\
7\end{array}$ & $\begin{array}{l}135 \\
140 \\
155 \\
157 \\
191 \\
198 \\
225.5 \\
233 \\
240\end{array}$ \\
\hline
\end{tabular}

149-095-04ADCC

(Log modified from Marion Hurinenko)

Altitude: 2,295 feet

Date drillet: $08-16-88$

\begin{tabular}{|c|c|c|c|c|c|}
\hline Malerial & $\begin{array}{l}\text { Thlck- } \\
\text { ness } \\
\text { (feet) }\end{array}$ & $\begin{array}{l}\text { Depth } \\
\text { (feot) }\end{array}$ & Material & $\begin{array}{l}\text { Thick- } \\
\text { ness } \\
\text { (feet) }\end{array}$ & $\begin{array}{l}\text { Depth } \\
\text { (feet) }\end{array}$ \\
\hline 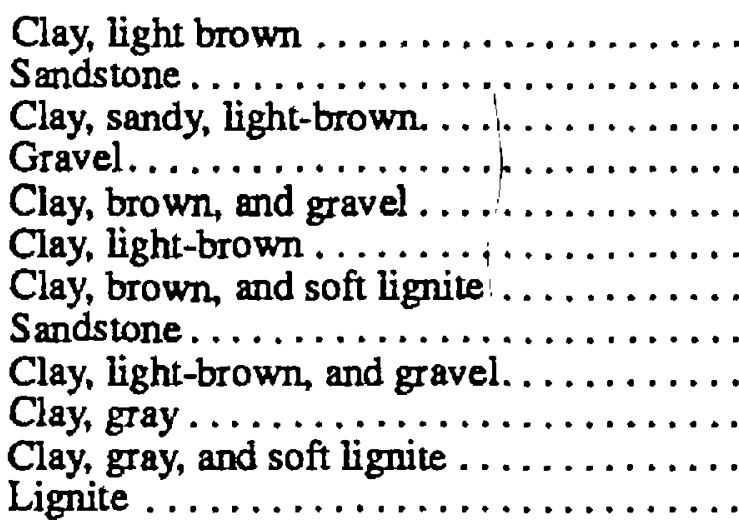 & 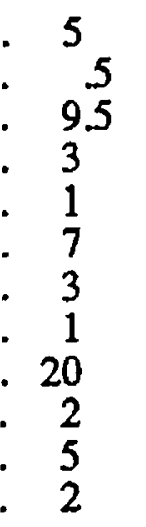 & $\begin{array}{l}5 \\
5.5 \\
15 \\
18 \\
19 \\
26 \\
29 \\
30 \\
50 \\
52 \\
57 \\
59\end{array}$ & 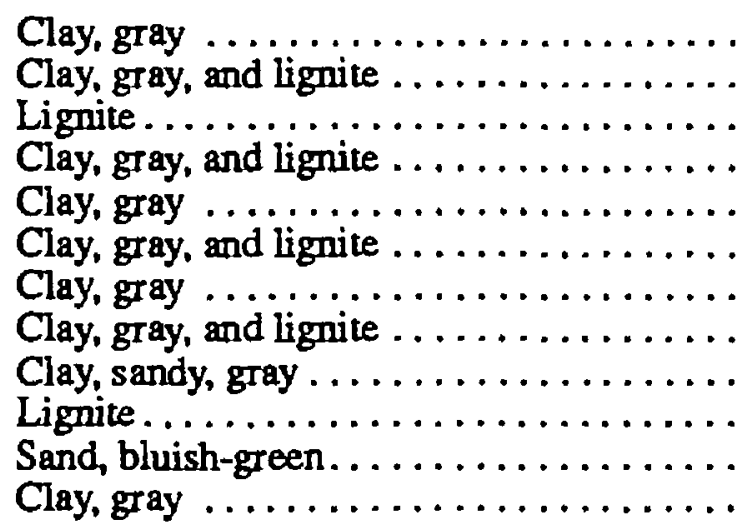 & $\begin{array}{r}10 \\
12 . \\
2 \\
1 C \\
17 \\
7 \\
33 \\
3 \\
15 \\
3 \\
9 \\
5\end{array}$ & $\begin{array}{r}69 \\
81 \\
83 \\
93 \\
110 \\
117 \\
150 \\
153 \\
168 \\
171 \\
180 \\
185\end{array}$ \\
\hline
\end{tabular}


Table 3. Drillers' logs of wells and test holes--Continued

149-095-06ADDB

(Log modified from Ralph Wold Well Driling)

Altitude: 2,258 te日t

Date drilled: $1 \mathrm{C}-06-79$

\begin{tabular}{|c|c|c|c|c|c|}
\hline Material & $\begin{array}{l}\text { Thlek- } \\
\text { ness } \\
\text { (feet) }\end{array}$ & $\begin{array}{l}\text { Depth } \\
\text { (feet) }\end{array}$ & Material & $\begin{array}{l}\text { Thlok- } \\
\text { nese } \\
\text { (feet) }\end{array}$ & $\begin{array}{l}\text { rioth } \\
\text { (feet) }\end{array}$ \\
\hline $\begin{array}{l}\text { Loam, sandy } \ldots \ldots \ldots \ldots \ldots \ldots \ldots \ldots \ldots \ldots \ldots \\
\text { Clay } \ldots \ldots \ldots \ldots \ldots \ldots \ldots \ldots \ldots \ldots \ldots \ldots \ldots \ldots \\
\text { Lignite } \ldots \ldots \ldots \ldots \ldots \ldots \ldots \ldots \ldots \ldots\end{array}$ & $\begin{array}{r}14 \\
31 \\
5\end{array}$ & $\begin{array}{l}14 \\
45 \\
50\end{array}$ & $\begin{array}{l}\text { Clay } \ldots \ldots \ldots \ldots \ldots \ldots \ldots \ldots \ldots \ldots \ldots \ldots \ldots \ldots \\
\text { Lignite } \ldots \ldots \ldots \ldots \ldots \ldots \ldots \ldots \ldots \ldots \ldots \ldots \ldots \ldots\end{array}$ & $\begin{array}{r}18 \\
3 \\
9\end{array}$ & $\begin{array}{l}68 \\
71 \\
80\end{array}$ \\
\hline
\end{tabular}

149-095-08AAC

(Log modifled from Thompson and Murie Driling)

Altitude: 2,235 feet

Date drilled: $08 \cdot 31-80$

\begin{tabular}{|c|c|c|c|c|c|}
\hline Materlal & $\begin{array}{l}\text { Thick- } \\
\text { ness } \\
\text { (foet) }\end{array}$ & $\begin{array}{l}\text { Depth } \\
\text { (feet) }\end{array}$ & Material & $\begin{array}{l}\text { Thlok. } \\
\text { ness } \\
\text { (foet) }\end{array}$ & $\begin{array}{l}\text { [onth } \\
\text { (feet) }\end{array}$ \\
\hline 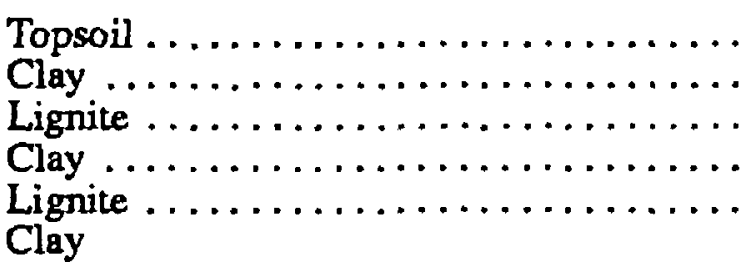 & $\begin{array}{r}3 \\
7 \\
3 \\
16 \\
1 \\
24\end{array}$ & $\begin{array}{r}3 \\
10 \\
13 \\
29 \\
30 \\
54\end{array}$ & 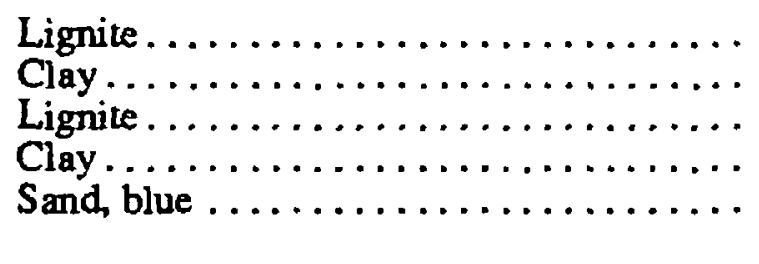 & $\begin{array}{r}3 \\
10 \\
3 \\
64 \\
41\end{array}$ & $\begin{array}{r}57 \\
67 \\
70 \\
134 \\
175\end{array}$ \\
\hline
\end{tabular}

149-095-36DBD

(Log trom Dingman and Gordon, 1954)

Altitude: $2,503.81$ feet

Date driiled: 1950

\begin{tabular}{|c|c|c|c|c|c|}
\hline Material & $\begin{array}{l}\text { Thlck- } \\
\text { ness } \\
\text { (feet) }\end{array}$ & $\begin{array}{l}\text { Depth } \\
\text { (feet) }\end{array}$ & Materlal & $\begin{array}{l}\text { Thlok- } \\
\text { nese } \\
\text { (feet) }\end{array}$ & $\begin{array}{l}\text { Cepth } \\
\text { (net) }\end{array}$ \\
\hline 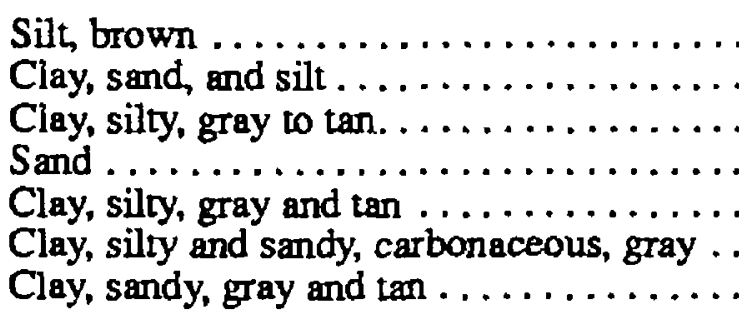 & 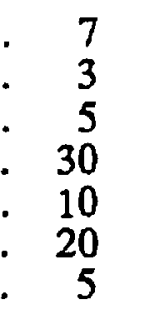 & $\begin{array}{r}7 \\
10 \\
15 \\
45 \\
55 \\
75 \\
80\end{array}$ & 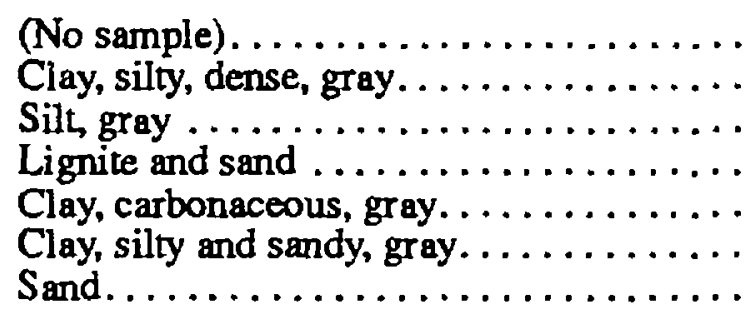 & $\begin{array}{r}25 \\
40 \\
6 \\
4 \\
5 \\
55 \\
10\end{array}$ & $\begin{array}{l}105 \\
145 \\
151 \\
155 \\
160 \\
215 \\
225\end{array}$ \\
\hline
\end{tabular}


Table 3. Drillers' logs of wells and test holes--Continued

150-088-18ADD3

(Log modifled from Mann Drilling Co.)

Altitude: 2,030 feet

Date drillin: $\quad 05-18-83$

\begin{tabular}{|c|c|c|c|c|c|}
\hline Material & $\begin{array}{l}\text { Thlck- } \\
\text { ness } \\
\text { (foet) }\end{array}$ & $\begin{array}{l}\text { Depth } \\
\text { (foet) }\end{array}$ & Materlal & $\begin{array}{l}\text { Thlck- } \\
\text { neqp } \\
\text { (fogt) }\end{array}$ & $\begin{array}{l}\text { Depth } \\
\text { (feet) }\end{array}$ \\
\hline 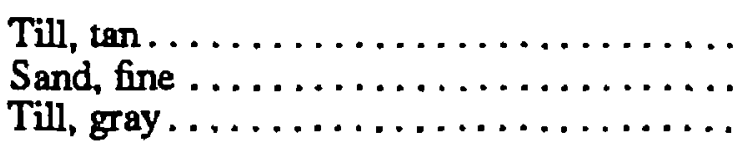 & $\begin{array}{r}21 \\
3 \\
24\end{array}$ & $\begin{array}{l}21 \\
24 \\
48\end{array}$ & $\begin{array}{l}\text { Sand, fine } \ldots \ldots \ldots \ldots \ldots \ldots \ldots \ldots \ldots \ldots \ldots \ldots \ldots \ldots \ldots \ldots \\
\text { Lignite } . \ldots \ldots \ldots \ldots \ldots \ldots \ldots\end{array}$ & $\begin{array}{r}11 \\
5\end{array}$ & $\begin{array}{l}59 \\
64\end{array}$ \\
\hline
\end{tabular}

150-088-29DAD

(Log modifled trom Mann Drilling Co.)

Altitude: 2,000 feet

Date drillict: $\quad 05-20-88$

\begin{tabular}{|c|c|c|c|c|c|}
\hline Materlal & $\begin{array}{l}\text { Thick- } \\
\text { ness } \\
\text { (feet) }\end{array}$ & $\begin{array}{l}\text { Depth } \\
\text { (feet) }\end{array}$ & Matertal & $\begin{array}{l}\text { Thlck- } \\
\text { ners } \\
\text { (fert) }\end{array}$ & $\begin{array}{l}\text { Depth } \\
\text { (feet) }\end{array}$ \\
\hline 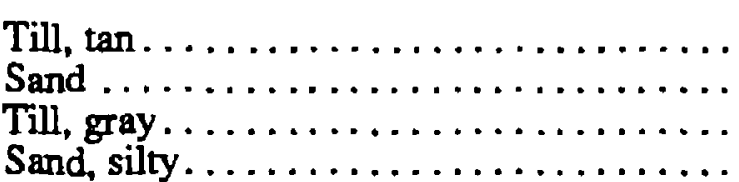 & $\begin{array}{r}52 \\
8 \\
34 \\
16\end{array}$ & $\begin{array}{r}52 \\
60 \\
94 \\
110\end{array}$ & 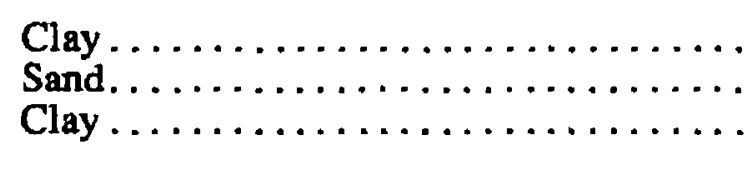 & $\begin{array}{r}105 \\
40 \\
5\end{array}$ & $\begin{array}{l}215 \\
255 \\
260\end{array}$ \\
\hline
\end{tabular}

150-088-33ADD

(Log modified from Mann-Stumvoll Drilling)

Altitude: 2,010 feet

Date drilled: $04-11-89$

\begin{tabular}{|c|c|c|c|c|c|}
\hline Materlal & $\begin{array}{l}\text { Thick- } \\
\text { ness } \\
\text { (feet) }\end{array}$ & $\begin{array}{l}\text { Depth } \\
\text { (feot) }\end{array}$ & Material & $\begin{array}{l}\text { Thl sk- } \\
\text { nev8 } \\
(\text { fe } 31)\end{array}$ & $\begin{array}{l}\text { Depth } \\
\text { (feet) }\end{array}$ \\
\hline 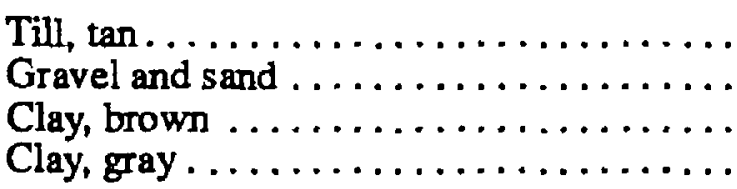 & $\begin{array}{r}24 \\
6 \\
50 \\
50\end{array}$ & $\begin{array}{r}24 \\
30 \\
80 \\
130\end{array}$ & 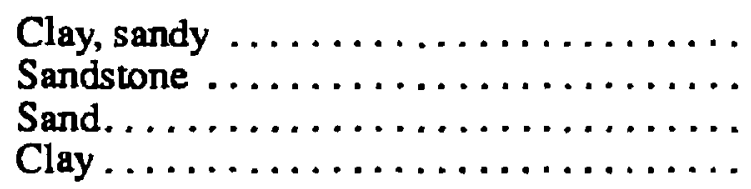 & $\begin{array}{r}21 \\
1 \\
3 ? \\
1\end{array}$ & $\begin{array}{l}151 \\
152 \\
191 \\
192\end{array}$ \\
\hline
\end{tabular}

150-088-34ABA

(Log modifled from Mann-Stumvoll Drilling)

Altitude: 2,020 feet

Date drilled: $05-17-90$

\begin{tabular}{|c|c|c|c|c|c|}
\hline Msterial & $\begin{array}{l}\text { Thlck- } \\
\text { ness } \\
\text { (feet) }\end{array}$ & $\begin{array}{l}\text { Depth } \\
\text { (feet) }\end{array}$ & Material & $\begin{array}{l}\text { Thi sk- } \\
\text { ne:s } \\
\text { (fert) }\end{array}$ & $\begin{array}{l}\text { Depth } \\
\text { (feet) }\end{array}$ \\
\hline 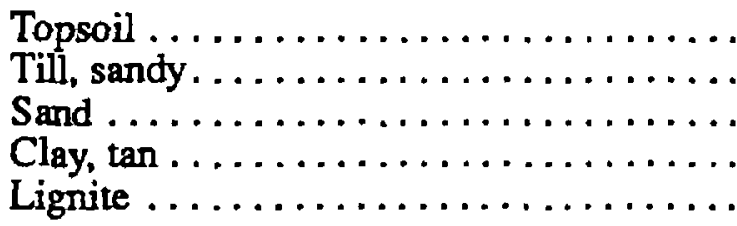 & $\begin{array}{r}2 \\
33 \\
8 \\
27 \\
1\end{array}$ & $\begin{array}{r}2 \\
35 \\
43 \\
70 \\
71\end{array}$ & 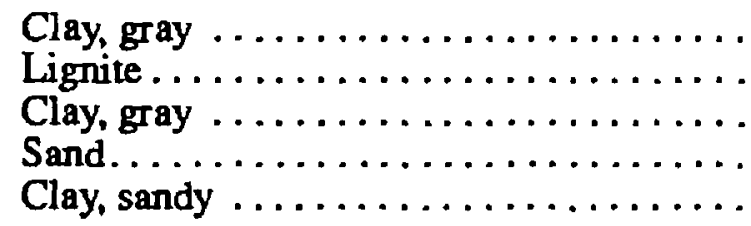 & $\begin{array}{r}7 \\
2 \\
90 \\
40 \\
10\end{array}$ & $\begin{array}{r}78 \\
80 \\
170 \\
210 \\
220\end{array}$ \\
\hline
\end{tabular}


Table 3. Drillers' logs of wells and test holes--Continued

150-088-34CcC

(Log modifled from Mann-Stumvoli Driliing)

Aittude: 2,020 feet

Date drilled: $09-05-89$

\begin{tabular}{|c|c|c|c|c|c|}
\hline Material & $\begin{array}{l}\text { Thick- } \\
\text { ness } \\
\text { (feet) }\end{array}$ & $\begin{array}{l}\text { Depth } \\
\text { (feet) }\end{array}$ & Material & $\begin{array}{l}\text { Thlck- } \\
\text { ness } \\
\text { (feet) }\end{array}$ & $\begin{array}{l}\text { Dinth } \\
\text { (frei) }\end{array}$ \\
\hline $\begin{array}{l}\text { Clay, } \tan \ldots \ldots \ldots \ldots \\
\text { Clay, gray } \ldots \ldots \ldots \ldots \\
\text { Lignite } \ldots \ldots \ldots \ldots\end{array}$ & $\begin{array}{r}82 \\
39 \\
1\end{array}$ & $\begin{array}{r}82 \\
121 \\
122\end{array}$ & $\begin{array}{l}\text { Clay } \ldots \ldots \ldots \ldots \ldots \ldots \ldots \ldots \ldots \ldots \ldots \\
\text { Clay, sandy } \ldots \ldots \ldots \ldots \ldots \ldots \ldots \ldots \ldots \ldots \\
\text { Sand........ }\end{array}$ & $\begin{array}{l}17 \\
13 \\
48\end{array}$ & $\begin{array}{l}139 \\
152 \\
200\end{array}$ \\
\hline
\end{tabular}

150-089-06BBC

(Log modified from Erck Driliing)

Altitude: 2,190 feet

Date drilled: $12-99-78$

\begin{tabular}{|c|c|c|c|c|c|}
\hline Material & $\begin{array}{l}\text { Thick- } \\
\text { ness } \\
\text { (feet) }\end{array}$ & $\begin{array}{l}\text { Depth } \\
\text { (feet) }\end{array}$ & Material & $\begin{array}{l}\text { Thick- } \\
\text { ness } \\
\text { (feet) }\end{array}$ & $\begin{array}{l}\text { Dinth } \\
(f \times g t)\end{array}$ \\
\hline $\begin{array}{l}\text { Topsoil, black . . . . . . . . . . . . . . . } \\
\text { Clay, yellow . . . . . . . . . . . . . . . . . . . . . . . } \\
\text { Clay, sandy, yellow. . . }\end{array}$ & $\begin{array}{r}2 \\
19 \\
69\end{array}$ & $\begin{array}{r}2 \\
21 \\
90\end{array}$ & 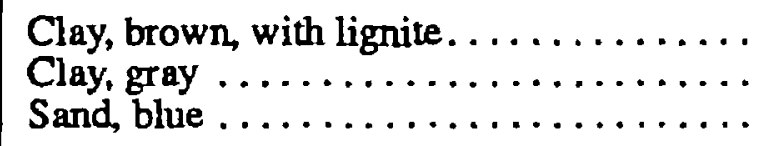 & $\begin{array}{r}7 \\
6 \\
14\end{array}$ & $\begin{array}{r}97 \\
103 \\
117\end{array}$ \\
\hline
\end{tabular}

150-089-14ADD

(Log modified from Mann-Stumvoli Drilling)

Aititude: 1,980 feet

Date drilled: $07-25-89$

\begin{tabular}{|c|c|c|c|c|c|}
\hline Materia] & $\begin{array}{l}\text { Thick- } \\
\text { noss } \\
\text { (feet) }\end{array}$ & $\begin{array}{l}\text { Depth } \\
\text { (feet) }\end{array}$ & Material & $\begin{array}{l}\text { Thick- } \\
\text { ness } \\
\text { (feet) }\end{array}$ & $\begin{array}{l}\text { Drnth } \\
(f \times g t)\end{array}$ \\
\hline $\begin{array}{l}\text { Topsoil } \ldots \ldots \ldots \ldots \ldots \ldots \ldots \ldots \ldots \ldots \ldots \ldots \ldots \\
\text { Sand, tan } \ldots \ldots \ldots \ldots \ldots \ldots \ldots \ldots \ldots \ldots \ldots \ldots \\
\text { Clay } \ldots \ldots \ldots \ldots \ldots \ldots \ldots \ldots \ldots \ldots\end{array}$ & $\begin{array}{r}2 \\
7 \\
25\end{array}$ & $\begin{array}{r}2 \\
9 \\
34\end{array}$ & $\begin{array}{l}\text { Sandstone } \ldots \ldots \ldots \ldots \ldots \ldots \ldots \ldots \ldots \ldots \ldots \ldots \\
\text { Clay, gray } \ldots \ldots \ldots \ldots \ldots \ldots \ldots \ldots \ldots \ldots \ldots \ldots \ldots \\
\text { Lignite } \ldots \ldots \ldots \ldots \ldots \ldots \ldots \ldots \ldots \ldots \ldots \ldots \ldots\end{array}$ & $\begin{array}{r}2 \\
8 \\
12\end{array}$ & $\begin{array}{l}36 \\
44 \\
56\end{array}$ \\
\hline
\end{tabular}

150-090-19ADB

(Log modified from Mohl Drilling, inc.)

Alttude: 1,930 feet

Date drilled: $10-01-81$

\begin{tabular}{|c|c|c|c|c|c|}
\hline Materiaj & $\begin{array}{l}\text { Thlck- } \\
\text { ness } \\
\text { (feet) }\end{array}$ & $\begin{array}{l}\text { Depth } \\
\text { (feet) }\end{array}$ & Material & $\begin{array}{l}\text { Thick- } \\
\text { ness } \\
\text { (feet) }\end{array}$ & $\begin{array}{l}\text { Denth } \\
\text { (fivgt) }\end{array}$ \\
\hline $\begin{array}{l}\text { Dirt sandy . . . . . . . } \\
\text { Rock . . . . . . . . . . }\end{array}$ & $\begin{array}{r}10 \\
5\end{array}$ & $\begin{array}{l}10 \\
15\end{array}$ & 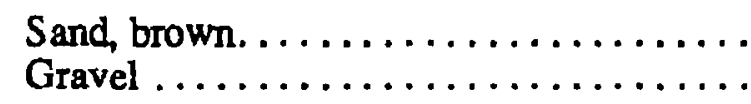 & $\begin{array}{r}60 \\
7\end{array}$ & $\begin{array}{l}75 \\
82\end{array}$ \\
\hline
\end{tabular}


Table 3. Drillers' logs of wells and test holes--Continued

150-090-24AAAB

(Log modifled from Water Supply, Inc.)

Altitude: 2,039 foet

Date drille f: $\quad 06-02-92$

\begin{tabular}{|c|c|c|c|c|c|}
\hline Material & $\begin{array}{l}\text { Thick- } \\
\text { neas } \\
\text { (feot) }\end{array}$ & $\begin{array}{l}\text { Depth } \\
\text { (feet) }\end{array}$ & Material & $\begin{array}{l}\text { Thirk- } \\
\text { nors } \\
\text { (fort) }\end{array}$ & $\begin{array}{l}\text { Depth } \\
\text { (feet) }\end{array}$ \\
\hline $\begin{array}{l}\text { Topsoil, silty, black. . . . . . . . . . . . . . } \\
\text { Gravel, fine, medium to coarse, about } \\
20 \text { percent sand . . . . . . . . . . . . . . }\end{array}$ & 1 & 1 & Clay, silty, bluish-gray; bedrock . . . . . . . . & $2^{5}$ & 40 \\
\hline
\end{tabular}

150-092-02ABA

(Log from Dingman and Gordon, 1954)

Altitude: $1,932.9$ feet

Date drilled: 1951

\begin{tabular}{|c|c|c|c|c|c|}
\hline Materlal & $\begin{array}{l}\text { Thlek- } \\
\text { nees } \\
\text { (feet) }\end{array}$ & $\begin{array}{l}\text { Depth } \\
\text { (feet) }\end{array}$ & Material & $\begin{array}{l}\text { Thirk- } \\
\text { ners } \\
\text { (fert) }\end{array}$ & $\begin{array}{l}\text { Depth } \\
\text { (feet) }\end{array}$ \\
\hline 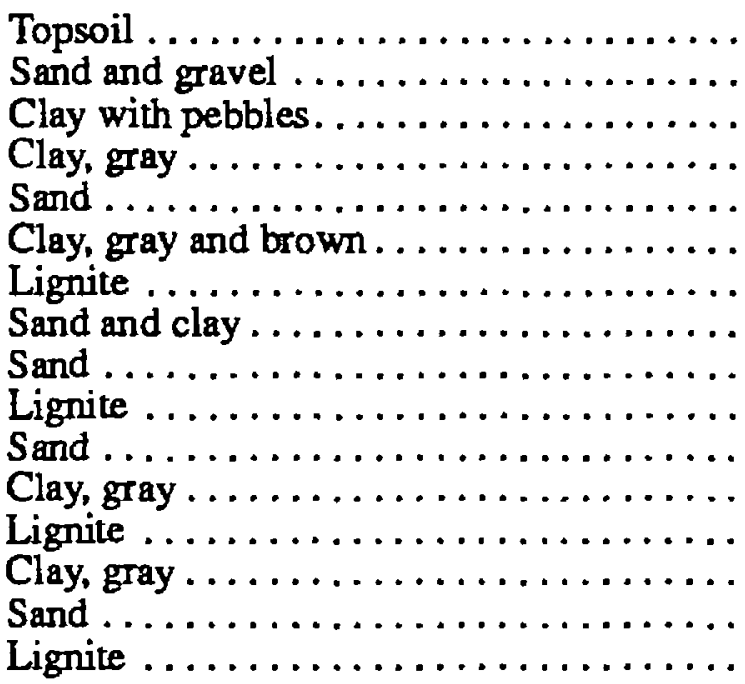 & $\begin{array}{r}2 \\
3 \\
25 \\
40 \\
34 \\
6 \\
5 \\
5 \\
5 \\
5 \\
3 \\
4 \\
3 \\
9 \\
36 \\
5\end{array}$ & $\begin{array}{r}2 \\
5 \\
30 \\
70 \\
104 \\
110 \\
115 \\
120 \\
125 \\
130 \\
133 \\
137 \\
140 \\
149 \\
185 \\
190\end{array}$ & 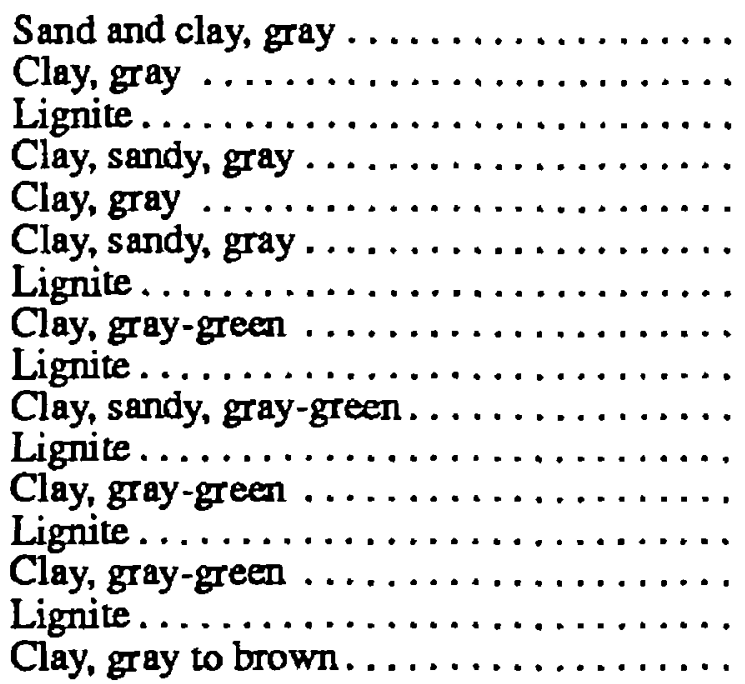 & $\begin{array}{r}16 \\
33 \\
2 \\
2 C \\
6 C \\
13 \\
17 \\
22 \\
3 \\
7 \\
3 \\
8 \\
2 \\
3 \\
2 \\
1 C\end{array}$ & $\begin{array}{l}200 \\
233 \\
235 \\
255 \\
315 \\
328 \\
345 \\
367 \\
370 \\
377 \\
380 \\
388 \\
390 \\
393 \\
395 \\
405\end{array}$ \\
\hline
\end{tabular}

150-092-12BBDA

(Log modified from Mariner Drilling Service)

Altitude: 2,020 feet

Date drille-1: 07-25-84

\begin{tabular}{|c|c|c|c|c|c|}
\hline Materlal & $\begin{array}{l}\text { Thick- } \\
\text { ness } \\
\text { (fool) }\end{array}$ & $\begin{array}{l}\text { Depth } \\
\text { (feet) }\end{array}$ & Materlal & $\begin{array}{l}\text { Thick- } \\
\text { ners } \\
\text { (foet) }\end{array}$ & $\begin{array}{l}\text { Depth } \\
\text { (feet) }\end{array}$ \\
\hline 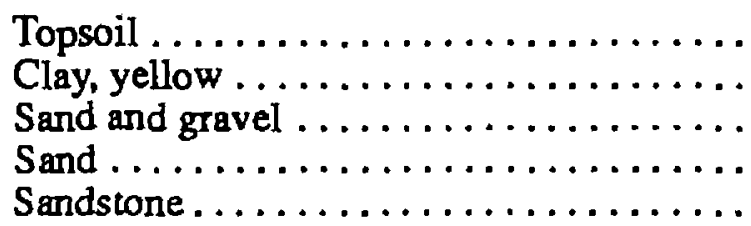 & $\begin{array}{r}2 \\
13 \\
15 \\
35 \\
\cdot\end{array}$ & $\begin{array}{r}2 \\
15 \\
30 \\
65 \\
67\end{array}$ & 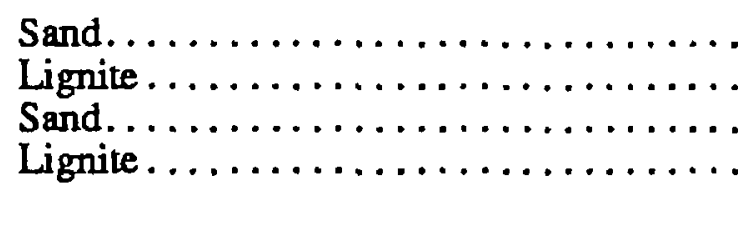 & $\begin{array}{r}23 \\
4 \\
18 \\
8\end{array}$ & $\begin{array}{r}90 \\
94 \\
112 \\
120\end{array}$ \\
\hline
\end{tabular}


Table 3. Drillers' logs of wells and test holes--Continued

150-093-01DDA

(Log from Dingman and Gordon, 1954)

\begin{tabular}{|c|c|c|c|c|c|}
\hline Material & $\begin{array}{l}\text { Thlck- } \\
\text { ness } \\
\text { (feet) }\end{array}$ & $\begin{array}{l}\text { Depth } \\
\text { (feet) }\end{array}$ & Material & $\begin{array}{l}\text { Thick- } \\
\text { ness } \\
\text { (feet) }\end{array}$ & $\begin{array}{l}\text { D-nth } \\
(i \propto 9 t)\end{array}$ \\
\hline 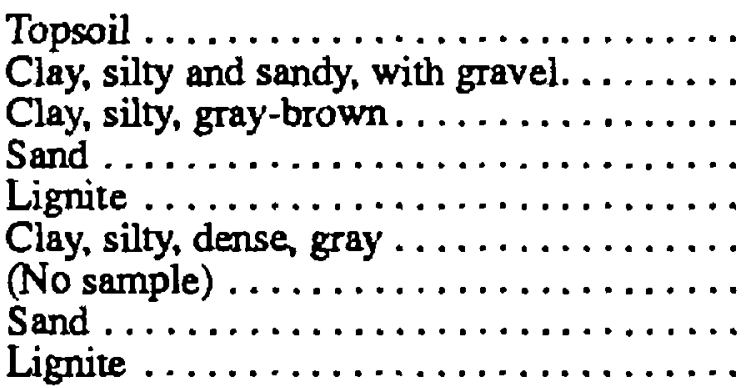 & $\begin{array}{r}3 \\
7 \\
5 \\
60 \\
5 \\
55 \\
15 \\
62 \\
3\end{array}$ & $\begin{array}{r}3 \\
10 \\
15 \\
75 \\
80 \\
135 \\
150 \\
212 \\
215\end{array}$ & 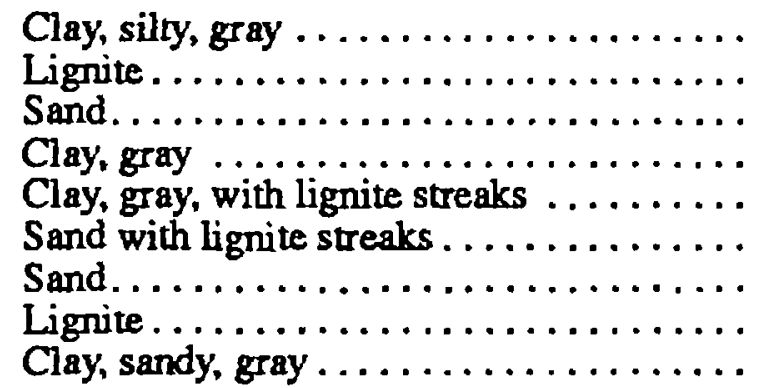 & $\begin{array}{r}5 \\
5 \\
5 \\
10 \\
15 \\
15 \\
40 \\
5 \\
15\end{array}$ & $\begin{array}{l}220 \\
225 \\
230 \\
240 \\
255 \\
270 \\
310 \\
315 \\
330\end{array}$ \\
\hline
\end{tabular}

150-093-02ADC

(Log from Dingman and Gordon, 1954)

Alttude: $2,141.7$ feet

Date drliled: 1951

\begin{tabular}{|c|c|c|c|c|c|}
\hline Materlal & $\begin{array}{l}\text { Thick- } \\
\text { ness } \\
\text { (feot) }\end{array}$ & $\begin{array}{l}\text { Depth } \\
\text { (feet) }\end{array}$ & Material & $\begin{array}{l}\text { Thick- } \\
\text { ness } \\
\text { (feet) }\end{array}$ & $\begin{array}{l}\text { Dinth } \\
\text { (feet) }\end{array}$ \\
\hline 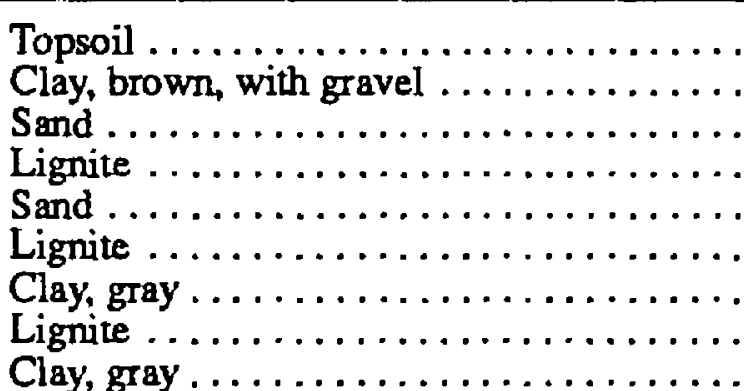 & $\begin{array}{r}5 \\
25 \\
10 \\
1 \\
18 \\
4 \\
53 \\
4 \\
26\end{array}$ & $\begin{array}{r}5 \\
30 \\
40 \\
41 \\
59 \\
63 \\
116 \\
120 \\
146\end{array}$ & 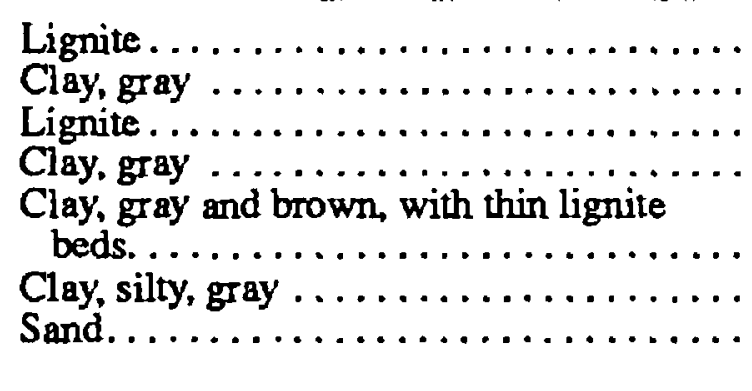 & $\begin{array}{r}8 \\
129 \\
7 \\
25 \\
15 \\
60 \\
15\end{array}$ & $\begin{array}{l}154 \\
283 \\
290 \\
315 \\
330 \\
390 \\
405\end{array}$ \\
\hline
\end{tabular}

150-093-02CBB

(Log from Dingman and Gordon, 1954)

Altitude: $2,166.8$ feet

Date drilled: 1951

\begin{tabular}{|c|c|c|c|c|c|}
\hline Material & $\begin{array}{l}\text { Thlck- } \\
\text { ness } \\
\text { (feet) }\end{array}$ & $\begin{array}{l}\text { Depth } \\
\text { (feet) }\end{array}$ & Materlal & $\begin{array}{l}\text { Thick- } \\
\text { ness } \\
\text { (feet) }\end{array}$ & $\begin{array}{l}\text { Dinth } \\
\text { (f iat) }\end{array}$ \\
\hline 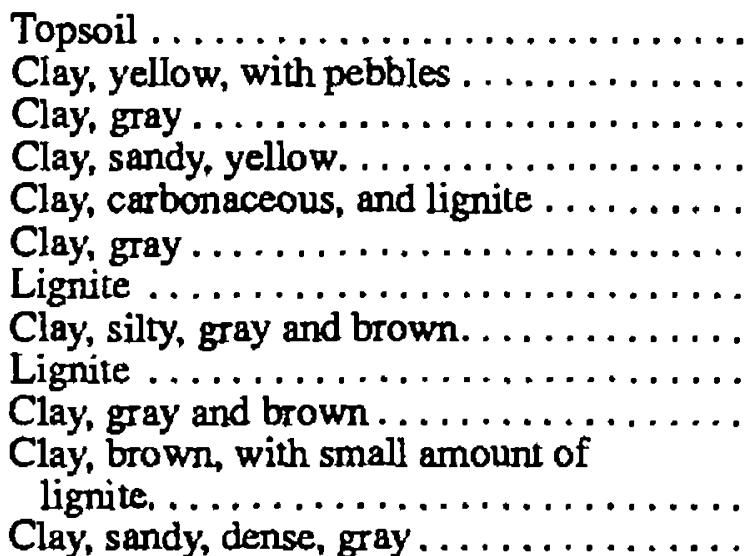 & $\begin{array}{r}3 \\
42 \\
5 \\
16 \\
2 \\
9 \\
3 \\
90 \\
3 \\
26 \\
\\
5\end{array}$ & $\begin{array}{r}3 \\
45 \\
50 \\
66 \\
68 \\
77 \\
80 \\
170 \\
173 \\
199\end{array}$ & 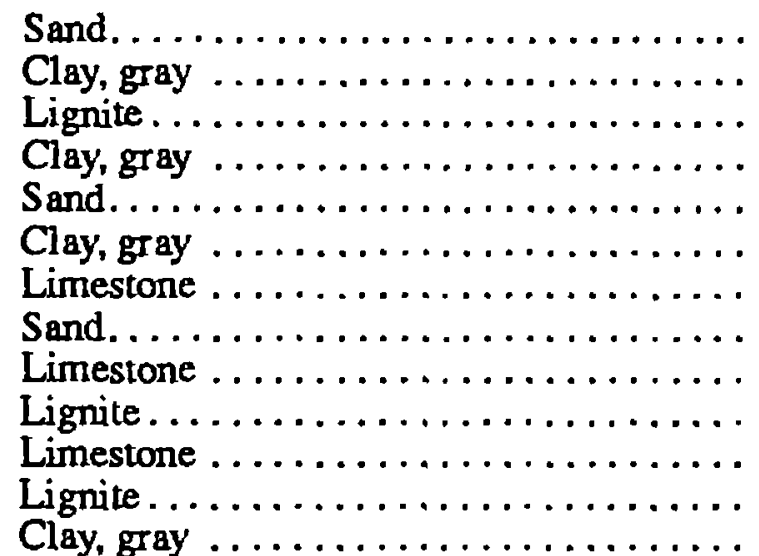 & $\begin{array}{r}1 \\
89 \\
3 \\
77 \\
10 \\
16 \\
4 \\
8 \\
1 \\
11 \\
3 \\
9 \\
33\end{array}$ & $\begin{array}{l}231 \\
220 \\
223 \\
400 \\
410 \\
426 \\
430 \\
438 \\
439 \\
450 \\
453 \\
462 \\
495\end{array}$ \\
\hline
\end{tabular}


Table 3. Drillers' logs of wells and test holes--Continued

150-093-11BAA

(Log trom Dingman and Gordon, 1954)

Alttude: 2,224.2 feet

Date drilled: 1951

\begin{tabular}{|c|c|c|c|c|c|}
\hline Material & $\begin{array}{l}\text { Thick- } \\
\text { ness } \\
\text { (feet) }\end{array}$ & $\begin{array}{l}\text { Depth } \\
\text { (feet) }\end{array}$ & Material & $\begin{array}{l}\text { Thick- } \\
\text { nese } \\
\text { (fert) }\end{array}$ & $\begin{array}{l}\text { Depth } \\
\text { (feet) }\end{array}$ \\
\hline 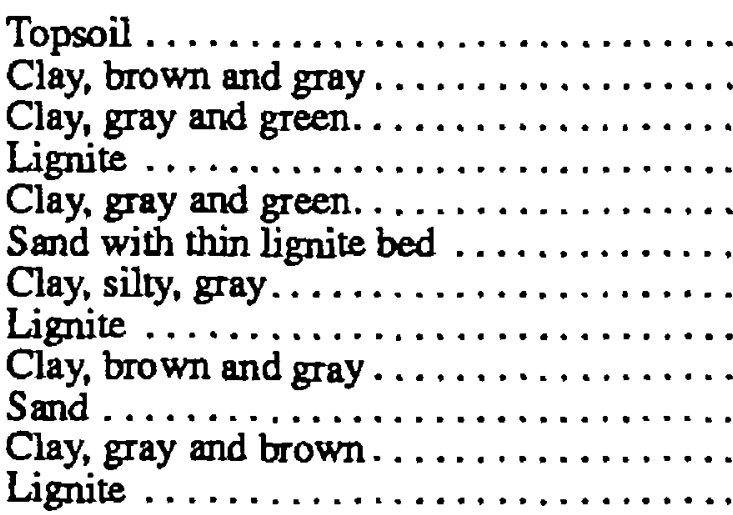 & $\begin{array}{r}3 \\
17 \\
13 \\
6 \\
61 \\
35 \\
10 \\
10 \\
40 \\
10 \\
8 \\
2\end{array}$ & $\begin{array}{r}3 \\
20 \\
33 \\
39 \\
100 \\
135 \\
145 \\
155 \\
195 \\
205 \\
213 \\
215\end{array}$ & 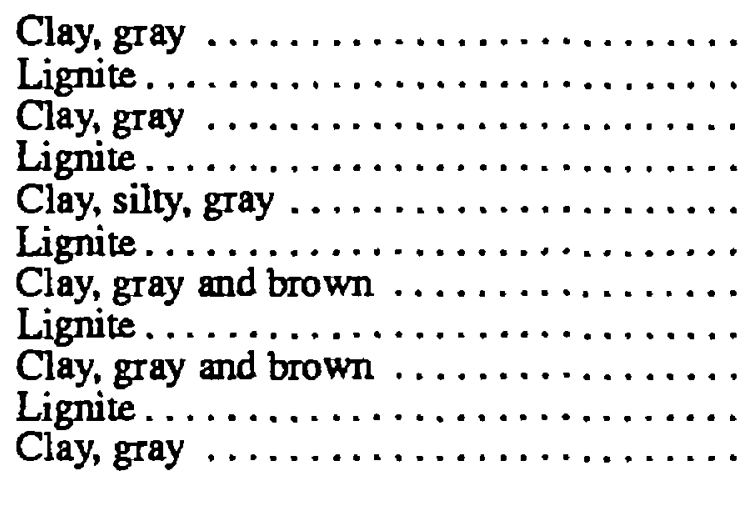 & $\begin{array}{r}15 \\
2 \\
\vdots \\
\vdots \\
31 \\
1 \\
65 \\
1 \\
30 \\
5 \\
3 C\end{array}$ & $\begin{array}{l}230 \\
232 \\
235 \\
238 \\
269 \\
270 \\
339 \\
340 \\
370 \\
375 \\
405\end{array}$ \\
\hline
\end{tabular}

150-094-19DDDA

(Log modifled from Gregory Driling, inc.)

Alttude: 2,180 feet

Date drillef: 04-21-89

\begin{tabular}{|c|c|c|c|c|c|}
\hline Material & $\begin{array}{l}\text { Thiok- } \\
\text { ness } \\
\text { (feet) }\end{array}$ & $\begin{array}{l}\text { Depth } \\
\text { (feet) }\end{array}$ & Materlal & $\begin{array}{l}\text { Thirk- } \\
\text { nese } \\
\text { (fert) }\end{array}$ & $\begin{array}{l}\text { Depth } \\
\text { (feet) }\end{array}$ \\
\hline 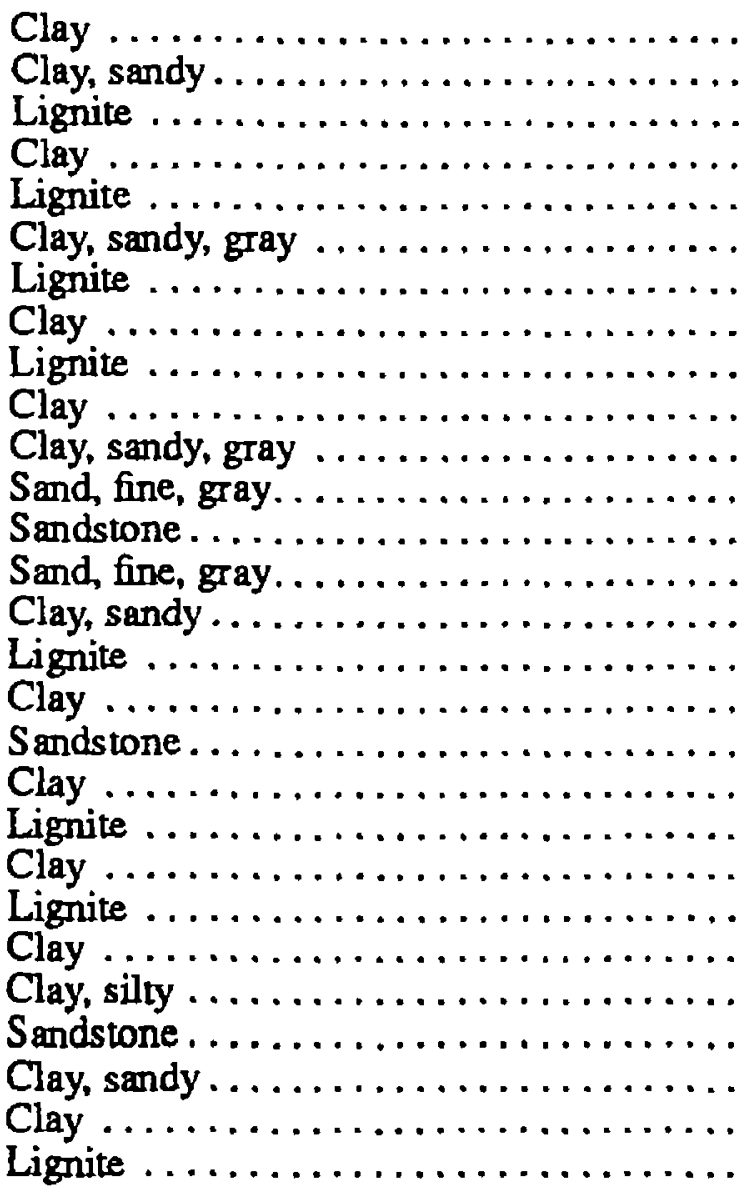 & $\begin{array}{r}6 \\
28 \\
3 \\
9 \\
2 \\
9 \\
2 \\
9 \\
2 \\
15 \\
8 \\
22 \\
1 \\
8 \\
9 \\
14 \\
63 \\
3 \\
52 \\
6 \\
6 \\
6 \\
64 \\
51 \\
1 \\
16 \\
17 \\
3\end{array}$ & $\begin{array}{r}6 \\
34 \\
37 \\
46 \\
48 \\
57 \\
59 \\
68 \\
70 \\
85 \\
93 \\
115 \\
116 \\
124 \\
133 \\
147 \\
210 \\
213 \\
265 \\
271 \\
277 \\
283 \\
347 \\
398 \\
399 \\
415 \\
432 \\
435\end{array}$ & 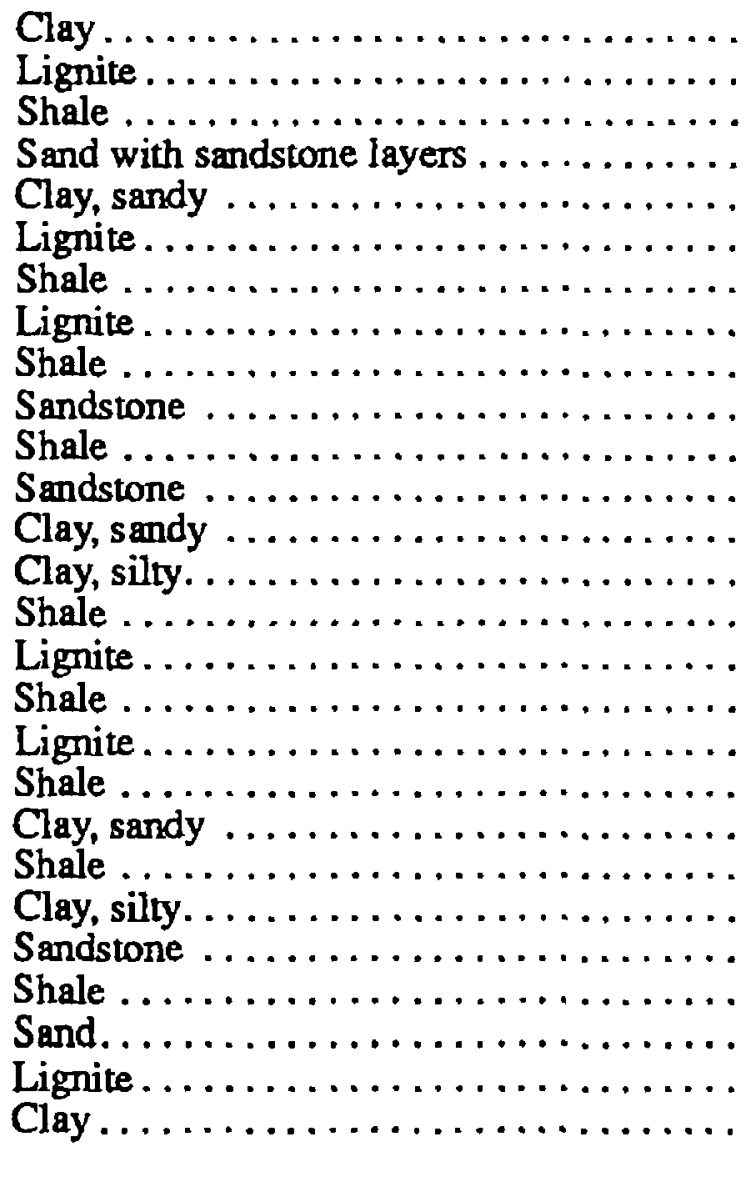 & $\begin{array}{r}35 \\
25 \\
25 \\
6 \\
5 \\
17 \\
8 \\
52 \\
1 \\
12 \\
1 \\
16 \\
21 \\
47 \\
7 \\
5 \\
4 \\
13 \\
14 \\
5 \\
11 \\
5 \\
18 \\
34 \\
3 \\
5\end{array}$ & $\begin{array}{l}474 \\
481 \\
506 \\
514 \\
520 \\
523 \\
540 \\
548 \\
600 \\
601 \\
613 \\
614 \\
630 \\
651 \\
698 \\
705 \\
714 \\
718 \\
731 \\
745 \\
754 \\
765 \\
770 \\
788 \\
822 \\
825 \\
830\end{array}$ \\
\hline
\end{tabular}


Table 3. Drillers' logs of wells and test holes--Continued

150-094-28ADA

(Log from Dingman and Gordon, 1954)

\begin{tabular}{|c|c|c|c|c|c|}
\hline Material & $\begin{array}{c}\text { Thlak- } \\
\text { ness } \\
\text { (feet) }\end{array}$ & $\begin{array}{l}\text { Depth } \\
\text { (feet) }\end{array}$ & Material & $\begin{array}{l}\text { Thick- } \\
\text { nese } \\
\text { (feet) }\end{array}$ & $\begin{array}{l}\text { Dinth } \\
\text { (feet) }\end{array}$ \\
\hline 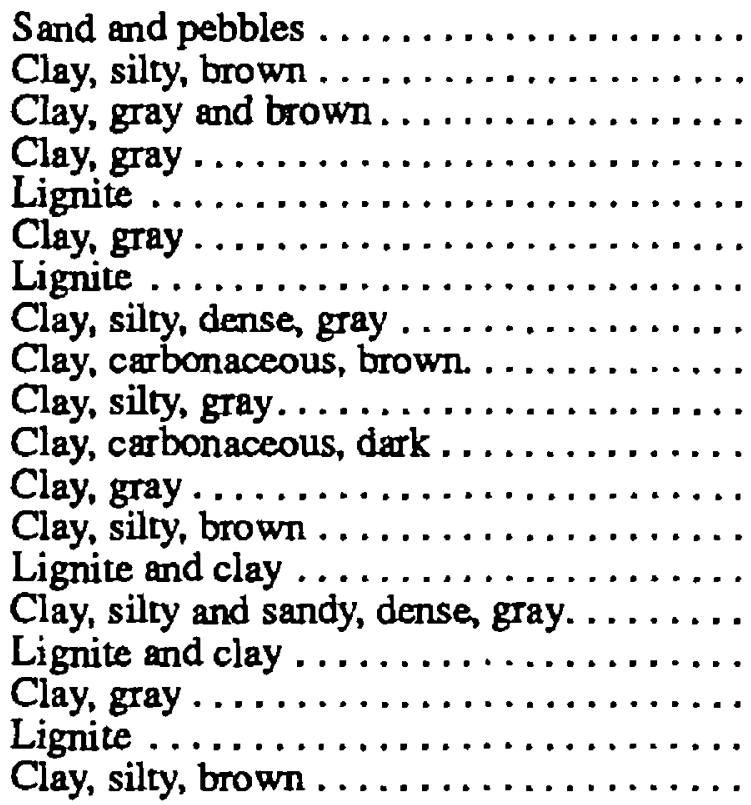 & $\begin{array}{r}12 \\
3 \\
8 \\
4 \\
3 \\
30 \\
2 \\
8 \\
3 \\
11 \\
1 \\
5 \\
4 \\
4 \\
43 \\
3 \\
21 \\
5 \\
4\end{array}$ & $\begin{array}{r}12 \\
15 \\
23 \\
27 \\
30 \\
60 \\
62 \\
70 \\
73 \\
84 \\
85 \\
90 \\
94 \\
98 \\
141 \\
144 \\
165 \\
170 \\
174\end{array}$ & 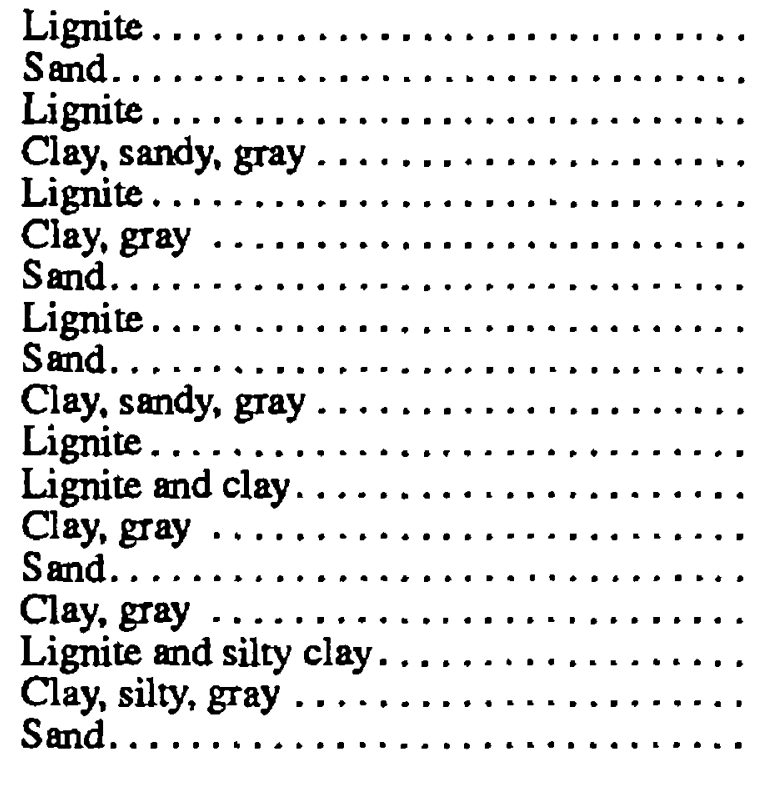 & $\begin{array}{r}3 \\
15 \\
3 \\
5 \\
3 \\
6 \\
46 \\
7 \\
23 \\
7 \\
5 \\
3 \\
15 \\
10 \\
22 \\
3 \\
10 \\
60\end{array}$ & $\begin{array}{l}177 \\
192 \\
195 \\
200 \\
203 \\
209 \\
255 \\
262 \\
285 \\
292 \\
297 \\
300 \\
315 \\
325 \\
347 \\
350 \\
360 \\
420\end{array}$ \\
\hline
\end{tabular}

150-094-32CCB

(Log from Dingman and Gordon, 1954)

\begin{tabular}{|c|c|c|c|c|c|}
\hline Material & $\begin{array}{l}\text { Thick- } \\
\text { nese } \\
\text { (feet) }\end{array}$ & $\begin{array}{l}\text { Depth } \\
\text { (feet) }\end{array}$ & Material & $\begin{array}{l}\text { Thick- } \\
\text { ness } \\
\text { (feet) }\end{array}$ & $\begin{array}{l}\text { Dinth } \\
\text { (feet) }\end{array}$ \\
\hline 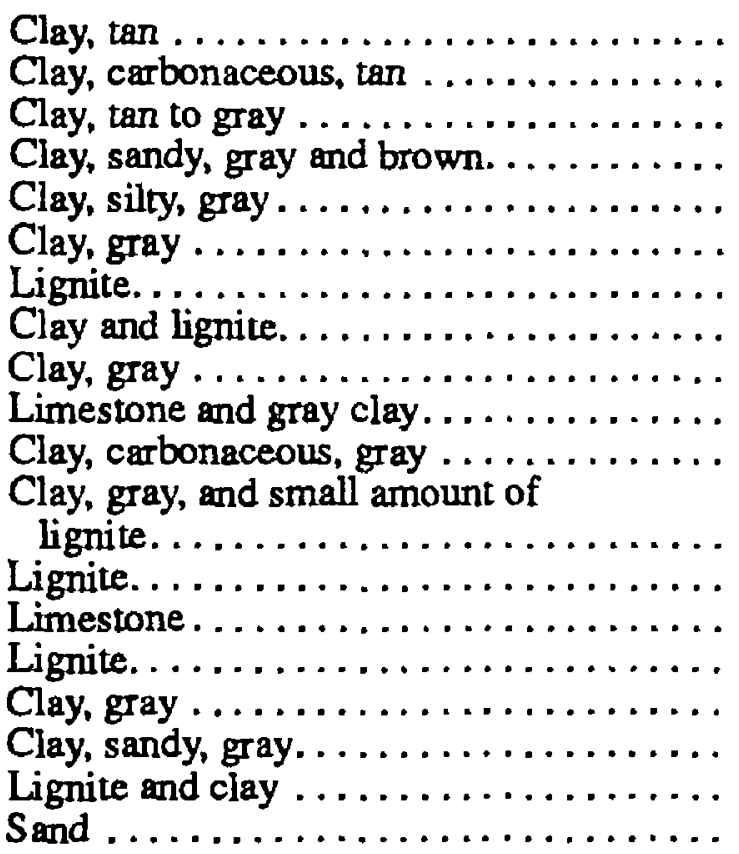 & $\begin{array}{r}20 \\
10 \\
15 \\
15 \\
5 \\
9 \\
6 \\
10 \\
10 \\
5 \\
10 \\
14 \\
9 \\
3 \\
4 \\
5 \\
8 \\
5 \\
2\end{array}$ & $\begin{array}{l}20 \\
30 \\
45 \\
60 \\
65 \\
74 \\
80 \\
90 \\
100 \\
105 \\
115 \\
129 \\
138 \\
141 \\
145 \\
150 \\
158 \\
163 \\
165\end{array}$ & 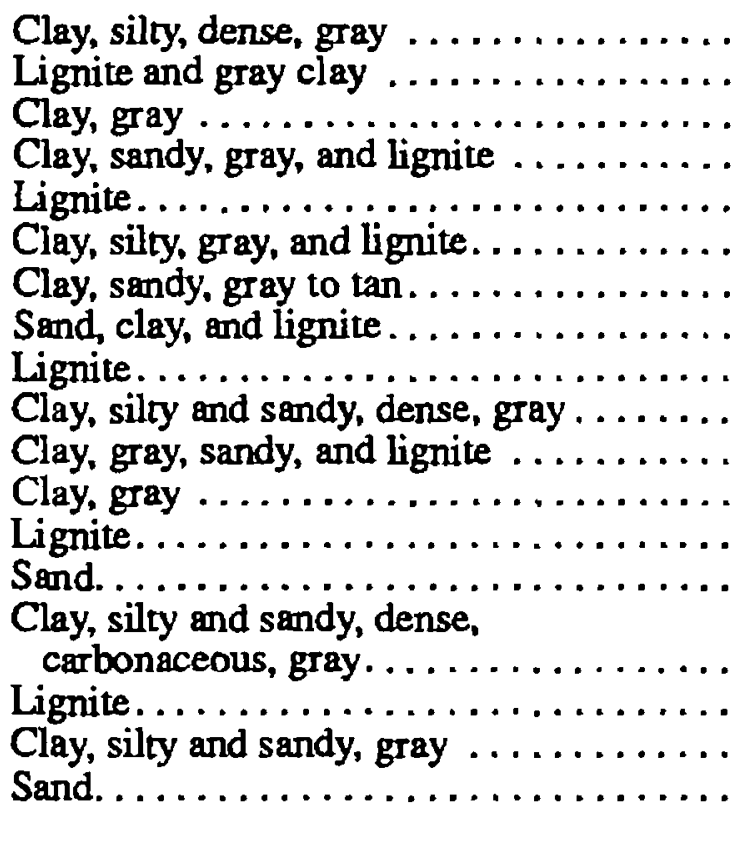 & $\begin{array}{r}15 \\
5 \\
5 \\
5 \\
5 \\
10 \\
5 \\
5 \\
5 \\
40 \\
5 \\
10 \\
5 \\
5 \\
40 \\
5 \\
45 \\
40\end{array}$ & $\begin{array}{l}180 \\
185 \\
190 \\
195 \\
200 \\
210 \\
215 \\
220 \\
225 \\
265 \\
270 \\
280 \\
285 \\
290 \\
330 \\
335 \\
380 \\
420\end{array}$ \\
\hline
\end{tabular}


Tabie 3. Drillers' logs of wells and test holes--Continued

150-094-35ACB

(Log from Dingman and Gordon, 1954)

\begin{tabular}{|c|c|c|c|c|c|}
\hline Material & $\begin{array}{l}\text { Thlck- } \\
\text { ness } \\
\text { (feet) }\end{array}$ & $\begin{array}{l}\text { Depth } \\
\text { (feat) }\end{array}$ & Materlal & $\begin{array}{l}\text { Thlek- } \\
\text { ness } \\
\text { (fert) }\end{array}$ & $\begin{array}{l}\text { Depth } \\
\text { (feet) }\end{array}$ \\
\hline 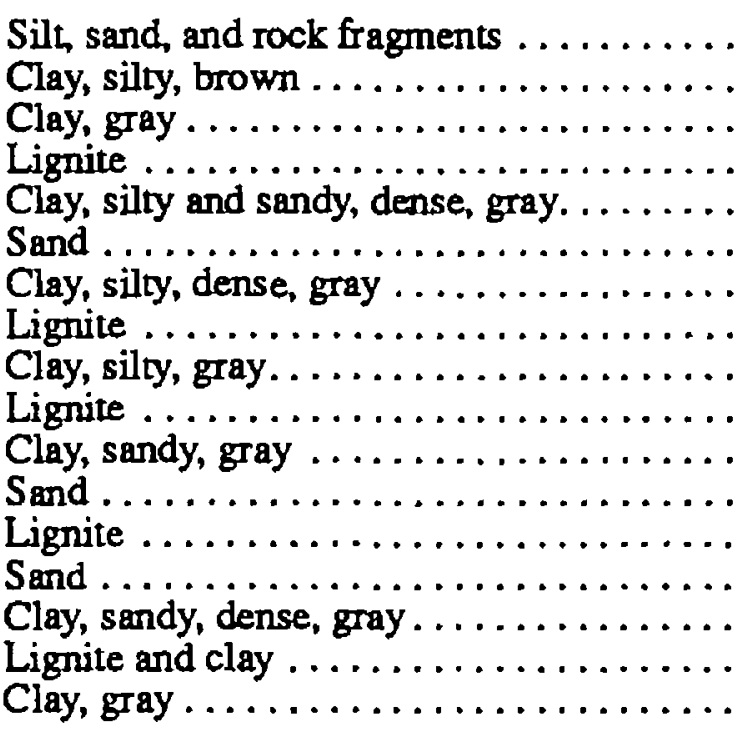 & $\begin{array}{r}5 \\
25 \\
4 \\
1 \\
55 \\
52 \\
19 \\
1 \\
18 \\
10 \\
5 \\
5 \\
2 \\
4 \\
8 \\
6 \\
6\end{array}$ & $\begin{array}{r}5 \\
30 \\
34 \\
35 \\
90 \\
142 \\
161 \\
162 \\
180 \\
190 \\
195 \\
200 \\
202 \\
206 \\
214 \\
220 \\
226\end{array}$ & 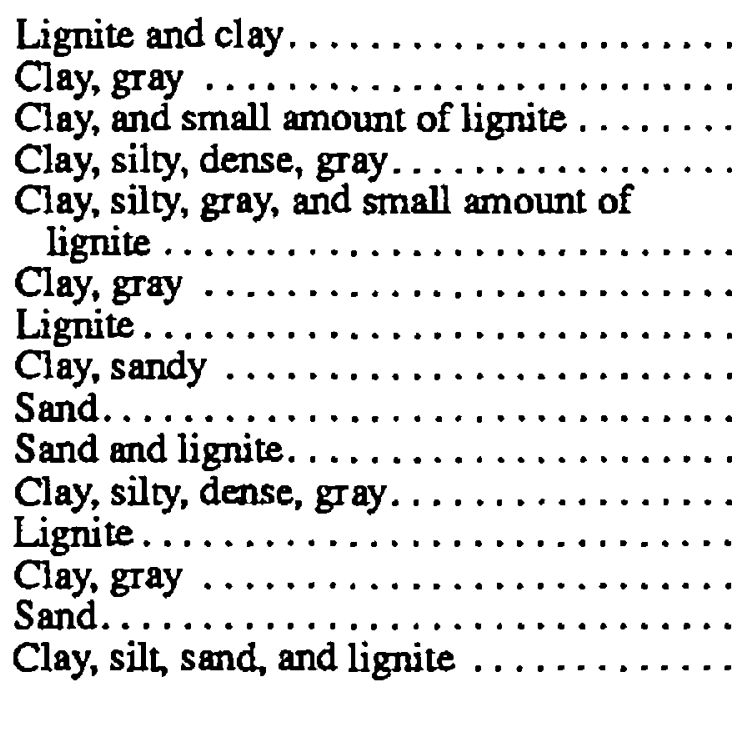 & $\begin{array}{r}1 \\
11 \\
2.5 \\
11.5 \\
1 \\
6 \\
9 \\
2 \\
8 \\
2 \\
45 \\
3 \\
17 \\
70 \\
5\end{array}$ & $\begin{array}{l}227 \\
238 \\
240.5 \\
252 \\
253 \\
259 \\
268 \\
270 \\
278 \\
280 \\
325 \\
328 \\
345 \\
415 \\
420\end{array}$ \\
\hline
\end{tabular}

150-095-05BBA1

(Log modifled trom Mann Drilling Co.)

Aititude: 2,385 feet

Date drilled: 03-02-82

\begin{tabular}{|c|c|c|c|c|c|}
\hline Material & $\begin{array}{l}\text { Thlck- } \\
\text { ness } \\
\text { (feet) }\end{array}$ & $\begin{array}{l}\text { Depth } \\
\text { (feet) }\end{array}$ & Materlat & $\begin{array}{l}\text { Thlete- } \\
\text { ness } \\
\text { (foet) }\end{array}$ & $\begin{array}{l}\text { Depth } \\
\text { (feet) }\end{array}$ \\
\hline $\begin{array}{l}\text { Clay, silty, tan. } \ldots \ldots \ldots \ldots \ldots \ldots \ldots \\
\text { Lignite } \ldots \ldots \ldots \ldots \\
\text { Clay } \ldots \ldots \ldots \ldots\end{array}$ & $\begin{array}{r}21 \\
4 \\
7 \\
6 \\
22\end{array}$ & $\begin{array}{l}21 \\
25 \\
32 \\
38 \\
60\end{array}$ & 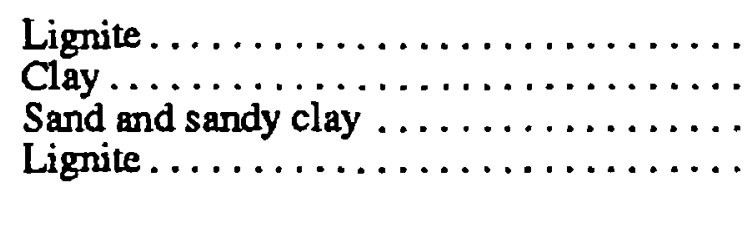 & $\begin{array}{l}26 \\
26 \\
52 \\
18\end{array}$ & $\begin{array}{r}62 \\
88 \\
140 \\
158\end{array}$ \\
\hline
\end{tabular}

150-095-09BAAB

(Log modifled from Sax Well Drllling)

Altitude: 2,220 feet

Date drillet: 09-01-82

\begin{tabular}{|c|c|c|c|c|c|}
\hline Matarial & $\begin{array}{c}\text { Thick- } \\
\text { ness } \\
\text { (feot) }\end{array}$ & $\begin{array}{l}\text { Depth } \\
\text { (feot) }\end{array}$ & Material & $\begin{array}{l}\text { Thlek- } \\
\text { ness } \\
\text { (feet) }\end{array}$ & $\begin{array}{l}\text { Depth } \\
\text { (feet) }\end{array}$ \\
\hline 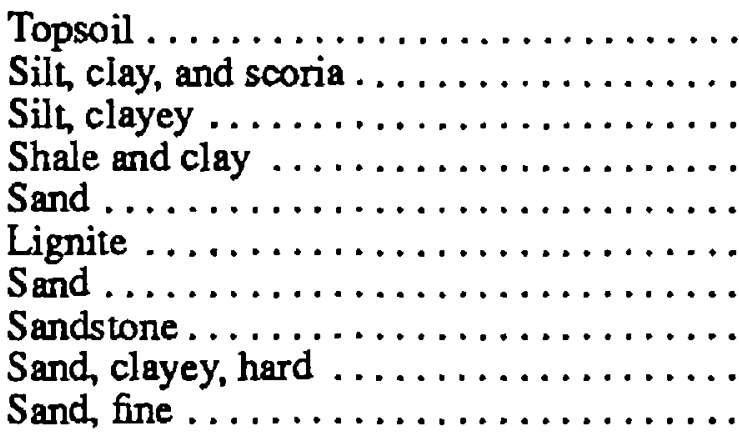 & $\begin{array}{r}2 \\
18 \\
10 \\
30 \\
10 \\
1 \\
4 \\
5 \\
7 \\
3\end{array}$ & $\begin{array}{l}2 \\
20 \\
30 \\
60 \\
70 \\
71 \\
75 \\
80 \\
87 \\
90\end{array}$ & 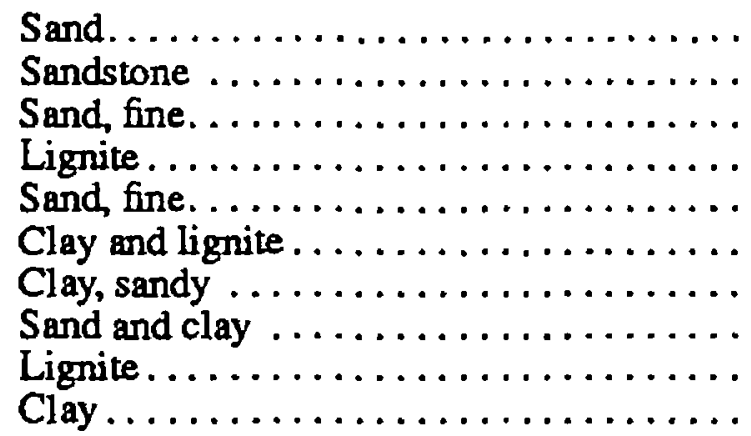 & $\begin{array}{r}21 \\
1 \\
8 \\
1 \\
8 \\
1 \\
4 \\
6 \\
5 \\
5\end{array}$ & $\begin{array}{l}111 \\
112 \\
120 \\
121 \\
129 \\
130 \\
134 \\
140 \\
145 \\
150\end{array}$ \\
\hline
\end{tabular}


Table 3. Drillers' logs of wells and test holes-Continued

150-095-09DBDC

(Log modified from Mariner Drilling Service)

Date drilled: $02-04-84$

\begin{tabular}{|c|c|c|c|c|c|}
\hline Material & $\begin{array}{l}\text { Thlek- } \\
\text { nese } \\
\text { (feel) }\end{array}$ & $\begin{array}{l}\text { Depth } \\
\text { (feet) }\end{array}$ & Material & $\begin{array}{l}\text { Thick- } \\
\text { ness } \\
\text { (feet) }\end{array}$ & $\begin{array}{l}\text { Depth } \\
(f \cdot 9 t)\end{array}$ \\
\hline 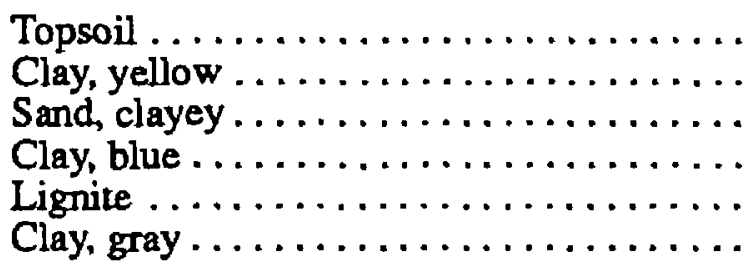 & $\begin{array}{r}1 \\
36 \\
2 \\
7 \\
2 \\
12\end{array}$ & $\begin{array}{l}1 \\
37 \\
39 \\
46 \\
48 \\
60\end{array}$ & 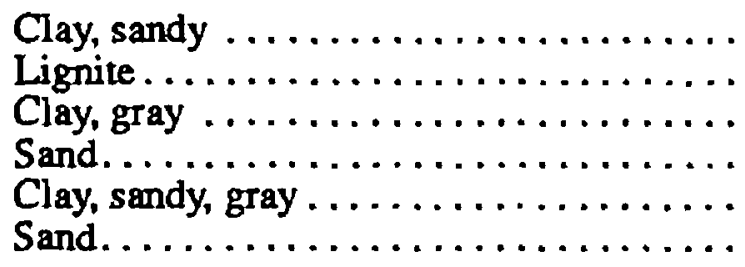 & $\begin{array}{r}45 \\
2 \\
32 \\
21 \\
26 \\
74\end{array}$ & $\begin{array}{l}175 \\
177 \\
139 \\
160 \\
186 \\
2 \times 0\end{array}$ \\
\hline
\end{tabular}

150-095-13CBCD

(Log modifled from Thompson and Murie Driliing)

Altitude: 2,070 feet

Date drilled: $05-19-88$

\begin{tabular}{|c|c|c|c|c|c|}
\hline Materlal & $\begin{array}{l}\text { Thlek- } \\
\text { ness } \\
\text { (feet) }\end{array}$ & $\begin{array}{l}\text { Depth } \\
\text { (feot) }\end{array}$ & Materlal & $\begin{array}{l}\text { Thick- } \\
\text { ness } \\
\text { (feet) }\end{array}$ & $\begin{array}{l}\text { Denth } \\
\text { (foot) }\end{array}$ \\
\hline 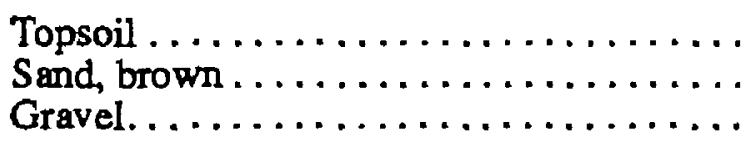 & $\begin{array}{r}2 \\
11 \\
7\end{array}$ & $\begin{array}{r}2 \\
13 \\
20\end{array}$ & 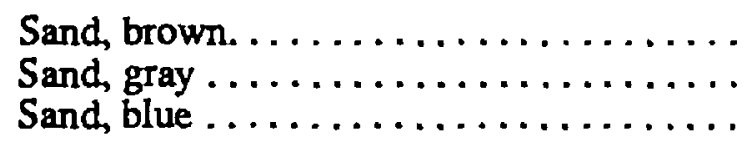 & $\begin{array}{r}15 \\
5 \\
25\end{array}$ & $\begin{array}{l}25 \\
40 \\
65\end{array}$ \\
\hline
\end{tabular}

150-095-13DCC

(Log from Dingman and Gordon, 1954)

Alttude: $2,169.58$ feet

Date drilled: 1950

\begin{tabular}{|c|c|c|c|c|c|}
\hline Materlal & $\begin{array}{l}\text { Thlck- } \\
\text { nese } \\
\text { (teet) }\end{array}$ & $\begin{array}{l}\text { Depth } \\
\text { (feet) }\end{array}$ & Matorlal & $\begin{array}{l}\text { Thick- } \\
\text { ness } \\
\text { (feet) }\end{array}$ & $\begin{array}{l}\text { Denth } \\
\text { (feat) }\end{array}$ \\
\hline 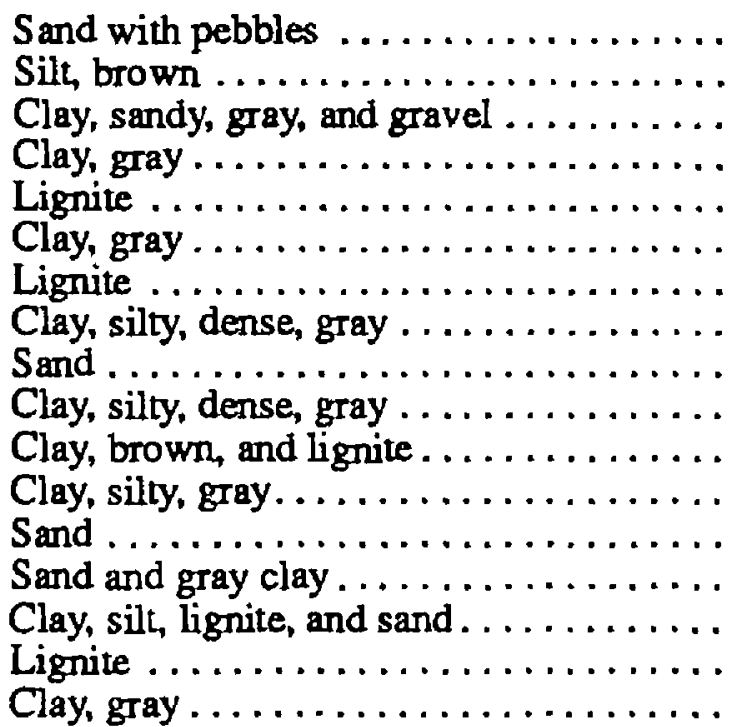 & $\begin{array}{r}20 \\
5 \\
7 \\
2 \\
9 \\
1 \\
6.5 \\
29.5 \\
7 \\
9 \\
6 \\
20 \\
63 \\
20 \\
15 \\
6.5 \\
3.5\end{array}$ & $\begin{array}{l}20 \\
25 \\
32 \\
34 \\
43 \\
44 \\
50.5 \\
80 \\
87 \\
96 \\
102 \\
122 \\
185 \\
205 \\
220 \\
226.5 \\
230\end{array}$ & 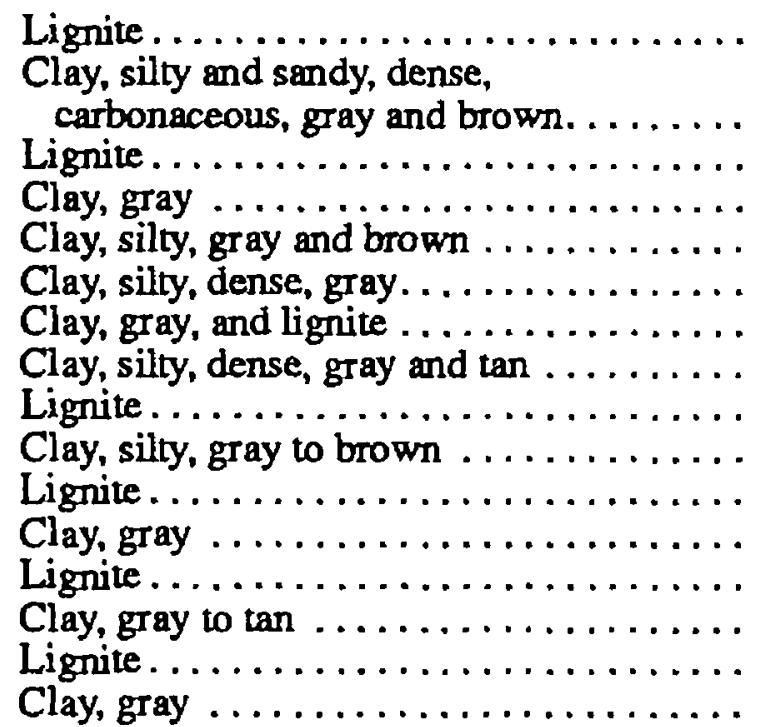 & $\begin{array}{r}4 \\
51 \\
4 \\
41 \\
20 \\
30 \\
5 \\
29 \\
6 \\
14 \\
3 \\
26 \\
6 \\
28 \\
4 \\
9\end{array}$ & $\begin{array}{l}2 ? 5 \\
2 ? 9 \\
330 \\
3: 7 \\
3 ? ? \\
3 ? 5 \\
414 \\
4 ? 0 \\
434 \\
437 \\
463 \\
469 \\
497 \\
501 \\
5 \cdot 7\end{array}$ \\
\hline
\end{tabular}


Table 3. Drillers' logs of wells and test holes--Continued

150-095-17CACA

(Log modifled from Thompson and Murie Drililing)

Altitude: 2,280 feet

Date drilled: $06-01-81$

\begin{tabular}{|c|c|c|c|c|c|}
\hline Material & $\begin{array}{l}\text { Thick- } \\
\text { ness } \\
\text { (feat) }\end{array}$ & $\begin{array}{l}\text { Depth } \\
\text { (feet) }\end{array}$ & Materlal & $\begin{array}{l}\text { Thlal - } \\
\text { near } \\
\text { (foel' }\end{array}$ & $\begin{array}{l}\text { Depth } \\
\text { (feel) }\end{array}$ \\
\hline 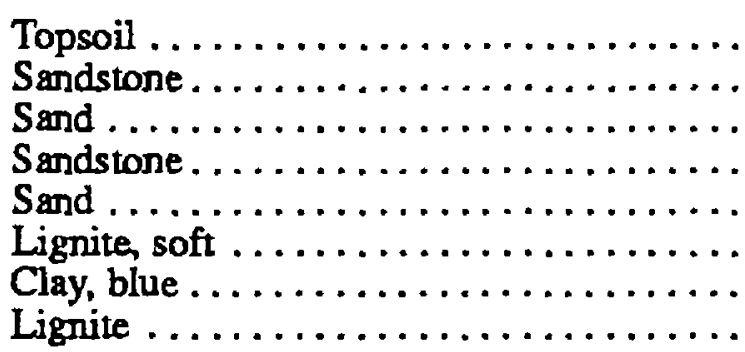 & $\begin{array}{r}3 \\
2 \\
9 \\
1 \\
5 \\
5 \\
15 \\
8\end{array}$ & $\begin{array}{r}3 \\
5 \\
14 \\
15 \\
20 \\
25 \\
40 \\
48\end{array}$ & 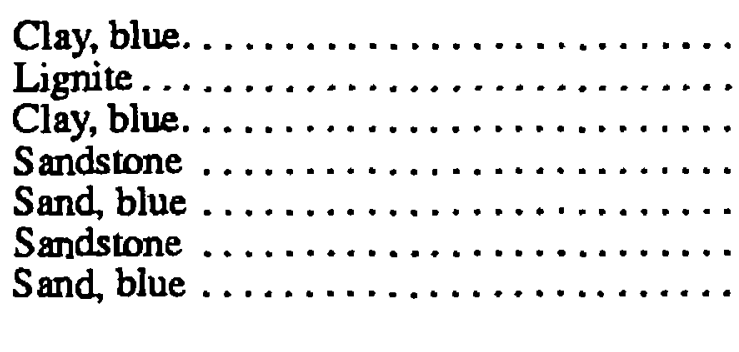 & $\begin{array}{r}29 \\
1 \\
23 \\
1 \\
13 \\
4 \\
53\end{array}$ & $\begin{array}{r}77 \\
78 \\
101 \\
102 \\
115 \\
119 \\
172\end{array}$ \\
\hline
\end{tabular}

150-095-22AAC

(Log modifled from Ralph Wold Well Drilling)

Altitude: 2,185 feet

Date drilied: $08-08-85$

\begin{tabular}{|c|c|c|c|c|c|}
\hline Materlal & $\begin{array}{l}\text { Thlok- } \\
\text { ness } \\
\text { (feet) }\end{array}$ & $\begin{array}{l}\text { Depth } \\
\text { (feet) }\end{array}$ & Materlal & $\begin{array}{l}\text { Thich - } \\
\text { near } \\
\text { (foet' }\end{array}$ & $\begin{array}{l}\text { Depth } \\
\text { (feet) }\end{array}$ \\
\hline 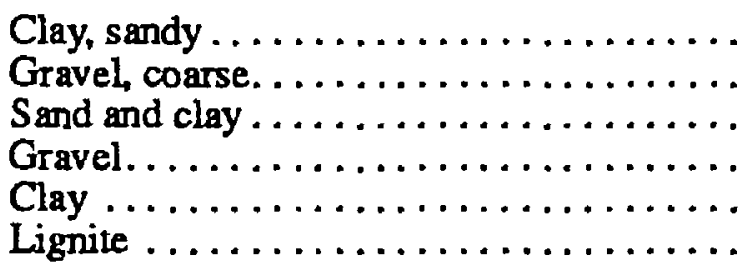 & $\begin{array}{r}10 \\
3 \\
7 \\
3 \\
8 \\
2\end{array}$ & $\begin{array}{l}10 \\
13 \\
20 \\
23 \\
31 \\
33\end{array}$ & 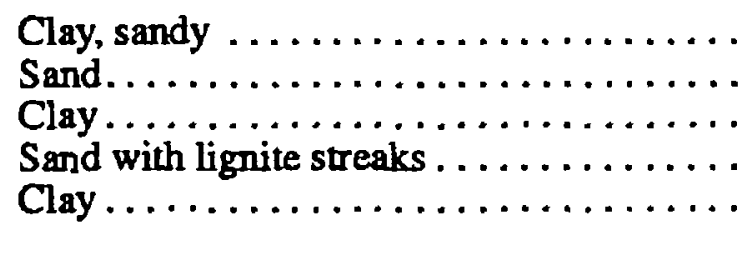 & $\begin{array}{r}57 \\
2 \\
28 \\
12 \\
5\end{array}$ & $\begin{array}{r}90 \\
92 \\
120 \\
132 \\
127\end{array}$ \\
\hline
\end{tabular}

150-095-29CAC

(Log modified from Ralph Wold Well Drilling)

Altitude: 2,300 feet

Date drilied: 08-23-75

\begin{tabular}{|c|c|c|c|c|c|}
\hline Material & $\begin{array}{l}\text { Thlck- } \\
\text { neas } \\
\text { (feet) }\end{array}$ & $\begin{array}{l}\text { Depth } \\
\text { (feet) }\end{array}$ & Material & $\begin{array}{l}\text { Thiot - } \\
\text { neses } \\
\text { (foot" }\end{array}$ & $\begin{array}{l}\text { Depth } \\
\text { (feet) }\end{array}$ \\
\hline 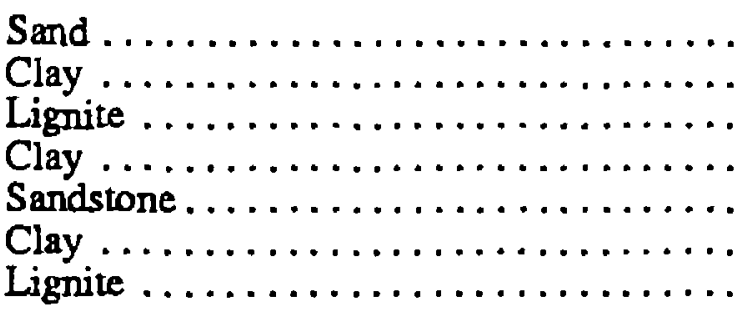 & $\begin{array}{r}5 \\
45 \\
4 \\
6 \\
2 \\
10 \\
33\end{array}$ & $\begin{array}{r}5 \\
50 \\
54 \\
60 \\
62 \\
72 \\
105\end{array}$ & 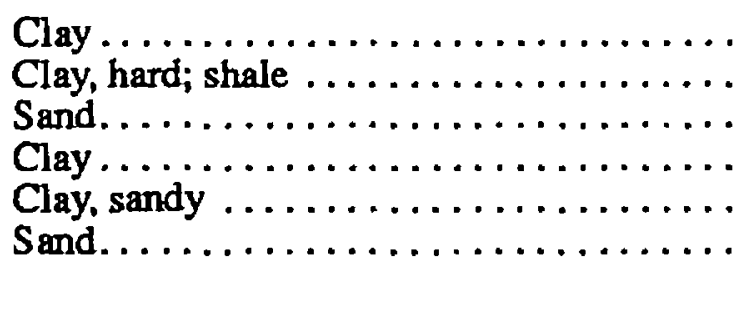 & $\begin{array}{r}20 \\
35 \\
4 \\
12 \\
34 \\
30\end{array}$ & $\begin{array}{l}125 \\
160 \\
164 \\
176 \\
210 \\
240\end{array}$ \\
\hline
\end{tabular}


Table 3. Drillers' logs of wells and test holes--Continued

150-095-32AACD

(Log modified from Sax Weil Drilling)

Altitude: 2,290 feet

Date drilled: $05-01-84$

\begin{tabular}{|c|c|c|c|c|c|}
\hline Material & $\begin{array}{l}\text { Thick- } \\
\text { nesa } \\
\text { (feel) }\end{array}$ & $\begin{array}{l}\text { Depth } \\
\text { (feet) }\end{array}$ & Material & $\begin{array}{l}\text { Thlak- } \\
\text { ness } \\
\text { (feet) }\end{array}$ & $\begin{array}{l}\text { Denpth } \\
(f \circ 9 t)\end{array}$ \\
\hline 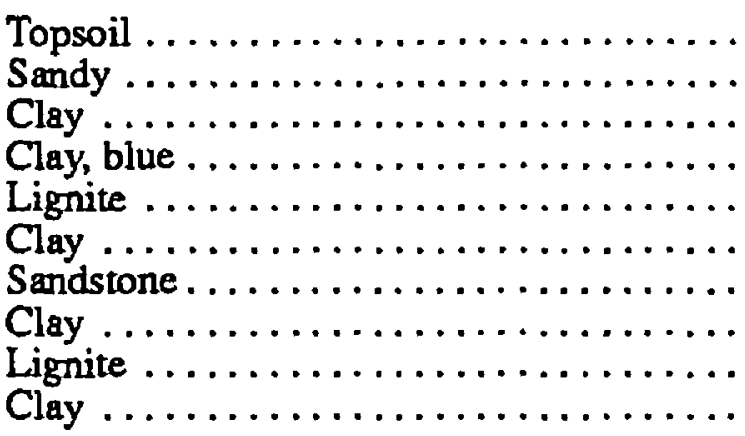 & $\begin{array}{r}1 \\
14 \\
5 \\
6 \\
1 \\
10 \\
1 \\
12 \\
4 \\
9\end{array}$ & $\begin{array}{l}1 \\
15 \\
20 \\
26 \\
27 \\
37 \\
38 \\
50 \\
54 \\
63\end{array}$ & 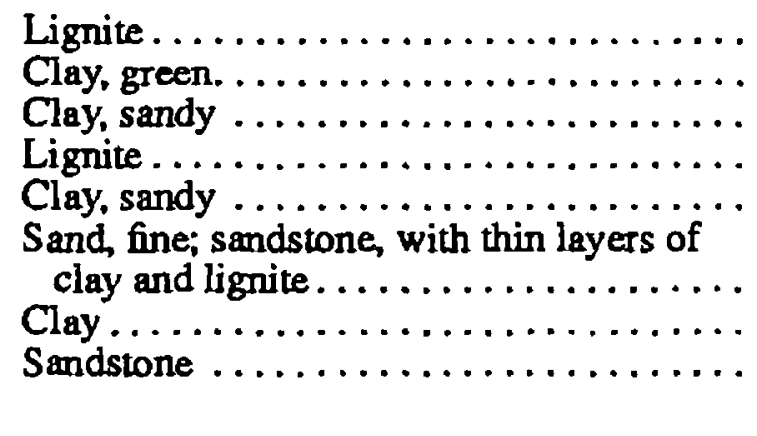 & $\begin{array}{r}5 \\
9 \\
51 \\
1 \\
51 \\
85 \\
1 \\
4\end{array}$ & $\begin{array}{r}68 \\
77 \\
128 \\
129 \\
180 \\
2.65 \\
2.66 \\
2.70\end{array}$ \\
\hline
\end{tabular}

151-088-01ABA2

(Log modifled from Mariner's Well Drilling)

Alttude: 2,095 feet

Date drilled: $09-26-81$

Meterial

151-088-25CCC

(Log modified from Mariner's Well Drilling)

Altitude: 2,155 feet

Date drilled: $11-28-81$

\begin{tabular}{|c|c|c|c|c|c|}
\hline Materlal & $\begin{array}{l}\text { Thick- } \\
\text { ness } \\
\text { (feet) }\end{array}$ & $\begin{array}{l}\text { Depth } \\
\text { (feet) }\end{array}$ & Material & $\begin{array}{l}\text { Thick- } \\
\text { ness } \\
\text { (feet) }\end{array}$ & $\begin{array}{l}\text { Depth } \\
\text { (fret) }\end{array}$ \\
\hline $\begin{array}{l}\text { Topsoil } \ldots \ldots \ldots \ldots \ldots \ldots \ldots \ldots \ldots \ldots \\
\text { Clay, sandy, yellow. } \ldots \ldots \ldots \ldots \ldots \ldots \ldots \\
\text { Clay, blue } \ldots \ldots \ldots \ldots \ldots \ldots \ldots\end{array}$ & $\begin{array}{r}2 \\
20 \\
24\end{array}$ & $\begin{array}{r}2 \\
22 \\
46\end{array}$ & 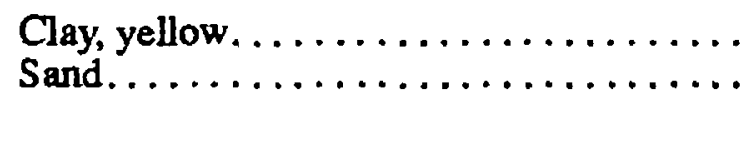 & $\begin{array}{r}15 \\
9\end{array}$ & $\begin{array}{l}61 \\
70\end{array}$ \\
\hline
\end{tabular}


Table 3. Drillers' logs of wells and test holes--Continued

151-090-03CCC

(Log modified from Water Supply, inc.)

Date drilled: Not available

\begin{tabular}{|c|c|c|c|c|c|}
\hline Material & $\begin{array}{l}\text { Thlek- } \\
\text { nees } \\
\text { (feet) }\end{array}$ & $\begin{array}{l}\text { Dopth } \\
\text { (foot) }\end{array}$ & Materjal & $\begin{array}{l}\text { Thlck- } \\
\text { noss } \\
\text { (foer' }\end{array}$ & $\begin{array}{l}\text { Depth } \\
\text { (foot) }\end{array}$ \\
\hline 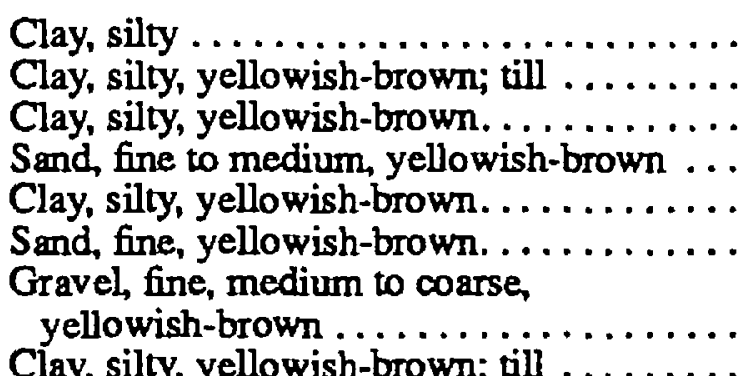 & $\begin{array}{r}1 \\
27 \\
4 \\
3 \\
5 \\
9 \\
3 \\
6\end{array}$ & $\begin{array}{l}1 \\
28 \\
32 \\
35 \\
40 \\
49 \\
52 \\
58\end{array}$ & 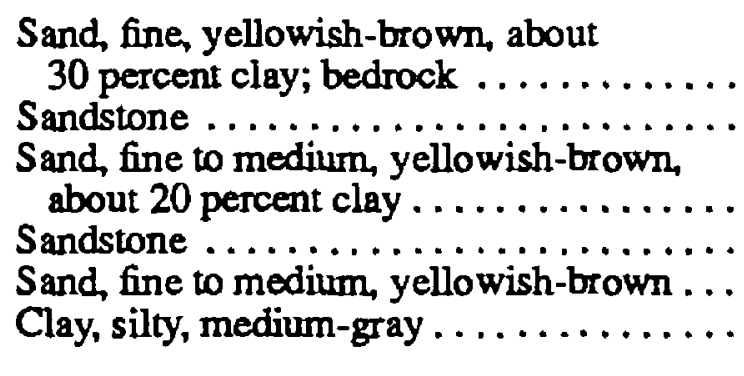 & $\begin{array}{r}17 \\
1 \\
14 \\
3 \\
12 \\
2\end{array}$ & $\begin{array}{r}75 \\
76 \\
90 \\
93 \\
105 \\
107\end{array}$ \\
\hline
\end{tabular}

151-090-06DAD

(Log modified from Water Supply, Inc.)

\begin{tabular}{|c|c|c|c|c|c|}
\hline Material & $\begin{array}{l}\text { Thick- } \\
\text { nees } \\
\text { (feet) }\end{array}$ & $\begin{array}{l}\text { Depth } \\
\text { (feot) }\end{array}$ & Material & $\begin{array}{l}\text { Thich } \\
\text { ness } \\
\text { (feet: }\end{array}$ & $\begin{array}{l}\text { Depth } \\
\text { (feot) }\end{array}$ \\
\hline $\begin{array}{l}\text { Topsoil, silty, black . . . . . . . . . . . . . . } \\
\text { Clay, silty, y ellowish-brown; till . . . . . . } \\
\text { Sand, fine to medium, yellowish-brown; } \\
\text { bedrock . . . . . . . . . . . . . . . . . . . } \\
\text { Clay, silty, yellowish-brown. . . . . . . . . } \\
\text { Clay, silty, medium-gray . . . . . . . . . . } \\
\text { Sandstone . . . . . . . . . . . . . . . . . . . . }\end{array}$ & $\begin{array}{r}1 \\
18 \\
13 \\
4 \\
11 \\
.5\end{array}$ & $\begin{array}{l}1 \\
19 \\
32 \\
36 \\
47 \\
47.5\end{array}$ & 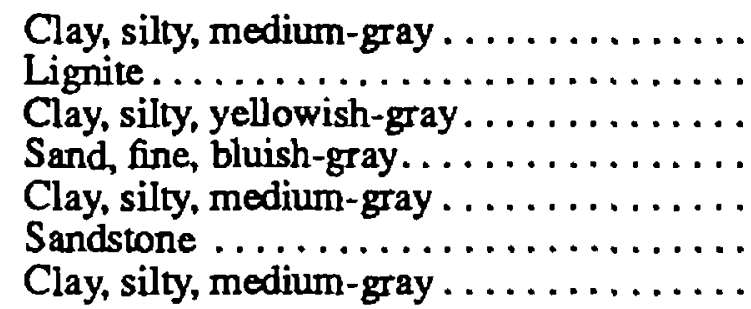 & $\begin{array}{r}21.5 \\
3 \\
9 \\
60 \\
10 \\
.5 \\
8.5\end{array}$ & $\begin{array}{l}69 \\
72 \\
81 \\
141 \\
151 \\
151.5 \\
160\end{array}$ \\
\hline
\end{tabular}

151-090-09BBB

(Log modifled from Water Supply, Inc.)

Alttude: 2,025 feet

Date drilled: $04-03-84$

\begin{tabular}{|c|c|c|c|c|c|}
\hline Matertal & $\begin{array}{l}\text { Thlak- } \\
\text { ness } \\
\text { (feel) }\end{array}$ & $\begin{array}{l}\text { Depth } \\
\text { (feet) }\end{array}$ & Materlal & $\begin{array}{l}\text { Thich - } \\
\text { nees } \\
\text { (feet' }\end{array}$ & $\begin{array}{l}\text { Depth } \\
\text { (feet) }\end{array}$ \\
\hline 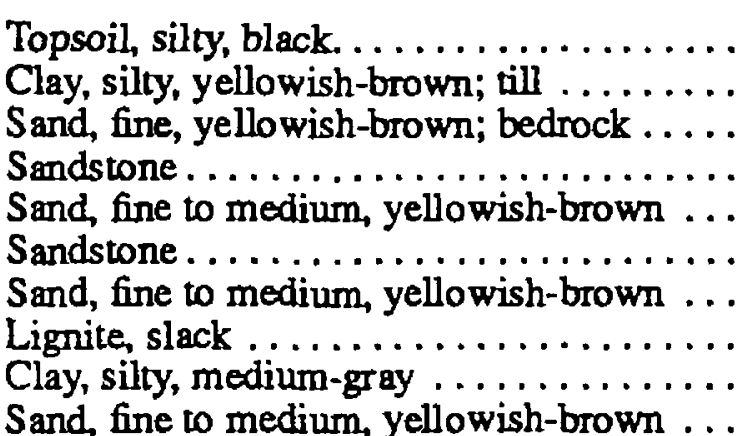 & $\begin{array}{r}1 \\
5 \\
33 \\
3 \\
9 \\
4 \\
29 \\
1 \\
15 \\
3\end{array}$ & $\begin{array}{r}1 \\
6 \\
39 \\
42 \\
51 \\
55 \\
84 \\
85 \\
100 \\
103\end{array}$ & 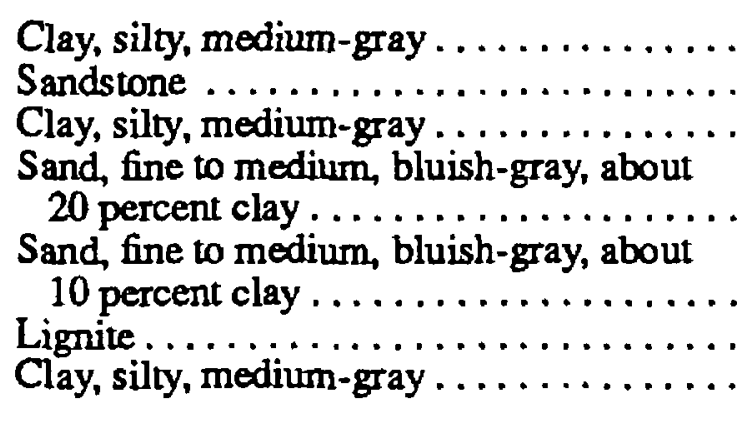 & $\begin{array}{r}12 \\
7.5 \\
11 \\
\\
5 \\
6 \\
15\end{array}$ & $\begin{array}{l}115 \\
115.5 \\
123 \\
134 \\
139 \\
145 \\
160\end{array}$ \\
\hline
\end{tabular}


Table 3. Drillers' logs of wells and test holes--Continued

151-090-11AAB

(Log modified from Dennis Water Well Driliing)

Aittude: 2,045 feet

Date drilled: 06-25-84

\begin{tabular}{|c|c|c|c|c|c|}
\hline Material & $\begin{array}{l}\text { Thlck- } \\
\text { neas } \\
\text { (feet) }\end{array}$ & $\begin{array}{l}\text { Depth } \\
\text { (feet) }\end{array}$ & Msterial & $\begin{array}{l}\text { Thick- } \\
\text { ness } \\
\text { (feet) }\end{array}$ & $\begin{array}{l}\text { Donth } \\
(f>\oplus)\end{array}$ \\
\hline 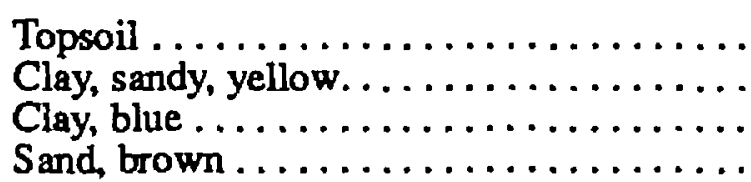 & $\begin{array}{l}1 \\
43 \\
24 \\
19\end{array}$ & $\begin{array}{r}1 \\
44 \\
68 \\
87\end{array}$ & 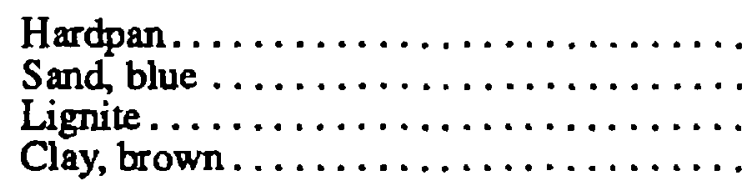 & $\begin{array}{r}2 \\
33 \\
2 \\
1\end{array}$ & $\begin{array}{r}89 \\
122 \\
124 \\
125\end{array}$ \\
\hline
\end{tabular}

151-090-19BAA

(Log modified trom Dennis Water Well Driiing)

Aititude: 2,110 feet

Date drilied: 07-09-85

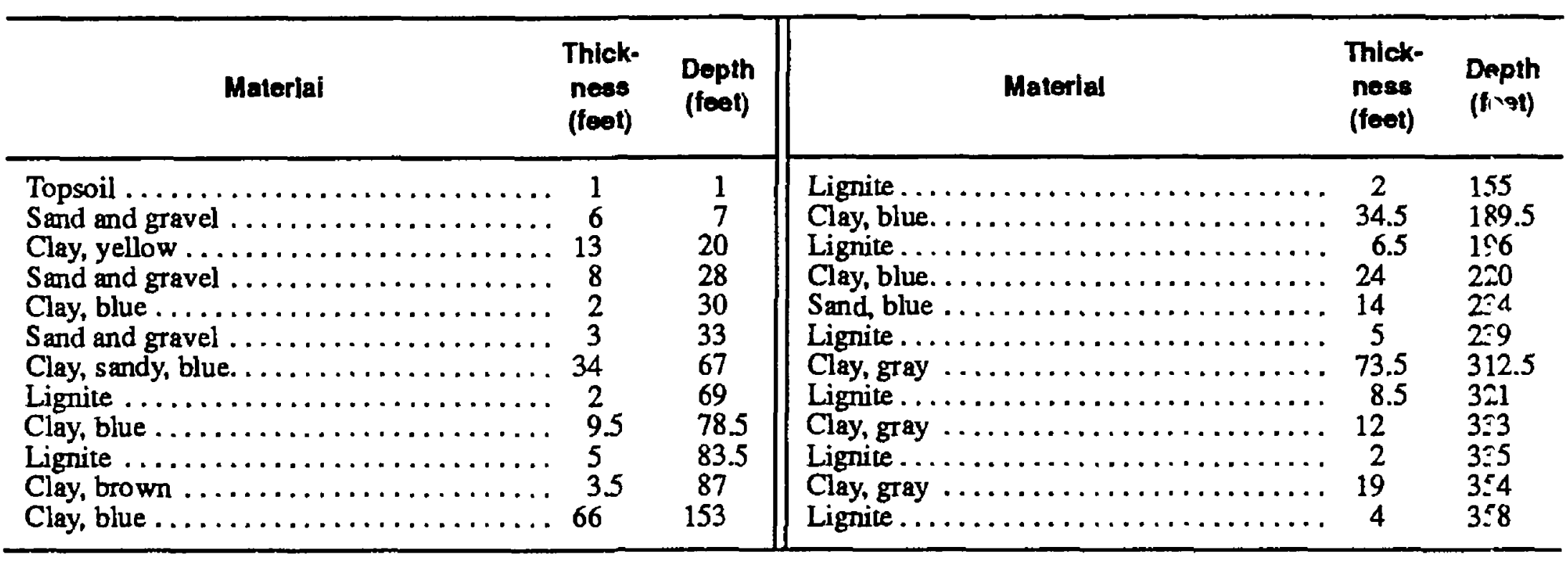

151-090-25BAA

(Log modified from Dennis Water Weli Dritiing)

Altitude: 2,190 feet

Date driiled: $10-13-84$

\begin{tabular}{|c|c|c|c|c|c|}
\hline Materisl & $\begin{array}{l}\text { Thick- } \\
\text { neas } \\
\text { (feet) }\end{array}$ & $\begin{array}{l}\text { Depth } \\
\text { (feet) }\end{array}$ & Material & $\begin{array}{l}\text { Thick- } \\
\text { ness } \\
\text { (feet) }\end{array}$ & $\begin{array}{l}\text { Depth } \\
\text { (frel) }\end{array}$ \\
\hline 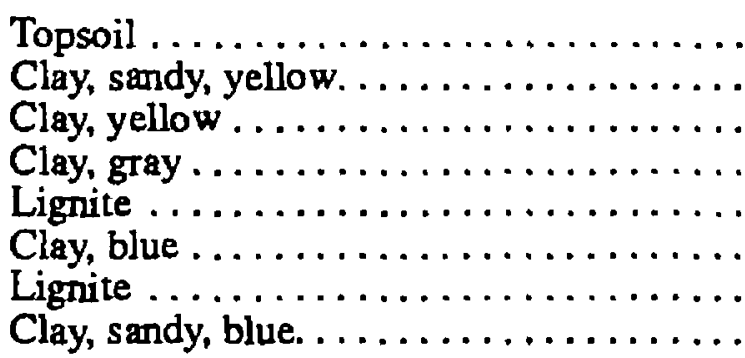 & $\begin{array}{r}1 \\
24 \\
20 \\
63 \\
1 \\
6 \\
2 \\
44\end{array}$ & $\begin{array}{r}1 \\
25 \\
45 \\
108 \\
109 \\
115 \\
117 \\
161\end{array}$ & 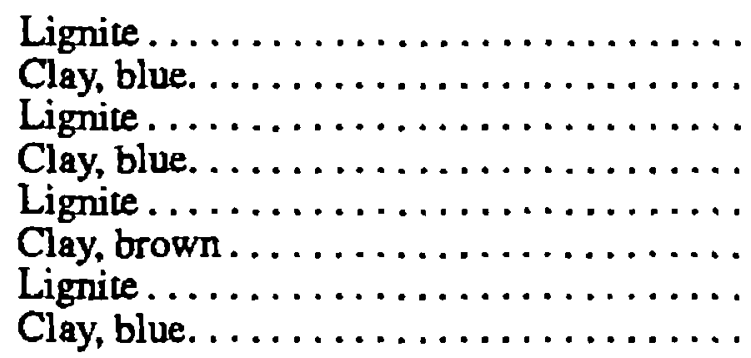 & $\begin{array}{l}1 \\
2 \\
2 \\
2 \\
2 \\
2 \\
2 \\
6\end{array}$ & $\begin{array}{l}162 \\
164 \\
166 \\
168 \\
170 \\
172 \\
174 \\
180\end{array}$ \\
\hline
\end{tabular}


Tabie 3. Drillers' logs of wells and test holes-Cortinued

151-090-29BBC

(Log modified from Mann Driliing Co.)

Aititude: 2,150 feet

Date drilted: $10-19-82$

\begin{tabular}{|c|c|c|c|c|c|}
\hline Materlal & $\begin{array}{l}\text { Thlck- } \\
\text { ness } \\
\text { (feol) }\end{array}$ & $\begin{array}{l}\text { Depth } \\
\text { (feet) }\end{array}$ & Meterial & $\begin{array}{l}\text { Thisk- } \\
\text { nere } \\
\text { (fert) }\end{array}$ & $\begin{array}{l}\text { Depth } \\
\text { (foet) }\end{array}$ \\
\hline 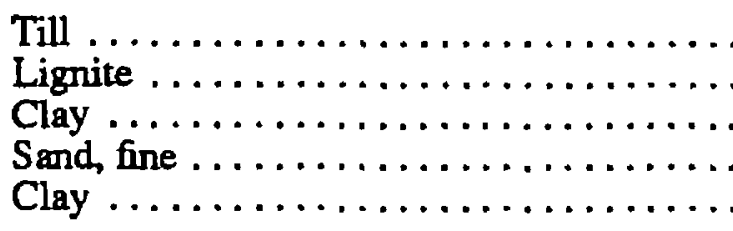 & $\begin{array}{r}40 \\
4 \\
266 \\
25 \\
205\end{array}$ & $\begin{array}{r}40 \\
44 \\
310 \\
335 \\
540\end{array}$ & $\begin{array}{l}\text { Sand } \ldots \ldots \ldots \ldots \ldots \ldots \ldots \ldots \ldots \ldots \ldots \ldots \ldots \ldots \\
\text { Clay } \ldots \ldots \ldots \ldots \ldots \ldots \ldots \ldots \ldots \ldots \ldots \ldots \ldots \ldots \ldots \ldots \\
\text { Sand. } \ldots \ldots \ldots \ldots \ldots \ldots \ldots \ldots \ldots \ldots \ldots \ldots\end{array}$ & $\begin{array}{r}30 \\
1,0 \times 0 \\
30 \\
10\end{array}$ & $\begin{array}{r}570 \\
1,580 \\
1,610 \\
1,620\end{array}$ \\
\hline
\end{tabular}

151-090-36ADD

(Log modifled from Dennis Water Weli Driiling)

Aititude: 2,175 foet

Date drill 3d: $10-16-84$

\begin{tabular}{l}
\hline Material \\
\end{tabular}

151-091-01BAA

(Log moditied from Water Supply, Inc.)

Altitude: 1,895 feet

Date drilled: $04-04-84$

\begin{tabular}{|c|c|c|c|c|c|}
\hline Material & $\begin{array}{l}\text { Thick- } \\
\text { ness } \\
\text { (feet) }\end{array}$ & $\begin{array}{l}\text { Depth } \\
\text { (feet) }\end{array}$ & Material & $\begin{array}{l}\text { Thick- } \\
\text { ners } \\
\text { (feet) }\end{array}$ & $\begin{array}{l}\text { Depth } \\
\text { (feet) }\end{array}$ \\
\hline 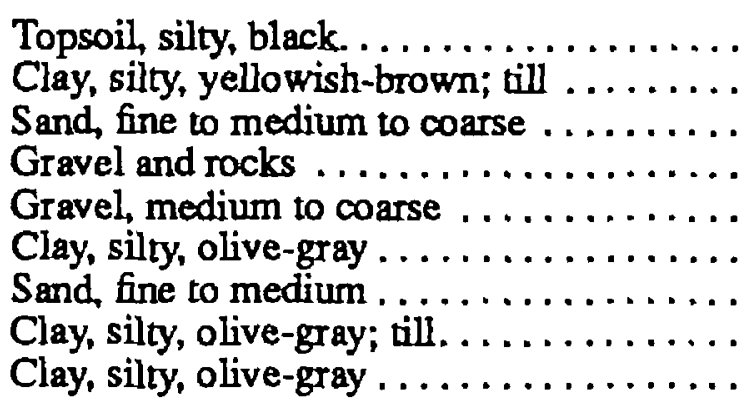 & $\begin{array}{r}1 \\
4 \\
2 \\
2 \\
8 \\
9 \\
3 \\
35 \\
6\end{array}$ & $\begin{array}{r}1 \\
5 \\
7 \\
9 \\
17 \\
26 \\
29 \\
64 \\
70\end{array}$ & 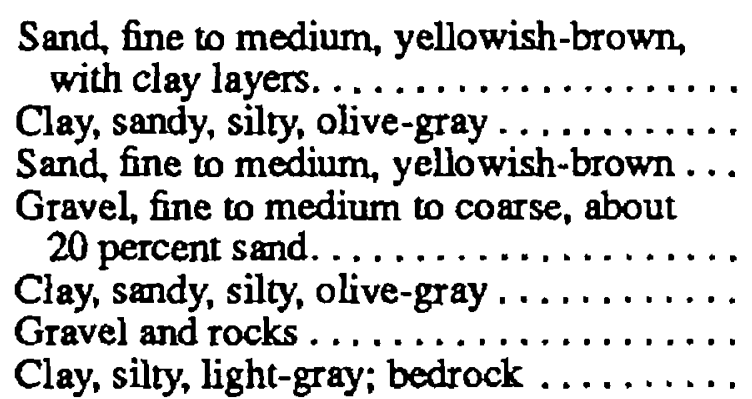 & $\begin{array}{r}14 \\
16 \\
9 \\
\\
15 \\
6 \\
1 \\
4\end{array}$ & $\begin{array}{r}84 \\
100 \\
109 \\
\\
124 \\
130 \\
131 \\
135\end{array}$ \\
\hline
\end{tabular}


Table 3. Drillers' logs of wells and test holes--Continued

151-091-02CDC

(Log modifiled from Mann Drilling Co.)

Alttude: 1,875 feet

Date drliled: $07-24-84$

\begin{tabular}{|c|c|c|c|c|c|}
\hline Material & $\begin{array}{l}\text { Thlok- } \\
\text { ness } \\
\text { (feet) }\end{array}$ & $\begin{array}{l}\text { Depth } \\
\text { (feet) }\end{array}$ & Material & $\begin{array}{l}\text { Thlok- } \\
\text { ness } \\
\text { (feet) }\end{array}$ & $\begin{array}{l}\text { Depth } \\
\left(f_{i} \times g t\right)\end{array}$ \\
\hline $\begin{array}{l}\text { Sand } \ldots \ldots \ldots \ldots \ldots \ldots \\
\text { Clay, silty . . . . . . . . }\end{array}$ & $\begin{array}{l}21 \\
44\end{array}$ & $\begin{array}{l}21 \\
65\end{array}$ & Sand fine. . . . . . . . . . . . . . . & 20 & 85 \\
\hline
\end{tabular}

151-091-11BAA1

(Log moditied from Mann Driling Co.)

Altitude: 1,875 feet

Date drilled: $\quad 09-17-82$

\begin{tabular}{|c|c|c|c|c|c|}
\hline Materlal & $\begin{array}{l}\text { Thlok- } \\
\text { ness } \\
\text { (feet) }\end{array}$ & $\begin{array}{l}\text { Depth } \\
\text { (feef) }\end{array}$ & Material & $\begin{array}{l}\text { Thick- } \\
\text { ness } \\
\text { (feet) }\end{array}$ & $\begin{array}{l}\text { Denth } \\
\text { (fint) }\end{array}$ \\
\hline $\begin{array}{l}\text { Sand, silty . . . . . . . . } \\
\text { Clay, silty . . . . . . }\end{array}$ & $\begin{array}{l}27 \\
29\end{array}$ & $\begin{array}{l}27 \\
56\end{array}$ & Gravel $\ldots \ldots \ldots \ldots \ldots \ldots \ldots \ldots \ldots$ & 9 & 65 \\
\hline
\end{tabular}

151-091-11BAA2

( $L o g$ modifled from Mann Drilling Co.)

Altitude: 1,875 foet

Date drliled: $07-24-84$

\begin{tabular}{|c|c|c|c|c|c|}
\hline Materlal & $\begin{array}{l}\text { Thick- } \\
\text { ness } \\
\text { (feet) }\end{array}$ & $\begin{array}{l}\text { Depth } \\
\text { (feet) }\end{array}$ & Matorlal & $\begin{array}{l}\text { Thick- } \\
\text { ness } \\
\text { (feet) }\end{array}$ & $\begin{array}{l}\text { Depth } \\
\text { (frat) }\end{array}$ \\
\hline $\begin{array}{l}\text { Sand } \ldots \ldots \ldots \ldots \ldots \ldots \\
\text { Till } \ldots \ldots \ldots \ldots \ldots \ldots\end{array}$ & $\begin{array}{l}12 \\
45\end{array}$ & $\begin{array}{l}12 \\
57\end{array}$ & 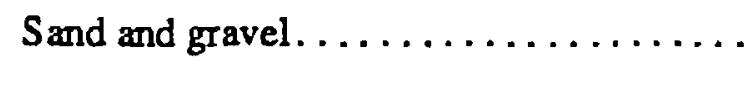 & 13 & 70 \\
\hline
\end{tabular}

151-091-11BBB2

(Log modifled from Mann Drilling Co.)

Altitude: 1,880 feet

Date drilled: $05-06-80$

\begin{tabular}{|c|c|c|c|c|c|}
\hline Material & $\begin{array}{l}\text { Thick- } \\
\text { ness } \\
\text { (feet) }\end{array}$ & $\begin{array}{l}\text { Depth } \\
\text { (feet) }\end{array}$ & Material & $\begin{array}{l}\text { Thlck- } \\
\text { ness } \\
\text { (feet) }\end{array}$ & $\begin{array}{l}\text { Denth } \\
\text { (fenat) }\end{array}$ \\
\hline 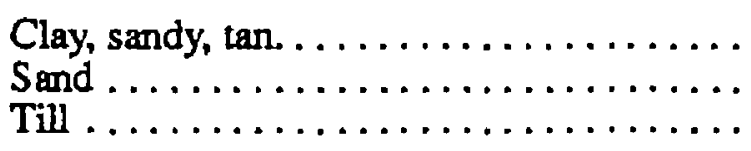 & $\begin{array}{l}12 \\
10 \\
88\end{array}$ & $\begin{array}{r}12 \\
22 \\
110\end{array}$ & 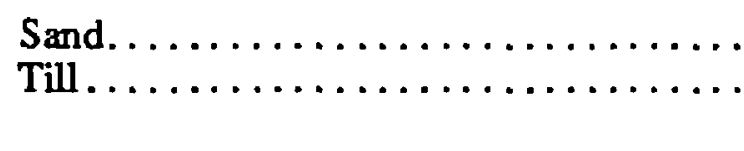 & $\begin{array}{l}10 \\
40\end{array}$ & $\begin{array}{l}120 \\
160\end{array}$ \\
\hline
\end{tabular}


Table 3. Drillers' logs of wells and test holes--Continued

151-091-11BBC

(Log modified from Mann Drilling Co.)

Altitude: 1,880 feet

Date drilled: $04-15-85$

\begin{tabular}{|c|c|c|c|c|c|}
\hline Materlal & $\begin{array}{l}\text { Thlek- } \\
\text { ness } \\
\text { (foot) }\end{array}$ & $\begin{array}{l}\text { Depth } \\
\text { (feot) }\end{array}$ & Materlal & $\begin{array}{l}\text { Thitr- } \\
\text { ners } \\
\text { (fevt) }\end{array}$ & $\begin{array}{l}\text { Depth } \\
\text { (feot) }\end{array}$ \\
\hline 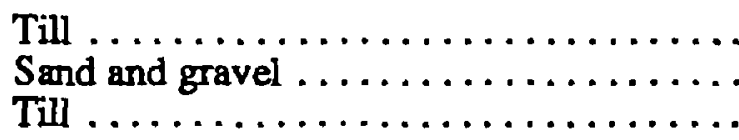 & $\begin{array}{l}60 \\
15 \\
20\end{array}$ & $\begin{array}{l}60 \\
75 \\
95\end{array}$ & 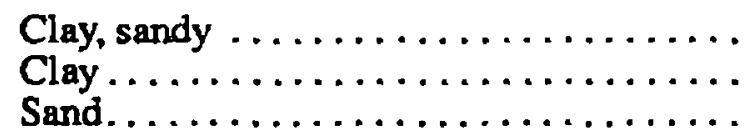 & $\begin{array}{r}155 \\
1,045 \\
45\end{array}$ & $\begin{array}{r}250 \\
1,295 \\
1,340\end{array}$ \\
\hline
\end{tabular}

151-091-11CDD

(Log modifled form Dennis Water Well Drilling)

Altitude: 1,935 feet

Date drilled: $\quad 06-21-85$

\begin{tabular}{|c|c|c|c|c|c|}
\hline Matarial & $\begin{array}{l}\text { Thlck- } \\
\text { ness } \\
\text { (feet) }\end{array}$ & $\begin{array}{l}\text { Depth } \\
\text { (feot) }\end{array}$ & Material & $\begin{array}{l}\text { Thlik- } \\
\text { ne rs } \\
\text { (fort) }\end{array}$ & $\begin{array}{l}\text { Depth } \\
\text { (feet) }\end{array}$ \\
\hline 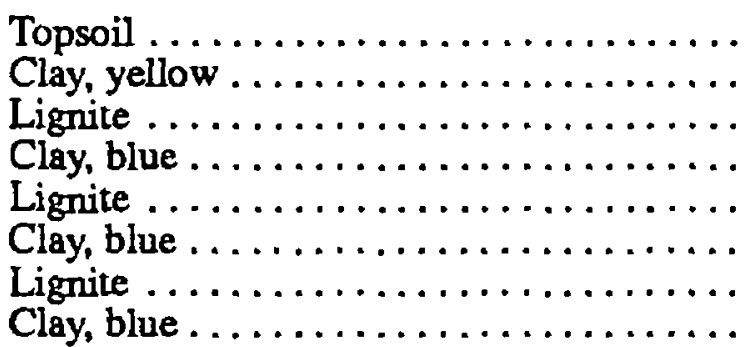 & $\begin{array}{r}1 \\
17 \\
2 \\
16 \\
2 \\
81 \\
8 \\
5 \\
14.5\end{array}$ & $\begin{array}{l}1 \\
18 \\
20 \\
36 \\
38 \\
119 \\
119.5 \\
134\end{array}$ & 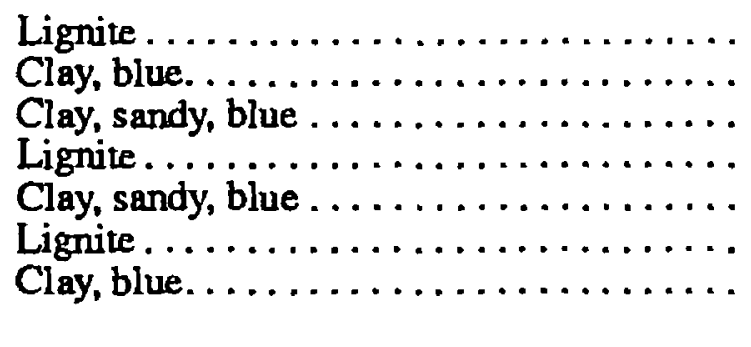 & $\begin{array}{l}2 \\
5 \\
16 \\
5 \\
65 \\
5 \\
6\end{array}$ & $\begin{array}{l}136 \\
141 \\
157 \\
157.5 \\
164 \\
169 \\
175\end{array}$ \\
\hline
\end{tabular}

151-091-12BBA1

(Log modifled from Dennis Water Well Drilling)

Altitude: 1,900 foet

Date drilied: $\quad 06-10-85$

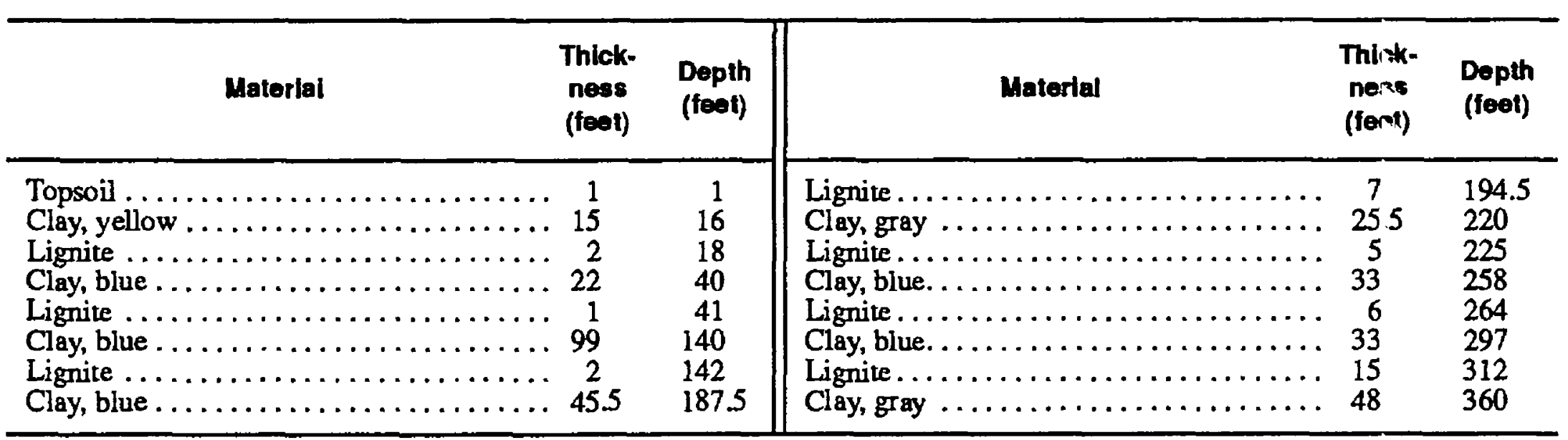


Table 3. Drillers' logs of wells and test holes--Continued

151-091-12BBA2

(Log modifled from Dennis Water Well Driliing)

Altitude: 1,880 feet

Date drilled: 06-13-85

Materlal $\quad \ldots \ldots \ldots \ldots$

151-092-28ABAB

(Log modified from Crowder-Dennis Driliing)

Altitude: 1,940 feet

Date driiled: $07-20-82$

\begin{tabular}{|c|c|c|c|c|c|}
\hline Material & $\begin{array}{l}\text { Thick- } \\
\text { nees } \\
\text { (feet) }\end{array}$ & $\begin{array}{l}\text { Depth } \\
\text { (feet) }\end{array}$ & Materlal & $\begin{array}{c}\text { Thlck- } \\
\text { ness } \\
\text { (feet) }\end{array}$ & $\begin{array}{l}\text { De nth } \\
\text { (fmot) }\end{array}$ \\
\hline 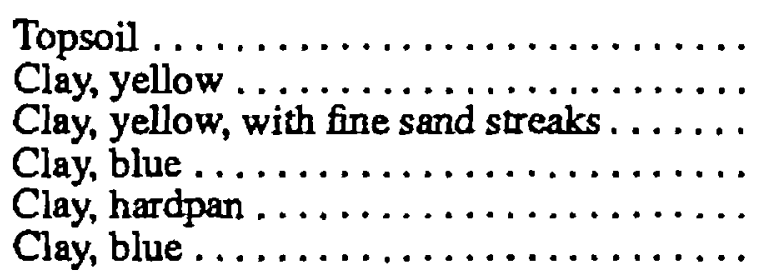 & $\begin{array}{r}1 \\
10 \\
74 \\
13 \\
1 \\
10\end{array}$ & $\begin{array}{r}1 \\
11 \\
85 \\
98 \\
99 \\
109\end{array}$ & $\begin{array}{l}\text { Clay, brown } \ldots \ldots \ldots \ldots \ldots \ldots \ldots \ldots \ldots \ldots \ldots \\
\text { Clay, blue. } \ldots \ldots \ldots \ldots \ldots \ldots \ldots \ldots \ldots \\
\text { Sand, fine, blue } \ldots \ldots \ldots \ldots \ldots \ldots \ldots \ldots \ldots \\
\text { Clay, blue. } \ldots \ldots \ldots \ldots \ldots \ldots \ldots \ldots \ldots \ldots \ldots \\
\text { Sand, fine, blue } \ldots \ldots \ldots \ldots \ldots \ldots \ldots \ldots \ldots\end{array}$ & $\begin{array}{r}2 \\
49 \\
27 \\
2 \\
11\end{array}$ & $\begin{array}{l}111 \\
160 \\
187 \\
189 \\
220\end{array}$ \\
\hline
\end{tabular}

151-093-02ADCA

(Log modified from Crowder-Dennis Driiling)

Altitude: 2,130 feet

Date drilled: $07-a .7-81$

\begin{tabular}{|c|c|c|c|c|c|}
\hline Materlal & $\begin{array}{c}\text { Thick } \\
\text { ness } \\
\text { (feet) }\end{array}$ & $\begin{array}{l}\text { Depth } \\
\text { (feet) }\end{array}$ & Materlal & $\begin{array}{l}\text { Thick- } \\
\text { ness } \\
\text { (feet) }\end{array}$ & $\begin{array}{l}\text { Denth } \\
\text { (frest) }\end{array}$ \\
\hline 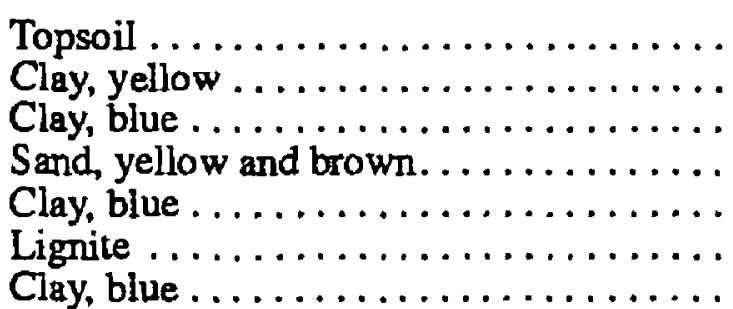 & $\begin{array}{c}1 \\
9 \\
. \quad 14 \\
. \quad 10.5 \\
.5 \\
6\end{array}$ & $\begin{array}{l}1 \\
10 \\
24 \\
78 \\
88.5 \\
90 \\
126\end{array}$ & 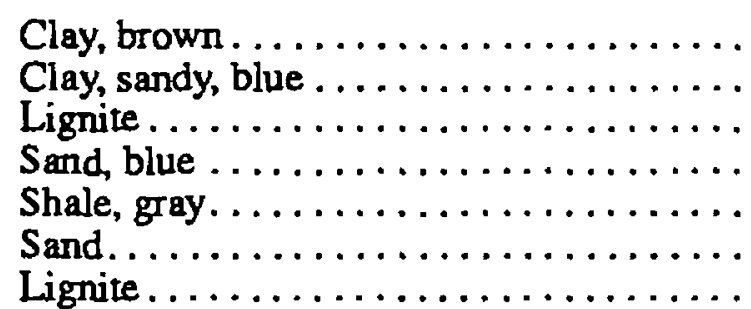 & $\begin{array}{l}2.5 \\
2 \\
2.5 \\
38 \\
16 \\
5 \\
1\end{array}$ & $\begin{array}{l}12 ? .5 \\
13 ? .5 \\
133 \\
171 \\
187 \\
192 \\
193\end{array}$ \\
\hline
\end{tabular}


Table 3. Drillers' logs of wells and test holes--Continued

151-093-10AAAB

(Log modifled from Crowder-Dennis Drilling)

Altitude: 2,164 toet

Date drilled: $07-27-81$

\begin{tabular}{|c|c|c|c|c|c|}
\hline Material & $\begin{array}{l}\text { Thick- } \\
\text { ness } \\
\text { (feol) }\end{array}$ & $\begin{array}{l}\text { Depth } \\
\text { (feet) }\end{array}$ & Materlal & $\begin{array}{l}\text { Thlik- } \\
\text { nere } \\
\text { (fert) }\end{array}$ & $\begin{array}{l}\text { Depth } \\
\text { (feet) }\end{array}$ \\
\hline 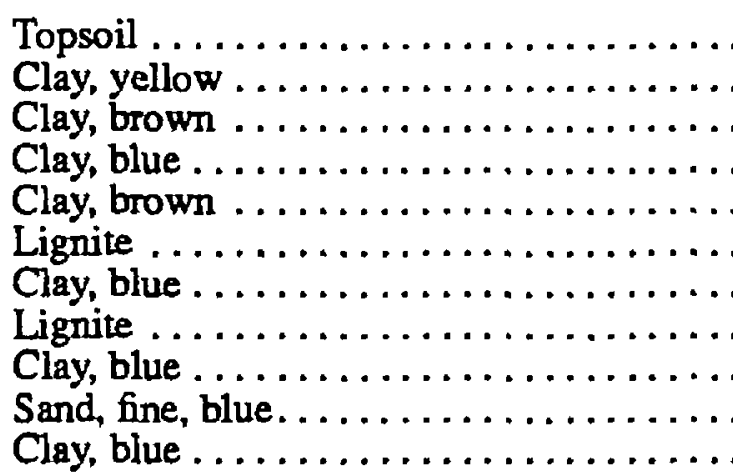 & $\begin{array}{r}2 \\
28 \\
2 \\
36 \\
11.5 \\
2.5 \\
10.5 \\
4.5 \\
53 \\
15 \\
25\end{array}$ & $\begin{array}{l}2 \\
30 \\
32 \\
68 \\
79.5 \\
82 \\
92.5 \\
97 \\
150 \\
165 \\
190\end{array}$ & 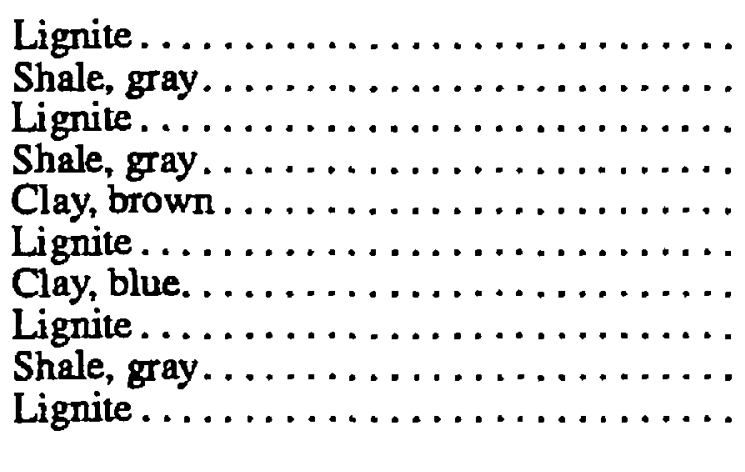 & $\begin{array}{c}4 \\
87.5 \\
2.5 \\
41 \\
3 \\
1 \\
59.5 \\
1.5 \\
255 \\
5.5\end{array}$ & $\begin{array}{l}194 \\
281.5 \\
284 \\
325 \\
328 \\
329 \\
388.5 \\
390 \\
415.5 \\
421\end{array}$ \\
\hline
\end{tabular}

151-093-10BAB

(Log modifled from Dennis Water Well Driillng)

Altitude: 2,020 feet

Date drllle d: $08-10-88$

\begin{tabular}{|c|c|c|c|c|c|}
\hline Material & $\begin{array}{l}\text { Thick- } \\
\text { ness } \\
\text { (feet) }\end{array}$ & $\begin{array}{l}\text { Depth } \\
\text { (feet) }\end{array}$ & Materlal & $\begin{array}{l}\text { Thlck- } \\
\text { ners } \\
\text { (fenl) }\end{array}$ & $\begin{array}{l}\text { Depth } \\
\text { (feet) }\end{array}$ \\
\hline 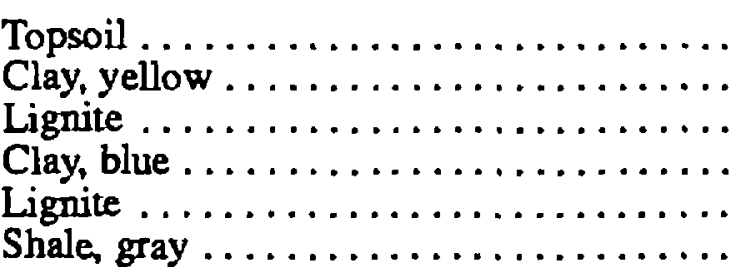 & $\begin{array}{r}1 \\
16 \\
1 \\
87 \\
2 \\
43\end{array}$ & $\begin{array}{r}1 \\
17 \\
18 \\
105 \\
107 \\
150\end{array}$ & 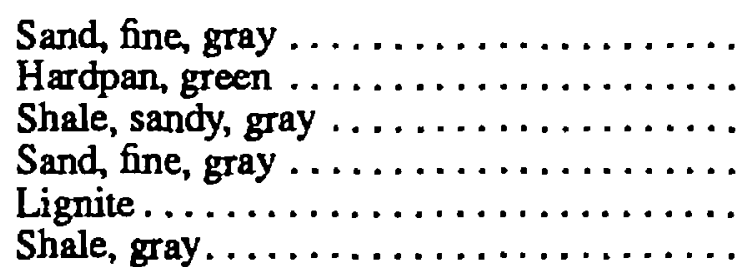 & $\begin{array}{r}48 \\
2 \\
2 \\
58 \\
4 \\
11\end{array}$ & $\begin{array}{l}198 \\
200 \\
202 \\
260 \\
264 \\
275\end{array}$ \\
\hline
\end{tabular}

151-093-14DBAD

(Log modifled from Crowder-Dennis Drilling)

Alttude: 2,060 feet

Date drllief: $\quad 07-16-82$

\begin{tabular}{|c|c|c|c|c|c|}
\hline Materlai & $\begin{array}{l}\text { Thick- } \\
\text { ness } \\
\text { (feet) }\end{array}$ & $\begin{array}{l}\text { Depth } \\
\text { (feot) }\end{array}$ & Material & $\begin{array}{l}\text { Thlck- } \\
\text { ners } \\
\text { (fent) }\end{array}$ & $\begin{array}{l}\text { Depth } \\
\text { (feet) }\end{array}$ \\
\hline 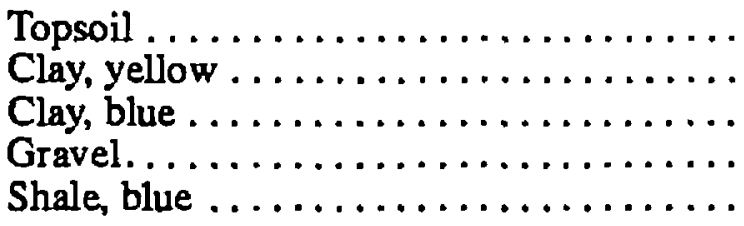 & $\begin{array}{r}3 \\
12 \\
44 \\
1 \\
12\end{array}$ & $\begin{array}{r}3 \\
15 \\
59 \\
60 \\
72\end{array}$ & 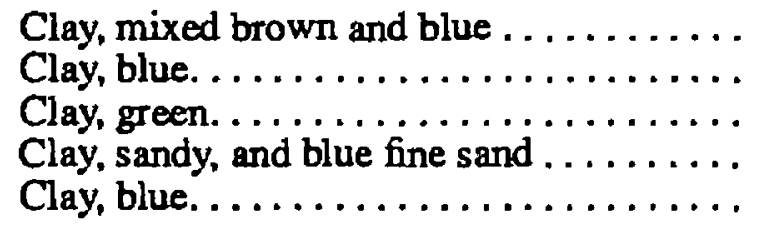 & $\begin{array}{r}3 \\
35 \\
20 \\
57 \\
2\end{array}$ & $\begin{array}{r}75 \\
110 \\
130 \\
187 \\
190\end{array}$ \\
\hline
\end{tabular}


Table 3. Drillers' logs of wells and test holes--Continued

151-093-28DDD2

(Log modified from Dennis Water Well Driiling)

Alfitude: 2,110 fe日t

Date driiled: $16 \cdot 10-87$

\begin{tabular}{|c|c|c|c|c|c|}
\hline Materlal & $\begin{array}{l}\text { Thlek- } \\
\text { neas } \\
\text { (foet) }\end{array}$ & $\begin{array}{l}\text { Depth } \\
\text { (feet) }\end{array}$ & Materlal & $\begin{array}{l}\text { Thick- } \\
\text { ness } \\
\text { (feet) }\end{array}$ & $\begin{array}{l}\text { Depth } \\
\text { (feet) }\end{array}$ \\
\hline 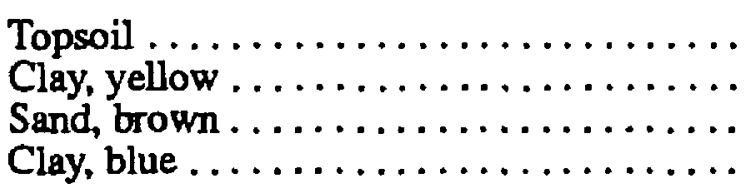 & $\begin{array}{r}1 \\
34 \\
45 \\
7\end{array}$ & $\begin{array}{l}1 \\
35 \\
80 \\
87\end{array}$ & 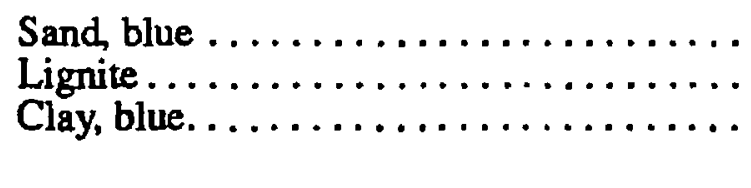 & $\begin{array}{l}7.5 \\
2.5 \\
6\end{array}$ & $\begin{array}{l}94.5 \\
97 \\
103\end{array}$ \\
\hline
\end{tabular}

151-093-34ABDA

( $L o g$ modified from $S$ and $L$ Driliing, inc.)

Aittude: 2,020 feet

Date drilied: $06-27-84$

\begin{tabular}{|c|c|c|c|c|c|}
\hline Material & $\begin{array}{l}\text { Thick- } \\
\text { ness } \\
\text { (feet) }\end{array}$ & $\begin{array}{l}\text { Depth } \\
\text { (feet) }\end{array}$ & Material & $\begin{array}{l}\text { Thick- } \\
\text { ness } \\
\text { (feat) }\end{array}$ & $\begin{array}{l}\text { Depth } \\
\text { (feet) }\end{array}$ \\
\hline 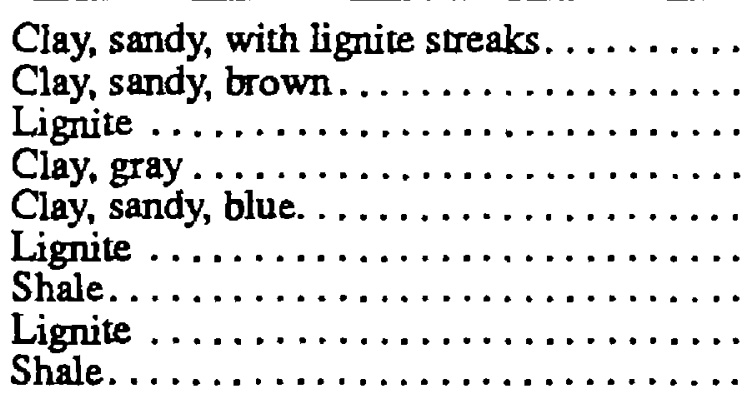 & $\begin{array}{r}20 \\
12 \\
4 \\
4 \\
12 \\
4 \\
15 \\
3 \\
17\end{array}$ & $\begin{array}{l}20 \\
32 \\
36 \\
40 \\
52 \\
56 \\
71 \\
74 \\
91\end{array}$ & 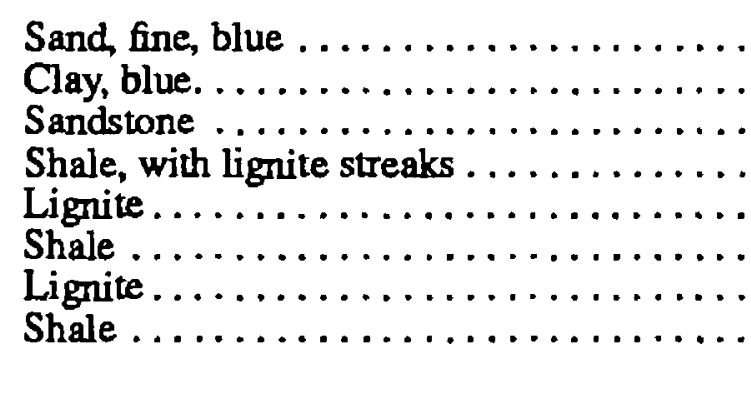 & $\begin{array}{r}6 \\
56 \\
3 \\
72 \\
10 \\
60 \\
10 \\
50\end{array}$ & $\begin{array}{r}97 \\
153 \\
156 \\
228 \\
238 \\
298 \\
308 \\
358\end{array}$ \\
\hline
\end{tabular}

151-093-35-BBB2

(Log modifled from Dennis Water Weil Driiling)

Alttude: 2,010 feet

Date drilled: 01-03-88

\begin{tabular}{|c|c|c|c|c|c|}
\hline Materlal & $\begin{array}{l}\text { Thlok- } \\
\text { nesa } \\
\text { (feet) }\end{array}$ & $\begin{array}{l}\text { Depth } \\
\text { (feet) }\end{array}$ & Material & $\begin{array}{l}\text { Thick- } \\
\text { ness } \\
\text { (feet) }\end{array}$ & $\begin{array}{l}\text { Inoth } \\
\text { (feet) }\end{array}$ \\
\hline 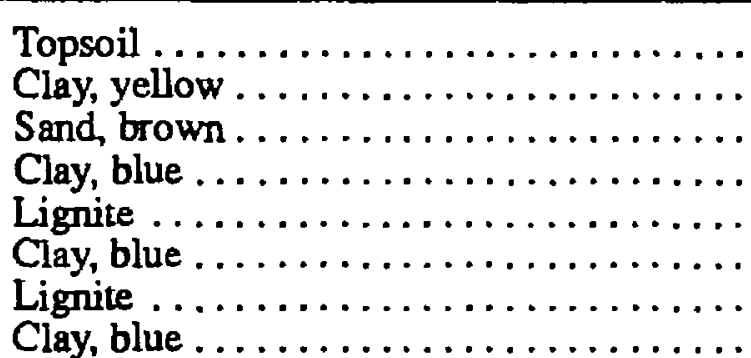 & $\begin{array}{r}1 \\
31 \\
23 \\
78 \\
2 \\
26 \\
3 \\
66\end{array}$ & $\begin{array}{r}1 \\
32 \\
55 \\
133 \\
135 \\
161 \\
164 \\
230\end{array}$ & 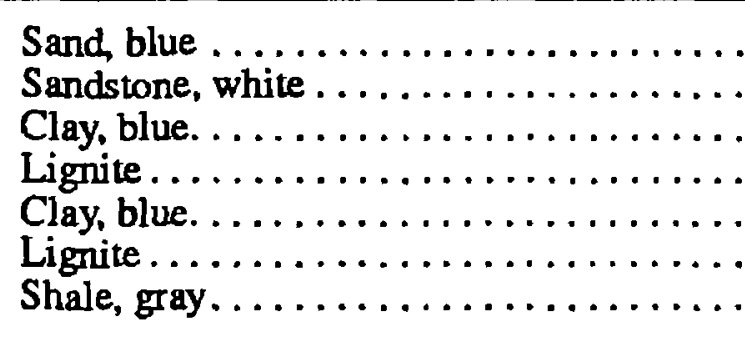 & $\begin{array}{r}26 \\
3 \\
16 \\
2 \\
8 \\
9 \\
14\end{array}$ & $\begin{array}{l}256 \\
259 \\
275 \\
277 \\
285 \\
294 \\
308\end{array}$ \\
\hline
\end{tabular}


Table 3. Drillers' logs of wells and test holes--Continued

151-094-06AAB2

(Log modifled trom Water Supply, Inc.)

\begin{tabular}{|c|c|c|c|c|c|}
\hline Materlal & $\begin{array}{l}\text { Thlck- } \\
\text { nces } \\
\text { (feet) }\end{array}$ & $\begin{array}{l}\text { Depth } \\
\text { (feot) }\end{array}$ & Material & $\begin{array}{c}\text { Thick. } \\
\text { nes } \\
\text { (feot) }\end{array}$ & $\begin{array}{l}\text { Depth } \\
\text { (feot) }\end{array}$ \\
\hline $\begin{array}{l}\text { Topsoil, silty, black. . . . . . . . . . . . . . } \\
\text { Clay, silty, yellowish-brown; till . . . . . . } \\
\text { Sand, fine, yellowish-brown; bedrock . . . } \\
\text { Sandstone . . . . . . . . . . . . . . . . . . } \\
\text { Sand, fine, clayey, yellowish-brown } \\
\text { about } 30 \text { percent clay . . . . . . . . . . } \\
\text { Lignite, soft . . . . . . . . . . . . . . . . } \\
\text { Clay, silty, medium-gray . . . . . . . . . . }\end{array}$ & $\begin{array}{r}1 \\
9 \\
27 \\
2 \\
19 \\
6 \\
23\end{array}$ & $\begin{array}{l}1 \\
10 \\
37 \\
39 \\
58 \\
64 \\
87\end{array}$ & 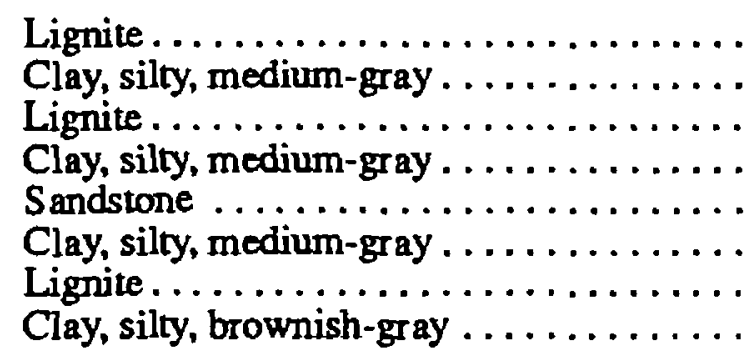 & $\begin{array}{r}1 \\
5 \\
5 \\
14 \\
2 \\
26 \\
12 \\
3\end{array}$ & $\begin{array}{r}88 \\
93 \\
98 \\
112 \\
114 \\
140 \\
152 \\
155\end{array}$ \\
\hline
\end{tabular}

151-094-09ADD

(Log from Dingman and Gordon, 1954)

Altitude: $2,124.54$ feet

Date drilled: 1950

\begin{tabular}{|c|c|c|c|c|c|}
\hline Material & $\begin{array}{l}\text { Thlak- } \\
\text { ness: } \\
\text { (foot) }\end{array}$ & $\begin{array}{l}\text { Depth } \\
\text { (feet) }\end{array}$ & Material & $\begin{array}{l}\text { Thick- } \\
\text { nes: } \\
\text { (feo') }\end{array}$ & $\begin{array}{l}\text { Depth } \\
\text { (feet) }\end{array}$ \\
\hline 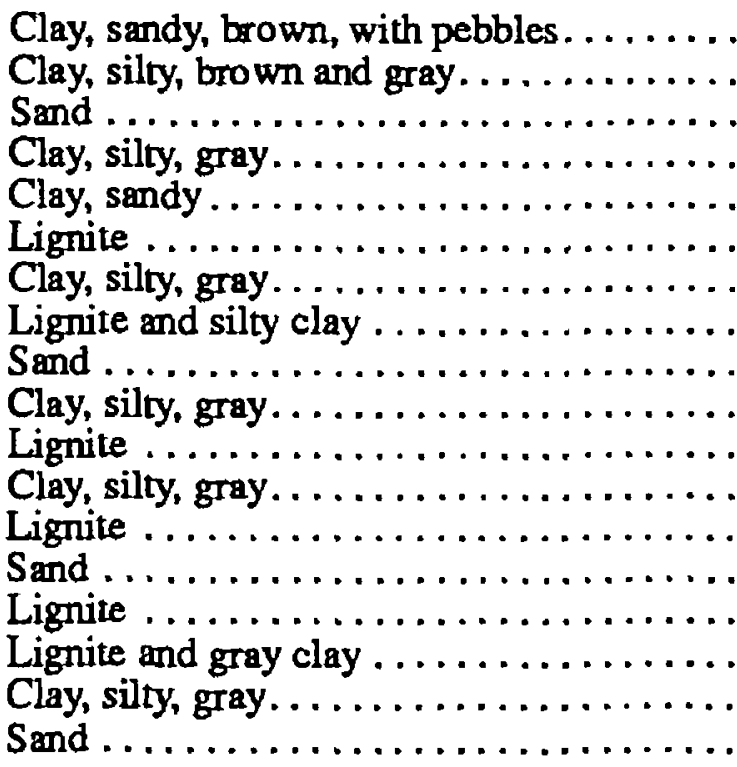 & 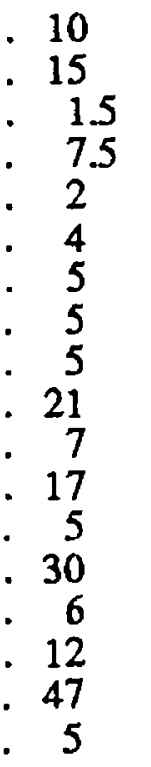 & $\begin{array}{l}10 \\
25 \\
26.5 \\
34 \\
36 \\
40 \\
45 \\
50 \\
55 \\
76 \\
83 \\
100 \\
105 \\
135 \\
141 \\
153 \\
200 \\
205\end{array}$ & 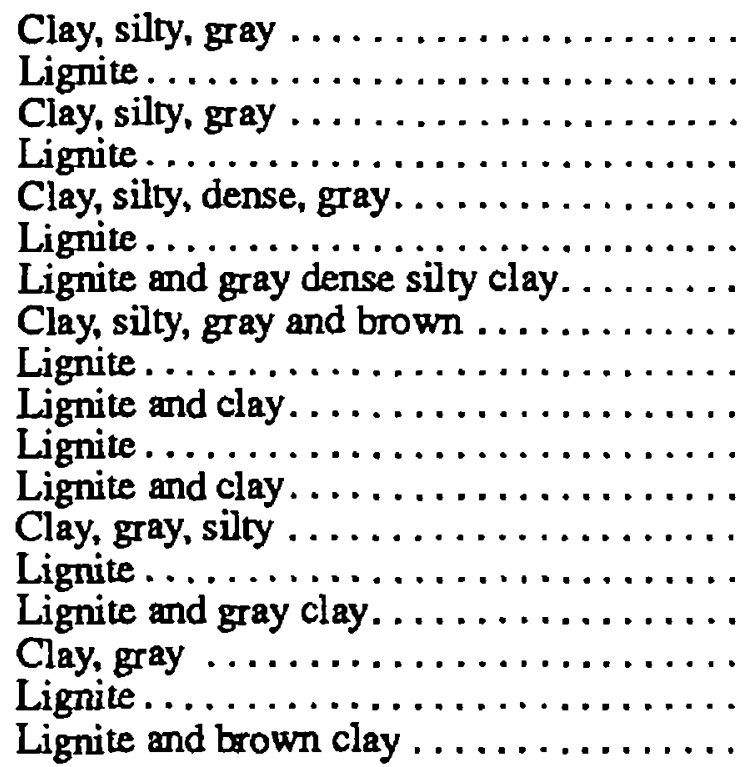 & $\begin{array}{r}20 \\
17 \\
5 \\
2 \\
48 \\
6 \\
32 \\
25 \\
15 \\
10 \\
10 \\
30 \\
60 \\
4 \\
6 \\
5 \\
5 \\
5\end{array}$ & $\begin{array}{l}225 \\
242 \\
247 \\
249 \\
297 \\
303 \\
335 \\
360 \\
375 \\
385 \\
395 \\
425 \\
485 \\
489 \\
495 \\
500 \\
505 \\
510\end{array}$ \\
\hline
\end{tabular}

151-094-28DAA

(Log from Dingman and Gordon, 1954)

Altitude: $2,348.49$ feet

Date drilied: 1950

\begin{tabular}{|c|c|c|c|c|c|}
\hline Material & $\begin{array}{l}\text { Thick- } \\
\text { ness } \\
\text { (feet) }\end{array}$ & $\begin{array}{l}\text { Depth } \\
\text { (foot) }\end{array}$ & Materiai & $\begin{array}{c}\text { Thicte- } \\
\text { ness } \\
\text { (feet) }\end{array}$ & $\begin{array}{l}\text { Depth } \\
\text { (feet) }\end{array}$ \\
\hline $\begin{array}{l}\text { Clay, silty and sandy, tan } \ldots \ldots \ldots \ldots \ldots \ldots \\
\text { Clay, silty, gray. } \ldots \ldots \ldots \ldots \ldots \ldots \ldots \\
\text { Lignite and gray clay } \ldots \ldots \ldots \ldots \ldots \ldots \\
\text { Clay, silty, dense, gray } \ldots \ldots \ldots \ldots \ldots \ldots \\
\text { Lignite } \ldots \ldots \ldots \ldots \ldots \ldots \ldots \ldots\end{array}$ & $\begin{array}{r}10 \\
23 \\
1 \\
79 \\
3\end{array}$ & $\begin{array}{r}10 \\
33 \\
34 \\
113 \\
116\end{array}$ & 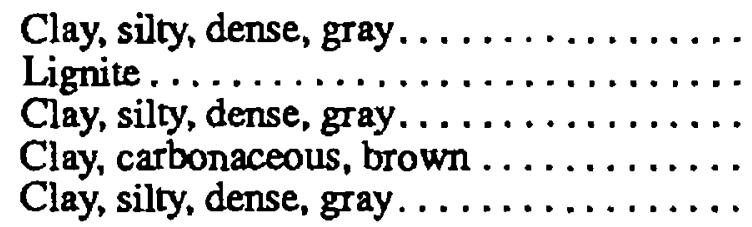 & $\begin{array}{r}57 \\
3 \\
32 \\
5 \\
27\end{array}$ & $\begin{array}{l}173 \\
176 \\
208 \\
213 \\
240\end{array}$ \\
\hline
\end{tabular}


Table 3. Drillers' logs of wells and test holes--Continued

151-095-24ACD

(Log from Dingman and Gordon, 1954)

\begin{tabular}{|c|c|c|c|c|c|}
\hline Materlal & $\begin{array}{l}\text { Thlck- } \\
\text { ness } \\
\text { (feet) }\end{array}$ & $\begin{array}{l}\text { Depth } \\
\text { (feet) }\end{array}$ & Material & $\begin{array}{l}\text { Thlok- } \\
\text { noses } \\
\text { (foet) }\end{array}$ & $\begin{array}{l}\text { Dopth } \\
\text { ('net) }\end{array}$ \\
\hline 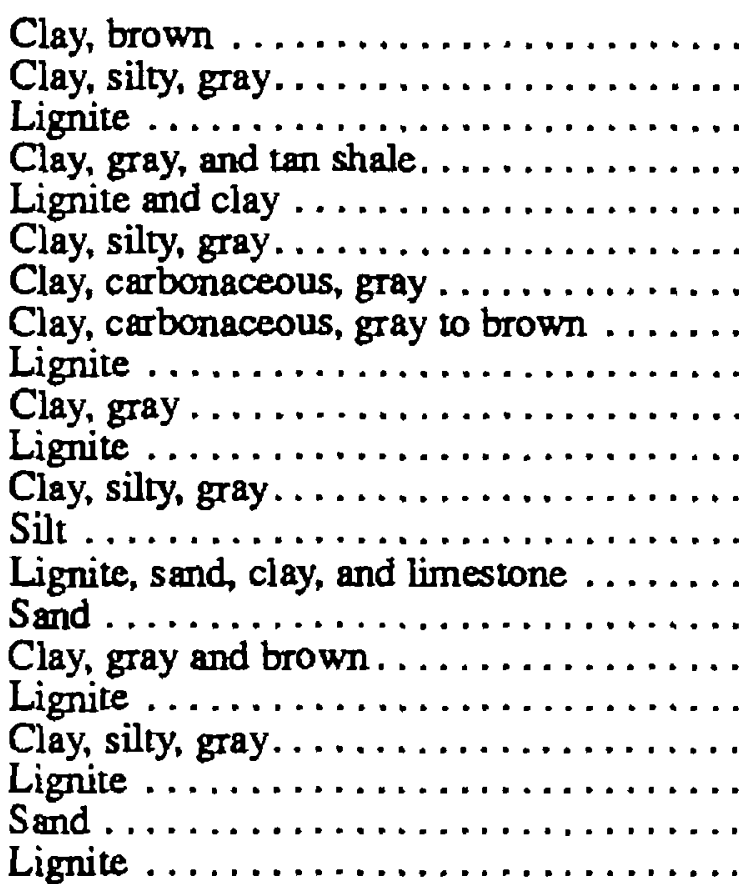 & $\begin{array}{r}5 \\
16.5 \\
5 \\
2 \\
14 \\
3 \\
4 \\
1 \\
5 \\
4 \\
6 \\
4 \\
5 \\
6 \\
5 \\
5 \\
11 \\
3 \\
9 \\
2\end{array}$ & $\begin{array}{l}5 \\
215 \\
22 \\
31 \\
33 \\
47 \\
50 \\
54 \\
55 \\
60 \\
64 \\
70 \\
74 \\
79 \\
85 \\
90 \\
95 \\
106 \\
109 \\
118 \\
120\end{array}$ & 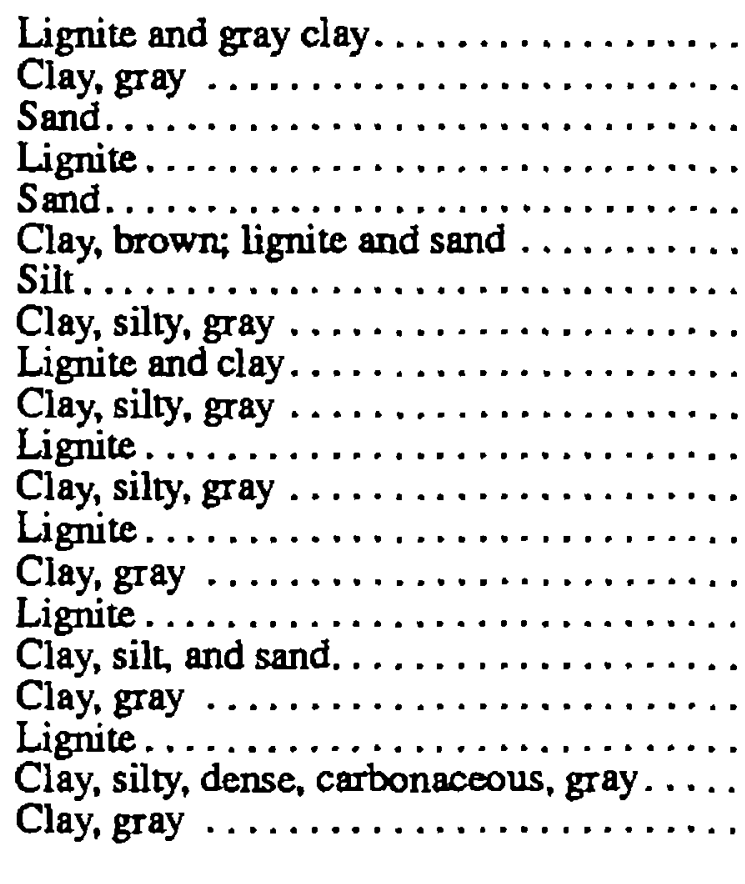 & $\begin{array}{r}5 \\
5 \\
35 \\
1 \\
14 \\
2 \\
8 \\
8 \\
2 \\
7 \\
3 \\
27 \\
13 \\
25 \\
19 \\
16 \\
3 \\
11 \\
34 \\
32\end{array}$ & $\begin{array}{l}125 \\
130 \\
165 \\
166 \\
180 \\
182 \\
190 \\
198 \\
200 \\
207 \\
210 \\
237 \\
250 \\
275 \\
294 \\
310 \\
313 \\
324 \\
358 \\
390\end{array}$ \\
\hline
\end{tabular}

151-095-30BBA

(Log modlfled from S and L Drilling, inc.)

Altitude: 2,355 feet

Date drilled: $06-28-83$

\begin{tabular}{|c|c|c|c|c|c|}
\hline Materlal & $\begin{array}{l}\text { Thlck- } \\
\text { ness } \\
\text { (feet) }\end{array}$ & $\begin{array}{l}\text { Depth } \\
\text { (feet) }\end{array}$ & Materlal & $\begin{array}{l}\text { Thlok- } \\
\text { ness } \\
\text { (feet) }\end{array}$ & $\begin{array}{l}\text { Drnth } \\
\text { (inet) }\end{array}$ \\
\hline 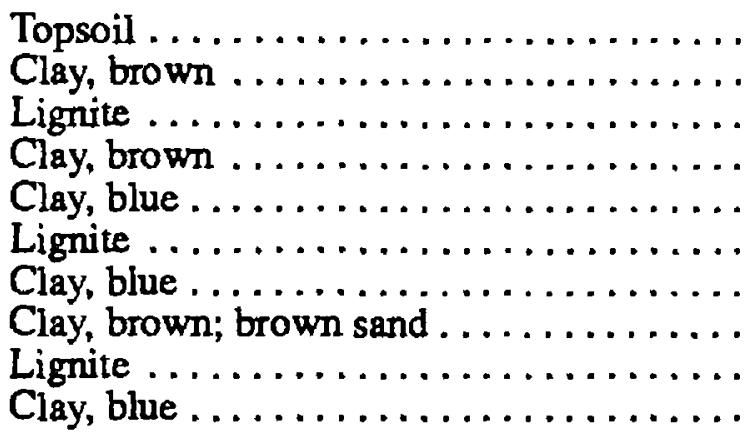 & $\begin{array}{r}2 \\
13 \\
2 \\
11 \\
14 \\
6 \\
3 \\
29 \\
20 \\
10\end{array}$ & $\begin{array}{r}2 \\
15 \\
17 \\
28 \\
42 \\
48 \\
51 \\
80 \\
100 \\
110\end{array}$ & 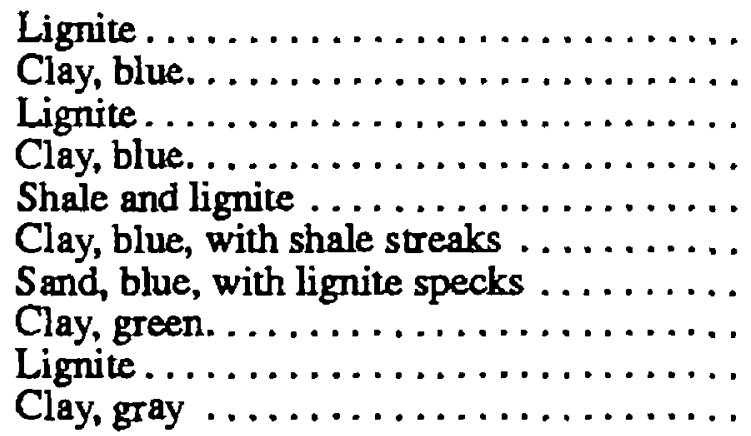 & $\begin{array}{r}2 \\
8 \\
3 \\
17 \\
8 \\
37 \\
60 \\
12 \\
6 \\
2\end{array}$ & $\begin{array}{l}112 \\
120 \\
123 \\
140 \\
148 \\
185 \\
245 \\
257 \\
263 \\
265\end{array}$ \\
\hline
\end{tabular}


Table 3. Drillers' logs of wells and test holes--Continued

151-095-30CDAC

(Log modified from Mariner Drliling Service)

\begin{tabular}{|c|c|c|c|c|c|}
\hline Material & $\begin{array}{l}\text { Thick- } \\
\text { neses } \\
\text { (feel) }\end{array}$ & $\begin{array}{l}\text { Depth } \\
\text { (feet) }\end{array}$ & Materlal & $\begin{array}{l}\text { Thick- } \\
\text { notk } \\
\text { (feet) }\end{array}$ & $\begin{array}{l}\text { Depth } \\
\text { (feet) }\end{array}$ \\
\hline 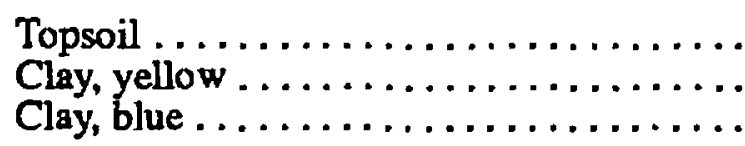 & $\begin{array}{r}4 \\
76 \\
160\end{array}$ & $\begin{array}{r}4 \\
80 \\
240\end{array}$ & 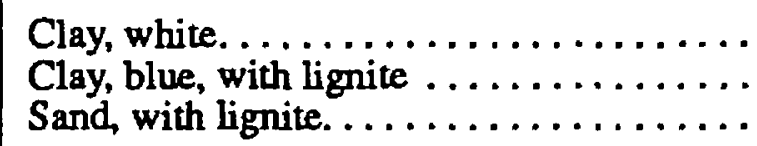 & $\begin{array}{r}60 \\
110 \\
30\end{array}$ & $\begin{array}{l}300 \\
410 \\
440\end{array}$ \\
\hline
\end{tabular}

151-095-36ACB

(Log from Dingman and Gordon, 1954)

Alttude: $2,297.94$ feet

Date d tlled: 1950

\begin{tabular}{|c|c|c|c|c|c|}
\hline Materlal & $\begin{array}{l}\text { Thlck- } \\
\text { nees } \\
\text { (feot) }\end{array}$ & $\begin{array}{l}\text { Depth } \\
\text { (feet) }\end{array}$ & Material & $\begin{array}{l}\text { Thick- } \\
\text { nes: } \\
\text { (foat) }\end{array}$ & $\begin{array}{l}\text { Depth } \\
\text { (feet) }\end{array}$ \\
\hline $\begin{array}{l}\text { Clay, silty, brown, with pebbles } \ldots \ldots \ldots \ldots \ldots \\
\text { Sand and gravel } \ldots \ldots \ldots \ldots \ldots \ldots \\
\text { Clay, silty, brown, with pebbles } \ldots \ldots \ldots \ldots \ldots \\
\text { (No sample) } \ldots \ldots \ldots \ldots \ldots \ldots \ldots \\
\text { Lignite(?) (no sample) } \ldots \ldots \ldots \ldots \ldots \ldots \ldots\end{array}$ & $\begin{array}{r}15 \\
10 \\
15 \\
47 \\
. \quad 6\end{array}$ & $\begin{array}{l}15 \\
25 \\
40 \\
87 \\
93\end{array}$ & $\begin{array}{l}\text { (No sample) . . . . . . . . . . . . . . . . } \\
\text { Clay, silty, dense, gray and brown. . . . . } \\
\text { (No sample) . . . . . . . . . . . . . . . . } \\
\text { Lignite(?) (no sample) . . . . . . . . . }\end{array}$ & $\begin{array}{l}57 \\
15 \\
45 \\
15\end{array}$ & $\begin{array}{l}150 \\
165 \\
210 \\
225\end{array}$ \\
\hline
\end{tabular}

152-087-27BCB

(Log modifled from Mann Drilling Co.)

Aittude: 2,080 feet

Date drillef: $10-04-81$

\begin{tabular}{|c|c|c|c|c|c|}
\hline Materia| & $\begin{array}{l}\text { Thick- } \\
\text { ness } \\
\text { (foet) }\end{array}$ & $\begin{array}{l}\text { Depth } \\
\text { (feot) }\end{array}$ & Malerial & $\begin{array}{l}\text { Thick- } \\
\text { nes: } \\
\text { (foet) }\end{array}$ & $\begin{array}{l}\text { Depth } \\
\text { (feet) }\end{array}$ \\
\hline $\begin{array}{l}\text { Topsoil . . . . . . . . . . } \\
\text { Clay, silty . . . . }\end{array}$ & $\begin{array}{r}2 \\
33\end{array}$ & $\begin{array}{r}2 \\
35\end{array}$ & $\begin{array}{l}\text { Till } \ldots \ldots \ldots \ldots \ldots \ldots \ldots \ldots \ldots \ldots \ldots \ldots \\
\text { Gravel and sand. } \ldots \ldots \ldots \ldots \ldots \ldots \ldots \ldots\end{array}$ & $\begin{array}{l}98 \\
25\end{array}$ & $\begin{array}{l}133 \\
158\end{array}$ \\
\hline
\end{tabular}

152-088-04BBAB

(Log moditied from Russell Driliing Co., inc.)

Altitude: 2,095 teet

Date drille d: $04-05-88$

Material $\ldots \ldots \ldots \ldots$


Table 3. Drillers' logs of wells and test holes-Continued

152-088-04BBBD1

(Log from North Dakota State Water Commission) 11803

\begin{tabular}{|c|c|c|c|c|c|}
\hline Material & $\begin{array}{l}\text { Thick- } \\
\text { neas } \\
\text { (fool) }\end{array}$ & $\begin{array}{l}\text { Depth } \\
\text { (feet) }\end{array}$ & Material & $\begin{array}{l}\text { Thick- } \\
\text { neas } \\
\text { (feet) }\end{array}$ & $\begin{array}{l}\text { Depth } \\
\text { (fait) }\end{array}$ \\
\hline 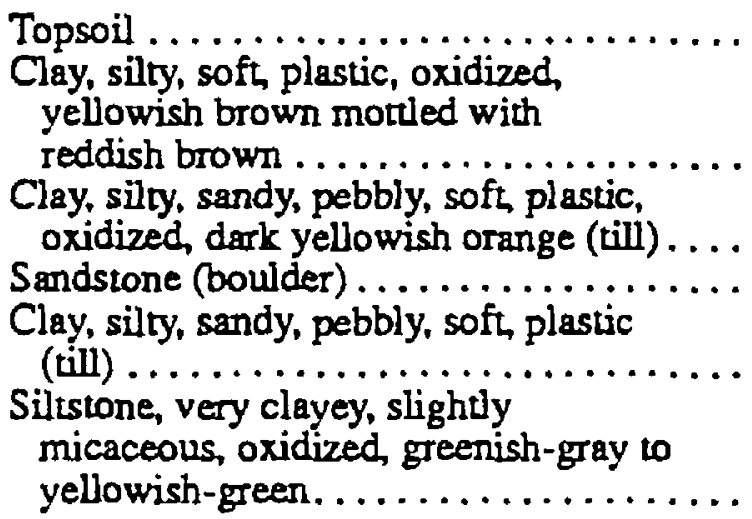 & $\begin{array}{r}2 \\
11 \\
10 \\
1 \\
13\end{array}$ & $\begin{array}{l}13 \\
23 \\
24 \\
37\end{array}$ & 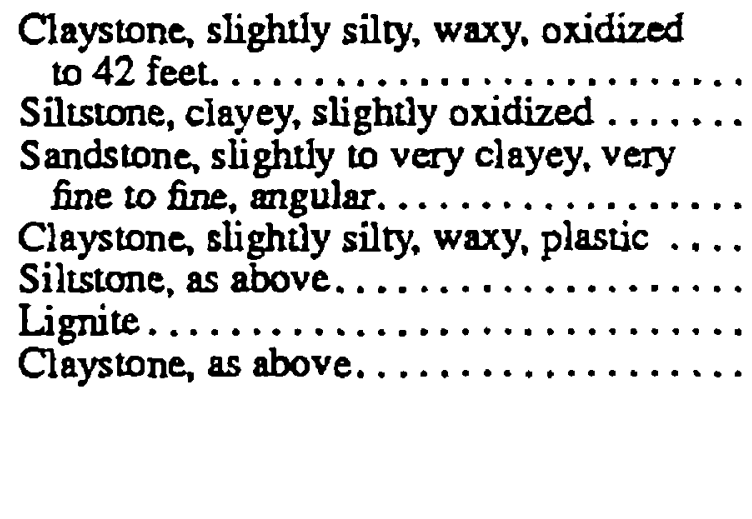 & $\begin{array}{r}3 \\
6 \\
12 \\
4 \\
3 \\
3 \\
9\end{array}$ & $\begin{array}{l}43 \\
4 ? \\
61 \\
65 \\
69 \\
71 \\
87\end{array}$ \\
\hline
\end{tabular}

152-088-04BBBD2

(Log from North Dakota State Water Commission) 11955

Alttude: 2,095 feet

Date drilied: $04-22-87$

\begin{tabular}{|c|c|c|c|c|c|}
\hline Material & $\begin{array}{l}\text { Thick- } \\
\text { ness } \\
\text { (feet) }\end{array}$ & $\begin{array}{l}\text { Dapth } \\
\text { (feot) }\end{array}$ & Material & $\begin{array}{l}\text { Thick- } \\
\text { ness } \\
\text { (foet) }\end{array}$ & $\begin{array}{l}\text { Depth } \\
\text { (fert) }\end{array}$ \\
\hline 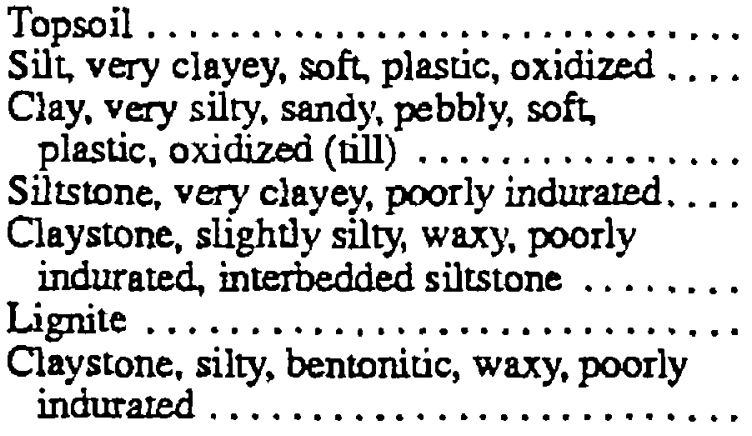 & $\begin{array}{r}2 \\
12 \\
29 \\
8 \\
\\
5 \\
1\end{array}$ & $\begin{array}{r}2 \\
14 \\
43 \\
51 \\
\\
56 \\
57\end{array}$ & 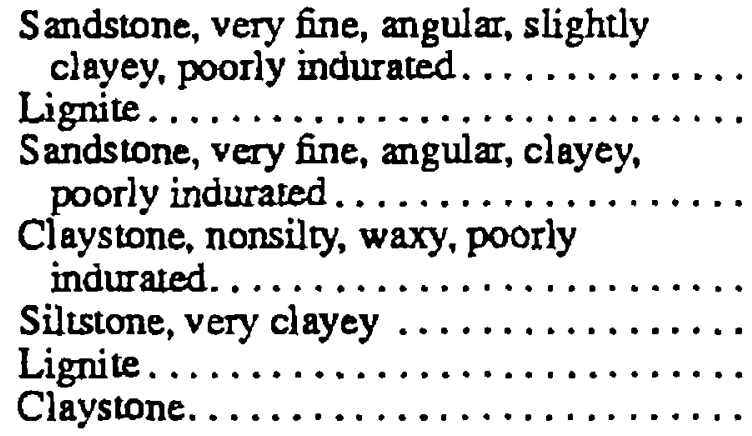 & $\begin{array}{l}1 \\
5 \\
6 \\
4 \\
3\end{array}$ & $\begin{array}{l}7 \\
75 \\
8 ? \\
85 \\
89\end{array}$ \\
\hline
\end{tabular}

152-088-04BDA

(Log modifled from Mann Drilling Co.)

Alttude: 2,090 feet

Date drilled: $08-25-86$

\begin{tabular}{|c|c|c|c|c|c|}
\hline Material & $\begin{array}{l}\text { Thick- } \\
\text { ness } \\
\text { (foot) }\end{array}$ & $\begin{array}{l}\text { Dapth } \\
\text { (feet) }\end{array}$ & Material & $\begin{array}{l}\text { Thick- } \\
\text { ness } \\
\text { (foet) }\end{array}$ & $\begin{array}{l}\text { Depth } \\
\text { (fert) }\end{array}$ \\
\hline 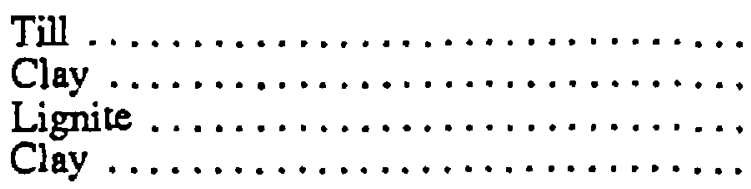 & $\begin{array}{r}42 \\
44 \\
4 \\
7\end{array}$ & $\begin{array}{l}42 \\
86 \\
90 \\
97\end{array}$ & 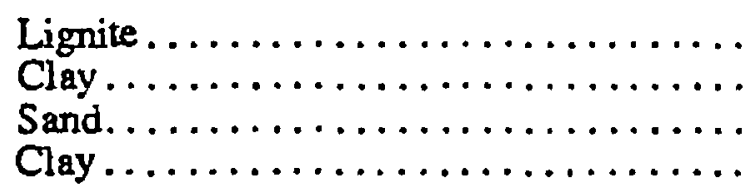 & $\begin{array}{r}4 \\
19 \\
12 \\
8\end{array}$ & $\begin{array}{l}101 \\
120 \\
132 \\
140\end{array}$ \\
\hline
\end{tabular}


Table 3. Drillers' logs of wells and test holes-Continued

152-088-05DAD2

(Log modffled from Mariner Drllling Service)

Date drilled: $08-02-84$

\begin{tabular}{|c|c|c|c|c|c|}
\hline Material & $\begin{array}{l}\text { Thick- } \\
\text { ness } \\
\text { (feat) }\end{array}$ & $\begin{array}{l}\text { Depth } \\
\text { (feat) }\end{array}$ & Material & $\begin{array}{l}\text { Thick. } \\
\text { nees } \\
\text { (foet) }\end{array}$ & $\begin{array}{l}\text { Depth } \\
\text { (feat) }\end{array}$ \\
\hline 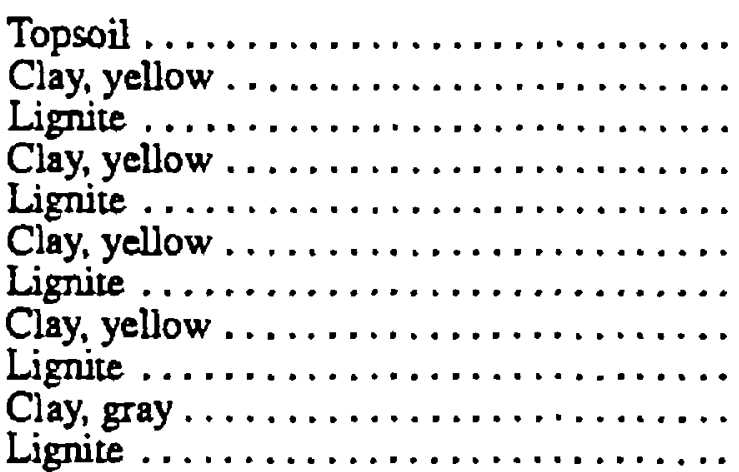 & $\begin{array}{r}1 \\
45 \\
3 \\
6 \\
5 \\
16 \\
4 \\
10 \\
5 \\
9 \\
1\end{array}$ & $\begin{array}{r}1 \\
46 \\
49 \\
55 \\
60 \\
76 \\
80 \\
90 \\
95 \\
104 \\
105\end{array}$ & 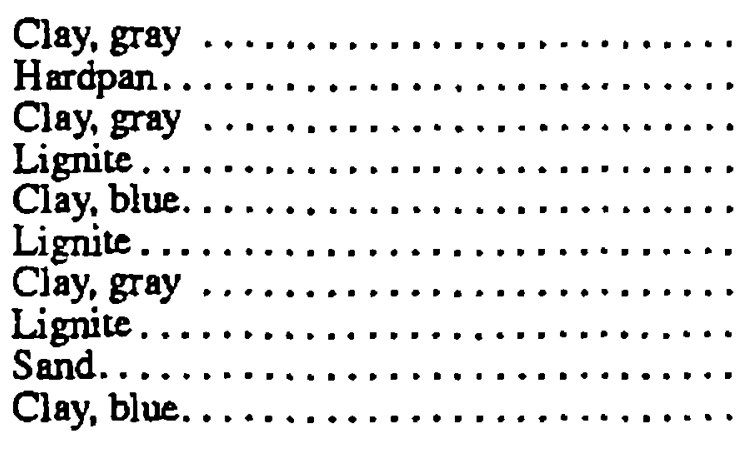 & $\begin{array}{r}10 \\
2 \\
13 \\
2 \\
7 \\
11 \\
30 \\
15 \\
43 \\
2\end{array}$ & $\begin{array}{l}115 \\
117 \\
130 \\
132 \\
139 \\
150 \\
180 \\
195 \\
238 \\
240\end{array}$ \\
\hline
\end{tabular}

152-088-28BBB2

(Log modifled from Mann Drilling Co.)

Altide: 2,100 fert

Date drilled

$09-10-79$

\begin{tabular}{|c|c|c|c|c|c|}
\hline Materia] & $\begin{array}{l}\text { Thick- } \\
\text { ness } \\
\text { (feet) }\end{array}$ & $\begin{array}{l}\text { Depth } \\
\text { (feet) }\end{array}$ & Material & $\begin{array}{l}\text { Thlck- } \\
\text { ness } \\
\text { (feet) }\end{array}$ & $\begin{array}{l}\text { Depth } \\
\text { (feet) }\end{array}$ \\
\hline $\begin{array}{l}\text { Till, } \tan \ldots \ldots \ldots \ldots \ldots \ldots \ldots \ldots \ldots \ldots \ldots \ldots \ldots \ldots \ldots \ldots \ldots \\
\text { Sand } \operatorname{silty} \ldots \ldots \ldots \ldots \ldots \ldots \ldots\end{array}$ & $\begin{array}{r}120 \\
64\end{array}$ & $\begin{array}{l}120 \\
184\end{array}$ & Lignite . . . . . . . . . . . . . . . . . & 6 & 190 \\
\hline
\end{tabular}

152-088-34BBB

(Log modified from Mann Drilling Co.)

Altitude: 2,105 feet

Date drilled: $\quad 07-14-80$

\begin{tabular}{|c|c|c|c|c|c|}
\hline Material & $\begin{array}{l}\text { Thick- } \\
\text { ness } \\
\text { (feot) }\end{array}$ & $\begin{array}{l}\text { Depth } \\
\text { (feet) }\end{array}$ & Material & $\begin{array}{l}\text { Thick- } \\
\text { ness } \\
\text { (foet) }\end{array}$ & $\begin{array}{l}\text { Depth } \\
\text { (feet) }\end{array}$ \\
\hline 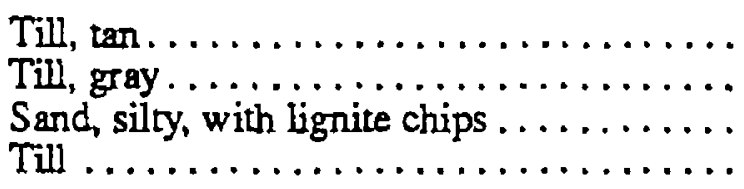 & $\begin{array}{l}32 \\
58 \\
15 \\
21\end{array}$ & $\begin{array}{r}32 \\
90 \\
105 \\
126\end{array}$ & 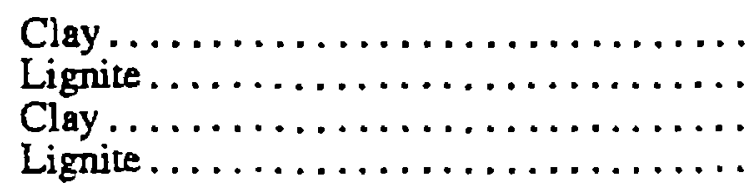 & $\begin{array}{r}24 \\
4 \\
53 \\
8\end{array}$ & $\begin{array}{l}150 \\
154 \\
207 \\
215\end{array}$ \\
\hline
\end{tabular}


Table 3. Drillers' logs of wells and test holes--Continued

152-089-05BACB

(Log modified from Mann Drilling Co.)

Altitude: 2,105 feet

Date drilled: 03-22-84

\begin{tabular}{|c|c|c|c|c|c|}
\hline Materlal & $\begin{array}{l}\text { Thlok- } \\
\text { ness } \\
\text { (foet) }\end{array}$ & $\begin{array}{l}\text { Depth } \\
\text { (feet) }\end{array}$ & Materlal & $\begin{array}{l}\text { Thick- } \\
\text { ness } \\
\text { (feet) }\end{array}$ & $\begin{array}{l}\text { Dinth } \\
\text { (frot) }\end{array}$ \\
\hline 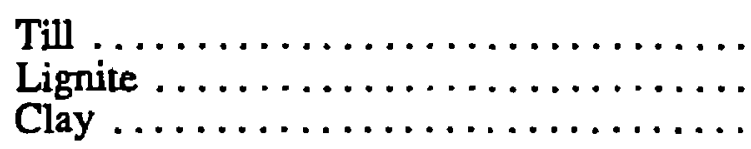 & $\begin{array}{r}18 \\
2 \\
45\end{array}$ & $\begin{array}{l}18 \\
20 \\
65\end{array}$ & $\begin{array}{l}\text { Lignite } \ldots \ldots \ldots \ldots \ldots \ldots \ldots \ldots \ldots \ldots \ldots \ldots \ldots \\
\text { Clay } \ldots \ldots \ldots \ldots \ldots \ldots \ldots \ldots \ldots\end{array}$ & $\begin{array}{l}4 \\
1\end{array}$ & $\begin{array}{l}69 \\
70\end{array}$ \\
\hline
\end{tabular}

152-089-19BCCC

(Log modifled from Mann Drilling Co.)

Altitude: 2,040 feet

Date drilled: $05-97-81$

Material

152-089-23ccc

(Log modified from Water Supply, Inc.)

Altitude: 1,970 feet

Date drilled: $10-13-77$

\begin{tabular}{|c|c|c|c|c|c|}
\hline Mater|s| & $\begin{array}{l}\text { Thlck- } \\
\text { nese } \\
\text { (feet) }\end{array}$ & $\begin{array}{l}\text { Depth } \\
\text { (feet) }\end{array}$ & Materlal & $\begin{array}{l}\text { Thick- } \\
\text { ness } \\
\text { (feet) }\end{array}$ & $\begin{array}{l}\text { Depth } \\
\text { (fivi) }\end{array}$ \\
\hline $\begin{array}{l}\text { Till, yellowish brown, cohesive, } \\
\text { calcareous, oxidized ................. } \\
\text { Sand, very fine to medium. } \\
\text { predominantly quartz; gray shale ........ } \\
\text { Till, olive-gray, cohesive, calcareous; } \\
\text { clay through gravel .................. } \\
\text { Gravel, sandy; medium sand to pebbles; } \\
\text { predominantly quartz sand; limestone; } \\
\text { shale gravel ....................... } \\
\text { Till, olive-gray, cohesive, calcareous; } \\
\text { clay through sand ................... }\end{array}$ & $\begin{array}{r}11 \\
2 \\
4 \\
5 \\
12\end{array}$ & $\begin{array}{l}11 \\
13 \\
17 \\
22 \\
34\end{array}$ & $\begin{array}{l}\text { Gravel, sandy; predominantly quartz } \\
\text { fine sand to pebbles; shale sand; } \\
\text { subrounded shale; carbonate gravel. ..... } \\
\text { Till, sandy, silty, medium-gray ......... } \\
\text { Siltstone, medium-gray to light-gray, } \\
\text { cohesive, fairly solid; slightly } \\
\text { calcareous very fine sand and lignite } \\
\text { inclusions ....................... }\end{array}$ & $\begin{array}{r}13 \\
8\end{array}$ & $\begin{array}{l}47 \\
55\end{array}$ \\
\hline
\end{tabular}


Table 3. Drillers' logs of wells and test holes--Continued

152-089-28DCD

(Log modifted from Dennis Water Well Drilling)

Alttude: 1,990 feet

Date drilled: $11-30-88$

\begin{tabular}{|c|c|c|c|c|c|}
\hline Materlal & $\begin{array}{l}\text { Thick- } \\
\text { nese } \\
\text { (feet) }\end{array}$ & $\begin{array}{l}\text { Depth } \\
\text { (fest) }\end{array}$ & Materlal & $\begin{array}{l}\text { Thlok- } \\
\text { ners } \\
\text { (feet) }\end{array}$ & $\begin{array}{l}\text { Depth } \\
\text { (feed) }\end{array}$ \\
\hline 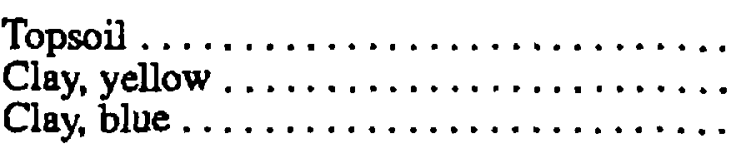 & $\begin{array}{r}1 \\
29 \\
18\end{array}$ & $\begin{array}{r}1 \\
30 \\
48\end{array}$ & $\begin{array}{l}\text { Sand, gravel, and lignite } \ldots \ldots \ldots \ldots \ldots \ldots \ldots \\
\text { Clay, blue. } \ldots \ldots \ldots \ldots \ldots \ldots \ldots \ldots \ldots \ldots \ldots \ldots \\
\text { Lignite } \ldots \ldots \ldots \ldots \ldots \ldots \ldots \ldots \ldots\end{array}$ & $\begin{array}{r}18 \\
3 \\
3\end{array}$ & $\begin{array}{l}66 \\
69 \\
72\end{array}$ \\
\hline
\end{tabular}

152-089-29CCC3

(Log modifled from Mann Drilling Co.)

Alttude: 1,955 feet

Date drilled: $10-08-81$

\begin{tabular}{|c|c|c|c|c|c|}
\hline Materiai & $\begin{array}{l}\text { Thick- } \\
\text { ness } \\
\text { (feet) }\end{array}$ & $\begin{array}{l}\text { Depth } \\
\text { (feet) }\end{array}$ & Material & $\begin{array}{l}\text { Thick- } \\
\text { ners } \\
\text { (feet) }\end{array}$ & $\begin{array}{l}\text { Depth } \\
\text { (feet) }\end{array}$ \\
\hline $\begin{array}{l}\text { Topsoil . . . . . . . . . . . . . . . . . . . } \\
\text { Gravel . . . }\end{array}$ & $\begin{array}{l}2 \\
2\end{array}$ & $\begin{array}{l}2 \\
4\end{array}$ & $\begin{array}{l}\text { Till } \ldots \ldots \ldots \ldots \ldots \ldots \ldots \ldots \ldots \ldots \ldots \ldots \\
\text { Sand and gravel } \ldots \ldots \ldots \ldots \ldots \ldots \ldots\end{array}$ & $\begin{array}{l}21 \\
12\end{array}$ & $\begin{array}{l}25 \\
37\end{array}$ \\
\hline
\end{tabular}

$152-089-29 \mathrm{CCC}_{4}$

(Log modifled from Mann Driliing Co.)

Aititude: 1,960 feet

Date drilind: $03-26-84$

\begin{tabular}{|c|c|c|c|c|c|}
\hline Material & $\begin{array}{c}\text { Thick- } \\
\text { nees } \\
\text { (feet) }\end{array}$ & $\begin{array}{l}\text { Depth } \\
\text { (feet) }\end{array}$ & Material & $\begin{array}{l}\text { Thick- } \\
\text { ners } \\
\text { (feet) }\end{array}$ & $\begin{array}{l}\text { Depth } \\
\text { (feet) }\end{array}$ \\
\hline 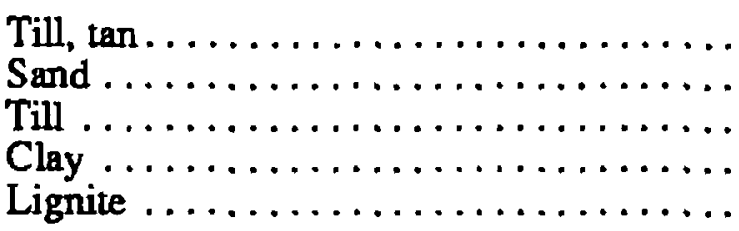 & $\begin{array}{r}25 \\
17 \\
29 \\
83 \\
2\end{array}$ & $\begin{array}{r}25 \\
42 \\
71 \\
154 \\
156\end{array}$ & 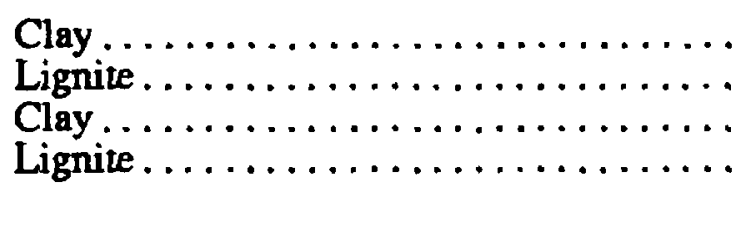 & $\begin{array}{r}24 \\
4 \\
96 \\
8\end{array}$ & $\begin{array}{l}180 \\
184 \\
280 \\
288\end{array}$ \\
\hline
\end{tabular}

152-089-29CCC5

(Log modified from Mann Driiling Co.)

Aittude: 1,955 feet

Date drilied: $03-29-84$

\begin{tabular}{|c|c|c|c|c|c|}
\hline Material & $\begin{array}{l}\text { Thick- } \\
\text { ness } \\
\text { (feat) }\end{array}$ & $\begin{array}{l}\text { Depth } \\
\text { (feet) }\end{array}$ & Matorial & $\begin{array}{l}\text { Thick- } \\
\text { ness } \\
\text { (feet) }\end{array}$ & $\begin{array}{l}\text { Depth } \\
\text { (feet) }\end{array}$ \\
\hline $\begin{array}{l}\text { Topsoil . . . . . . . . . . . } \\
\text { Gravel. . . . . . . }\end{array}$ & $\begin{array}{l}1 \\
9\end{array}$ & $\begin{array}{r}1 \\
10\end{array}$ & $\begin{array}{l}\text { Till, gray ............ } \\
\text { Sand and gravel ...... }\end{array}$ & $\begin{array}{l}18 \\
10\end{array}$ & $\begin{array}{l}28 \\
38\end{array}$ \\
\hline
\end{tabular}


Table 3. Drillers' logs of wells and test holes--Continued

152-089-34ABB

(Log modified from Mariner Drilling Service)

Altitude: 2,050 feet

Date drilled: $07-02-79$

\begin{tabular}{|c|c|c|c|c|c|}
\hline Material & $\begin{array}{l}\text { Thlok- } \\
\text { noss } \\
\text { (feet) }\end{array}$ & $\begin{array}{l}\text { Depth } \\
\text { (feet) }\end{array}$ & Material & $\begin{array}{l}\text { Thlok- } \\
\text { nese } \\
\text { (foet) }\end{array}$ & $\begin{array}{l}\text { Dopth } \\
(f \vee \vartheta t)\end{array}$ \\
\hline $\begin{array}{l}\text { Topsoil } \ldots \ldots \ldots \ldots \ldots \ldots \ldots \ldots \ldots \ldots \ldots \ldots \ldots \\
\text { Clay, yellow } \ldots \ldots \ldots \ldots \ldots \ldots \ldots \ldots \ldots \ldots \ldots \ldots \\
\text { Clay, blue } \ldots \ldots \ldots \ldots \ldots \ldots \ldots \ldots \ldots \ldots \ldots \ldots\end{array}$ & $\begin{array}{r}1 \\
53 \\
47\end{array}$ & $\begin{array}{r}1 \\
54 \\
101\end{array}$ & $\begin{array}{l}\text { Sand, blue and gray } \ldots \ldots \ldots \ldots \ldots \ldots \ldots \ldots \\
\text { Clay, sandy } \ldots \ldots \ldots \ldots \ldots \ldots \ldots\end{array}$ & $\begin{array}{r}9 \\
10\end{array}$ & $\begin{array}{l}110 \\
120\end{array}$ \\
\hline
\end{tabular}

152-090-02CDDA

(Log modifled from Mann Driling Co.)

Altitude: 2,080 feet

Date drilled: 09-27-84

\begin{tabular}{|c|c|c|c|c|c|}
\hline Materlal & $\begin{array}{l}\text { Thlck- } \\
\text { neas } \\
\text { (feet) }\end{array}$ & $\begin{array}{l}\text { Depth } \\
\text { (feet) }\end{array}$ & Materfal & $\begin{array}{l}\text { Thlak- } \\
\text { neas } \\
\text { (feet) }\end{array}$ & $\begin{array}{l}\text { Dopth } \\
\text { (fivit) }\end{array}$ \\
\hline $\begin{array}{l}\text { Till, tan . . . . . . . . . } \\
\text { Clay, gray . . . . . . . }\end{array}$ & $\begin{array}{r}110 \\
85\end{array}$ & $\begin{array}{l}110 \\
195\end{array}$ & $\begin{array}{l}\text { Sand } \ldots \ldots \ldots \ldots \ldots \ldots \ldots \ldots \ldots \ldots \ldots \ldots \ldots \ldots \ldots \ldots \ldots \ldots \ldots \ldots \ldots \ldots \\
\text { Lignite } \ldots \ldots \ldots \ldots \ldots \ldots \ldots \ldots\end{array}$ & $\begin{array}{r}45 \\
3\end{array}$ & $\begin{array}{l}2.40 \\
2.43\end{array}$ \\
\hline
\end{tabular}

152-090-11DDD1

(Log modified from Mariner Driliing Service)

Altitude: 2,110 feet

Date drilled: $10-26-78$

\begin{tabular}{|c|c|c|c|c|c|}
\hline Matorial & $\begin{array}{l}\text { Thlck- } \\
\text { neses } \\
\text { (feet) }\end{array}$ & $\begin{array}{l}\text { Depth } \\
\text { (feat) }\end{array}$ & Materlal & $\begin{array}{l}\text { Thlok- } \\
\text { neas } \\
\text { (feet) }\end{array}$ & $\begin{array}{l}\text { Denth } \\
\text { (fingt) }\end{array}$ \\
\hline 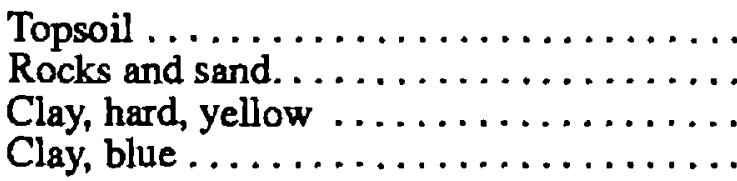 & $\begin{array}{r}1 \\
4 \\
20 \\
40\end{array}$ & $\begin{array}{r}1 \\
5 \\
25 \\
65\end{array}$ & 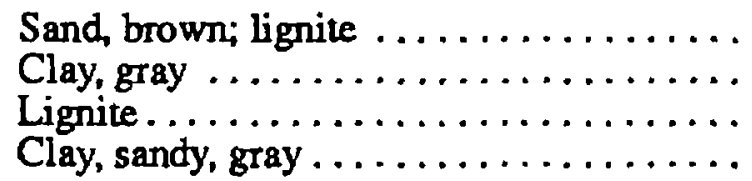 & $\begin{array}{r}5 \\
27 \\
10 \\
8\end{array}$ & $\begin{array}{r}70 \\
97 \\
107 \\
115\end{array}$ \\
\hline
\end{tabular}

152-090-11DDD2

(Log modifled from Mariner Drilling Service)

Alttude: 2,110 teet

Date drilled: $07-15-79$

\begin{tabular}{|c|c|c|c|c|c|}
\hline Material & $\begin{array}{l}\text { Thick- } \\
\text { neas } \\
\text { (feot) }\end{array}$ & $\begin{array}{l}\text { Depth } \\
\text { (feot) }\end{array}$ & Matertal & $\begin{array}{l}\text { Thick. } \\
\text { ness } \\
\text { (feet) }\end{array}$ & $\begin{array}{l}\text { De nth } \\
\text { (feet) }\end{array}$ \\
\hline 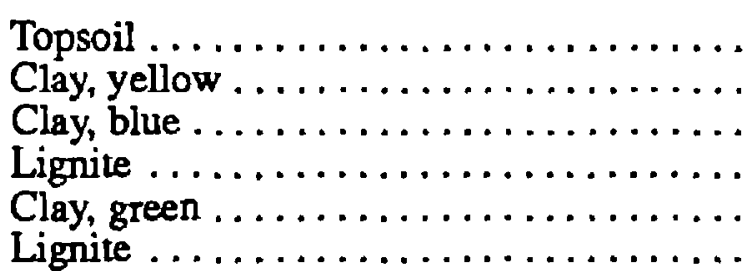 & $\begin{array}{r}1 \\
20 \\
54 \\
2 \\
13 \\
1\end{array}$ & $\begin{array}{l}1 \\
21 \\
75 \\
77 \\
90 \\
91\end{array}$ & 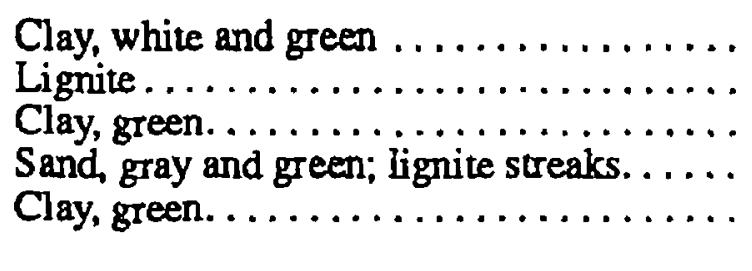 & $\begin{array}{r}8 \\
2 \\
7 \\
17 \\
15\end{array}$ & $\begin{array}{r}99 \\
101 \\
108 \\
125 \\
140\end{array}$ \\
\hline
\end{tabular}


Table 3. Drillers' logs of wells and test holes--Continued

152-090-11DDD3

(Log modifled from Mann-Stumvoll Drilling)

Altitude: 2,105 feet

Date driliec: $04-25-89$

\begin{tabular}{|c|c|c|c|c|c|}
\hline Material & $\begin{array}{l}\text { Thiok- } \\
\text { nese } \\
\text { (feet) }\end{array}$ & $\begin{array}{l}\text { Depth } \\
\text { (feot) }\end{array}$ & Material & $\begin{array}{l}\text { Thicte- } \\
\text { ness } \\
\text { (feet) }\end{array}$ & $\begin{array}{l}\text { Depth } \\
\text { (feet) }\end{array}$ \\
\hline 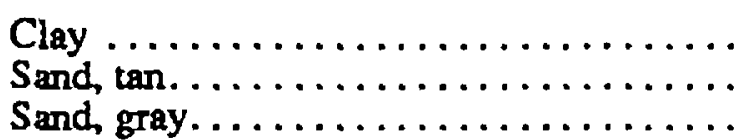 & $\begin{array}{l}10 \\
41 \\
12\end{array}$ & $\begin{array}{l}10 \\
51 \\
63\end{array}$ & $\begin{array}{l}\text { Clay, gray } \ldots \ldots \ldots \ldots \ldots \ldots \ldots \ldots \ldots \ldots \ldots \ldots \\
\text { Lignite } \ldots \ldots \ldots \ldots \ldots \ldots \ldots \ldots \ldots \ldots \ldots \\
\text { Clay } \ldots \ldots \ldots \ldots \ldots \ldots \ldots \ldots \ldots \ldots\end{array}$ & $\begin{array}{r}28 \\
8 \\
1\end{array}$ & $\begin{array}{r}91 \\
99 \\
100\end{array}$ \\
\hline
\end{tabular}

152-090-13DAA2

(Log modified from Dennis Water Weli Drilling)

Altitude: 2,110 feet

Date drilie t: $11-20-87$

\begin{tabular}{|c|c|c|c|c|c|}
\hline Material & $\begin{array}{l}\text { Thick- } \\
\text { ness } \\
\text { (foet) }\end{array}$ & $\begin{array}{l}\text { Depth } \\
\text { (feet) }\end{array}$ & Material & $\begin{array}{l}\text { Thicte- } \\
\text { ness } \\
\text { (feof) }\end{array}$ & $\begin{array}{l}\text { Depth } \\
\text { (feet) }\end{array}$ \\
\hline 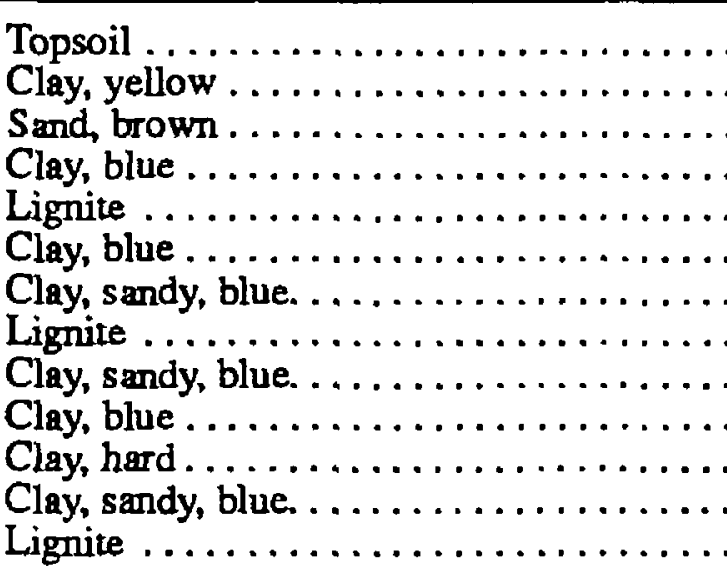 & $\begin{array}{r}1 \\
22 \\
10 \\
27 \\
10 \\
70 \\
15 \\
1 \\
10 \\
8 \\
3.5 \\
30.5 \\
1.5\end{array}$ & $\begin{array}{l}1 \\
23 \\
33 \\
60 \\
70 \\
140 \\
155 \\
156 \\
166 \\
174 \\
177.5 \\
208 \\
209.5\end{array}$ & 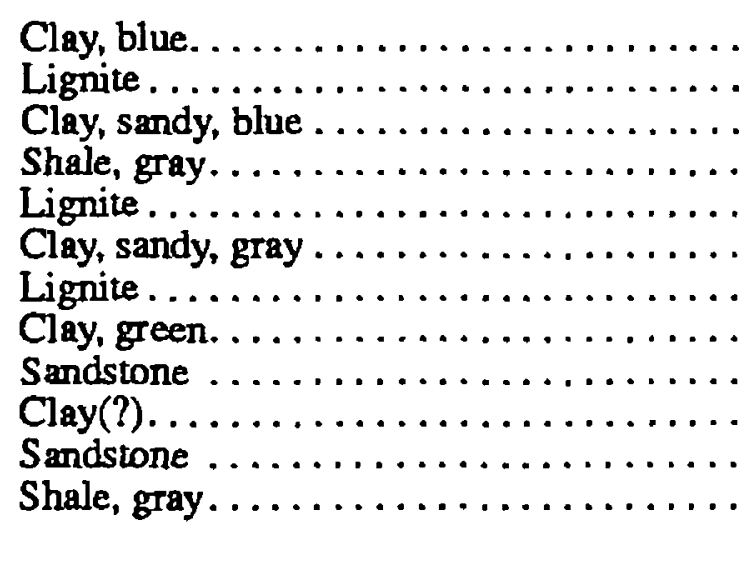 & $\begin{array}{r}49.5 \\
2 \\
29 \\
26 \\
2 \\
40 \\
2 \\
7 \\
1 \\
1 \\
1 \\
15\end{array}$ & $\begin{array}{l}259 \\
261 \\
290 \\
316 \\
318 \\
358 \\
360 \\
367 \\
368 \\
369 \\
370 \\
385\end{array}$ \\
\hline
\end{tabular}

152-090-15BAD

(Log modified from Dennis Water Weil Driiling)

Altitude: 2,035 feet

Date drille + : $06-15-88$

\begin{tabular}{|c|c|c|c|c|c|}
\hline Material & $\begin{array}{l}\text { Thick- } \\
\text { neas } \\
\text { (foet) }\end{array}$ & $\begin{array}{l}\text { Depth } \\
\text { (feet) }\end{array}$ & Material & $\begin{array}{l}\text { Thlete. } \\
\text { nes? } \\
\text { (feer) }\end{array}$ & $\begin{array}{l}\text { Depth } \\
\text { (feet) }\end{array}$ \\
\hline 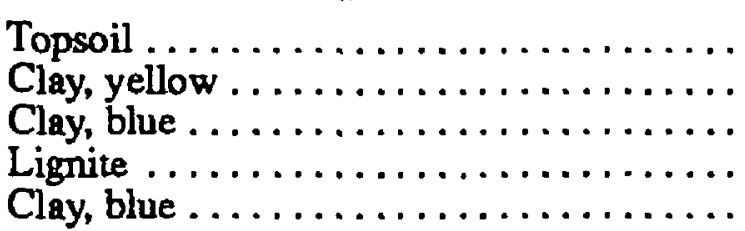 & $\begin{array}{l}1 \\
21 \\
25 \\
10 \\
19\end{array}$ & $\begin{array}{r}1 \\
22 \\
47 \\
57 \\
76\end{array}$ & 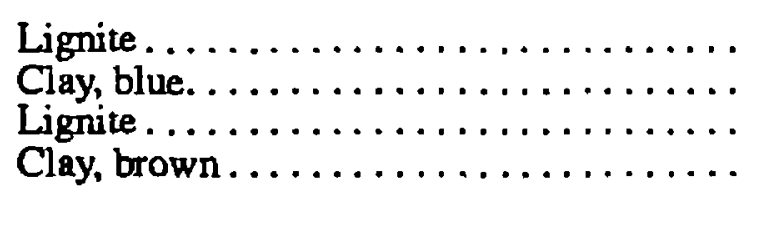 & $\begin{array}{r}2 \\
18 \\
4.5 \\
5.5\end{array}$ & $\begin{array}{l}78 \\
96 \\
100.5 \\
106\end{array}$ \\
\hline
\end{tabular}


Table 3. Drillers' logs of wells and test holes--Continued

152-091-05DBB

(Log modified from Mariner Drilling Service)

Altitude: 2,060 feet

Date drilled: 08-07-81

\begin{tabular}{|c|c|c|c|c|c|}
\hline Materlal & $\begin{array}{l}\text { Thick- } \\
\text { ness: } \\
\text { (foet) }\end{array}$ & $\begin{array}{l}\text { Depth } \\
\text { (feet) }\end{array}$ & Material & $\begin{array}{l}\text { Thlak- } \\
\text { ness } \\
\text { (feet) }\end{array}$ & $\begin{array}{l}\text { Depth } \\
\text { (foet) }\end{array}$ \\
\hline 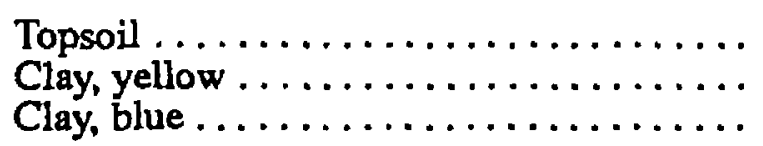 & $\begin{array}{r}1 \\
38 \\
36\end{array}$ & $\begin{array}{r}1 \\
39 \\
75\end{array}$ & 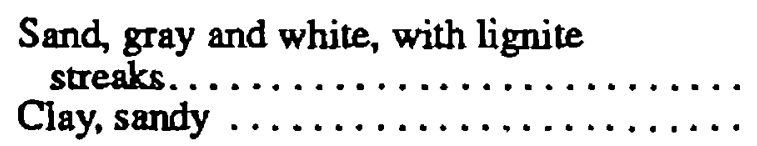 & $\begin{array}{r}15 \\
2\end{array}$ & $\begin{array}{l}90 \\
92\end{array}$ \\
\hline
\end{tabular}

152-091-09DDD2

(Log modifled from Dennis Water Well Drilling)

Altitude: 2,075 feet

Date drilied: $10-20-86$

\begin{tabular}{|c|c|c|c|c|c|}
\hline Materiai & $\begin{array}{l}\text { Thick- } \\
\text { ness } \\
\text { (feet) }\end{array}$ & $\begin{array}{l}\text { Depth } \\
\text { (feet) }\end{array}$ & Material & $\begin{array}{l}\text { Thick- } \\
\text { ness } \\
\text { (feet) }\end{array}$ & $\begin{array}{l}\text { Depth } \\
\text { (feot) }\end{array}$ \\
\hline 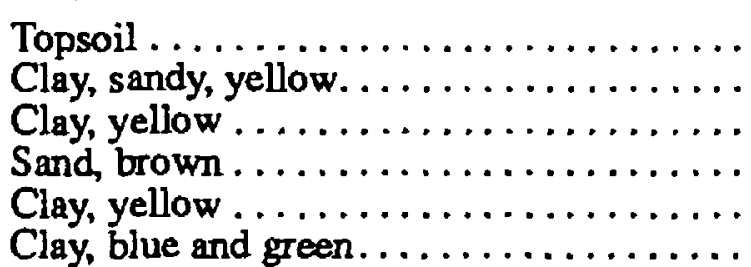 & $\begin{array}{r}1 \\
13 \\
18 \\
28 \\
2 \\
18\end{array}$ & $\begin{array}{l}1 \\
14 \\
32 \\
60 \\
62 \\
80\end{array}$ & 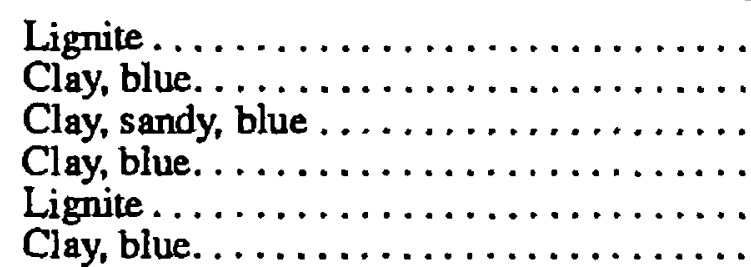 & $\begin{array}{r}2 \\
11 \\
47 \\
6 \\
10 \\
4\end{array}$ & $\begin{array}{r}82 \\
93 \\
140 \\
146 \\
156 \\
160\end{array}$ \\
\hline
\end{tabular}

152-091-15BCCC

(Log modified from Dennis Water Well Drilling)

Aititude: 2,015 feet

Date drilied: $11-08-86$

\begin{tabular}{|c|c|c|c|c|c|}
\hline Materiai & $\begin{array}{l}\text { Thick- } \\
\text { ness } \\
\text { (feet) }\end{array}$ & $\begin{array}{l}\text { Depth } \\
\text { (feet) }\end{array}$ & Materlal & $\begin{array}{l}\text { Thlck- } \\
\text { ness } \\
\text { (feet) }\end{array}$ & $\begin{array}{l}\text { Depth } \\
\text { (feet) }\end{array}$ \\
\hline 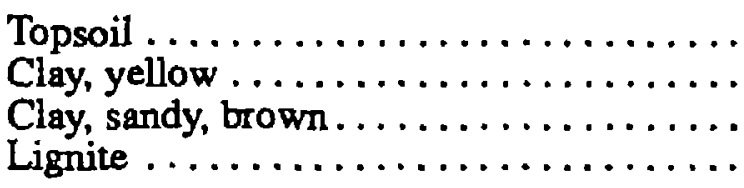 & $\begin{array}{r}1 \\
35 \\
25 \\
6\end{array}$ & $\begin{array}{r}1 \\
36 \\
61 \\
67\end{array}$ & 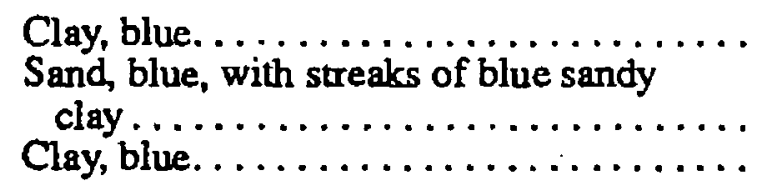 & $\begin{array}{r}35 \\
37 \\
6\end{array}$ & $\begin{array}{l}102 \\
139 \\
145\end{array}$ \\
\hline
\end{tabular}

152-091-18CDA

(Log modified from Crowder Well Drilling)

Altitude: 1,930 feet

Date drilled: $07-26-82$

\begin{tabular}{|c|c|c|c|c|c|}
\hline Material & $\begin{array}{l}\text { Thick- } \\
\text { ness } \\
\text { (feet) }\end{array}$ & $\begin{array}{l}\text { Depth } \\
\text { (feet) }\end{array}$ & Material & $\begin{array}{l}\text { Thick- } \\
\text { ness } \\
\text { (feet) }\end{array}$ & $\begin{array}{l}\text { [noth } \\
\text { (feet) }\end{array}$ \\
\hline $\begin{array}{l}\text { Topsoil . . . . . . . . . . . . . . . . . . . } \\
\text { Clay, yellow; gravel . . . . . . . . . . . . } \\
\text { Clay, blue; gravel . . . . . . . . . . . . }\end{array}$ & $\begin{array}{r}1 \\
49 \\
20\end{array}$ & $\begin{array}{l}1 \\
50 \\
70\end{array}$ & 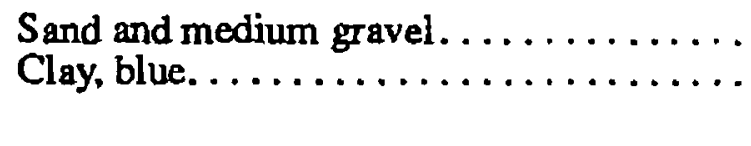 & $\begin{array}{r}26 \\
4\end{array}$ & $\begin{array}{r}96 \\
100\end{array}$ \\
\hline
\end{tabular}


Table 3. Drillers' logs of wells and test holes-Continued

152-091-32ABB

(Log modified from Dennis Water Well Drilling)

Altide: 1,880 foet

Date drilled: $08-06-88$

\begin{tabular}{|c|c|c|c|c|c|}
\hline Material & $\begin{array}{l}\text { Thick- } \\
\text { ness } \\
\text { (foet) }\end{array}$ & $\begin{array}{l}\text { Depth } \\
\text { (feot) }\end{array}$ & Material & $\begin{array}{l}\text { Thick- } \\
\text { nest } \\
\text { (foet) }\end{array}$ & $\begin{array}{l}\text { Depth } \\
\text { (feet) }\end{array}$ \\
\hline 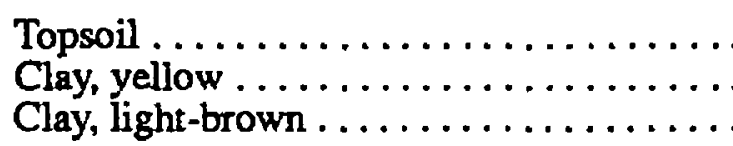 & $\begin{array}{r}1 \\
9 \\
12\end{array}$ & $\begin{array}{r}1 \\
10 \\
22\end{array}$ & 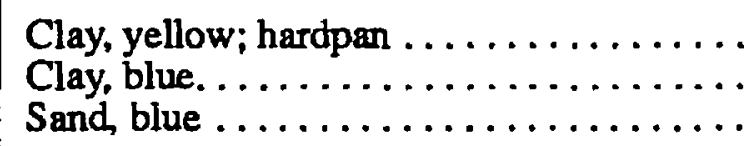 & $\begin{array}{r}3 \\
60 \\
45\end{array}$ & $\begin{array}{r}25 \\
85 \\
130\end{array}$ \\
\hline
\end{tabular}

152-091-32BBA

(Log modifled from Mann Drilling Co.)

Alttude: 1,890 feet

Date drillert: $04-24-87$

\begin{tabular}{|c|c|c|c|c|c|}
\hline Materlal & $\begin{array}{l}\text { Thick- } \\
\text { nesa } \\
\text { (feet) }\end{array}$ & $\begin{array}{l}\text { Depth } \\
\text { (feol) }\end{array}$ & Material & $\begin{array}{l}\text { Thlck- } \\
\text { ness } \\
\text { (fee') }\end{array}$ & $\begin{array}{l}\text { Depth } \\
\text { (feet) }\end{array}$ \\
\hline 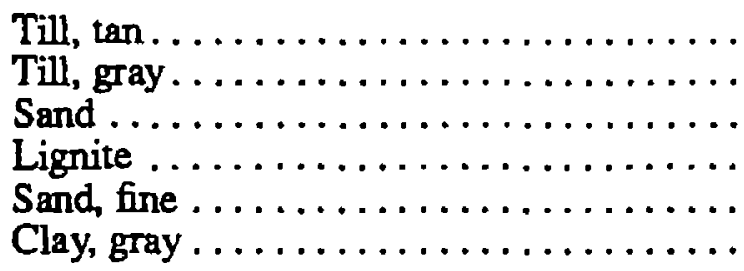 & $\begin{array}{r}43 \\
95 \\
6 \\
3 \\
18 \\
78\end{array}$ & $\begin{array}{r}43 \\
138 \\
144 \\
147 \\
165 \\
243\end{array}$ & 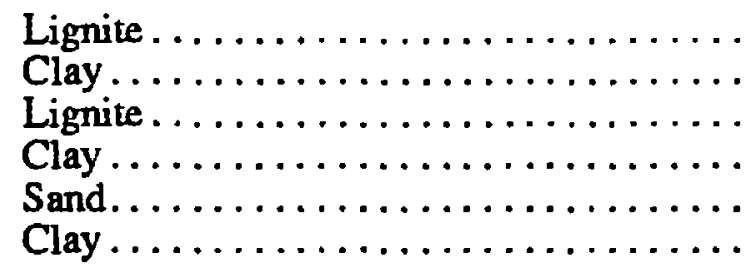 & $\begin{array}{r}\hat{\vdots} \\
10 \\
245 \\
6 \frac{5}{5}\end{array}$ & $\begin{array}{l}246 \\
256 \\
266 \\
515 \\
580 \\
585\end{array}$ \\
\hline
\end{tabular}

152-092-07AAA

(Log modifled trom S and L Drliling, inc.)

Altitude: 2,080 feet

Date drilied: $04-28-83$

\begin{tabular}{|c|c|c|c|c|c|}
\hline Materlal & $\begin{array}{l}\text { Thick- } \\
\text { ness } \\
\text { (feet) }\end{array}$ & $\begin{array}{l}\text { Depth } \\
\text { (foet) }\end{array}$ & Material & $\begin{array}{l}\text { Thick- } \\
\text { nes: } \\
\text { (fee") }\end{array}$ & $\begin{array}{l}\text { Depth } \\
\text { (feet) }\end{array}$ \\
\hline 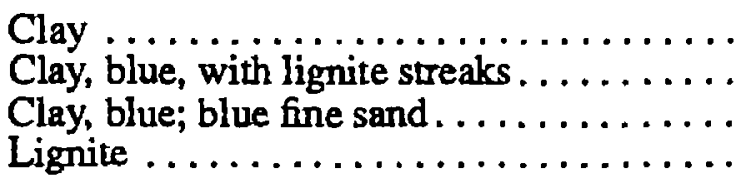 & $\begin{array}{r}22 \\
20 \\
20 \\
8\end{array}$ & $\begin{array}{l}22 \\
42 \\
62 \\
70\end{array}$ & 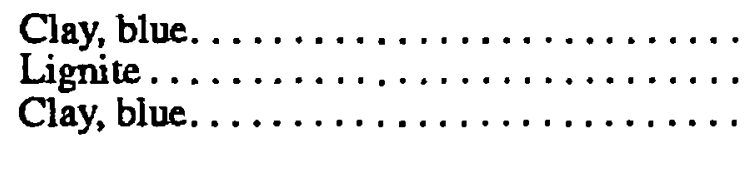 & $\begin{array}{l}4 \\
5 \\
1\end{array}$ & $\begin{array}{l}74 \\
79 \\
80\end{array}$ \\
\hline
\end{tabular}


Table 3. Drillers' logs of wells and test holes--Continued

152-092-07AABB

(Log modifled from $S$ and $L$ Drilling, inc.)

Date drilled: 03-01-85

\begin{tabular}{|c|c|c|c|c|c|}
\hline Material & $\begin{array}{l}\text { Thick- } \\
\text { ness } \\
\text { (feot) }\end{array}$ & $\begin{array}{l}\text { Depth } \\
\text { (feet) }\end{array}$ & Materlal & $\begin{array}{l}\text { Thlck- } \\
\text { nese } \\
\text { (feet) }\end{array}$ & $\begin{array}{l}\text { D inth } \\
\text { (fret) }\end{array}$ \\
\hline 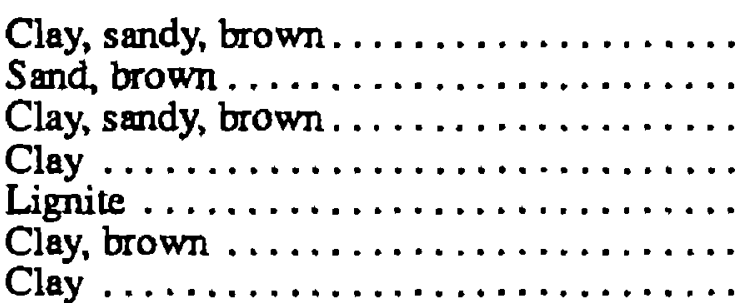 & $\begin{array}{r}10 \\
5 \\
9 \\
15 \\
4 \\
3 \\
27\end{array}$ & $\begin{array}{l}10 \\
15 \\
24 \\
39 \\
43 \\
46 \\
73\end{array}$ & 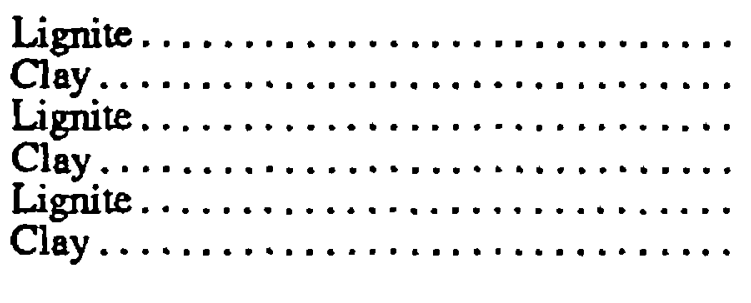 & $\begin{array}{l}2 \\
4 \\
8 \\
7 \\
6 \\
3\end{array}$ & $\begin{array}{r}75 \\
79 \\
87 \\
94 \\
100 \\
103\end{array}$ \\
\hline
\end{tabular}

152-092-12DDD

(Log modifled from Dennis Water Well Driliing)

Aititude: 1,970 feet

Date drilied: $07-? 3-88$

\begin{tabular}{|c|c|c|c|c|c|}
\hline Material & $\begin{array}{l}\text { Thick- } \\
\text { ness } \\
\text { (feet) }\end{array}$ & $\begin{array}{l}\text { Depth } \\
\text { (feet) }\end{array}$ & Materlal & $\begin{array}{l}\text { Thlck- } \\
\text { ness } \\
\text { (feet) }\end{array}$ & $\begin{array}{l}\text { Dinth } \\
(f>-t)\end{array}$ \\
\hline 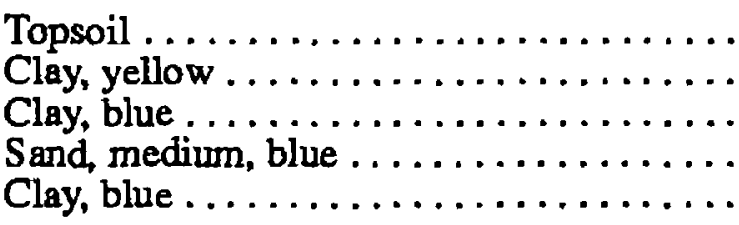 & $\begin{array}{r}1 \\
17 \\
27 \\
2 \\
17\end{array}$ & $\begin{array}{l}1 \\
18 \\
45 \\
47 \\
64\end{array}$ & 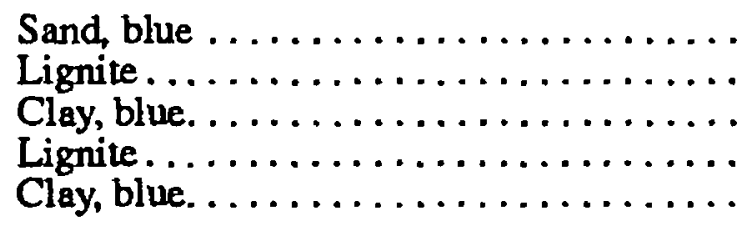 & $\begin{array}{l}6 \\
3 \\
6.5 \\
1.5 \\
39\end{array}$ & $\begin{array}{l}70 \\
73 \\
79.5 \\
81 \\
120\end{array}$ \\
\hline
\end{tabular}

152-092-16CDBD

(Log modified from Tandeskl Water Weii Driilling)

Altitude: 1,955 feet

Date drilled: $05-30-80$

\begin{tabular}{|c|c|c|c|c|c|}
\hline Material & $\begin{array}{l}\text { Thlck- } \\
\text { ness } \\
\text { (feet) }\end{array}$ & $\begin{array}{l}\text { Depth } \\
\text { (feot) }\end{array}$ & Materlal & $\begin{array}{l}\text { Thick- } \\
\text { ness } \\
\text { (feet) }\end{array}$ & $\begin{array}{l}\text { Drnth } \\
(f \backslash 9 t)\end{array}$ \\
\hline $\begin{array}{l}\text { Topsoil, sandy, black ... } \\
\text { Sand and gravel ...... }\end{array}$ & $\begin{array}{r}5 \\
62\end{array}$ & $\begin{array}{r}5 \\
67\end{array}$ & Sand with water. $\ldots \ldots \ldots \ldots \ldots \ldots$ & 23 & 90 \\
\hline
\end{tabular}

152-092-16CDDC

( Log modifled from $S$ and L Drlling, Inc.)

Altidu: 1,955 feet

Date drilled: $11-02-82$

\begin{tabular}{|c|c|c|c|c|c|}
\hline Matorial & $\begin{array}{l}\text { Thick- } \\
\text { ness } \\
\text { (feet) }\end{array}$ & $\begin{array}{l}\text { Depth } \\
\text { (feet) }\end{array}$ & Materlal & $\begin{array}{l}\text { Thlck- } \\
\text { ness } \\
\text { (feet) }\end{array}$ & $\begin{array}{l}\text { Depth } \\
\text { (fivgt) }\end{array}$ \\
\hline $\begin{array}{l}\text { Sand and gravel } \ldots \ldots \ldots \\
\text { Clay, brown } \ldots \ldots \ldots \ldots \\
\text { Clay, blue } \ldots \ldots \ldots \ldots\end{array}$ & $\begin{array}{r}30 \\
20 \\
125\end{array}$ & $\begin{array}{r}30 \\
50 \\
175\end{array}$ & $\begin{array}{l}\text { Sand, fine to coarse; gravel streaks and } \\
\text { lignite chips } \ldots \ldots \ldots \ldots \ldots \ldots \ldots \ldots \ldots \\
\text { Clay, blue. } \ldots \ldots \ldots \ldots \ldots \ldots \ldots \ldots\end{array}$ & $\begin{array}{r}35 \\
5\end{array}$ & $\begin{array}{l}210 \\
215\end{array}$ \\
\hline
\end{tabular}


Table 3. Drillers' logs of wells and test holes--Continued

152-092-17BDCB

(Log modifled from Mohl Drilling, inc.)

Altitude: 1,945 feet

Date drilled: $11-01-81$

\begin{tabular}{|c|c|c|c|c|c|}
\hline Materlal & $\begin{array}{l}\text { Thlok- } \\
\text { neses } \\
\text { (foet) }\end{array}$ & $\begin{array}{l}\text { Depth } \\
\text { (feet) }\end{array}$ & Material & $\begin{array}{l}\text { Thlok- } \\
\text { nese } \\
\text { (fert) }\end{array}$ & $\begin{array}{l}\text { Depth } \\
\text { (feet) }\end{array}$ \\
\hline 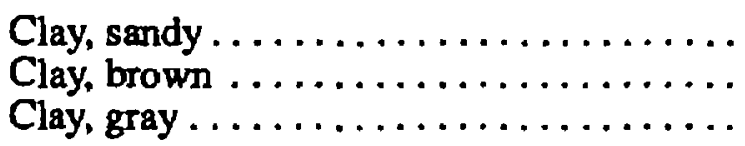 & $\begin{array}{r}5 \\
75 \\
60\end{array}$ & $\begin{array}{r}5 \\
80 \\
140\end{array}$ & 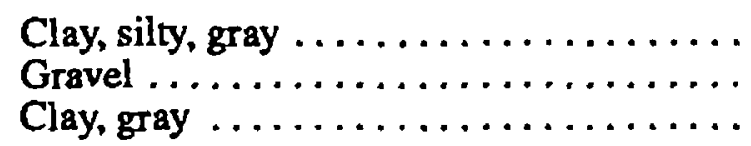 & $\begin{array}{l}95 \\
11 \\
14\end{array}$ & $\begin{array}{l}235 \\
246 \\
260\end{array}$ \\
\hline
\end{tabular}

152-092-17DDDA

(Log modifled from Dennis Water Well Drililng)

Altitude: 1,908 feet

Date drillind: $06-20-88$

\begin{tabular}{|c|c|c|c|c|c|}
\hline Material & $\begin{array}{l}\text { Thlck- } \\
\text { ness } \\
\text { (feet) }\end{array}$ & $\begin{array}{l}\text { Dopth } \\
\text { (feet) }\end{array}$ & Matertal & $\begin{array}{l}\text { Thlck- } \\
\text { ness } \\
\text { (forl) }\end{array}$ & $\begin{array}{l}\text { Depth } \\
\text { (feet) }\end{array}$ \\
\hline $\begin{array}{l}\text { Topsoil } \ldots \ldots \ldots \ldots \ldots \ldots \ldots \ldots \ldots \ldots \ldots \\
\text { Clay, yellow } \ldots \ldots \ldots \ldots \ldots \ldots \ldots \\
\text { Sand, fine, brown } \ldots \ldots \ldots \ldots \ldots \ldots \\
\text { Clay, blue, with gravel stringers. } \ldots \ldots \ldots \ldots \\
\text { Sand, coarse } \ldots \ldots \ldots \ldots \ldots \ldots \ldots \ldots\end{array}$ & $\begin{array}{r}1 \\
14 \\
5 \\
175 \\
10\end{array}$ & $\begin{array}{r}1 \\
15 \\
20 \\
195 \\
205\end{array}$ & 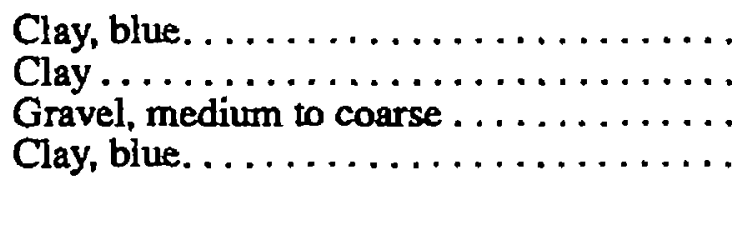 & $\begin{array}{l}6 \\
1 \\
9 \\
6\end{array}$ & $\begin{array}{l}211 \\
212 \\
221 \\
227\end{array}$ \\
\hline
\end{tabular}

152-092-18AADD

(Log modifled from LTP Enterprises, Inc.)

Altitude: 1,945 feet

Date drillet: $12-18-85$

\begin{tabular}{|c|c|c|c|c|c|}
\hline Material & $\begin{array}{l}\text { Thlck- } \\
\text { ness } \\
\text { (feel) }\end{array}$ & $\begin{array}{l}\text { Depth } \\
\text { (feet) }\end{array}$ & Materlal & $\begin{array}{l}\text { Thick- } \\
\text { ness } \\
\text { (fent) }\end{array}$ & $\begin{array}{l}\text { Depth } \\
\text { (feet) }\end{array}$ \\
\hline 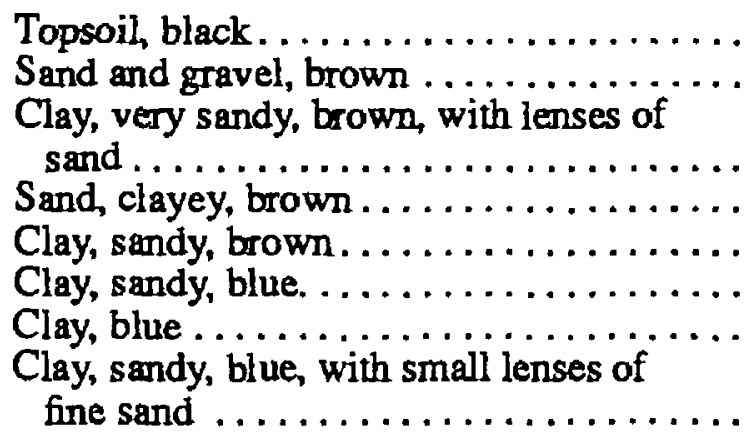 & $\begin{array}{r}2 \\
11 \\
3 \\
3 \\
21 \\
40 \\
111 \\
\\
3.5\end{array}$ & $\begin{array}{r}2 \\
13 \\
16 \\
19 \\
40 \\
80 \\
191 \\
194.5\end{array}$ & 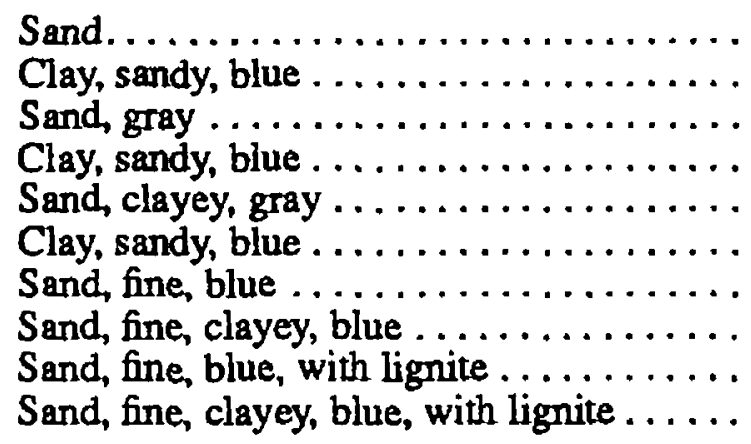 & $\begin{array}{l}2.5 \\
21 \\
3.5 \\
8 \\
4.5 \\
2 \\
11 \\
5 \\
7 \\
9\end{array}$ & $\begin{array}{l}197 \\
218 \\
221.5 \\
229.5 \\
234 \\
236 \\
247 \\
252 \\
259 \\
268\end{array}$ \\
\hline
\end{tabular}


Table 3. Drillers' logs of weils and test holes--Continued

152-092-18ABBB

(Log modified from S and L Drilling, inc.)

Alttude: 2,000 feet

Date drilled: $10-23-82$

\begin{tabular}{|c|c|c|c|c|c|}
\hline Material & $\begin{array}{l}\text { Thlck- } \\
\text { nees } \\
\text { (feet) }\end{array}$ & $\begin{array}{l}\text { Depth } \\
\text { (feet) }\end{array}$ & Msterial & $\begin{array}{l}\text { Thlck- } \\
\text { ness } \\
\text { (feet) }\end{array}$ & $\begin{array}{l}\text { De rth } \\
\text { (feat) }\end{array}$ \\
\hline $\begin{array}{l}\text { Loam } \ldots \ldots \ldots \ldots \ldots \\
\text { Sand } \ldots \ldots \ldots \ldots \ldots \\
\text { Clay, blue } \ldots \ldots \ldots \ldots\end{array}$ & $\begin{array}{r}3 \\
47 \\
70\end{array}$ & $\begin{array}{r}3 \\
50 \\
120\end{array}$ & 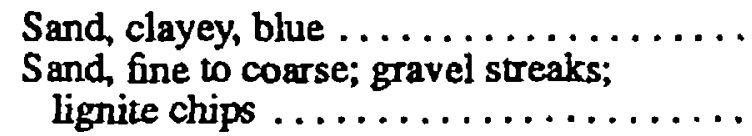 & 90 & 260 \\
\hline
\end{tabular}

152-092-18DABB

(Log modifled from C.A. Simpson \& Son)

Altitude: 1,910 feet

Date drilled: $09-05-78$

\begin{tabular}{|c|c|c|c|c|c|}
\hline Material & $\begin{array}{l}\text { Thlck- } \\
\text { nees } \\
\text { (feet) }\end{array}$ & $\begin{array}{l}\text { Depth } \\
\text { (feet) }\end{array}$ & Matertal & $\begin{array}{l}\text { Thick- } \\
\text { nees } \\
\text { (foot) }\end{array}$ & $\begin{array}{l}\text { Desth } \\
\text { (fast) }\end{array}$ \\
\hline 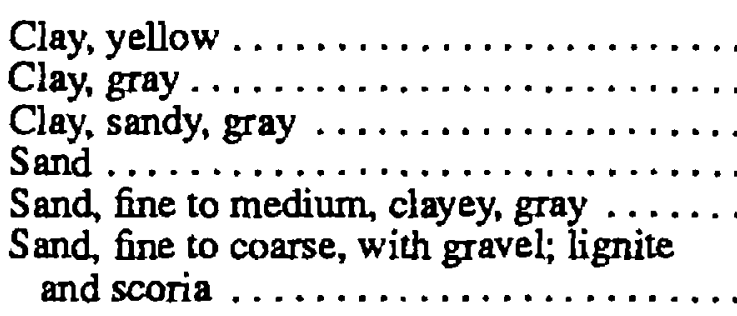 & $\begin{array}{r}34 \\
52 \\
24 \\
10 \\
6 \\
10\end{array}$ & $\begin{array}{r}34 \\
86 \\
110 \\
120 \\
126 \\
136\end{array}$ & 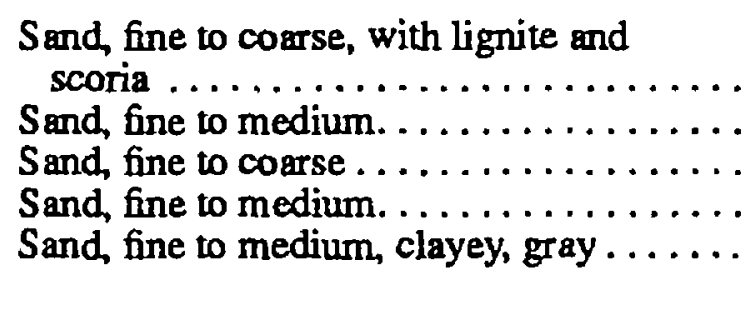 & $\begin{array}{r}21 \\
10 \\
5 \\
4 \\
6\end{array}$ & $\begin{array}{l}157 \\
167 \\
172 \\
176 \\
182\end{array}$ \\
\hline
\end{tabular}

152-092-19AAA4

(Log modifled from LTP Enterprises, Inc.)

Altikude: 1,895 feet

Date drilled: $12-03-82$

\begin{tabular}{|c|c|c|c|c|c|}
\hline Materia! & $\begin{array}{l}\text { Thlck- } \\
\text { nees } \\
\text { (feot) }\end{array}$ & $\begin{array}{l}\text { Depth } \\
\text { (feet) }\end{array}$ & Materlal & $\begin{array}{l}\text { Thick- } \\
\text { ness } \\
\text { (feet) }\end{array}$ & $\begin{array}{l}\text { Depth } \\
\text { (fert) }\end{array}$ \\
\hline 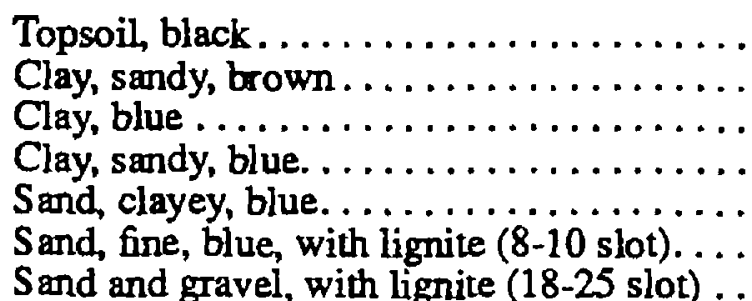 & $\begin{array}{r}2 \\
38 \\
73 \\
25 \\
10 \\
10 \\
5\end{array}$ & $\begin{array}{r}2 \\
40 \\
113 \\
138 \\
148 \\
158 \\
163\end{array}$ & 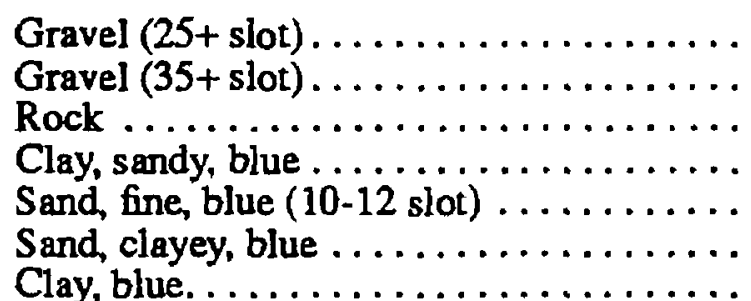 & $\begin{array}{r}5 \\
10 \\
2 \\
4 \\
9 \\
9 \\
1\end{array}$ & $\begin{array}{l}168 \\
178 \\
180 \\
184 \\
193 \\
202 \\
2 c^{2}\end{array}$ \\
\hline
\end{tabular}


Table 3. Drillers' logs of wells and test holes--Continued

152-092-19ABBD

(Log modifled from Dennis Water Well Drilling)

Altitude: 1,870 feet

Date drill-A: 04-29-88

\begin{tabular}{|c|c|c|c|c|c|}
\hline Material & $\begin{array}{l}\text { Thlok- } \\
\text { noes } \\
\text { (feet) }\end{array}$ & $\begin{array}{l}\text { Depth } \\
\text { (feet) }\end{array}$ & Materlal & $\begin{array}{l}\text { Thick- } \\
\text { nese } \\
(f \circ-1)\end{array}$ & $\begin{array}{l}\text { Depth } \\
\text { (feet) }\end{array}$ \\
\hline 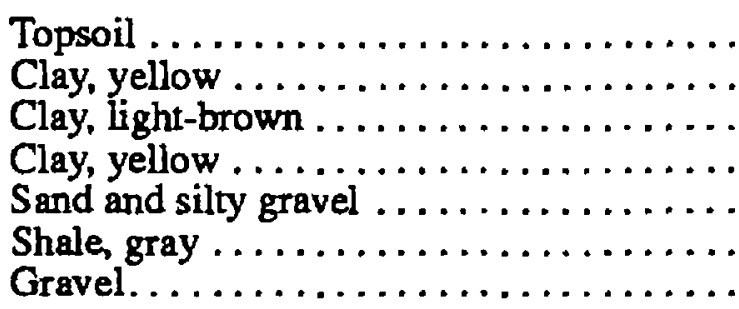 & $\begin{array}{r}1 \\
19 \\
5 \\
30 \\
10 \\
1 \\
1\end{array}$ & $\begin{array}{l}1 \\
20 \\
25 \\
55 \\
65 \\
66 \\
67\end{array}$ & 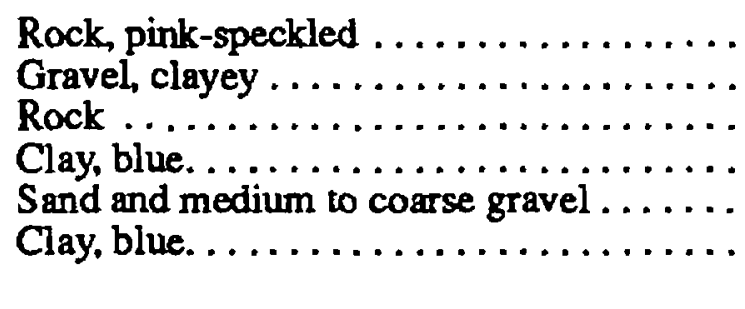 & $\begin{array}{r}3 \\
3 \\
4 \\
5 \\
11 \\
5\end{array}$ & $\begin{array}{l}70 \\
73 \\
77 \\
82 \\
93 \\
98\end{array}$ \\
\hline
\end{tabular}

152-092-21ADAA

(Log modifled trom Sax Well Drilling)

Altitude: 1,895 feet

Date drill $\times$ : $\quad 04-25-80$

\begin{tabular}{|c|c|c|c|c|c|}
\hline Material & $\begin{array}{l}\text { Thlck- } \\
\text { nees } \\
\text { (feet) }\end{array}$ & $\begin{array}{l}\text { Depth } \\
\text { (feot) }\end{array}$ & Materlal & $\begin{array}{l}\text { Thlck- } \\
\text { neas } \\
\text { (feet) }\end{array}$ & $\begin{array}{l}\text { Depth } \\
\text { (feet) }\end{array}$ \\
\hline 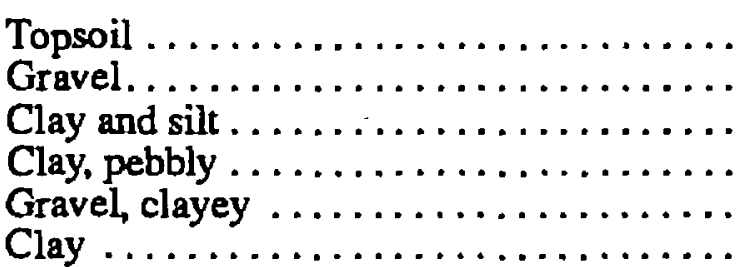 & $\begin{array}{r}1 \\
1 \\
8 \\
54 \\
1 \\
8\end{array}$ & $\begin{array}{r}1 \\
2 \\
10 \\
64 \\
65 \\
73\end{array}$ & 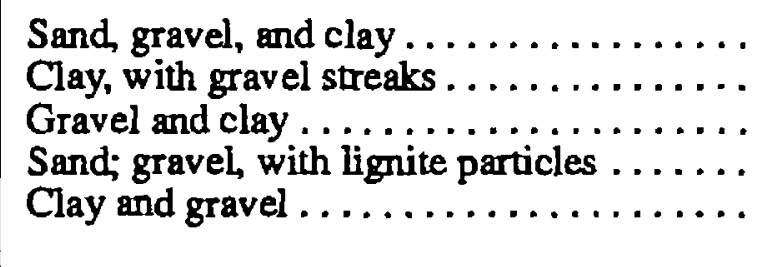 & $\begin{array}{r}3 \\
1 ? \\
31 \\
9 \\
17\end{array}$ & $\begin{array}{r}76 \\
95 \\
126 \\
135 \\
145\end{array}$ \\
\hline
\end{tabular}

152-092-22ADCD

(Log modifled from S and L Drilling, Inc.)

Altitude: 1,875 feet

Date drillod: $06-20-83$

\begin{tabular}{|c|c|c|c|c|c|}
\hline Material & $\begin{array}{l}\text { Thlck- } \\
\text { nesa } \\
\text { (feet) }\end{array}$ & $\begin{array}{l}\text { Depth } \\
\text { (feet) }\end{array}$ & Matorial & $\begin{array}{l}\text { Thlck- } \\
\text { ne9s } \\
\text { (fe } 7 \text { t) }\end{array}$ & $\begin{array}{l}\text { Depth } \\
\text { (feet) }\end{array}$ \\
\hline $\begin{array}{l}\text { Clay, gray; pebbles...... } \\
\text { Clay, blue ............ }\end{array}$ & $\begin{array}{l}31 \\
32\end{array}$ & $\begin{array}{l}31 \\
63\end{array}$ & 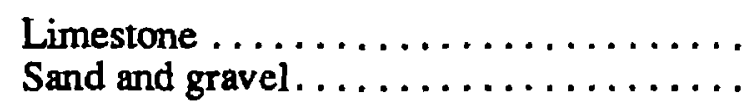 & $\begin{array}{r}3 \\
37\end{array}$ & $\begin{array}{r}66 \\
100\end{array}$ \\
\hline
\end{tabular}


Table 3. Drillers' logs of wells and test holes-Continued

152-093-01CCDA

(Log modifled from Dennis Water Well Drilling)

Altitude: 1,855 feet

Date drilled: $07-31-87$

\begin{tabular}{|c|c|c|c|c|c|}
\hline Material & $\begin{array}{l}\text { Thick- } \\
\text { nees } \\
\text { (teet) }\end{array}$ & $\begin{array}{l}\text { Depth } \\
\text { (feot) }\end{array}$ & Materlal & $\begin{array}{l}\text { Thick- } \\
\text { neas } \\
\text { (feat) }\end{array}$ & $\begin{array}{l}\text { D rpth } \\
\text { ("net) }\end{array}$ \\
\hline 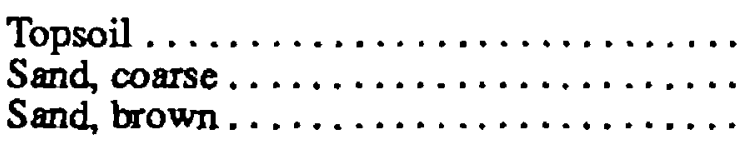 & $\begin{array}{r}1 \\
39 \\
35\end{array}$ & $\begin{array}{r}1 \\
40 \\
75\end{array}$ & 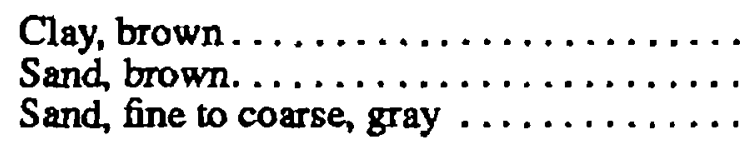 & $\begin{array}{r}5 \\
21 \\
64\end{array}$ & $\begin{array}{r}80 \\
101 \\
165\end{array}$ \\
\hline
\end{tabular}

152-093-01CCDC

(Log modifled from Dennis Water Well Drilling)

Altitude: 1,855 feet

Date drilied: $\quad 05 \cdot 27-89$

\begin{tabular}{|c|c|c|c|c|c|}
\hline Matarla| & $\begin{array}{l}\text { Thick- } \\
\text { ness } \\
\text { (feet) }\end{array}$ & $\begin{array}{l}\text { Depth } \\
\text { (feet) }\end{array}$ & Material & $\begin{array}{l}\text { Thlck- } \\
\text { ness } \\
\text { (feet) }\end{array}$ & $\begin{array}{l}\text { Dinth } \\
\text { (int) }\end{array}$ \\
\hline $\begin{array}{l}\text { Topsoil } \ldots \ldots \ldots \ldots \ldots \ldots \ldots \ldots \ldots \ldots \ldots \ldots \\
\text { Sand, brown . . } \ldots \ldots \ldots \ldots \ldots \ldots \ldots \ldots \ldots \\
\text { Clay, sandy, brown } \ldots \ldots \ldots \ldots \ldots \ldots \ldots\end{array}$ & $\begin{array}{r}2 \\
48 \\
51\end{array}$ & $\begin{array}{r}2 \\
50 \\
101\end{array}$ & $\begin{array}{l}\text { Sand, medium, brown } \ldots \ldots \ldots \ldots \ldots \ldots \ldots \\
\text { Clay, brown } . \ldots \ldots \ldots \ldots \ldots \ldots \ldots\end{array}$ & $\begin{array}{r}100 \\
5\end{array}$ & $\begin{array}{l}201 \\
206\end{array}$ \\
\hline
\end{tabular}

152-093-13CACA

(Log modified from Sax Woll Drlliing)

Altitude: 1,870 feet

Date drilied: $00-00-00$

\begin{tabular}{|c|c|c|c|c|c|}
\hline Material & $\begin{array}{l}\text { Thick- } \\
\text { ness } \\
\text { (feet) }\end{array}$ & $\begin{array}{l}\text { Depth } \\
\text { (feet) }\end{array}$ & Material & $\begin{array}{l}\text { Thick- } \\
\text { ness } \\
\text { (feet) }\end{array}$ & $\begin{array}{l}\text { Dinth } \\
\text { (inet) }\end{array}$ \\
\hline 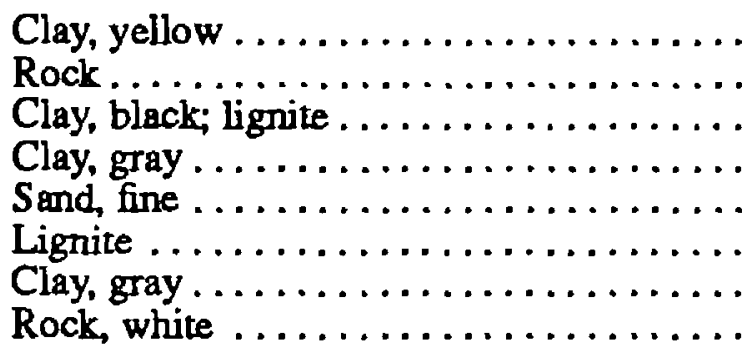 & $\begin{array}{r}11 \\
2 \\
2 \\
9 \\
1 \\
2 \\
8 \\
2\end{array}$ & $\begin{array}{l}11 \\
13 \\
15 \\
24 \\
25 \\
27 \\
35 \\
37\end{array}$ & 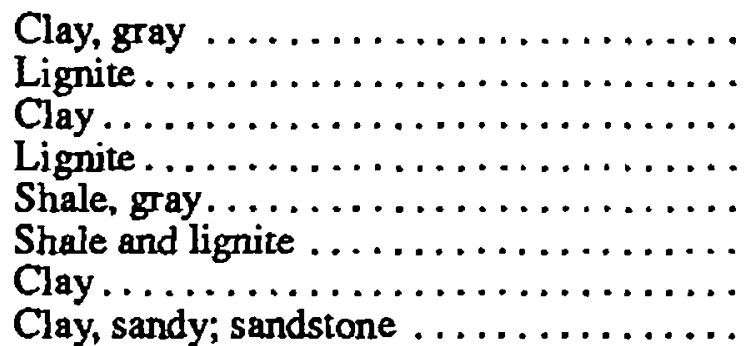 & $\begin{array}{r}15 \\
1 \\
3 \\
1 \\
2 \\
6 \\
5 \\
10\end{array}$ & $\begin{array}{l}52 \\
53 \\
56 \\
57 \\
59 \\
65 \\
70 \\
80\end{array}$ \\
\hline
\end{tabular}

152-093-18DCB

(Log from Dingman and Gordon, 1954)

Altitude: Not available

Date drilied: 1951

\begin{tabular}{|c|c|c|c|c|c|}
\hline Materlal & $\begin{array}{l}\text { Thick- } \\
\text { ness } \\
\text { (feet) }\end{array}$ & $\begin{array}{l}\text { Depth } \\
\text { (foot) }\end{array}$ & Materlal & $\begin{array}{l}\text { Thlck- } \\
\text { ness } \\
\text { (feet) }\end{array}$ & $\begin{array}{l}\text { Dinth } \\
\text { (foet) }\end{array}$ \\
\hline $\begin{array}{l}\text { Clay and gravel } \ldots \ldots \ldots \ldots \ldots \ldots \ldots \\
\text { Sand, medium to coarse, brown . . . . . }\end{array}$ & $\begin{array}{r}11 \\
154\end{array}$ & $\begin{array}{r}11 \\
165\end{array}$ & $\begin{array}{l}\text { Sand, medium to coarse, gray } \ldots \ldots \ldots \ldots \\
\text { Clay and sand } \ldots \ldots \ldots \ldots \ldots \ldots \ldots \ldots\end{array}$ & $\begin{array}{r}56 \\
4\end{array}$ & $\begin{array}{l}221 \\
225\end{array}$ \\
\hline
\end{tabular}


Table 3. Drillers' logs of wells and test holes--Continued

152-093-20BAA

(Log from Dingman and Gordon, 1954)

Altitude: 1,975 feet

Date d-1lled: 1851

\begin{tabular}{|c|c|c|c|c|c|}
\hline Material & $\begin{array}{l}\text { Thlok- } \\
\text { ness } \\
\text { (feat) }\end{array}$ & $\begin{array}{l}\text { Depth } \\
\text { (feet) }\end{array}$ & Material & $\begin{array}{l}\text { Thlck- } \\
\text { ners } \\
\text { (feet) }\end{array}$ & $\begin{array}{l}\text { Depth } \\
\text { (feet) }\end{array}$ \\
\hline 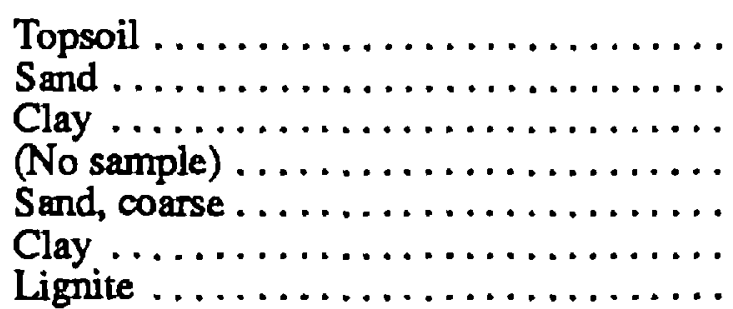 & $\begin{array}{r}18 \\
7 \\
5 \\
15 \\
12 \\
43 \\
5\end{array}$ & $\begin{array}{r}18 \\
25 \\
30 \\
45 \\
57 \\
100 \\
105\end{array}$ & 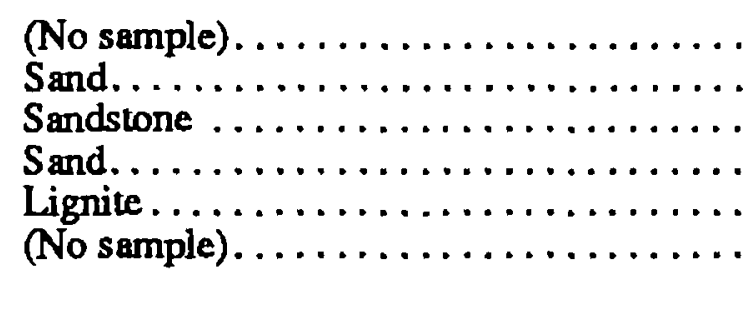 & $\begin{array}{r}13 \\
5 \\
4 \\
13 \\
5 \\
110\end{array}$ & $\begin{array}{l}118 \\
123 \\
127 \\
140 \\
145 \\
255\end{array}$ \\
\hline
\end{tabular}

152-093-20BAC

(Log from Dingman and Gordon, 1954)

Altitude: $1,933.46$ feet

Date d flled: 1950

\begin{tabular}{|c|c|c|c|c|c|}
\hline Material & $\begin{array}{l}\text { Thick- } \\
\text { neas } \\
\text { (feet) }\end{array}$ & $\begin{array}{l}\text { Depth } \\
\text { (feet) }\end{array}$ & Material & $\begin{array}{l}\text { Thick- } \\
\text { nese } \\
\text { (fees? }\end{array}$ & $\begin{array}{l}\text { Depth } \\
\text { (feet) }\end{array}$ \\
\hline 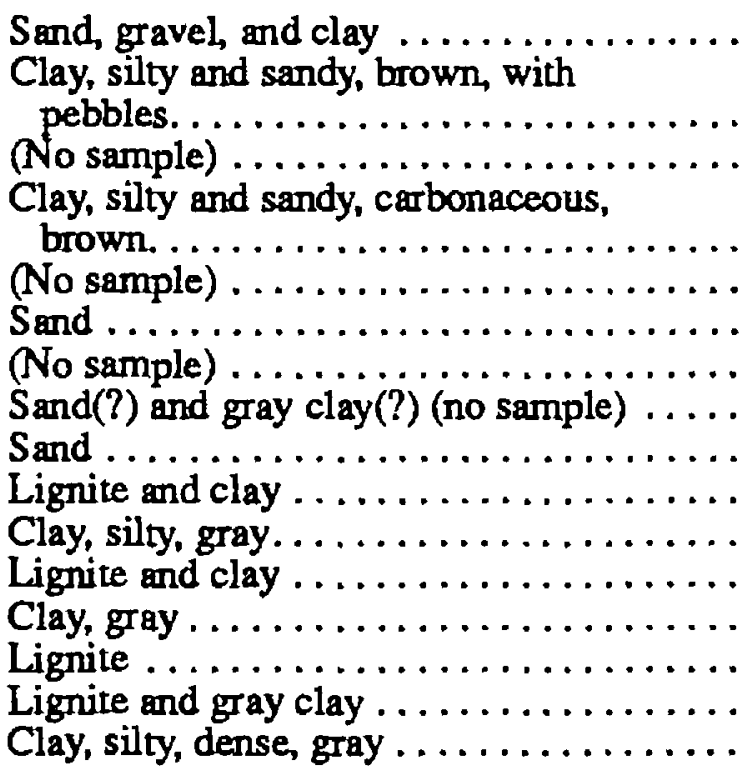 & $\begin{array}{c}10 \\
18 \\
34 \\
1 \\
12 \\
60 \\
40 \\
15 \\
20 \\
15 \\
3.5 \\
2 \\
22 \\
2.5 \\
11 \\
9\end{array}$ & $\begin{array}{l}10 \\
28 \\
62 \\
63 \\
75 \\
135 \\
175 \\
190 \\
210 \\
225 \\
228.5 \\
230.5 \\
252.5 \\
255 \\
266 \\
275\end{array}$ & 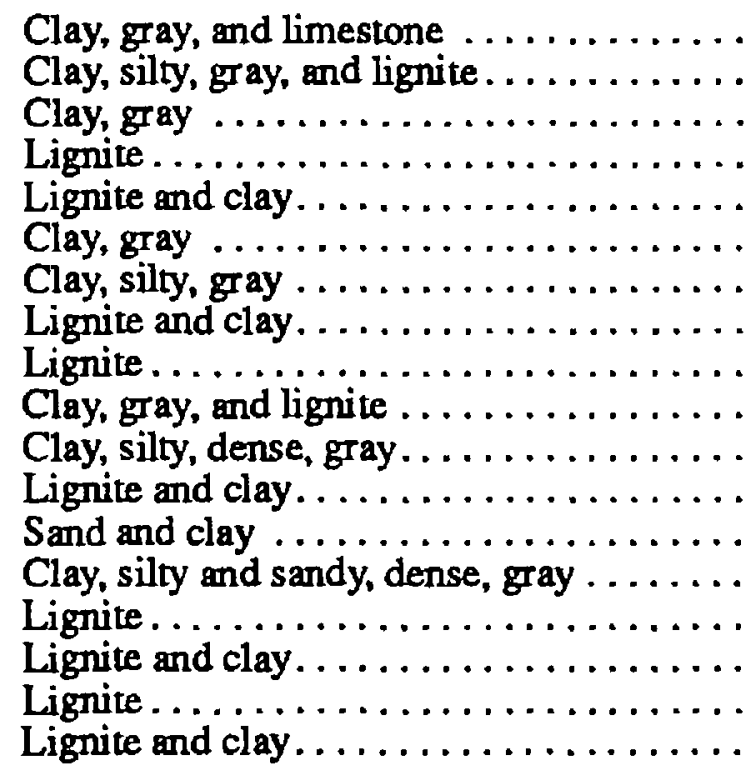 & $\begin{array}{r}7 \\
1 \\
13 \\
2 \\
7 \\
25 \\
28 \\
7 \\
7 \\
8 \\
10 \\
7 \\
13 \\
56 \\
16 \\
3 \\
10 \\
15\end{array}$ & $\begin{array}{l}282 \\
283 \\
296 \\
298 \\
305 \\
330 \\
358 \\
365 \\
372 \\
380 \\
390 \\
397 \\
410 \\
466 \\
482 \\
485 \\
495 \\
510\end{array}$ \\
\hline
\end{tabular}

152-093-24AADA

(Log modifled from Crowder Well Drilling)

Altitude: 1,950 fe日t

Date drllied: $06-23-80$

\begin{tabular}{|c|c|c|c|c|c|}
\hline Material & $\begin{array}{l}\text { Thick- } \\
\text { neess } \\
\text { (feel) }\end{array}$ & $\begin{array}{l}\text { Depth } \\
\text { (feet) }\end{array}$ & Materlal & $\begin{array}{c}\text { Thlel- } \\
\text { ness } \\
\text { (fee') }\end{array}$ & $\begin{array}{l}\text { Depth } \\
\text { (feet) }\end{array}$ \\
\hline 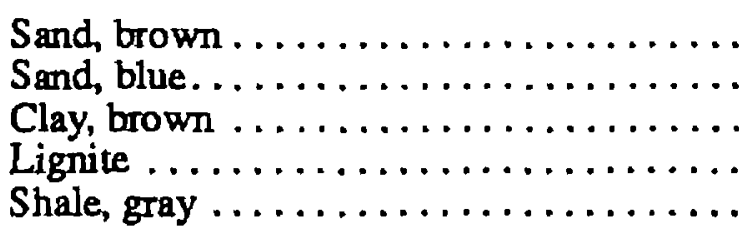 & $\begin{array}{r}15 \\
13 \\
9 \\
6 \\
36\end{array}$ & $\begin{array}{l}15 \\
28 \\
37 \\
43 \\
79\end{array}$ & $\begin{array}{l}\text { Lignite } \ldots \ldots \ldots \ldots \ldots \ldots \ldots \ldots \ldots \ldots \ldots \ldots \ldots \ldots \\
\text { Shale, gray. } \ldots \ldots \ldots \ldots \ldots \ldots \ldots \ldots \ldots \ldots \ldots \ldots \\
\text { Lignite } \ldots \ldots \ldots \ldots \ldots \ldots \ldots \ldots \ldots \ldots \ldots \ldots \ldots \\
\text { Shale, gray } \ldots \ldots \ldots \ldots \ldots \ldots \ldots \ldots \ldots \ldots \ldots \ldots\end{array}$ & $\begin{array}{r}2 \\
9 \\
1 \\
21\end{array}$ & $\begin{array}{r}81 \\
90 \\
91 \\
112\end{array}$ \\
\hline
\end{tabular}


Table 3. Drillers' logs of wells and test holes--Continued

152-093-34DAA2

(Log modifled from Crowder-Dennis Driling)

\begin{tabular}{|c|c|c|c|c|c|}
\hline Matertal & $\begin{array}{l}\text { Thick- } \\
\text { ness } \\
\text { (feet) }\end{array}$ & $\begin{array}{l}\text { Depth } \\
\text { (feet) }\end{array}$ & Materlal & $\begin{array}{l}\text { Thick- } \\
\text { nese } \\
\text { (feet) }\end{array}$ & $\begin{array}{l}\text { Dipth } \\
\text { (foet) }\end{array}$ \\
\hline 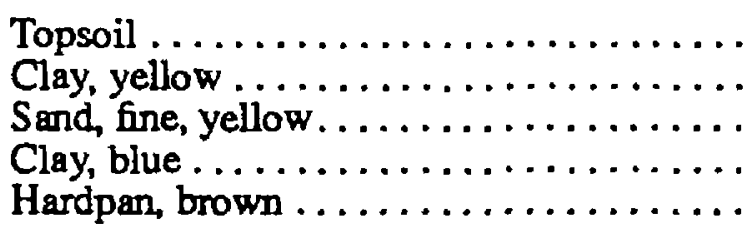 & $\begin{array}{r}1 \\
14 \\
5 \\
30 \\
1\end{array}$ & $\begin{array}{l}1 \\
15 \\
20 \\
50 \\
51\end{array}$ & 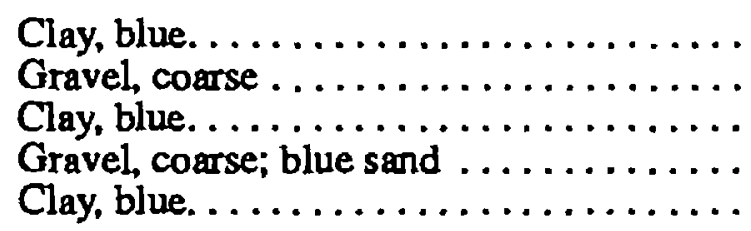 & $\begin{array}{r}59 \\
1 \\
3 \\
2 \\
64\end{array}$ & $\begin{array}{l}110 \\
111 \\
114 \\
116 \\
180\end{array}$ \\
\hline
\end{tabular}

152-094-11DAC

(Log from Dingman and Gordon, 1854)

Altitude: 1,980 fe日t

Date drilied: 1951

\begin{tabular}{|c|c|c|c|c|c|}
\hline Material & $\begin{array}{l}\text { Thick- } \\
\text { ness } \\
\text { (feet) }\end{array}$ & $\begin{array}{l}\text { Depth } \\
\text { (feot) }\end{array}$ & Materlal & $\begin{array}{l}\text { Thick- } \\
\text { ness } \\
\text { (feet) }\end{array}$ & $\begin{array}{l}\text { Druth } \\
\text { (ieet) }\end{array}$ \\
\hline 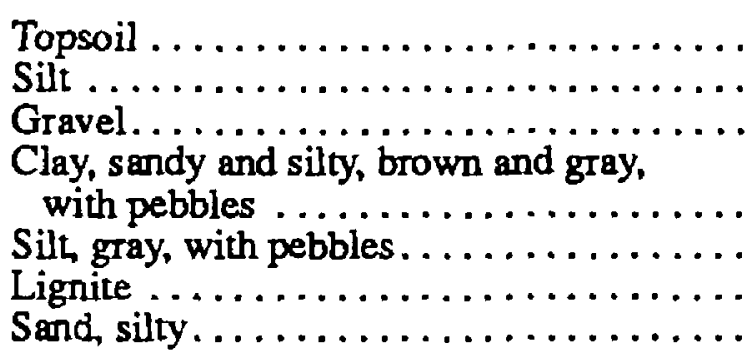 & $\begin{array}{r}2 \\
8 \\
2 \\
30 \\
44 \\
1 \\
18\end{array}$ & $\begin{array}{r}2 \\
10 \\
12 \\
42 \\
86 \\
87 \\
105\end{array}$ & 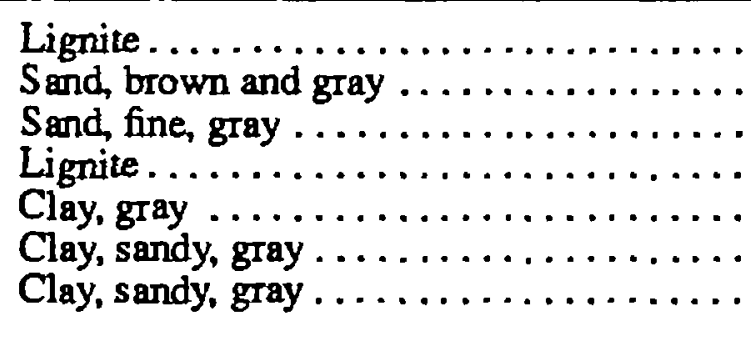 & $\begin{array}{r}2 \\
11 \\
17 \\
13 \\
6 \\
16 \\
20\end{array}$ & $\begin{array}{l}107 \\
118 \\
135 \\
148 \\
154 \\
170 \\
190\end{array}$ \\
\hline
\end{tabular}

152-094-16CCA

(Log from Dingman and Gordon, 1954)

Altitude: $2,145.6$ feet

Date drilled: 1950

\begin{tabular}{|c|c|c|c|c|c|}
\hline Matarial & $\begin{array}{l}\text { Thlck- } \\
\text { ness } \\
\text { (feet) }\end{array}$ & $\begin{array}{l}\text { Depth } \\
\text { (feet) }\end{array}$ & Material & $\begin{array}{l}\text { Thlak- } \\
\text { ness } \\
\text { (feet) }\end{array}$ & $\begin{array}{l}\text { Dinth } \\
\text { (feet) }\end{array}$ \\
\hline 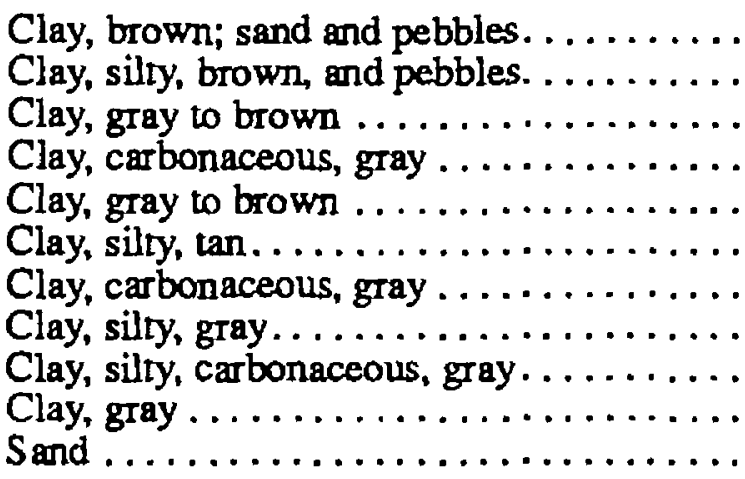 & $\begin{array}{r}5 \\
10 \\
5 \\
4 \\
3 \\
5 \\
13 \\
35 \\
10 \\
5 \\
5\end{array}$ & $\begin{array}{r}5 \\
15 \\
20 \\
24 \\
27 \\
32 \\
45 \\
80 \\
90 \\
95 \\
100\end{array}$ & 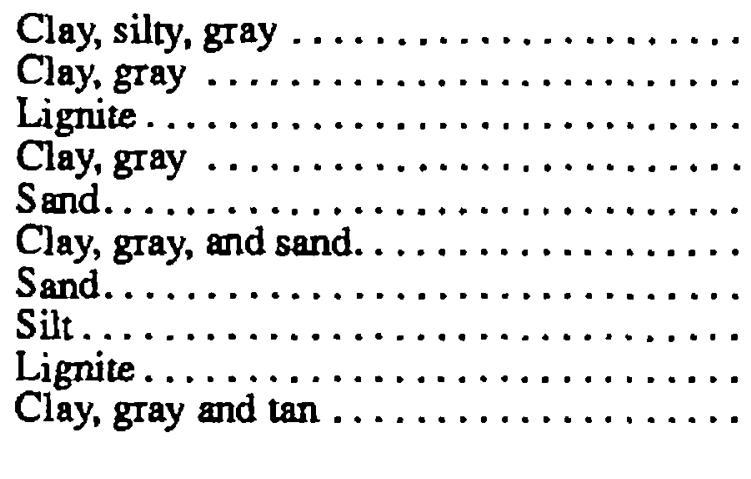 & $\begin{array}{c}25 \\
2.5 \\
2.5 \\
5 \\
10 \\
5 \\
5 \\
3 \\
11 \\
11\end{array}$ & $\begin{array}{l}125 \\
127.5 \\
130 \\
135 \\
145 \\
150 \\
155 \\
158 \\
169 \\
180\end{array}$ \\
\hline
\end{tabular}


Table 3. Drillers' logs of wells and test holes--Continued

152-094-25CCC

(Log from Dingman and Gordon, 1954)

\begin{tabular}{|c|c|c|c|c|c|}
\hline Material & $\begin{array}{l}\text { Thlok- } \\
\text { ness } \\
\text { (feet) }\end{array}$ & $\begin{array}{l}\text { Depth } \\
\text { (feet) }\end{array}$ & Material & $\begin{array}{l}\text { Thicle- } \\
\text { near } \\
\text { (feet) }\end{array}$ & $\begin{array}{l}\text { Depth } \\
\text { (feet) }\end{array}$ \\
\hline 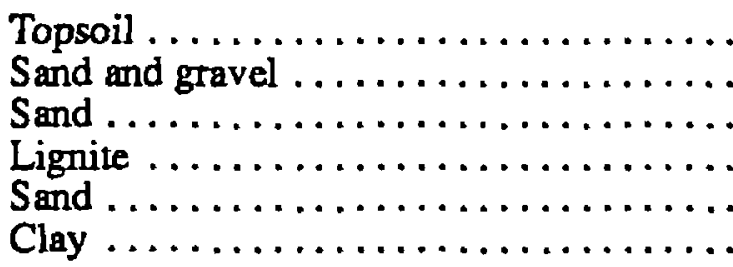 & $\begin{array}{r}7 \\
8 \\
22 \\
5 \\
20 \\
88\end{array}$ & $\begin{array}{r}7 \\
15 \\
37 \\
42 \\
62 \\
150\end{array}$ & 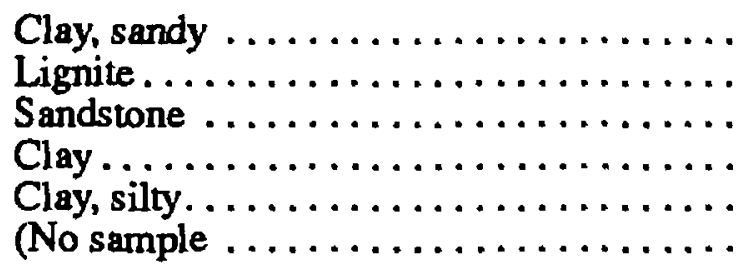 & $\begin{array}{r}12 \\
8 \\
1 \\
29 \\
15 \\
15\end{array}$ & $\begin{array}{l}162 \\
170 \\
171 \\
200 \\
215 \\
230\end{array}$ \\
\hline
\end{tabular}

152-094-25DAA

(Log from Dingman and Gordon, 1954)

Altitude: $2,014.02$ feet

Date drilled: 1950

\begin{tabular}{|c|c|c|c|c|c|}
\hline Materlal & $\begin{array}{l}\text { Thick- } \\
\text { nees } \\
\text { (feet) }\end{array}$ & $\begin{array}{l}\text { Depth } \\
\text { (feet) }\end{array}$ & Materlal & $\begin{array}{l}\text { Thick- } \\
\text { nos: } \\
\left(f 00^{*}\right)\end{array}$ & $\begin{array}{l}\text { Depth } \\
\text { (feet) }\end{array}$ \\
\hline 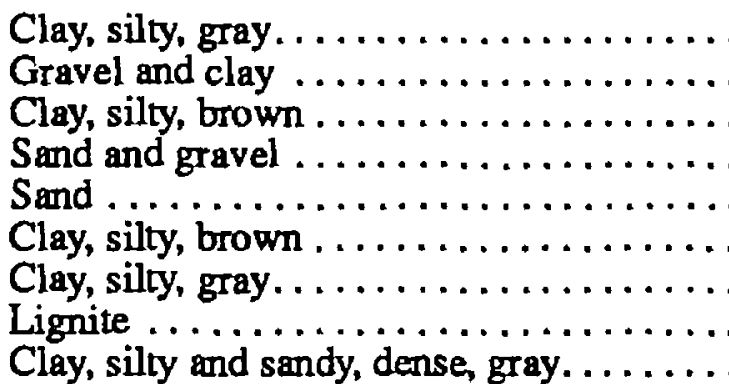 & $\begin{array}{l}5 \\
15 \\
14 \\
16 \\
10 \\
72 \\
58 \\
2.5 \\
17.5\end{array}$ & $\begin{array}{l}5 \\
20 \\
34 \\
50 \\
60 \\
132 \\
190 \\
192.5 \\
210\end{array}$ & 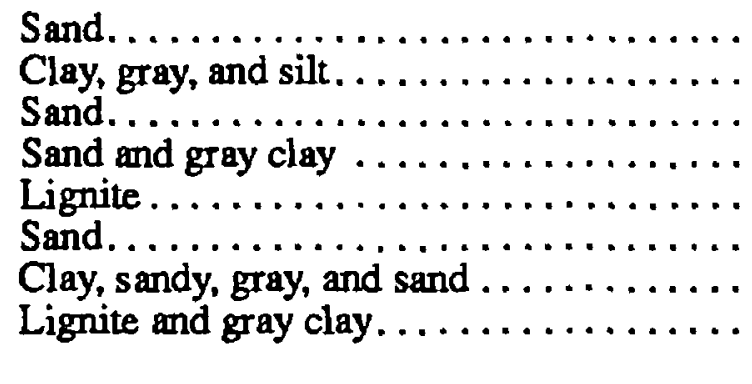 & $\begin{array}{l}7 \\
1 \\
7 \\
3.5 \\
7.5 \\
4 \\
5 \\
10\end{array}$ & $\begin{array}{l}217 \\
218 \\
225 \\
228.5 \\
236 \\
240 \\
245 \\
255\end{array}$ \\
\hline
\end{tabular}

152-094-32BBB

(Log from Dingman and Gordon, 1954)

Altitude: $2,185.9$ feet

Date drilled: 1950

\begin{tabular}{|c|c|c|c|c|c|}
\hline Materiai & $\begin{array}{l}\text { Thick- } \\
\text { ness } \\
\text { (foet) }\end{array}$ & $\begin{array}{l}\text { Depth } \\
\text { (feet) }\end{array}$ & Material & $\begin{array}{l}\text { Thict- } \\
\text { nes: } \\
\text { (feet) }\end{array}$ & $\begin{array}{l}\text { Depth } \\
\text { (feot) }\end{array}$ \\
\hline 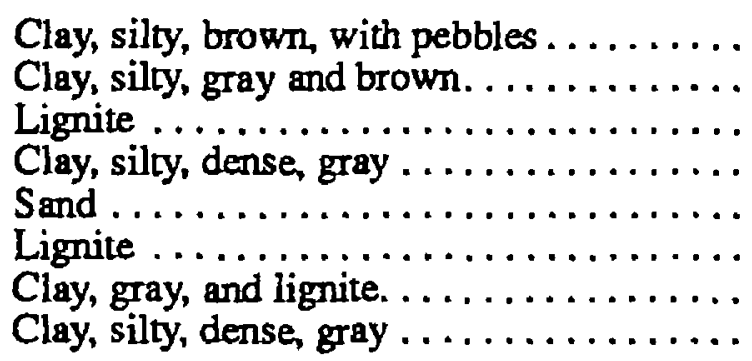 & $\begin{array}{r}10 \\
33 \\
7 \\
35 \\
18 \\
7 \\
5 \\
23\end{array}$ & $\begin{array}{r}10 \\
43 \\
50 \\
85 \\
103 \\
110 \\
115 \\
138\end{array}$ & 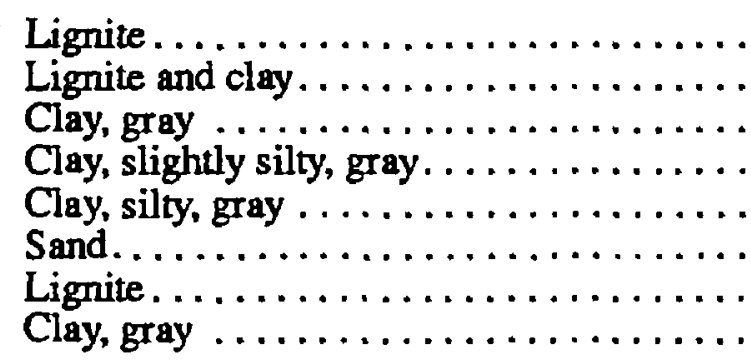 & $\begin{array}{r}5 \\
2 \\
5 \\
10 \\
5 \\
51 \\
8 \\
1\end{array}$ & $\begin{array}{l}143 \\
145 \\
150 \\
160 \\
165 \\
216 \\
224 \\
225\end{array}$ \\
\hline
\end{tabular}


Table 3. Drillers' logs of wells and test holes-Continued

152-094-33BBB

(Log from Dingman and Gordon, 1954)

Altitude: 2,188 feet

Date drilled: 1951

\begin{tabular}{|c|c|c|c|c|c|}
\hline Matertal & $\begin{array}{l}\text { Thick- } \\
\text { ness } \\
\text { (feet) }\end{array}$ & $\begin{array}{l}\text { Depth } \\
\text { (foet) }\end{array}$ & Material & $\begin{array}{l}\text { Thick- } \\
\text { ness } \\
\text { (feet) }\end{array}$ & $\begin{array}{l}\text { Denth } \\
\text { (fret) }\end{array}$ \\
\hline $\begin{array}{l}\text { Topsoil and gravel } \ldots \ldots \ldots \ldots \ldots \ldots \ldots \ldots \ldots \ldots \ldots \ldots \ldots \\
\text { Clay and gravel } \ldots \ldots \ldots \ldots \ldots \ldots \ldots \ldots \\
\text { (No sample) } \ldots \ldots \ldots \ldots \ldots \ldots \ldots\end{array}$ & $\begin{array}{l}10 \\
18 \\
77\end{array}$ & $\begin{array}{r}10 \\
28 \\
105\end{array}$ & $\begin{array}{l}\text { Clay, sandy } \ldots \ldots \ldots \ldots \ldots \ldots \ldots \ldots \ldots \ldots \ldots \ldots \\
\text { (No sample) } \ldots \ldots \ldots \ldots \ldots \ldots \ldots\end{array}$ & $\begin{array}{r}23 \\
147\end{array}$ & $\begin{array}{l}128 \\
275\end{array}$ \\
\hline
\end{tabular}

152-094-35DCA

(Log from Dingman and Gordon, 1954)

Altitude: $2,116.02$ feet

Date drilled: 1950

\begin{tabular}{|c|c|c|c|c|c|}
\hline Material & $\begin{array}{l}\text { Thlck- } \\
\text { noes: } \\
\text { (feet) }\end{array}$ & $\begin{array}{l}\text { Depth } \\
\text { (feet) }\end{array}$ & Material & $\begin{array}{l}\text { Thick- } \\
\text { ness } \\
\text { (foet) }\end{array}$ & $\begin{array}{l}\text { Dinth } \\
(f+e t)\end{array}$ \\
\hline 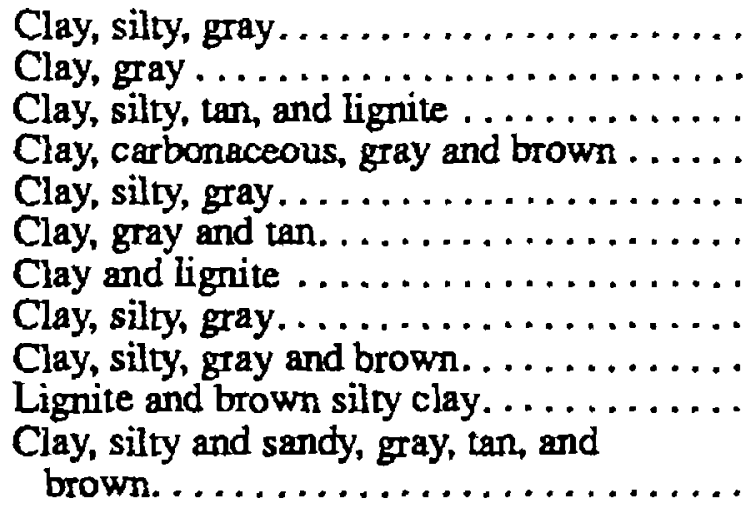 & $\begin{array}{c}28 \\
3 \\
1 \\
3 \\
10 \\
21 \\
2.5 \\
6.5 \\
23 \\
.5 \\
16.5\end{array}$ & $\begin{array}{l}28 \\
31 \\
32 \\
35 \\
45 \\
66 \\
68.5 \\
75 \\
98 \\
98.5\end{array}$ & 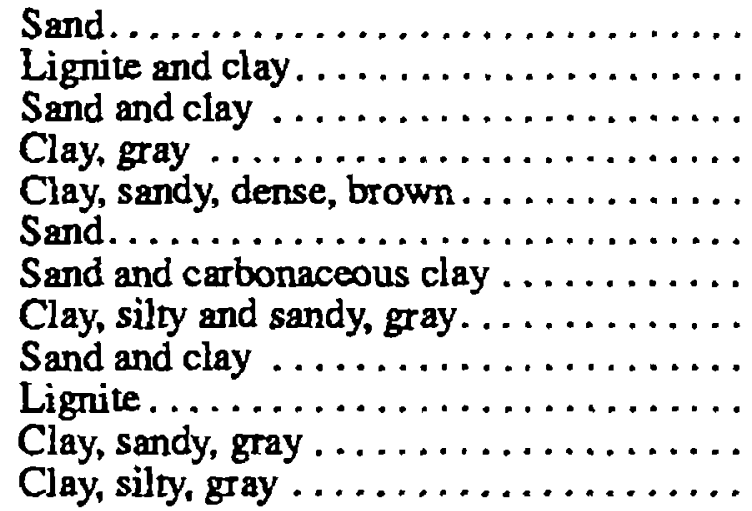 & $\begin{array}{r}12.5 \\
12 \\
5 \\
5 \\
13 \\
12 \\
5 \\
6 \\
4 \\
5 \\
15\end{array}$ & $\begin{array}{l}127.5 \\
128 \\
140 \\
145 \\
150 \\
163 \\
175 \\
180 \\
186 \\
190 \\
195 \\
2.10\end{array}$ \\
\hline
\end{tabular}


Table 4. U.S. Geological Survey geophysical and lithologic logs

LOCATION: $146-089-10 C B D$

ALTITUDE: 1,880

(FEET ABOVE SEA LEVEL)
DATE DRILLED: $06-25-92$

DEPTH: 250

(FEET)

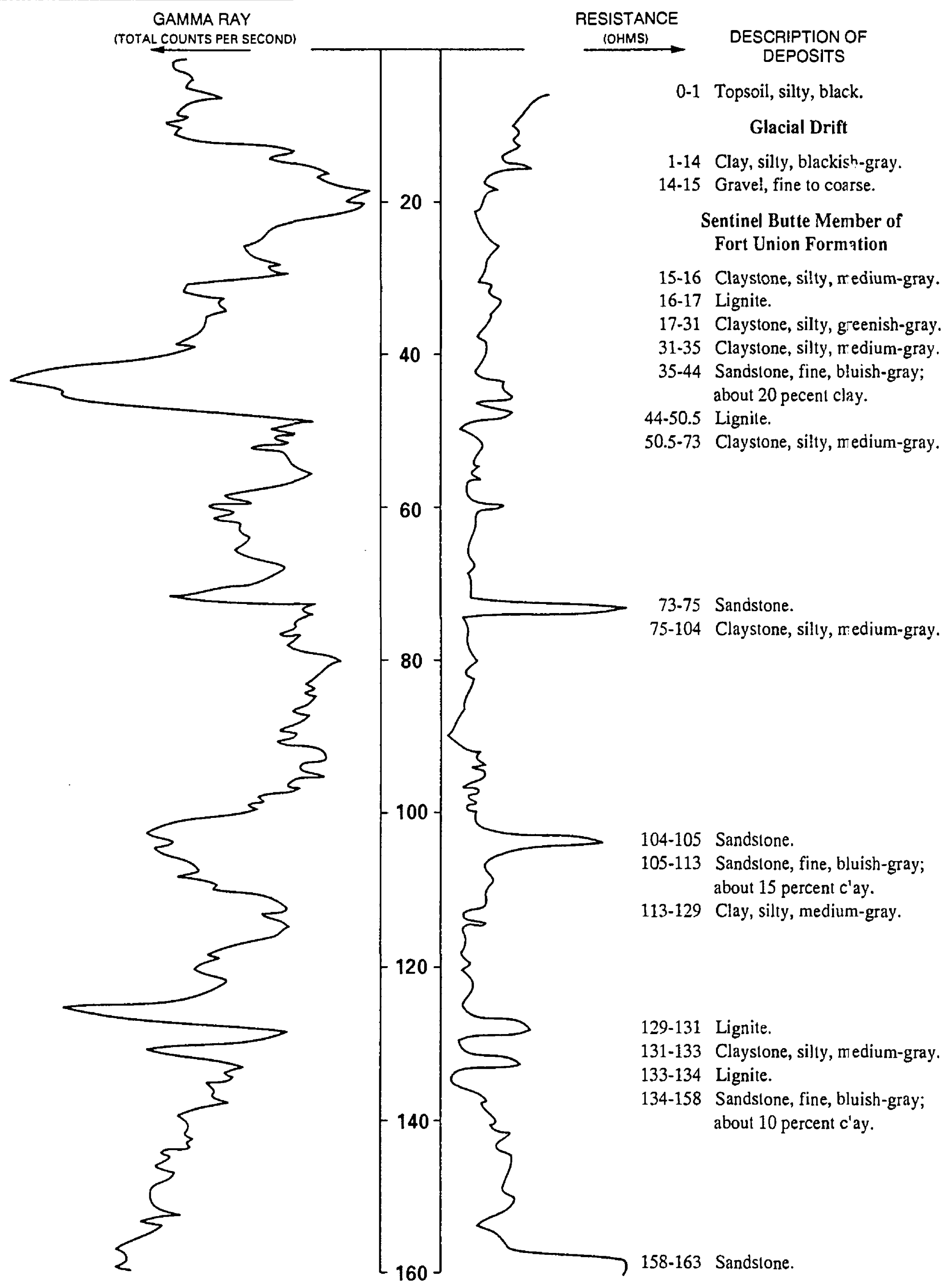


Table 4. U.S. Geological Survey geophysical and lithologic logs--Continued

LOCATION: $146-089-10 C B D$

ALTITUDE: 1,880

(FEET ABOVE SEA LEVEL)
DATE DRILLED: $06-25-92$

DEPTH: 250

(FEET)

\section{GAMMA RAY}

(TOTAL COUNTS PER SECONDI

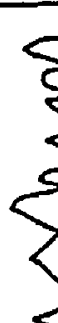

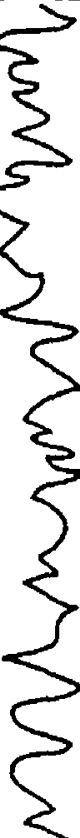

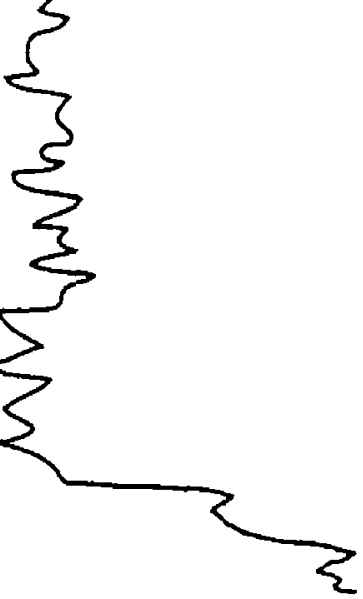

RESISTANCE (OHMS)

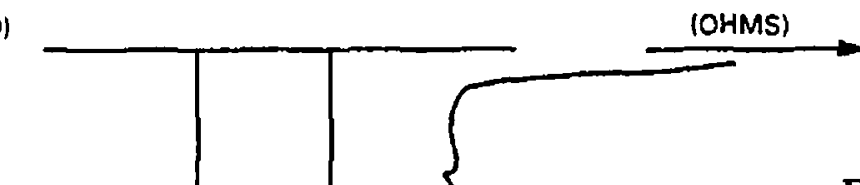

DESCRIPTION OF

Sentinel Butte Member of

Fort Union Formation, Continued

163-247 Sandstone, fine, bluish-gray; about 10 percent clay.

247-250 Claystone, silty, mediur-gray. 
Table 4. U.S. Geological Survey geophysical and lithologic logs--Continued

LOCATION: $147-091-15 C C D$

ALTITUDE: 2,310

(FEET ABOVE SEA LEVEL)
DATE DRILLED: 06-24-92

DEPTH: 272

(FEET)

\section{RESISTANCE}

(OHMS)

DESCRIPTION CF

DEPOSITS

0-1 Topsoil, silty, black.

Sentinel Butte Member of Fort Union Form ation

1.32 Claystone, silty, yellc wish-brown.

32-51 Sandstone, fine, yellowish-brown; about 15 percent clay.

51-121 Claystone, silty, greenish-gray.
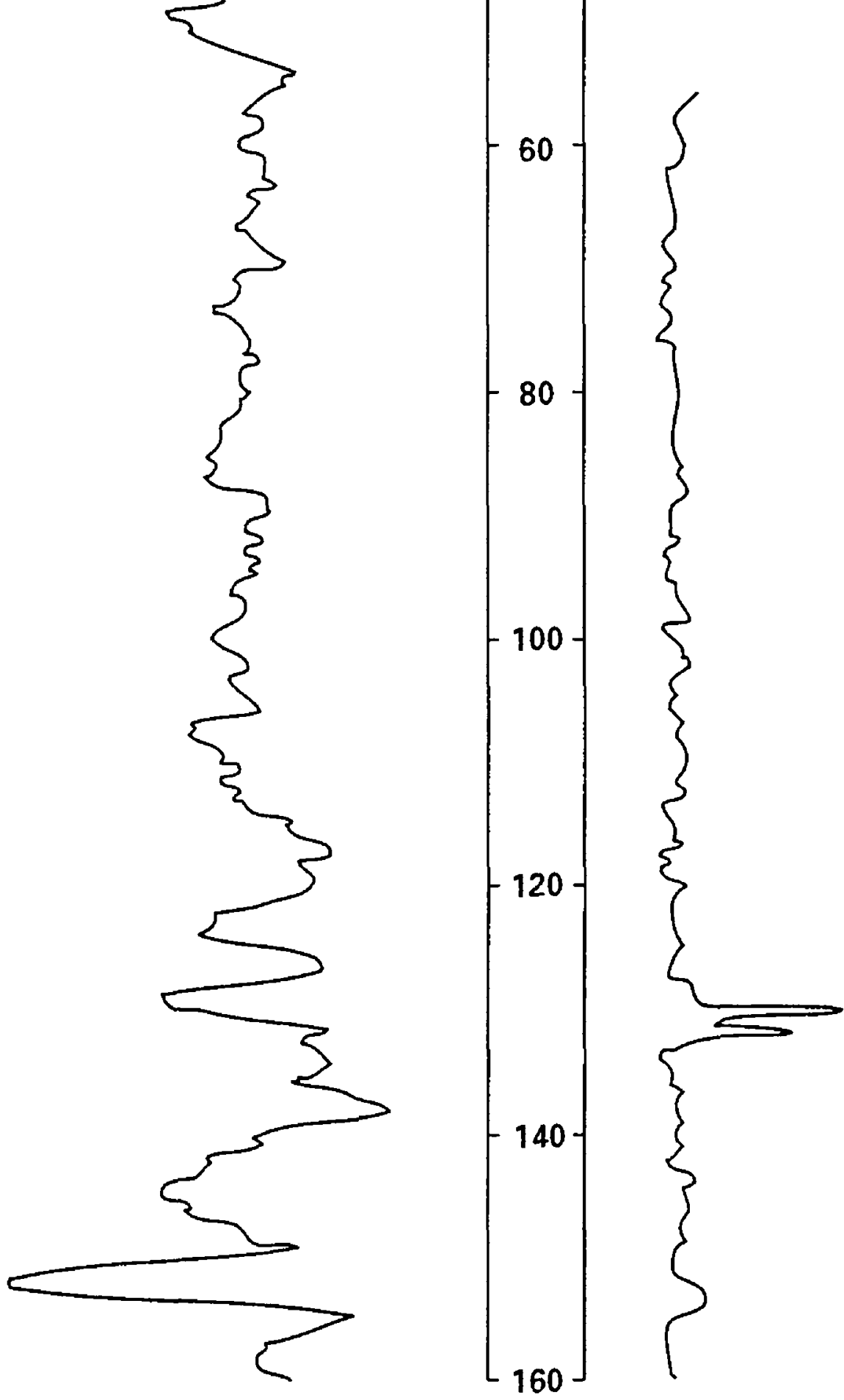

121-129 Sandstone, fine, bluis'-gray; about 20 percent clay.

129-132 Sandstone, hard.

132-143 Claystone, silty, greerish-gray.

143-156 Sandstone, fine, bluish-gray; about 10 percent clay.

156-158 Lignite, soft.

158-168 Claystone, silty, medium-gray. 
Table 4. U.S. Geological Survey geophysical and lithologic logs--Continued

LOCATION: $147-091-15 C C D$

ALTITUDE: 2,310 (FEET ABOVE SEA LEVEL)
DATE DRILLED: $06-24-92$

DEPTH: 272 (FEET)

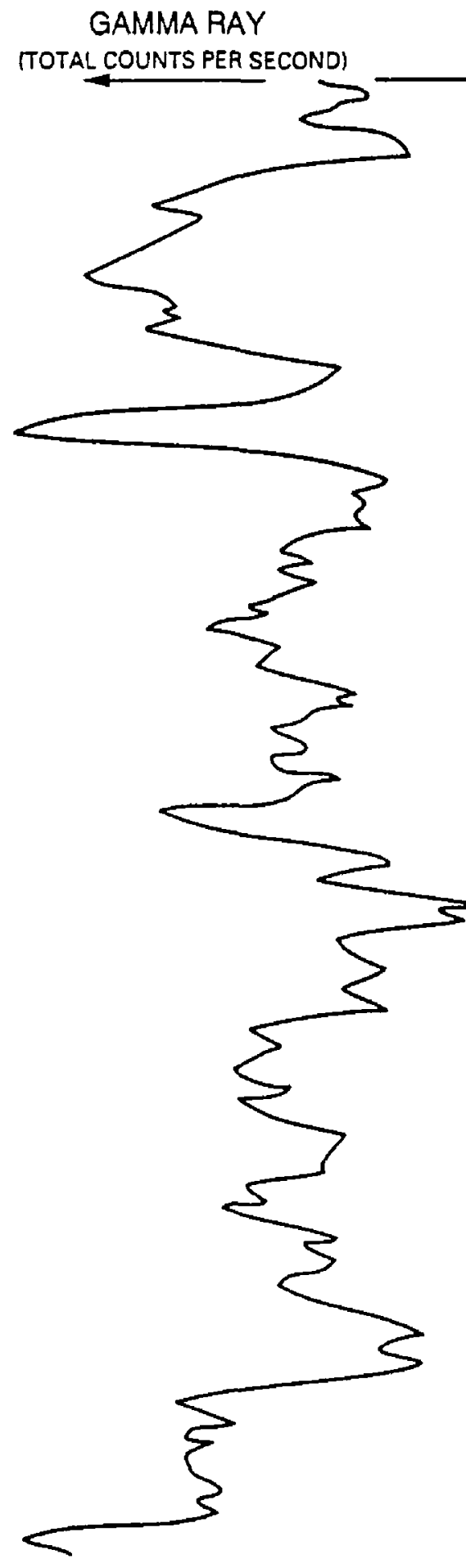

RESISTANCE

(OHMS)

DESCRIPTION OF

DEPOSITS

Sentinel Butte Member of Fort Union Formation, Continced

168-175 Sandstone, fine, bluish-gray; about 15 percent clay.

175-176 Sandstone.

176-185 Sandstone, fine, bluish-gray; about 15 percent clay.

185-210 Claystone, silty, medium-g-ay.

210-215 Lignite, brownish-gray.

215-267 Claystone, silty, medium-gray.

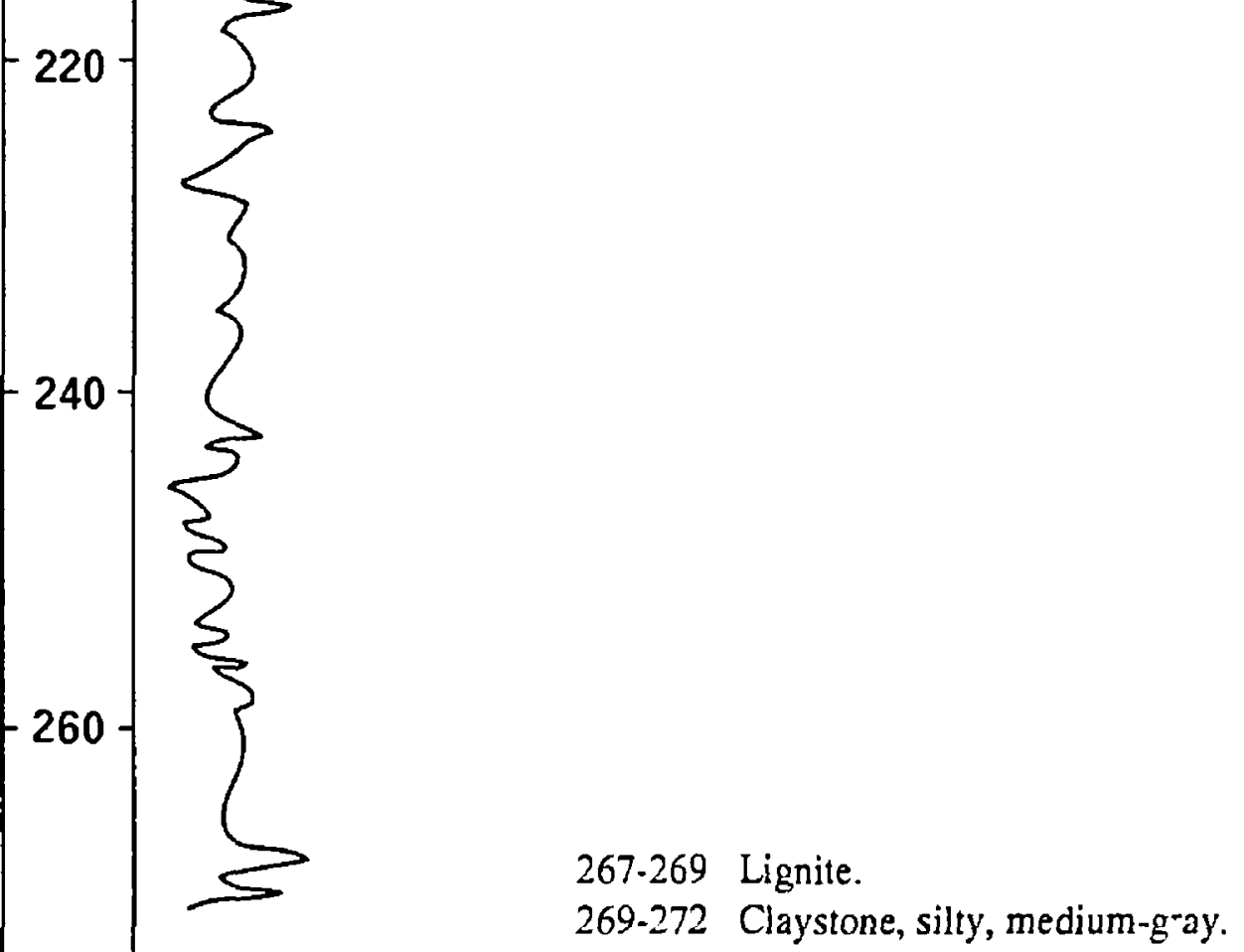


Table 4. U.S. Geological Survey geophysical and lithologic logs--Continued

LOCATION: $147-092-210 D B$

DATE DRILLED: $06-24-92$

ALTITUDE: 2,285

DEPTH: 300

(FEET ABOVE SEA LEVEL)

(FEET)

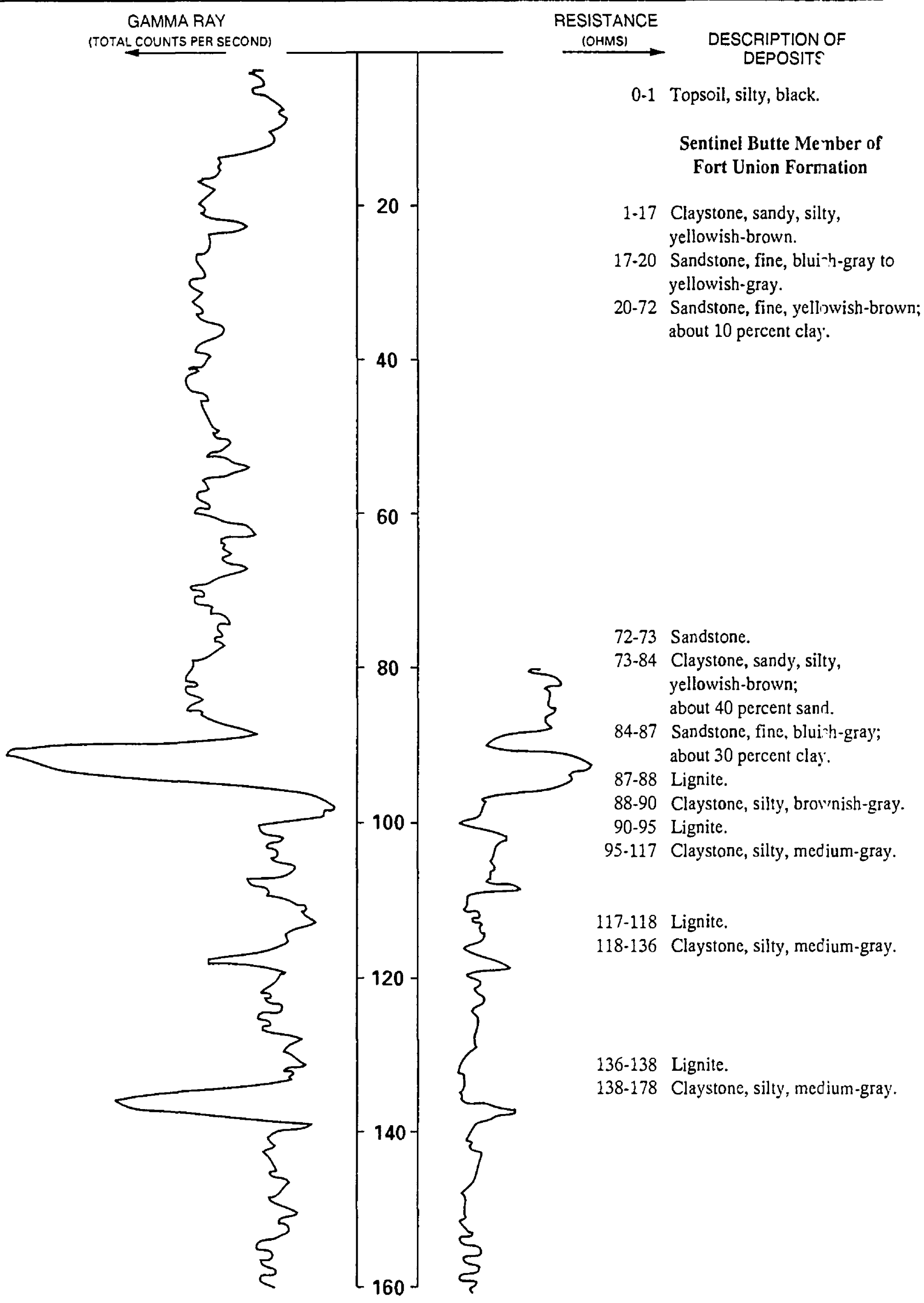


Table 4. U.S. Geological Survey geophysical and lithologic logs--Continued

LOCATION: 147-092-21DDB

ALTITUDE: 2,285

(FEET ABOVE SEA LEVEL)
DATE DRILLED: $06-24-92$

DEPTH: 300

(FEET)

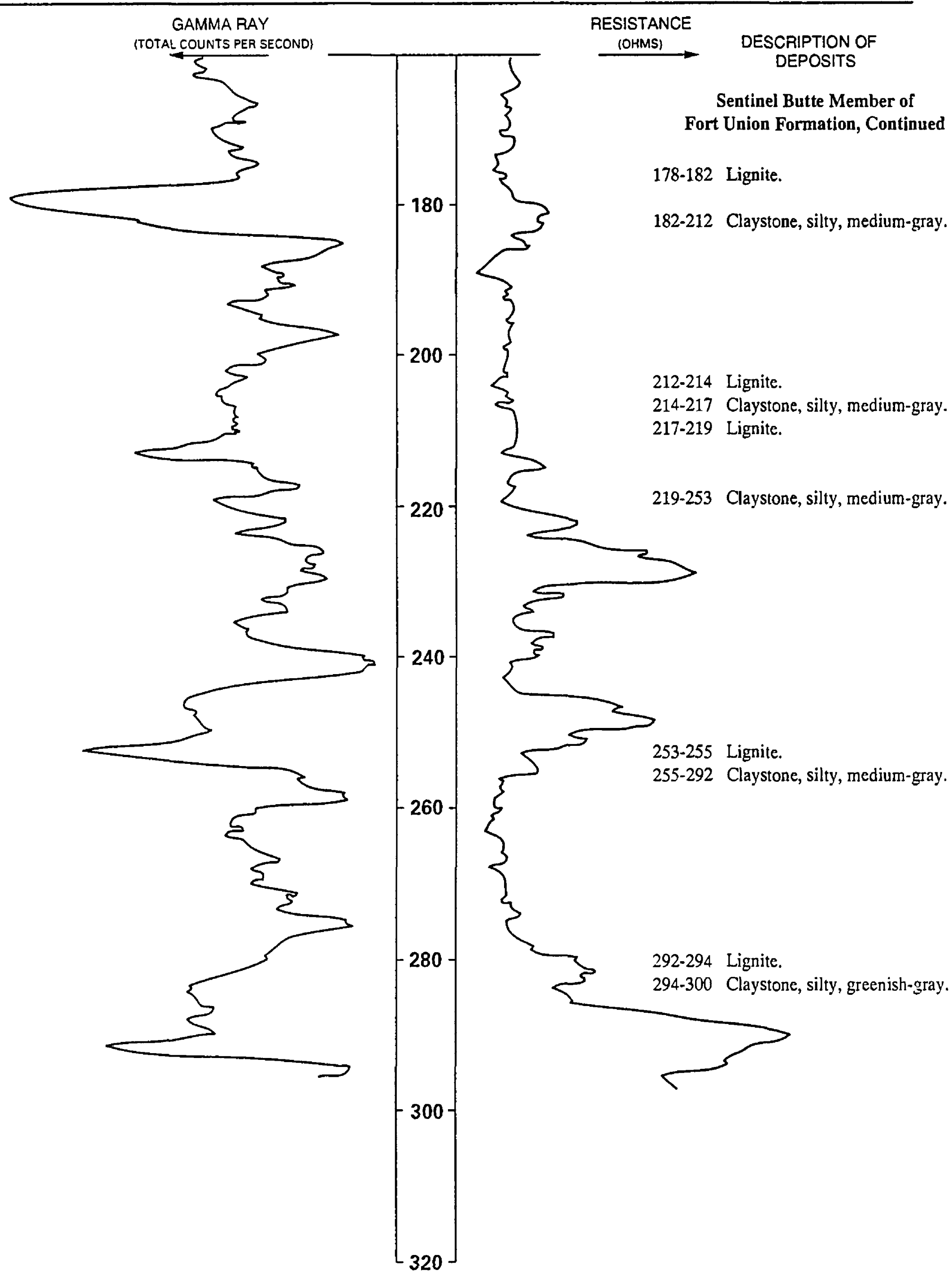


Table 4. U.S. Geological Survey geophysical and lithologic logs--Continued

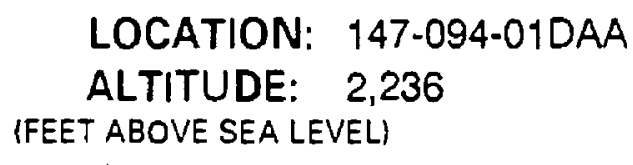

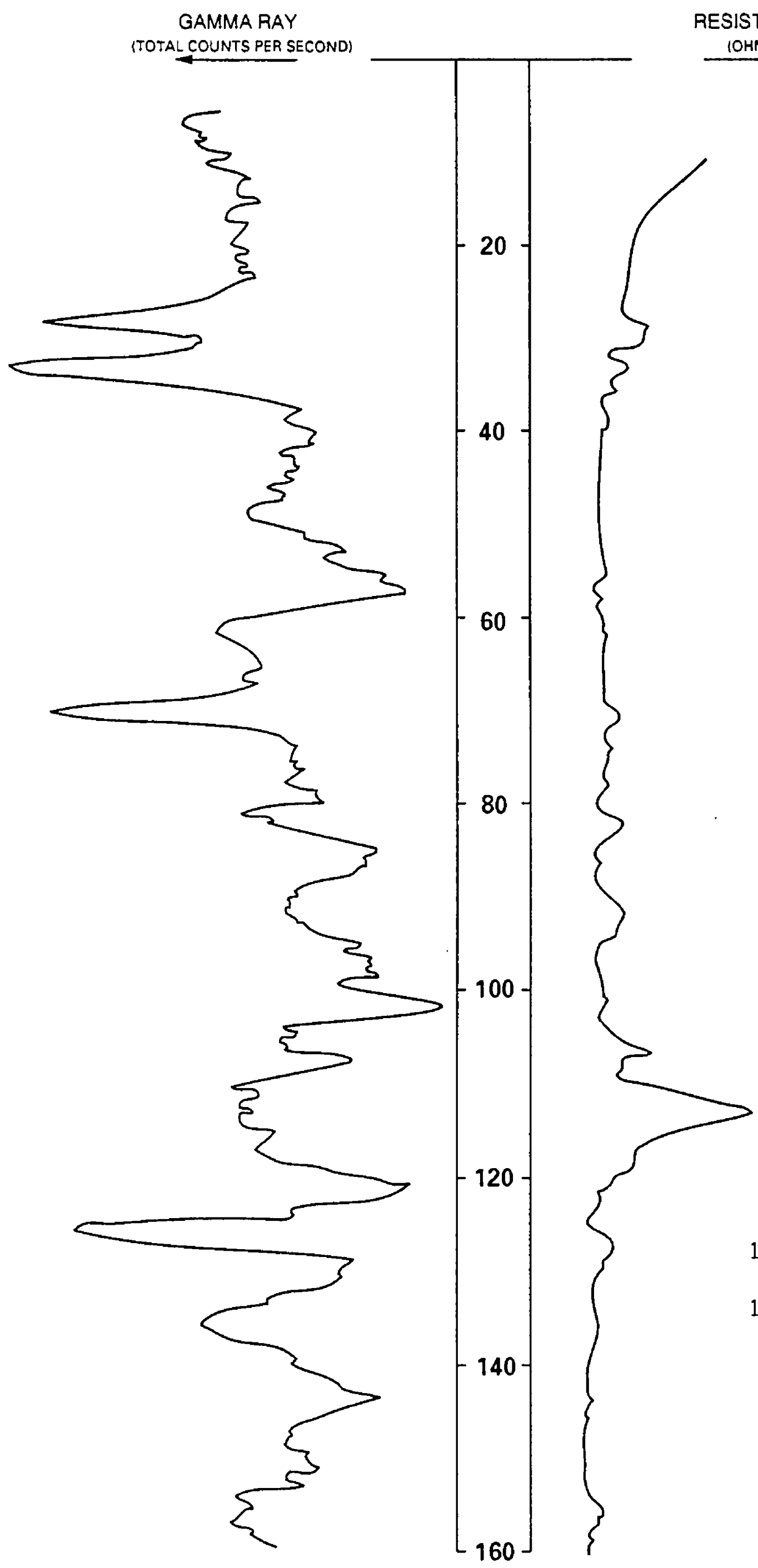

DATE DRILLED: 06-23-92

DEPTH: 300 (FEET)

RESISTANCE

0-1 Topsoil, silty, black.

\section{Glacial Drif:}

1.27 Clay, silty, yellowish-brown; till.

Sentinel Butte Member of Fort Union Formation

27-28 Lignite, soft.

28-54 Claystone, silty, yell Jwish-brown.

54-69 Claystone, silty, medium-gray.

69-71 Lignite.

71-85 Claystone, silty, greenish-gray.

85-86 Lignite.

86-126 Claystone, silty, medium-gray.

126-128 Lignite.

128-196 Claystone, silty, medium-gray. 
Table 4. U.S. Geological Survey geophysical and lithologic logs--Continued

LOCATION: 147-094-01DAA

ALTITUDE: 2,236

(FEET ABOVE SEA LEVEL)
DATE DRILLED: 06-23-92

DEPTH: 300 (FEET)

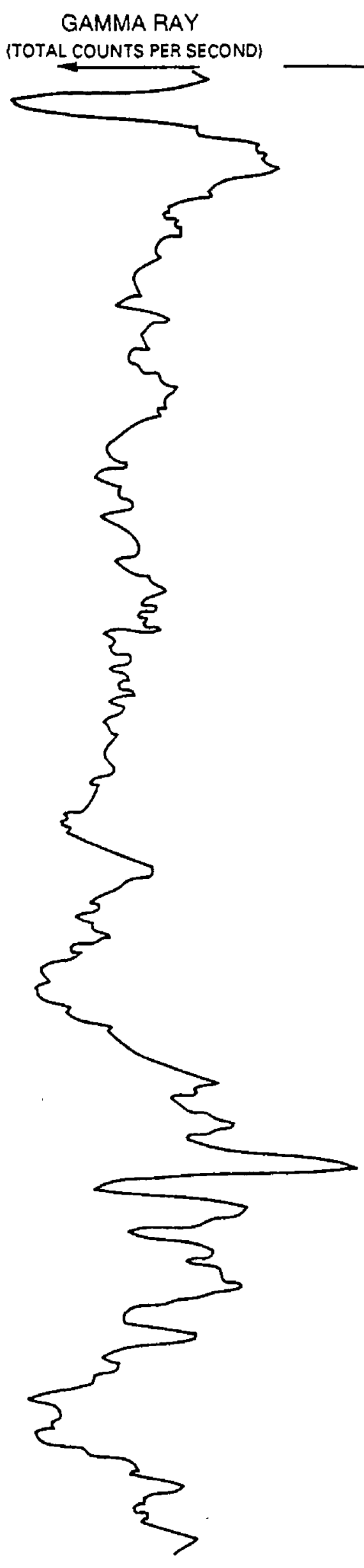

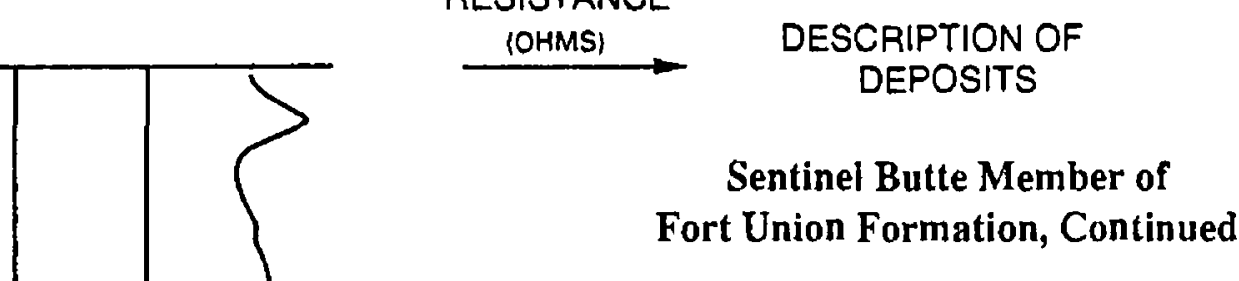

180
196-197.5 Sandstone.

197.5-205 Claystone, silty, medium-gray.

205-215 Claystone, sandy, bluish-gray.

215-230 Claystone, silty, medium-gray.

230-232 Sandstone.

232-241 Claystone, silty, medium-gray.

241-251 Sandstone, fine, bluish-gray; about 30 percent clay.

251-264 Claystone, silty, greenish-gray.

264-265 Lignite.

265-300 Claystone, silty, medium-gray. 
Table 4. U.S. Geological Survey geophysical and lithologic logs--Continued

LOCATION: $148-092-23 A B B$

ALTITUDE: 2,010 (FEET ABOVE SEA LEVEL)
DATE DRILLED: 06-12-92

DEPTH: 300

(FEET)

GAMMA RAY

(TOTAL COUNTS PER SECONDI

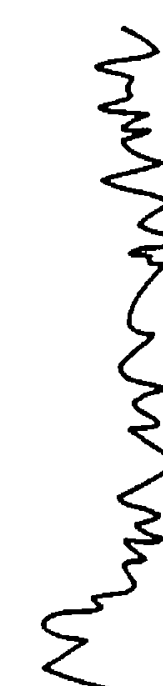

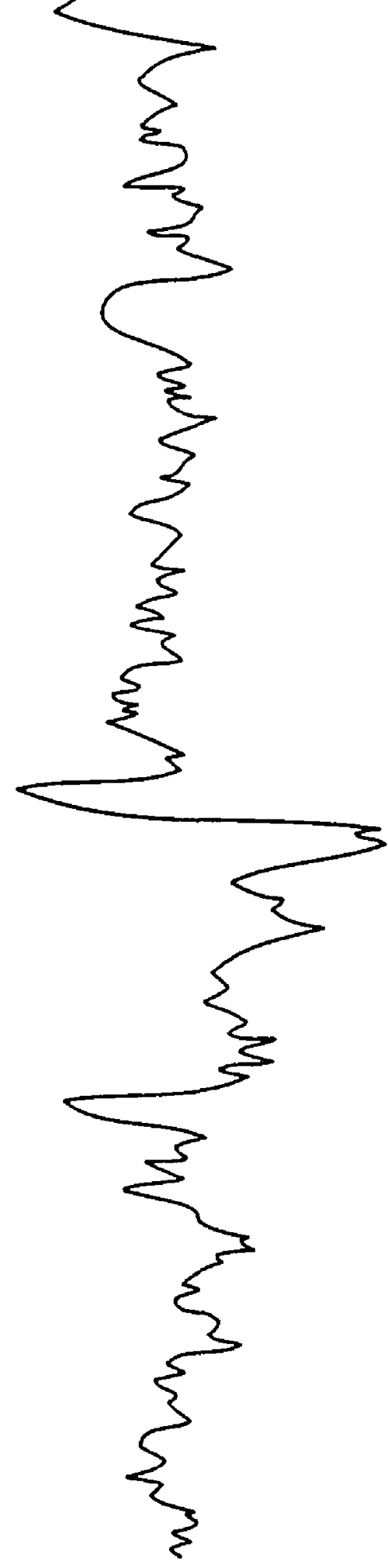

RESISTANCE

IOHMS1

DESCRIPTION OF

DEPOSITS

0-1 Topsoil, silty, black.

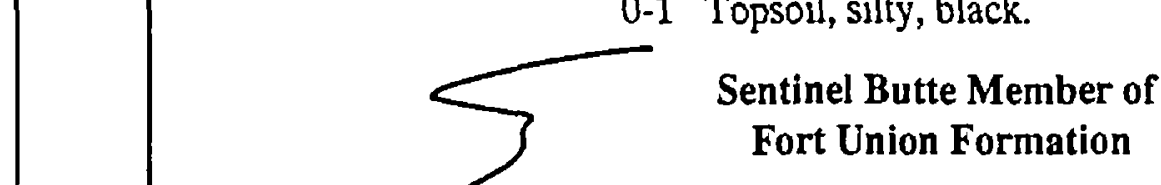

$-20$

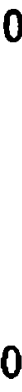

40

60

80

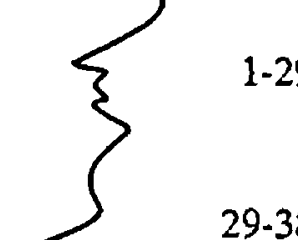

1.29 Sandsione, fine, yellowish-brown.

29-38 Claystone, sandy, silty, yellowish-brown.

38-45 Sandstone.

45-80 Sandstone, fine, yellcwish-brown; about 10 percent clay.

60
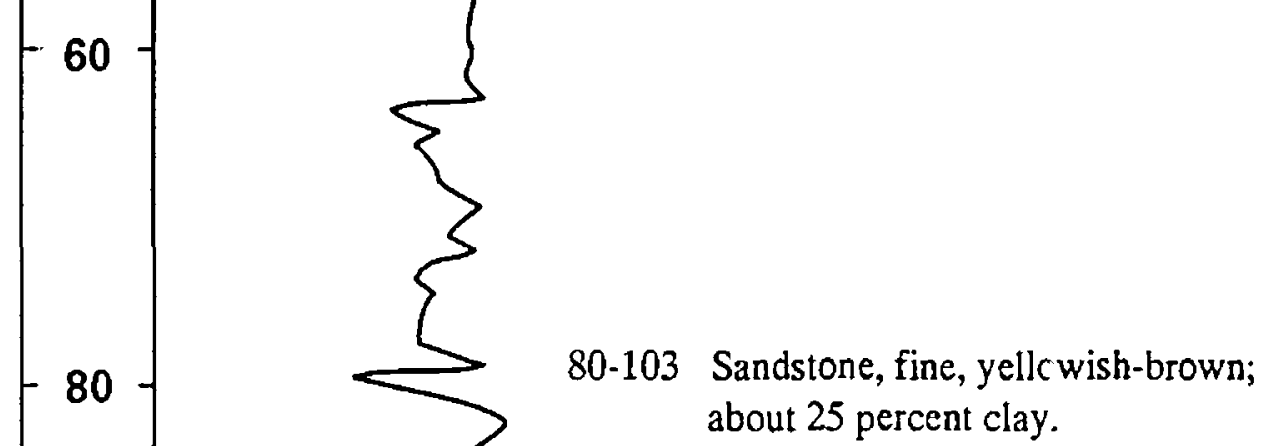

120

100
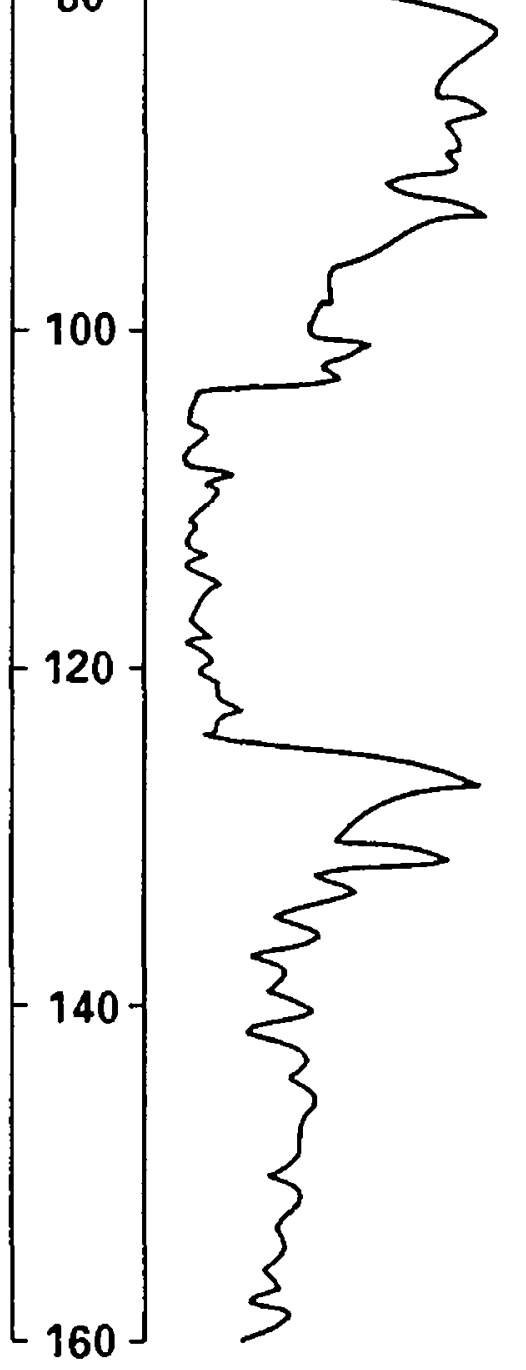

103-105 Lignite.

105-126 Claystone, silty, med um-gray.

126-128 Sandstone.

128-132 Claystone, silty, medium-gray.

132-134 Sandstone.

134-169 Sandstone, fine, bluish-gray; about 20 percent clay. 
Table 4. U.S. Geological Survey geophysical and lithologic logs--Continued

LOCATION: $148-092-23 A B B$

DATE DRILLED: $06-12-92$

ALTITUDE: 2,010

DEPTH: 300

(FEET ABOVE SEA LEVEL)

(FEET)
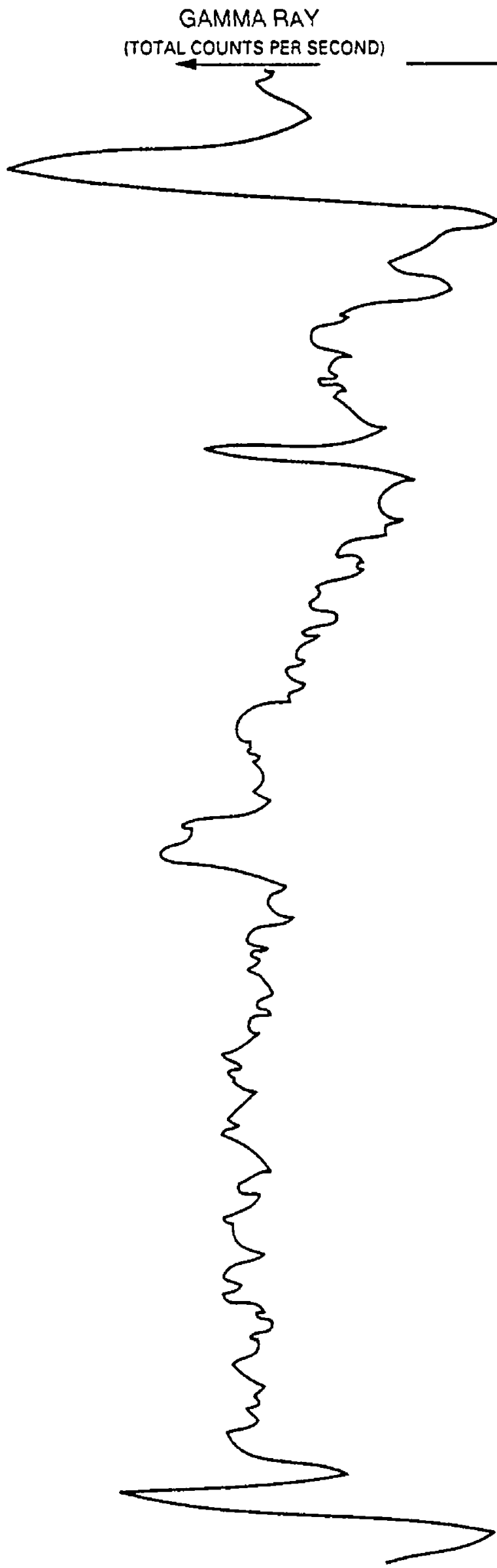

RESISTANCE

(DHMS)

DESCRIPTION OF DEPOSITS

Sentinel Butte Member of Fort Union Formation, Continued

169-173 Lignite.

173-175 Claystone, silty, brownish-gray:

175-191 Claystone, silty, medium-gray.

191-195 Sandstone, fine, bluish-gray.

195-198 Lignite.

198-211 Claystone, silty, brownish-gray:

211-230 Claystone, sandy, silty, bluish-gray; about 40 percent sand.

220
291-293 Lignite.

293-300 Claystone, silty, medium-gray.
230-235 Sandstone, hard.

235-291 Sandstone, fine, bluish-gray; about 10 percent clay. 


\section{Table 4. U.S. Ge}

\section{LOCATION: $148-094-14 \mathrm{AAB}$ ALTITUDE: 2,250 (FEET ABOVE SEA LEVEL)}
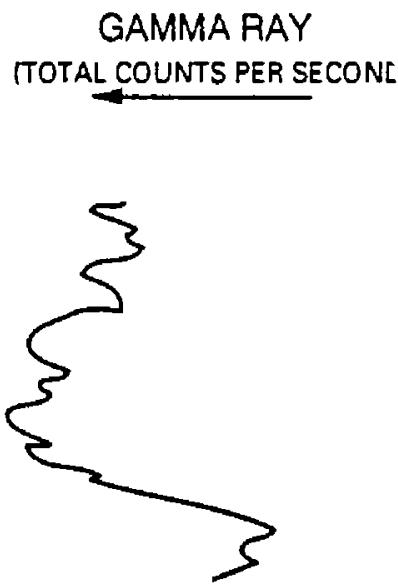
Table 4. U.S. Geological Survey geophysical and lithologic logs--Continued

LOCATION: 148-094-14AAB

ALTITUDE: 2,250

(FEET ABOVE SEA LEVEL)
DATE DRILLED: $06-23-92$

DEPTH: 315 (FEET)

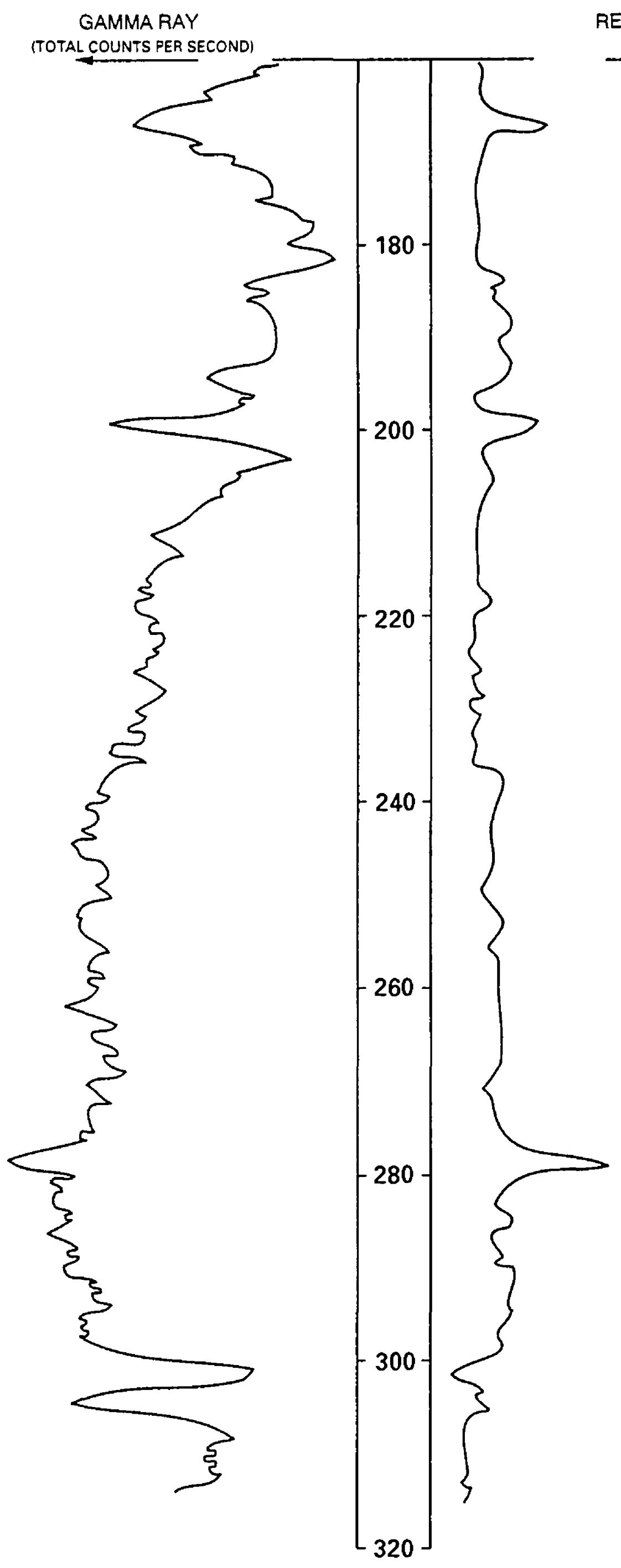

RESISTANCE

(OHMS)

DESCRIPTION OF

DEPOSITS

Sentinel Butte Member of

Fort Union Formation, Contine'ed

164-165 Sandstone.

165-242 Claystone, silty, medium-gray.

242-275 Sandstone, fine, bluish-gray; about 20 percent clay.

275.277 Sandstone, hard.

277.305 Sandstone, fine, bluish-gray; about 20 percent clay.

305-315 Claystone, silty, medium-g-ay. 
Table 4. U.S. Geological Survey geophysical and lithologic logs--Continued

LOCATION: $148-095-12 D C C 1$

ALTITUDE: 2,450 (FEET ABOVE SEA LEVEL)
DATE DRILLED: 06-23-92

DEPTH: 300

(FEET)

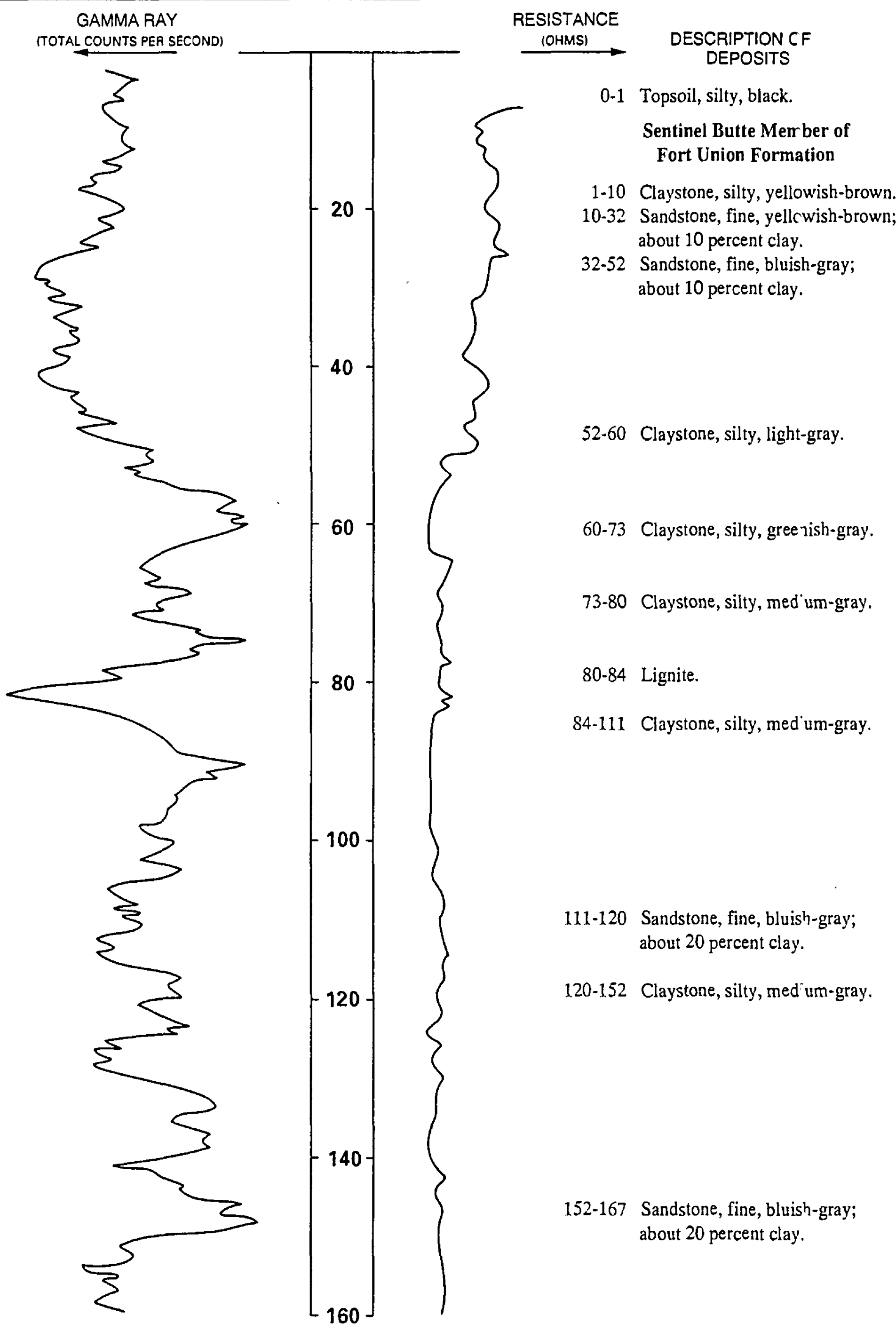


Tabie 4. U.S. Geological Survey geophysical and lithologic logs--Continued

LOCATION: $148-095-12 D C C 1$

ALTITUDE: 2,450 (FEET ABOVE SEA LEVEL)
DATE DRILLED: $06-23-92$

DEPTH: 300 (FEET)

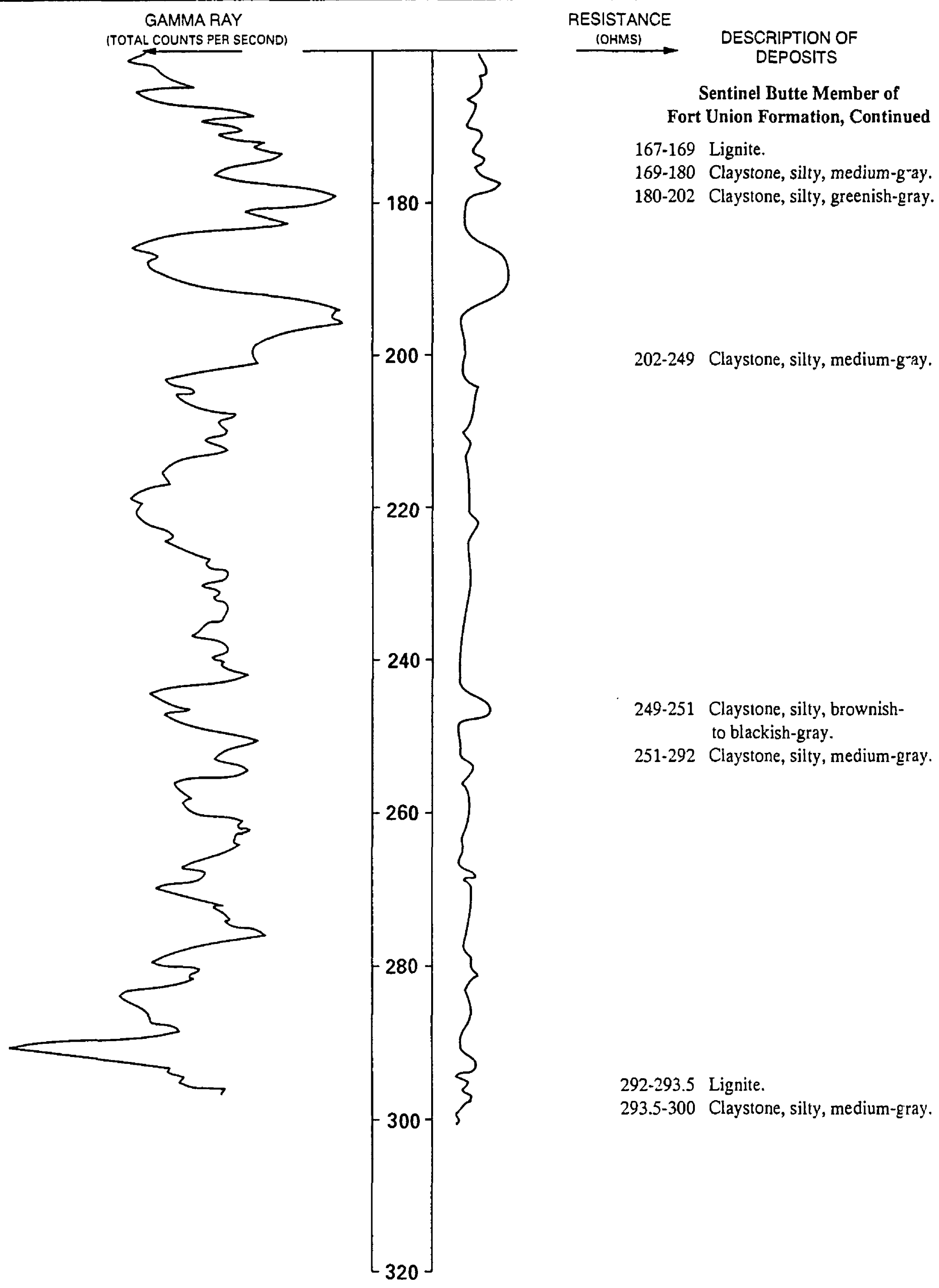


Table 4. U.S. Geological Survey geophysical and lithologic logs--Continued

LOCATION: $149-088-11 C D C$

ALTITUDE: 1,995 (FEET ABOVE SEA LEVEL)
DATE DRILLED: $06-03-92$

DEPTH: 100

(FEET)

GAMMA RAY

(TOTAL COUNTS PER SECOND)

ב

RESISTANCE

(OHMS)

DESCRIPTION O=
DEPOSITS

0-1 Topsoil, silty, black.

\section{Glacial Drift}

1.12 Clay, silty, yellowish-brown; till.

12-20 Clay, silty, yellowish-brown.

20-25 Gravel, fine to coarse.

25-39 Clay, silty, yellowish-brown; till.

39-72 Sand, fine to coarse, ye'lowish-gray.

2.76 Clay, silty, yellowish-gray; till.

76-89 Clay, sandy, silty, yellowish-brown.

89-100 Clay, silty, medium-gray.

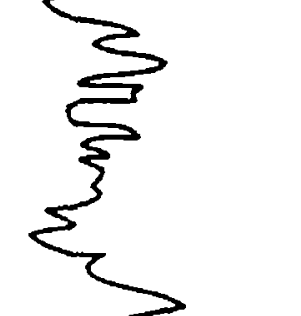


Table 4. U.S. Geological Survey geophysical and lithologic logs--Continued

LOCATION: $149-088-26 \mathrm{BAB}$

ALTITUDE: 1,988

(FEET ABOVE SEA LEVEL)
DATE DRILLED: 06-01-92

DEPTH: 390

(FEET)

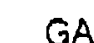

(TOTAL COUNTS PER SECONO)

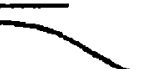

RESISTANCE

IOHMS

(NO RESISTANCE LOG)
0-1 Topsoil, silty, black.

Glacial Drift

1-28 Clay, silty, yellowish-brown; till.

28-42 Clay, silty, olive-gray; with a few rocks; till.

42-49 Sand, fine to coarse, yellowish-brown. 49-52 Clay, sandy, silty, yellowish-gray; till. 52.74 Clay, silty, yellowish-gray; till.

74-76 Gravel and rocks.

76-86 Clay, silty, yellowish-gray; till.

86-107 Clay, silty, olive-gray; till.

107.111 Gravel, fine to coarse.

111-197 Clay, silty, sandy, olive-gray; till. 
Table 4. U.S. Geological Survey geophysical and lithologic logs--Continued

LOCATION: $149-088-26 \mathrm{BAB}$

ALTITUDE: 1,988

(FEET ABOVE SEA LEVEL)
DATE DRILLED: 06-01-92

DEPTH: 390 (FEET)

GAMMA RAY

ITOTAL COUNTS PER SECONDI

RESISTANCE

(OHMS)
(NO RESISTANCE LOG)

DESCRIPTIONCF

DEPOSITS

Glacial Drift, Continued

197-207 Clay, silty, olive-gray; till.

207-209 Gravel, fine to coarse.

209-220 Clay, silty, olive-gray; till.

220-246 Sand, fine to medium, nedium-gray.

246-300 Gravel, fine to coarse; about 30 percent sand.
300-309 Sand, fine to coarse, sil y.

309-315 Gravel, fine to coarse; with clay layers.

315-321 Gravel, fine to coarse; about 20 percent sand. 
Table 4. U.S. Geological Survey geophysical and lithologic logs--Continued

LOCATION: 149-088-26BAB

ALTITUDE: 1,988 (FEET ABOVE SEA LEVEL)
DATE DRILLED: 06-01-92

DEPTH: 390 (FEET)

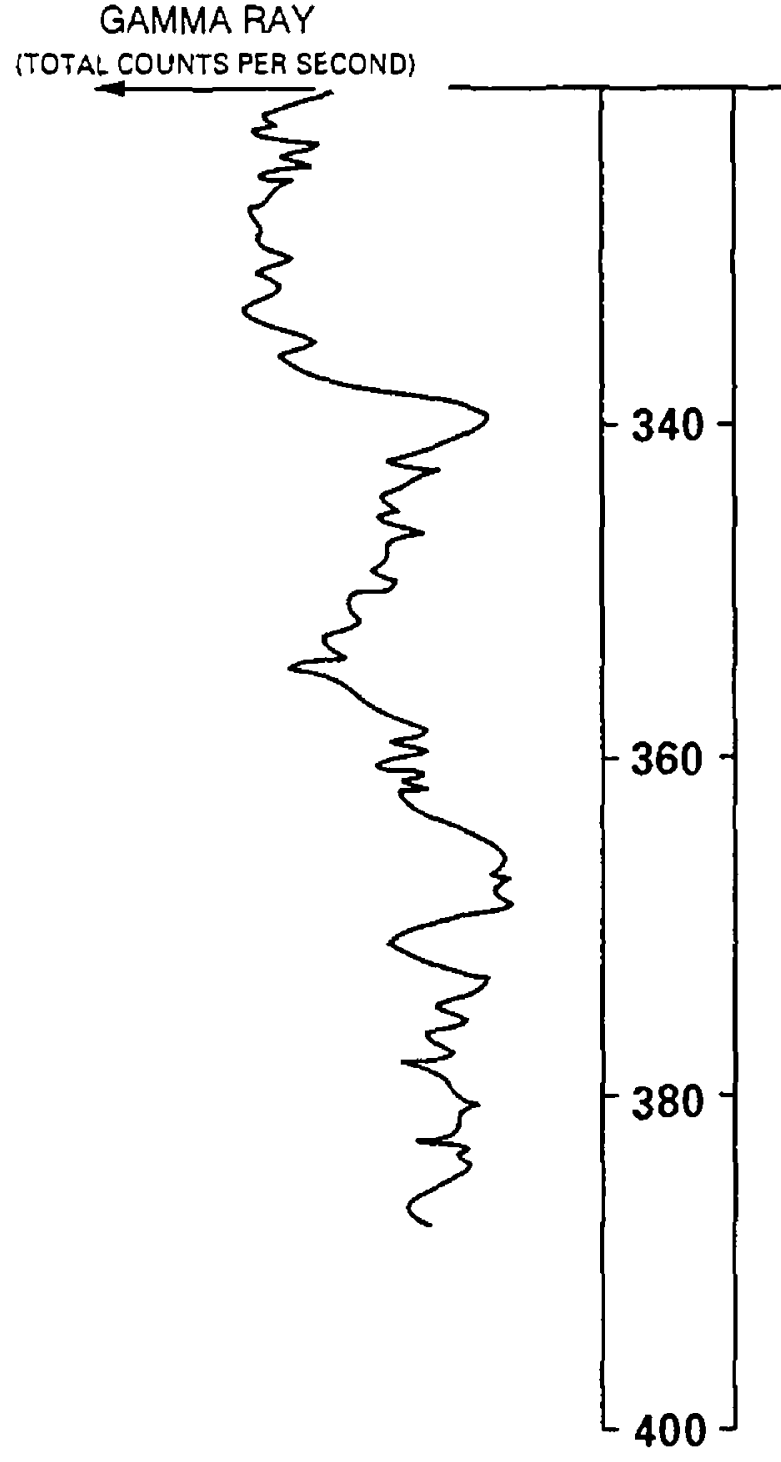

321-335 Sand and gravel; with abundant clay. 335-342 Gravel, fine to coarse; with a few rocks.

\section{Tongue River Member of Fort Union Formation}

342-390 Claystone, sandy, silty, medium-gray. 
Table 4. U.S. Geological Survey geophysical and lithologic logs--Continued

LOCATION: 149-091-31BAA

ALTITUDE: 2,200

(FEET ABOVE SEA LEVEL)
DATE DRILLED: $06-11-92$

DEPTH: 305 (FEET)

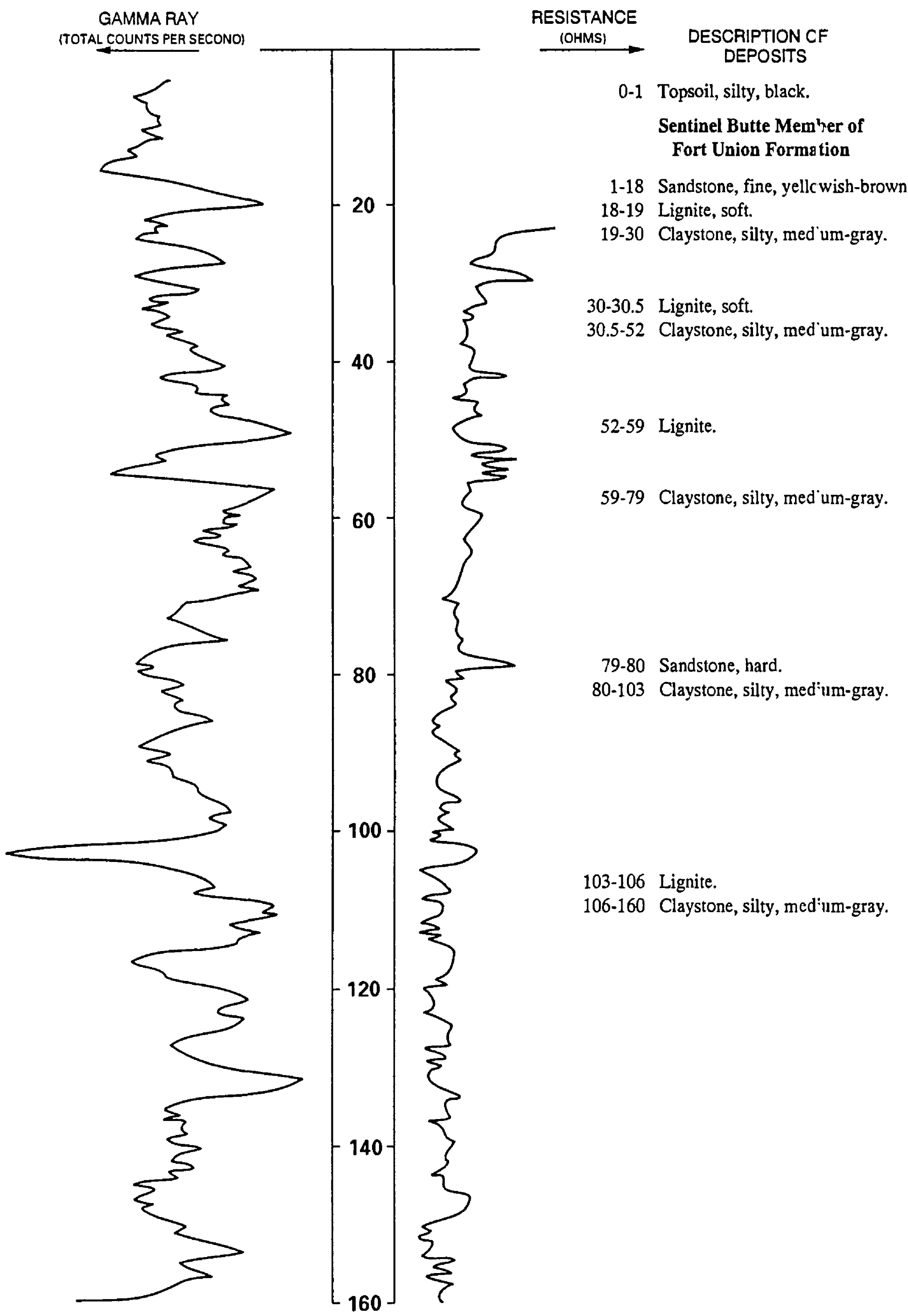


Table 4. U.S. Geological Survey geophysical and lithologic logs---Continued

LOCATION: 149-091-31BAA

ALTITUDE: 2,200 (FEET ABOVE SEA LEVEL)
DATE DRILLED: $06-11-92$

DEPTH: 305 (FEET)

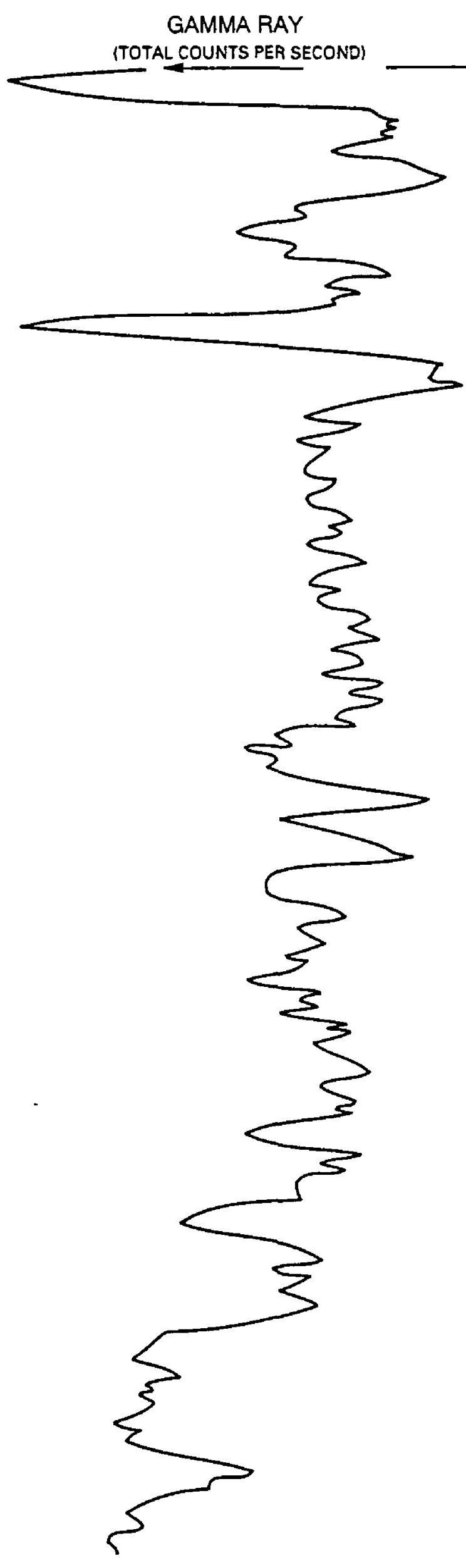

RESISTANCE

(OHMS)

DESCRIPTION OF

DEPOSITS

Sentinel Butte Member of Fort Union Formation, Continied

160-164 Lignite.

164-170 Claystone, silty, brownish-gray.

170-186 Claystone, silty, greenish-gray.

186-188 Lignite.

188-204 Claystone, silty, medium-gray.

204-231 Claystone, silty, greenish-gray.

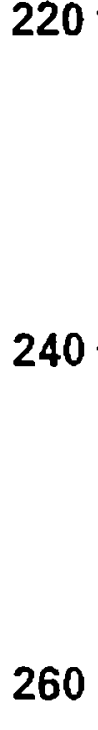

200

-260
-260

280

$-300$

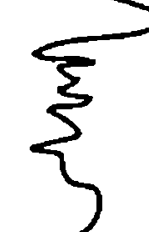

5

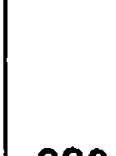

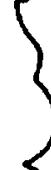

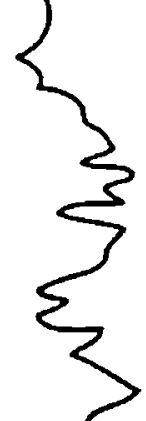

231-258 Claystone, silty, light-gray.

258-263 Claystone, sandy, silty, bluish-gray.

263-285 Claystone, silty, medium-gray.

285-295 Sandstone, fine, bluish-gray; about 30 percent clay.

295-300 Claystone, silty, brownish-gray. 300-305 Limestone. 
Table 4. U.S. Geological Survey geophysical and lithologic logs--Continued

LOCATION: $149-093-12 B B B$

ALTITUDE: 2,286 (FEET ABOVE SEA LEVEL)
DATE DRILLED: 06-11-92

DEPTH: 240 (FEET)

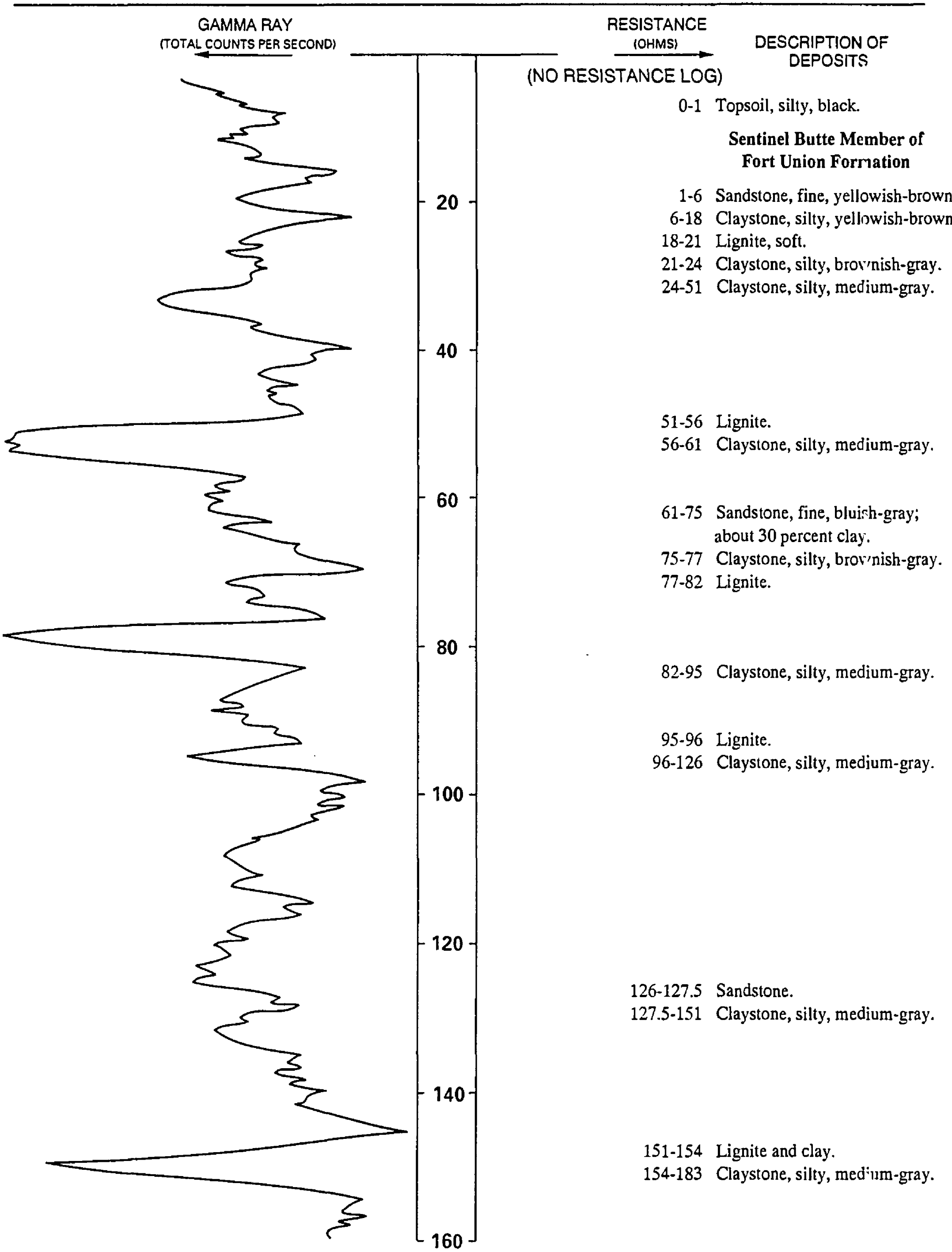


Table 4. U.S. Geological Survey geophysical and lithologic logs--Continued

LOCATION: 149-093-12BBB

DATE DRILLED: $06-11-92$

ALTITUDE: 2,286

(FEET ABOVE SEA LEVEL)

DEPTH: 240

(FEET)
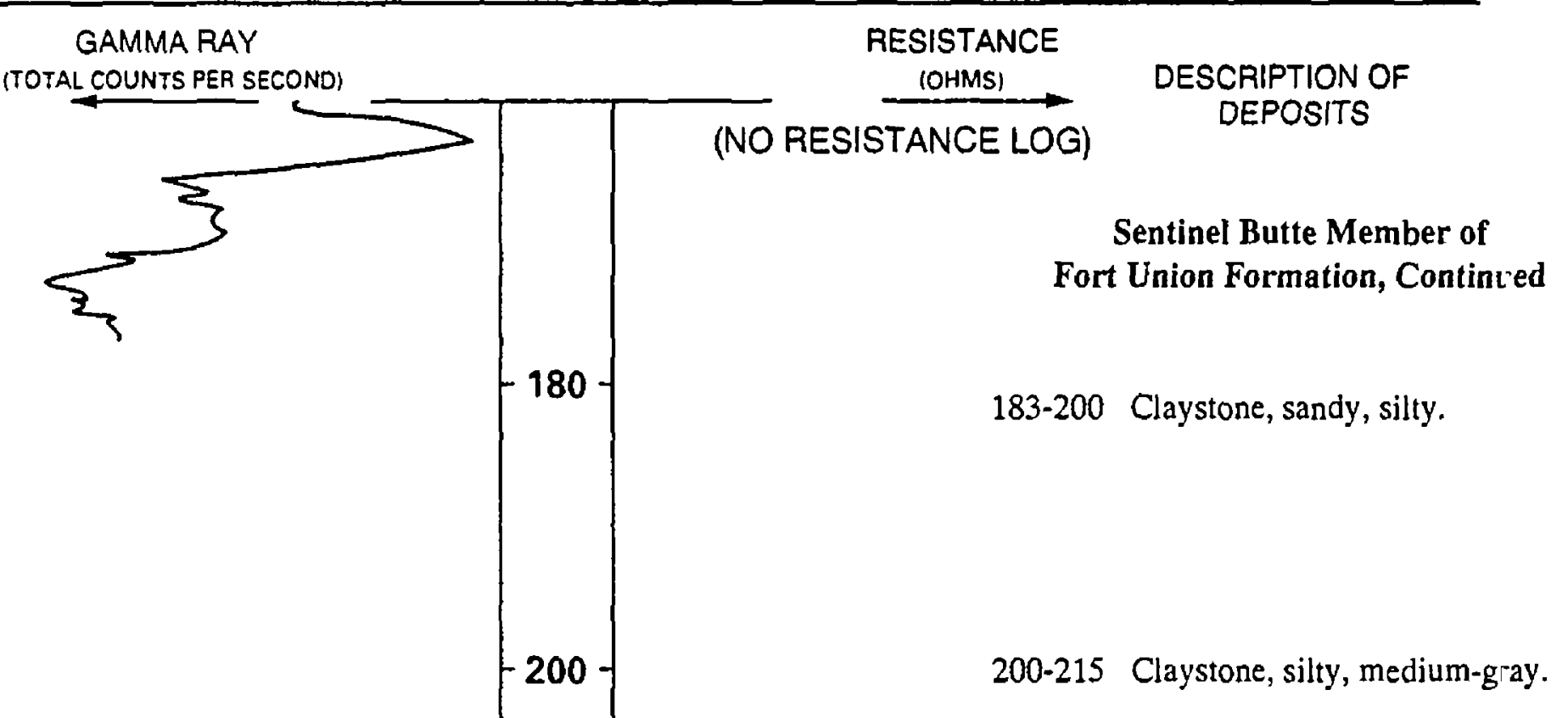

$\left[\begin{array}{c}220 \\ 240 \\ 260 \\ -280 \\ 320\end{array}\right]$

215-219 Lignite, soft; taking water.

219-235 Claystone, silty, medium-g-ay.

235-238 Sandstone.

238-240 Claystone, silty, medium-gray.

Lost circulation at 240 feet. Hole caved back to 180 feet. Abandoned hole. 
Table 4. U.S. Geological Survey geophysical and lithologic logs--Continued

LOCATION: $149-093-26 A D B$

ALTITUDE: 2,220

(FEET ABOVE SEA LEVEL)
DATE DRILLED: 06-22-92

DEPTH: 300

(FEET)

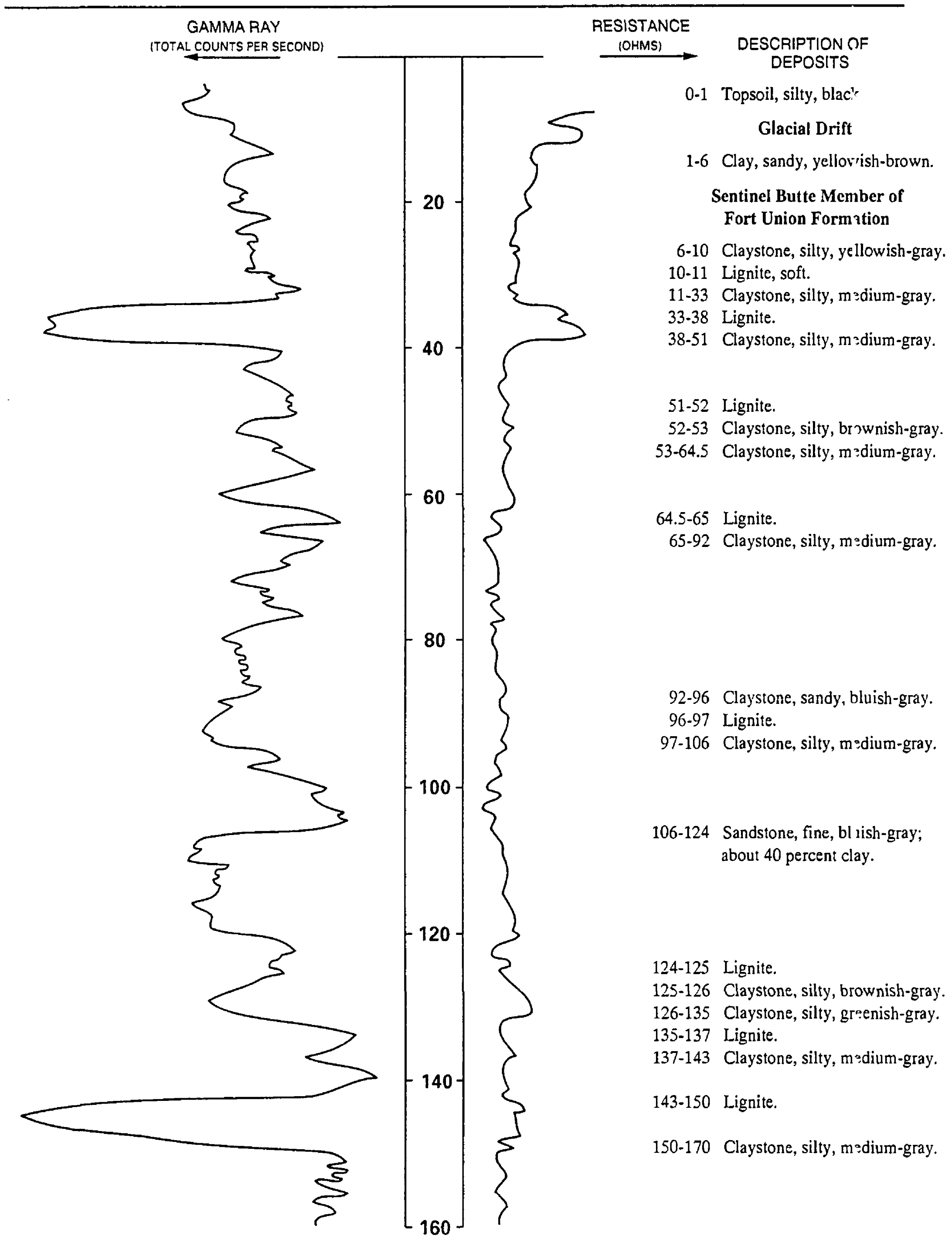


Table 4. U.S. Geological Survey geophysical and lithologic logs--Continued

LOCATION: 149-093-26ADB

ALTITUDE: $\quad 2,220$

(FEET ABOVE SEA LEVEL)
DATE DRILLED: $06-22-92$

DEPTH: 300

(FEET)

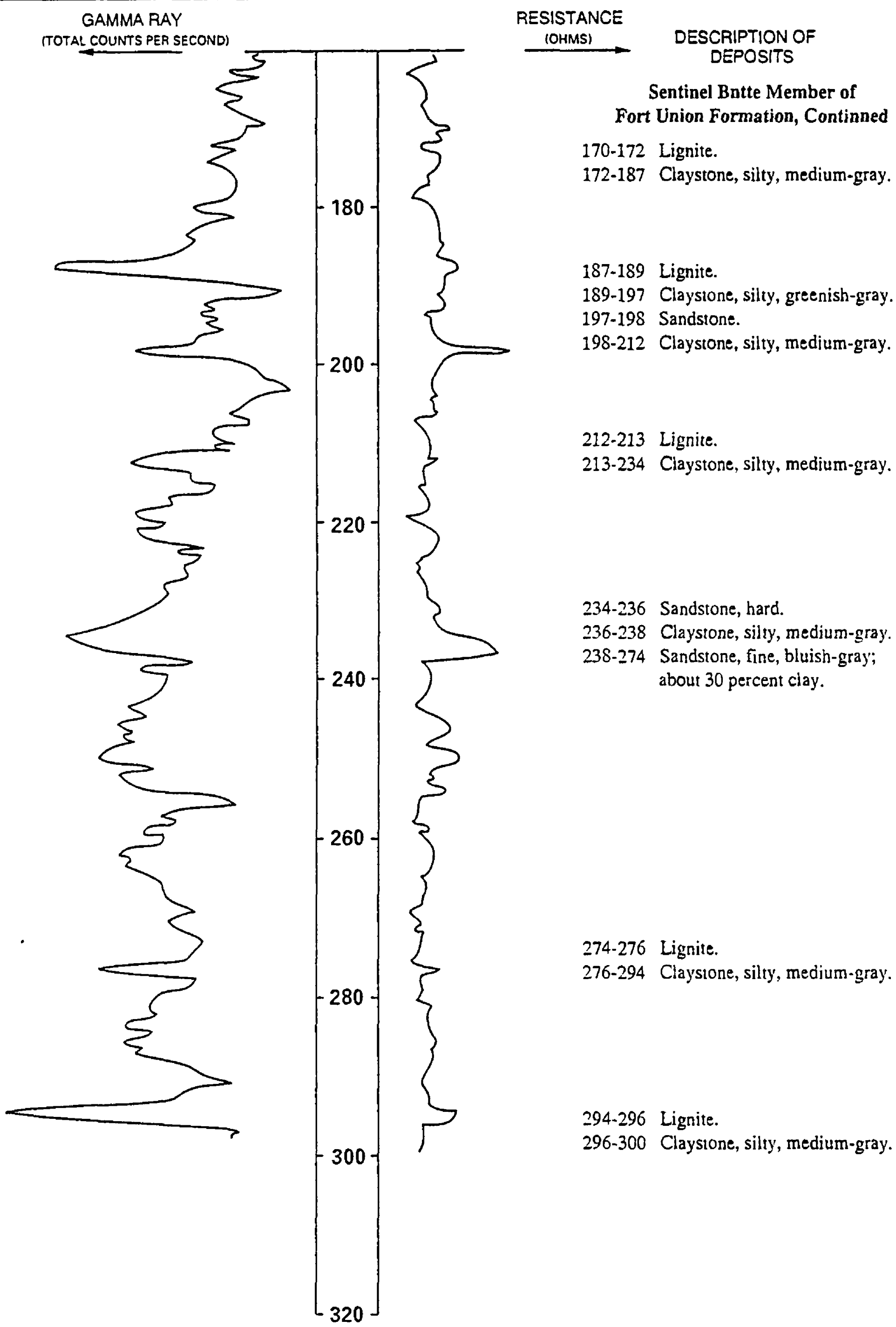


Table 4. U.S. Geological Survey geophysical and lithologic logs--Continued

LOCATION: 149-094-28AAA1

ALTITUDE: 2,300

(FEET ABOVE SEA LEVEL)
DATE DRILLED: $06-10-92$

DEPTH: 320

(FEET)

\section{RESISTANCE} (OHMS)

\section{DESCRIPTION OF} DEPOSITS

0-1 Topsoil, silty, black.

\section{Glacial Drift}

1-13 Clay, silty, yellowish-bro"n; till.

13-16 Sand, fine to medium, yellowish-brown.

16-20 Clay, silty, yellowish-bro"rn; till.

20.28 Sand, fine, yellowish-bro'n; with clay layers.

28-50 Clay, silty, yellowish-bro"'n; till.

\section{Sentinel Butte Member of Fort Union Formation}

50.58 Claystone, silty, yellowish-brown. 58-60 Claystone, silty, blackish -gray.

60-64 Lignite, soft.

64-70 Claystone, silty, medium gray.

70-74 Claystone, sandy, bluish-gray.

74-81 Claystone, silty, greenish-gray.

81-94 Claystone, silty, medium gray.

94-96 Sandstone, fine, bluish-g ay"; about 20 percent clay.

96-125 Sandstone, fine, bluish-g־ay; about 10 percent clay.

125-129 Lignite, soft.

129-156 Claystone, silty, medium-gray.

156-170 Sandstone, fine, bluish-g-ay; about 30 percent clay. 
Table 4. U.S. Geological Survey geophysical and lithologic logs--Continued

LOCATION: 149-094-28AAA1

ALTITUDE: 2,300

(FEET ABOVE SEA LEVEL)
DATE DRILLED: $06-10-92$

DEPTH: 320

(FEET)

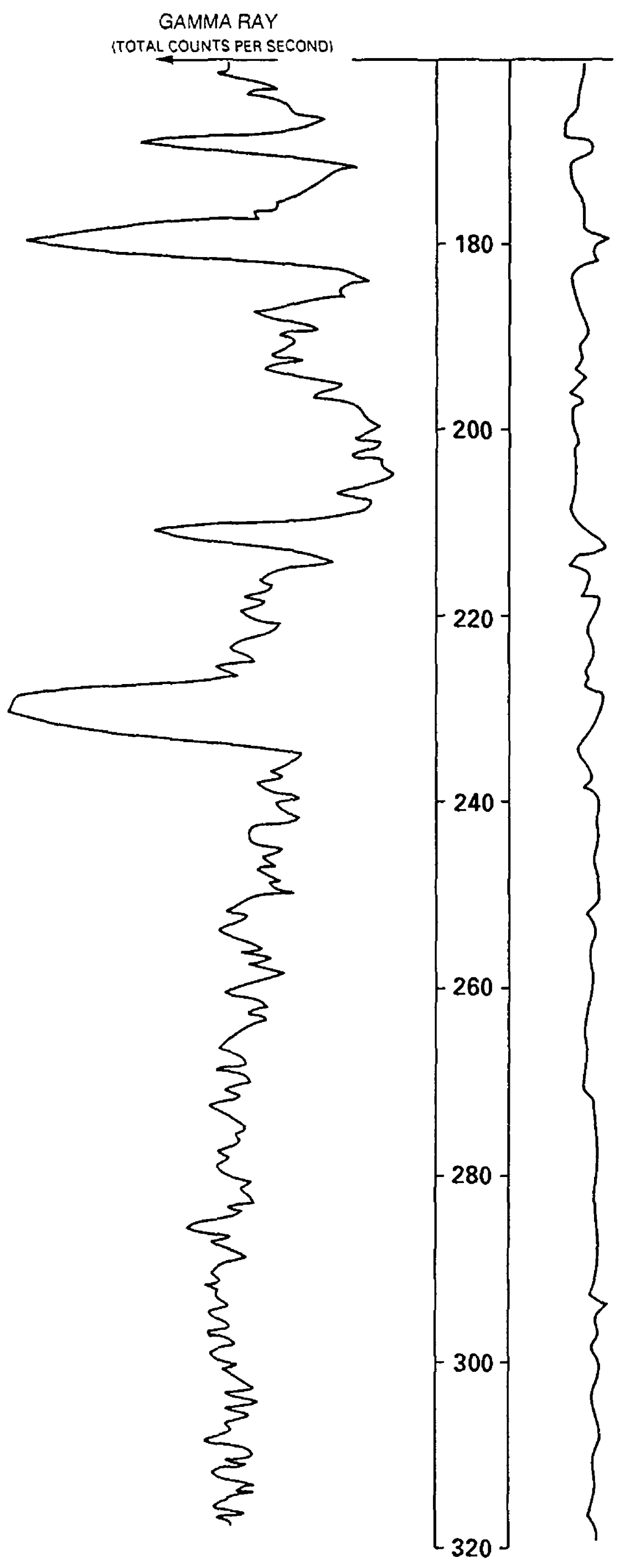

\section{RESISTANCE IOHMSI \\ DESCRIPTION OF DEPOSITS}

Sentinel Butte Member of Fort Union Formation, Contirued

170-173 Lignite.

173-179 Claystone, sitty, medium-gray. 179-184 Lignite.

184-198 Claystone, silty, medium-gray. 198-199 Sandstone.

199-212 Claystone, silty, medium-gray.

212-214 Lignite.

214-230 Claystone, sandy, silty, bluish-g-ay; about 30 percent sand.

230-235 Lignite.

235-246 Sandstone, fine, bluish-gray; abundant clay.

246-315 Sandstone, fine, bluish-gray; about 20 percent clay. 
Table 4. U.S. Geological Survey geophysical and lithologic logs--Continued

LOCATION: $150-089-13$ CDD

ALTITUDE: 1,992 (FEET ABOVE SEA LEVEL)
DATE DRILLED: $06-02.92$

DEPTH: 180 (FEET)

\section{RESISTANCE (OHMS) DESCRIPTION OF DEPOSITS}

0-1 Topsoil, silty, black.

\section{Glacial Drift}

1-24 Clay, silty, yellowish-brown; till.

24-95 Clay, silty, olive-gray; till.

95-97 Sand, fine to coarse; with abundant lignite.

97-100 Clay, silly, olive-gray; till.

100-107 Sand, fine to coarse; with abundant lignite.

107-110 Clay, silty, gravelly, o'ive-gray; till.

110-112 Gravel and sand.

112-125 Clay, silty, olive-gray; gravel layers; till.

125-131 Sand, fine to coarse; with abundant lignite.

131-155 Clay, silty, olive-gray; gravel layers; till.

\section{Sentinel Butte Mernber of Fort Union Formation}

155-180 Claystone, silty, brownish-gray to greenish-gray. 
Table 4. U.S. Geological Survey geophysical and lithologic logs--Continued

LOCATION: 150-089-13CDD

ALTITUDE: 1,992

(FEET ABOVE SEA LEVEL)
DATE DRILLED: 06-02-92

DEPTH: 180 (FEET)

GAMMA RAY

(TOTAL COUNTS PER SECOND)
RESISTANCE

(OHMS)

\{
DESCRIPTION OF

DEPOSITS 
Table 4. U.S. Geological Survey geophysical and lithologic logs--Continued

LOCATION: $150 \cdot 094-33 A C C$

ALTITUDE: 2,290 (FEET ABOVE SEA LEVEL)
DATE DRILLED: 06-09-92

DEPTH: 235

(FEET)

\section{RESISTANCE}

(OHMS)

\section{DESCRIPTIONCF \\ DEPOSITS}

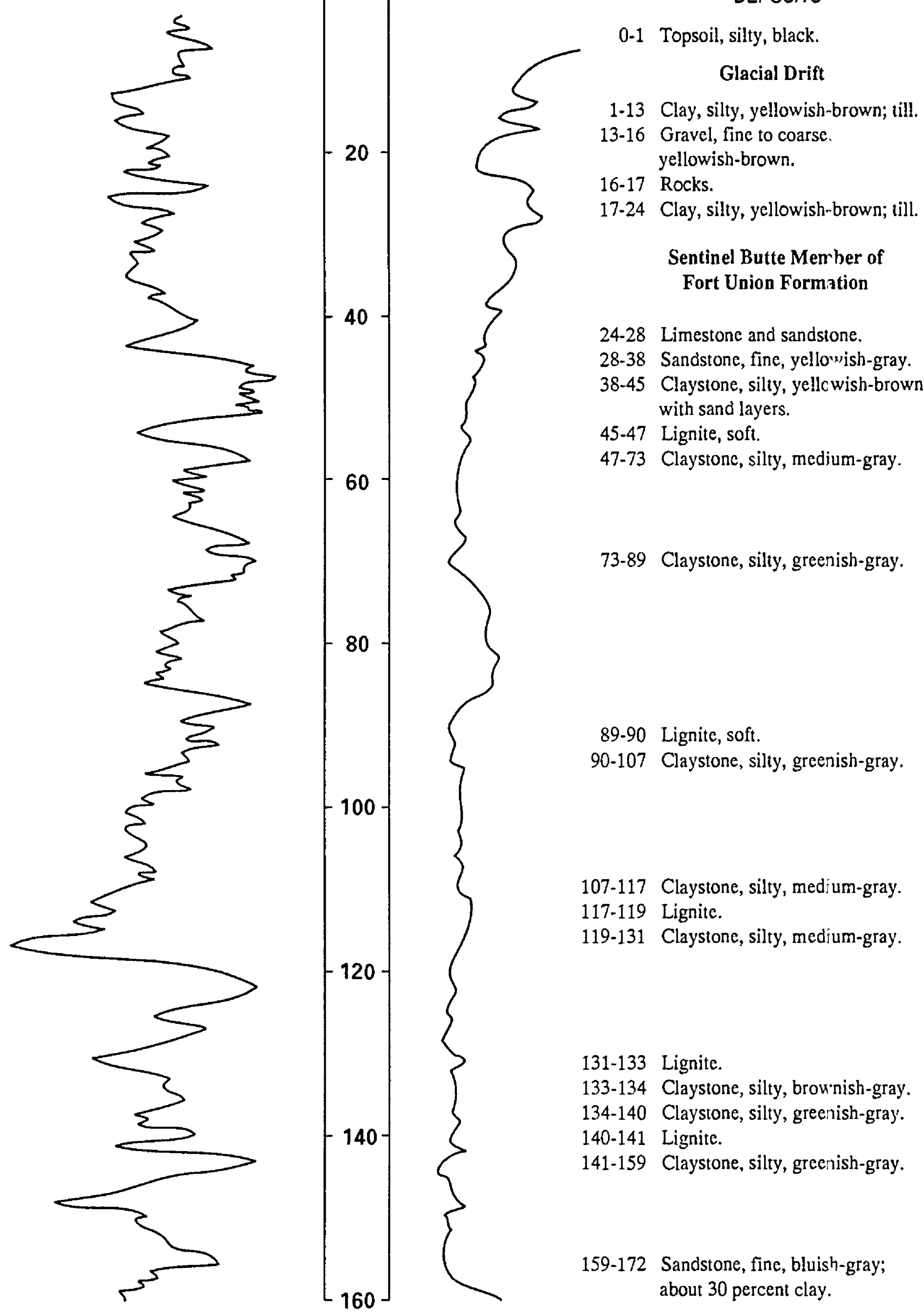


Tabie 4. U.S. Geological Survey geophysical and lithologic logs--Continued

LOCATION: 150-094-33ACC

ALTITUDE: 2,290 (FEET ABOVE SEA LEVEL)
DATE DRILLED: 06-09-92

DEPTH: 235 (FEET)

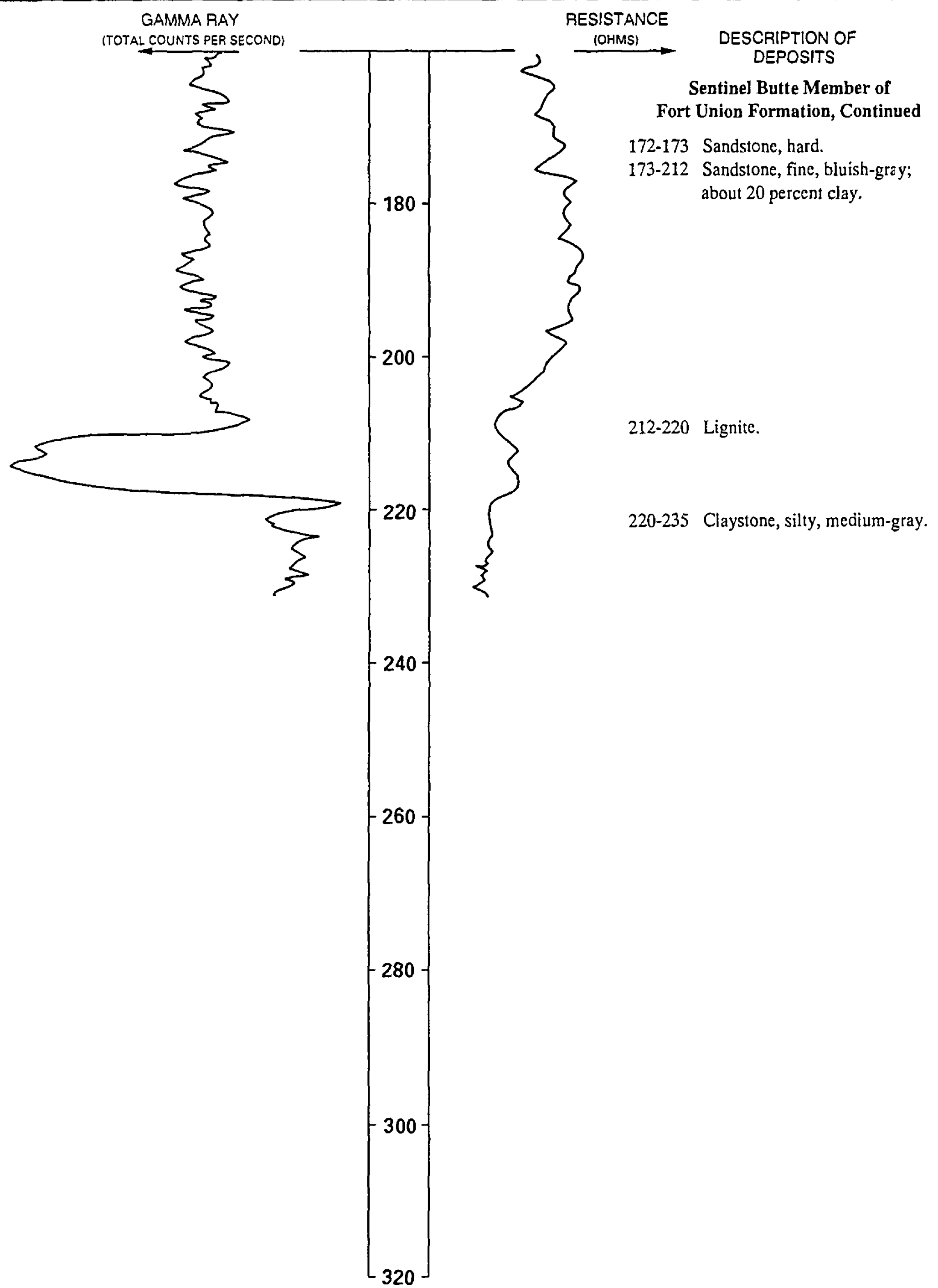


Table 4. U.S. Geological Survey geophysical and lithologic logs--Continued

LOCATION: 151.092-30ADD

ALTITUDE: 1,898 (FEET ABOVE SEA LEVEL)

DATE DRILLED: 06-04-92

DEPTH: 240

(FEET)

GAMMA RAY
(TOTAL COUNTS PER SECOND)

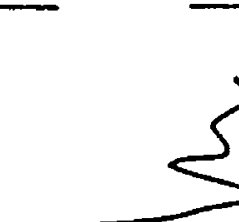

5<smiles>CCCC1CC1</smiles>

$\sum$<smiles>CCCCCCCCC</smiles><smiles></smiles>

S

5

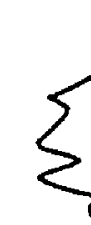

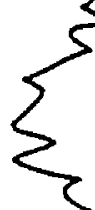

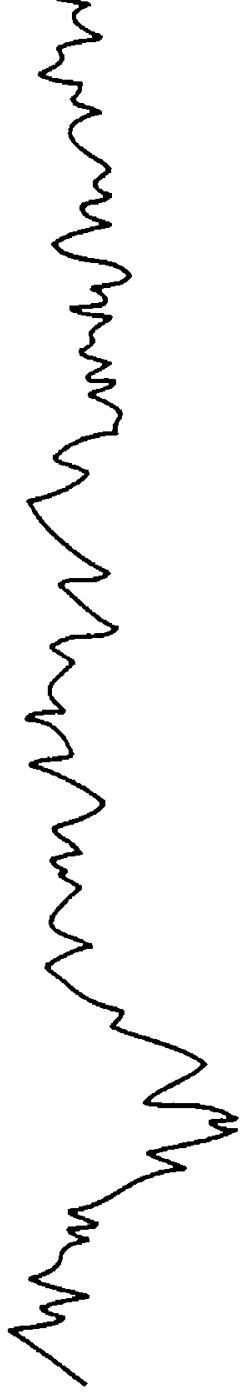

RESISTANCE

(OHMS)

0-1 Topsoil, silty, black.

Glacial Drift

1-11 Clay, silty, yellowish-gray; till. 11-15 Gravel, fine to coarse.

15.20 Clay, silty, yellowish-gray; till. 20.26 Gravel and sand, yellowish-brown. 26-55 Clay, silty, olive-gray; till.

\section{5-60 Gravel, fine to coarse.}

60-175 Sand, fine to medium, medium-gray; some lignite. 
Table 4. U.S. Geological Survey geophysical and lithologic logs--Continued

LOCATION: $151-092 \cdot 30 A D D$

ALTITUDE: 1,898

(FEET ABOVE SEA LEVEL)
DATE DRILLED: 06-04-92

DEPTH: 240 (FEET)

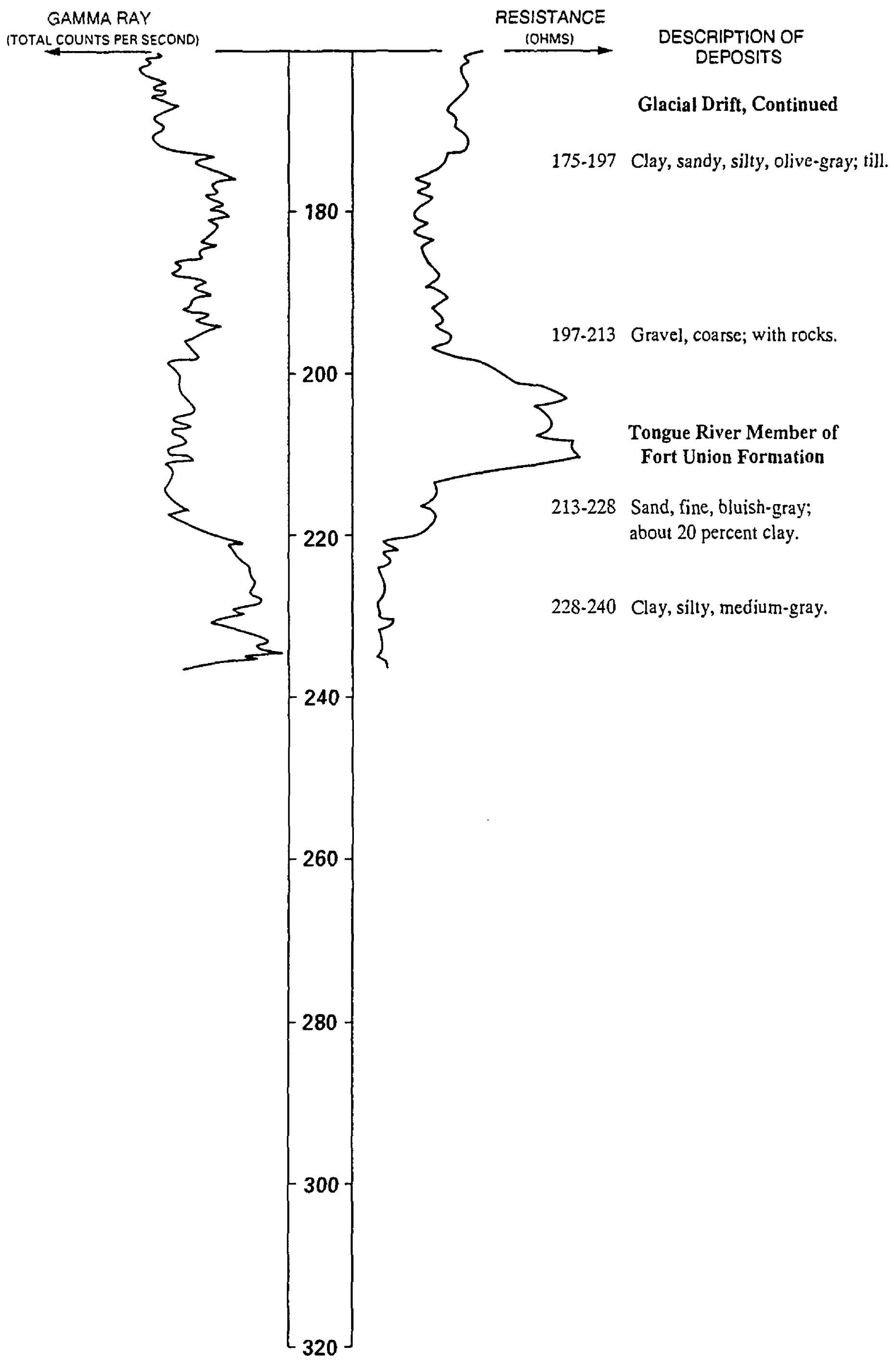


Table 4. U.S. Geological Survey geophysical and lithologic logs--Continued

LOCATION: 151-093-21ADD

ALTITUDE: 1,995 (FEET ABOVE SEA LEVEL)

DATE DRILLED: $06-05-92$ DEPTH: 327 (FEET)

GAMMA RAY
TTOTAL COUNTS PER SECONDI

RESISTANCE
(OHMS)
$\longrightarrow$

0-1 Topsoil, silty, black.

\section{Glacial Drift}

1-4 Clay, silty, yellowish-brown; till.

4-6 Gravel, fine to coarse, yellowish-brown.

6-40 Clay, silty, yellowish-brown; till.

40-84 Sand, fine to coarse, yell jwish-brown.
84-90 Clay, sandy, silty, brownish-gray; till.

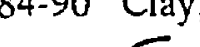<smiles>CCCCCCCCCCCCCC</smiles>

Sentinel Butte Member of Fort Unjon Formation

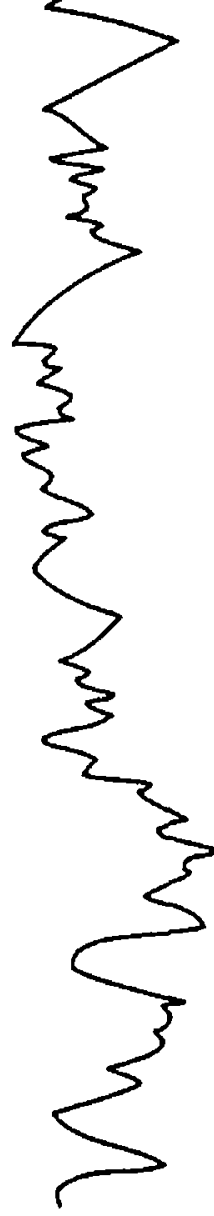

$-10$

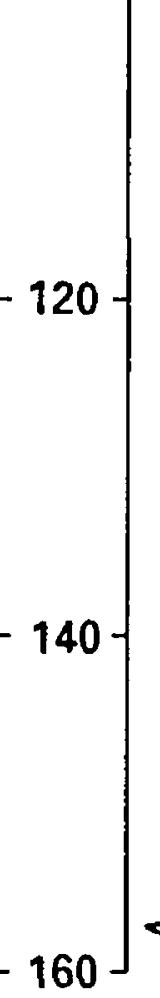


Table 4. U.S. Geological Survey geophysical and lithologic logs--Continued

LOCATION: 151-093-21ADD

ALTITUDE: 1,995 (FEET ABOVE SEA LEVEL)
DATE DRILLED: $06-05-92$

DEPTH: 327 (FEET)

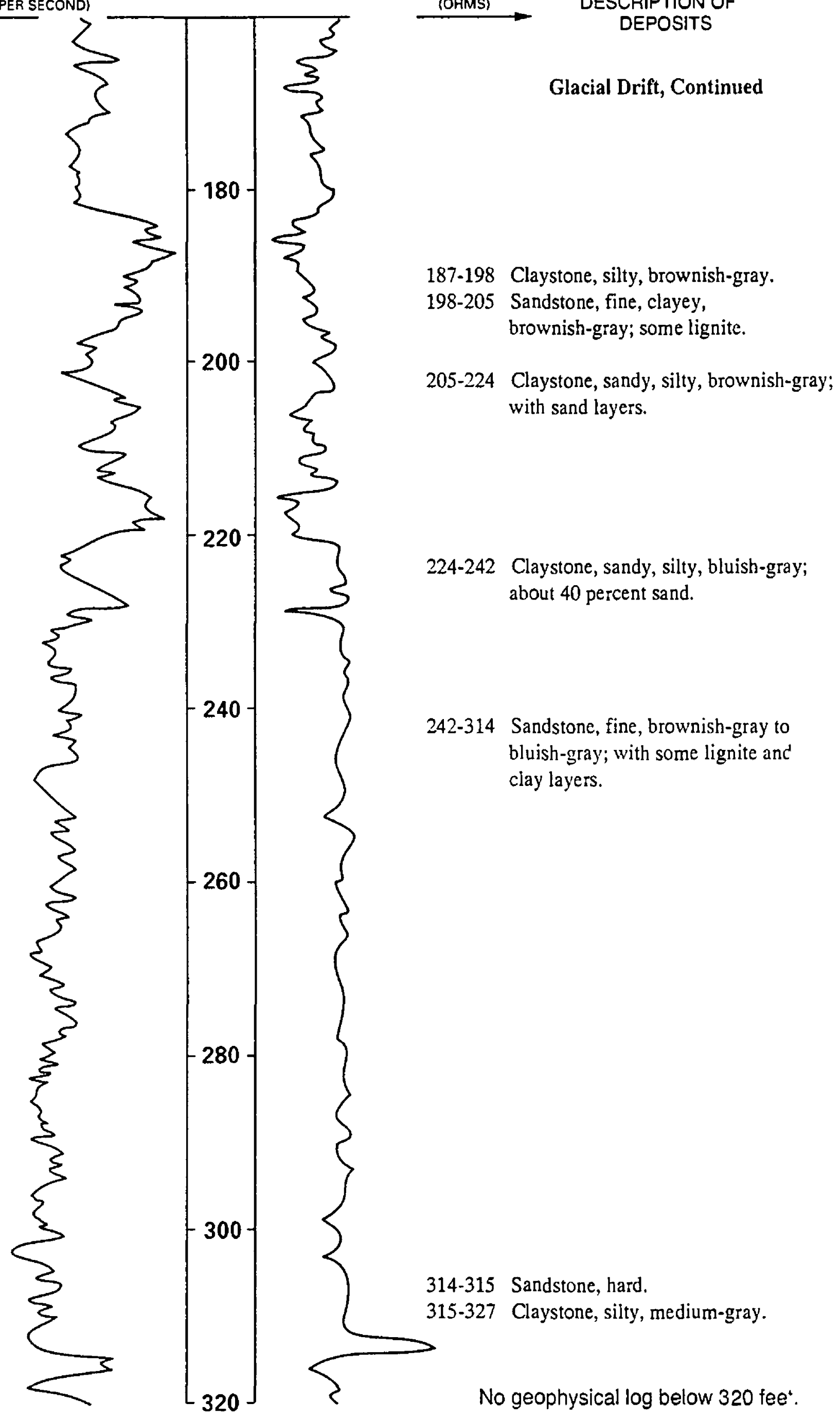


Table 4. U.S. Geological Survey geophysical and lithologic logs--Continued

LOCATION: 151-093-24DCC

ALTITUDE: 1,925

(FEET ABOVE SEA LEVEL)
DATE DRILLED: $06-03-92$

DEPTH: 260

(FEET)

RESISTANCE

(OHMS)

DESCRIPTION OF

DEPOSITS

0-1 Topsoil, silty, black.

\section{Glacial Drift}

1-12 Clay, silty, yellowish-brown; till.

12-17 Clay, silty, blackish-gray; till.

17-19 Gravel, fine to coarse, yellowish-brown.

19-63 Clay, silty, olive-gray; till.

63-238 Sand, fine to medium, bluish-gray; with some lignite and clay layers. 
Table 4. U.S. Geological Survey geophysical and lithologic logs--Continued

LOCATION: 151-093-24DCC

ALTITUDE: 1,925

(FEET ABOVE SEA LEVEL)
DATE DRILLED: $06-03.92$

DEPTH: 260

(FEET)
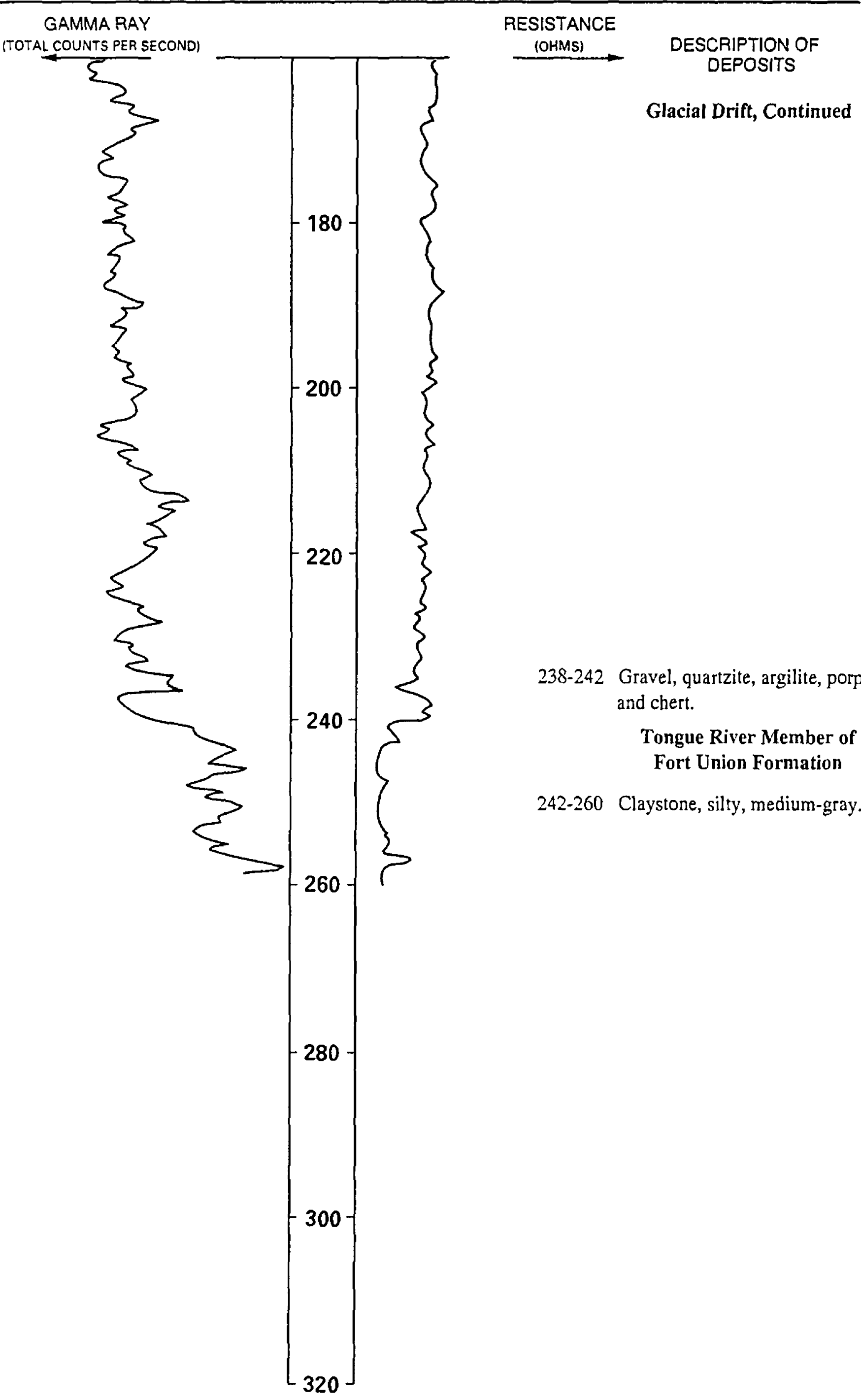

238-242 Gravel, quartzite, argilite, porplyry, and chert.

Tongue River Member of Fort Union Formation

242-260 Claystone, silty, medium-gray. 
Table 4. U.S. Geological Survey geophysical and lithologic logs--Continued

LOCATION: $151.093 .27 B B B$

ALTITUDE: 1,985

(FEET ABOVE SEA LEVEL)
DATE DRILLED: 06-04-92

DEPTH: 310

(FEET)

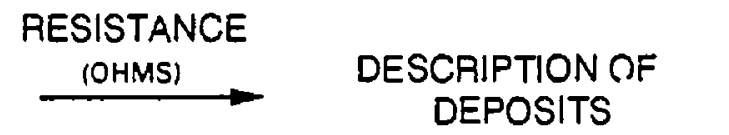

0-1 Topsoil, silty, black.

\section{Glacial Drift}

1-40 Clay, silty, yellowish-brown; till.

40-64 Sand, fine to medium, yel owish-brown.

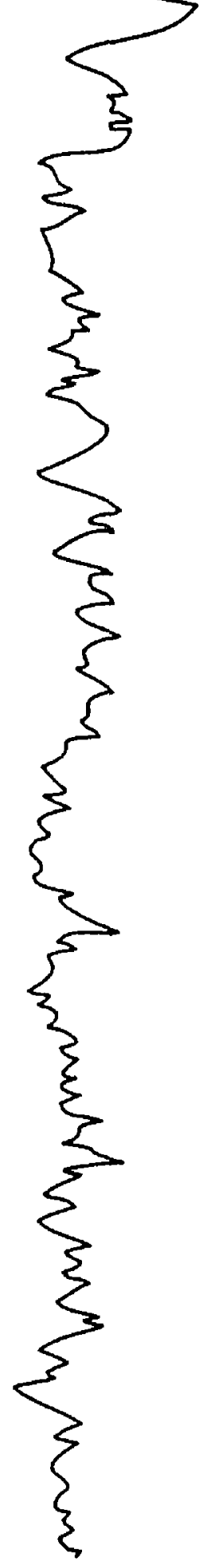

-80

60<smiles>C1CC1</smiles>

100

$-120$

140

140

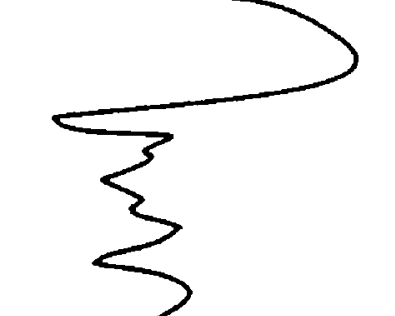

\section{with clay layers.}

64-101 Clay, sandy, silty, yellowish-gray to brownish-gray; tiil.

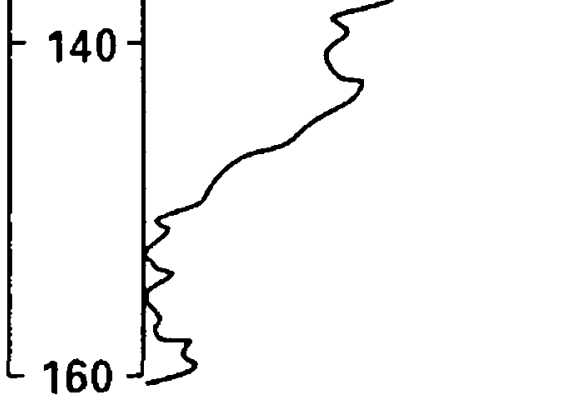


Table 4. U.S. Geological Survey geophysical and lithologic logs--Continued

LOCATION: $151-093-27 \mathrm{BBB}$

ALTITUDE: 1,985 (FEET ABOVE SEA LEVEL)
DATE DRILLED: 06-04-92

DEPTH: 310 (FEET)

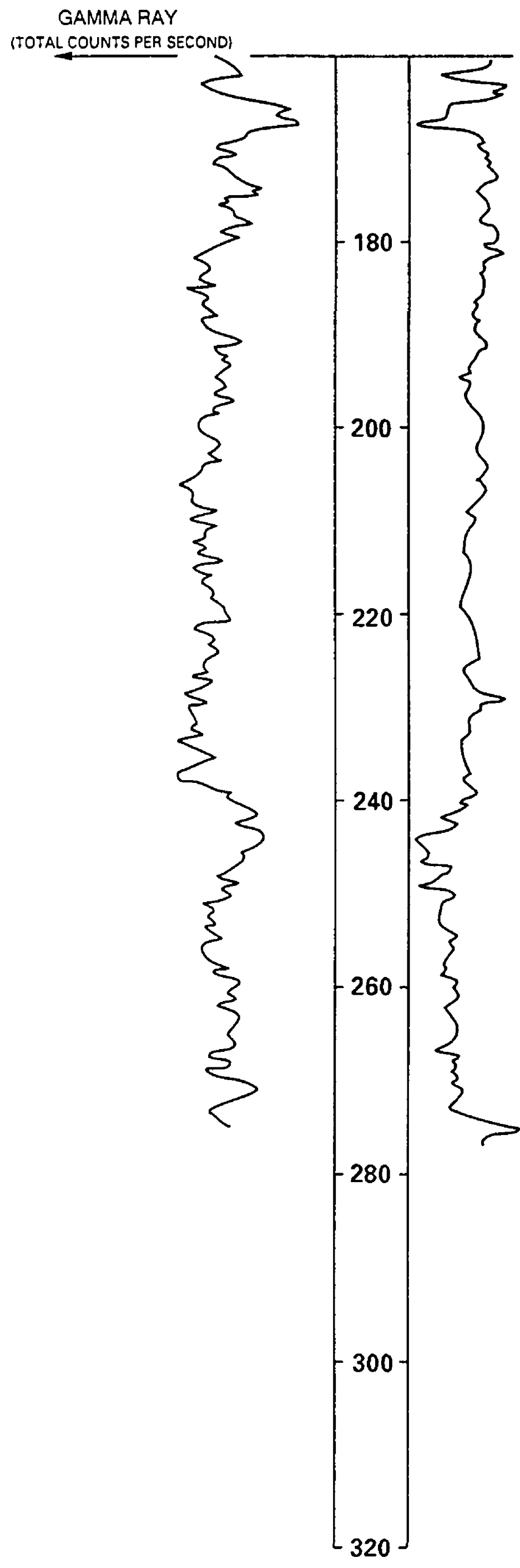

RESISTANCE

(OHMS)

DESCRIPTION OF

DEPOSITS

Sentinel Butte Member of Fort Union Formation

238-241 Limestone.

241-308 Sandstone, fine, bluish-gra?; about 20 percent clay.

308-310 Sandstone, hard. 
Table 4. U.S. Geological Survey geophysical and lithologic logs--Continued

LOCATION: $151 \cdot 094-06 A B B 1$

ALTITUDE: 2,138

(FEET ABOVE SEA LEVEL)
DATE DRILLED: $06-08-92$ DEPTH: 300 (FEET)

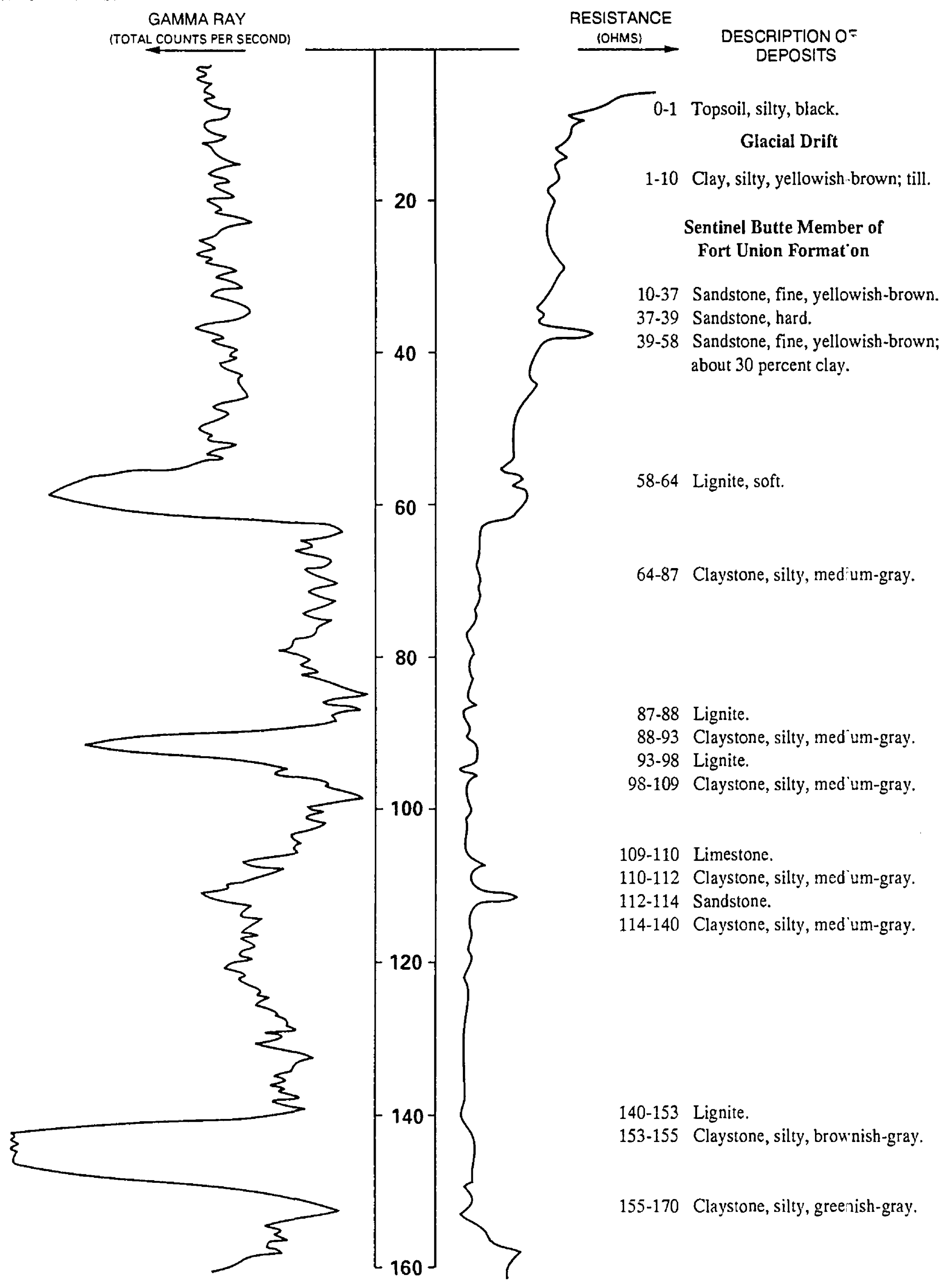


Table 4. U.S. Geological Survey geophysical and lithologic logs--Continued

LOCATION: $151-094-06 A B B 1$

ALTITUDE: 2,138

(FEET ABOVE SEA LEVEL)
DATE DRILLED: $06-08-92$

DEPTH: 300

(FEET)

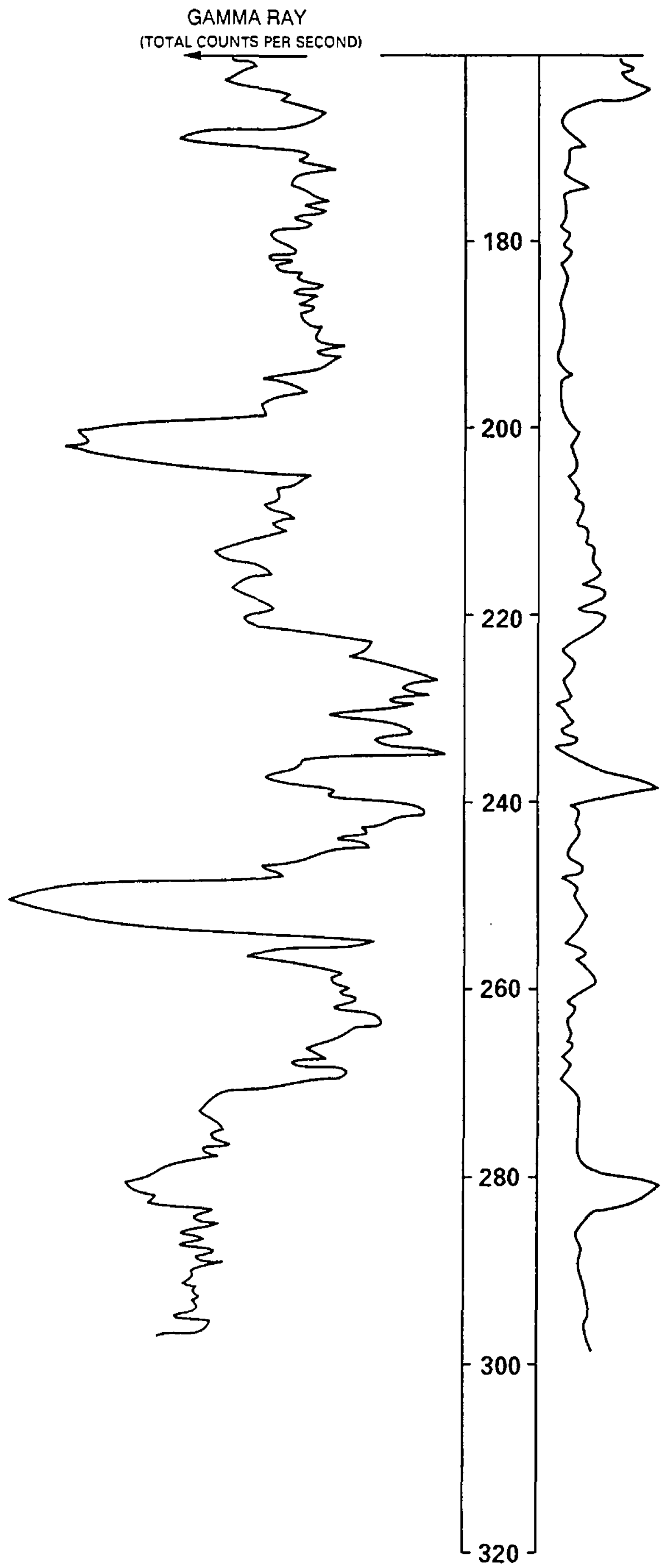

\section{RESISTANCE}

(OHMS)

\section{DESCRIPTION OF}

Sentinel Butte Member of Fort Union Formation, Continued

170-172 Lignite.

172-175 Claystone, silty, greenish-gray.

175-176 Sandstone, hard.

176-182 Claystone, silty, greenish-gray.

182-203 Claystone, silty, medium-gray.

203-204 Lignite.

204-204.5 Claystone, silty, brownish-gray.

204.5-206 Lignite.

206-220 Claystone, silty, light-gray.

220-225 Claystone, sandy, silty, light-gray.

225-249 Claystone, silty, light-medium-gray.

249-251 Claystone, silty, brownish-gray.

251-255 Lignite.

255-255.5 Claystone, silty, brownish-gray. 255.5-258 Lignite.

258-283 Claystone, silty, medium-gray.

\section{3-285 Sandstone, hard.}

285-300 Claystone, silfy, medium-gray. 
Table 4. U.S. Geological Survey geophysical and lithologic logs--Continued

LOCATION: $151-094-33 B C A$

ALTITUDE: 2,368

\{FEET ABOVE SEA LEVEL\}
DATE DRILLED: 06-09-92

DEPTH: 300 (FEET)

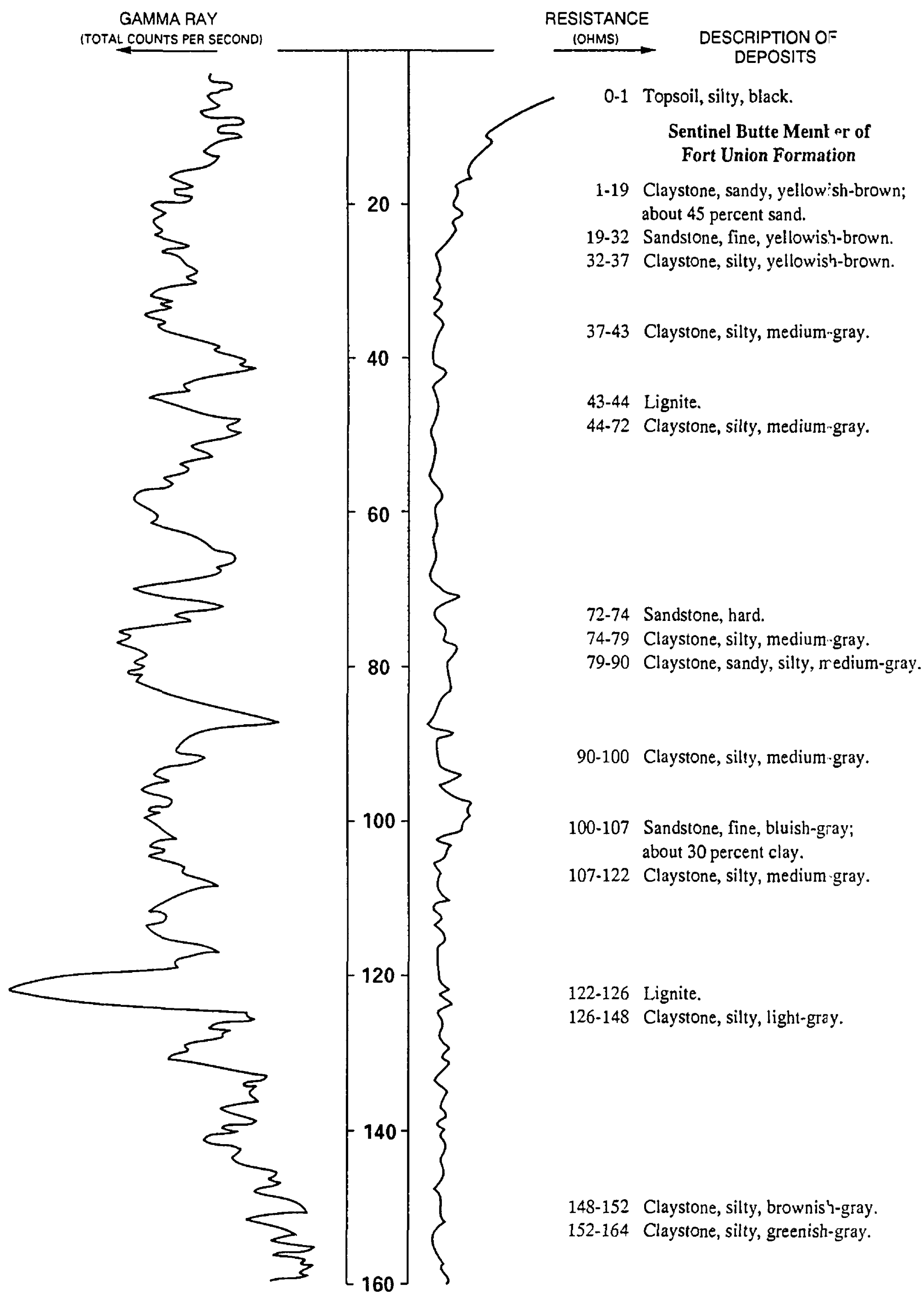


Table 4. U.S. Geological Survey geophysical and lithologic logs--Continued

LOCATION: 151-094-33BCA

ALTITUDE: $\quad 2,368$ (FEET ABOVE SEA LEVEL)
DATE DRILLED: 06-09-92 DEPTH: 300 (FEET)

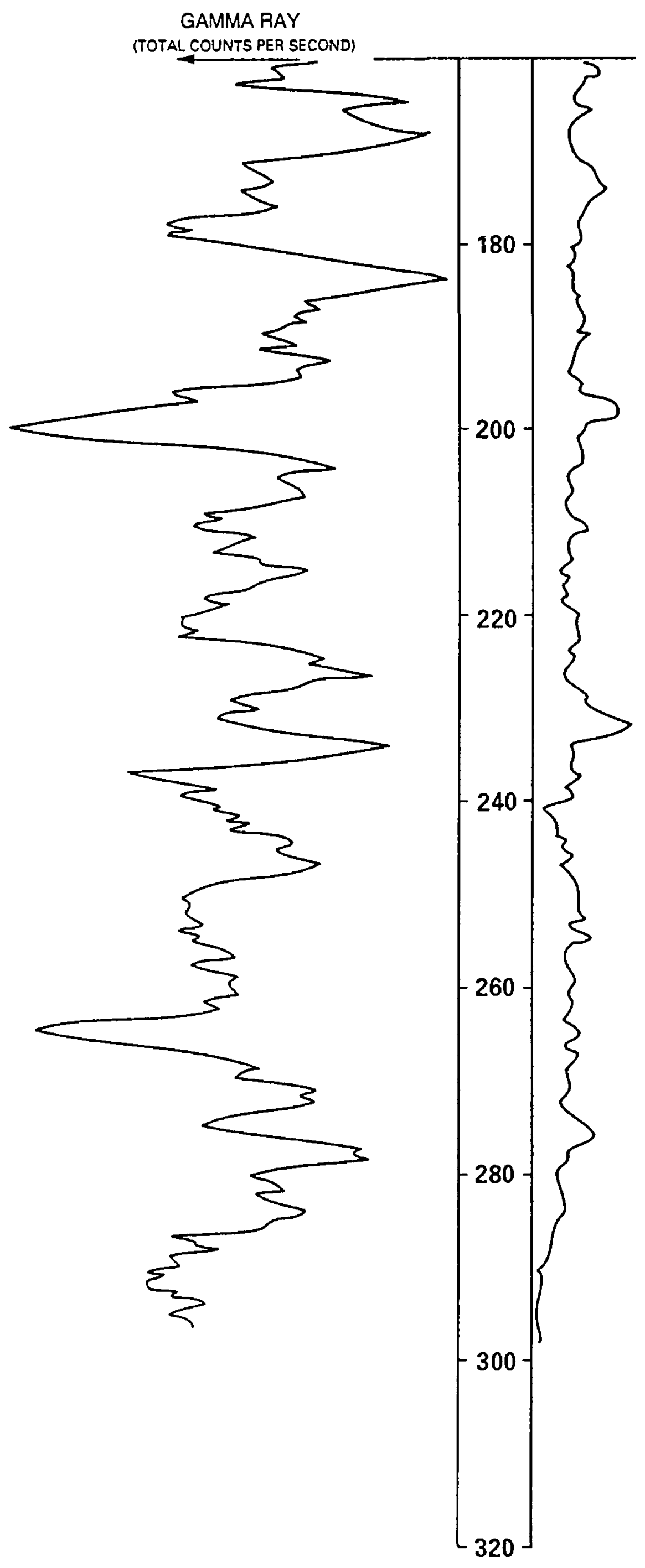

RESISTANCE

(OHMS)

DESCRIPTION OF

DEPOSITS

Sentinel Butte Member of Fort Union Formation, Continued

164-165 Claystone, silty, brownish-gray. 165-166 Lignite.

166-172 Claystone, silty, greenish-gray.

172-200 Claystone, silty, medium-g־ay.

200-204 Claystone, silty, brownish-black. 204-242 Claystone, silty, medium-g־ay.

242-265 Claystone, silty, greenish-g*ay.

265-266.5 Lignite.

266.5-300 Claystone, silty, medium-g ay. 
Table 5. Physical properties and major-ion concentrations in water from wells

\section{Aqulfer code}

Pleistocene

112BDVL

Buried valley deposits

112BGFV

Buried glaciofluvial deposits

112HDLK

Hidden Lake aquifer

112NWTN New Town aquifer

112OTSH Outwash deposits

112SANISH Sanish aquifer

112SLCK

112TILL

112VANG

Shell Creek aquifer system

Till deposits

112WSLD White Shield aquifer

Paleocene

125 SNLB

Sentinel Butte Member of Fort Union Formation

125TGRV

Tongue River Member of Fort Union Formation

Cretaceous

211FXHL

Fox Hills Sandstone

$211 \mathrm{HCFH}$

Hell Creek Formation-Fox Hills Sandstone

\section{Abbrevlations and symbols}

$\mu \mathrm{S} / \mathrm{cm}$, microsiemens per centimeter at 25 degrees Celsius

$\mathrm{mg} / \mathrm{L}$, milligrams per liter

$<$, less than

,-- no data or not applicable 
$\ln$ IIII!? init?

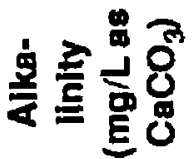

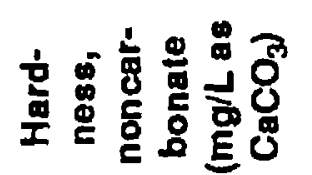

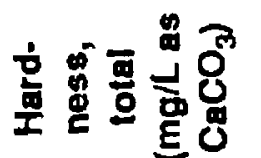

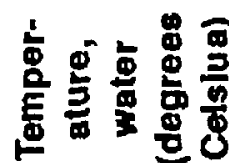

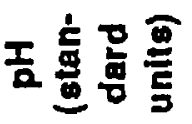

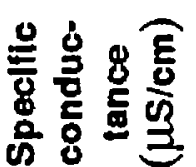

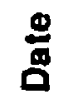
$\overline{0}$ 咅言要

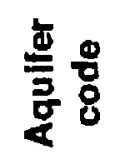
ह\$

\section{윢ํㅠㅁำ miูn}

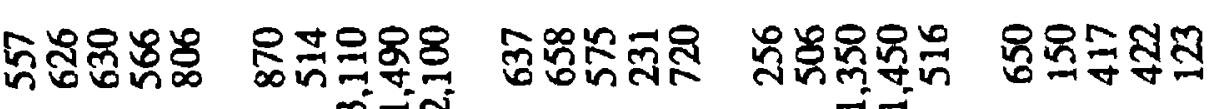

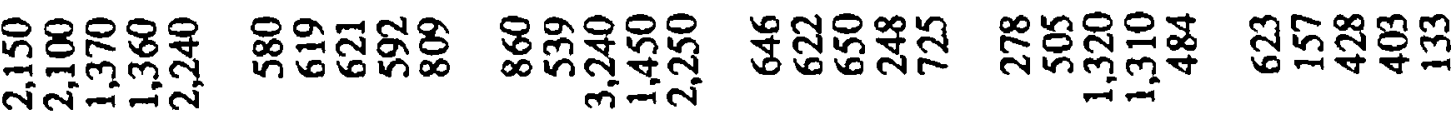

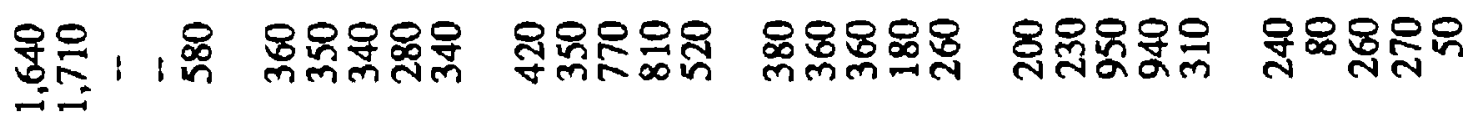

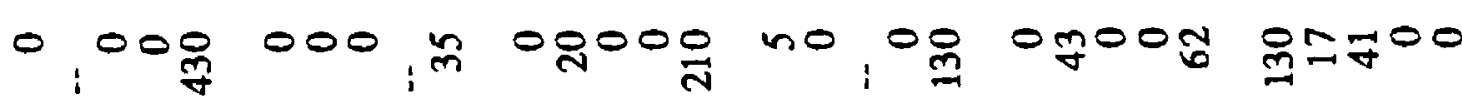

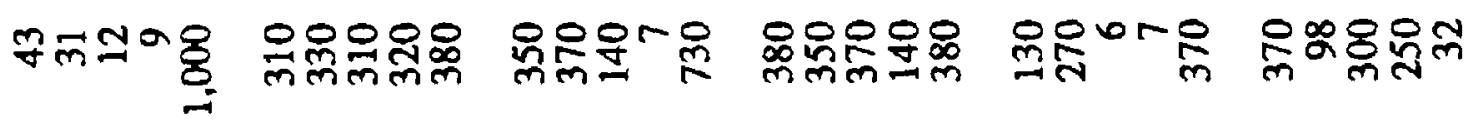

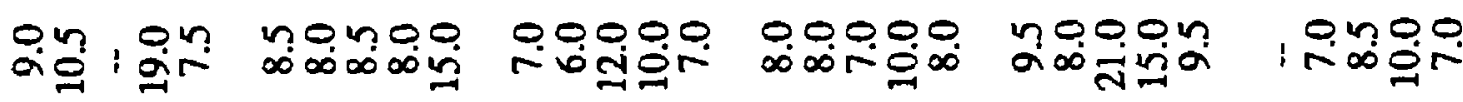

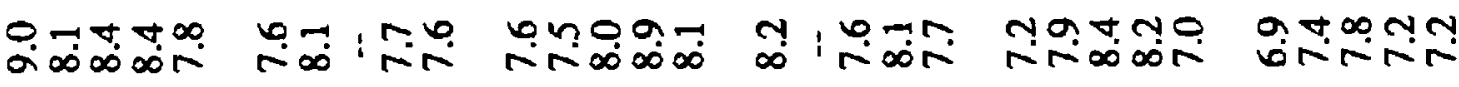

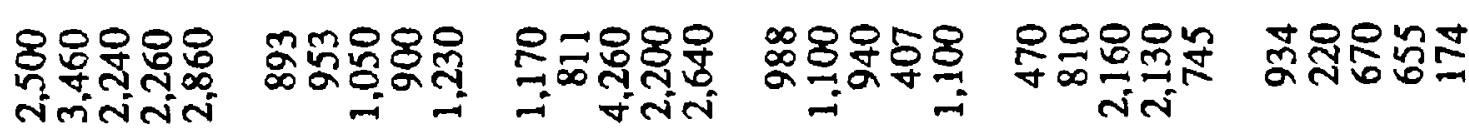

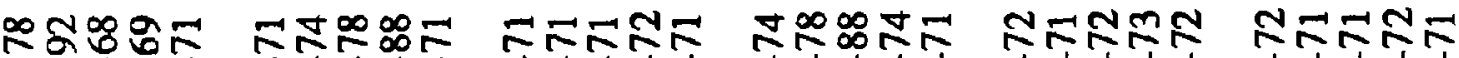

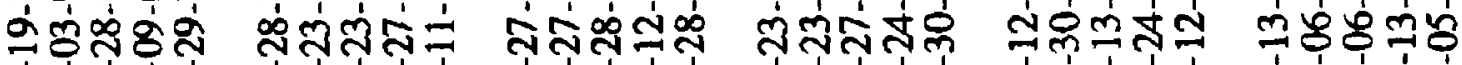

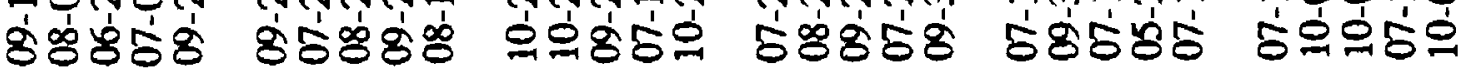

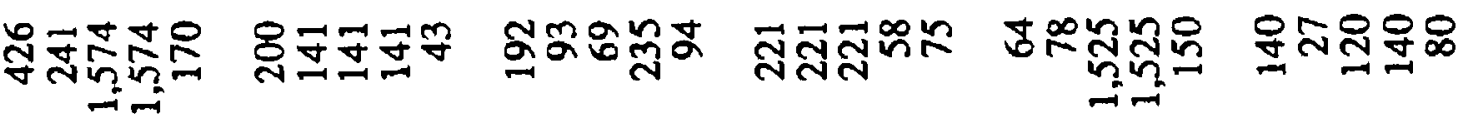

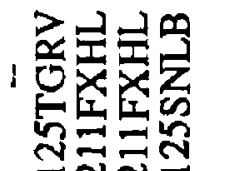

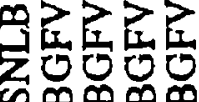

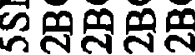
$\exists=\Xi$

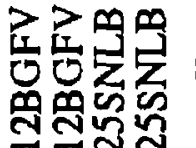
$= \pm$ I
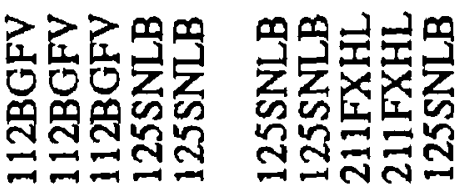

$m \infty m$

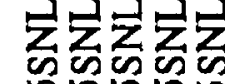
กูกูลู

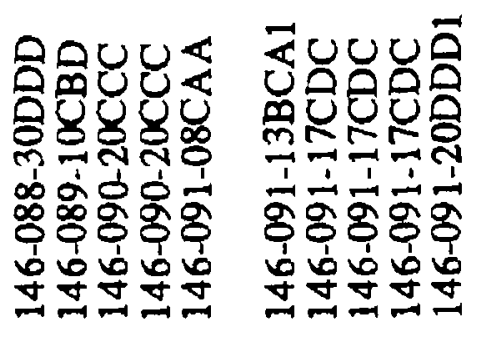

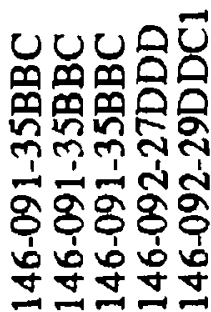

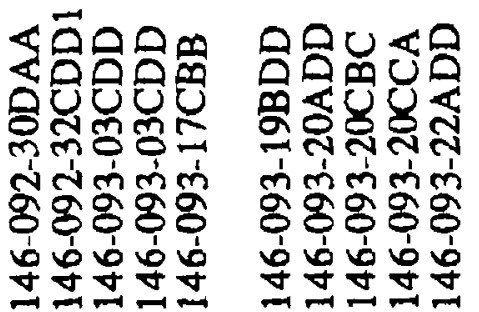




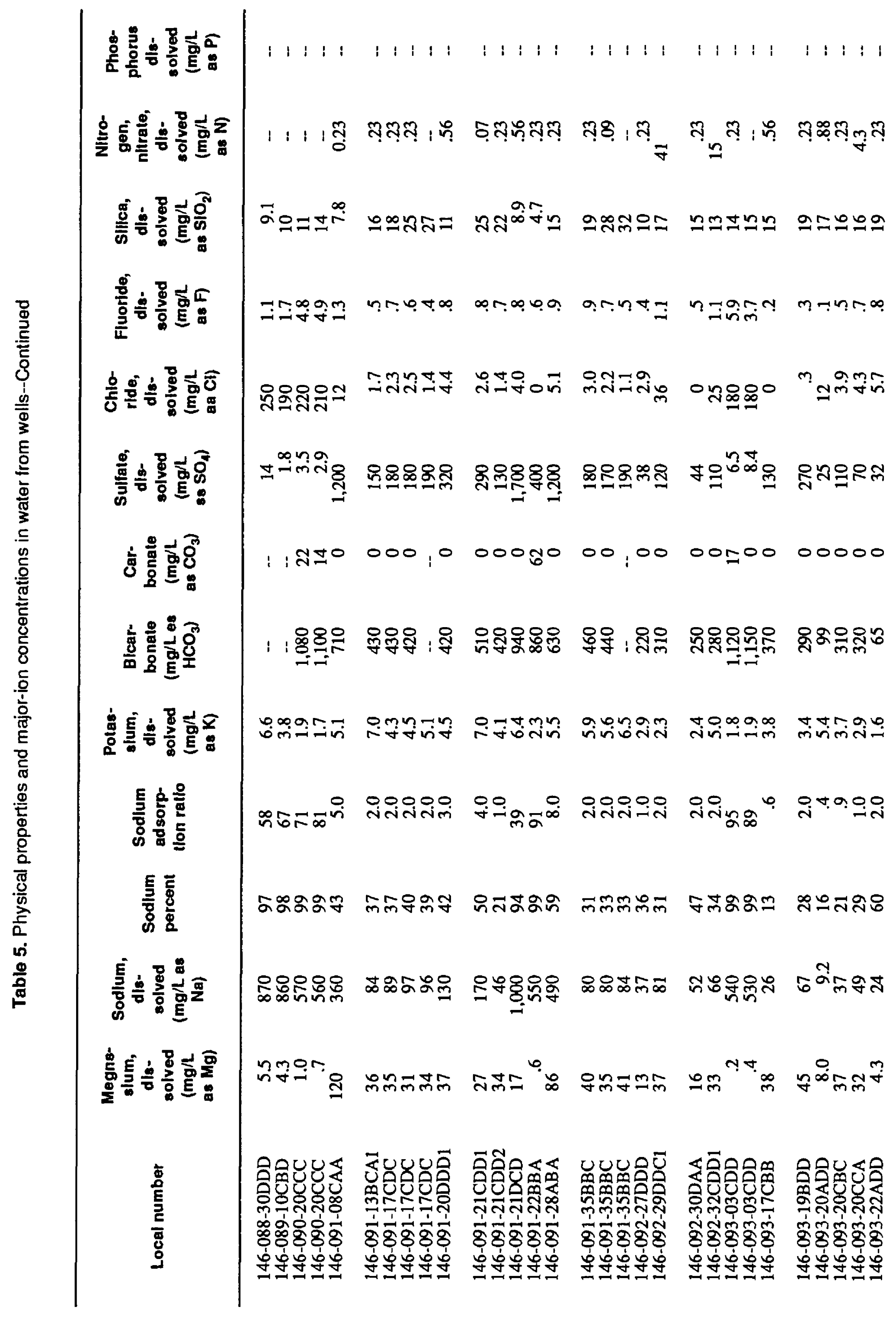




\begin{tabular}{|c|c|c|c|c|c|c|}
\hline 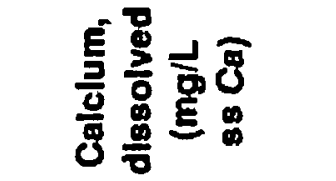 & 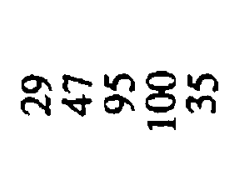 & 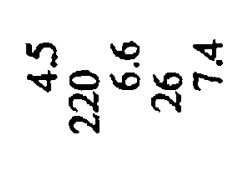 & ฌষ্ণী & 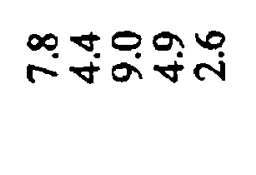 & 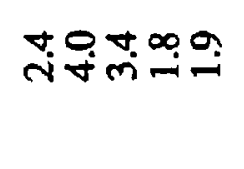 & 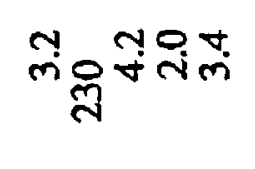 \\
\hline 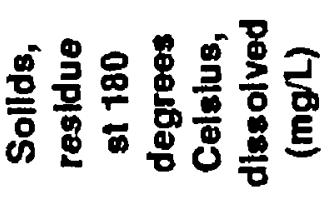 & 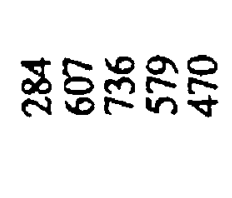 & 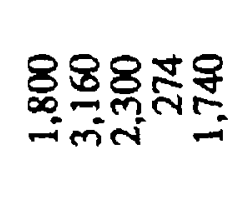 & 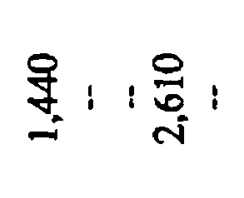 & 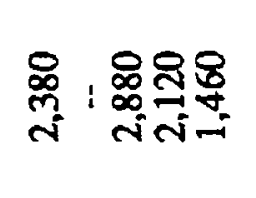 & 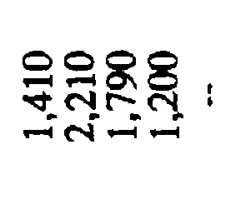 & 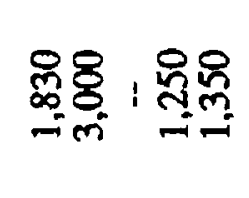 \\
\hline 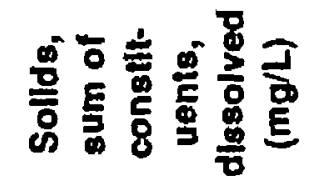 & 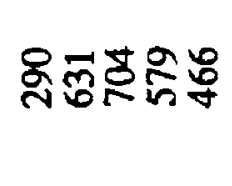 & 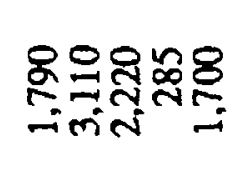 & 最是员要: & $\begin{array}{l}\text { 总 } \\
\text { N }\end{array}$ & 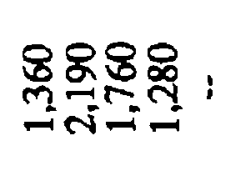 & 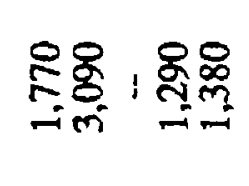 \\
\hline 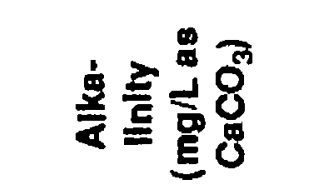 & 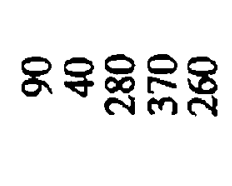 & 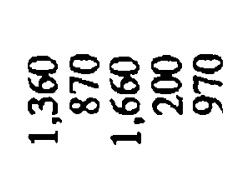 & : 1 & 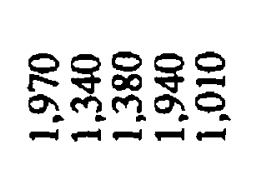 & 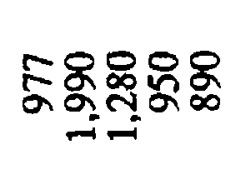 & 역유역영영 \\
\hline 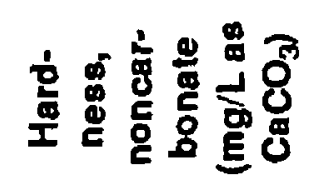 & 웅유웡 & 0,8000 & $\stackrel{\infty}{\sim}$ i & 0,000 & 0000 & $0 \%$ : \\
\hline 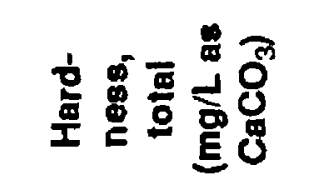 & 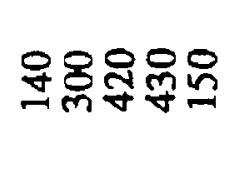 & 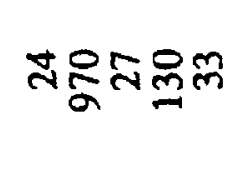 & 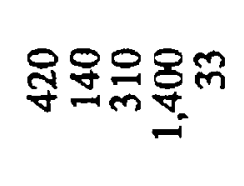 & mニロ & $a \pi \boxplus \infty$ & 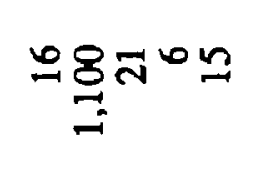 \\
\hline 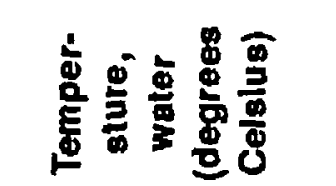 & nninoo: & 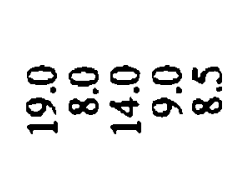 & 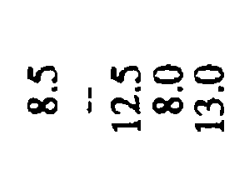 & $m=12 n$ & ํํㅇ & 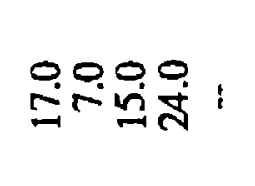 \\
\hline 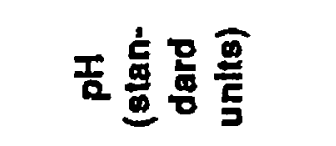 & 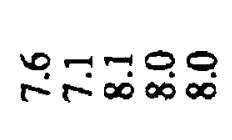 & 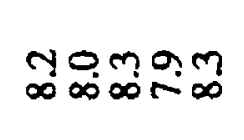 & 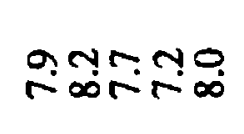 & तुलित्र & 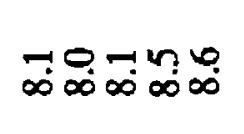 & 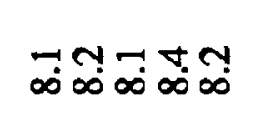 \\
\hline 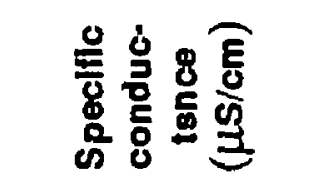 & 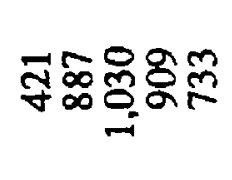 & 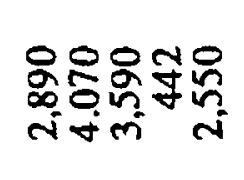 & $\begin{array}{l}\text { 애영애 } \\
\text { inminm }\end{array}$ & 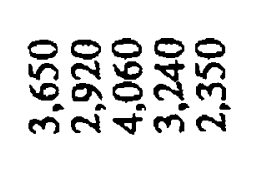 & 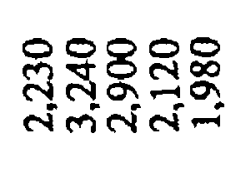 & 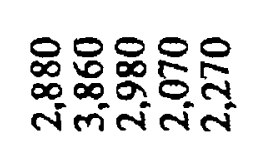 \\
\hline$\stackrel{0}{\mathrm{~g}}$ & 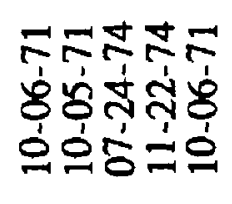 & 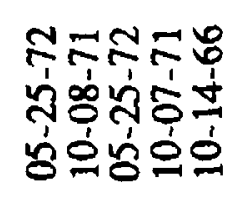 & 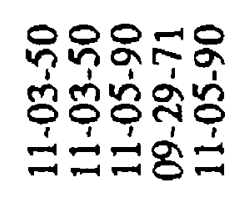 & 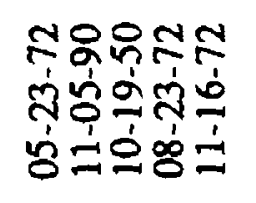 & 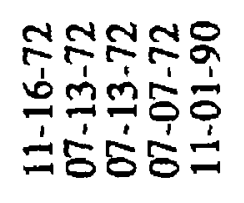 & 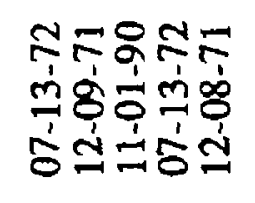 \\
\hline 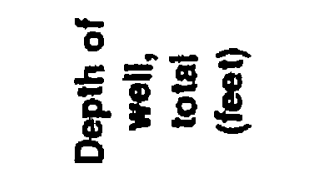 & உロ유 & 영정요 & ถูกสูปร & 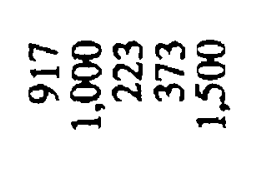 & 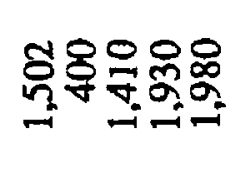 & 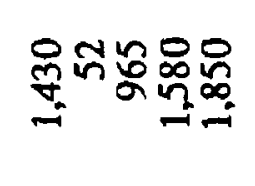 \\
\hline 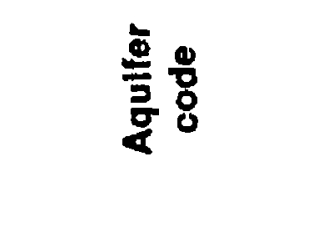 & 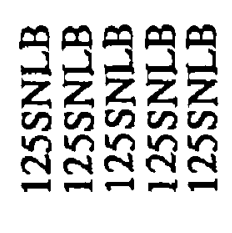 & 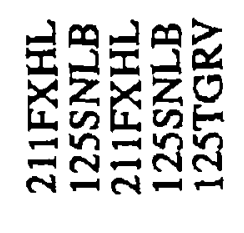 & 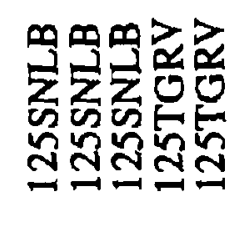 & 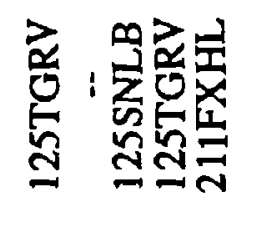 & 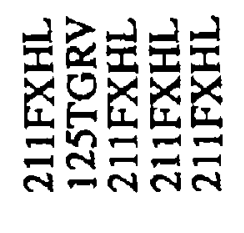 & 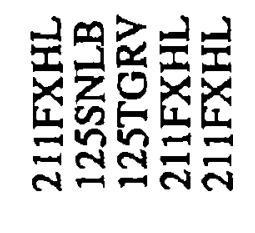 \\
\hline 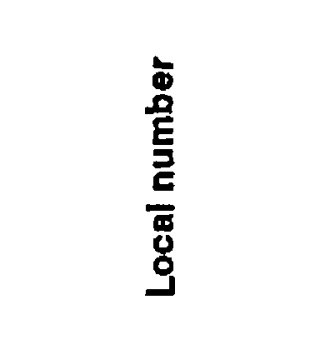 & 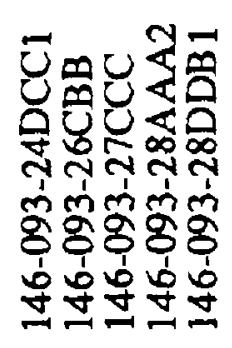 & 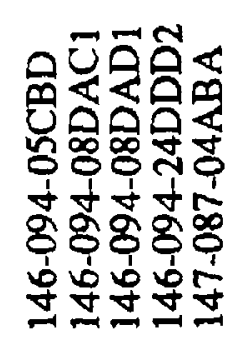 & 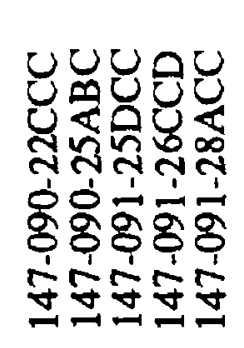 & 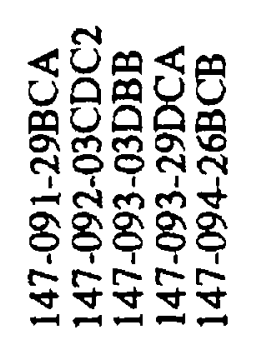 & 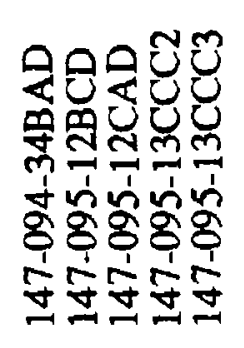 & 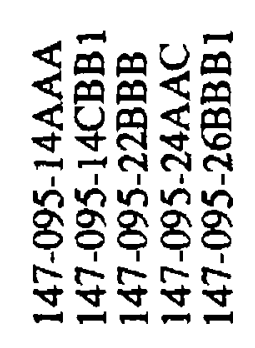 \\
\hline
\end{tabular}




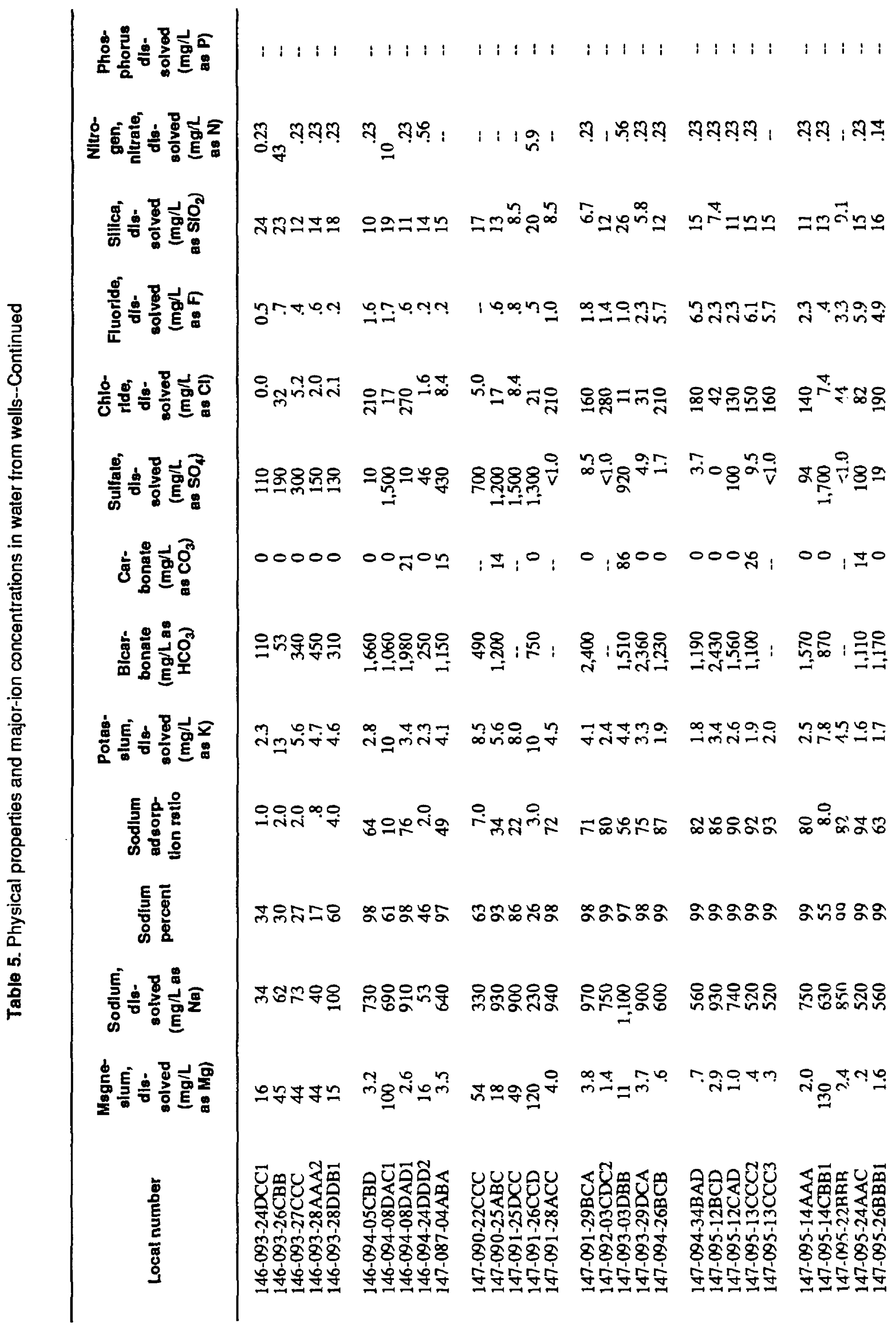




\begin{tabular}{|c|c|c|c|c|c|c|}
\hline 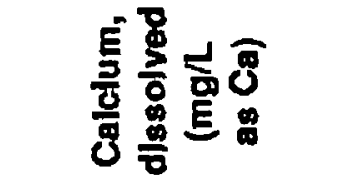 & 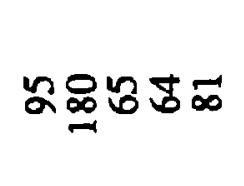 & 뭉ำำ & 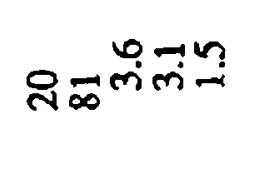 & miñ & gånơ⿱ & $\hat{\alpha}_{\infty}=88$ \\
\hline 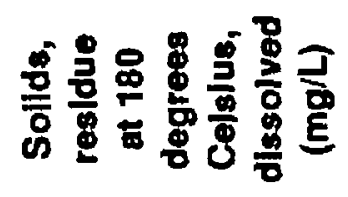 & ผำ & 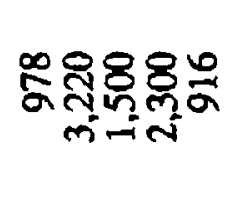 & 응 : : : & $1: 8 \begin{array}{c}8 \\
\text { (1) }\end{array}$ & 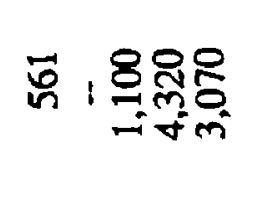 & 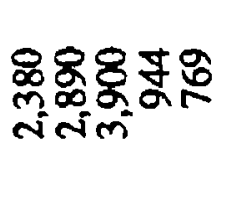 \\
\hline 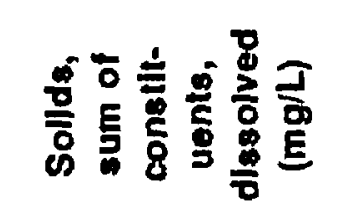 & 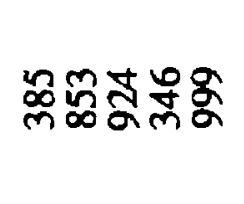 & 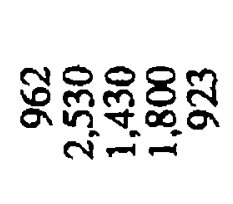 & 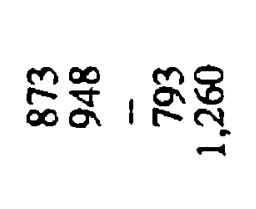 & 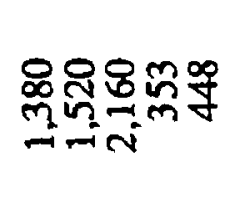 & 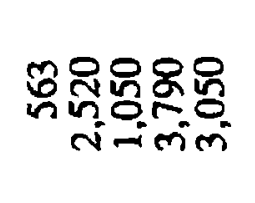 & 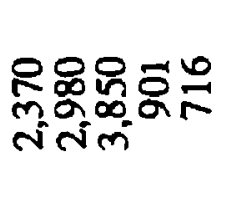 \\
\hline 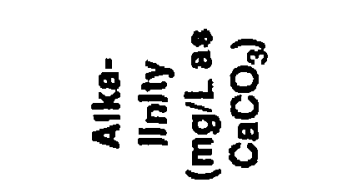 & $1:$ : & : & 양욤 : 일: & 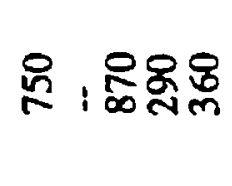 & 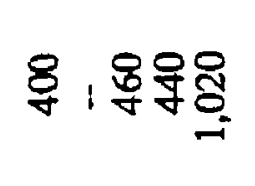 & \\
\hline 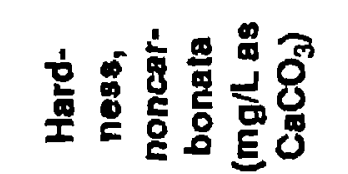 & $\pi, 090$ & 8000 & 00,11 & & 0 : $\frac{0.00}{2}$ & $000 \xi$ \\
\hline 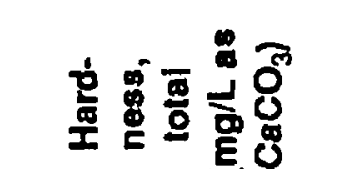 & 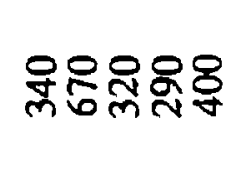 & 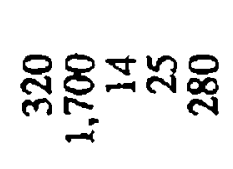 & 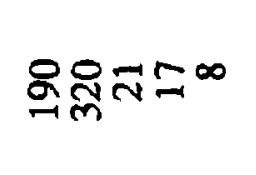 & 푬요 & 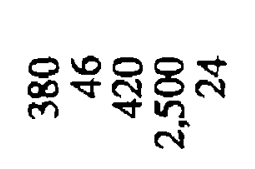 & 闹 \\
\hline 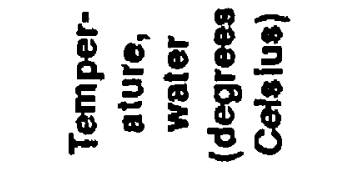 & no & 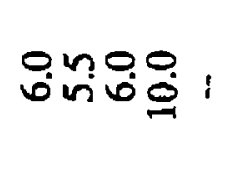 & 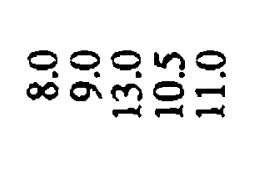 & 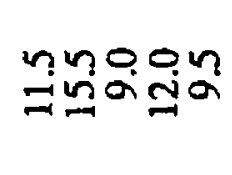 & ñ. & 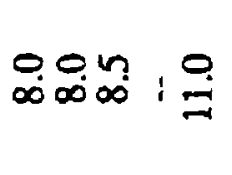 \\
\hline 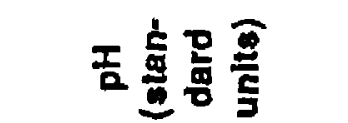 & 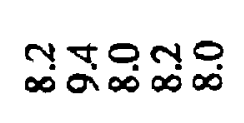 & 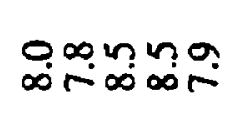 & 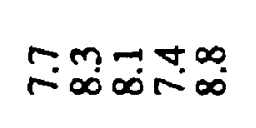 & 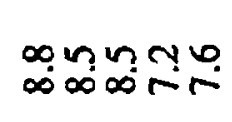 & minotid & $\begin{array}{l}\infty \rightarrow 0 \\
\infty \\
\infty\end{array}$ \\
\hline 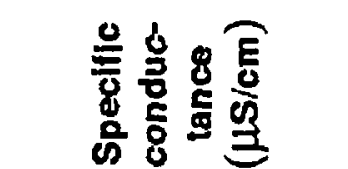 & 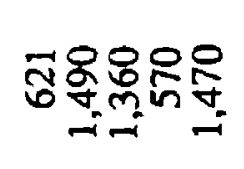 & 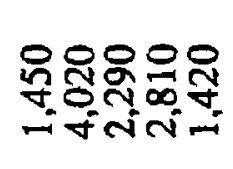 & 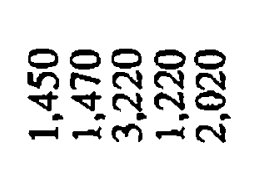 & 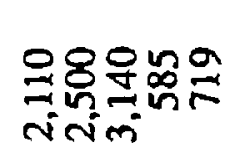 & 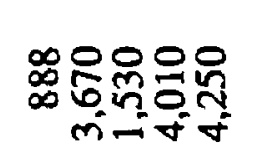 & 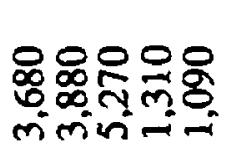 \\
\hline$\stackrel{\circ}{\square}$ & 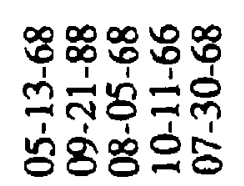 & 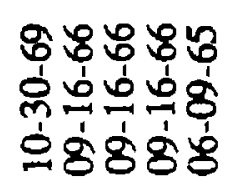 & 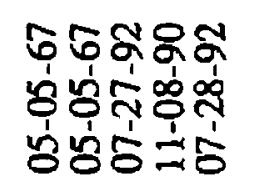 & 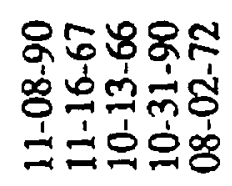 & 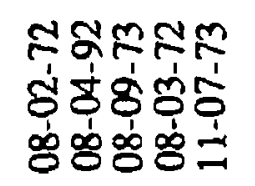 & 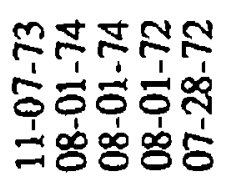 \\
\hline 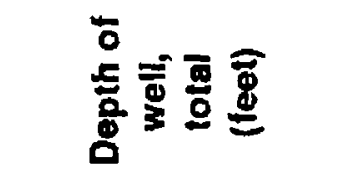 & 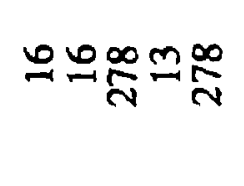 & 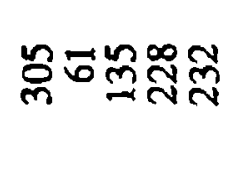 & 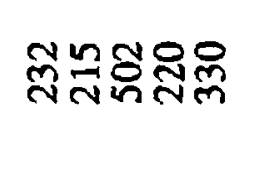 & 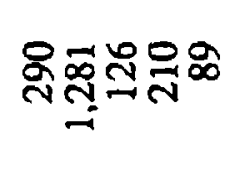 & ๙ & 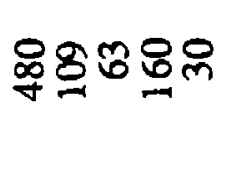 \\
\hline$\frac{5}{5}$ & 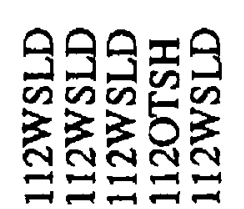 & 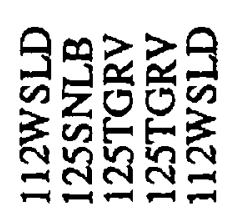 & 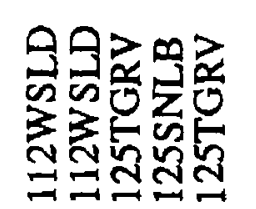 & 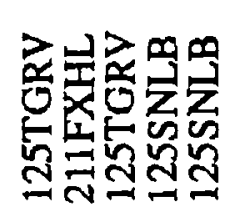 & 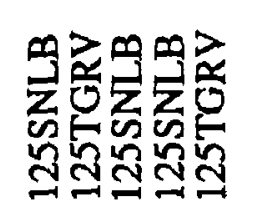 & 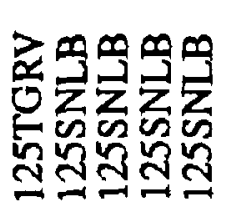 \\
\hline 总 & 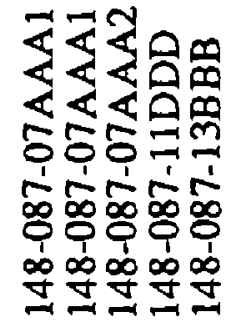 & 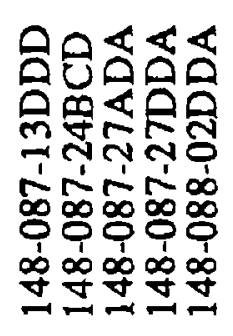 & 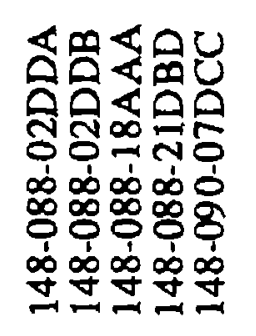 & 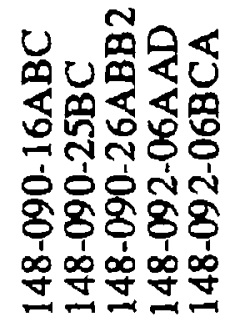 & 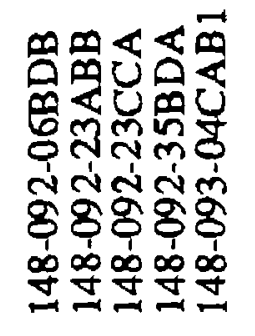 & 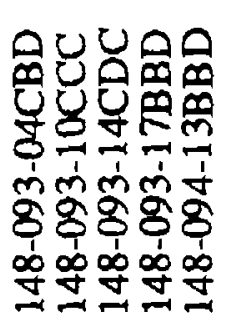 \\
\hline
\end{tabular}




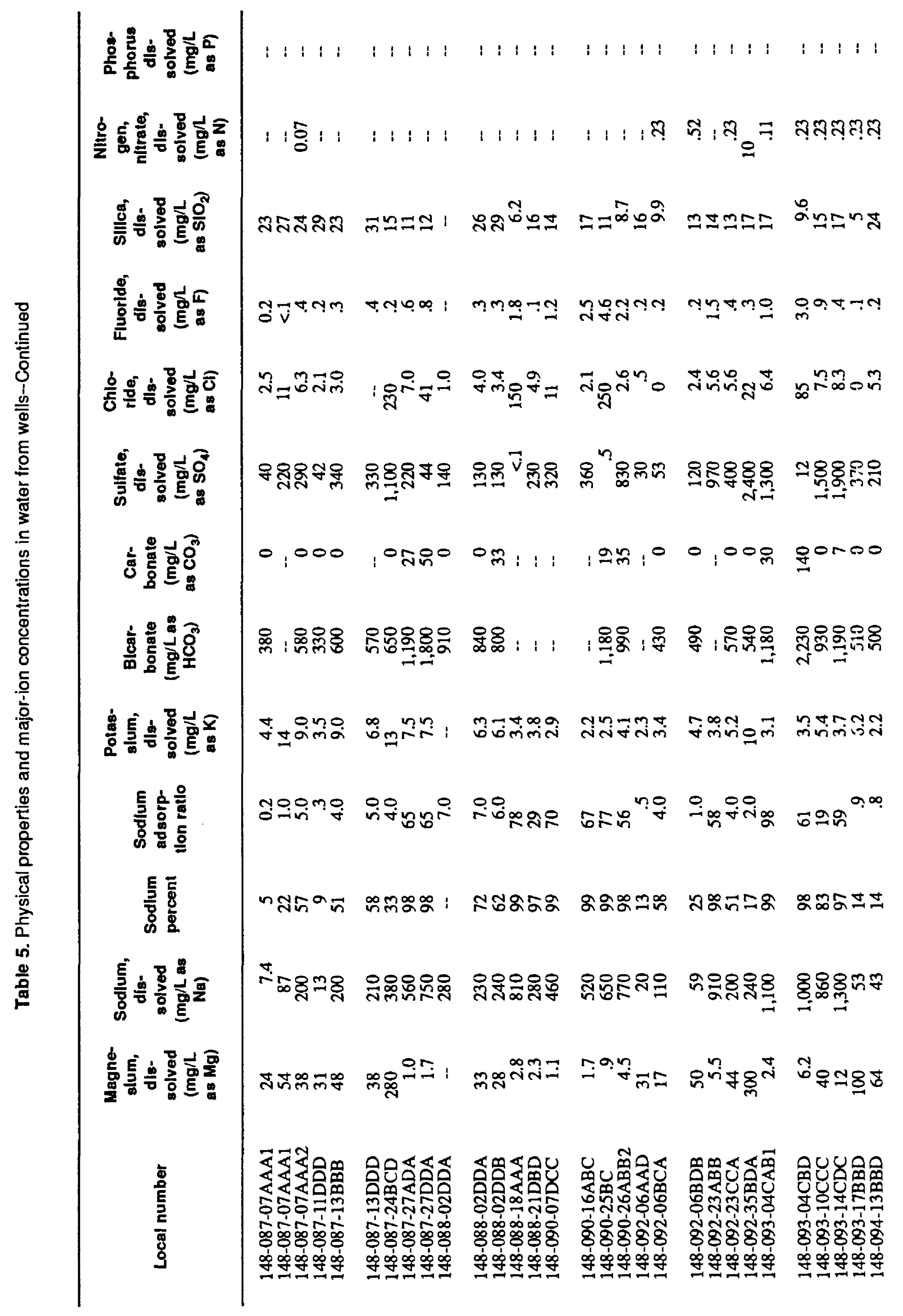




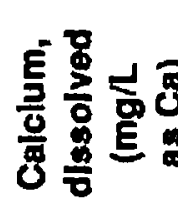

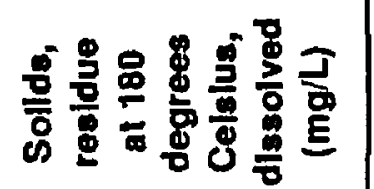

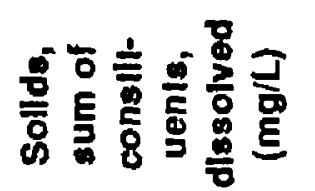

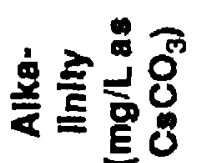

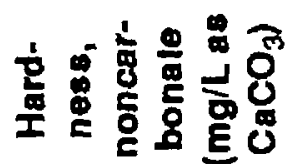

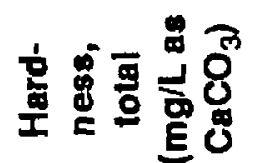

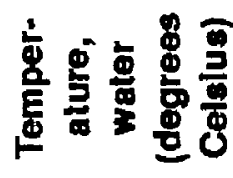

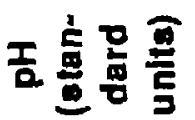

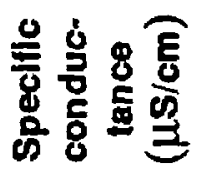

$\stackrel{9}{\mathrm{D}}$

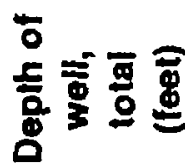

高 :

홍

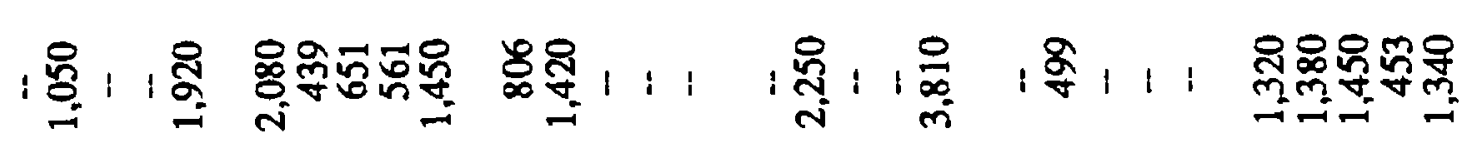

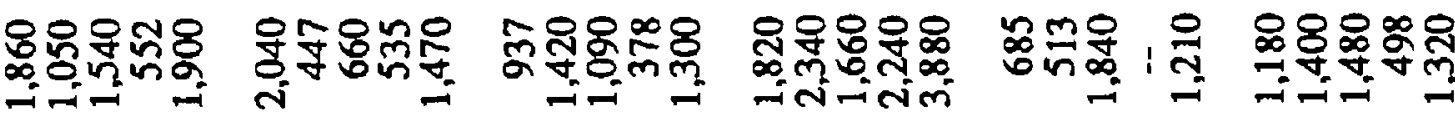

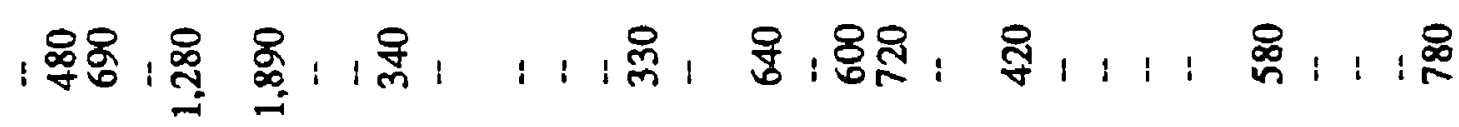

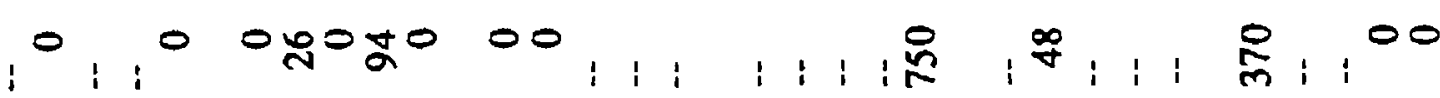

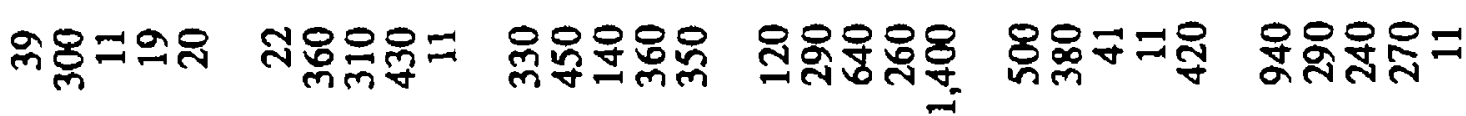

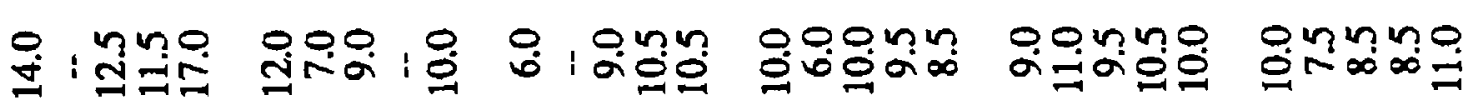

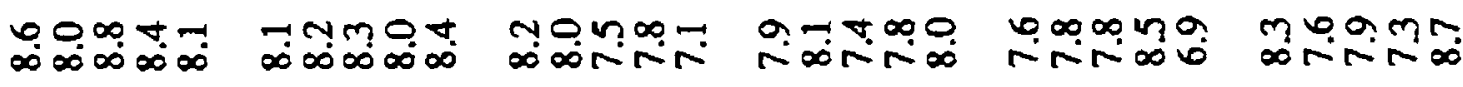

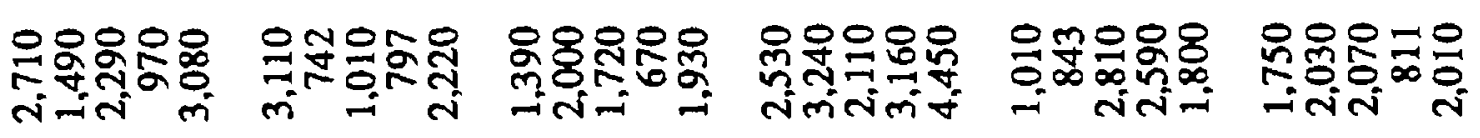

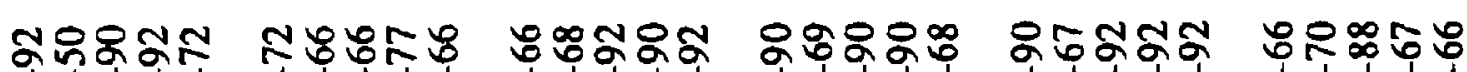

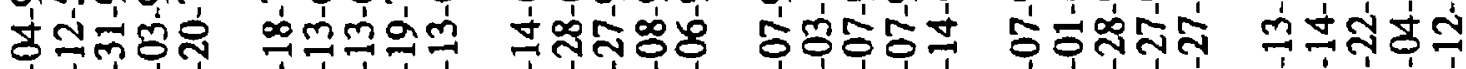

ஆ웡ㅇㅇㅇ

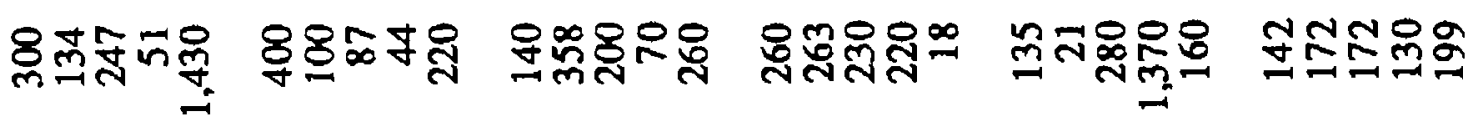

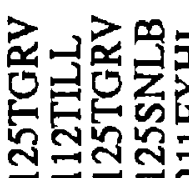

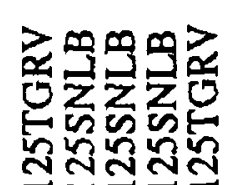

触最

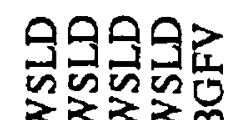

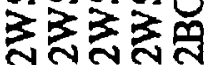

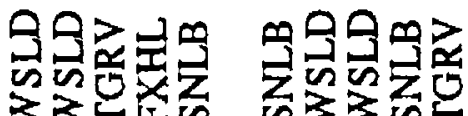

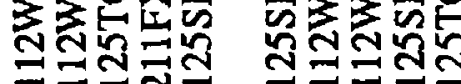

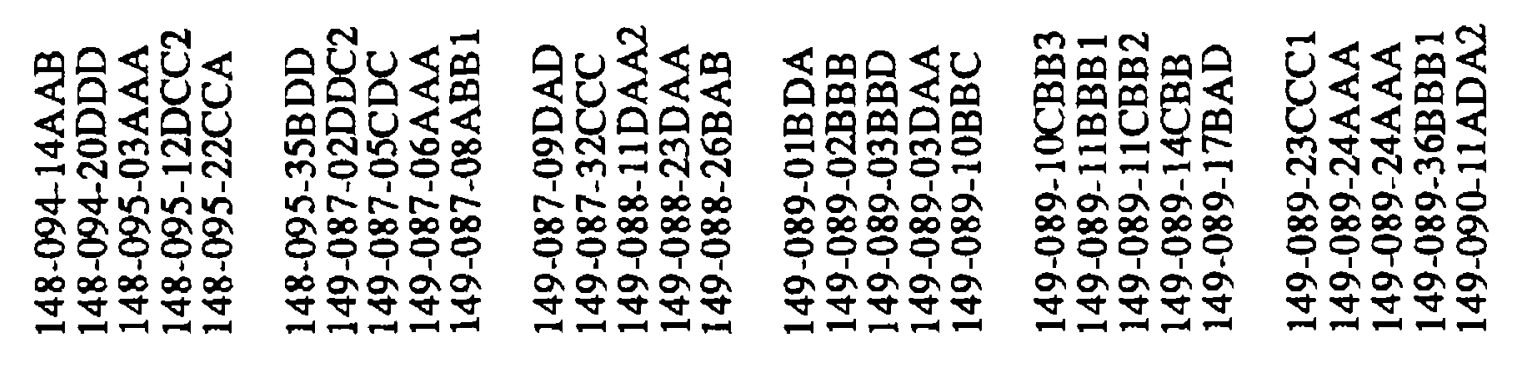




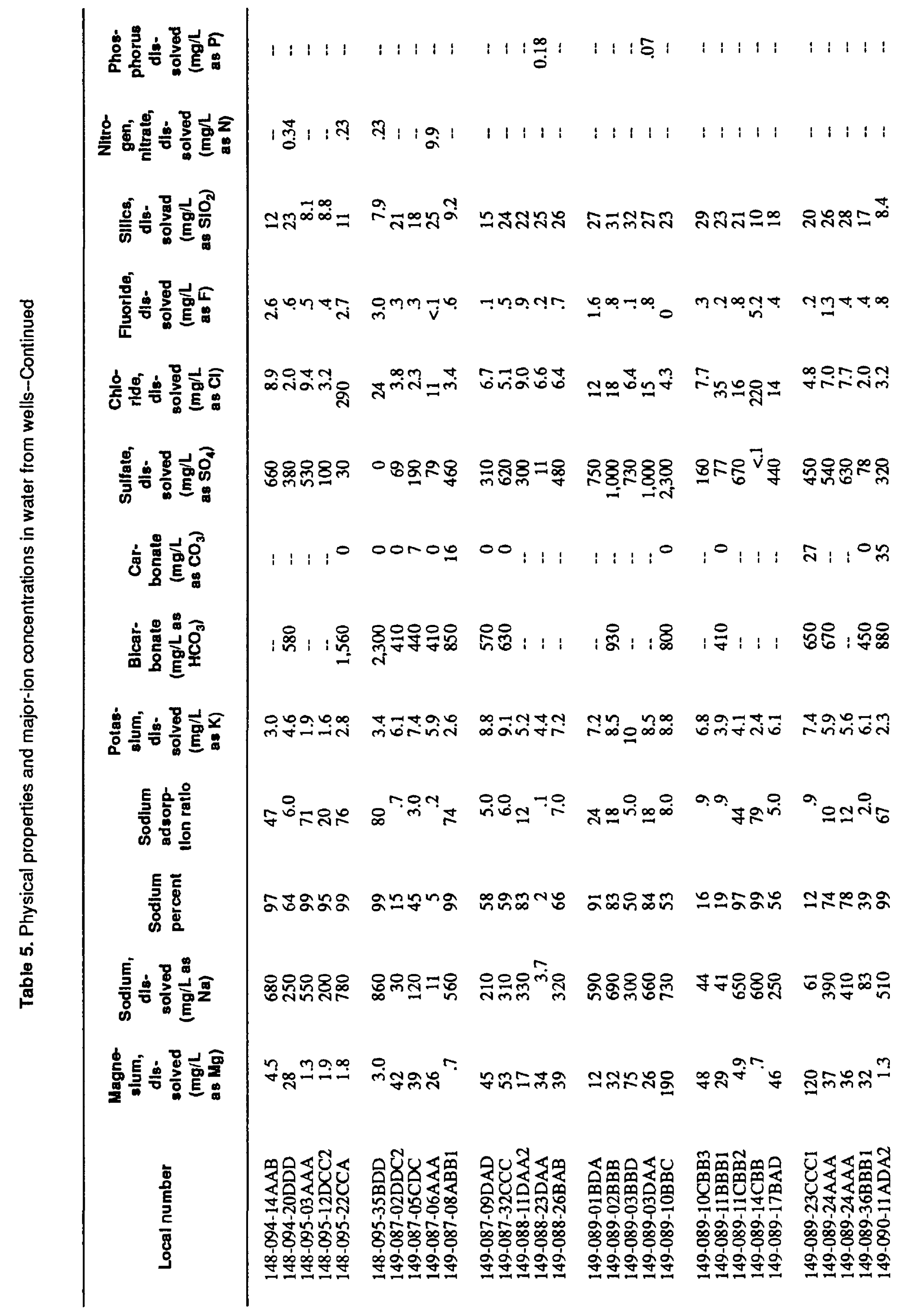




\begin{tabular}{|c|c|c|c|c|c|c|}
\hline 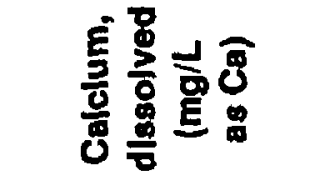 & 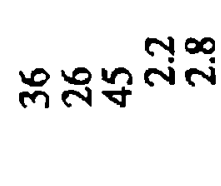 & 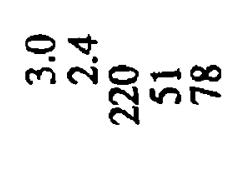 & $3906^{n}$ & 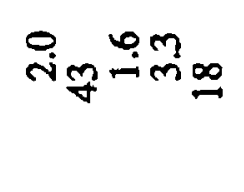 & 윰요용 & ஜสㅊ융 \\
\hline 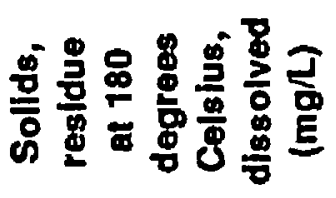 & 1158 & 旁 & 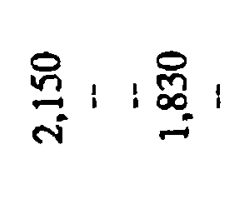 & 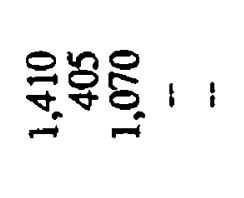 & 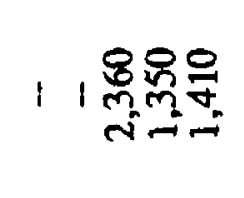 & : \\
\hline 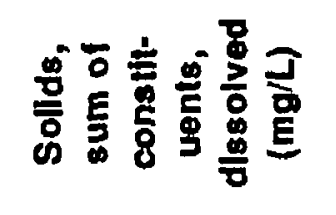 & 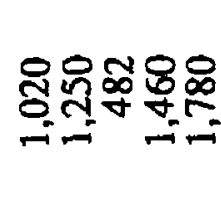 & 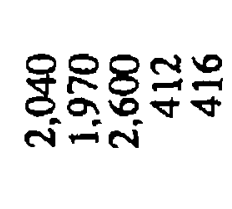 & 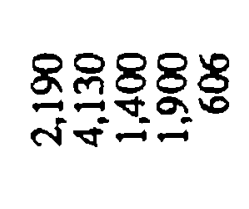 & 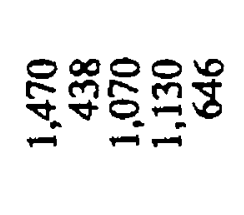 & 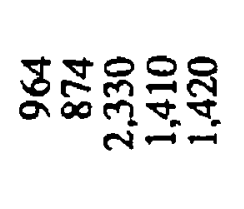 & 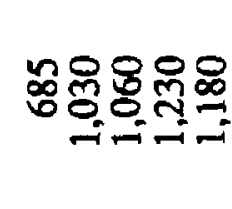 \\
\hline 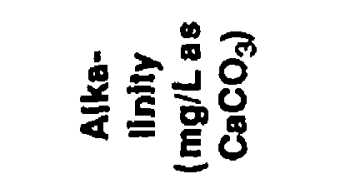 & : : 유양영 & 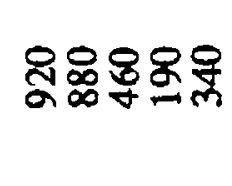 & $\stackrel{0}{0} 11: \stackrel{0}{\circ}$ & i & 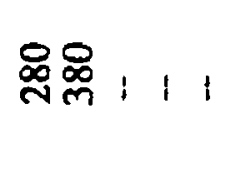 & 品1: 揭总 \\
\hline 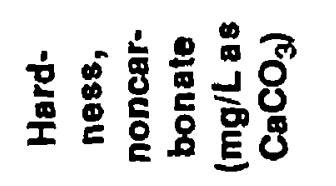 & $11^{000}$ & - & $0: 1: 1$ & $i^{\infty}: 1$ & $::^{0} i:$ & $: 1::$ \\
\hline 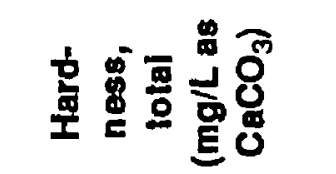 & 응윰유 조 & 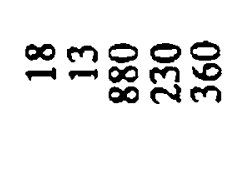 & 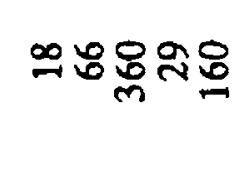 & 엇 용 & 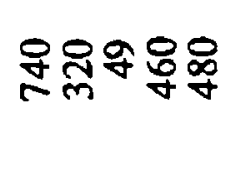 & 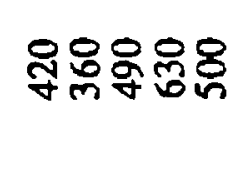 \\
\hline 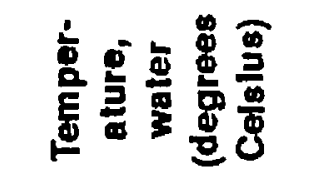 & n.0.000. & 学: & 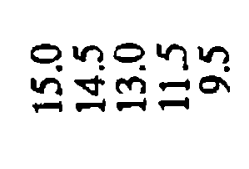 & 영 : & 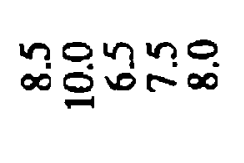 & noon \\
\hline 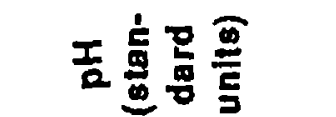 & mand & 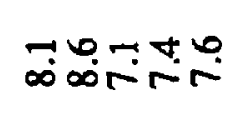 & 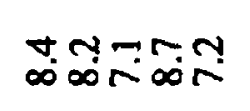 & : min & 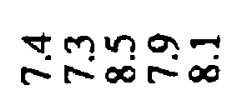 & $\stackrel{m}{\sim}: 0.00$ \\
\hline 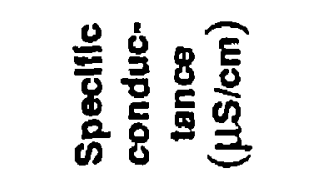 & 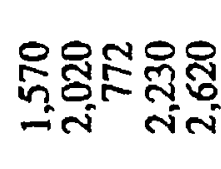 & $\begin{array}{l}\text { 융응 } \\
\text { miñ }\end{array}$ & 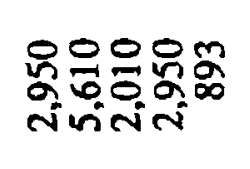 & 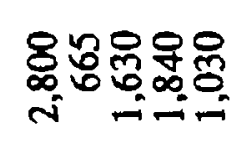 & 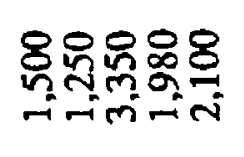 & 홍용요 \\
\hline$\stackrel{\text { ğ }}{\mathrm{a}}$ & 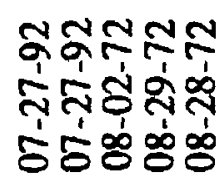 & 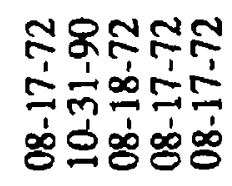 & 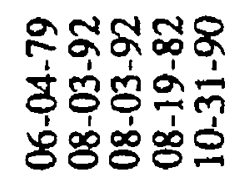 & 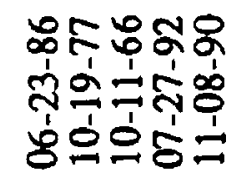 & 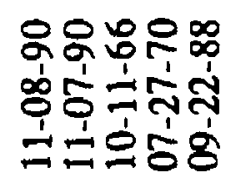 & 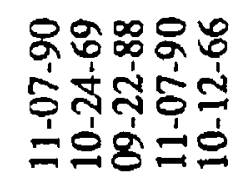 \\
\hline 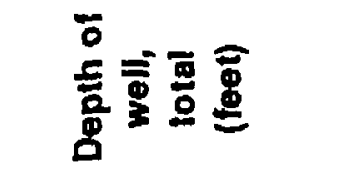 & $\stackrel{\circ}{=}$ \& & 象车的的 & 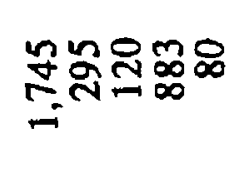 & క్ర్య & 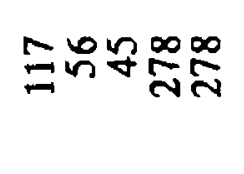 & 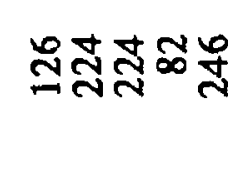 \\
\hline 离苋 & 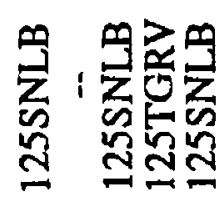 & 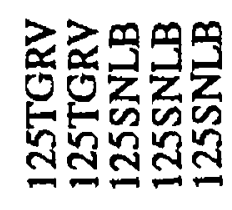 & 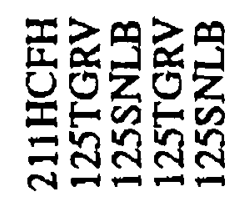 & 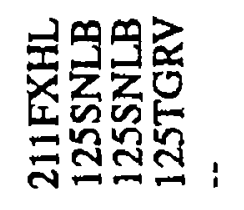 & 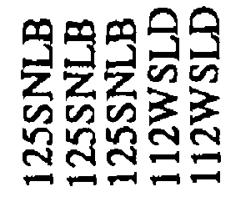 & 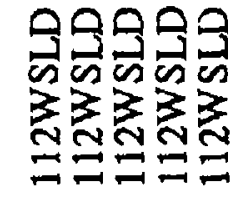 \\
\hline 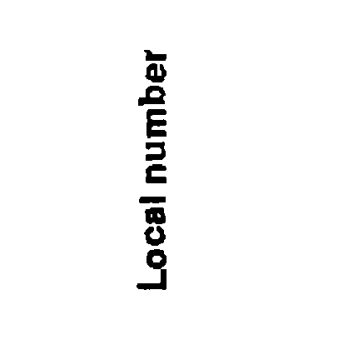 & 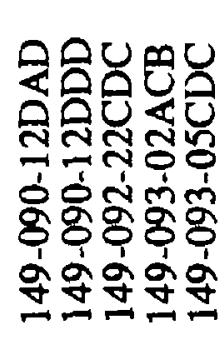 & 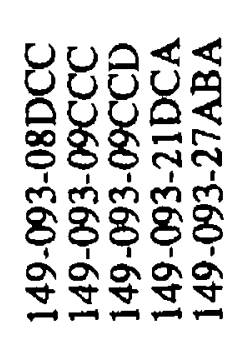 & 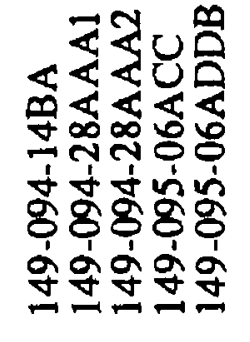 & 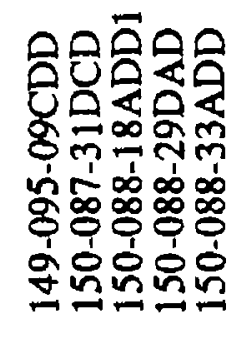 & 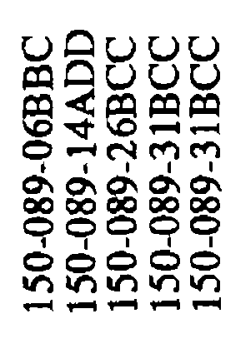 & 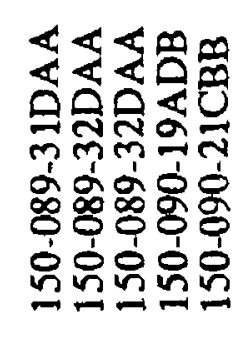 \\
\hline
\end{tabular}




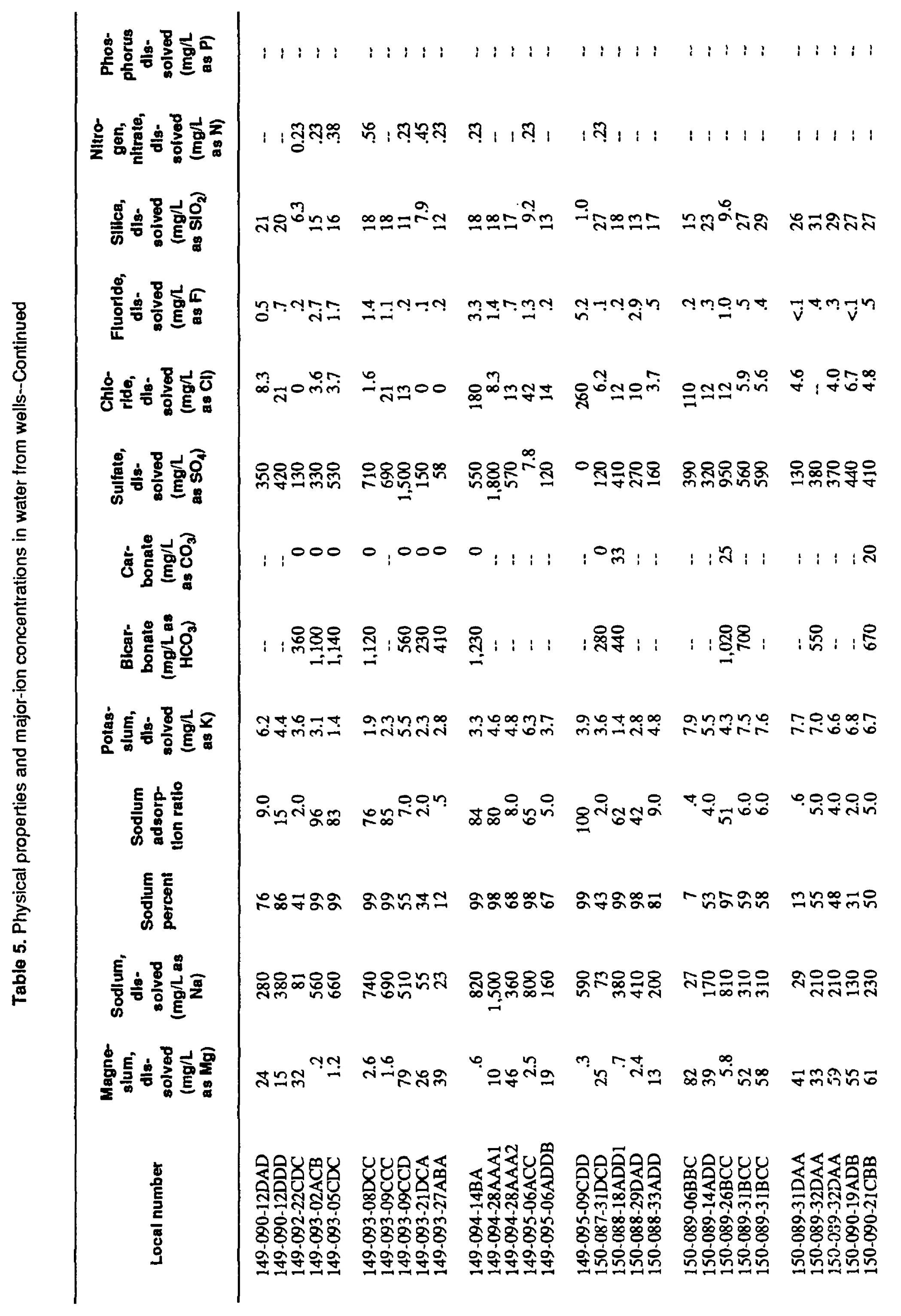




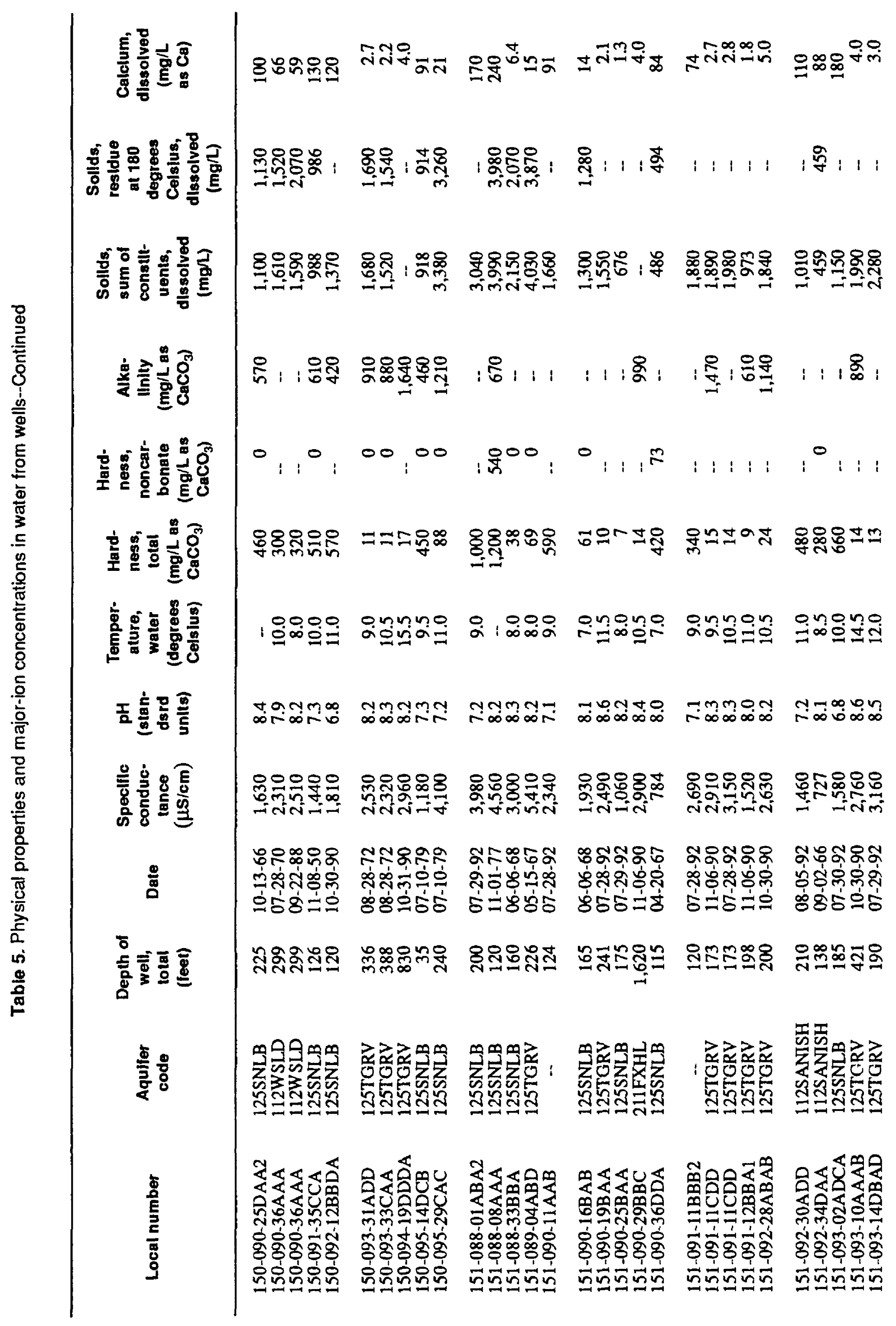




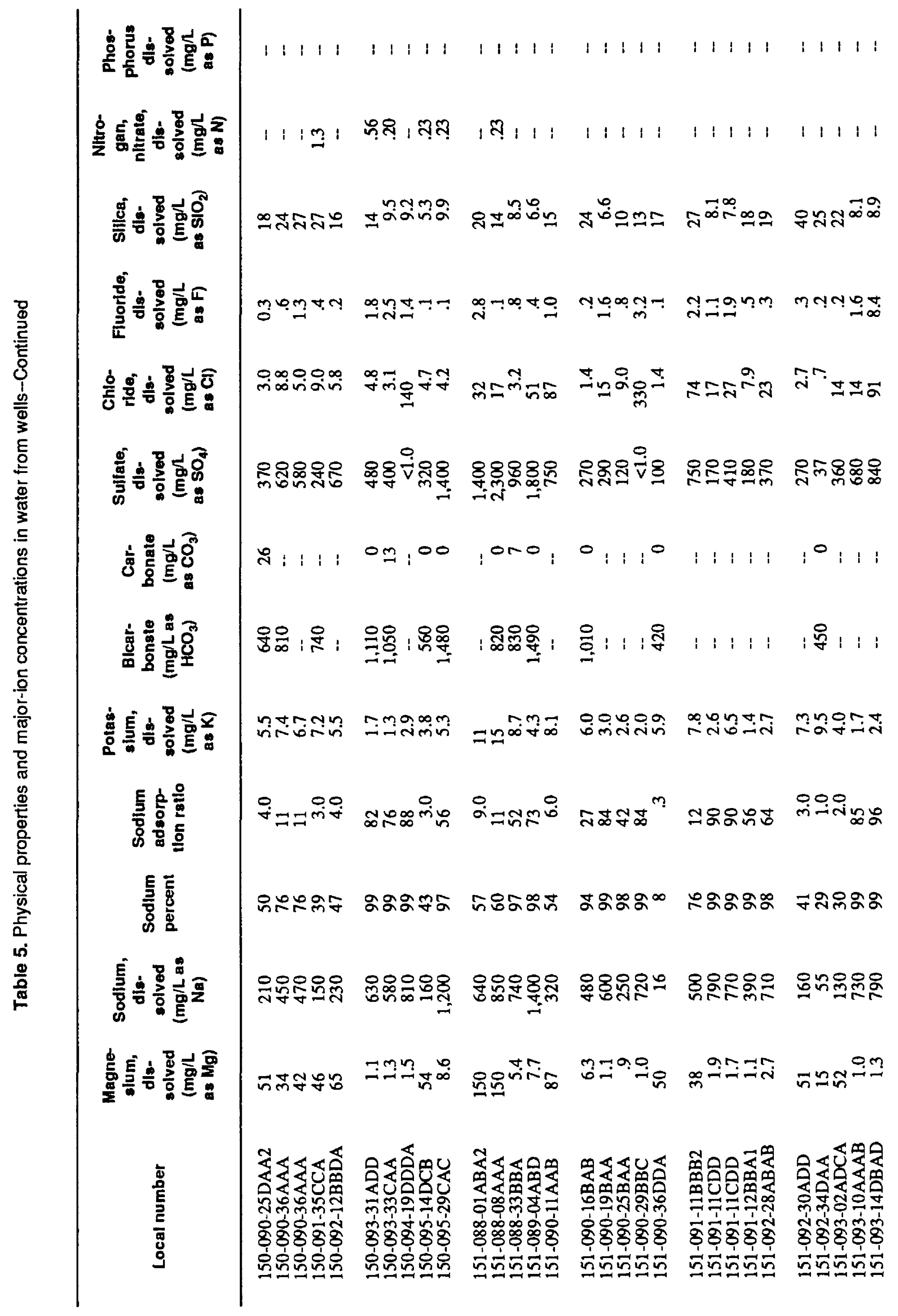




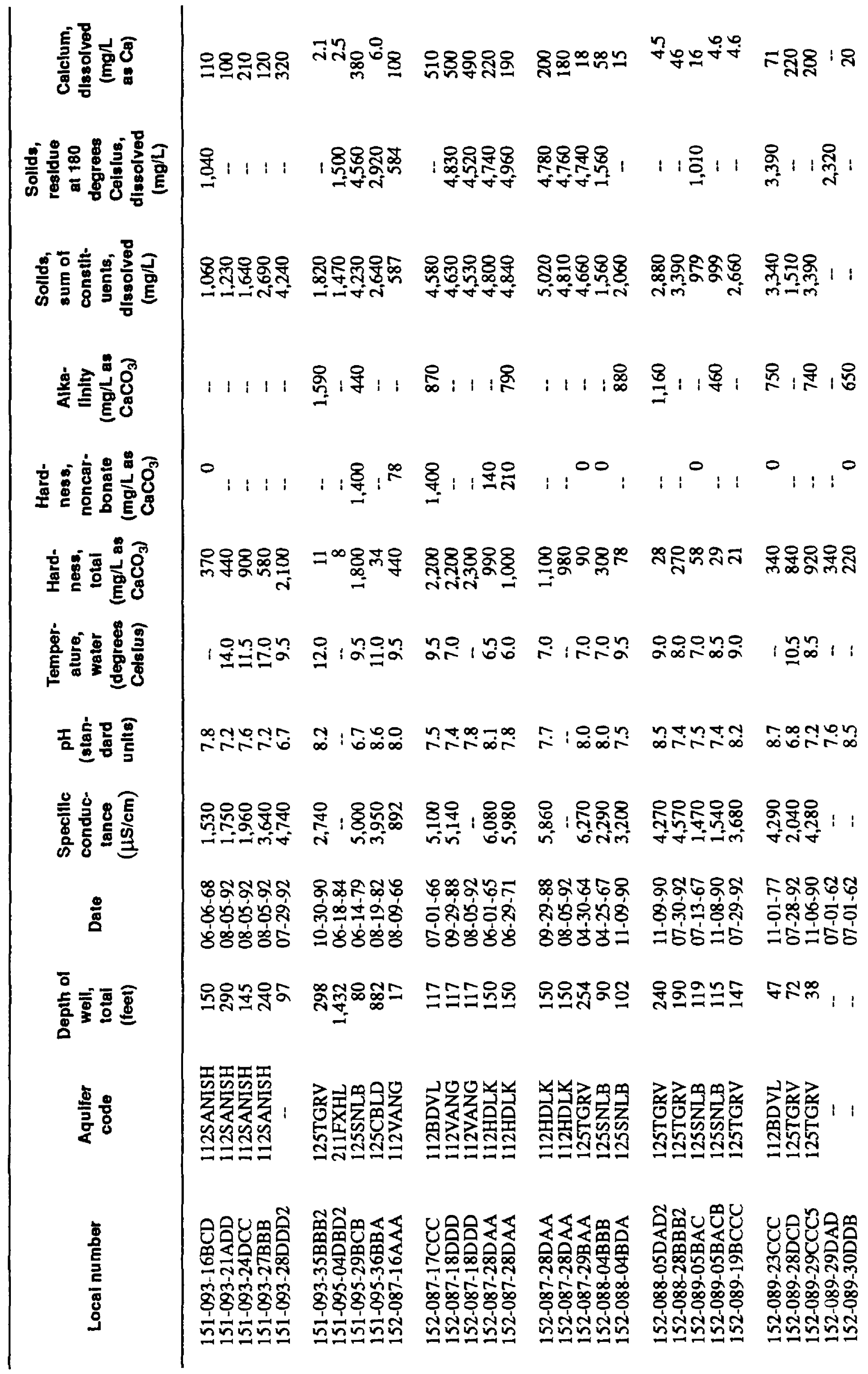




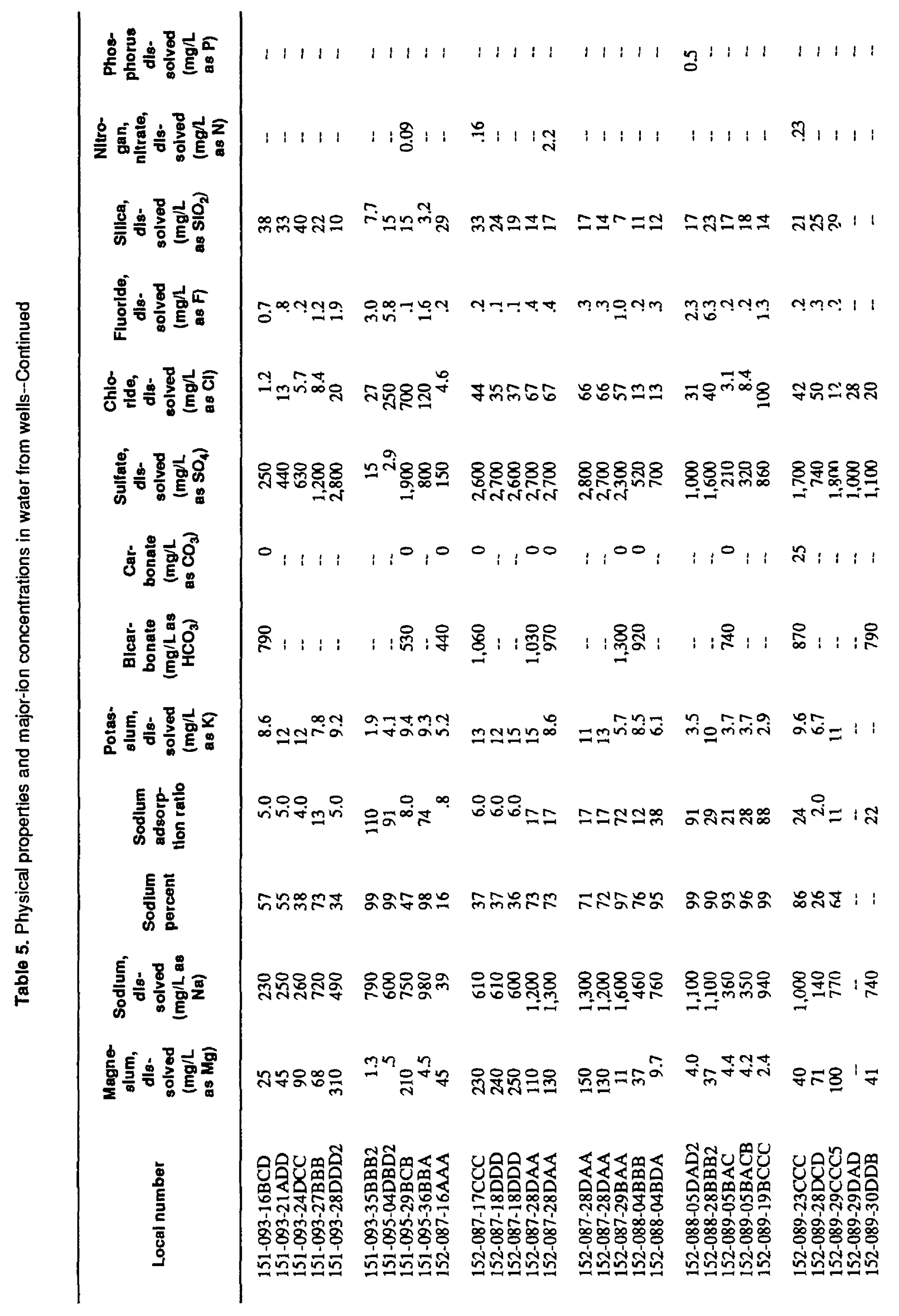




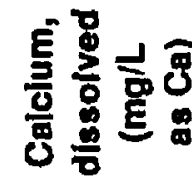

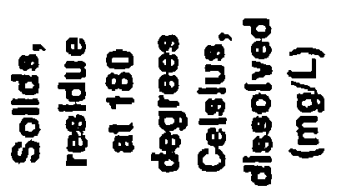

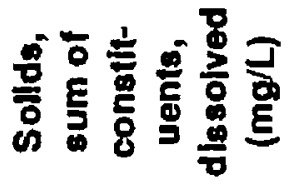

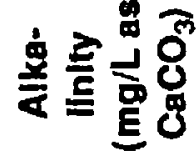

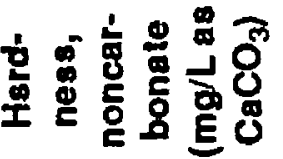

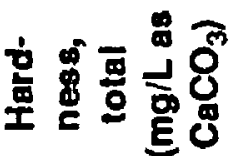

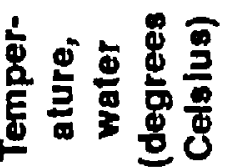
吉畜 总

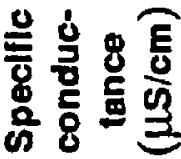
$\stackrel{\mathscr{\Xi}}{\Delta}$ 立言产 产苛

兽

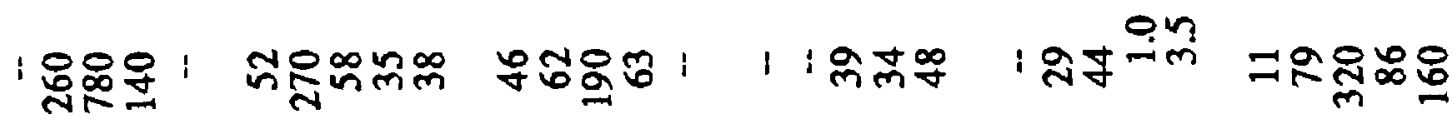

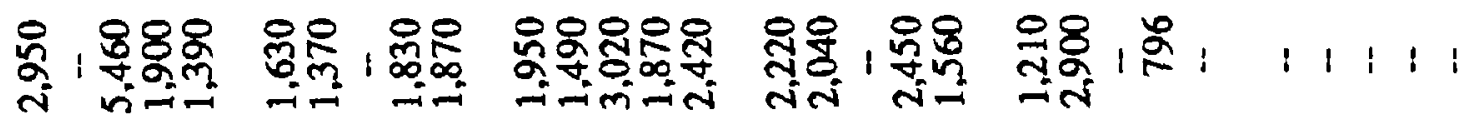

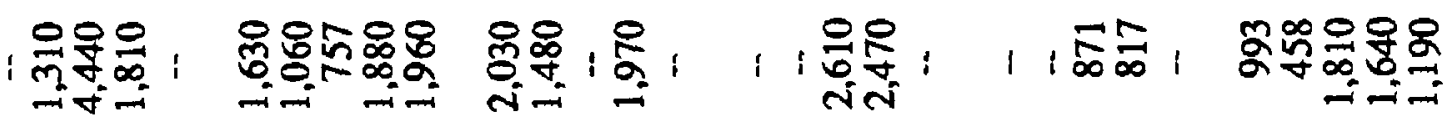

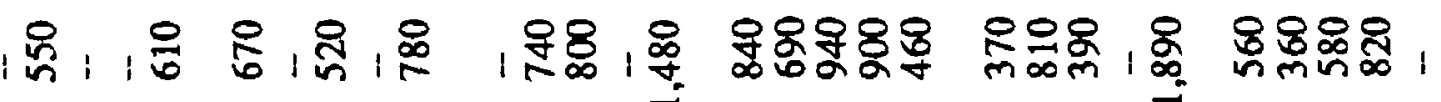

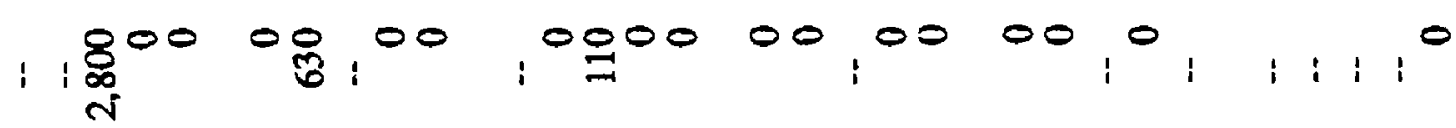

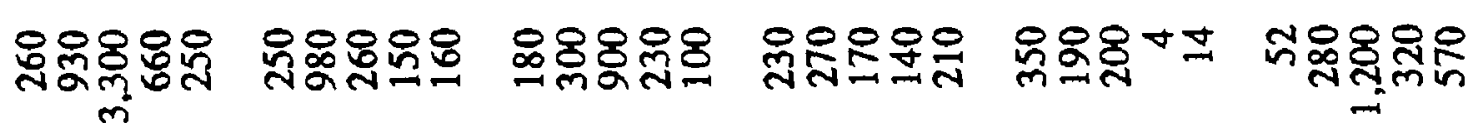

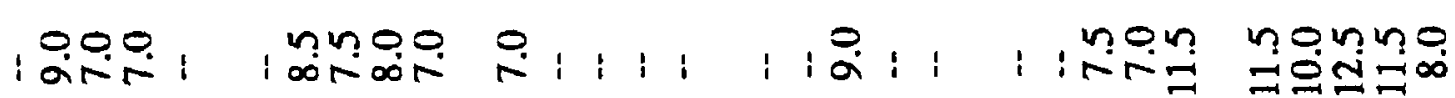

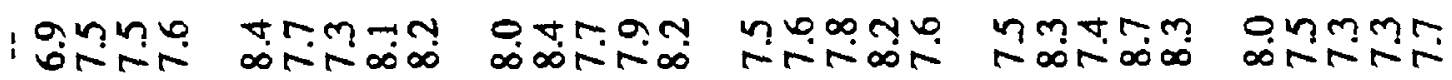

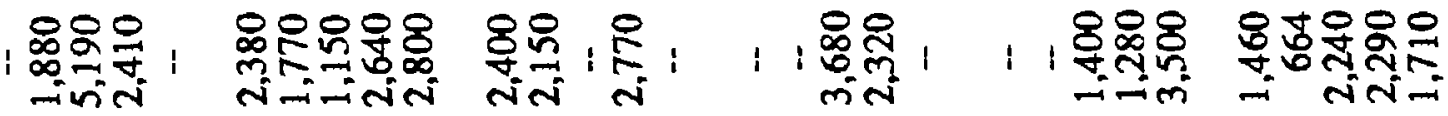

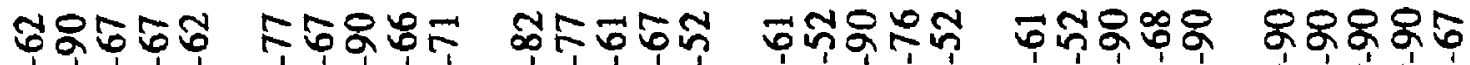

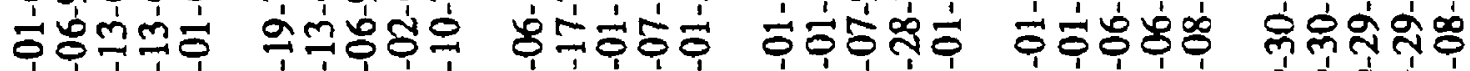

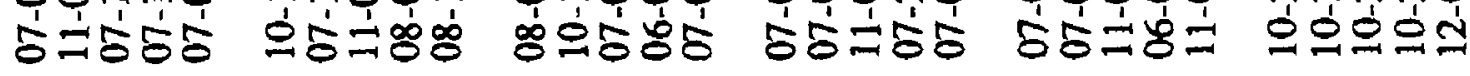

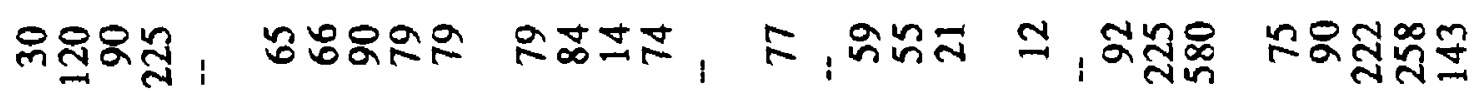

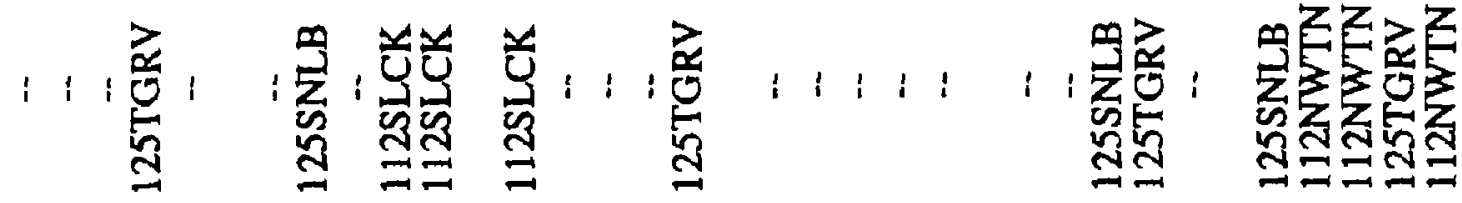

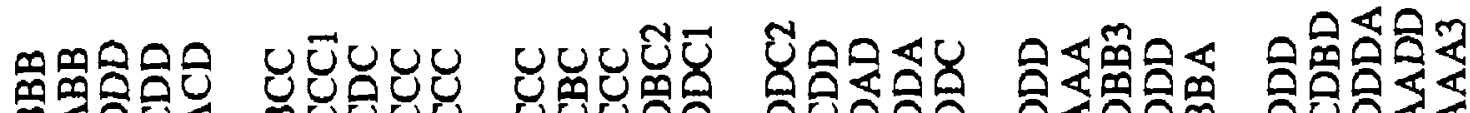

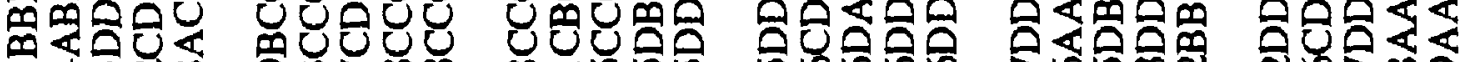

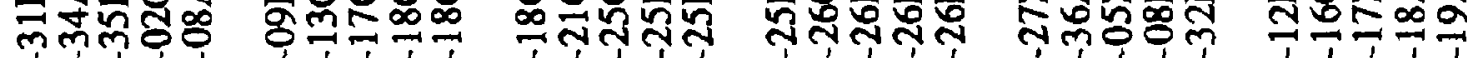

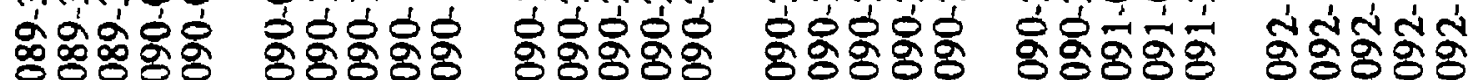

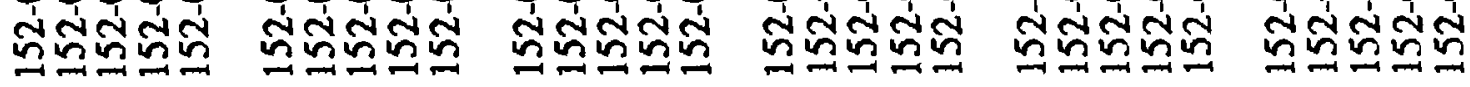




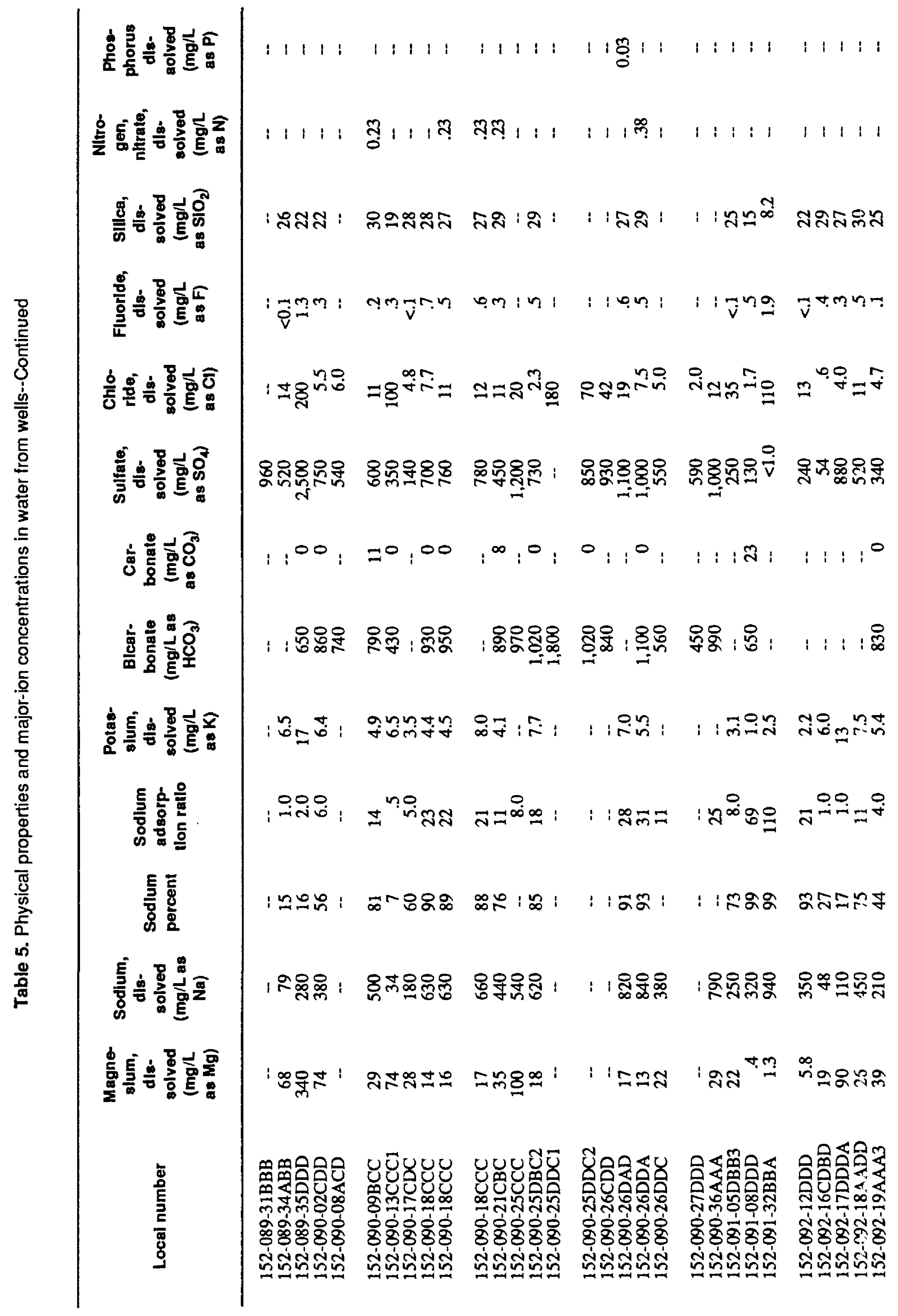




\begin{tabular}{|c|c|c|c|c|c|c|}
\hline \multirow{3}{*}{ 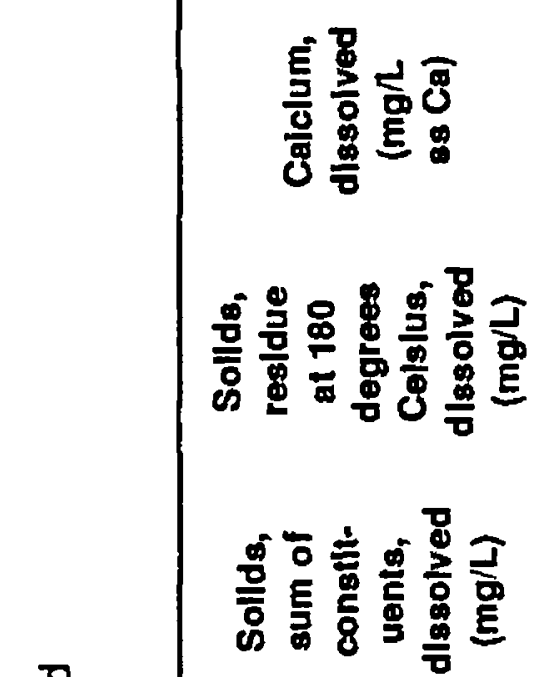 } & 욤욤융으 & మ్తిన్ల్తి స్తి & 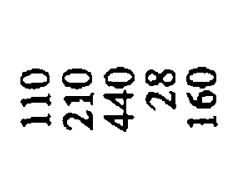 & ஜํํํํำ & 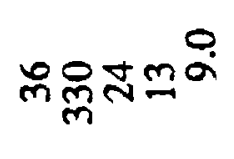 & 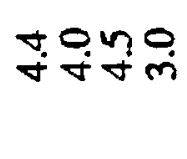 \\
\hline & 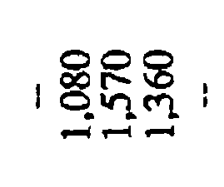 & 丳: & 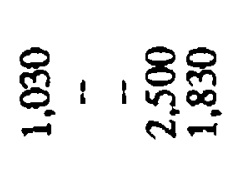 & 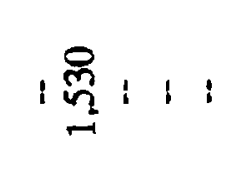 & 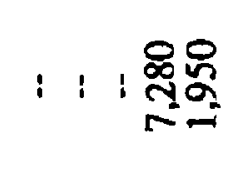 & \&最是: \\
\hline & 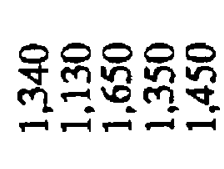 & 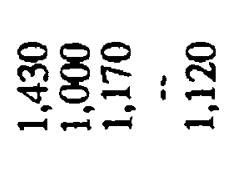 & 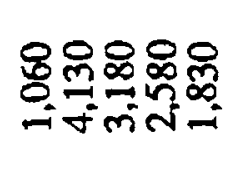 & 总号杲 1 & : : i 용요 & 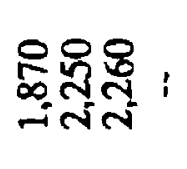 \\
\hline 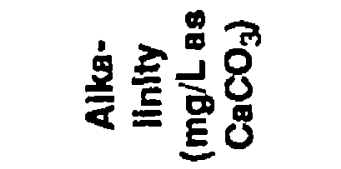 & స్రిం: : : : & $1: 1: 11$ & : ్ㅑㅇ్ : : & 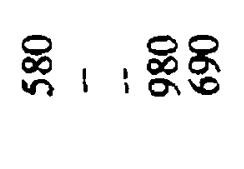 & 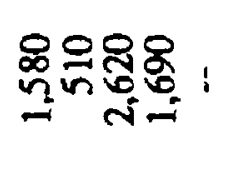 & 8 \\
\hline 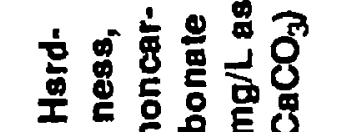 & $i^{n} ;: i$ & $\vec{v}_{i}^{0}$ & $\Omega_{1}$ oᄋ & $i^{0} i: i$ & $1: 1^{\circ}:$ & $0: 11$ \\
\hline 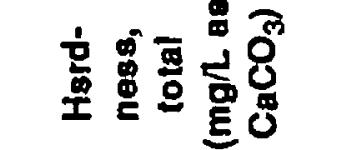 & 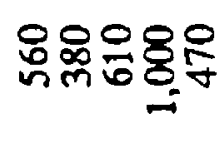 & 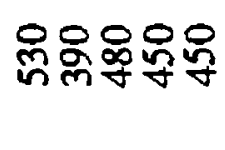 & 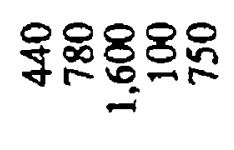 & $\begin{array}{l}8 \infty \\
2\end{array}$ & 용요 & $\approx \pm 9=$ \\
\hline 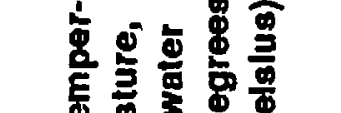 & 불 : & 20000 & nod:00 & 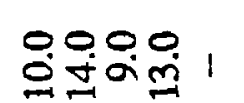 & $1: \frac{0}{i}$ & 웅욤ำ \\
\hline 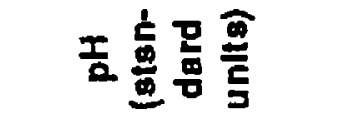 & 움욤욤 & 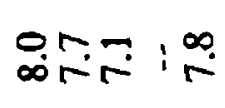 & 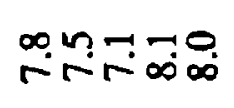 & చే & 움유. & $\begin{array}{l}0.0 n \\
\infty \\
\infty\end{array} \infty \infty \infty \infty$ \\
\hline 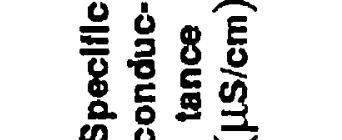 & 융영영 & 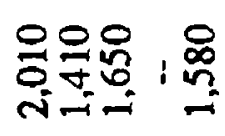 & 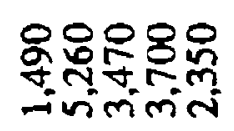 & 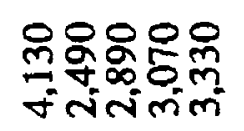 & 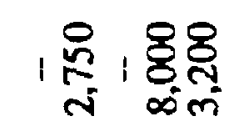 & $\begin{array}{l}\text { 웅야용요 } \\
\text { mimini }\end{array}$ \\
\hline$\stackrel{0}{\Delta}$ & 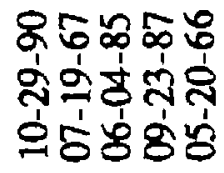 & 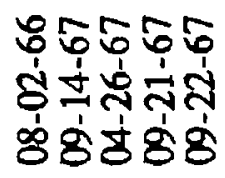 & 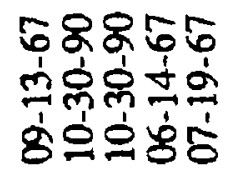 & 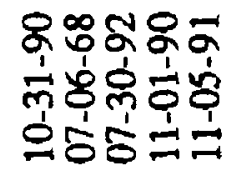 & 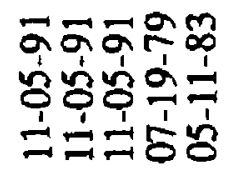 & 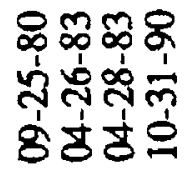 \\
\hline 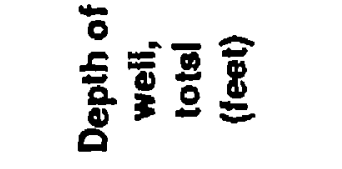 & 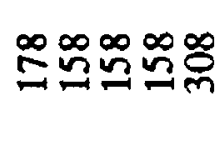 & ర్లి: : & 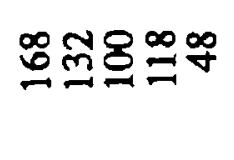 & 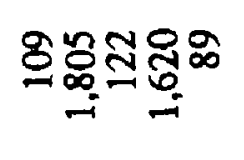 & 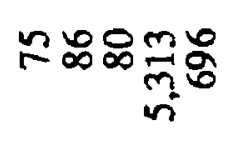 & 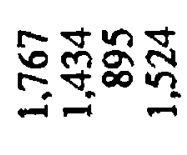 \\
\hline 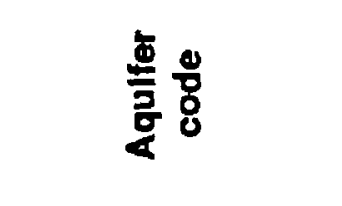 & 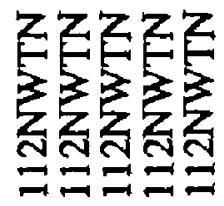 & 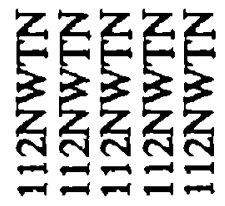 & 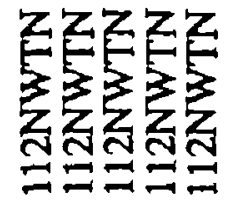 & 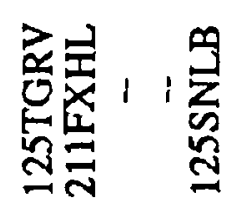 & 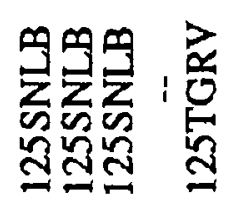 & 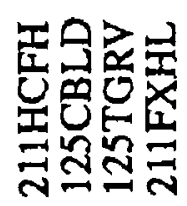 \\
\hline 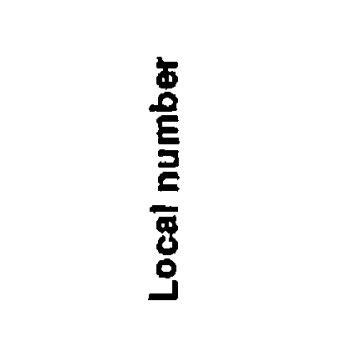 & 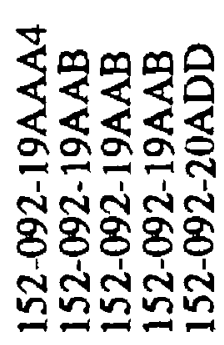 & 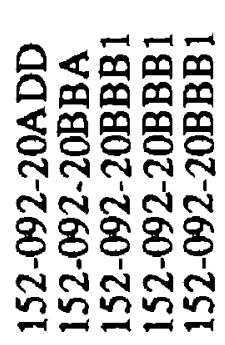 & 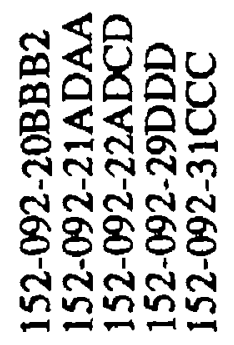 & 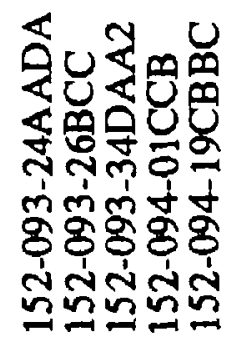 & 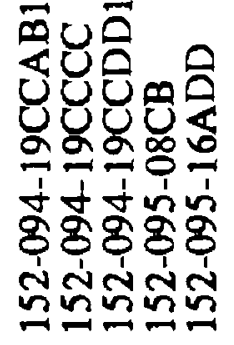 & 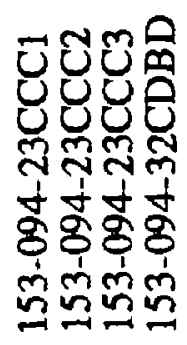 \\
\hline
\end{tabular}




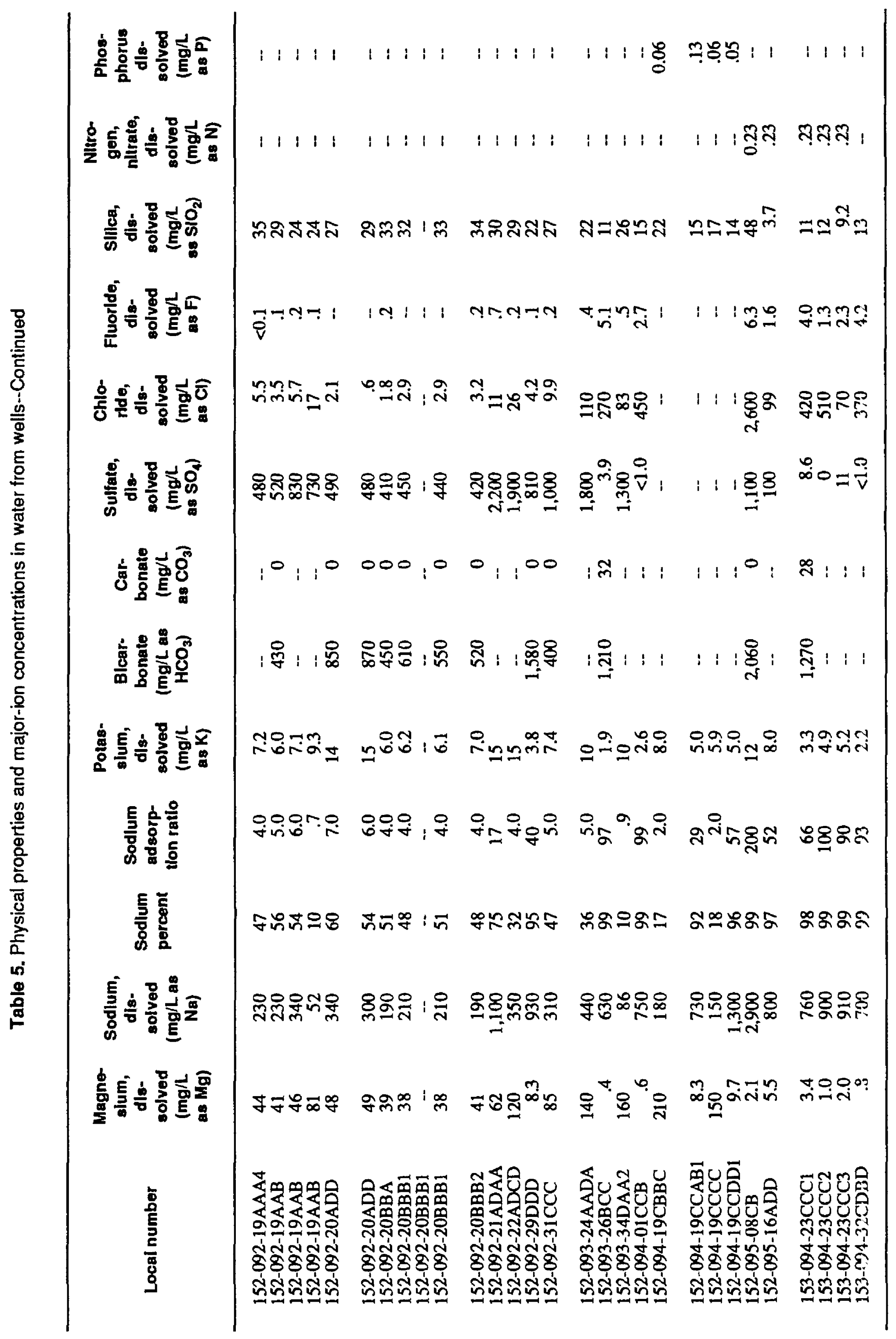


Table 6. Trace-element concentrations in water from wells

\section{Aqulfer code}

\section{Pleistocene}

112BDVL

112BGFV

112 HDLK

112 NWTN

$112 \mathrm{OTSH}$

112SANISH

112 SLCK

112 TILL

112VANG

Buried valley deposits

Buried glaciofluvial deposits

Hidden Lake aquifer

New Town aquifer

Outwash deposits

Sanish aquifer

Shell Creek aquifer system

Till deposits

Vang aquifer

112WSLD

White Shield aquifer

Paleocene

125 SNLB

125TGRV

Sentinel Butte Member of Fort Union Formation

Tongue River Member of Fort Union Formation

Cretaceous

211FXHL

Fox Hills Sandstone

$211 \mathrm{HCFH}$

Hell Creek Formation-Fox Hills Sandstone

\section{Abbreviatlons and symbols}

$\mu \mathrm{g} / \mathrm{L}$, micrograms per liter

,-- no data

$<$, less than

$\mathrm{ND}$, not detected 
Table 6. Trace-element concentrations in water from wells--Continued

\begin{tabular}{|c|c|c|c|c|c|c|c|c|c|}
\hline Local number & $\begin{array}{l}\text { Aquifer } \\
\text { code }\end{array}$ & $\begin{array}{l}\text { Depth of } \\
\text { well, } \\
\text { total } \\
\text { (feet) }\end{array}$ & Date & $\begin{array}{l}\text { Boron, } \\
\text { dis- } \\
\text { solved } \\
(\mu g / L \\
\text { as B) }\end{array}$ & $\begin{array}{c}\text { Cadmium, } \\
\text { diasolved } \\
(\mu g / L \\
\text { as Cd) }\end{array}$ & $\begin{array}{l}\text { Chro- } \\
\text { mlum, } \\
\text { dis- } \\
\text { solved } \\
(\mu g / L \\
\text { as Cr) }\end{array}$ & $\begin{array}{l}\text { Cobalt, } \\
\text { dis- } \\
\text { solved } \\
(\mu g / L \\
\text { as Co) }\end{array}$ & $\begin{array}{l}\text { Copper, } \\
\text { d's- } \\
\text { ao'ved } \\
\text { ( } \mu \text { gll } \\
\text { as Cu) }\end{array}$ & $\begin{array}{l}\text { Iron, } \\
\text { dls- } \\
\text { solved } \\
(\mu g / L \\
\text { as } \mathrm{Fe})\end{array}$ \\
\hline $\begin{array}{l}146-088-30 D D D \\
146-090-20 C C C \\
146-090-20 \mathrm{CC} \\
146-091-08 \mathrm{CAA} \\
146-091-13 \mathrm{BCA} 1\end{array}$ & $\begin{array}{l}\text { 125TGRY } \\
\text { 211FXHL } \\
211 \text { FXHL } \\
\text { 125SNLB } \\
\text { 125SNLB }\end{array}$ & $\begin{array}{r}426 \\
1,574 \\
1,574 \\
170 \\
200\end{array}$ & $\begin{array}{l}09-19-78 \\
06-28-68 \\
07-09-69 \\
09-29-71 \\
09-28-71\end{array}$ & $\begin{array}{r}290 \\
2,400 \\
1,700 \\
130 \\
40\end{array}$ & $\begin{array}{l}-- \\
-- \\
-- \\
-- \\
--\end{array}$ & $\begin{array}{l}-- \\
- \\
- \\
-\end{array}$ & $\begin{array}{l}- \\
-- \\
- \\
- \\
-\end{array}$ & $\begin{array}{l}- \\
- \\
- \\
-\end{array}$ & $\begin{array}{r}20 \\
5,000 \\
240 \\
0 \\
6,700\end{array}$ \\
\hline $\begin{array}{l}146-091-17 C D C \\
146-091-17 C D C \\
146-091-20 D D D 1 \\
146-091-21 C D D 1 \\
146-091-21 C D D 2\end{array}$ & $\begin{array}{l}112 \mathrm{BGFV} \\
112 \mathrm{BGFV} \\
112 \mathrm{BGFV} \\
112 \mathrm{BGFV} \\
112 \mathrm{BGFV}\end{array}$ & $\begin{array}{r}141 \\
141 \\
43 \\
192 \\
93\end{array}$ & $\begin{array}{l}07-23-74 \\
08-23-78 \\
08-11-71 \\
10-27-71 \\
10-27-71\end{array}$ & $\begin{array}{r}160 \\
260 \\
440 \\
0 \\
40\end{array}$ & $\begin{array}{l}-- \\
-- \\
-- \\
-\end{array}$ & $\begin{array}{l}- \\
- \\
- \\
-\end{array}$ & $\begin{array}{l}- \\
-- \\
- \\
-\end{array}$ & $\begin{array}{l}- \\
- \\
- \\
-\end{array}$ & $\begin{array}{r}1,600 \\
280 \\
0 \\
1,300 \\
0\end{array}$ \\
\hline $\begin{array}{l}146-091-21 \mathrm{DCD} \\
146-091-22 \mathrm{BBA} \\
146-091-28 \mathrm{ABA} \\
146-091-35 \mathrm{BBC} \\
146-091-35 \mathrm{BBC}\end{array}$ & $\begin{array}{l}125 S N L B \\
125 S N L B \\
112 B G F V \\
112 B G F V \\
112 B G F V\end{array}$ & $\begin{array}{r}69 \\
235 \\
94 \\
221 \\
221\end{array}$ & $\begin{array}{l}09-28-71 \\
07-12-72 \\
10-28-71 \\
07-23-74 \\
08-23-78\end{array}$ & $\begin{array}{l}440 \\
360 \\
400 \\
120 \\
330\end{array}$ & $\begin{array}{l}-- \\
-- \\
-- \\
-- \\
--\end{array}$ & $\begin{array}{l}- \\
- \\
- \\
-\end{array}$ & $\begin{array}{l}- \\
- \\
- \\
-\end{array}$ & $\begin{array}{l}- \\
\ldots \\
- \\
-\end{array}$ & $\begin{array}{r}0 \\
620 \\
0 \\
2,700 \\
320\end{array}$ \\
\hline $\begin{array}{l}146-092-27 D D D \\
146-092-29 D D C 1 \\
146-092-30 D A A \\
146-092-32 C D D 1 \\
146-093-03 C D D\end{array}$ & $\begin{array}{l}125 S N L B \\
125 S N L B \\
125 S N L B \\
125 S N L B \\
211 F X H L\end{array}$ & $\begin{array}{r}58 \\
75 \\
64 \\
78 \\
1,525\end{array}$ & $\begin{array}{l}07-24-74 \\
09-30-71 \\
07-12-72 \\
09-30-71 \\
07-13-72\end{array}$ & $\begin{array}{r}80 \\
0 \\
40 \\
0 \\
1,600\end{array}$ & $\begin{array}{l}-- \\
-- \\
-- \\
-- \\
--\end{array}$ & $\begin{array}{l}-- \\
-- \\
- \\
-\end{array}$ & $\begin{array}{l}- \\
- \\
- \\
-\end{array}$ & $\begin{array}{l}- \\
- \\
- \\
-\end{array}$ & $\begin{array}{r}<10 \\
0 \\
100 \\
50 \\
90\end{array}$ \\
\hline $\begin{array}{l}146-093-03 C D D \\
146-093-17 C B B \\
146-093-19 B D D \\
146-093-20 A D D \\
146-093-20 C B C\end{array}$ & $\begin{array}{l}\text { 211FXHL } \\
\text { 125SNLB } \\
125 S N L B \\
125 S N L B \\
125 S N L B\end{array}$ & $\begin{array}{r}1,525 \\
150 \\
140 \\
27 \\
120\end{array}$ & $\begin{array}{l}05-24-73 \\
07-12-72 \\
07-13-72 \\
10-06-71 \\
10-06-71\end{array}$ & $\begin{array}{r}2,400 \\
210 \\
70 \\
40 \\
90\end{array}$ & $\begin{array}{l}\text { ND } \\
- \\
-- \\
-- \\
--\end{array}$ & $\begin{array}{l}\text { ND } \\
- \\
- \\
-\end{array}$ & $\begin{array}{l}<2 \\
-- \\
- \\
- \\
--\end{array}$ & $\begin{array}{l}5 \\
-- \\
- \\
--\end{array}$ & $\begin{array}{r}50 \\
3,100 \\
2,100 \\
1,200 \\
4,300\end{array}$ \\
\hline $\begin{array}{l}146-093-20 \mathrm{CCA} \\
146-093-22 A D D \\
146-093-24 D C C 1 \\
146-093-26 C B B \\
146-093-27 C C C\end{array}$ & $\begin{array}{l}\text { 125SNLB } \\
125 S N L B \\
125 S N L B \\
125 S N L B \\
125 S N L B\end{array}$ & $\begin{array}{r}140 \\
80 \\
115 \\
60 \\
76\end{array}$ & $\begin{array}{l}07-13-72 \\
10-05-71 \\
10-06-71 \\
10-05-71 \\
07-24-74\end{array}$ & $\begin{array}{r}110 \\
0 \\
0 \\
0 \\
550\end{array}$ & $\begin{array}{l}-- \\
-- \\
-- \\
--\end{array}$ & $\begin{array}{l}- \\
-- \\
- \\
-\end{array}$ & $\begin{array}{l}-- \\
- \\
- \\
-\end{array}$ & $\begin{array}{l}- \\
-- \\
-- \\
-\end{array}$ & $\begin{array}{r}1,300 \\
6,200 \\
14,000 \\
220 \\
40\end{array}$ \\
\hline $\begin{array}{l}\text { 146-093-28AAA2 } \\
146-093-28 D D B 1 \\
146-094-05 \mathrm{CBD} \\
\text { 146-094-08DAC1 } \\
146-094-08 \mathrm{DAD} 1\end{array}$ & $\begin{array}{l}\text { 125SNLB } \\
125 S N L B \\
211 F X H L \\
125 S N L B \\
211 F X H L\end{array}$ & $\begin{array}{r}76 \\
84 \\
1,410 \\
25 \\
1,404\end{array}$ & $\begin{array}{l}11-22-74 \\
10-06-71 \\
05-25-72 \\
10-08-71 \\
05-25-72\end{array}$ & $\begin{array}{l}430 \\
440 \\
710 \\
580 \\
570\end{array}$ & $\begin{array}{l}-- \\
-- \\
-- \\
--\end{array}$ & $\begin{array}{l}-- \\
- \\
- \\
-\end{array}$ & $\begin{array}{l}-- \\
-- \\
-- \\
--\end{array}$ & $\begin{array}{l}- \\
- \\
-- \\
--\end{array}$ & $\begin{array}{r}100 \\
530 \\
0 \\
0 \\
40\end{array}$ \\
\hline $\begin{array}{l}146-094-24 \mathrm{DDD} 2 \\
147-087-04 \mathrm{ABA} \\
147-090-22 \mathrm{CCC} \\
147-090-25 \mathrm{ABC} \\
147-091-25 \mathrm{DCC}\end{array}$ & $\begin{array}{l}\text { 125SNLB } \\
125 T G R Y \\
125 S N L B \\
125 S N L B \\
125 S N L B\end{array}$ & $\begin{array}{r}60 \\
380 \\
150 \\
155 \\
92\end{array}$ & $\begin{array}{l}10-07-71 \\
10-14-66 \\
11-03-50 \\
11-03-50 \\
11-05-90\end{array}$ & $\begin{array}{r}310 \\
3,700 \\
300 \\
0 \\
620\end{array}$ & $\begin{array}{c}-- \\
-- \\
-- \\
-- \\
<3.0\end{array}$ & $\begin{array}{l}- \\
- \\
- \\
<20\end{array}$ & $\begin{array}{l}- \\
- \\
-- \\
- \\
<9\end{array}$ & $\begin{array}{c}- \\
- \\
\overrightarrow{<30}\end{array}$ & $\begin{array}{r}120 \\
-- \\
1,700 \\
1,500 \\
47\end{array}$ \\
\hline $\begin{array}{l}147-091-26 C C D \\
147-091-28 A C C \\
147-091-29 B C A \\
147-092-03 C D C 2 \\
147-093-03 D B B\end{array}$ & $\begin{array}{c}\text { 125TGRV } \\
\text { 125TGRV } \\
125 T G R V \\
- \\
125 \text { SNLB }\end{array}$ & $\begin{array}{r}925 \\
707 \\
917 \\
1,000 \\
223\end{array}$ & $\begin{array}{l}09-29-71 \\
11-05-90 \\
05-23-72 \\
11-05-90 \\
10-19-50\end{array}$ & $\begin{array}{r}130 \\
270 \\
0 \\
2,100 \\
0\end{array}$ & $\begin{array}{l}<\overline{3.0} \\
-\overline{-} \\
<3.0\end{array}$ & $<\frac{20}{20}$ & $\begin{array}{l}-\overline{<9} \\
<9 \\
-\end{array}$ & $\begin{array}{c}-\overline{-} \\
<30 \\
<30 \\
-\end{array}$ & $\begin{array}{r}0 \\
96 \\
90 \\
93 \\
160\end{array}$ \\
\hline $\begin{array}{l}147-093-29 D C A \\
147-094-26 \mathrm{BCB} \\
147-094-34 \mathrm{BAD} \\
147-095-12 \mathrm{BCD} \\
147-095-12 \mathrm{CAD}\end{array}$ & $\begin{array}{l}\text { 125TGRY } \\
\text { 211FXHL } \\
211 \mathrm{FXHL} \\
125 \mathrm{TGRV} \\
\text { 211FXHL }\end{array}$ & $\begin{array}{r}373 \\
1,500 \\
1,502 \\
400 \\
1,410\end{array}$ & $\begin{array}{l}08-23-72 \\
11-16-72 \\
11-16-72 \\
07-13-72 \\
07-13-72\end{array}$ & $\begin{array}{r}210 \\
2,500 \\
2,100 \\
250 \\
1,500\end{array}$ & $\begin{array}{l}-- \\
-. \\
-. \\
-- \\
-\end{array}$ & $\begin{array}{l}- \\
-- \\
-- \\
- \\
-\end{array}$ & $\begin{array}{l}- \\
- \\
- \\
-\end{array}$ & $\begin{array}{l}- \\
- \\
- \\
-\end{array}$ & $\begin{array}{r}80 \\
<10 \\
100 \\
0 \\
530\end{array}$ \\
\hline
\end{tabular}


Table 6. Trace-element concentrations in water from wells--Continued

\begin{tabular}{|c|c|c|c|c|c|c|c|c|c|c|}
\hline Locai number & $\begin{array}{l}\text { Lead, } \\
\text { dle- } \\
\text { solved } \\
(\mu g / L \\
\text { as } \mathrm{Pb})\end{array}$ & $\begin{array}{l}\text { Lthium, } \\
\text { dis- } \\
\text { soived } \\
(\mu g / L \\
\text { as L) }\end{array}$ & $\begin{array}{l}\text { Mange- } \\
\text { nese, } \\
\text { dissolved } \\
(\mu g / L \\
\text { as Mn) }\end{array}$ & $\begin{array}{c}\text { Moiyb- } \\
\text { denum, } \\
\text { dis. } \\
\text { solved } \\
\left(\mu_{g} / L\right. \\
\text { as Mo) }\end{array}$ & $\begin{array}{c}\text { Nickei, } \\
\text { dis- } \\
\text { solved } \\
\text { ( } \mu \text { g/L } \\
\text { as Ni) }\end{array}$ & $\begin{array}{c}\text { Sele- } \\
\text { nium, } \\
\text { dis- } \\
\text { solved } \\
\left(\mu_{g / L}\right. \\
\left.\text { as } \mathrm{S}_{\theta}\right)\end{array}$ & $\begin{array}{c}\text { Silver, } \\
\text { dis- } \\
\text { solved } \\
\text { ( } \mu g / L \\
\text { as Ag) }\end{array}$ & $\begin{array}{c}\text { Stron- } \\
\text { tlum, } \\
\text { dissolved } \\
(\mu g / L \\
\text { as Sr) }\end{array}$ & $\begin{array}{l}\text { Vana- } \\
\text { dium, } \\
\text { dis- } \\
\text { solved } \\
(\mu g / L \\
\text { gs V) }\end{array}$ & $\begin{array}{l}\text { Zinc, } \\
\text { dls- } \\
\text { so'ved } \\
(\mu g / L \\
\text { as } Z n)\end{array}$ \\
\hline 146-088-30DDD & -- & -- & $<10$ & 1 & - & -. & -. & 420 & -- & -- \\
\hline $146-090-20 C C C$ & $\cdots$ & -- & -- & -- & - & - & - & -- & -- & -- \\
\hline 146-090-20CCC & -- & -- & $\vec{n}$ & -- & - & - & $-\cdot$ & -- & -- & - \\
\hline 146-091-08CAA & -- & -- & 350 & -- & - & - & - & -- & -- & -- \\
\hline 146-091-13BCA1 & -. & -- & 50 & -- & - & - & & & -- & \\
\hline 146-091-17CDC & -- & -. & 240 & -. & - & - & -- & -. & -- & - \\
\hline $146-091-17 C D C$ & -- & -- & 240 & -- & - & - & - & -. & -- & - \\
\hline 146-091-20DDD1 & -- & -- & 10 & -- & - & - & -- & -- & $\cdot-$ & -- \\
\hline 146-091-21CDD1 & -. & $-\cdot$ & 160 & -- & -- & -- & - & - & -- & - \\
\hline $146-091-21 C D D 2$ & -- & -- & 550 & -- & -- & -. & - & $-\cdot$ & -. & -- \\
\hline $146-091-21 D C D$ & -. & .- & 80 & -- & - & - & -. & -- & -- & -- \\
\hline 146-091-22BBA & -- & -- & 30 & -- & - & -- & - & -- & -- & -- \\
\hline $146.091-28 \mathrm{ABA}$ & -. & -- & 520 & -. & -. & -- & - & -. & -. & -. \\
\hline 146-091-35BBC & -- & -- & 160 & -- & $-\cdot$ & - & -- & -- & -- & -- \\
\hline 146-091-35BBC & -- & -- & 160 & -- & - & - & -- & - & -- & - \\
\hline $146-092-27 D D D$ & -. & -- & 180 & -- & -- & - & - & -- & -- & -. \\
\hline 146-092-29DDC1 & -- & -- & 20 & -- & -- & -- & - & -- & -- & - \\
\hline 146-092-30DAA & -- & 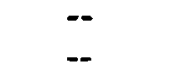 & $\begin{array}{l}30 \\
40\end{array}$ & -- & - & - & - & -- & -- & - \\
\hline $\begin{array}{l}146-092-32 C D D 1 \\
146-093-03 C D D\end{array}$ & -- & -. & $\begin{array}{r}40 \\
0\end{array}$ & $\begin{array}{l}-- \\
--\end{array}$ & $\overline{-}$ & $\overline{-}$ & $\overline{-}$ &.- & $\approx$ & -. \\
\hline 146-093-03CDD & & & & & & & & & $\cdots$ & - \\
\hline 146-093-03CDD & ND & 70 & $<10$ & 4 & 7 & $<1$ & ND & 600 & 1 & $<20$ \\
\hline $146-093-17 \mathrm{CBB}$ & -. & -- & 420 & -- & -- & -- & - & -- & -- & -- \\
\hline 146-093-19BDD & -- & -- & 580 & -. & - & -- & - & -- & -- & - \\
\hline $146-093-20 \mathrm{ADD}$ & -. & -- & 60 & -- & - & -- & -- & -- & -- & -- \\
\hline $146-093-20 \mathrm{CBC}$ & -- & -- & 10 & -- & - & - & - & -- & -- & -- \\
\hline $146-093-20 \mathrm{CCA}$ & -- & -- & 320 & -. & -- & -- & -- & -. & -- & -. \\
\hline $146-093-22 \mathrm{ADD}$ & -- & -- & 140 & -- & - & - & - & -- & -- & - \\
\hline 146-093-24DCC1 & -- & -. & 130 & -- & -. & -- & -- & -- & -- & -- \\
\hline 146-093-26CBB & -- & - & 400 & -- & -- & -. & - & -. & - & -. \\
\hline $146-093-27 C C C$ & -- & -- & 300 & -- & -- & - & - & -- & -- & -- \\
\hline 146-093-28AAA2 & - & -- & 800 & -. & - & -- & -- & -- & -- & - \\
\hline 146-093-28DDB1 & -. & -- & 10 & -- & - & -- & -- & -- & -- & -- \\
\hline $146-094-05 \mathrm{CBD}$ & -- & -. & 40 & -. & - & -- & .. & .. & -. & .. \\
\hline 146-094-08DAC1 & -- & -- & 180 & -- & -- & - & -. & -- & -- & -- \\
\hline $146-094-08 \mathrm{DADI}$ & -. & -- & 40 & -- & -- & - & - & -- & -. & - \\
\hline 146-094-24DDD2 & -- & -- & 190 & -- & -- & - & - & -- & -- & - \\
\hline $147-087-04 \mathrm{ABA}$ & -- & -- & -- & -- & -- & -. & -- & -- & -. & -- \\
\hline $147-090-22 \mathrm{CCC}$ & $\cdots$ & -- & -- & -- & -- & - & - & -- & -- & -- \\
\hline $\begin{array}{l}147-090-25 \mathrm{ABC} \\
147-091-25 \mathrm{DCC}\end{array}$ & $<-\overline{30}$ & $\ddot{92}$ & $\overline{350}$ & $<30$ & $-\overline{60}$ & - & $<\overline{3.0}$ & $\overline{1,-\overline{600}}$ & $<-i 8$ & $\overline{89}$ \\
\hline $147-091-26 \mathrm{CCD}$ & -- & .- & 620 & -. & .. & - & - & .. & $\ldots$ & .. \\
\hline $147.091-28 \mathrm{ACC}$ & $<30$ & 78 & $<3$ & $<30$ & $<30$ & - & $<3.0$ & 320 & $<18$ & 310 \\
\hline $147-091-29 \mathrm{BCA}$ & - & $\ldots$ & 40 & -- & - & - & - & $\ldots$ & & -- \\
\hline $147.092-03 \mathrm{CDC} 2$ & $<30$ & 80 & 5 & $<30$ & $<30$ & .- & $<3.0$ & 210 & $<18$ & 13 \\
\hline $147-093-03 \mathrm{DBB}$ & -- & -- & - & -- & -- & -- & -- & - & - & -- \\
\hline $147.093-29 D C A$ & -- & .. & 0 & -. & - & -. & -- & -- & .- & - \\
\hline $147-094-26 \mathrm{BCB}$ & -- & -. & $<10$ & -. & - & -- & -- & -- & -- & -- \\
\hline $147.09434 \mathrm{BAD}$ & -. & -- & $<10$ & -- & -- & - & - & -- & -- & -- \\
\hline $147-095-12 B C D$ & -- & -- & 10 & -- & - & -- & - & -. & -- & -. \\
\hline $147-095-12 \mathrm{CAD}$ & -. & -- & 10 & -- & - & -- & - & .- & .. & -- \\
\hline
\end{tabular}


Table 6. Trace-element concentrations in water from wells--Continued

\begin{tabular}{|c|c|c|c|c|c|c|c|c|c|}
\hline Local number & $\begin{array}{l}\text { Aquifer } \\
\text { code }\end{array}$ & $\begin{array}{l}\text { Depth of } \\
\text { well, } \\
\text { total } \\
\text { (feet) }\end{array}$ & Date & $\begin{array}{l}\text { Boron, } \\
\text { dis- } \\
\text { solved } \\
\text { ( } \mu \mathrm{g} / \mathrm{L} \\
\text { as B) }\end{array}$ & $\begin{array}{l}\text { Cadmium, } \\
\text { diasolved } \\
(\mu g / L \\
a s \mathrm{Cd})\end{array}$ & $\begin{array}{l}\text { Chro- } \\
\text { mium, } \\
\text { dls- } \\
\text { solved } \\
(\mu g / L \\
\text { as Cr) }\end{array}$ & $\begin{array}{l}\text { Cobait, } \\
\text { dis- } \\
\text { aoived } \\
(\mu g / L \\
\text { as Co) }\end{array}$ & $\begin{array}{l}\text { Copper, } \\
\text { dir- } \\
\text { soived } \\
\left(\mu g^{n} \text {. }\right. \\
\text { as C.u) }\end{array}$ & $\begin{array}{l}\text { Iron, } \\
\text { dia- } \\
\text { soived } \\
\text { (Kg/L } \\
\text { aB Fe) }\end{array}$ \\
\hline $\begin{array}{l}147-095-13 \mathrm{CCC} 2 \\
147-095-13 \mathrm{CCC} 3 \\
147-095-14 \mathrm{AAA} \\
147-095-14 \mathrm{CBB} 1 \\
147-095-24 \mathrm{AAC}\end{array}$ & $\begin{array}{l}\text { 211FXHL } \\
\text { 211FXHL } \\
\text { 211FXHL } \\
\text { 125SNLB } \\
\text { 211FXHL }\end{array}$ & $\begin{array}{r}1,930 \\
1,980 \\
1,430 \\
52 \\
1,580\end{array}$ & $\begin{array}{l}07-07-72 \\
11-01-90 \\
07-13-72 \\
12-09-71 \\
07-13-72\end{array}$ & $\begin{array}{r}1,600 \\
2,000 \\
1,400 \\
310 \\
1,500\end{array}$ & $\begin{array}{c}-- \\
<3.0 \\
-- \\
-- \\
--\end{array}$ & $\begin{array}{l}-\overline{20} \\
- \\
-\end{array}$ & $\begin{array}{l}-\overline{9} \\
- \\
--\end{array}$ & $\begin{array}{l}-- \\
<37 \\
- \\
-\end{array}$ & $\begin{array}{r}250 \\
210 \\
0 \\
2.200 \\
0\end{array}$ \\
\hline $\begin{array}{l}\text { 147-095-26BBB1 } \\
148-087-07 \mathrm{AAA} 1 \\
148-087-07 \mathrm{AAA} 2 \\
148-087-11 \mathrm{DDD} \\
148-087-13 \mathrm{BBB}\end{array}$ & $\begin{array}{l}\text { 211FXHL } \\
112 W S L D \\
112 W S L D \\
112 \text { OTSH } \\
112 W S L D\end{array}$ & $\begin{array}{r}1,850 \\
16 \\
278 \\
13 \\
278\end{array}$ & $\begin{array}{l}12-08-71 \\
05-13-68 \\
08-05-68 \\
10-11-66 \\
07-30-68\end{array}$ & $\begin{array}{r}1,600 \\
0 \\
590 \\
180 \\
490\end{array}$ & $\begin{array}{l}-- \\
- \\
- \\
--\end{array}$ & $\begin{array}{l}-- \\
- \\
-- \\
--\end{array}$ & $\begin{array}{l}-- \\
- \\
-- \\
-\end{array}$ & $\begin{array}{l}- \\
\ddot{-} \\
- \\
-\end{array}$ & $\begin{array}{r}200 \\
100 \\
4,900 \\
150 \\
0\end{array}$ \\
\hline $\begin{array}{l}148-087-13 D D D \\
148-087-24 \mathrm{BCD} \\
148-087-27 \mathrm{ADA} \\
148-087-27 \mathrm{DDA} \\
148-088-02 \mathrm{DDA}\end{array}$ & $\begin{array}{l}\text { 112WSLD } \\
\text { 125SNLB } \\
\text { 125TGRV } \\
\text { 125TGRV } \\
\text { 112WSLD }\end{array}$ & $\begin{array}{r}305 \\
61 \\
135 \\
228 \\
232\end{array}$ & $\begin{array}{l}10-30-69 \\
09-16-66 \\
09-16-66 \\
09-16-66 \\
06-09-65\end{array}$ & $\begin{array}{r}- \\
40 \\
140 \\
--\end{array}$ & $\begin{array}{l}-- \\
- \\
-- \\
-- \\
--\end{array}$ & $\begin{array}{l}-. \\
-- \\
-- \\
-- \\
-\end{array}$ & $\begin{array}{l}-- \\
-- \\
-- \\
--\end{array}$ & $\begin{array}{l}-- \\
-- \\
- \\
-- \\
-\end{array}$ & $\begin{array}{r}200 \\
7,800 \\
440 \\
300\end{array}$ \\
\hline $\begin{array}{l}148-088-02 D D A \\
148-088-02 D D B \\
148-088-21 D B D \\
148-090-16 A B C \\
148-090-25 B C\end{array}$ & $\begin{array}{l}\text { 112WSLD } \\
112 W S L D \\
125 S N L B \\
125 T G R V \\
211 \text { FXHL }\end{array}$ & $\begin{array}{r}232 \\
215 \\
220 \\
290 \\
1,281\end{array}$ & $\begin{array}{l}05-05-67 \\
05-05-67 \\
11-08-90 \\
11-08-90 \\
11-16-67\end{array}$ & $\begin{array}{r}390 \\
350 \\
290 \\
570 \\
2,800\end{array}$ & $\begin{array}{l}-- \\
<1.0 \\
<3.0 \\
--\end{array}$ & $\begin{array}{c}-- \\
<5 \\
<20 \\
--\end{array}$ & $\begin{array}{l}-- \\
<3 \\
<9 \\
--\end{array}$ & $\begin{array}{l}- \\
-- \\
<10 \\
<37 \\
--\end{array}$ & $\begin{array}{r}10,000 \\
1,900 \\
120 \\
34 \\
70\end{array}$ \\
\hline $\begin{array}{l}148-090-26 \mathrm{ABB} 2 \\
148-092-06 \mathrm{AAD} \\
148-092-06 \mathrm{BCA} \\
148-092-06 \mathrm{BDB} \\
148-092-23 \mathrm{CCA}\end{array}$ & $\begin{array}{l}\text { 125TGRV } \\
125 \text { SNLB } \\
125 \text { SNLB } \\
125 \text { SNLB } \\
125 \text { SNLB }\end{array}$ & $\begin{array}{r}126 \\
210 \\
89 \\
98 \\
23\end{array}$ & $\begin{array}{l}10-13-66 \\
10-31-90 \\
08-02-72 \\
08-02-72 \\
08-09-73\end{array}$ & $\begin{array}{r}500 \\
40 \\
750 \\
710 \\
470\end{array}$ & $\begin{array}{c}-- \\
-- \\
-- \\
--\end{array}$ & $\begin{array}{l}- \\
<5 \\
-- \\
-- \\
--\end{array}$ & $\begin{array}{l}\overline{<3} \\
- \\
- \\
-\end{array}$ & $\begin{array}{c}-- \\
<10 \\
-- \\
-\end{array}$ & $\begin{array}{r}17 \\
160 \\
0 \\
2,400\end{array}$ \\
\hline $\begin{array}{l}148-092-35 B D A \\
148-093-04 C A B 1 \\
148-093-04 C B D \\
148-093-10 C C C \\
148-093-14 C D C\end{array}$ & $\begin{array}{l}\text { 125SNLB } \\
125 T G R Y \\
125 T G R V \\
125 S N L B \\
125 S N L B\end{array}$ & $\begin{array}{r}65 \\
340 \\
480 \\
109 \\
63\end{array}$ & $\begin{array}{l}08-03-72 \\
11-07-73 \\
11-07-73 \\
08-01-74 \\
08-01-74\end{array}$ & $\begin{array}{l}570 \\
430 \\
220 \\
430 \\
430\end{array}$ & $\begin{array}{l}-- \\
-- \\
- \\
- \\
-\end{array}$ & $\begin{array}{l}- \\
- \\
- \\
- \\
-\end{array}$ & $\begin{array}{l}-- \\
-- \\
- \\
-\end{array}$ & $\begin{array}{l}-- \\
- \\
- \\
--\end{array}$ & $\begin{array}{r}40 \\
<10 \\
230 \\
390 \\
430\end{array}$ \\
\hline $\begin{array}{l}148-093-17 \mathrm{BBD} \\
148-094-13 \mathrm{BBD} \\
148-094-20 \mathrm{DDD} \\
148-095-03 \mathrm{AAA} \\
148-095-35 \mathrm{BDD}\end{array}$ & $\begin{array}{l}\text { 125SNLB } \\
\text { 125SNLB } \\
\text { 112TLLL } \\
\text { 125TGRV } \\
\text { 125TGRV }\end{array}$ & $\begin{array}{r}160 \\
30 \\
134 \\
247 \\
400\end{array}$ & $\begin{array}{l}08-01-72 \\
07-28-72 \\
10-12-50 \\
10-31-90 \\
07-18-72\end{array}$ & $\begin{array}{r}360 \\
70 \\
100 \\
520 \\
180\end{array}$ & $\begin{array}{c}-- \\
-- \\
-- \\
<3.0 \\
--\end{array}$ & $\begin{array}{l}-- \\
\overline{-} \\
<20 \\
--\end{array}$ & $\begin{array}{l}-- \\
- \\
- \\
--\end{array}$ & $\begin{array}{c}-- \\
-- \\
<\overline{30} \\
-\end{array}$ & $\begin{array}{r}2,700 \\
1,000 \\
440 \\
62 \\
250\end{array}$ \\
\hline $\begin{array}{l}149-087-02 \mathrm{DDC} 2 \\
149-087-05 \mathrm{CDC} \\
149-087-06 \mathrm{AAA} \\
149-087-08 \mathrm{ABB} 1 \\
149-087-09 \mathrm{DAD}\end{array}$ & $\begin{array}{l}125 S N L B \\
125 S N L B \\
125 S N L B \\
125 T G R V \\
125 S N L B\end{array}$ & $\begin{array}{r}100 \\
87 \\
44 \\
220 \\
140\end{array}$ & $\begin{array}{l}09-13-66 \\
09-13-66 \\
10-19-77 \\
09-13-66 \\
09-14-66\end{array}$ & $\begin{array}{l}210 \\
760 \\
100 \\
820 \\
430\end{array}$ & $\begin{array}{l}-- \\
-- \\
-- \\
-- \\
--\end{array}$ & $\begin{array}{l}- \\
\ddot{-} \\
-- \\
-\end{array}$ & $\begin{array}{l}-- \\
- \\
-- \\
-\end{array}$ & $\begin{array}{l}- \\
-- \\
- \\
- \\
-\end{array}$ & $\begin{array}{r}200 \\
60 \\
280 \\
7,50 \\
1,100\end{array}$ \\
\hline $\begin{array}{l}149-087-32 \mathrm{CCC} \\
149-088-23 \mathrm{DAA} \\
149-089-01 \mathrm{BDA} \\
149-089-02 \mathrm{BBB} \\
149-089-03 \mathrm{BBD}\end{array}$ & $\begin{array}{l}112 W S L D \\
125 S N L B \\
112 W S L D \\
112 W S L D \\
112 W S L D\end{array}$ & $\begin{array}{r}358 \\
70 \\
260 \\
263 \\
230\end{array}$ & $\begin{array}{l}07-28-68 \\
11-08-90 \\
11-07-90 \\
10-03-69 \\
11-07-90\end{array}$ & $\begin{array}{r}630 \\
70 \\
590 \\
- \\
610\end{array}$ & $\begin{array}{l}<\overline{1.0} \\
<3.0 \\
-- \\
<3.0\end{array}$ & $\begin{array}{l}<5 \\
<20 \\
<20\end{array}$ & $\begin{array}{l}- \\
<3 \\
<9 \\
- \\
<9\end{array}$ & $\begin{array}{l}< \\
<10 \\
<30 \\
<30\end{array}$ & $\begin{array}{r}500 \\
330 \\
240 \\
400 \\
2,500\end{array}$ \\
\hline $\begin{array}{l}149-089-03 \mathrm{DAA} \\
149-089-10 \mathrm{BBC} \\
149-089-10 \mathrm{CBB} 3 \\
149-089-11 \mathrm{BBB} 1 \\
149-089-23 \mathrm{CCC} 1\end{array}$ & $\begin{array}{l}\text { 112WSLD } \\
112 B G F V \\
112 W S L D \\
112 W S L D \\
125 S N L\end{array}$ & $\begin{array}{r}220 \\
18 \\
135 \\
21 \\
142\end{array}$ & $\begin{array}{l}11-07-90 \\
05-14-68 \\
11-07-90 \\
06-01-67 \\
10-13-66\end{array}$ & $\begin{array}{l}640 \\
340 \\
290 \\
100 \\
460\end{array}$ & $\begin{array}{c}<3.0 \\
-- \\
<1.0 \\
-- \\
--\end{array}$ & $\begin{array}{l}<20 \\
- \\
<5 \\
-- \\
-\end{array}$ & $\begin{array}{l}<9 \\
- \\
<3 \\
- \\
-\end{array}$ & $\begin{array}{c}<30 \\
-- \\
<10 \\
--\end{array}$ & $\begin{array}{r}950 \\
3,600 \\
3,100 \\
40\end{array}$ \\
\hline
\end{tabular}


Table 6. Trace-element concentrations in water from wells--Continued

\begin{tabular}{|c|c|c|c|c|c|c|c|c|c|c|}
\hline Local number & $\begin{array}{l}\text { Lead, } \\
\text { dla- } \\
\text { aolved } \\
(\mu g / L \\
\text { as Pb) }\end{array}$ & $\begin{array}{l}\text { Lithlum, } \\
\text { dis- } \\
\text { solved } \\
(\mu g / L \\
\text { as L) }\end{array}$ & $\begin{array}{c}\text { Mange- } \\
\text { nese, } \\
\text { dlssolved } \\
(\mu g / L \\
\text { as Mn) }\end{array}$ & $\begin{array}{l}\text { Molyb- } \\
\text { denum, } \\
\text { dls- } \\
\text { solvod } \\
\text { ( } \mu \text { g } / \mathrm{L} \\
\text { as Mo) }\end{array}$ & $\begin{array}{c}\text { Nickel, } \\
\text { dis- } \\
\text { solved } \\
(\mu g / L \\
\text { as NI) }\end{array}$ & $\begin{array}{l}\text { Selo- } \\
\text { nlum, } \\
\text { dis- } \\
\text { aolvod } \\
\text { ( } \mu \text { g/L } \\
\text { aa Se) }\end{array}$ & $\begin{array}{l}\text { Sllver, } \\
\text { dis- } \\
\text { aolved } \\
\text { (flg/L } \\
\text { es Ag) }\end{array}$ & $\begin{array}{l}\text { Stron- } \\
\text { tium, } \\
\text { dissolved } \\
(\mu g / L \\
\text { aa Sr) }\end{array}$ & $\begin{array}{l}\text { Vana- } \\
\text { dium, } \\
\text { dis- } \\
\text { solved } \\
(\mu g / L \\
\text { as V) }\end{array}$ & $\begin{array}{l}\text { Zinc, } \\
\text { d's- } \\
\text { ao'ved } \\
(\mu g / L \\
\text { as Zn) }\end{array}$ \\
\hline $\begin{array}{l}147-095-13 C C C 2 \\
147-095-13 C C C 3 \\
147-095-14 A A A \\
147-095-14 C B B 1 \\
147-095-24 A A C\end{array}$ & $\begin{array}{c}- \\
<30 \\
- \\
-- \\
--\end{array}$ & $\begin{array}{l}-\ddot{62} \\
-- \\
--\end{array}$ & $\begin{array}{r}20 \\
8 \\
10 \\
30 \\
20\end{array}$ & $\begin{array}{l}\ddot{-} \\
<30 \\
-- \\
--\end{array}$ & $\begin{array}{l}<30 \\
- \\
-\end{array}$ & $\begin{array}{l}-- \\
- \\
-\end{array}$ & $\begin{array}{c}-\overline{3.0} \\
\overline{-} \\
\overline{-}\end{array}$ & $\begin{array}{l}- \\
82 \\
-- \\
--\end{array}$ & $\begin{array}{l}<18 \\
-- \\
--\end{array}$ & $\begin{array}{l}\ddot{<9} \\
- \\
-\end{array}$ \\
\hline $\begin{array}{l}\text { 147-095-26BBB } \\
148-087-07 \mathrm{AAA} 1 \\
148-087-07 \mathrm{AAA} 2 \\
148-087-11 \mathrm{DDD} \\
148-087-13 \mathrm{BBB}\end{array}$ & $\begin{array}{l}-- \\
- \\
-- \\
- \\
--\end{array}$ & $\begin{array}{l}- \\
- \\
-- \\
-- \\
--\end{array}$ & $\begin{array}{r}20 \\
150 \\
10 \\
-30\end{array}$ & $\begin{array}{l}-- \\
-- \\
-- \\
--\end{array}$ & $\begin{array}{l}- \\
- \\
- \\
-\end{array}$ & $\begin{array}{l}- \\
\ddot{-} \\
- \\
-\end{array}$ & $\begin{array}{l}- \\
\overline{-} \\
-\end{array}$ & $\begin{array}{l}-- \\
- \\
- \\
- \\
-\end{array}$ & $\begin{array}{l}-- \\
- \\
-- \\
-- \\
--\end{array}$ & $\begin{array}{l}- \\
- \\
-\end{array}$ \\
\hline $\begin{array}{l}\text { 148-087-13DDD } \\
148-087-24 \mathrm{BCD} \\
148-087-27 \mathrm{ADA} \\
148-087-27 \mathrm{DDA} \\
148-088-02 \mathrm{DDA}\end{array}$ & $\begin{array}{l}-- \\
-- \\
- \\
--\end{array}$ & $\begin{array}{l}-- \\
-- \\
- \\
-- \\
--\end{array}$ & $\begin{array}{l}10 \\
- \\
- \\
--\end{array}$ & $\begin{array}{l}-- \\
-- \\
-- \\
-\end{array}$ & $\begin{array}{l}-- \\
- \\
-- \\
-\end{array}$ & $\begin{array}{l}- \\
- \\
- \\
-\end{array}$ & $\begin{array}{l}-- \\
\ddot{-} \\
- \\
-\end{array}$ & $\begin{array}{l}-- \\
-- \\
-- \\
-- \\
-\end{array}$ & $\begin{array}{l}-- \\
-- \\
-- \\
- \\
-\end{array}$ & $\begin{array}{l}- \\
- \\
- \\
- \\
-\end{array}$ \\
\hline $\begin{array}{l}148-088-02 D D A \\
148-088-02 D D B \\
148-088-21 D B D \\
148-090-16 A B C \\
148-090-25 B C\end{array}$ & $\begin{array}{l}- \\
<- \\
<10 \\
<30 \\
--\end{array}$ & $\begin{array}{c}180 \\
-- \\
34 \\
32 \\
--\end{array}$ & $\begin{array}{r}- \\
50 \\
8 \\
<3 \\
40\end{array}$ & $\begin{array}{l}- \\
<- \\
<30 \\
--\end{array}$ & $\begin{array}{l}- \\
<\overline{10} \\
<30 \\
--\end{array}$ & $\begin{array}{l}-- \\
-- \\
- \\
- \\
-\end{array}$ & $\begin{array}{l}-- \\
<1.0 \\
<3.0 \\
-\end{array}$ & $\begin{array}{l}-- \\
- \\
120 \\
83 \\
--\end{array}$ & $\begin{array}{l}-- \\
-- \\
<6 \\
<18 \\
--\end{array}$ & $\begin{array}{r}- \\
6 \\
<9 \\
--\end{array}$ \\
\hline $\begin{array}{l}148-090-26 \mathrm{ABB} 2 \\
148-092-06 \mathrm{AAD} \\
148-092-06 \mathrm{BCA} \\
148-092-06 \mathrm{BDB} \\
148-092-23 \mathrm{CCA}\end{array}$ & $\begin{array}{l}<- \\
<10 \\
-- \\
--\end{array}$ & $\begin{array}{l}\ddot{2} \\
-\because \\
-\because \\
--\end{array}$ & $\begin{array}{r}- \\
25 \\
70 \\
20 \\
100\end{array}$ & $\begin{array}{l}<10 \\
-- \\
--\end{array}$ & $\begin{array}{l}<10 \\
\ddot{-} \\
-\end{array}$ & $\begin{array}{l}-- \\
- \\
- \\
- \\
-\end{array}$ & $\begin{array}{l}-\overline{-} \\
<-.0 \\
-- \\
--\end{array}$ & $\begin{array}{l}- \\
390 \\
-- \\
--\end{array}$ & $\begin{array}{l}-- \\
<6 \\
-- \\
-- \\
--\end{array}$ & $\begin{array}{l}- \\
30 \\
- \\
--\end{array}$ \\
\hline $\begin{array}{l}148-092-35 \mathrm{BDA} \\
148-093-04 \mathrm{CAB} 1 \\
148-093-04 \mathrm{CBD} \\
148-093-10 \mathrm{CCC} \\
148-093-14 C D C\end{array}$ & $\begin{array}{l}-- \\
-- \\
- \\
- \\
-\end{array}$ & $\begin{array}{l}-. \\
-- \\
- \\
--\end{array}$ & $\begin{array}{r}20 \\
20 \\
60 \\
220 \\
160\end{array}$ & $\begin{array}{l}-- \\
-- \\
-- \\
- \\
--\end{array}$ & $\begin{array}{l}-- \\
\ddot{-} \\
- \\
-\end{array}$ & $\begin{array}{l}- \\
- \\
- \\
- \\
-\end{array}$ & $\begin{array}{l}- \\
- \\
- \\
- \\
-\end{array}$ & $\begin{array}{l}-- \\
- \\
-- \\
- \\
--\end{array}$ & $\begin{array}{l}-- \\
-- \\
- \\
-- \\
--\end{array}$ & $\begin{array}{l}- \\
-- \\
- \\
- \\
-\end{array}$ \\
\hline $\begin{array}{l}148-093-17 \mathrm{BBD} \\
148-094-13 \mathrm{BBD} \\
148-094-20 \mathrm{DDD} \\
148-095-03 \mathrm{AAA} \\
148-095-35 \mathrm{BDD}\end{array}$ & $\begin{array}{l}- \\
- \\
<30 \\
--\end{array}$ & $\begin{array}{l}-- \\
-- \\
<-12 \\
--\end{array}$ & $\begin{array}{r}20 \\
520 \\
-- \\
15 \\
10\end{array}$ & $\begin{array}{l}-- \\
-- \\
<30 \\
--\end{array}$ & $\begin{array}{c}- \\
- \\
-\overline{30} \\
-\end{array}$ & $\begin{array}{l}- \\
- \\
- \\
-\end{array}$ & $\begin{array}{l}- \\
- \\
\overline{4} .0 \\
--\end{array}$ & $\begin{array}{l}-- \\
-- \\
-- \\
--\end{array}$ & $\begin{array}{l}-- \\
-- \\
<18 \\
--\end{array}$ & $\begin{array}{l}- \\
- \\
-\end{array}$ \\
\hline $\begin{array}{l}149-087-02 D D C 2 \\
149-087-05 \mathrm{CDC} \\
149-087-06 \mathrm{AAA} \\
149-087-08 \mathrm{ABB} 1 \\
149-087-09 \mathrm{DAD}\end{array}$ & $\begin{array}{l}-- \\
-- \\
-- \\
--\end{array}$ & $\begin{array}{l}-- \\
-- \\
-- \\
-- \\
--\end{array}$ & $\begin{array}{l}- \\
\ddot{100} \\
- \\
-\end{array}$ & $\begin{array}{l}-- \\
-- \\
- \\
- \\
--\end{array}$ & $\begin{array}{l}- \\
- \\
-- \\
- \\
--\end{array}$ & $\begin{array}{l}- \\
- \\
- \\
- \\
-\end{array}$ & $\begin{array}{l}-- \\
-- \\
- \\
- \\
-\end{array}$ & $\begin{array}{l}-. \\
- \\
- \\
- \\
--\end{array}$ & $\begin{array}{l}-- \\
- \\
- \\
- \\
--\end{array}$ & $\begin{array}{l}- \\
- \\
- \\
- \\
-\end{array}$ \\
\hline $\begin{array}{l}149-087-32 \mathrm{CCC} \\
149-088-23 \mathrm{DAA} \\
149-089-01 \mathrm{BDA} \\
149-089-02 \mathrm{BBB} \\
149-089-03 \mathrm{BBD}\end{array}$ & $\begin{array}{l}<- \\
<10 \\
<30 \\
<30\end{array}$ & $\begin{array}{c}\overline{42} \\
75 \\
\overline{110}\end{array}$ & $\begin{array}{r}10 \\
230 \\
18 \\
-\quad \\
100\end{array}$ & $\begin{array}{l}<- \\
<10 \\
<30 \\
-- \\
<30\end{array}$ & $\begin{array}{l}<- \\
<10 \\
<30 \\
<30\end{array}$ & $\begin{array}{l}- \\
- \\
- \\
- \\
-\end{array}$ & $\begin{array}{l}<\ddot{1.0} \\
<3.0 \\
<\ddot{3.0}\end{array}$ & $\begin{array}{r}1, \overline{200} \\
600 \\
\ddot{2,000}\end{array}$ & $\begin{array}{l}- \\
<6 \\
<18 \\
-\ddot{18}\end{array}$ & $\begin{array}{l}\overline{14} \\
14 \\
- \\
18\end{array}$ \\
\hline $\begin{array}{l}149-089-03 \mathrm{DAA} \\
149-089-10 \mathrm{BBC} \\
149-089-10 \mathrm{CBB} 3 \\
149-089-11 \mathrm{BBB} 1 \\
149-089-23 \mathrm{CCC} 1\end{array}$ & $\begin{array}{l}<30 \\
<10 \\
-- \\
--\end{array}$ & $\begin{array}{l}84 \\
-- \\
-- \\
--\end{array}$ & $\begin{array}{l}33 \\
840 \\
210 \\
- \\
-\end{array}$ & $\begin{array}{l}<30 \\
<- \\
<10 \\
-- \\
--\end{array}$ & $\begin{array}{l}<30 \\
<10 \\
-- \\
--\end{array}$ & $\begin{array}{l}- \\
- \\
- \\
-\end{array}$ & $\begin{array}{l}<3.0 \\
<1.0 \\
-- \\
--\end{array}$ & $\begin{array}{c}1,100 \\
-- \\
1,200 \\
- \\
--\end{array}$ & $\begin{array}{l}<18 \\
<6 \\
-- \\
--\end{array}$ & $\begin{array}{l}17 \\
\ddot{19} \\
- \\
-\end{array}$ \\
\hline
\end{tabular}


Table 6. Trace-element concentrations in water from wells--Continued

\begin{tabular}{|c|c|c|c|c|c|c|c|c|c|}
\hline Local number & $\begin{array}{l}\text { Aquifer } \\
\text { coda }\end{array}$ & $\begin{array}{l}\text { Depth of } \\
\text { well, } \\
\text { total } \\
\text { (foet) }\end{array}$ & Dato & $\begin{array}{l}\text { Boron, } \\
\text { dis- } \\
\text { solvod } \\
(\mu g / L \\
\text { as B) }\end{array}$ & $\begin{array}{l}\text { Cadmlum, } \\
\text { dissolved } \\
\text { ( } \mu g / L \\
\text { as Cd) }\end{array}$ & $\begin{array}{l}\text { Chro- } \\
\text { mlum, } \\
\text { dls- } \\
\text { solved } \\
\text { ( } \mu g / \mathrm{L} \\
\text { as } \mathrm{Cr})\end{array}$ & $\begin{array}{l}\text { Cobalt, } \\
\text { dis- } \\
\text { solvod } \\
(\mu g / L \\
\text { as Co) }\end{array}$ & $\begin{array}{l}\text { Cofpor, } \\
\text { dis- } \\
\text { sol iod } \\
(\mu g / L \\
\text { as Cu) }\end{array}$ & $\begin{array}{l}\text { Iron, } \\
\text { dis- } \\
\text { solvod } \\
\text { ( } \mu \text { g/L } \\
\text { as Fo) }\end{array}$ \\
\hline $\begin{array}{l}\text { 149-089-24AAA } \\
149-089-36 \mathrm{BBB} 1 \\
149-090-11 \mathrm{ADA} 2 \\
149-092-22 \mathrm{CDC} \\
149-093-02 \mathrm{ACB}\end{array}$ & $\begin{array}{l}\text { 112WSLD } \\
125 S N L B \\
125 T G R V \\
125 S N L B \\
125 T G R V\end{array}$ & $\begin{array}{r}172 \\
130 \\
199 \\
40 \\
647\end{array}$ & $\begin{array}{l}07-14-70 \\
05-04-67 \\
10-12-66 \\
08-02-72 \\
08-29-72\end{array}$ & $\begin{array}{l}270 \\
390 \\
660 \\
290 \\
300\end{array}$ & $\begin{array}{l}- \\
- \\
- \\
-\end{array}$ & $\begin{array}{l}- \\
\overline{-} \\
\overline{-}\end{array}$ & $\begin{array}{l}- \\
- \\
-\end{array}$ & $\begin{array}{l}- \\
\overline{-} \\
\overline{-} \\
-\end{array}$ & $\begin{array}{r}3,800 \\
40 \\
-\quad \\
1,800 \\
540\end{array}$ \\
\hline $\begin{array}{l}149-093-05 C D C \\
149-093-08 D C C \\
149-093-09 C C C \\
149-093-09 C C D \\
149-093-21 D C A\end{array}$ & $\begin{array}{l}\text { 125SNLB } \\
125 \mathrm{TGRV} \\
125 \mathrm{TGRV} \\
125 \mathrm{SNLB} \\
125 \mathrm{SNLB}\end{array}$ & $\begin{array}{r}84 \\
500 \\
440 \\
65 \\
35\end{array}$ & $\begin{array}{l}08-28-72 \\
08-17-72 \\
10-31-90 \\
08-18-72 \\
08-17-72\end{array}$ & $\begin{array}{l}130 \\
290 \\
320 \\
140 \\
110\end{array}$ & $\begin{array}{c}\ddot{-} \\
<3.0 \\
\ddot{-}\end{array}$ & $\begin{array}{l}\overline{-} \\
<20 \\
- \\
-\end{array}$ & $\begin{array}{l}- \\
<9 \\
-\end{array}$ & $\begin{array}{c}- \\
<\overline{30} \\
- \\
-\end{array}$ & $\begin{array}{r}200 \\
300 \\
28 \\
1,200 \\
1,000\end{array}$ \\
\hline $\begin{array}{l}\text { 149-093-27ABA } \\
149-094-14 \mathrm{BA} \\
149-095-06 \mathrm{ACC} \\
149-095-06 \mathrm{ADDB} \\
149-095-09 \mathrm{CDD}\end{array}$ & $\begin{array}{l}\text { 125SNLB } \\
211 \mathrm{HCFH} \\
125 \mathrm{TGRV} \\
\text { 125SNLB } \\
\text { 211FXHL }\end{array}$ & $\begin{array}{r}65 \\
1,745 \\
883 \\
80 \\
1,564\end{array}$ & $\begin{array}{l}08-17-72 \\
06-04-79 \\
08-19-82 \\
10-31-90 \\
06-23-86\end{array}$ & $\begin{array}{r}250 \\
320 \\
620 \\
460 \\
2,200\end{array}$ & $\begin{array}{l}\ddot{-} \\
\ddot{1.0} \\
\ddot{-}\end{array}$ & $\begin{array}{l}- \\
- \\
-5\end{array}$ & $\begin{array}{l}- \\
\overline{-} \\
-\end{array}$ & $\overline{-}$ & $\begin{array}{r}0 \\
300 \\
80 \\
540 \\
50\end{array}$ \\
\hline $\begin{array}{l}\text { 150-087-31DCD } \\
150-088-18 \mathrm{ADD} 1 \\
150-088-33 \mathrm{ADD} \\
150-089-06 \mathrm{BBC} \\
150-089-14 \mathrm{ADD}\end{array}$ & $\begin{array}{c}125 S N L B \\
125 S N L B \\
- \\
125 \text { SNLB } \\
125 S N L B\end{array}$ & $\begin{array}{r}88 \\
58 \\
192 \\
117 \\
56\end{array}$ & $\begin{array}{l}10-19-77 \\
10-11-66 \\
11-08-90 \\
11-08-90 \\
11-07-90\end{array}$ & $\begin{array}{l}290 \\
550 \\
300 \\
220 \\
560\end{array}$ & $\begin{array}{l}-- \\
<1.0 \\
<1.0 \\
<1.0\end{array}$ & $\begin{array}{l}- \\
<5 \\
<5 \\
<5\end{array}$ & $\begin{array}{l}- \\
- \\
<3 \\
<3 \\
<3\end{array}$ & $\begin{array}{l}\overrightarrow{-} \\
<10 \\
<10 \\
<10\end{array}$ & $\begin{array}{r}320 \\
80 \\
160 \\
1,100 \\
71\end{array}$ \\
\hline $\begin{array}{l}150-089-26 \mathrm{BCC} \\
150-089-31 \mathrm{BCC} \\
150-089-31 \mathrm{DAA} \\
150-089-32 \mathrm{DAA} \\
150-090-19 \mathrm{ADB}\end{array}$ & $\begin{array}{l}125 S N L B \\
112 W S L D \\
112 W S L D \\
112 W S L D \\
112 W S L D\end{array}$ & $\begin{array}{r}45 \\
278 \\
126 \\
224 \\
82\end{array}$ & $\begin{array}{l}10-11-66 \\
07-27-70 \\
11-07-90 \\
10-24-69 \\
11-07-90\end{array}$ & $\begin{array}{l}410 \\
630 \\
540 \\
-- \\
360\end{array}$ & $\begin{array}{l}-- \\
<\overline{1.0} \\
<\overline{1.0}\end{array}$ & $\begin{array}{l}- \\
- \\
<5 \\
\overline{<5}\end{array}$ & $\begin{array}{l}- \\
\overline{<3} \\
\overline{<3}\end{array}$ & $\begin{array}{l}-- \\
<10 \\
<10\end{array}$ & $\begin{array}{r}220 \\
960 \\
810 \\
640 \\
3,800\end{array}$ \\
\hline $\begin{array}{l}150-090-21 \mathrm{CBB} \\
150-090-25 \mathrm{DAA} 2 \\
150-090-36 \mathrm{AAA} \\
150-091-35 \mathrm{CCA} \\
150-092-12 \mathrm{BBDA}\end{array}$ & $\begin{array}{l}\text { 112WSLD } \\
125 \text { SNLB } \\
112 W S L D \\
125 S N L B \\
125 S N B\end{array}$ & $\begin{array}{l}246 \\
225 \\
299 \\
126 \\
120\end{array}$ & $\begin{array}{l}10-12-66 \\
10-13-66 \\
07-28-70 \\
11-08-50 \\
10-30-90\end{array}$ & $\begin{array}{r}560 \\
610 \\
750 \\
0 \\
390\end{array}$ & $\begin{array}{l}-- \\
-- \\
-- \\
<\overline{1.0}\end{array}$ & $\begin{array}{l}- \\
- \\
- \\
<5\end{array}$ & $\begin{array}{l}\overline{-} \\
\overline{<3}\end{array}$ & $\begin{array}{c}- \\
- \\
- \\
<- \\
<10\end{array}$ & $\begin{array}{c}- \\
200 \\
3,800 \\
2,000\end{array}$ \\
\hline $\begin{array}{l}\text { 150-093-31ADD } \\
150-093-33 \mathrm{CAA} \\
150-094 \text { 19DDDA } \\
150-095-14 \mathrm{DCB} \\
150-095-29 \mathrm{CAC}\end{array}$ & $\begin{array}{l}\text { 125TGRV } \\
\text { 125TGRV } \\
\text { 125TGRV } \\
\text { 125SNLB } \\
125 \text { SNLB }\end{array}$ & $\begin{array}{r}336 \\
388 \\
830 \\
35 \\
240\end{array}$ & $\begin{array}{l}08-28-72 \\
08-28-72 \\
10-31-90 \\
07-10-79 \\
07-10-79\end{array}$ & $\begin{array}{r}90 \\
260 \\
660 \\
30 \\
630\end{array}$ & $\begin{array}{c}-- \\
<3.0 \\
-- \\
--\end{array}$ & $\begin{array}{l}- \\
<20 \\
-\end{array}$ & $\begin{array}{l}-- \\
\ddot{<9} \\
- \\
-\end{array}$ & $\begin{array}{c}- \\
<30 \\
\ddot{-}\end{array}$ & $\begin{array}{l}250 \\
250 \\
260 \\
470 \\
220\end{array}$ \\
\hline $\begin{array}{l}151-088-08 \mathrm{AAA} \\
151-088-33 \mathrm{BBA} \\
151-089-04 \mathrm{ABD} \\
151-090-16 \mathrm{BAB} \\
151-090-29 \mathrm{BBC}\end{array}$ & $\begin{array}{l}\text { 125SNLB } \\
125 S N L B \\
125 \mathrm{TGRV} \\
125 \mathrm{SNLB} \\
211 \mathrm{FXHL}\end{array}$ & $\begin{array}{r}120 \\
160 \\
226 \\
165 \\
1,620\end{array}$ & $\begin{array}{l}11-01-77 \\
06-06-68 \\
05-15-67 \\
06-06-68 \\
11-06-90\end{array}$ & $\begin{array}{r}1,200 \\
1,000 \\
120 \\
440 \\
3,500\end{array}$ & $\begin{array}{c}-- \\
\ddot{-} \\
\ddot{<} \\
<3.0\end{array}$ & $\begin{array}{l}\overline{-} \\
\ddot{<20}\end{array}$ & $\begin{array}{l}- \\
- \\
\ddot{<} \\
<9\end{array}$ & $\begin{array}{c}- \\
\ddot{-} \\
\ddot{<30}\end{array}$ & $\begin{array}{r}20 \\
260 \\
360 \\
0 \\
99\end{array}$ \\
\hline $\begin{array}{l}\text { 151-090-36DDA } \\
151-091-11 \mathrm{CDD} \\
151-091-12 \mathrm{BBA} 1 \\
\text { 151-092-28ABAB } \\
\text { 151-092-34DAA }\end{array}$ & $\begin{array}{c}\text { 125SNLB } \\
\text { 125TGRV } \\
\text { 125TGRV } \\
125 \mathrm{TGRV} \\
\text { 112SANISH }\end{array}$ & $\begin{array}{l}115 \\
173 \\
198 \\
200 \\
138\end{array}$ & $\begin{array}{l}04-20-67 \\
11-06-90 \\
11-06-90 \\
10-30-90 \\
09-02-66\end{array}$ & $\begin{array}{r}590 \\
80 \\
270 \\
600 \\
120\end{array}$ & $\begin{array}{l}<- \\
<3.0 \\
<1.0 \\
<3.0 \\
--\end{array}$ & $\begin{array}{l}<- \\
<20 \\
<5 \\
<20 \\
-\end{array}$ & $\begin{array}{l}<- \\
<9 \\
<3 \\
<9 \\
--\end{array}$ & $\begin{array}{l}\ddot{<0} \\
<10 \\
<20 \\
--\end{array}$ & $\begin{array}{r}1,700 \\
82 \\
110 \\
48 \\
8,600\end{array}$ \\
\hline $\begin{array}{l}\text { 151-093-10AAAB } \\
151-093-16 \mathrm{BCD} \\
151-093-35 \mathrm{BBB} 2 \\
151-095-29 \mathrm{BCB} \\
152-087-16 \mathrm{AAA}\end{array}$ & $\begin{array}{c}\text { 12STGRV } \\
\text { 112SANISH } \\
\text { 12STGRV } \\
\text { 125SNLB } \\
\text { 112VANG }\end{array}$ & $\begin{array}{r}421 \\
150 \\
298 \\
80 \\
17\end{array}$ & $\begin{array}{l}10-30-90 \\
06-06-68 \\
10-30-90 \\
06-14-79 \\
08-09-66\end{array}$ & $\begin{array}{r}550 \\
780 \\
170 \\
160 \\
0\end{array}$ & $\begin{array}{c}<3.0 \\
<\ddot{3.0} \\
-. \\
-.\end{array}$ & $\begin{array}{l}<20 \\
<20 \\
- \\
-\end{array}$ & $\begin{array}{l}<9 \\
\overline{<9} \\
-\end{array}$ & $\begin{array}{l}<20 \\
\ddot{2} 0 \\
- \\
-\end{array}$ & $\begin{array}{r}450 \\
6,300 \\
150 \\
2,900 \\
2,700\end{array}$ \\
\hline
\end{tabular}


Table 6. Trace-element concentrations in water from wells--Continued

\begin{tabular}{|c|c|c|c|c|c|c|c|c|c|c|}
\hline Local number & $\begin{array}{c}\text { Lead, } \\
\text { dis- } \\
\text { aolved } \\
(\mu g / L \\
\text { as } \mathrm{Pb})\end{array}$ & $\begin{array}{l}\text { Lithlum, } \\
\text { dls- } \\
\text { solved } \\
\text { ( } \mu g \text { g/L } \\
\text { as L) }\end{array}$ & $\begin{array}{l}\text { Manga- } \\
\text { nese, } \\
\text { dissolvod } \\
\text { ( } \mu g / L \\
\text { as Mn) }\end{array}$ & $\begin{array}{l}\text { Molyb- } \\
\text { denum, } \\
\text { dis- } \\
\text { solved } \\
\text { ( } \mu \text { g/L } \\
\text { as Mo) }\end{array}$ & $\begin{array}{c}\text { Nickel, } \\
\text { dls- } \\
\text { solved } \\
(\text { (Hg/L } \\
\text { as NI) }\end{array}$ & $\begin{array}{c}\text { Sele- } \\
\text { nlum, } \\
\text { dis- } \\
\text { solved } \\
\text { ( } \mu g \text { g'l } \\
\text { aa Se) }\end{array}$ & $\begin{array}{l}\text { Silver, } \\
\text { dis- } \\
\text { solvod } \\
\text { ( } \mu g / L \\
\text { as Ag) }\end{array}$ & $\begin{array}{c}\text { Stron- } \\
\text { tlum, } \\
\text { dissolved } \\
(\mu g / L \\
\text { as Sr) }\end{array}$ & $\begin{array}{l}\text { Vana- } \\
\text { dium, } \\
\text { dls- } \\
\text { aolved } \\
(\mu g / L \\
\text { ag V) }\end{array}$ & $\begin{array}{l}\text { Zinc, } \\
\text { dis- } \\
\text { sclved } \\
(\mu g / L \\
\text { as Zn) }\end{array}$ \\
\hline 149-089-24AAA & -. & -. & 20 & -- & - & - & - & -. & -. & - \\
\hline 149-089-36BBB 1 & -- & -. & - & -- & - & - & - & -- & -- & - \\
\hline 149-090-11ADA2 & -- & -- & $\overline{10}$ & -. & -- & - & -- & -- & -- & - \\
\hline 149-092-22CDC & -- & -- & 190 & - & -- & - & - & -- & -- & - \\
\hline $149-093-02 \mathrm{ACB}$ & -. & - & 0 & - & - & - & - & -- & -- & - \\
\hline 149-093-05CDC & -- & -- & 0 & - & - & - & - & -- & -. & -. \\
\hline 149-093-08DCC & $\ddot{n}$ & $\because$ & 60 & $\ddot{-}$ & - & - & $\ddot{n}$ & - & $\because$ & - \\
\hline $149-093-09 \mathrm{CCC}$ & $<30$ & 39 & 29 & $<30$ & $<30$ & - & $<3.0$ & 84 & $<18$ & 91 \\
\hline $149-093-09 \mathrm{CCD}$ & -. & $\ldots$ & 400 & -. & _- & .- & -. & -- & .. & - \\
\hline 149-093-21DCA & - & -. & 180 & - & - & - & - & -- & -- & -. \\
\hline 149-093-27ABA & -- & -- & 40 & -- & - & - & - & -- & -- & -- \\
\hline $149-094-14 \mathrm{BA}$ & -- & -- & 60 & - & - & - & -. & -- & -- & - \\
\hline $149-095-06 \mathrm{ACC}$ & $\because$ & $\ddot{-}$ & 20 & - & - & - & $\ddot{-}$ & $\ddot{z}$ & - & -- \\
\hline 149-095-06ADDB & $<10$ & 30 & 160 & $<10$ & $<10$ & -- & $<1.0$ & 530 & $<6$ & 8 \\
\hline 149-095-09CDD & -- & -- & 10 & -- & - & - & - & -- & -- & -- \\
\hline $150-087-31 D C D$ & -- & -- & 120 & -. & -- & - & _- & -. & -- & .- \\
\hline 150-088-18ADD1 & - & - & $\cdots$ & - & - & - & -- & -- & -. & - \\
\hline 150-088-33ADD & $<10$ & 47 & 23 & $<10$ & $<10$ & - & $<1.0$ & 400 & $<6$ & 12 \\
\hline 150-089-06BBC & $<10$ & 68 & 230 & $<10$ & $<10$ & - & $<1.0$ & 1,500 & $<6$ & 110 \\
\hline 150-089-14ADD & $<10$ & 59 & 140 & $<10$ & $<10$ & -- & $<1.0$ & 1,000 & $<6$ & 9 \\
\hline $150-089-26 \mathrm{BCC}$ & -. & -- & -- & -- & -- & - & - & -- & -- & - \\
\hline $150-089-31 \mathrm{BCC}$ & -- & -- & 50 & -- & - & - & -- & -- & -- & -- \\
\hline $150-089-31 \mathrm{DAA}$ & $<10$ & 110 & 77 & $<10$ & $<10$ & -- & $<1.0$ & 1400 & $<6$ & 300 \\
\hline 150-089-32DAA & -- & 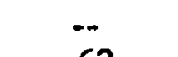 & 10 & -- & $=$ & - & - & $-\overline{0}=0$ & 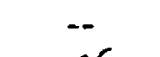 & 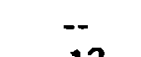 \\
\hline $150-090-19 \mathrm{ADB}$ & $<10$ & 63 & 580 & $<10$ & $<10$ & - & $<1.0$ & 850 & $<6$ & 13 \\
\hline $150-090-21 \mathrm{CBB}$ & -- & -- & - & $=$ & -. & - & -- & -. & -- & -- \\
\hline $150-090-25 \mathrm{DAA} 2$ & -- & -- & - & -- & -- & -- & - & -- & -- & -- \\
\hline 150-090-36AAA & -- & -. & 40 & -. & -- & -. & - & -. & -- & - \\
\hline $150-091-35 \mathrm{CCA}$ & -- & - & - & -- & -- & - & - & -- & -- & -- \\
\hline $150-092-12 \mathrm{BBDA}$ & $<10$ & 120 & 480 & $<10$ & $<10$ & - & 1.0 & 950 & $<6$ & 6 \\
\hline 150-093-31ADD & -- & -- & 0 & -- & -- & -- & - & -- & -. & -- \\
\hline $150-093-33 \mathrm{CAA}$ & -- & -- & 0 & -- & -- & -- & - & -- & -- & - \\
\hline 150-094-19DDDA & $<30$ & 77 & 6 & $<30$ & $<30$ & - & $<3.0$ & 200 & $<18$ & 89 \\
\hline $150-095-14 \mathrm{DCB}$ & -- & -- & 320 & - & - & - & $-\cdots$ & - & -- & -- \\
\hline $150-095-29 \mathrm{CAC}$ & -- & -. & 140 & -- & - & -. & -- & -- & -- & - \\
\hline 151-088-08AAA & -- & -- & 2,800 & -. & .- & - & -- & .. & -- & .- \\
\hline $151-088-33 \mathrm{BBA}$ & -. & -- & - & -. & - & -- & -- & -- & -- & -- \\
\hline 151-089-04ABD & -- & -- & -- & -- & - & -- & - & -- & -- & -- \\
\hline $151-090-16 \mathrm{BAB}$ & -. & -. & -. & -- & - & -- & -- & -. & .. & -- \\
\hline $151-090-29 \mathrm{BBC}$ & $<30$ & 90 & 4 & $<30$ & $<30$ & - & $<3.0$ & 150 & $<18$ & 250 \\
\hline $151-090-36 \mathrm{DDA}$ & -- & -. & -- & -- & - & - & -- & - & .- & - \\
\hline 151-091-11CDD & $<30$ & 36 & 9 & $<30$ & $<30$ & .. & $<3.0$ & 130 & $<18$ & 9 \\
\hline 151-091-12BBA1 & $<10$ & 25 & 8 & $<10$ & $<10$ & -- & $<1.0$ & 55 & $<6$ & 16 \\
\hline $151-092-28 \mathrm{ABAB}$ & $<30$ & 53 & 28 & $<30$ & $<30$ & -- & $<3.0$ & 130 & $<18$ & $<9$ \\
\hline 151-092-34DAA & 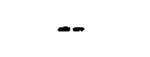 & - & - & -- & -- & -- & - & -- & -- & - \\
\hline $151-093-10 \mathrm{AAAB}$ & $<30$ & 27 & 63 & $<30$ & $<30$ & .. & $<3.0$ & 150 & 60 & 100 \\
\hline $151-093-16 \mathrm{BCD}$ & . & $\ldots$ & - & $\ldots$ & .. & - & $\ldots$ & $\ldots$ & -. & - \\
\hline 151-093-35BBB2 & $<30$ & 28 & 24 & $<30$ & $<30$ & -- & 4.0 & 100 & $<18$ & $<9$ \\
\hline $151-095-29 \mathrm{BCB}$ & -- & -- & 1,400 & - & - & - & - & - & -- & - \\
\hline 152-087-16AAA & & -- & -- & 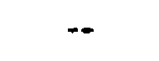 & .. & -- & -- & -. & -- & - \\
\hline
\end{tabular}


Table 6. Trace-element concentrations in water from wells--Continued

\begin{tabular}{|c|c|c|c|c|c|c|c|c|c|}
\hline Local number & $\begin{array}{l}\text { Aquifer } \\
\text { code }\end{array}$ & $\begin{array}{c}\text { Depth of } \\
\text { well, } \\
\text { lotal } \\
\text { (feet) }\end{array}$ & Date & $\begin{array}{l}\text { Boron, } \\
\text { dis- } \\
\text { eolved } \\
\text { ( } \mu g / L \\
\text { es B) }\end{array}$ & $\begin{array}{c}\text { Cadmium, } \\
\text { dissolved } \\
\text { ( } \mu g / L \\
\text { as Cd) }\end{array}$ & $\begin{array}{l}\text { Chro- } \\
\text { mlum, } \\
\text { dis- } \\
\text { solved } \\
(\mu g / L \\
\text { as Cr) }\end{array}$ & $\begin{array}{l}\text { Cobalt, } \\
\text { dis- } \\
\text { solved } \\
(\mu \mathrm{lg} / \mathrm{L} \\
\text { as Co) }\end{array}$ & $\begin{array}{l}\text { Copner, } \\
\text { dis- } \\
\text { eolved } \\
(\mu g / L \\
\text { as Cu) }\end{array}$ & $\begin{array}{l}\text { Iron, } \\
\text { dis- } \\
\text { solved } \\
(\mu g / L \\
\text { a\& } F e)\end{array}$ \\
\hline $\begin{array}{l}152-087-28 \mathrm{DAA} \\
152-087-28 \mathrm{DAA} \\
152-088-04 \mathrm{BBB} \\
152-088-04 \mathrm{BDA} \\
152-088-05 \mathrm{DAD} 2\end{array}$ & $\begin{array}{l}\text { 112HDLK } \\
112 \mathrm{HDLK} \\
125 \mathrm{SNLB} \\
\text { 125SNLB } \\
\text { 125TGRV }\end{array}$ & $\begin{array}{r}150 \\
150 \\
90 \\
102 \\
240\end{array}$ & $\begin{array}{l}06-01-65 \\
06-29-71 \\
04-25-67 \\
11-09-90 \\
11-09-90\end{array}$ & $\begin{array}{l}550 \\
350 \\
470 \\
440 \\
450\end{array}$ & $\begin{array}{l}-. \\
-. \\
<3.0 \\
<3.0\end{array}$ & $\begin{array}{l}- \\
\overline{-} \\
<20 \\
<20\end{array}$ & $\begin{array}{l}- \\
- \\
<9 \\
<9\end{array}$ & $\begin{array}{l}- \\
- \\
<30 \\
<30\end{array}$ & $\begin{array}{r}400 \\
2,200 \\
1,100 \\
320 \\
100\end{array}$ \\
\hline $\begin{array}{l}152-089-05 \mathrm{BAC} \\
152-089-05 \mathrm{BACB} \\
152-089-23 \mathrm{CCC} \\
152-089-29 \mathrm{CCC} 5 \\
152-089-34 \mathrm{ABB}\end{array}$ & $\begin{array}{c}\text { 125SNLB } \\
\text { 125SNLB } \\
\text { 112BDVL } \\
\text { 125TGRV } \\
--\end{array}$ & $\begin{array}{r}119 \\
115 \\
47 \\
38 \\
120\end{array}$ & $\begin{array}{l}07-13-67 \\
11-08-90 \\
11-01-77 \\
11-06-90 \\
11-06-90\end{array}$ & $\begin{array}{r}860 \\
1,000 \\
190 \\
820 \\
190\end{array}$ & $\begin{array}{l}<\overrightarrow{1.0} \\
<\overrightarrow{3.0} \\
<1.0\end{array}$ & $\begin{array}{l}-- \\
<5 \\
\overline{20} \\
<5\end{array}$ & $\begin{array}{l}\overrightarrow{<3} \\
<- \\
<3\end{array}$ & $\begin{array}{l}<\overrightarrow{10} \\
-\overline{30} \\
20\end{array}$ & $\begin{array}{r}2,500 \\
90 \\
<10 \\
6,800 \\
14\end{array}$ \\
\hline $\begin{array}{l}152-089-35 D D D \\
152-090-02 C D D \\
152-090-09 B C C \\
152-090-13 C C C 1 \\
152-090-17 C D C\end{array}$ & $\begin{array}{l}\text { 125TGRV } \\
\text {-- } \\
125 \text { SNLB } \\
-\end{array}$ & $\begin{array}{r}90 \\
225 \\
65 \\
66 \\
90\end{array}$ & $\begin{array}{l}07-13-67 \\
07-13-67 \\
10-19-77 \\
07-13-67 \\
11-06-90\end{array}$ & $\begin{array}{r}230 \\
510 \\
140 \\
40 \\
330\end{array}$ & $\begin{array}{c}-- \\
-- \\
-- \\
-- \\
<1.0\end{array}$ & $\begin{array}{l}- \\
- \\
- \\
<5\end{array}$ & $\begin{array}{l}- \\
\overline{-} \\
\overline{<3}\end{array}$ & $\begin{array}{l}- \\
- \\
- \\
<10\end{array}$ & $\begin{array}{r}220 \\
5,900 \\
400 \\
80 \\
1,300\end{array}$ \\
\hline $\begin{array}{l}152-090-18 C C C \\
152-090-18 C C C \\
152-090-18 C C C \\
152-090-21 C B C \\
152-090-25 D B C 2\end{array}$ & $\begin{array}{c}\text { 112SLCK } \\
112 \text { SLCK } \\
112 S L C K \\
- \\
-\end{array}$ & $\begin{array}{l}79 \\
79 \\
79 \\
84 \\
74\end{array}$ & $\begin{array}{l}08-02-66 \\
08-10-71 \\
08-06-82 \\
10-17-77 \\
06-07-67\end{array}$ & $\begin{array}{l}700 \\
930 \\
250 \\
430 \\
590\end{array}$ & $\begin{array}{l}-- \\
-- \\
-- \\
-- \\
--\end{array}$ & $\begin{array}{l}-- \\
-- \\
-- \\
-\end{array}$ & $\begin{array}{l}- \\
- \\
- \\
-\end{array}$ & $\begin{array}{l}-- \\
- \\
-- \\
-\end{array}$ & $\begin{array}{r}1,000 \\
0 \\
520 \\
570 \\
250\end{array}$ \\
\hline $\begin{array}{l}152-090-26 \mathrm{DAA} \\
152-090-26 \mathrm{DAD} \\
152-091-05 \mathrm{DBB} 3 \\
152-091-08 \mathrm{DDD} \\
152-091-32 \mathrm{BBA}\end{array}$ & $\begin{array}{c}\overline{-} \\
\text { 125SNLB } \\
\text { 125TGRV } \\
-\end{array}$ & $\begin{array}{r}55 \\
59 \\
92 \\
225 \\
580\end{array}$ & $\begin{array}{l}07-28-76 \\
11-07-90 \\
11-06-90 \\
06-06-68 \\
11-08-90\end{array}$ & $\begin{array}{l}760 \\
550 \\
290 \\
590 \\
260\end{array}$ & $\begin{array}{l}<\overline{3.0} \\
<1.0 \\
<\overline{3.0}\end{array}$ & $\begin{array}{l}<\overline{20} \\
<5 \\
-\overline{20}\end{array}$ & $\begin{array}{l}- \\
<9 \\
<3 \\
- \\
<9\end{array}$ & $\begin{array}{r}<\overline{30} \\
50 \\
- \\
<30\end{array}$ & $\begin{array}{r}1,600 \\
1,700 \\
560 \\
3,100 \\
48\end{array}$ \\
\hline $\begin{array}{l}152-092-12 D D D \\
152-092-16 C D B D \\
152-092-17 D D D A \\
152-092-18 A A D D \\
152-092-19 A A A 3\end{array}$ & $\begin{array}{l}\text { 125SNLB } \\
112 N W T N \\
112 N W T N \\
125 T G R V \\
112 N W T N\end{array}$ & $\begin{array}{r}75 \\
90 \\
222 \\
258 \\
143\end{array}$ & $\begin{array}{l}10-30-90 \\
10-30-90 \\
10-29-90 \\
10-29-90 \\
12-08-67\end{array}$ & $\begin{array}{l}200 \\
240 \\
620 \\
410 \\
260\end{array}$ & $\begin{array}{l}<1.0 \\
<1.0 \\
<3.0 \\
<3.0 \\
--\end{array}$ & $\begin{array}{r}<5 \\
<5 \\
<20 \\
<20 \\
-\end{array}$ & $\begin{array}{l}<3 \\
<3 \\
<9 \\
<9 \\
-\end{array}$ & $\begin{array}{l}<10 \\
<10 \\
<30 \\
<30 \\
-\end{array}$ & $\begin{array}{r}340 \\
1,300 \\
7,700 \\
4,700 \\
4,900\end{array}$ \\
\hline $\begin{array}{l}152-092-19 \mathrm{AAA} 4 \\
152-092-19 \mathrm{AAB} \\
152-092-19 \mathrm{AAB} \\
152-092-19 \mathrm{AAB} \\
152-092-20 \mathrm{BBA}\end{array}$ & $\begin{array}{l}112 N W T N \\
112 N W T N \\
112 N W T N \\
112 N W T N \\
112 N W T N\end{array}$ & $\begin{array}{l}178 \\
158 \\
158 \\
158 \\
166\end{array}$ & $\begin{array}{l}10-29-90 \\
07-19-67 \\
06-04-85 \\
09-23-87 \\
09-14-67\end{array}$ & $\begin{array}{l}370 \\
170 \\
220 \\
160 \\
260\end{array}$ & $\begin{array}{l}2.0 \\
-- \\
-- \\
\cdots \\
--\end{array}$ & $\begin{array}{l}<5 \\
- \\
-- \\
-\end{array}$ & $\begin{array}{l}<3 \\
-- \\
-- \\
- \\
-\end{array}$ & $\begin{array}{l}<10 \\
- \\
-- \\
-\end{array}$ & $\begin{array}{r}5,200 \\
2,200 \\
3,500 \\
100 \\
4,300\end{array}$ \\
\hline $\begin{array}{l}152-092-20 \mathrm{BBB} 2 \\
152-092-21 \mathrm{ADAA} \\
152-092-22 \mathrm{ADCD} \\
152-092-29 \mathrm{DDD} \\
152-092-31 \mathrm{CCC}\end{array}$ & $\begin{array}{l}112 \text { NWTN } \\
112 N W T N \\
112 N W T N \\
112 N W T N \\
112 N W T N\end{array}$ & $\begin{array}{r}168 \\
132 \\
100 \\
118 \\
48\end{array}$ & $\begin{array}{l}09-13-67 \\
10-30-90 \\
10-30-90 \\
06-14-67 \\
07-19-67\end{array}$ & $\begin{array}{l}220 \\
540 \\
560 \\
620 \\
270\end{array}$ & $\begin{array}{l}<3.0 \\
<3.0 \\
-- \\
\cdots\end{array}$ & $\begin{array}{l}- \\
<20 \\
<20 \\
-\end{array}$ & $\begin{array}{l}- \\
<9 \\
<9 \\
- \\
-\end{array}$ & $\begin{array}{l}-- \\
<30 \\
<30 \\
-- \\
--\end{array}$ & $\begin{array}{r}1,500 \\
8,600 \\
3,400 \\
80 \\
3,300\end{array}$ \\
\hline $\begin{array}{l}152-093-24 A A D A \\
152-093-26 \mathrm{BCC} \\
152-094-01 \mathrm{CCB} \\
152-094-19 \mathrm{CBBC} \\
152-094-19 \mathrm{CCAB} 1\end{array}$ & $\begin{array}{c}\text { 125TGRV } \\
\text { 211FXHL } \\
-- \\
\text { 125SNLB } \\
125 S N L B\end{array}$ & $\begin{array}{r}109 \\
1,805 \\
1,620 \\
89 \\
75\end{array}$ & $\begin{array}{l}10-31-90 \\
07-06-68 \\
11-01-90 \\
11-05-91 \\
11-05-91\end{array}$ & $\begin{array}{c}500 \\
3,200 \\
3,200 \\
-- \\
--\end{array}$ & $\begin{array}{l}<3.0 \\
-- \\
<3.0 \\
<3.0 \\
5.0\end{array}$ & $\begin{array}{l}<20 \\
<20 \\
<20 \\
<20\end{array}$ & $\begin{array}{l}<9 \\
<9 \\
<9 \\
<9\end{array}$ & $\begin{array}{r}<30 \\
-- \\
<30 \\
30 \\
<30\end{array}$ & $\begin{array}{r}1,500 \\
320 \\
25 \\
3,100 \\
32\end{array}$ \\
\hline $\begin{array}{l}152-094-19 C C C C \\
152-094-19 C C D D 1 \\
152-095-08 C B \\
152-095-16 A D D \\
153-094-32 C D B D\end{array}$ & $\begin{array}{l}\text { 125SNLB } \\
125 S N L B \\
- \\
\text { 125TGRV } \\
\text { 211FXHL }\end{array}$ & $\begin{array}{r}86 \\
80 \\
5,313 \\
696 \\
1,524\end{array}$ & $\begin{array}{l}11-05-91 \\
11-05-91 \\
07-19-79 \\
05-11-83 \\
10-31-90\end{array}$ & $\begin{array}{c}\cdots \\
5,400 \\
420 \\
3,300\end{array}$ & $\begin{array}{c}<3.0 \\
<3.0 \\
-- \\
-- \\
<3.0\end{array}$ & $\begin{array}{c}<20 \\
<20 \\
- \\
- \\
<20\end{array}$ & $\begin{array}{l}<9 \\
<9 \\
- \\
- \\
<9\end{array}$ & $\begin{array}{c}<30 \\
<30 \\
- \\
- \\
<30\end{array}$ & $\begin{array}{r}36 \\
110 \\
340 \\
30 \\
230\end{array}$ \\
\hline
\end{tabular}


Table 6. Trace-element concentrations in water from wells--Continued

\begin{tabular}{|c|c|c|c|c|c|c|c|c|c|c|}
\hline Local number & $\begin{array}{c}\text { Lead, } \\
\text { dis- } \\
\text { aolved } \\
(\mu g / L \\
\text { as } \mathrm{Pb})\end{array}$ & $\begin{array}{l}\text { Uthlum, } \\
\text { dls- } \\
\text { aolved } \\
(\mu g / L \\
\text { aa L L) }\end{array}$ & $\begin{array}{c}\text { Manga- } \\
\text { neae, } \\
\text { dissolved } \\
(\mu g / L \\
\text { aa Mn) }\end{array}$ & $\begin{array}{l}\text { Molyb- } \\
\text { denum, } \\
\text { dls- } \\
\text { solved } \\
(\mu g / L \\
\text { as Mo) }\end{array}$ & $\begin{array}{l}\text { Nickei, } \\
\text { dis- } \\
\text { solved } \\
(\mu g / L \\
\text { as Ni) }\end{array}$ & $\begin{array}{l}\text { Sele- } \\
\text { nlum, } \\
\text { dis- } \\
\text { solved } \\
(\mu g / L \\
\text { as Se) }\end{array}$ & $\begin{array}{c}\text { Silver, } \\
\text { dis- } \\
\text { golved } \\
(\mu g / L \\
\text { as Ag) }\end{array}$ & $\begin{array}{l}\text { Stron- } \\
\text { tlum, } \\
\text { dissolved } \\
(\mu g / L \\
\text { aa Sr) }\end{array}$ & $\begin{array}{l}\text { Vana- } \\
\text { dlum, } \\
\text { dlis- } \\
\text { solved } \\
(\mu g / L \\
\text { as V) }\end{array}$ & $\begin{array}{c}\text { Zlnc, } \\
\text { dis- } \\
\text { sol'red } \\
(\mu \mathrm{g} / L \\
\text { aa } Z n)\end{array}$ \\
\hline 152-087-28DAA & -- & -- & -- & -- & - & - & -- & .- & -. & - \\
\hline 152-087-28DAA & -- & $\ddot{-}$ & 80 & $-\cdot$ & - & - & -- & -- & -- & - \\
\hline $\begin{array}{l}152-088-04 \mathrm{BBB} \\
152-088-04 \mathrm{BDA}\end{array}$ & $<30$ & $\ddot{190}$ & - & $<30$ & $<\overline{30}$ & $\overline{-}$ & $<\ddot{3.0}$ & $\ddot{550}$ & $<-\ddot{18}$ & $\overline{76}$ \\
\hline $152-088-05 \mathrm{DAD} 2$ & $<30$ & 64 & 22 & $<30$ & $<30$ & - & $<3.0$ & 280 & $<18$ & $<9$ \\
\hline 152-089-05BAC & -- & -- & - & -- & -- & - & -- & -. & -- & -- \\
\hline 152-089-05BACB & $<10$ & 89 & 8 & $<10$ & $<10$ & - & $<1.0$ & 160 & $<6$ & 12 \\
\hline $\begin{array}{l}152-089-23 C C C \\
152-089020 C 5\end{array}$ & $<30$ & $\pi$ & 80 & $\ddot{2 n}$ & $-\overline{30}$ & - & $-\ddot{3}$ & $\ddot{0 m}$ & $\because 0$ & $\ddot{n}$ \\
\hline $\begin{array}{l}152-089-29 \mathrm{CCC} 5 \\
152-089-34 \mathrm{ABB}\end{array}$ & $\begin{array}{l}<30 \\
<10\end{array}$ & $\begin{array}{r}250 \\
99\end{array}$ & $\begin{array}{l}360 \\
280\end{array}$ & $\begin{array}{l}<30 \\
<10\end{array}$ & $\begin{array}{l}<30 \\
<10\end{array}$ & - & $\begin{array}{l}<3.0 \\
<1.0\end{array}$ & $\begin{array}{l}4,200 \\
1,700\end{array}$ & $\begin{array}{r}<18 \\
<6\end{array}$ & $\begin{array}{l}22 \\
27\end{array}$ \\
\hline 152-089-35DDD & .. & $\ldots$ & - & -- & - & $\ldots$ & -- & .- & .. & - \\
\hline 152-090-02CDD & -- & -. & $\because$ & - & -- & - & -- & -. & -. & -. \\
\hline $152-090-09 \mathrm{BCC}$ & $-\cdot$ & -. & 180 & -- & - & - & -- & -. & $\cdot-$ & -- \\
\hline 152-090-13CCC1 & $\overline{10}$ & $\ddot{50}$ & $\overline{380}$ & $\ddot{10}$ & $\ddot{10}$ & - & $-\overline{10}$ & $\ddot{\theta 10}$ & $\ddot{-6}$ & $\ddot{3}_{3}$ \\
\hline $152-090-17 C D C$ & & 52 & 380 & $<10$ & $<10$ & & $<1.0$ & & & 3 \\
\hline $152-090-18 C C C$ & -- & -- & -- & -- & -- & - & -- & -- & -- & -. \\
\hline $152-090-18 C C C$ & -- & $-\cdot$ & 40 & -. & -. & - & -- & -. & $-\cdot$ & -- \\
\hline $152-090-18 \mathrm{CCC}$ & -. & -. & 200 & -. & - & -- & - & - & -- & -. \\
\hline $152-090-21 \mathrm{CBC}$ & -- & -- & 140 & -- & -- & -- & - & - & -- & -- \\
\hline $152-090-25 \mathrm{DBC} 2$ & -- & - & -- & -- & - & - & - & -- & -- & -- \\
\hline 152-090-26DAA & -- & & 80 & -- & -- & -. & & $\cdots$ & - & \\
\hline 152-090-26DAD & $<30$ & 100 & 51 & $<30$ & $<30$ & -- & $<3.0$ & 790 & $<18$ & $<9$ \\
\hline 152-091-05DBB3 & $<10$ & 63 & 280 & $<10$ & $<10$ & - & $<1.0$ & 340 & $<6$ & 15 \\
\hline $\begin{array}{l}\text { 152-091-08DDD } \\
152-091-32 \mathrm{BBA}\end{array}$ & $<\ddot{30}$ & 264 & -4 & $<\ddot{30}$ & $<\overline{30}$ & $\overline{-}$ & $<\overline{3.0}$ & 160 & $<\overline{18}$ & $\ddot{<9}$ \\
\hline 152-092-12DDD & $<10$ & 29 & 33 & $<10$ & $<10$ & -- & $<1.0$ & 240 & $<6$ & 4 \\
\hline $152-092-16 \mathrm{CDBD}$ & $<10$ & 56 & 360 & 10 & $<10$ & -. & $<1.0$ & 530 & $<6$ & $<3$ \\
\hline 152-092-17DDDA & $<30$ & 180 & 960 & $<30$ & $<30$ & - & $<3.0$ & 2,100 & $<18$ & $<9$ \\
\hline 152-092-18AADD & $<30$ & 79 & 170 & $<30$ & $<30$ & -- & $<3.0$ & 680 & $<18$ & $<9$ \\
\hline 152-092-19AAA3 & -- & -- & -- & -. & -- & - & - & -- & -. & -. \\
\hline 152-092-19AAA4 & $<10$ & 87 & 260 & $<10$ & $<10$ & -- & $<1.0$ & $1 ; 000$ & $<6$ & $<3$ \\
\hline $152-092-19 \mathrm{AAB}$ & -- & -. & $\ddot{z}$ & -. & -- & - & - & -- & -. & -. \\
\hline $152-092-19 \mathrm{AAB}$ & - & 90 & 460 & -- & - & 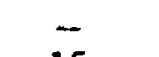 & -- & 1 0 & -- & \\
\hline $152-092-19 \mathrm{AAB}$ & $<1$ & 190 & 320 & 2 & - & 15 & -. & 1,300 & -. & -. \\
\hline 152-092-20BBA & - & -- & - & -- & - & -- & - & -- & -. & -- \\
\hline $152-092-20 \mathrm{BBB} 2$ & -. & -- & -- & -. & - & -- & - & $\because$ & -- & -. \\
\hline $152-092-21 \mathrm{ADAA}$ & $<30$ & 200 & 370 & $<30$ & $<30$ & -- & $<3.0$ & 1,900 & $<18$ & 40 \\
\hline 152-092-22ADCD & 50 & 330 & 1,700 & $<30$ & $<30$ & -. & 3.0 & 2,100 & $<18$ & 60 \\
\hline 152-092-29DDD & -- & -- & - & -- & - & - & - & -- & -- & -- \\
\hline $152-092-31 C C C$ & 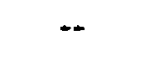 & -- & -- & -- & - & -- & -- & 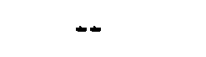 & -- & - \\
\hline 152-093-24AADA & $<30$ & 130 & 8,400 & $<30$ & $<30$ & - & $<3.0$ & 2,600 & $<18$ & 33 \\
\hline 152-093-26BCC & $\ddot{n}$ & & & & & - & & & & \\
\hline $\begin{array}{l}152-094-01 C C B \\
152-094-19 \mathrm{CBBC}\end{array}$ & $\begin{array}{l}<30 \\
<30\end{array}$ & 110 & 2600 & $\begin{array}{l}<30 \\
<30\end{array}$ & $\begin{array}{l}<30 \\
<30\end{array}$ & $\because$ & $\begin{array}{l}<3.0 \\
<3.0\end{array}$ & $\begin{array}{r}150 \\
1800\end{array}$ & $\begin{array}{l}<18 \\
<18\end{array}$ & $<9$ \\
\hline $\begin{array}{l}152-04-19 \mathrm{CBBC} \\
152-094-19 \mathrm{CCAB} 1\end{array}$ & $\begin{array}{l}<30 \\
<30\end{array}$ & $\begin{array}{l}120 \\
100\end{array}$ & $\begin{array}{r}2,000 \\
290\end{array}$ & $<30$ & $<30$ & $\ddot{-}$ & $<3.0$ & $\begin{array}{r}1,000 \\
210\end{array}$ & $<18$ & $\begin{array}{l}24 \\
15\end{array}$ \\
\hline $152-094-19 \mathrm{CCCC}$ & $<10$ & 100 & 1,700 & $<10$ & 30 & -- & $<3.0$ & 1,400 & $<18$ & 20 \\
\hline $152-094-19 \mathrm{CCDD} 1$ & 30 & 84 & 120 & $<30$ & 40 & -- & $<3.0$ & 280 & $<18$ & 10 \\
\hline $152-095-08 \mathrm{CB}$ & 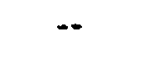 & -- & $<10$ & -• & - & -- & - & -- & -- & - \\
\hline 152-095-16ADD & $\ddot{n}$ & $\ddot{z}$ & 10 & $\ddot{n}$ & - & - & $\vec{n}$ & $\because$ & - & - \\
\hline $153-094-32 \mathrm{CDBD}$ & $<30$ & 94 & 7 & $<30$ & $<30$ & -- & $<3.0$ & 140 & $<18$ & $<9$ \\
\hline
\end{tabular}


Table 7. Physical properties and major-ion concentrations in water from springs

\section{Aqulfer code}

Pleistocene

112ICCC Ice contact deposits

Paleocene

125 SNLB

Sentinel Butte Member of Fort Union Formation

\section{Abbrevlations and symbois}

$\mu \mathrm{S} / \mathrm{cm}$, microsiemens per centimeter at 25 degrees Celsius

$\mathrm{mg} / \mathrm{L}$, milligrams per liter

$\mu \mathrm{g} / \mathrm{L}$, micrograms per liter

,-- no data 


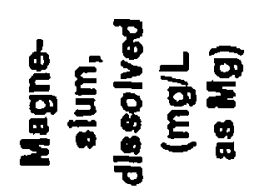

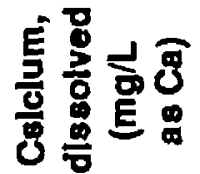

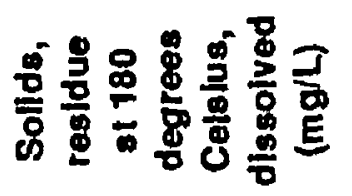

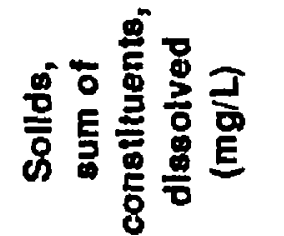

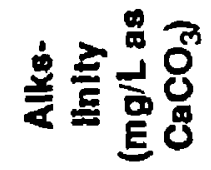

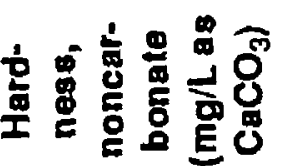

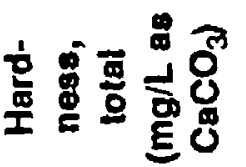

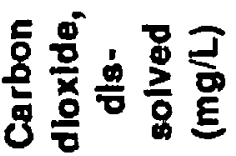

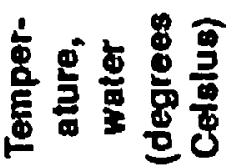

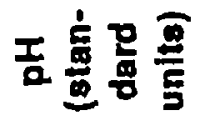

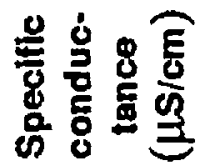

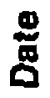

产 :

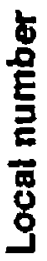

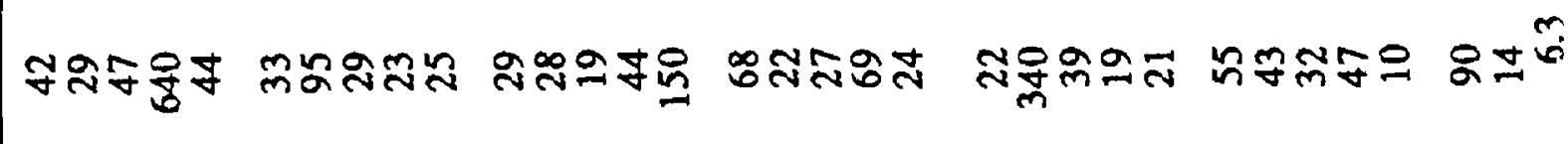

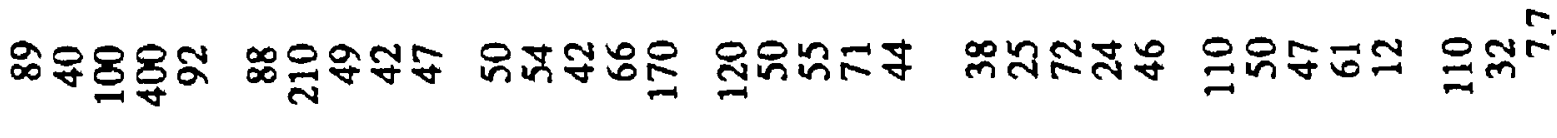

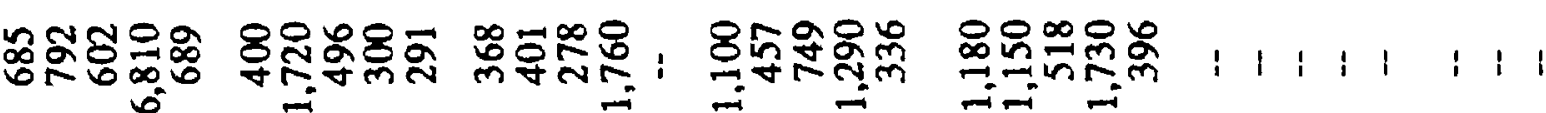

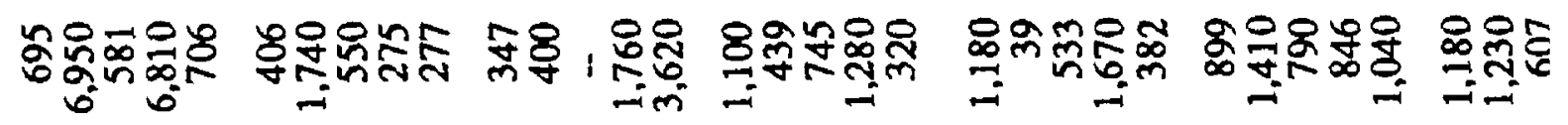

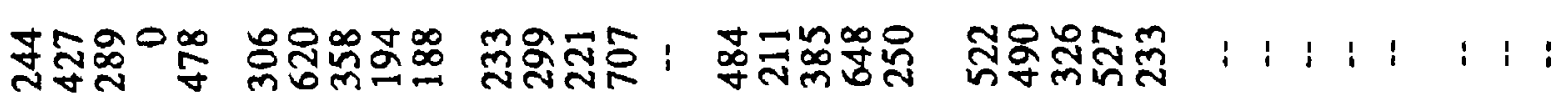

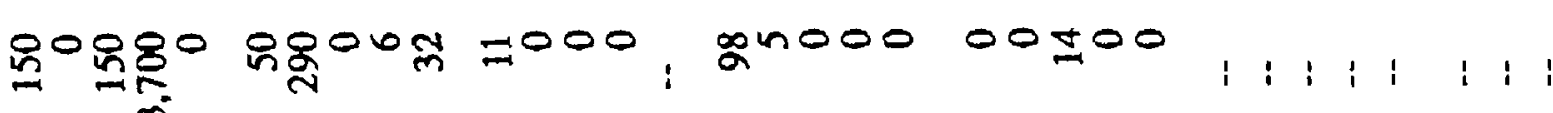

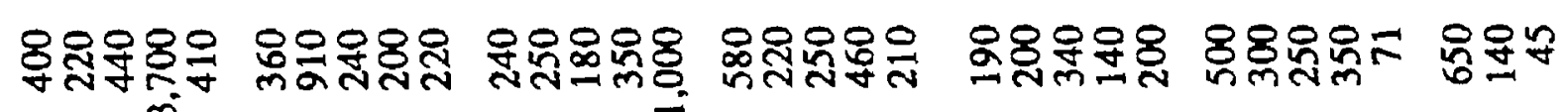

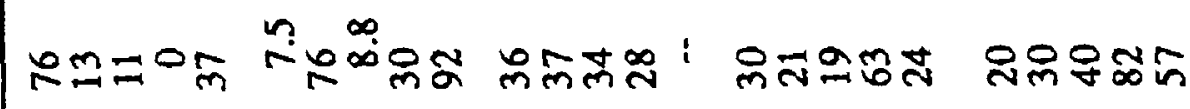

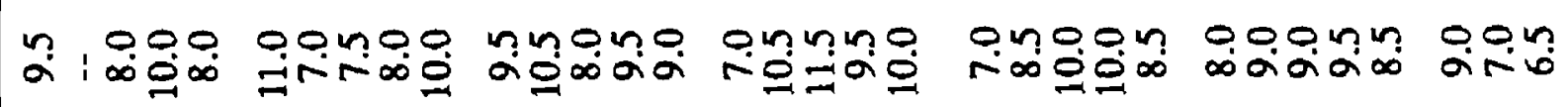

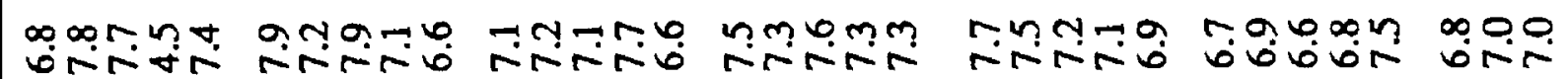

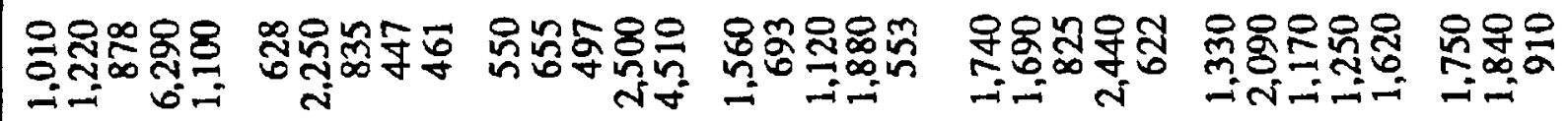

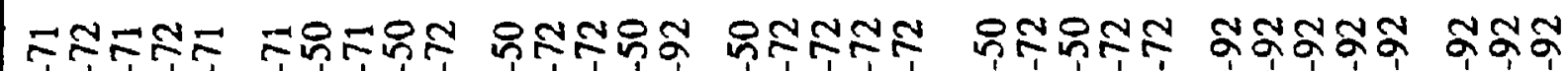

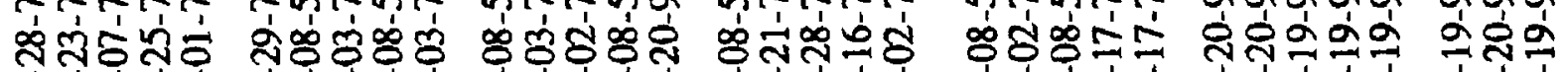

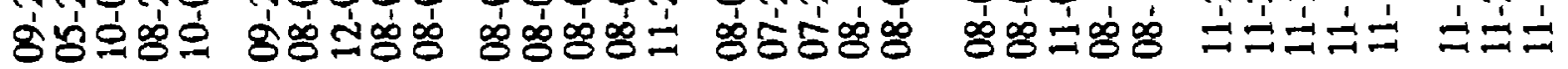

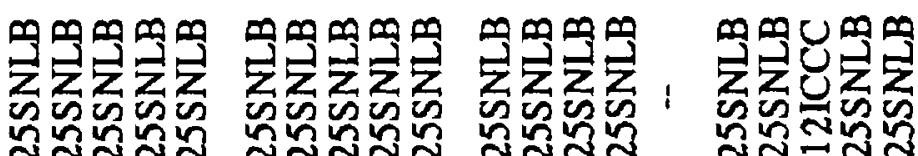

ณ

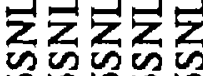

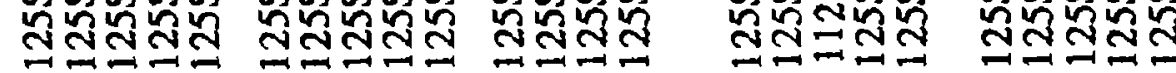

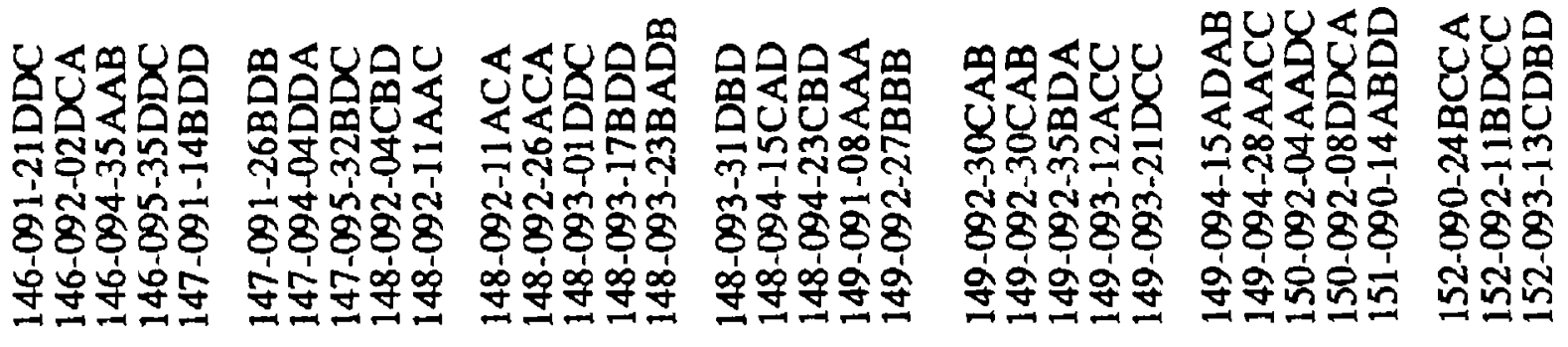




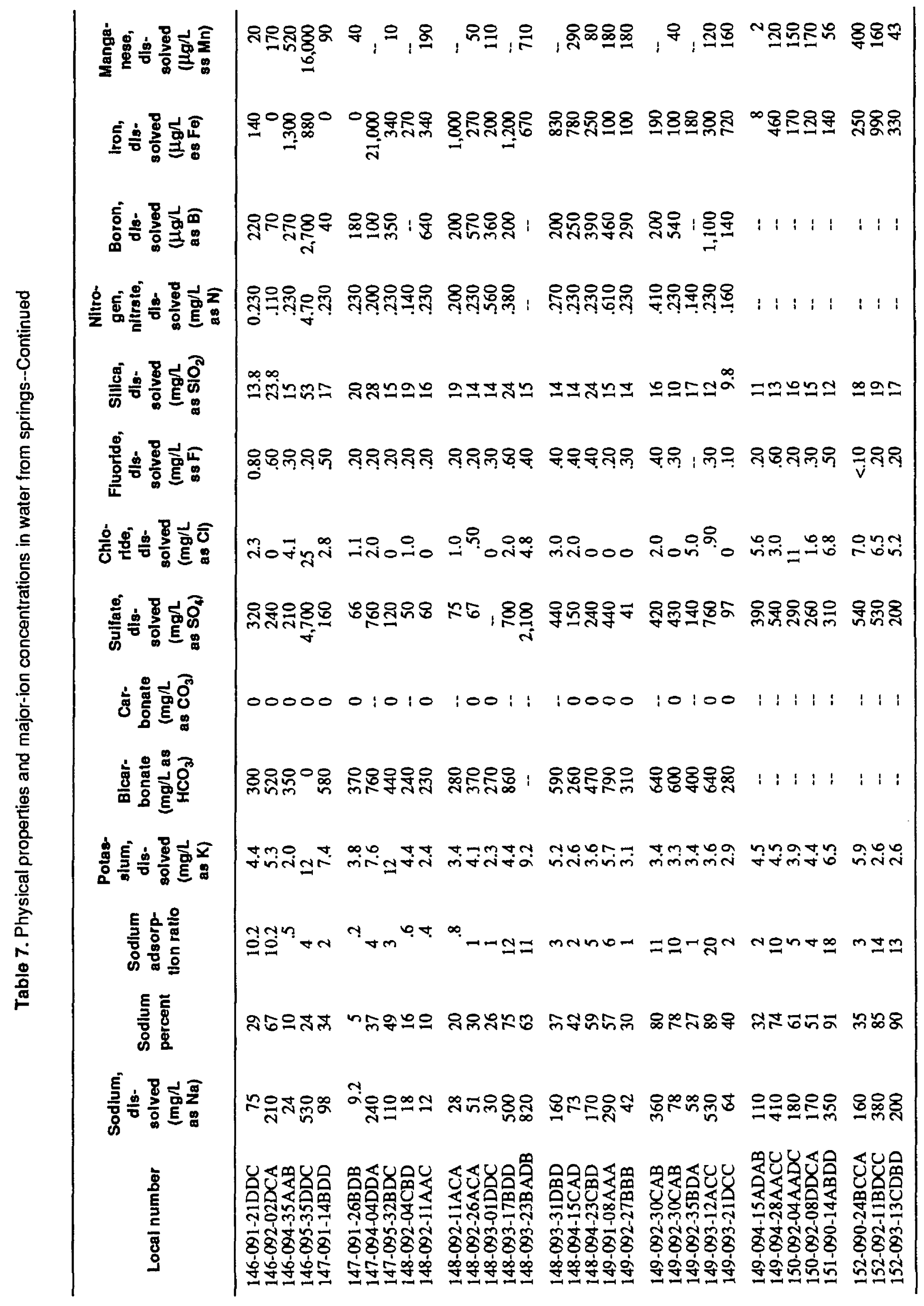


Table 8. Latitude, longitude, altitude, Bouguer gravity, and residual gravity values

[Latitude and longitude values are in decimal degrees; the negative sign of the longitude is the convention referencing longitude west of the prime meridian; altinde is in meters above sea level; the Bouguer gravity values and residual gravity values are in the units of milliga's]

\begin{tabular}{|c|c|c|c|c|}
\hline Latltude & Longitude & Altitude & Bouguer gravlty & Resldual grsul'u \\
\hline $\begin{array}{l}47.966 \\
47.949 \\
47.935 \\
47.924 \\
47.920\end{array}$ & $\begin{array}{l}-102.494 \\
-102.493 \\
-102.493 \\
-102.493 \\
-102.493\end{array}$ & $\begin{array}{l}571.75 \\
586.04 \\
589.67 \\
586.38 \\
587.96\end{array}$ & $\begin{array}{r}-0.441 \\
-.808 \\
-.910 \\
-.861 \\
-.433\end{array}$ & $\begin{array}{r}0.765 \\
-.843 \\
-1.693 \\
-2.034 \\
-1.335\end{array}$ \\
\hline $\begin{array}{l}47.914 \\
47.977 \\
47.974 \\
47.971 \\
47.964\end{array}$ & $\begin{array}{l}-102.496 \\
-102.472 \\
-102.472 \\
-102.472 \\
-102.472\end{array}$ & $\begin{array}{l}614.28 \\
581.37 \\
590.03 \\
589.77 \\
584.36\end{array}$ & $\begin{array}{r}-.654 \\
.108 \\
2.390 \\
.353 \\
-.890\end{array}$ & $\begin{array}{r}-1.898 \\
.925 \\
5.302 \\
1.038 \\
-1.951\end{array}$ \\
\hline $\begin{array}{l}47.960 \\
47.956 \\
47.952 \\
47.949 \\
47.945\end{array}$ & $\begin{array}{l}-102.472 \\
-102.472 \\
-102.472 \\
-102.472 \\
-102.472\end{array}$ & $\begin{array}{l}582.07 \\
577.20 \\
573.35 \\
573.01 \\
579.06\end{array}$ & $\begin{array}{r}.007 \\
-.552 \\
.467 \\
-.033 \\
.016\end{array}$ & $\begin{array}{r}-.354 \\
-1.713 \\
.128 \\
-1.043 \\
-1.170\end{array}$ \\
\hline $\begin{array}{l}47.942 \\
47.938 \\
47.935 \\
47.931 \\
47.927\end{array}$ & $\begin{array}{l}-102.472 \\
-102.472 \\
-102.472 \\
-102.472 \\
-102.472\end{array}$ & $\begin{array}{l}578.27 \\
576.97 \\
576.35 \\
576.48 \\
576.91\end{array}$ & $\begin{array}{r}.091 \\
.153 \\
1.088 \\
.391 \\
-.191\end{array}$ & $\begin{array}{r}-1.222 \\
-1.175 \\
.564 \\
-1.010 \\
-2.343\end{array}$ \\
\hline $\begin{array}{l}47.924 \\
47.920 \\
47.917 \\
47.913 \\
47.906\end{array}$ & $\begin{array}{l}-102.472 \\
-102.472 \\
-102.472 \\
-102.472 \\
-102.472\end{array}$ & $\begin{array}{l}577.13 \\
579.08 \\
582.35 \\
586.79 \\
610.31\end{array}$ & $\begin{array}{r}.067 \\
-.026 \\
.069 \\
-.094 \\
-.032\end{array}$ & $\begin{array}{l}-1.933 \\
-2.183 \\
-2.072 \\
-2.470 \\
-2.552\end{array}$ \\
\hline $\begin{array}{l}47.902 \\
47.898 \\
47.895 \\
47.891 \\
47.888\end{array}$ & $\begin{array}{l}-102.472 \\
-102.472 \\
-102.472 \\
-102.472 \\
-102.472\end{array}$ & $\begin{array}{l}621.92 \\
635.00 \\
636.07 \\
628.55 \\
629.57\end{array}$ & $\begin{array}{r}.226 \\
.259 \\
-.019 \\
.498 \\
.515\end{array}$ & $\begin{array}{l}-2.092 \\
-1.964 \\
-2.581 \\
-1.579 \\
-1.570\end{array}$ \\
\hline $\begin{array}{l}47.885 \\
47.881 \\
47.878 \\
47.978 \\
47.974\end{array}$ & $\begin{array}{l}-102.472 \\
-102.472 \\
-102.472 \\
-102.450 \\
-102.450\end{array}$ & $\begin{array}{l}626.97 \\
615.29 \\
605.57 \\
581.33 \\
578.86\end{array}$ & $\begin{array}{r}504 \\
.773 \\
.587 \\
1.661 \\
2.225\end{array}$ & $\begin{array}{r}-1.581 \\
-1.024 \\
-1.416 \\
2.299 \\
3.133\end{array}$ \\
\hline $\begin{array}{l}47.971 \\
47.906 \\
47.906 \\
47.873 \\
47.870\end{array}$ & $\begin{array}{l}-102.450 \\
-102.557 \\
-102.563 \\
-102.429 \\
-102.429\end{array}$ & $\begin{array}{l}578.11 \\
643.72 \\
646.97 \\
576.53 \\
578.84\end{array}$ & $\begin{array}{l}2.017 \\
7.475 \\
9.208 \\
2.422 \\
2.740\end{array}$ & $\begin{array}{r}2.554 \\
17.747 \\
21.303 \\
-1.406 \\
-.767\end{array}$ \\
\hline $\begin{array}{l}47.862 \\
47.856 \\
47.852 \\
47.849 \\
47.839\end{array}$ & $\begin{array}{l}-102.427 \\
-102.427 \\
-102.429 \\
-102.428 \\
-102.429\end{array}$ & $\begin{array}{l}576.27 \\
576.41 \\
578.09 \\
584.55 \\
604.84\end{array}$ & $\begin{array}{l}3.334 \\
3.272 \\
3.192 \\
2.776 \\
7.412\end{array}$ & $\begin{array}{r}.446 \\
.400 \\
.610 \\
-.166 \\
9.496\end{array}$ \\
\hline $\begin{array}{l}47.836 \\
47.830 \\
47.827 \\
47.819 \\
47.819\end{array}$ & $\begin{array}{l}-102.429 \\
-102.427 \\
-102.429 \\
-102.409 \\
-102.414\end{array}$ & $\begin{array}{l}608.40 \\
604.48 \\
600.74 \\
618.95 \\
605.49\end{array}$ & $\begin{array}{r}6.656 \\
-.075 \\
-3.886 \\
4.634 \\
4.789\end{array}$ & $\begin{array}{r}8.139 \\
-5.288 \\
-12.542 \\
3.086 \\
3.829\end{array}$ \\
\hline
\end{tabular}


Table 8. Latitude, longitude, altitude, Bouguer gravity, and residual gravity values--Continue-

[Latirude and longitude values are in decimal degrees; the negative sign of the longitude is the convention referencing longitude west of the prime meridian; altimde is in meters above sea level; the Bouguer gravity values and residual gravity values are in the units of milligals]

\begin{tabular}{|c|c|c|c|c|}
\hline Latitude & Longltude & Altltude & Bouguer gravlty & Residinal gravity \\
\hline $\begin{array}{l}47.819 \\
47.819 \\
47.819 \\
47.819 \\
47.819\end{array}$ & $\begin{array}{l}-102.419 \\
-102.424 \\
-102.429 \\
-102.435 \\
-102.440\end{array}$ & $\begin{array}{l}595.48 \\
587.39 \\
585.09 \\
588.90 \\
591.13\end{array}$ & $\begin{array}{l}4.557 \\
4.234 \\
3.271 \\
2.883 \\
3.170\end{array}$ & $\begin{array}{l}3.740 \\
3.719 \\
2.295 \\
2.142 \\
3.091\end{array}$ \\
\hline $\begin{array}{l}47.819 \\
47.819 \\
47.819 \\
47.819 \\
47.819\end{array}$ & $\begin{array}{l}-102.445 \\
-102.450 \\
-102.455 \\
-102.460 \\
-102.466\end{array}$ & $\begin{array}{l}592.72 \\
586.94 \\
588.75 \\
592.30 \\
591.23\end{array}$ & $\begin{array}{l}2.645 \\
2.613 \\
2.367 \\
2.144 \\
1.732\end{array}$ & $\begin{array}{l}2.416 \\
2.977 \\
2.735 \\
2.664 \\
2.340\end{array}$ \\
\hline $\begin{array}{l}47.819 \\
47.819 \\
47.819 \\
47.819 \\
47.819\end{array}$ & $\begin{array}{l}-102.471 \\
-102.478 \\
-102.483 \\
-102.494 \\
-102.505\end{array}$ & $\begin{array}{l}596.88 \\
607.68 \\
615.93 \\
618.75 \\
639.17\end{array}$ & $\begin{array}{r}1.461 \\
1.274 \\
.745 \\
1.404 \\
-.662\end{array}$ & $\begin{array}{r}2.423 \\
2.549 \\
1.679 \\
2.747 \\
.365\end{array}$ \\
\hline $\begin{array}{l}47.819 \\
47.819 \\
47.825 \\
47.826 \\
47.826\end{array}$ & $\begin{array}{l}-102.510 \\
-102.511 \\
-102.515 \\
-102.521 \\
-102.527\end{array}$ & $\begin{array}{l}645.59 \\
644.06 \\
641.07 \\
647.41 \\
650.70\end{array}$ & $\begin{array}{r}.771 \\
-.500 \\
-.779 \\
-1.128 \\
-1.252\end{array}$ & $\begin{array}{r}2.606 \\
1.065 \\
.457 \\
-.040 \\
.212\end{array}$ \\
\hline $\begin{array}{l}47.826 \\
47.832 \\
47.833 \\
47.833 \\
47.833\end{array}$ & $\begin{array}{l}-102.532 \\
-102.537 \\
-102.541 \\
-102.546 \\
-102.552\end{array}$ & $\begin{array}{l}659.57 \\
662.35 \\
672.82 \\
674.93 \\
677.41\end{array}$ & $\begin{array}{l}-2.017 \\
-1.943 \\
-2.478 \\
-2.424 \\
-2.665\end{array}$ & $\begin{array}{l}-1.191 \\
-1.182 \\
-2.079 \\
-1.846 \\
-2.078\end{array}$ \\
\hline $\begin{array}{l}47.838 \\
47.840 \\
47.842 \\
47.845 \\
47.849\end{array}$ & $\begin{array}{l}-102.557 \\
-102.557 \\
-102.557 \\
-102.557 \\
-102.557\end{array}$ & $\begin{array}{l}659.28 \\
658.25 \\
653.96 \\
650.33 \\
647.58\end{array}$ & $\begin{array}{l}-6.488 \\
-3.301 \\
-2.782 \\
-2.920 \\
-2.685\end{array}$ & $\begin{array}{l}-0.504 \\
-.239 \\
-2.318 \\
-2.666 \\
-2.279\end{array}$ \\
\hline $\begin{array}{l}47.852 \\
47.855 \\
47.859 \\
47.862 \\
47.866\end{array}$ & $\begin{array}{l}-102.557 \\
-102.557 \\
-102.557 \\
-102.557 \\
-102.557\end{array}$ & $\begin{array}{l}647.93 \\
634.52 \\
614.41 \\
610.75 \\
613.99\end{array}$ & $\begin{array}{l}-2.840 \\
-2.833 \\
-3.438 \\
-2.975 \\
-3.465\end{array}$ & $\begin{array}{r}-2.673 \\
-2.743 \\
-1.089 \\
-2.146 \\
-1.236\end{array}$ \\
\hline $\begin{array}{l}47.869 \\
47.875 \\
47.880 \\
47.883 \\
47.887\end{array}$ & $\begin{array}{l}-102.557 \\
-102.557 \\
-102.557 \\
-102.557 \\
-102.557\end{array}$ & $\begin{array}{l}610.15 \\
606.98 \\
597.85 \\
590.95 \\
590.85\end{array}$ & $\begin{array}{l}-3.313 \\
-3.144 \\
-3.015 \\
-3.153 \\
-2.920\end{array}$ & $\begin{array}{r}-.909 \\
-.628 \\
-2.394 \\
-.695 \\
-.196\end{array}$ \\
\hline $\begin{array}{l}47.890 \\
47.891 \\
47.894 \\
47.897 \\
47.901\end{array}$ & $\begin{array}{l}-102.557 \\
-102.557 \\
-102.557 \\
-102.557 \\
-102.557\end{array}$ & $\begin{array}{l}595.94 \\
600.67 \\
612.38 \\
619.92 \\
635.43\end{array}$ & $\begin{array}{l}-4.114 \\
-3.979 \\
-3.524 \\
-3.394 \\
-3.614\end{array}$ & $\begin{array}{r}-5.673 \\
-5.379 \\
-4.438 \\
-.150 \\
-.506\end{array}$ \\
\hline $\begin{array}{l}47.904 \\
47.908 \\
47.911 \\
47.915 \\
47.918\end{array}$ & $\begin{array}{l}-102.557 \\
-102.557 \\
-102.557 \\
-102.557 \\
-102.557\end{array}$ & $\begin{array}{l}642.62 \\
641.39 \\
647.82 \\
655.68 \\
661.47\end{array}$ & $\begin{array}{l}-3.451 \\
-3.483 \\
-3.412 \\
-3.614 \\
-3.199\end{array}$ & $\begin{array}{r}-.055 \\
-4.066 \\
-2.949 \\
-4.243 \\
-2.328\end{array}$ \\
\hline
\end{tabular}


Table 8. Latitude, longitude, altitude, Bouguer gravity, and residual gravity values--Continued

[Latitude and longitude values are in decimal degrees; the negative sign of the longinde is the convention referencing longitude west of the prime meridian; altinde is in meters above sea level; the Bouguer gravity values and residual gravity values are in the units of milligals]

\begin{tabular}{|c|c|c|c|c|}
\hline Latitude & Longitude & Aitltude & Bouguer gravity & Resldual grevity \\
\hline $\begin{array}{l}47.922 \\
47.925 \\
47.929 \\
47.933 \\
47.935\end{array}$ & $\begin{array}{l}-102.557 \\
-102.557 \\
-102.557 \\
-102.557 \\
-102.557\end{array}$ & $\begin{array}{l}667.69 \\
654.79 \\
645.10 \\
638.08 \\
635.45\end{array}$ & $\begin{array}{l}-4.538 \\
-3.444 \\
-3.564 \\
-3.319 \\
-2.381\end{array}$ & $\begin{array}{l}-5.868 \\
-3.549 \\
-3.751 \\
-3.077 \\
-1.010\end{array}$ \\
\hline $\begin{array}{l}47.934 \\
47.934 \\
47.934 \\
47.934 \\
47.934\end{array}$ & $\begin{array}{l}-102.557 \\
-102.552 \\
-102.547 \\
-102.542 \\
-102.536\end{array}$ & $\begin{array}{l}635.30 \\
625.17 \\
622.81 \\
617.51 \\
611.79\end{array}$ & $\begin{array}{l}-2.544 \\
-2.239 \\
-2.123 \\
-1.940 \\
-1.734\end{array}$ & $\begin{array}{r}-1.385 \\
-1.212 \\
-.980 \\
-.927 \\
-.890\end{array}$ \\
\hline $\begin{array}{l}47.934 \\
47.934 \\
47.934 \\
47.934 \\
47.934\end{array}$ & $\begin{array}{l}-102.530 \\
-102.525 \\
-102.520 \\
-102.514 \\
-102.509\end{array}$ & $\begin{array}{l}607.41 \\
603.38 \\
600.74 \\
600.04 \\
598.62\end{array}$ & $\begin{array}{l}-1.603 \\
-1.336 \\
-1.174 \\
-1.111 \\
-1.789\end{array}$ & $\begin{array}{r}-.902 \\
-.493 \\
-.607 \\
-.769 \\
-2.587\end{array}$ \\
\hline $\begin{array}{l}47.934 \\
47.935 \\
47.935 \\
47.877 \\
47.877\end{array}$ & $\begin{array}{l}-102.504 \\
-102.493 \\
-102.472 \\
-102.423 \\
-102.418\end{array}$ & $\begin{array}{l}594.93 \\
589.67 \\
576.35 \\
571.60 \\
572.65\end{array}$ & $\begin{array}{r}-.933 \\
-.462 \\
.648 \\
3.596 \\
3.868\end{array}$ & $\begin{array}{r}-1.062 \\
-.797 \\
-.316 \\
.269 \\
.346\end{array}$ \\
\hline $\begin{array}{l}47.877 \\
47.877 \\
47.877 \\
47.877 \\
47.877\end{array}$ & $\begin{array}{l}-102.478 \\
-102.483 \\
-102.489 \\
-102.493 \\
-102.500\end{array}$ & $\begin{array}{l}584.27 \\
583.89 \\
581.78 \\
581.98 \\
583.26\end{array}$ & $\begin{array}{r}.302 \\
-.083 \\
-.563 \\
-.661 \\
-1.176\end{array}$ & $\begin{array}{l}-1.286 \\
-1.902 \\
-2.204 \\
-2.150 \\
-2.742\end{array}$ \\
\hline $\begin{array}{l}47.877 \\
47.877 \\
47.877 \\
47.877 \\
47.877\end{array}$ & $\begin{array}{l}-102.505 \\
-102.511 \\
-102.516 \\
-102.521 \\
-102.527\end{array}$ & $\begin{array}{l}584.83 \\
582.60 \\
582.76 \\
585.46 \\
586.93\end{array}$ & $\begin{array}{l}-1.601 \\
-1.772 \\
-2.334 \\
-2.777 \\
-2.809\end{array}$ & $\begin{array}{l}-3.342 \\
-3.309 \\
-4.183 \\
-4.757 \\
-4.354\end{array}$ \\
\hline $\begin{array}{l}47.877 \\
47.877 \\
47.877 \\
47.877 \\
47.877\end{array}$ & $\begin{array}{l}-102.536 \\
-102.541 \\
-102.554 \\
-102.563 \\
-102.569\end{array}$ & $\begin{array}{l}587.61 \\
589.43 \\
593.18 \\
611.26 \\
599.73\end{array}$ & $\begin{array}{r}-3.314 \\
-3.446 \\
-3.867 \\
-4.496 \\
-4.268\end{array}$ & $\begin{array}{l}-5.018 \\
-5.032 \\
-5.374 \\
-6.228 \\
-5.614\end{array}$ \\
\hline $\begin{array}{l}47.877 \\
47.877 \\
47.877 \\
47.875 \\
47.833\end{array}$ & $\begin{array}{l}-102.574 \\
-102.579 \\
-102.586 \\
-102.590 \\
-102.381\end{array}$ & $\begin{array}{l}593.72 \\
606.17 \\
615.53 \\
616.62 \\
570.48\end{array}$ & $\begin{array}{r}-5.700 \\
-4.438 \\
-6.286 \\
-6.131 \\
4.027\end{array}$ & $\begin{array}{l}-8.478 \\
-5.674 \\
-9.245 \\
-8.819 \\
-2.444\end{array}$ \\
\hline $\begin{array}{l}47.833 \\
47.833 \\
47.833 \\
47.833 \\
47.833\end{array}$ & $\begin{array}{l}-102.386 \\
-102.381 \\
-102.386 \\
-102.391 \\
-102.395\end{array}$ & $\begin{array}{l}569.52 \\
570.48 \\
569.52 \\
575.03 \\
584.22\end{array}$ & $\begin{array}{l}3.957 \\
3.057 \\
3.541 \\
3.381 \\
2.109\end{array}$ & $\begin{array}{l}-1.834 \\
-4.384 \\
-2.666 \\
-2.486 \\
-4.530\end{array}$ \\
\hline $\begin{array}{l}47.833 \\
47.833 \\
47.833 \\
47.833 \\
47.833\end{array}$ & $\begin{array}{l}-102.402 \\
-102.407 \\
-102.413 \\
-102.419 \\
-102.425\end{array}$ & $\begin{array}{l}608.55 \\
618.77 \\
603.55 \\
600.43 \\
599.94\end{array}$ & $\begin{array}{l}3.223 \\
3.092 \\
3.113 \\
2.624 \\
1.107\end{array}$ & $\begin{array}{r}-1.521 \\
-1.001 \\
-.334 \\
-.966 \\
-3.375\end{array}$ \\
\hline
\end{tabular}


Table 8. Latitude, longitude, altitude, Bouguer gravity, and residual gravity values--Continued

[Latitude and longitude values are in decimal degrees; the negative sign of the longiude is the convention referencing longituce west of the prime meritian; altimde is in meters above sea level; the Bouguer gravity values and residual gravity values are in the units of milligals]

\begin{tabular}{|c|c|c|c|c|}
\hline Latltude & Longltude & Altitude & Bouguer gravity & Realdial gravity \\
\hline $\begin{array}{l}47.834 \\
47.833 \\
47.833 \\
47.833 \\
47.833\end{array}$ & $\begin{array}{l}-102.429 \\
-102.435 \\
-102.439 \\
-102.445 \\
-102.450\end{array}$ & $\begin{array}{l}617.17 \\
613.30 \\
605.68 \\
617.72 \\
628.98\end{array}$ & $\begin{array}{l}3.059 \\
1.502 \\
1.439 \\
1.734 \\
2.672\end{array}$ & $\begin{array}{r}1.063 \\
-1.431 \\
-1.179 \\
-.214 \\
-.346\end{array}$ \\
\hline $\begin{array}{l}47.833 \\
47.833 \\
47.862 \\
47.862 \\
47.862\end{array}$ & $\begin{array}{l}-102.568 \\
-102.579 \\
-102.622 \\
-102.600 \\
-102.557\end{array}$ & $\begin{array}{l}674.28 \\
671.38 \\
645.67 \\
648.05 \\
610.75\end{array}$ & $\begin{array}{l}-.601 \\
-.423 \\
1.878 \\
2.103 \\
6.171\end{array}$ & $\begin{array}{r}2.646 \\
2.252 \\
7.873 \\
7.885 \\
15.146\end{array}$ \\
\hline $\begin{array}{l}47.862 \\
47.914 \\
47.912 \\
47.908 \\
47.906\end{array}$ & $\begin{array}{l}-102.536 \\
-102.496 \\
-102.499 \\
-102.500 \\
-102.500\end{array}$ & $\begin{array}{l}610.44 \\
614.28 \\
618.86 \\
622.41 \\
632.73\end{array}$ & $\begin{array}{r}11.788 \\
-1.172 \\
7.561 \\
-.637 \\
-.766\end{array}$ & $\begin{array}{r}25.318 \\
-2.934 \\
14.828 \\
-1.579 \\
-1.895\end{array}$ \\
\hline $\begin{array}{l}47.905 \\
47.903 \\
47.899 \\
47.896 \\
47.892\end{array}$ & $\begin{array}{l}-102.495 \\
-102.493 \\
-102.493 \\
-102.493 \\
-102.493\end{array}$ & $\begin{array}{l}621.78 \\
625.02 \\
633.24 \\
632.82 \\
634.49\end{array}$ & $\begin{array}{r}-.447 \\
-.493 \\
-1.116 \\
-.457 \\
-.373\end{array}$ & $\begin{array}{l}-1.516 \\
-1.767 \\
-2.088 \\
-1.799 \\
-1.615\end{array}$ \\
\hline $\begin{array}{l}47.891 \\
47.887 \\
47.884 \\
47.880 \\
47.877\end{array}$ & $\begin{array}{l}-102.493 \\
-102.493 \\
-102.494 \\
-102.493 \\
-102.493\end{array}$ & $\begin{array}{l}638.36 \\
638.10 \\
621.51 \\
598.21 \\
581.98\end{array}$ & $\begin{array}{l}-.706 \\
-.580 \\
-.542 \\
-.956 \\
-.593\end{array}$ & $\begin{array}{l}-2.333 \\
-2.094 \\
-2.024 \\
-2.776 \\
-2.014\end{array}$ \\
\hline $\begin{array}{l}47.873 \\
47.869 \\
47.866 \\
47.862 \\
47.898\end{array}$ & $\begin{array}{l}-102.493 \\
-102.493 \\
-102.493 \\
-102.493 \\
-102.514\end{array}$ & $\begin{array}{l}579.39 \\
578.97 \\
581.24 \\
598.10 \\
630.85\end{array}$ & $\begin{array}{r}-1.130 \\
-.892 \\
-.732 \\
-.613 \\
-1.532\end{array}$ & $\begin{array}{l}-. .072 \\
-2.548 \\
-2.206 \\
-1.828 \\
-2.492\end{array}$ \\
\hline $\begin{array}{l}47.895 \\
47.909 \\
47.912 \\
47.916 \\
47.920\end{array}$ & $\begin{array}{l}-102.514 \\
-102.514 \\
-102.514 \\
-102.514 \\
-102.514\end{array}$ & $\begin{array}{l}624.30 \\
637.25 \\
627.68 \\
611.79 \\
607.08\end{array}$ & $\begin{array}{l}-1.190 \\
-1.469 \\
-1.533 \\
-1.387 \\
-1.242\end{array}$ & $\begin{array}{l}-1.876 \\
-2.288 \\
-2.358 \\
-1.989 \\
-1.578\end{array}$ \\
\hline $\begin{array}{l}47.924 \\
47.927 \\
47.931 \\
47.938 \\
47.942\end{array}$ & $\begin{array}{l}-102.514 \\
-102.514 \\
-102.514 \\
-102.514 \\
-102.514\end{array}$ & $\begin{array}{l}613.66 \\
606.26 \\
596.13 \\
618.93 \\
619.49\end{array}$ & $\begin{array}{r}-1.653 \\
-1.232 \\
-1.450 \\
-1.405 \\
-.028\end{array}$ & $\begin{array}{r}-2.253 \\
-1.300 \\
-1.619 \\
-1.253 \\
1.654\end{array}$ \\
\hline $\begin{array}{l}47.945 \\
47.949 \\
47.953 \\
47.957 \\
47.960\end{array}$ & $\begin{array}{l}-102.514 \\
-102.514 \\
-102.514 \\
-102.514 \\
-102.514\end{array}$ & $\begin{array}{l}615.45 \\
615.24 \\
605.54 \\
594.60 \\
592.92\end{array}$ & $\begin{array}{r}-1.223 \\
-1.152 \\
-.805 \\
-1.022 \\
-.929\end{array}$ & $\begin{array}{r}-.547 \\
-.208 \\
.749 \\
.425 \\
.841\end{array}$ \\
\hline $\begin{array}{l}47.963 \\
47.966 \\
47.970 \\
47.949 \\
47.949\end{array}$ & $\begin{array}{l}-102.514 \\
-102.514 \\
-102.514 \\
-102.499 \\
-102.507\end{array}$ & $\begin{array}{l}591.49 \\
590.82 \\
612.12 \\
591.21 \\
608.82\end{array}$ & $\begin{array}{r}-.915 \\
-.770 \\
-1.140 \\
-.703 \\
.328\end{array}$ & $\begin{array}{l}1.111 \\
1.580 \\
1.088 \\
-.208 \\
2.354\end{array}$ \\
\hline
\end{tabular}


Table 8. Latitude, longitude, aititude, Bouguer gravity, and residual gravity values--Continued

[Latitade and longitude values are in decimal degrees; the negative sign of the longitude is the convention referencing longitude west of the prime meridian; altioude is in meters above sea level; the Bouguer gravity values and residual gravity values are in the units of milligal!?

\begin{tabular}{|c|c|c|c|c|}
\hline Latlifude & Longltude & Altitude & Bouguer gravity & Resldual grevit' \\
\hline $\begin{array}{l}47.949 \\
47.949 \\
47.949 \\
47.949 \\
47.949\end{array}$ & $\begin{array}{l}-102.510 \\
-102.514 \\
-102.520 \\
-102.525 \\
-102.531\end{array}$ & $\begin{array}{l}615.53 \\
615.24 \\
609.16 \\
618.67 \\
621.90\end{array}$ & $\begin{array}{r}-1.050 \\
-.952 \\
-1.245 \\
-1.675 \\
-1.821\end{array}$ & $\begin{array}{r}-0.215 \\
.192 \\
-.042 \\
-.527 \\
-.632\end{array}$ \\
\hline $\begin{array}{l}47.949 \\
47.949 \\
47.949 \\
47.949 \\
47.949\end{array}$ & $\begin{array}{l}-102.536 \\
-102.541 \\
-102.546 \\
-102.552 \\
-102.557\end{array}$ & $\begin{array}{l}625.37 \\
630.20 \\
636.05 \\
645.48 \\
633.97\end{array}$ & $\begin{array}{l}-1.714 \\
-1.824 \\
-1.989 \\
-2.333 \\
-1.936\end{array}$ & $\begin{array}{l}-.168 \\
-.075 \\
-.280 \\
-.656 \\
.513\end{array}$ \\
\hline $\begin{array}{l}47.848 \\
47.851 \\
47.855 \\
47.858 \\
47.862\end{array}$ & $\begin{array}{l}-102.536 \\
-102.536 \\
-102.536 \\
-102.536 \\
-102.536\end{array}$ & $\begin{array}{l}640.98 \\
643.01 \\
633.58 \\
616.05 \\
610.44\end{array}$ & $\begin{array}{l}-2.028 \\
-2.098 \\
-2.488 \\
-2.022 \\
-2.212\end{array}$ & $\begin{array}{l}-1.912 \\
-2.257 \\
-3.102 \\
-2.260 \\
-2.682\end{array}$ \\
\hline $\begin{array}{l}47.866 \\
47.869 \\
47.873 \\
47.877 \\
47.880\end{array}$ & $\begin{array}{l}-102.536 \\
-102.536 \\
-102.536 \\
-102.536 \\
-102.536\end{array}$ & $\begin{array}{l}605.97 \\
600.70 \\
595.52 \\
587.61 \\
587.98\end{array}$ & $\begin{array}{l}-2.290 \\
-2.738 \\
-2.770 \\
-2.651 \\
-2.632\end{array}$ & $\begin{array}{l}-2.948 \\
-3.903 \\
-3.983 \\
-3.692 \\
-3.740\end{array}$ \\
\hline $\begin{array}{l}47.883 \\
47.884 \\
47.888 \\
47.891 \\
47.893\end{array}$ & $\begin{array}{l}-102.536 \\
-102.536 \\
-102.536 \\
-102.537 \\
-102.539\end{array}$ & $\begin{array}{l}595.40 \\
599.31 \\
618.12 \\
624.01 \\
628.32\end{array}$ & $\begin{array}{l}-2.368 \\
-2.752 \\
-2.376 \\
-2.250 \\
-2.264\end{array}$ & $\begin{array}{l}-3.201 \\
-3.896 \\
-3.241 \\
-2.991 \\
-2.785\end{array}$ \\
\hline $\begin{array}{l}47.896 \\
47.906 \\
47.906 \\
47.898 \\
47.898\end{array}$ & $\begin{array}{l}-102.540 \\
-102.563 \\
-102.557 \\
-102.563 \\
-102.568\end{array}$ & $\begin{array}{l}622.63 \\
646.97 \\
643.72 \\
618.62 \\
614.49\end{array}$ & $\begin{array}{l}-1.945 \\
-2.907 \\
-2.741 \\
-2.939 \\
-2.950\end{array}$ & $\begin{array}{l}-2.068 \\
-2.927 \\
-2.685 \\
-2.985 \\
-2.890\end{array}$ \\
\hline $\begin{array}{l}47.898 \\
47.898 \\
47.898 \\
47.897 \\
47.897\end{array}$ & $\begin{array}{l}-102.573 \\
-102.578 \\
-102.584 \\
-102.589 \\
-102.594\end{array}$ & $\begin{array}{l}614.54 \\
607.83 \\
602.10 \\
584.35 \\
568.08\end{array}$ & $\begin{array}{l}-3.340 \\
-3.536 \\
-3.68 \mathrm{PG} 7 \\
-4.199 \\
4.303\end{array}$ & $\begin{array}{l}-3.545 \\
-3.625 \\
-3.974 \\
-5.010 \\
-4.925\end{array}$ \\
\hline $\begin{array}{l}47.894 \\
47.890 \\
47.886 \\
47.885 \\
47.848\end{array}$ & $\begin{array}{l}-102.596 \\
-102.595 \\
-102.597 \\
-102.599 \\
-102.600\end{array}$ & $\begin{array}{l}565.73 \\
569.04 \\
574.22 \\
577.67 \\
668.34\end{array}$ & $\begin{array}{l}4.314 \\
4.529 \\
4.812 \\
4.429 \\
4.122\end{array}$ & $\begin{array}{l}-5.005 \\
-5.474 \\
-6.105 \\
-5.274 \\
-4.225\end{array}$ \\
\hline $\begin{array}{l}47.964 \\
47.963 \\
47.964 \\
47.963 \\
47.964\end{array}$ & $\begin{array}{l}-102.491 \\
-102.489 \\
-102.484 \\
-102.478 \\
-102.472\end{array}$ & $\begin{array}{l}570.26 \\
574.77 \\
571.91 \\
587.24 \\
584.36\end{array}$ & $\begin{array}{r}-.324 \\
-.149 \\
-.284 \\
-.226 \\
.416\end{array}$ & $\begin{array}{r}.870 \\
1.018 \\
.324 \\
. .011 \\
.661\end{array}$ \\
\hline $\begin{array}{l}47.963 \\
47.963 \\
47.963 \\
47.963 \\
47.965\end{array}$ & $\begin{array}{l}-102.467 \\
-102.462 \\
-102.457 \\
-102.451 \\
-102.450\end{array}$ & $\begin{array}{l}584.89 \\
579.58 \\
569.92 \\
570.84 \\
572.45\end{array}$ & $\begin{array}{r}.682 \\
1.074 \\
.918 \\
.984 \\
1.323\end{array}$ & $\begin{array}{r}.868 \\
1.152 \\
.362 \\
.100 \\
.807\end{array}$ \\
\hline
\end{tabular}


Table 8. Latitude, longitude, aititude, Bouguer gravity, and residual gravity values-Continued

[Latitude and longiude values are in decimal degrees; the negative sign of the longitude is the convention referencing longitude west of the prime meridian; altitude is in meters above sea level; the Bouguer gravity values and residual gravity values are in the units of milligals]

\begin{tabular}{|c|c|c|c|c|}
\hline Latltude & Longltude & Altltude & Bouguer gravity & Residual gravlty \\
\hline $\begin{array}{l}47.963 \\
47.963 \\
47.964 \\
47.964 \\
47.978\end{array}$ & $\begin{array}{l}-102.446 \\
-102.440 \\
-102.435 \\
-102.432 \\
-102.450\end{array}$ & $\begin{array}{l}573.71 \\
573.60 \\
571.31 \\
566.58 \\
581.33\end{array}$ & $\begin{array}{l}1.704 \\
2.041 \\
1.801 \\
2.207 \\
1.448\end{array}$ & $\begin{array}{r}1.037 \\
1.023 \\
.119 \\
.431 \\
1.873\end{array}$ \\
\hline $\begin{array}{l}47.974 \\
47.971 \\
47.967 \\
47.963 \\
47.959\end{array}$ & $\begin{array}{l}-102.450 \\
-102.450 \\
-102.450 \\
-102.451 \\
-102.450\end{array}$ & $\begin{array}{l}578.86 \\
578.11 \\
574.47 \\
570.88 \\
579.61\end{array}$ & $\begin{array}{l}1.230 \\
1.367 \\
1.172 \\
1.034 \\
1.026\end{array}$ & $\begin{array}{l}1.143 \\
1.254 \\
.573 \\
C \\
-.158\end{array}$ \\
\hline $\begin{array}{l}47.956 \\
47.952 \\
47.949 \\
47.945 \\
47.941\end{array}$ & $\begin{array}{l}-102.450 \\
-102.450 \\
-102.450 \\
-102.450 \\
-102.450\end{array}$ & $\begin{array}{l}577.60 \\
577.66 \\
573.38 \\
571.95 \\
573.81\end{array}$ & $\begin{array}{r}.915 \\
1.063 \\
1.245 \\
1.142 \\
1.285\end{array}$ & $\begin{array}{l}-.583 \\
-.467 \\
-.288 \\
-.754 \\
-.618\end{array}$ \\
\hline $\begin{array}{l}47.938 \\
47.930 \\
47.927 \\
47.924 \\
47.920\end{array}$ & $\begin{array}{l}-102.450 \\
-102.450 \\
-102.450 \\
-102.450 \\
-102.450\end{array}$ & $\begin{array}{l}574.99 \\
584.02 \\
580.09 \\
579.99 \\
577.28\end{array}$ & $\begin{array}{l}1.130 \\
1.449 \\
1.612 \\
1.395 \\
1.702\end{array}$ & $\begin{array}{r}-.992 \\
-.662 \\
-.483 \\
-1.079 \\
-.477\end{array}$ \\
\hline $\begin{array}{l}47.915 \\
47.913 \\
47.910 \\
47.906 \\
47.902\end{array}$ & $\begin{array}{l}-102.450 \\
-102.450 \\
-102.450 \\
-102.450 \\
-102.450\end{array}$ & $\begin{array}{l}585.46 \\
592.44 \\
588.95 \\
594.85 \\
609.43\end{array}$ & $\begin{array}{l}2.733 \\
1.627 \\
1.651 \\
1.551 \\
1.481\end{array}$ & $\begin{array}{r}1.463 \\
-.777 \\
-.834 \\
-1.101 \\
-1.315\end{array}$ \\
\hline $\begin{array}{l}47.899 \\
47.895 \\
47.891 \\
47.888 \\
47.884\end{array}$ & $\begin{array}{l}-102.450 \\
-102.450 \\
-102.450 \\
-102.450 \\
-102.450\end{array}$ & $\begin{array}{l}615.90 \\
621.27 \\
616.99 \\
625.16 \\
623.06\end{array}$ & $\begin{array}{l}1.430 \\
1.414 \\
1.992 \\
1.827 \\
2.138\end{array}$ & $\begin{array}{r}-1.368 \\
-1.365 \\
-.278 \\
-.696 \\
.071\end{array}$ \\
\hline $\begin{array}{l}47.880 \\
47.877 \\
47.873 \\
47.869 \\
47.866\end{array}$ & $\begin{array}{l}-102.450 \\
-102.450 \\
-102.450 \\
-102.450 \\
-102.450\end{array}$ & $\begin{array}{l}611.49 \\
603.99 \\
607.32 \\
610.16 \\
589.99\end{array}$ & $\begin{array}{l}2.516 \\
2.572 \\
2.105 \\
2.262 \\
2.442\end{array}$ & $\begin{array}{l}.849 \\
.908 \\
.011 \\
.334 \\
.844\end{array}$ \\
\hline $\begin{array}{l}47.898 \\
47.898 \\
47.898 \\
47.877 \\
47.873\end{array}$ & $\begin{array}{l}-102.557 \\
-102.551 \\
-102.546 \\
-102.579 \\
-102.579\end{array}$ & $\begin{array}{l}625.75 \\
636.94 \\
635.05 \\
606.17 \\
610.73\end{array}$ & $\begin{array}{l}-3.074 \\
-3.029 \\
-2.729 \\
-4.798 \\
-4.839\end{array}$ & $\begin{array}{l}-3.451 \\
-3.736 \\
-3.386 \\
-6.394 \\
-6.490\end{array}$ \\
\hline $\begin{array}{l}47.866 \\
47.858 \\
47.855 \\
47.852 \\
47.848\end{array}$ & $\begin{array}{l}-102.579 \\
-102.579 \\
-102.579 \\
-102.579 \\
-102.582\end{array}$ & $\begin{array}{l}631.21 \\
651.07 \\
650.75 \\
644.18 \\
647.24\end{array}$ & $\begin{array}{l}-2.780 \\
-4.000 \\
-4.253 \\
-4.137 \\
-4.068\end{array}$ & $\begin{array}{r}-2.303 \\
-4.559 \\
-5.007 \\
-4.729 \\
-4.426\end{array}$ \\
\hline $\begin{array}{l}47.898 \\
47.898 \\
47.898 \\
47.898 \\
47.898\end{array}$ & $\begin{array}{l}-102.524 \\
-102.519 \\
-102.508 \\
-102.503 \\
-102.498\end{array}$ & $\begin{array}{l}641.08 \\
641.22 \\
616.02 \\
624.94 \\
632.37\end{array}$ & $\begin{array}{l}-3.787 \\
-3.129 \\
-2.180 \\
-1.938 \\
-1.678\end{array}$ & $\begin{array}{r}-6.619 \\
-5.428 \\
-4.217 \\
-4.116 \\
-2.846\end{array}$ \\
\hline
\end{tabular}


Table 8. Latitude, longitude, altitude, Bouguer gravity, and residual gravity values--Continued

[Latitude and longitude values are in decimal degrees; the negative sign of the longitude is the convention referencing longitude west of the prime ineridian; altimde is in meters above sea level; the Bouguer gravity values and residual gravity values are in the units of milliga's]

\begin{tabular}{|c|c|c|c|c|}
\hline Latitude & Longitude & Altitude & Bouguer gravity & Realdual gravity \\
\hline $\begin{array}{l}47.898 \\
47.898 \\
47.898 \\
47.891 \\
47.887\end{array}$ & $\begin{array}{l}-102.493 \\
-102.488 \\
-102.483 \\
-102.514 \\
-102.514\end{array}$ & $\begin{array}{l}634.78 \\
635.00 \\
633.55 \\
608.05 \\
613.26\end{array}$ & $\begin{array}{r}-1.507 \\
-1.024 \\
-.755 \\
-2.173 \\
-2.115\end{array}$ & $\begin{array}{l}-3.817 \\
-3.351 \\
-3.188 \\
-3.900 \\
-3.844\end{array}$ \\
\hline $\begin{array}{l}47.883 \\
47.879 \\
47.862 \\
47.859 \\
47.855\end{array}$ & $\begin{array}{l}-102.514 \\
-102.514 \\
-102.622 \\
-102.622 \\
-102.622\end{array}$ & $\begin{array}{l}608.37 \\
590.99 \\
645.67 \\
646.56 \\
644.48\end{array}$ & $\begin{array}{r}-2.450 \\
-2.340 \\
-5.313 \\
-4.563 \\
-5.317\end{array}$ & $\begin{array}{l}-4.407 \\
-4.222 \\
-6.509 \\
4.993 \\
-6.448\end{array}$ \\
\hline $\begin{array}{l}47.851 \\
47.848 \\
47.848 \\
47.978 \\
47.961\end{array}$ & $\begin{array}{l}-102.622 \\
-102.617 \\
-102.611 \\
-101.958 \\
-102.132\end{array}$ & $\begin{array}{l}656.91 \\
654.30 \\
659.22 \\
633.84 \\
605.34\end{array}$ & $\begin{array}{r}-5.101 \\
-5.051 \\
-4.728 \\
3.374 \\
2.913\end{array}$ & $\begin{array}{r}-5.951 \\
-5.833 \\
-5.058 \\
4.924 \\
2.262\end{array}$ \\
\hline $\begin{array}{l}47.844 \\
47.841 \\
47.836 \\
47.829 \\
47.826\end{array}$ & $\begin{array}{l}-101.829 \\
-101.829 \\
-101.829 \\
-101.829 \\
-101.829\end{array}$ & $\begin{array}{l}660.05 \\
658.13 \\
661.70 \\
661.18 \\
661.15\end{array}$ & $\begin{array}{l}-4.127 \\
-4.209 \\
-4.353 \\
-4.568 \\
-4.637\end{array}$ & $\begin{array}{l}-4.243 \\
-4.257 \\
-4.455 \\
-4.617 \\
-4.646\end{array}$ \\
\hline $\begin{array}{l}47.822 \\
47.819 \\
47.814 \\
47.811 \\
47.807\end{array}$ & $\begin{array}{l}-101.829 \\
-101.829 \\
-101.829 \\
-101.829 \\
-101.829\end{array}$ & $\begin{array}{l}661.87 \\
663.62 \\
659.43 \\
658.62 \\
653.49\end{array}$ & $\begin{array}{l}4.868 \\
-4.948 \\
4.214 \\
4.506 \\
4.826\end{array}$ & $\begin{array}{r}-4.991 \\
-5.026 \\
-3.397 \\
-3.922 \\
-4.443\end{array}$ \\
\hline $\begin{array}{l}47.799 \\
47.796 \\
47.793 \\
47.790 \\
47.785\end{array}$ & $\begin{array}{l}-101.829 \\
-101.829 \\
-101.829 \\
-101.829 \\
-101.829\end{array}$ & $\begin{array}{l}647.53 \\
650.23 \\
651.12 \\
660.84 \\
656.46\end{array}$ & $\begin{array}{l}-4.892 \\
-4.947 \\
-5.399 \\
-5.846 \\
-6.054\end{array}$ & $\begin{array}{r}-4.269 \\
-4.261 \\
-5.062 \\
-5.814 \\
-6.077\end{array}$ \\
\hline $\begin{array}{l}47.775 \\
47.767 \\
47.764 \\
47.761 \\
47.758\end{array}$ & $\begin{array}{l}-101.829 \\
-101.829 \\
-101.829 \\
-101.829 \\
-101.829\end{array}$ & $\begin{array}{l}654.00 \\
651.07 \\
648.28 \\
639.80 \\
636.05\end{array}$ & $\begin{array}{l}-6.534 \\
-7.668 \\
-7.362 \\
-8.680 \\
-7.529\end{array}$ & $\begin{array}{r}-6.650 \\
-8.653 \\
-7.874 \\
-10.428 \\
-8.003\end{array}$ \\
\hline $\begin{array}{l}47.755 \\
47.751 \\
47.741 \\
47.738 \\
47.735\end{array}$ & $\begin{array}{l}-101.829 \\
-101.829 \\
-101.829 \\
-101.829 \\
-101.829\end{array}$ & $\begin{array}{l}638.35 \\
638.81 \\
637.62 \\
637.64 \\
636.58\end{array}$ & $\begin{array}{l}-7.685 \\
-7.930 \\
-8.176 \\
-8.459 \\
-7.975\end{array}$ & $\begin{array}{l}-8.150 \\
-8.549 \\
-8.578 \\
-9.032 \\
-7.942\end{array}$ \\
\hline $\begin{array}{l}47.732 \\
47.727 \\
47.724 \\
47.717 \\
47.713\end{array}$ & $\begin{array}{l}-101.829 \\
-101.829 \\
-101.829 \\
-101.829 \\
-101.829\end{array}$ & $\begin{array}{l}635.74 \\
637.51 \\
638.20 \\
638.91 \\
634.05\end{array}$ & $\begin{array}{l}-8.233 \\
-8.479 \\
-8.684 \\
-7.365 \\
-7.530\end{array}$ & $\begin{array}{l}-8.319 \\
-8.570 \\
-8.891 \\
-5.975 \\
-6.132\end{array}$ \\
\hline $\begin{array}{l}47.710 \\
47.707 \\
47.703 \\
47.699 \\
47.827\end{array}$ & $\begin{array}{l}-101.829 \\
-101.829 \\
-101.829 \\
-101.829 \\
-101.850\end{array}$ & $\begin{array}{l}628.57 \\
626.35 \\
625.72 \\
620.76 \\
659.11\end{array}$ & $\begin{array}{l}-7.666 \\
-8.455 \\
-8.152 \\
-8.009 \\
-2.945\end{array}$ & $\begin{array}{l}-6.248 \\
-7.660 \\
-6.867 \\
-6.436 \\
-1.967\end{array}$ \\
\hline
\end{tabular}


Table 8. Latitude, longitude, aititude, Bouguer gravity, and residual gravity values--Continued

[Latitude and longitude values are in decimal degrees; the negative sign of the longitude is the convention referencing longitude west of the prime meridian; altimde is in meters above sea level; the Bonguer gravity values and residual gravity values are in the units of milligals]

\begin{tabular}{|c|c|c|c|c|}
\hline Latitude & Longitude & Altitude & Bouguer gravity & Residual gravity \\
\hline $\begin{array}{l}47.823 \\
47.819 \\
47.815 \\
47.807 \\
47.797\end{array}$ & $\begin{array}{l}-101.850 \\
-101.850 \\
-101.850 \\
-101.850 \\
-101.851\end{array}$ & $\begin{array}{l}659.74 \\
655.63 \\
653.86 \\
652.79 \\
645.81\end{array}$ & $\begin{array}{l}-3.270 \\
-3.045 \\
-3.250 \\
-3.711 \\
-4.240\end{array}$ & $\begin{array}{l}-2.522 \\
-1.895 \\
-2.237 \\
-2.879 \\
-3.631\end{array}$ \\
\hline $\begin{array}{l}47.793 \\
47.790 \\
47.785 \\
47.783 \\
47.778\end{array}$ & $\begin{array}{l}-101.851 \\
-101.851 \\
-101.851 \\
-101.851 \\
-101.851\end{array}$ & $\begin{array}{l}651.14 \\
654.85 \\
652.91 \\
651.82 \\
646.54\end{array}$ & $\begin{array}{l}-4.260 \\
-4.409 \\
-4.812 \\
4.511 \\
-4.538\end{array}$ & $\begin{array}{l}-3487 \\
-3726 \\
-4367 \\
-3658 \\
-3.548\end{array}$ \\
\hline $\begin{array}{l}47.775 \\
47.768 \\
47.761 \\
47.743 \\
47.739\end{array}$ & $\begin{array}{l}-101.851 \\
-101.851 \\
-101.872 \\
-101.850 \\
-101.850\end{array}$ & $\begin{array}{l}639.87 \\
644.28 \\
634.94 \\
638.09 \\
639.45\end{array}$ & $\begin{array}{l}-5.142 \\
-5.480 \\
-6.080 \\
-7.059 \\
-7.148\end{array}$ & $\begin{array}{l}-4.634 \\
-5.056 \\
-6.661 \\
-7.176 \\
-7.244\end{array}$ \\
\hline $\begin{array}{l}47.736 \\
47.729 \\
47.725 \\
47.717 \\
47.710\end{array}$ & $\begin{array}{l}-101.850 \\
-101.850 \\
-101.850 \\
-101.850 \\
-101.850\end{array}$ & $\begin{array}{l}637.08 \\
640.02 \\
638.61 \\
631.10 \\
62434\end{array}$ & $\begin{array}{l}-7.257 \\
-7.707 \\
-8.030 \\
-8.398 \\
-8.594\end{array}$ & $\begin{array}{l}-7.270 \\
-7.901 \\
-8.383 \\
-8813 \\
-8903\end{array}$ \\
\hline $\begin{array}{l}47.707 \\
47.703 \\
47.699 \\
47.696 \\
47.692\end{array}$ & $\begin{array}{l}-101.850 \\
-101.850 \\
-101.850 \\
-101.850 \\
-101.850\end{array}$ & $\begin{array}{l}620.01 \\
614.52 \\
611.24 \\
610.12 \\
607.85\end{array}$ & $\begin{array}{l}-8.676 \\
-8.801 \\
-8.911 \\
-8.960 \\
-9.141\end{array}$ & $\begin{array}{l}-8.913 \\
-8.944 \\
-9.032 \\
-8938 \\
-9.158\end{array}$ \\
\hline $\begin{array}{l}47.685 \\
47.681 \\
47.677 \\
47.674 \\
47.650\end{array}$ & $\begin{array}{l}-101.850 \\
-101.850 \\
-101.850 \\
-101.847 \\
-101.844\end{array}$ & $\begin{array}{l}604.82 \\
605.83 \\
605.36 \\
605.79 \\
615.38\end{array}$ & $\begin{array}{r}-9.635 \\
-10.000 \\
-9.995 \\
-10.121 \\
-10.869\end{array}$ & $\begin{array}{r}-9.806 \\
-10.380 \\
-10195 \\
-10.164 \\
-10.333\end{array}$ \\
\hline $\begin{array}{l}47.736 \\
47.732 \\
47.729 \\
47.725 \\
47.722\end{array}$ & $\begin{array}{l}-101.872 \\
-101.872 \\
-101.872 \\
-101.872 \\
-101.872\end{array}$ & $\begin{array}{l}634.82 \\
633.16 \\
63136 \\
628.14 \\
626.59\end{array}$ & $\begin{array}{l}-6.625 \\
-6.878 \\
-7.076 \\
-7.252 \\
-7.342\end{array}$ & $\begin{array}{l}-6824 \\
-7.114 \\
-7.436 \\
-7.601 \\
-7.651\end{array}$ \\
\hline $\begin{array}{l}47.717 \\
47.714 \\
47.710 \\
47.703 \\
47.699\end{array}$ & $\begin{array}{l}-101.872 \\
-101.872 \\
-101.872 \\
-101.872 \\
-101.872\end{array}$ & $\begin{array}{l}625.48 \\
622.62 \\
613.99 \\
611.05 \\
606.43\end{array}$ & $\begin{array}{l}-7.811 \\
-7.808 \\
-7.878 \\
-8.306 \\
-8.641\end{array}$ & $\begin{array}{l}-8414 \\
-8.273 \\
-8.229 \\
-8786 \\
-9.298\end{array}$ \\
\hline $\begin{array}{l}47.696 \\
47.685 \\
47.681 \\
47.678 \\
47.674\end{array}$ & $\begin{array}{l}-101.872 \\
-101.872 \\
-101.872 \\
-101.872 \\
-101.872\end{array}$ & $\begin{array}{l}605.63 \\
606.71 \\
611.39 \\
611.79 \\
611.98\end{array}$ & $\begin{array}{l}-8.756 \\
-8.427 \\
-8.722 \\
-9.051 \\
-9.071\end{array}$ & $\begin{array}{l}-9.336 \\
-8.234 \\
-8.643 \\
-9.172 \\
-9.009\end{array}$ \\
\hline $\begin{array}{l}48.001 \\
47.998 \\
47.994 \\
47.990 \\
47.987\end{array}$ & $\begin{array}{l}-101.893 \\
-101.893 \\
-101.893 \\
-101.893 \\
-101.893\end{array}$ & $\begin{array}{l}635.89 \\
623.74 \\
624.52 \\
631.77 \\
634.59\end{array}$ & $\begin{array}{r}.742 \\
.761 \\
1.765 \\
.797 \\
.517\end{array}$ & $\begin{array}{r}.524 \\
.642 \\
2.673 \\
.804 \\
.261\end{array}$ \\
\hline
\end{tabular}


Table B. Latitude, longitude, altitude, Bouguer gravity, and residual gravity values--Continued

[Latitude and longinde values are in decimal degrees; the negative sign of the longiude is the convention referencing longitude west of the prime meridian; atritude is in meters above sea level; the Bouguer gravity values and residual gravity values are in the units of milliga's]

\begin{tabular}{|c|c|c|c|c|}
\hline Latitude & Longitude & Altitude & Bouguer gravity & Residual gravity \\
\hline $\begin{array}{l}47.983 \\
47.979 \\
47.976 \\
47.973 \\
47.965\end{array}$ & $\begin{array}{l}-101.893 \\
-101.893 \\
-101.893 \\
-101.893 \\
-101.893\end{array}$ & $\begin{array}{l}637.01 \\
638.86 \\
637.66 \\
642.39 \\
635.08\end{array}$ & $\begin{array}{r}0.404 \\
.490 \\
-.003 \\
-2.349 \\
-2.175\end{array}$ & $\begin{array}{r}0.081 \\
.327 \\
-.656 \\
-5.278 \\
-4.831\end{array}$ \\
\hline $\begin{array}{l}47.962 \\
47.958 \\
47.955 \\
47.951 \\
47.949\end{array}$ & $\begin{array}{l}-101.893 \\
-101.893 \\
-101.893 \\
-101.893 \\
-101.893\end{array}$ & $\begin{array}{l}636.36 \\
636.96 \\
636.16 \\
638.96 \\
638.48\end{array}$ & $\begin{array}{l}-2.318 \\
-2.279 \\
-2.357 \\
-2.443 \\
-2.491\end{array}$ & $\begin{array}{r}-5.065 \\
-4.946 \\
-5.044 \\
-5.119 \\
-5.187\end{array}$ \\
\hline $\begin{array}{l}47.945 \\
47.917 \\
47.913 \\
47.909 \\
47.906\end{array}$ & $\begin{array}{l}-101.893 \\
-101.893 \\
-101.893 \\
-101.893 \\
-101.893\end{array}$ & $\begin{array}{l}637.88 \\
638.65 \\
642.29 \\
641.78 \\
642.58\end{array}$ & $\begin{array}{r}-2.583 \\
-1.712 \\
-.897 \\
-.978 \\
-1.083\end{array}$ & $\begin{array}{l}-5.299 \\
-3.061 \\
-1.303 \\
-1.438 \\
-1.543\end{array}$ \\
\hline $\begin{array}{l}47.902 \\
47.898 \\
47.895 \\
47.891 \\
47.888\end{array}$ & $\begin{array}{l}-101.893 \\
-101.893 \\
-101.893 \\
-101.893 \\
-101.893\end{array}$ & $\begin{array}{l}647.42 \\
646.10 \\
650.25 \\
649.03 \\
649.82\end{array}$ & $\begin{array}{l}-1.197 \\
-1.278 \\
-1.347 \\
-1.472 \\
-1.499\end{array}$ & $\begin{array}{l}-1.681 \\
-1.783 \\
-1.822 \\
-2.030 \\
-1.993\end{array}$ \\
\hline $\begin{array}{l}47.884 \\
47.880 \\
47.877 \\
47.873 \\
47.869\end{array}$ & $\begin{array}{l}-101.893 \\
-101.893 \\
-101.893 \\
-101.893 \\
-101.893\end{array}$ & $\begin{array}{l}651.73 \\
649.95 \\
652.16 \\
656.64 \\
655.63\end{array}$ & $\begin{array}{l}-1.593 \\
-1.698 \\
-1.885 \\
-2.017 \\
-2.106\end{array}$ & $\begin{array}{l}-2.106 \\
-2.179 \\
-2.481 \\
-2.650 \\
-2.717\end{array}$ \\
\hline $\begin{array}{l}47.866 \\
47.859 \\
47.855 \\
47.851 \\
47.848\end{array}$ & $\begin{array}{l}-101.893 \\
-101.893 \\
-101.893 \\
-101.893 \\
-101.893\end{array}$ & $\begin{array}{l}656.84 \\
657.81 \\
658.10 \\
658.34 \\
657.05\end{array}$ & $\begin{array}{l}-2.374 \\
-2.558 \\
-2.671 \\
-2.647 \\
-2.704\end{array}$ & $\begin{array}{l}-3.217 \\
-3.365 \\
-3.524 \\
-3.361 \\
-3.410\end{array}$ \\
\hline $\begin{array}{l}47.790 \\
47.761 \\
47.729 \\
47.725 \\
47.722\end{array}$ & $\begin{array}{l}-101.893 \\
-101.893 \\
-101.893 \\
-101.893 \\
-101.893\end{array}$ & $\begin{array}{l}636.05 \\
621.98 \\
617.03 \\
614.72 \\
614.98\end{array}$ & $\begin{array}{l}-2.197 \\
-3.488 \\
-5.122 \\
-5.059 \\
-5.377\end{array}$ & $\begin{array}{r}-.615 \\
-2.213 \\
-4.224 \\
-3.991 \\
-4.446\end{array}$ \\
\hline $\begin{array}{l}47.709 \\
47.706 \\
47.692 \\
47.674 \\
47.670\end{array}$ & $\begin{array}{l}-101.893 \\
-101.893 \\
-101.893 \\
-101.893 \\
-101.886\end{array}$ & $\begin{array}{l}607.52 \\
608.48 \\
607.57 \\
619.02 \\
620.13\end{array}$ & $\begin{array}{r}-5.845 \\
-7.102 \\
-7.395 \\
-8.467 \\
-11.315\end{array}$ & $\begin{array}{r}-4.872 \\
-7.287 \\
-7.257 \\
-8.566 \\
-13.867\end{array}$ \\
\hline $\begin{array}{l}47.666 \\
47.663 \\
47.661 \\
47.657 \\
47.654\end{array}$ & $\begin{array}{l}-101.886 \\
-101.887 \\
-101.886 \\
-101.887 \\
-101.887\end{array}$ & $\begin{array}{l}618.62 \\
617.74 \\
618.78 \\
622.16 \\
625.31\end{array}$ & $\begin{array}{r}-11.097 \\
-10.682 \\
-10.532 \\
-6.018 \\
-6.096\end{array}$ & $\begin{array}{r}-13.244 \\
-12.235 \\
-11.847 \\
-2.672 \\
-2.690\end{array}$ \\
\hline $\begin{array}{l}47.651 \\
47.982 \\
47.974 \\
47.971 \\
47.963\end{array}$ & $\begin{array}{l}-101.887 \\
-101.915 \\
-101.915 \\
-101.915 \\
-101.915\end{array}$ & $\begin{array}{l}621.45 \\
633.98 \\
630.37 \\
636.27 \\
641.26\end{array}$ & $\begin{array}{r}-7.611 \\
.995 \\
1.474 \\
1.056 \\
.981\end{array}$ & $\begin{array}{r}-5.560 \\
.889 \\
1.930 \\
1.117 \\
1.065\end{array}$ \\
\hline
\end{tabular}


Table 8. Latitude, longitude, altitude, Bouguer gravity, and residual gravity values--Continued

[Latitude and longitude values are in decimal degrees; the negative sign of the longitude is the convention referencing longitud : west of the prime meridian; altimde is in meters above sea level; the Bouguer gravity values and residual gravity values are in the units of milligals]

\begin{tabular}{|c|c|c|c|c|}
\hline Latltude & Longltude & Altitude & Bouguer gravlty & Reoldual gravity \\
\hline $\begin{array}{l}47.960 \\
47.949 \\
47.934 \\
47.927 \\
47.924\end{array}$ & $\begin{array}{l}-101.915 \\
-101.915 \\
-101.915 \\
-101.915 \\
-101.915\end{array}$ & $\begin{array}{l}641.35 \\
640.96 \\
646.24 \\
642.70 \\
641.97\end{array}$ & $\begin{array}{r}0.873 \\
.789 \\
.368 \\
.202 \\
-.111\end{array}$ & $\begin{array}{r}0916 \\
.940 \\
.313 \\
.089 \\
-.438\end{array}$ \\
\hline $\begin{array}{l}47.920 \\
47.913 \\
47.909 \\
47.905 \\
47.902\end{array}$ & $\begin{array}{l}-101.915 \\
-101.915 \\
-101.915 \\
-101.915 \\
-101.915\end{array}$ & $\begin{array}{l}637.38 \\
638.47 \\
640.24 \\
648.12 \\
642.08\end{array}$ & $\begin{array}{l}.202 \\
-.033 \\
-.120 \\
-.213 \\
-.104\end{array}$ & $\begin{array}{r}.217 \\
-.081 \\
-.202 \\
-.301 \\
.006\end{array}$ \\
\hline $\begin{array}{l}47.898 \\
47.891 \\
47.887 \\
47.884 \\
47.877\end{array}$ & $\begin{array}{l}-101.915 \\
-101.915 \\
-101.915 \\
-101.915 \\
-101.915\end{array}$ & $\begin{array}{l}644.55 \\
647.36 \\
651.69 \\
649.52 \\
651.37\end{array}$ & $\begin{array}{r}-.704 \\
-1.170 \\
-.768 \\
-.925 \\
-1.087\end{array}$ & $\begin{array}{r}-1.145 \\
-1.925 \\
-.997 \\
-1.283 \\
-1.404\end{array}$ \\
\hline $\begin{array}{l}47.869 \\
47.855 \\
47.852 \\
47.848 \\
47.844\end{array}$ & $\begin{array}{l}-101.915 \\
-101.915 \\
-101.915 \\
-101.915 \\
-101.915\end{array}$ & $\begin{array}{l}654.79 \\
652.93 \\
651.50 \\
647.57 \\
646.16\end{array}$ & $\begin{array}{l}-1.777 \\
-2.055 \\
-1.796 \\
-1.982 \\
-2.339\end{array}$ & $\begin{array}{l}-2.614 \\
-2.855 \\
-2.265 \\
-2.528 \\
-3.091\end{array}$ \\
\hline $\begin{array}{l}47.840 \\
47.836 \\
47.829 \\
47.822 \\
47.819\end{array}$ & $\begin{array}{l}-101.915 \\
-101.915 \\
-101.915 \\
-101.915 \\
-101.915\end{array}$ & $\begin{array}{l}647.66 \\
650.51 \\
646.53 \\
645.68 \\
647.92\end{array}$ & $\begin{array}{l}-1.994 \\
-3.106 \\
-2.104 \\
-2.091 \\
-2.924\end{array}$ & $\begin{array}{l}-2.354 \\
-4.433 \\
-2.253 \\
-2.050 \\
-3.590\end{array}$ \\
\hline $\begin{array}{l}47.815 \\
47.811 \\
47.808 \\
47.801 \\
47.797\end{array}$ & $\begin{array}{l}-101.915 \\
-101.915 \\
-101.915 \\
-101.915 \\
-101.915\end{array}$ & $\begin{array}{l}646.67 \\
645.00 \\
635.65 \\
628.81 \\
632.14\end{array}$ & $\begin{array}{l}-3.219 \\
-2.900 \\
-2.870 \\
-2.862 \\
-3.244\end{array}$ & $\begin{array}{l}-4.044 \\
-3.330 \\
-3.132 \\
-2.924 \\
-3.534\end{array}$ \\
\hline $\begin{array}{l}47.793 \\
47.790 \\
47.782 \\
47.728 \\
47.725\end{array}$ & $\begin{array}{l}-101.915 \\
-101.915 \\
-101.915 \\
-101.915 \\
-101.915\end{array}$ & $\begin{array}{l}628.28 \\
626.19 \\
626.53 \\
604.81 \\
601.72\end{array}$ & $\begin{array}{l}-3.103 \\
-3.251 \\
-3.832 \\
-8.422 \\
-8.574\end{array}$ & $\begin{array}{r}-3152 \\
-3.335 \\
-4.259 \\
-11.503 \\
-11.677\end{array}$ \\
\hline $\begin{array}{l}47.721 \\
47.714 \\
47.710 \\
47.706 \\
47.701\end{array}$ & $\begin{array}{l}-101.915 \\
-101.915 \\
-101.915 \\
-101.915 \\
-101.915\end{array}$ & $\begin{array}{l}604.60 \\
601.11 \\
602.56 \\
602.84 \\
601.39\end{array}$ & $\begin{array}{l}-8.863 \\
-9.186 \\
-9.337 \\
-8.748 \\
-9.166\end{array}$ & $\begin{array}{l}-12.146 \\
-12.442 \\
-12.605 \\
-11.312 \\
-11.901\end{array}$ \\
\hline $\begin{array}{l}47.945 \\
47.941 \\
47.938 \\
47.931 \\
47.927\end{array}$ & $\begin{array}{l}-101.936 \\
-101.936 \\
-101.936 \\
-101.936 \\
-101.936\end{array}$ & $\begin{array}{l}640.61 \\
641.77 \\
643.23 \\
639.45 \\
641.05\end{array}$ & $\begin{array}{l}3.884 \\
3.818 \\
3.591 \\
3.241 \\
3.229\end{array}$ & $\begin{array}{l}6724 \\
6654 \\
6278 \\
5.664 \\
5.723\end{array}$ \\
\hline $\begin{array}{l}47.923 \\
47.823 \\
47.819 \\
47.815 \\
47.812\end{array}$ & $\begin{array}{l}-101.937 \\
-101.936 \\
-101.936 \\
-101.936 \\
-101.937\end{array}$ & $\begin{array}{l}642.72 \\
627.70 \\
625.92 \\
630.80 \\
625.55\end{array}$ & $\begin{array}{r}3.160 \\
-2.623 \\
-3.023 \\
-3.198 \\
-3.401\end{array}$ & $\begin{array}{r}5.576 \\
-3.672 \\
-4.320 \\
-4.613 \\
-4.932\end{array}$ \\
\hline
\end{tabular}


Tabie 8. Latitude, longitude, altitude, Bouguer gravity, and residual gravity values--Continued

[Latitude and longitude values are in decimal degrees; the negative sign of the longitude is the convention referencing longitude west of the prime meridian; altitude is in meters above sea level; the Bouguer gravity values and residual gravity values are in the units of milligals]

\begin{tabular}{|c|c|c|c|c|}
\hline Latitude & Longltude & Altitude & Bouguer gravity & Residusl grsvil"e \\
\hline $\begin{array}{l}47.808 \\
47.804 \\
47.800 \\
47.797 \\
47.794\end{array}$ & $\begin{array}{l}-101.936 \\
-101.936 \\
-101.936 \\
-101.937 \\
-101.937\end{array}$ & $\begin{array}{l}623.49 \\
622.76 \\
621.42 \\
613.68 \\
609.01\end{array}$ & $\begin{array}{l}-3.469 \\
-3.579 \\
-3.739 \\
-3.896 \\
-4.079\end{array}$ & $\begin{array}{r}-4.940 \\
-5.024 \\
-5.254 \\
-5.477 \\
-5.764\end{array}$ \\
\hline $\begin{array}{l}47.790 \\
47.786 \\
47.782 \\
47.779 \\
47.775\end{array}$ & $\begin{array}{l}-101.936 \\
-101.936 \\
-101.936 \\
-101.936 \\
-101.936\end{array}$ & $\begin{array}{l}616.19 \\
607.32 \\
618.32 \\
612.81 \\
606.78\end{array}$ & $\begin{array}{l}-4.141 \\
-3.995 \\
-4.235 \\
-4.356 \\
-4.426\end{array}$ & $\begin{array}{l}-5.731 \\
-5.304 \\
-5.694 \\
-5.835 \\
-5.795\end{array}$ \\
\hline $\begin{array}{l}47.774 \\
47.769 \\
47.765 \\
47.761 \\
47.758\end{array}$ & $\begin{array}{l}-101.936 \\
-101.936 \\
-101.936 \\
-101.936 \\
-101.936\end{array}$ & $\begin{array}{l}607.31 \\
612.52 \\
614.10 \\
614.69 \\
613.07\end{array}$ & $\begin{array}{l}-4.728 \\
-4.868 \\
-5.068 \\
-5.420 \\
-5.695\end{array}$ & $\begin{array}{l}-6.358 \\
-6.484 \\
-6.777 \\
-7.324 \\
-7.791\end{array}$ \\
\hline $\begin{array}{l}47.751 \\
47.746 \\
47.963 \\
47.960 \\
47.957\end{array}$ & $\begin{array}{l}-101.936 \\
-101.936 \\
-101.958 \\
-101.958 \\
-101.958\end{array}$ & $\begin{array}{l}611.08 \\
608.18 \\
637.95 \\
642.32 \\
642.72\end{array}$ & $\begin{array}{r}-6.071 \\
-6.290 \\
2.841 \\
3.195 \\
3.347\end{array}$ & $\begin{array}{r}-8.298 \\
-8.548 \\
4.008 \\
4.776 \\
5.117\end{array}$ \\
\hline $\begin{array}{l}47.953 \\
47.945 \\
47.942 \\
47.938 \\
47.934\end{array}$ & $\begin{array}{l}-101.958 \\
-101.958 \\
-101.958 \\
-101.958 \\
-101.958\end{array}$ & $\begin{array}{l}639.53 \\
642.49 \\
641.56 \\
641.83 \\
641.16\end{array}$ & $\begin{array}{l}3.079 \\
3.821 \\
2.584 \\
2.479 \\
2.513\end{array}$ & $\begin{array}{l}4.617 \\
6.235 \\
3.764 \\
3.613 \\
3.773\end{array}$ \\
\hline $\begin{array}{l}47.931 \\
47.891 \\
47.866 \\
47.862 \\
47.859\end{array}$ & $\begin{array}{l}-101.958 \\
-101.958 \\
-101.958 \\
-101.958 \\
-101.958\end{array}$ & $\begin{array}{l}644.27 \\
648.62 \\
647.58 \\
646.43 \\
648.05\end{array}$ & $\begin{array}{r}2.507 \\
-1.100 \\
-5.183 \\
-3.118 \\
-3.373\end{array}$ & $\begin{array}{r}3.786 \\
-2.700 \\
-10.377 \\
-6.115 \\
-6.570\end{array}$ \\
\hline $\begin{array}{l}47.855 \\
47.852 \\
47.848 \\
47.999 \\
47.995\end{array}$ & $\begin{array}{l}-101.958 \\
-101.958 \\
-101.958 \\
-101.980 \\
-101.980\end{array}$ & $\begin{array}{l}644.13 \\
643.38 \\
642.67 \\
631.25 \\
624.92\end{array}$ & $\begin{array}{r}-3.335 \\
-5.304 \\
-5.456 \\
5.788 \\
3.974\end{array}$ & $\begin{array}{r}-6.390 \\
-10.248 \\
-10.467 \\
9.248 \\
5.651\end{array}$ \\
\hline $\begin{array}{l}47.992 \\
47.989 \\
47.985 \\
47.981 \\
47.960\end{array}$ & $\begin{array}{l}-101.980 \\
-101.979 \\
-101.980 \\
-101.979 \\
-101.980\end{array}$ & $\begin{array}{l}624.84 \\
626.92 \\
631.06 \\
632.35 \\
638.44\end{array}$ & $\begin{array}{l}4.076 \\
4.104 \\
4.299 \\
4.367 \\
2.867\end{array}$ & $\begin{array}{l}5.878 \\
5.943 \\
6.363 \\
6.590 \\
3.739\end{array}$ \\
\hline $\begin{array}{l}47.956 \\
47.953 \\
47.717 \\
47.714 \\
47.707\end{array}$ & $\begin{array}{l}-101.980 \\
-101.980 \\
-101.979 \\
-101.979 \\
-101.979\end{array}$ & $\begin{array}{l}635.71 \\
635.52 \\
603.73 \\
604.35 \\
604.69\end{array}$ & $\begin{array}{l}2.866 \\
2.804 \\
-4.261 \\
-4.645 \\
-5.016\end{array}$ & $\begin{array}{l}3.804 \\
3.730 \\
4.661 \\
-5.322 \\
-5.802\end{array}$ \\
\hline $\begin{array}{l}47.703 \\
47.699 \\
47.696 \\
47.692 \\
47.686\end{array}$ & $\begin{array}{l}-101.979 \\
-101.979 \\
-101.979 \\
-101.979 \\
-101.979\end{array}$ & $\begin{array}{l}604.83 \\
607.31 \\
611.46 \\
610.96 \\
620.70\end{array}$ & $\begin{array}{l}-3.790 \\
-5.523 \\
-6.208 \\
-5.663 \\
-5.778\end{array}$ & $\begin{array}{l}-3.175 \\
-6.497 \\
-7.716 \\
-6.545 \\
-6.484\end{array}$ \\
\hline
\end{tabular}


Table 8. Latitude, longitude, altitude, Bouguer gravity, and residual gravity values--Continued

[Latitude and longitude values are in decimal degrees; the negative sign of the longinde is the convention referencing longitud: west of the prime meridian; altitude is in meters above sea level; the Bouguer gravity values and residual gravity values are in the units of milligals]

\begin{tabular}{|c|c|c|c|c|}
\hline Latltude & Longltude & Altitude & Bouguer gravity & Residual gravity \\
\hline $\begin{array}{l}47.682 \\
47.678 \\
47.674 \\
47.960 \\
47.956\end{array}$ & $\begin{array}{l}-101.979 \\
-101.979 \\
-101.979 \\
-102.000 \\
-102.000\end{array}$ & $\begin{array}{l}628.48 \\
626.44 \\
638.55 \\
623.37 \\
634.30\end{array}$ & $\begin{array}{r}-6.442 \\
-6.485 \\
-8.050 \\
3.470 \\
5.081\end{array}$ & $\begin{array}{r}-7.653 \\
-7.541 \\
-10561 \\
4.664 \\
7.894\end{array}$ \\
\hline $\begin{array}{l}47.953 \\
47.949 \\
47.945 \\
47.937 \\
47.935\end{array}$ & $\begin{array}{l}-102.000 \\
-102.000 \\
-102.000 \\
-102.000 \\
-102.001\end{array}$ & $\begin{array}{l}635.05 \\
639.94 \\
645.58 \\
646.84 \\
650.56\end{array}$ & $\begin{array}{l}3.884 \\
5.444 \\
3.241 \\
3.975 \\
4.034\end{array}$ & $\begin{array}{l}5.547 \\
8747 \\
4.380 \\
5.929 \\
6066\end{array}$ \\
\hline $\begin{array}{l}47.931 \\
47.924 \\
47.920 \\
47.917 \\
47.913\end{array}$ & $\begin{array}{l}-102.000 \\
-102.000 \\
-102.001 \\
-102.001 \\
-102.001\end{array}$ & $\begin{array}{l}646.24 \\
647.15 \\
646.98 \\
645.99 \\
644.38\end{array}$ & $\begin{array}{l}3.104 \\
6.777 \\
6.902 \\
6.166 \\
6.352\end{array}$ & $\begin{array}{r}4269 \\
11.727 \\
12.038 \\
10570 \\
10998\end{array}$ \\
\hline $\begin{array}{l}47.909 \\
47.905 \\
47.902 \\
47.895 \\
47.891\end{array}$ & $\begin{array}{l}-102.001 \\
-102.001 \\
-102.001 \\
-102.001 \\
-102.001\end{array}$ & $\begin{array}{l}645.49 \\
643.95 \\
643.50 \\
646.26 \\
645.64\end{array}$ & $\begin{array}{l}2.140 \\
1.018 \\
.716 \\
1.979 \\
1.643\end{array}$ & $\begin{array}{r}2.669 \\
.479 \\
-.090 \\
2.575 \\
1.937\end{array}$ \\
\hline $\begin{array}{l}47.887 \\
47.884 \\
47.880 \\
47.877 \\
47.877\end{array}$ & $\begin{array}{l}-102.001 \\
-102.001 \\
-102.001 \\
-102.001 \\
-102.001\end{array}$ & $\begin{array}{l}645.46 \\
645.24 \\
645.19 \\
644.82 \\
639.91\end{array}$ & $\begin{array}{l}-1.475 \\
-1.674 \\
-1.838 \\
-1.697 \\
-2.769\end{array}$ & $\begin{array}{l}-4.218 \\
-4.575 \\
-4.816 \\
-4.436 \\
-6539\end{array}$ \\
\hline $\begin{array}{l}47.869 \\
47.848 \\
47.837 \\
47.830 \\
47.826\end{array}$ & $\begin{array}{l}-102.001 \\
-102.001 \\
-102.001 \\
-102.001 \\
-102.001\end{array}$ & $\begin{array}{l}638.39 \\
631.82 \\
617.21 \\
619.63 \\
621.56\end{array}$ & $\begin{array}{r}-2.354 \\
-.668 \\
-1.113 \\
-.933 \\
-.894\end{array}$ & $\begin{array}{l}-5.626 \\
-1.824 \\
-2.493 \\
-1.904 \\
-1.746\end{array}$ \\
\hline $\begin{array}{l}47.823 \\
47.819 \\
47.797 \\
47.790 \\
47.775\end{array}$ & $\begin{array}{l}-102.001 \\
-102.001 \\
-102.001 \\
-102.001 \\
-102.001\end{array}$ & $\begin{array}{l}619.27 \\
619.86 \\
609.56 \\
603.11 \\
595.94\end{array}$ & $\begin{array}{r}-1.032 \\
-.816 \\
-1.369 \\
-1.283 \\
-2.000\end{array}$ & $\begin{array}{l}-1.976 \\
-1.419 \\
-1.941 \\
-1.578 \\
-2.620\end{array}$ \\
\hline $\begin{array}{l}47.768 \\
47.765 \\
47.761 \\
47.743 \\
47.739\end{array}$ & $\begin{array}{l}-102.001 \\
-102.000 \\
-102.001 \\
-102.001 \\
-102.001\end{array}$ & $\begin{array}{l}594.87 \\
593.67 \\
588.42 \\
589.05 \\
595.26\end{array}$ & $\begin{array}{r}-2.091 \\
-1.933 \\
-2.124 \\
.298 \\
-.303\end{array}$ & $\begin{array}{r}-2.603 \\
-2.186 \\
-2.397 \\
2.970 \\
1.906\end{array}$ \\
\hline $\begin{array}{l}47.736 \\
47.978 \\
47.974 \\
47.971 \\
47.967\end{array}$ & $\begin{array}{l}-102.001 \\
-102.043 \\
-102.043 \\
-102.043 \\
-102.043\end{array}$ & $\begin{array}{l}599.34 \\
628.88 \\
629.88 \\
620.12 \\
607.80\end{array}$ & $\begin{array}{l}-.443 \\
2.933 \\
2.932 \\
3.060 \\
3.125\end{array}$ & $\begin{array}{l}1.766 \\
2.905 \\
2.940 \\
3.204 \\
3.367\end{array}$ \\
\hline $\begin{array}{l}47.963 \\
47.960 \\
47.956 \\
47.953 \\
47.946\end{array}$ & $\begin{array}{l}-102.043 \\
-102.043 \\
-102.043 \\
-102.043 \\
-102.043\end{array}$ & $\begin{array}{l}602.70 \\
611.24 \\
625.51 \\
628.02 \\
626.00\end{array}$ & $\begin{array}{l}3.132 \\
4.233 \\
3.241 \\
3.240 \\
4.327\end{array}$ & $\begin{array}{l}3.383 \\
5.614 \\
3.715 \\
3.737 \\
5.968\end{array}$ \\
\hline
\end{tabular}


Table 8. Latitude, longitude, aititude, Bouguer gravity, and residual gravity values--Continued

[Latitude and longinude values are in decimal degrees; the negative sign of the longitude is the convention referencing longitude west of the prime meridian; altiwde is in meters above sea level; the Bouguer gravity values and residual gravity values are in the units of milligals]

\begin{tabular}{|c|c|c|c|c|}
\hline Lattude & Longltude & Altitude & Bouguer gravity & Residual gravity \\
\hline $\begin{array}{l}47.942 \\
47.938 \\
47.931 \\
47.927 \\
47.924\end{array}$ & $\begin{array}{l}-102.043 \\
-102.043 \\
-102.043 \\
-102.043 \\
-102.043\end{array}$ & $\begin{array}{l}633.24 \\
626.35 \\
636.19 \\
637.90 \\
642.80\end{array}$ & $\begin{array}{l}3.296 \\
3.279 \\
3.620 \\
3.961 \\
4.628\end{array}$ & $\begin{array}{l}3.926 \\
3.952 \\
4.702 \\
5.450 \\
6.823\end{array}$ \\
\hline $\begin{array}{l}47.916 \\
47.913 \\
47.910 \\
47.902 \\
47.898\end{array}$ & $\begin{array}{l}-102.043 \\
-102.043 \\
-102.043 \\
-102.043 \\
-102.043\end{array}$ & $\begin{array}{l}646.84 \\
649.24 \\
650.52 \\
646.59 \\
643.97\end{array}$ & $\begin{array}{l}2.895 \\
2.657 \\
2.444 \\
2.086 \\
2.031\end{array}$ & $\begin{array}{l}3.420 \\
3.000 \\
2.608 \\
1.987 \\
1.910\end{array}$ \\
\hline $\begin{array}{l}47.895 \\
47.891 \\
47.888 \\
47.884 \\
47.880\end{array}$ & $\begin{array}{l}-102.043 \\
-102.043 \\
-102.043 \\
-102.043 \\
-102.043\end{array}$ & $\begin{array}{l}641.65 \\
642.81 \\
645.34 \\
638.73 \\
645.63\end{array}$ & $\begin{array}{r}1.685 \\
2.508 \\
1.255 \\
.979 \\
.804\end{array}$ & $\begin{array}{r}1.283 \\
3.027 \\
.523 \\
.078 \\
-.224\end{array}$ \\
\hline $\begin{array}{l}47.874 \\
47.870 \\
47.867 \\
47.862 \\
47.856\end{array}$ & $\begin{array}{l}-102.043 \\
-102.043 \\
-102.043 \\
-102.043 \\
-102.043\end{array}$ & $\begin{array}{l}636.04 \\
635.78 \\
635.69 \\
635.68 \\
642.77\end{array}$ & $\begin{array}{l}.572 \\
.370 \\
.905 \\
.107 \\
-.132\end{array}$ & $\begin{array}{r}-.564 \\
-.908 \\
.237 \\
-1.333 \\
-1.673\end{array}$ \\
\hline $\begin{array}{l}47.852 \\
47.848 \\
47.826 \\
47.825 \\
47.816\end{array}$ & $\begin{array}{l}-102.043 \\
-102.043 \\
-102.043 \\
-102.043 \\
-102.043\end{array}$ & $\begin{array}{l}640.41 \\
636.80 \\
613.65 \\
615.02 \\
608.21\end{array}$ & $\begin{array}{r}.730 \\
.882 \\
. .529 \\
.173 \\
.409\end{array}$ & $\begin{array}{r}.146 \\
.540 \\
-1.856 \\
-.443 \\
.250\end{array}$ \\
\hline $\begin{array}{l}47.812 \\
47.808 \\
47.804 \\
47.803 \\
47.798\end{array}$ & $\begin{array}{l}-102.043 \\
-102.043 \\
-102.043 \\
-102.043 \\
-102.043\end{array}$ & $\begin{array}{l}607.13 \\
604.44 \\
606.12 \\
606.82 \\
604.82\end{array}$ & $\begin{array}{r}.157 \\
.135 \\
.512 \\
.877 \\
-.138\end{array}$ & $\begin{array}{r}-.194 \\
-.134 \\
.742 \\
1.476 \\
-.396\end{array}$ \\
\hline $\begin{array}{l}47.794 \\
47.790 \\
47.786 \\
47.783 \\
47.779\end{array}$ & $\begin{array}{l}-102.043 \\
-102.043 \\
-102.043 \\
-102.043 \\
-102.043\end{array}$ & $\begin{array}{l}601.82 \\
597.45 \\
594.14 \\
593.61 \\
590.68\end{array}$ & $\begin{array}{r}-.877 \\
-2.527 \\
-2.907 \\
-2.977 \\
-2.301\end{array}$ & $\begin{array}{r}-1.810 \\
-4.975 \\
-5.649 \\
-5.683 \\
-4.233\end{array}$ \\
\hline $\begin{array}{l}47.775 \\
47.743 \\
47.735 \\
47.728 \\
47.725\end{array}$ & $\begin{array}{l}-102.043 \\
-102.044 \\
-102.044 \\
-102.044 \\
-102.044\end{array}$ & $\begin{array}{l}589.64 \\
581.26 \\
583.17 \\
585.40 \\
588.36\end{array}$ & $\begin{array}{r}-.940 \\
-1.874 \\
-2.687 \\
-2.632 \\
-2.777\end{array}$ & $\begin{array}{l}-1.445 \\
-2.331 \\
-3.758 \\
-3.387 \\
-3.577\end{array}$ \\
\hline $\begin{array}{l}47.721 \\
47.717 \\
47.714 \\
47.710 \\
47.707\end{array}$ & $\begin{array}{l}-102.044 \\
-102.044 \\
-102.044 \\
-102.044 \\
-102.044\end{array}$ & $\begin{array}{l}587.46 \\
595.49 \\
596.39 \\
602.53 \\
608.22\end{array}$ & $\begin{array}{l}-2.583 \\
-2.606 \\
-3.533 \\
-3.224 \\
-3.187\end{array}$ & $\begin{array}{l}-3.065 \\
-3.008 \\
-4.748 \\
-4.014 \\
-3.784\end{array}$ \\
\hline $\begin{array}{l}47.699 \\
47.695 \\
47.692 \\
47.688 \\
47.685\end{array}$ & $\begin{array}{l}-102.044 \\
-102.044 \\
-102.044 \\
-102.044 \\
-102.044\end{array}$ & $\begin{array}{l}620.98 \\
616.79 \\
609.16 \\
613.87 \\
618.45\end{array}$ & $\begin{array}{l}-4.125 \\
-4.019 \\
-4.059 \\
-4.376 \\
-4.632\end{array}$ & $\begin{array}{l}-5.420 \\
-5.064 \\
-5.052 \\
-5.538 \\
-5.925\end{array}$ \\
\hline
\end{tabular}


Table 8. Latitude, longitude, altitude, Bouguer gravity, and residual gravity values--Continuef

[Latitude and longiude values are in decimal degrees; the negative sign of the longinde is the convention referencing longitude west of the prime meridian; altimde is in meters above sea level; the Bouguer gravity values and residual gravity values are in the units of milligals]

\begin{tabular}{|c|c|c|c|c|}
\hline Latitudo & Longltude & Altlude & Bouguer gravity & Resldi'al gravity \\
\hline $\begin{array}{l}47.681 \\
47.674 \\
47.833 \\
47.818 \\
47.814\end{array}$ & $\begin{array}{l}-102.044 \\
-102.043 \\
-102.065 \\
-102.065 \\
-102.065\end{array}$ & $\begin{array}{l}621.05 \\
627.92 \\
640.61 \\
633.47 \\
629.49\end{array}$ & $\begin{array}{l}-4.852 \\
-5.222 \\
1.894 \\
3.181 \\
2.301\end{array}$ & $\begin{array}{l}-6.236 \\
-6.681 \\
2.472 \\
5.403 \\
3.681\end{array}$ \\
\hline $\begin{array}{l}47.811 \\
47.808 \\
47.804 \\
47.801 \\
47.797\end{array}$ & $\begin{array}{l}-102.065 \\
-102.065 \\
-102.065 \\
-102.065 \\
-102.065\end{array}$ & $\begin{array}{l}629.18 \\
632.18 \\
628.22 \\
626.10 \\
618.75\end{array}$ & $\begin{array}{l}5.102 \\
5.361 \\
5.071 \\
4.549 \\
3.340\end{array}$ & $\begin{array}{l}9.378 \\
9.936 \\
9.473 \\
8.491 \\
6.179\end{array}$ \\
\hline $\begin{array}{l}47.794 \\
47.790 \\
47.787 \\
47.783 \\
47.775\end{array}$ & $\begin{array}{l}-102.065 \\
-102.065 \\
-102.065 \\
-102.065 \\
-102.065\end{array}$ & $\begin{array}{l}613.15 \\
614.61 \\
613.67 \\
600.43 \\
596.38\end{array}$ & $\begin{array}{r}2.633 \\
2.293 \\
1.426 \\
.930 \\
.917\end{array}$ & $\begin{array}{l}4.873 \\
4.255 \\
2.589 \\
1.692 \\
1.852\end{array}$ \\
\hline $\begin{array}{l}47.743 \\
47.739 \\
47.735 \\
47.732 \\
47.728\end{array}$ & $\begin{array}{l}-102.065 \\
-102.065 \\
-102.065 \\
-102.065 \\
-102.065\end{array}$ & $\begin{array}{l}573.87 \\
579.16 \\
584.50 \\
582.90 \\
587.01\end{array}$ & $\begin{array}{l}1.972 \\
1.282 \\
1.079 \\
1.090 \\
.921\end{array}$ & $\begin{array}{l}4.909 \\
3.605 \\
3.348 \\
3.482 \\
3.243\end{array}$ \\
\hline $\begin{array}{l}47.725 \\
47.721 \\
47.713 \\
47.710 \\
47.706\end{array}$ & $\begin{array}{l}-102.065 \\
-102.065 \\
-102.065 \\
-102.065 \\
-102.065\end{array}$ & $\begin{array}{l}592.97 \\
593.63 \\
609.81 \\
613.12 \\
622.18\end{array}$ & $\begin{array}{l}.847 \\
.726 \\
.441 \\
.467 \\
.142\end{array}$ & $\begin{array}{l}3.203 \\
3.075 \\
2.749 \\
2.904 \\
2.391\end{array}$ \\
\hline $\begin{array}{l}47.703 \\
47.699 \\
47.697 \\
47.693 \\
47.688\end{array}$ & $\begin{array}{l}-102.065 \\
-102.065 \\
-102.065 \\
-102.065 \\
-102.065\end{array}$ & $\begin{array}{l}622.27 \\
618.22 \\
613.85 \\
608.06 \\
603.35\end{array}$ & $\begin{array}{r}.029 \\
-.197 \\
-5.605 \\
-5.385 \\
-5.739\end{array}$ & $\begin{array}{r}2.291 \\
1.959 \\
-8.797 \\
-8.229 \\
-8.760\end{array}$ \\
\hline $\begin{array}{l}47.685 \\
47.682 \\
47.679 \\
47.674 \\
47.667\end{array}$ & $\begin{array}{l}-102.065 \\
-102.065 \\
-102.065 \\
-102.058 \\
-102.058\end{array}$ & $\begin{array}{l}609.60 \\
613.03 \\
616.29 \\
620.29 \\
630.28\end{array}$ & $\begin{array}{l}-5.808 \\
-5.91 \\
-5.991 \\
-4.459 \\
-5.032\end{array}$ & $\begin{array}{l}-8.768 \\
-8.852 \\
-8.927 \\
-5.527 \\
-6.366\end{array}$ \\
\hline $\begin{array}{l}47.664 \\
47.661 \\
47.657 \\
47.654 \\
47.651\end{array}$ & $\begin{array}{l}-102.058 \\
-102.058 \\
-102.058 \\
-102.058 \\
-102.057\end{array}$ & $\begin{array}{l}637.99 \\
643.46 \\
643.17 \\
643.35 \\
635.43\end{array}$ & $\begin{array}{l}-5.341 \\
-6.032 \\
-5.851 \\
-5.933 \\
-5.886\end{array}$ & $\begin{array}{l}-6.875 \\
-8.146 \\
-7.618 \\
-7.724 \\
-7.470\end{array}$ \\
\hline $\begin{array}{l}47.978 \\
47.956 \\
47.953 \\
47.942 \\
47.938\end{array}$ & $\begin{array}{l}-102.087 \\
-102.087 \\
-102.087 \\
-102.087 \\
-102.087\end{array}$ & $\begin{array}{l}621.78 \\
599.02 \\
592.31 \\
625.95 \\
629.97\end{array}$ & $\begin{array}{l}2.268 \\
2.917 \\
3.167 \\
3.253 \\
3.457\end{array}$ & $\begin{array}{l}1.223 \\
2.643 \\
\hat{\vdots} .128 \\
\therefore .398 \\
\therefore .838\end{array}$ \\
\hline $\begin{array}{l}47.935 \\
47.930 \\
47.927 \\
47.924 \\
47.920\end{array}$ & $\begin{array}{l}-102.087 \\
-102.087 \\
-102.087 \\
-102.087 \\
-102.087\end{array}$ & $\begin{array}{l}631.16 \\
634.15 \\
634.03 \\
630.13 \\
634.92\end{array}$ & $\begin{array}{l}3.389 \\
3.375 \\
3.391 \\
3.409 \\
3.285\end{array}$ & $\begin{array}{l}2.718 \\
2.715 \\
2.775 \\
2.873 \\
2.680\end{array}$ \\
\hline
\end{tabular}


Table 8. Latitude, longitude, altitude, Bouguer gravity, and residual gravity values--Continued

[Latitude and longiude values are in decimal degrees; the negative sign of the longitude is the convention referencing longitude west of the prime meridian; altiude is in meters above sea level; the Bouguer gravity values and residual gravity values are in the units of milligal ?

\begin{tabular}{|c|c|c|c|c|}
\hline Latlude & Longlitude & Altitude & Bouguar gravity & Realdual gravly' \\
\hline $\begin{array}{l}47.917 \\
47.913 \\
47.909 \\
47.902 \\
47.898\end{array}$ & $\begin{array}{l}-102.087 \\
-102.087 \\
-102.087 \\
-102.087 \\
-102.087\end{array}$ & $\begin{array}{l}635.64 \\
636.67 \\
638.21 \\
643.30 \\
645.65\end{array}$ & $\begin{array}{l}3.326 \\
3.427 \\
3.443 \\
3.480 \\
3.305\end{array}$ & $\begin{array}{l}3.763 \\
4.044 \\
4.072 \\
4.275 \\
3.933\end{array}$ \\
\hline $\begin{array}{l}47.895 \\
47.891 \\
47.888 \\
47.884 \\
47.880\end{array}$ & $\begin{array}{l}-102.087 \\
-102.087 \\
-102.087 \\
-102.087 \\
-102.087\end{array}$ & $\begin{array}{l}646.26 \\
648.81 \\
649.71 \\
653.16 \\
656.49\end{array}$ & $\begin{array}{l}3.305 \\
3.192 \\
3.208 \\
3.016 \\
3.037\end{array}$ & $\begin{array}{l}3.991 \\
3.781 \\
3.888 \\
3.560 \\
3.616\end{array}$ \\
\hline $\begin{array}{l}47.877 \\
47.873 \\
47.869 \\
47.866 \\
47.862\end{array}$ & $\begin{array}{l}-102.087 \\
-102.087 \\
-102.087 \\
-102.087 \\
-102.087\end{array}$ & $\begin{array}{l}656.37 \\
653.73 \\
656.38 \\
657.84 \\
658.68\end{array}$ & $\begin{array}{l}3.048 \\
2.555 \\
2.414 \\
2.440 \\
2.957\end{array}$ & $\begin{array}{l}3.737 \\
2.786 \\
2.574 \\
2.672 \\
3.749\end{array}$ \\
\hline $\begin{array}{l}47.858 \\
47.855 \\
47.851 \\
47.848 \\
47.830\end{array}$ & $\begin{array}{l}-102.087 \\
-102.087 \\
-102.087 \\
-102.087 \\
-102.086\end{array}$ & $\begin{array}{l}661.17 \\
662.79 \\
664.47 \\
654.52 \\
649.04\end{array}$ & $\begin{array}{l}3.311 \\
2.211 \\
2.074 \\
2.565 \\
2.522\end{array}$ & $\begin{array}{l}4.522 \\
2.377 \\
2.205 \\
3.194 \\
3.451\end{array}$ \\
\hline $\begin{array}{l}47.822 \\
47.819 \\
47.793 \\
47.790 \\
47.783\end{array}$ & $\begin{array}{l}-102.086 \\
-102.086 \\
-102.086 \\
-102.086 \\
-102.086\end{array}$ & $\begin{array}{l}646.52 \\
651.09 \\
606.50 \\
607.18 \\
608.34\end{array}$ & $\begin{array}{r}2.084 \\
1.874 \\
.818 \\
.662 \\
1.221\end{array}$ & $\begin{array}{r}2.720 \\
2.413 \\
.845 \\
.595 \\
1.918\end{array}$ \\
\hline $\begin{array}{l}47.779 \\
47.775 \\
47.772 \\
47.768 \\
47.765\end{array}$ & $\begin{array}{l}-102.086 \\
-102.086 \\
-102.086 \\
-102.086 \\
-102.086\end{array}$ & $\begin{array}{l}604.58 \\
605.32 \\
600.78 \\
600.86 \\
598.92\end{array}$ & $\begin{array}{l}1.325 \\
1.200 \\
1.005 \\
.936 \\
.939\end{array}$ & $\begin{array}{l}2.178 \\
2.052 \\
1.779 \\
1.683 \\
1.774\end{array}$ \\
\hline $\begin{array}{l}47.761 \\
47.754 \\
47.751 \\
47.714 \\
47.710\end{array}$ & $\begin{array}{l}-102.086 \\
-102.086 \\
-102.086 \\
-102.086 \\
-102.086\end{array}$ & $\begin{array}{l}597.55 \\
586.67 \\
581.70 \\
619.46 \\
610.15\end{array}$ & $\begin{array}{r}.860 \\
1.303 \\
1.522 \\
-2.109 \\
-2.106\end{array}$ & $\begin{array}{r}1.718 \\
2.802 \\
3.382 \\
-2.820 \\
-2.673\end{array}$ \\
\hline $\begin{array}{l}47.706 \\
47.699 \\
47.696 \\
47.692 \\
47.688\end{array}$ & $\begin{array}{l}-102.086 \\
-102.086 \\
-102.086 \\
-102.086 \\
-102.086\end{array}$ & $\begin{array}{l}601.78 \\
605.67 \\
600.58 \\
595.41 \\
604.09\end{array}$ & $\begin{array}{l}-2.258 \\
-2.693 \\
-2.779 \\
-3.011 \\
-3.338\end{array}$ & $\begin{array}{r}-2.897 \\
-3.549 \\
-3.587 \\
-3.919 \\
-4.457\end{array}$ \\
\hline $\begin{array}{l}47.685 \\
47.681 \\
47.677 \\
47.906 \\
47.862\end{array}$ & $\begin{array}{l}-102.086 \\
-102.086 \\
-102.086 \\
-102.108 \\
-102.108\end{array}$ & $\begin{array}{l}606.20 \\
613.97 \\
618.40 \\
639.74 \\
659.01\end{array}$ & $\begin{array}{r}-3.475 \\
-2.621 \\
-3.992 \\
3.424 \\
4.711\end{array}$ & $\begin{array}{r}-4.592 \\
-2.786 \\
-5.359 \\
3.891 \\
7.034\end{array}$ \\
\hline $\begin{array}{l}47.790 \\
47.775 \\
47.732 \\
47.728 \\
47.725\end{array}$ & $\begin{array}{l}-102.108 \\
-102.108 \\
-102.108 \\
-102.108 \\
-102.108\end{array}$ & $\begin{array}{l}614.74 \\
599.94 \\
577.55 \\
598.64 \\
604.79\end{array}$ & $\begin{array}{r}2.479 \\
2.078 \\
-1.936 \\
-1.212 \\
-1.692\end{array}$ & $\begin{array}{r}3.919 \\
3.459 \\
-3.432 \\
-1.860 \\
-2.757\end{array}$ \\
\hline
\end{tabular}


Table 8. Latitude, longitude, aititude, Bouguer gravity, and residual gravity values--Continued

[Latitude and longitude values are in decimal degrees; the negative sign of the longinde is the convention referencing longitude west of the prime meridian; altitude is in inelers above sea level; the Bouguer gravity values and residual gravity values are in the units of milligals]

\begin{tabular}{|c|c|c|c|c|}
\hline Latitude & Longltude & Altitude & Bouguer gravity & Residual gravity \\
\hline $\begin{array}{l}47.721 \\
47.717 \\
47.712 \\
47.708 \\
47.705\end{array}$ & $\begin{array}{l}-102.108 \\
-102.108 \\
-102.108 \\
-102.108 \\
-102.108\end{array}$ & $\begin{array}{l}611.25 \\
601.61 \\
606.74 \\
602.44 \\
584.85\end{array}$ & $\begin{array}{l}-0.564 \\
-1.421 \\
-2.013 \\
-2.232 \\
-2.299\end{array}$ & $\begin{array}{l}-0.410 \\
-2.002 \\
-2.984 \\
-3.331 \\
-3.365\end{array}$ \\
\hline $\begin{array}{l}47.702 \\
47.699 \\
47.696 \\
47.692 \\
47.688\end{array}$ & $\begin{array}{l}-102.108 \\
-102.108 \\
-102.108 \\
-102.108 \\
-102.108\end{array}$ & $\begin{array}{l}596.04 \\
604.20 \\
604.78 \\
610.40 \\
620.94\end{array}$ & $\begin{array}{l}-2.390 \\
-2.725 \\
-2.635 \\
-1.973 \\
-3.666\end{array}$ & $\begin{array}{l}-3.417 \\
-4.048 \\
-3.728 \\
-2.287 \\
-5.555\end{array}$ \\
\hline $\begin{array}{l}47.685 \\
47.682 \\
47.679 \\
47.674 \\
47.999\end{array}$ & $\begin{array}{l}-102.108 \\
-102.108 \\
-102.108 \\
-102.108 \\
-102.129\end{array}$ & $\begin{array}{l}628.87 \\
629.71 \\
630.49 \\
633.73 \\
644.60\end{array}$ & $\begin{array}{r}-3.500 \\
-3.662 \\
-5.368 \\
4.218 \\
1.295\end{array}$ & $\begin{array}{r}-5.087 \\
-5.308 \\
-8.623 \\
-6.163 \\
-.997\end{array}$ \\
\hline $\begin{array}{l}47.995 \\
47.992 \\
47.989 \\
47.985 \\
47.982\end{array}$ & $\begin{array}{l}-102.129 \\
-102.129 \\
-102.129 \\
-102.129 \\
-102.129\end{array}$ & $\begin{array}{l}646.68 \\
648.09 \\
647.72 \\
644.54 \\
642.27\end{array}$ & $\begin{array}{l}1.342 \\
1.353 \\
1.548 \\
1.805 \\
1.973\end{array}$ & $\begin{array}{r}-.877 \\
-.872 \\
-.485 \\
.061 \\
.355\end{array}$ \\
\hline $\begin{array}{l}47.978 \\
47.975 \\
47.971 \\
47.968 \\
47.964\end{array}$ & $\begin{array}{l}-102.129 \\
-102.129 \\
-102.129 \\
-102.129 \\
-102.129\end{array}$ & $\begin{array}{l}642.51 \\
634.87 \\
625.43 \\
612.32 \\
609.20\end{array}$ & $\begin{array}{l}2.007 \\
2.332 \\
2.363 \\
2.570 \\
2.696\end{array}$ & $\begin{array}{l}.470 \\
1.131 \\
1.162 \\
1.626 \\
1.860\end{array}$ \\
\hline $\begin{array}{l}47.960 \\
47.956 \\
47.953 \\
47.949 \\
47.949\end{array}$ & $\begin{array}{l}-102.129 \\
-102.129 \\
-102.129 \\
-102.129 \\
-102.129\end{array}$ & $\begin{array}{l}605.26 \\
592.45 \\
588.81 \\
588.80 \\
588.80\end{array}$ & $\begin{array}{l}2.869 \\
3.024 \\
3.166 \\
3.315 \\
3.207\end{array}$ & $\begin{array}{l}2.200 \\
2.541 \\
2.851 \\
3.155 \\
2.939\end{array}$ \\
\hline $\begin{array}{l}47.945 \\
47.937 \\
47.934 \\
47.931 \\
47.927\end{array}$ & $\begin{array}{l}-102.129 \\
-102.129 \\
-102.129 \\
-102.129 \\
-102.129\end{array}$ & $\begin{array}{l}587.88 \\
601.84 \\
606.47 \\
613.40 \\
616.52\end{array}$ & $\begin{array}{l}3.364 \\
3.430 \\
3.381 \\
3.474 \\
3.509\end{array}$ & $\begin{array}{l}3.321 \\
3.456 \\
3.418 \\
3.582 \\
3.711\end{array}$ \\
\hline $\begin{array}{l}47.924 \\
47.920 \\
47.916 \\
47.912 \\
47.906\end{array}$ & $\begin{array}{l}-102.129 \\
-102.129 \\
-102.129 \\
-102.129 \\
-102.129\end{array}$ & $\begin{array}{l}623.45 \\
625.80 \\
629.90 \\
635.36 \\
644.73\end{array}$ & $\begin{array}{l}3.776 \\
3.367 \\
3.467 \\
3.409 \\
2.919\end{array}$ & $\begin{array}{l}4.271 \\
3.455 \\
3.689 \\
3.622 \\
2.681\end{array}$ \\
\hline $\begin{array}{l}47.902 \\
47.898 \\
47.895 \\
47.891 \\
47.887\end{array}$ & $\begin{array}{l}-102.129 \\
-102.129 \\
-102.129 \\
-102.129 \\
-102.129\end{array}$ & $\begin{array}{l}645.52 \\
649.68 \\
654.25 \\
654.91 \\
653.53\end{array}$ & $\begin{array}{l}3.033 \\
2.951 \\
3.088 \\
3.957 \\
3.998\end{array}$ & $\begin{array}{l}2.963 \\
2.853 \\
3.122 \\
4.956 \\
5.013\end{array}$ \\
\hline $\begin{array}{l}47.884 \\
47.879 \\
47.877 \\
47.833 \\
47.830\end{array}$ & $\begin{array}{l}-102.129 \\
-102.129 \\
-102.129 \\
-102.129 \\
-102.129\end{array}$ & $\begin{array}{l}656.53 \\
658.22 \\
660.61 \\
673.40 \\
672.24\end{array}$ & $\begin{array}{l}2.827 \\
3.280 \\
4.650 \\
3.828 \\
2.535\end{array}$ & $\begin{array}{l}2.758 \\
3.693 \\
6479 \\
5459 \\
2.934\end{array}$ \\
\hline
\end{tabular}


Table 8. Latitude, longitude, alttude, Bouguer gravity, and residual gravity values--Continued

[Latitude and longiude values are in decimal degrees; the negative sign of the longitude is the convention referencing longitude west of the prime meridian; altitude is in meters above sea level; the Bouguer gravity values and residual gravity values are in the units of milligals]

\begin{tabular}{|c|c|c|c|c|}
\hline Latltude & Longltude & Altitude & Bouguer gravlty & Resldual gravity \\
\hline $\begin{array}{l}47.826 \\
47.822 \\
47.819 \\
47.815 \\
47.812\end{array}$ & $\begin{array}{l}-102.129 \\
-102.129 \\
-102.129 \\
-102.129 \\
-102.129\end{array}$ & $\begin{array}{l}666.55 \\
660.77 \\
649.50 \\
637.79 \\
632.70\end{array}$ & $\begin{array}{l}2.581 \\
2.643 \\
2.555 \\
2.459 \\
2.422\end{array}$ & $\begin{array}{l}3.118 \\
3.310 \\
3.180 \\
3.055 \\
3.056\end{array}$ \\
\hline $\begin{array}{l}47.808 \\
47.804 \\
47.802 \\
47.798 \\
47.795\end{array}$ & $\begin{array}{l}-102.129 \\
-102.129 \\
-102.129 \\
-102.129 \\
-102.129\end{array}$ & $\begin{array}{l}634.41 \\
634.27 \\
632.37 \\
625.50 \\
624.62\end{array}$ & $\begin{array}{l}1.866 \\
2.179 \\
1.884 \\
1.659 \\
1.604\end{array}$ & $\begin{array}{l}2.014 \\
2.708 \\
2.205 \\
1.787 \\
1.768\end{array}$ \\
\hline $\begin{array}{l}47.790 \\
47.785 \\
47.779 \\
47.775 \\
47.771\end{array}$ & $\begin{array}{l}-102.129 \\
-102.129 \\
-102.129 \\
-102.129 \\
-102.129\end{array}$ & $\begin{array}{l}620.35 \\
616.32 \\
609.72 \\
609.79 \\
607.37\end{array}$ & $\begin{array}{r}1.593 \\
1.464 \\
2.300 \\
.892 \\
1.066\end{array}$ & $\begin{array}{r}1.827 \\
1.697 \\
3.507 \\
.789 \\
1.193\end{array}$ \\
\hline $\begin{array}{l}47.768 \\
47.765 \\
47.761 \\
47.757 \\
47.753\end{array}$ & $\begin{array}{l}-102.129 \\
-102.129 \\
-102.129 \\
-102.129 \\
-102.129\end{array}$ & $\begin{array}{l}600.09 \\
603.08 \\
603.37 \\
607.25 \\
612.37\end{array}$ & $\begin{array}{l}.947 \\
.501 \\
.449 \\
.088 \\
.935\end{array}$ & $\begin{array}{r}1.047 \\
.257 \\
.213 \\
. .433 \\
1.393\end{array}$ \\
\hline $\begin{array}{l}47.750 \\
47.669 \\
47.664 \\
47.661 \\
47.658\end{array}$ & $\begin{array}{l}-102.129 \\
-102.121 \\
-102.121 \\
-102.121 \\
-102.121\end{array}$ & $\begin{array}{l}609.01 \\
660.24 \\
646.79 \\
653.77 \\
652.58\end{array}$ & $\begin{array}{r}-.369 \\
-2.558 \\
-2.627 \\
-2.893 \\
-2.894\end{array}$ & $\begin{array}{l}-1.156 \\
-2.973 \\
-2.942 \\
-3.311 \\
-3.217\end{array}$ \\
\hline $\begin{array}{l}47.653 \\
47.650 \\
47.647 \\
48.000 \\
47.996\end{array}$ & $\begin{array}{l}-102.121 \\
-102.121 \\
-102.120 \\
-102.150 \\
-102.150\end{array}$ & $\begin{array}{l}642.17 \\
636.41 \\
627.81 \\
635.99 \\
639.64\end{array}$ & $\begin{array}{r}-2.407 \\
-5.514 \\
-5.547 \\
1.896 \\
1.827\end{array}$ & $\begin{array}{r}-2.087 \\
-8.202 \\
-8.101 \\
.193 \\
.032\end{array}$ \\
\hline $\begin{array}{l}47.992 \\
47.989 \\
47.985 \\
47.981 \\
47.978\end{array}$ & $\begin{array}{l}-102.150 \\
-102.150 \\
-102.150 \\
-102.150 \\
-102.150\end{array}$ & $\begin{array}{l}643.90 \\
633.47 \\
631.10 \\
627.39 \\
628.92\end{array}$ & $\begin{array}{l}2.022 \\
2.148 \\
2.365 \\
2.428 \\
2.623\end{array}$ & $\begin{array}{l}.432 \\
.666 \\
1.121 \\
1.223 \\
1.615\end{array}$ \\
\hline $\begin{array}{l}47.974 \\
47.971 \\
47.967 \\
47.964 \\
47.961\end{array}$ & $\begin{array}{l}-102.150 \\
-102.150 \\
-102.150 \\
-102.150 \\
-102.150\end{array}$ & $\begin{array}{l}617.16 \\
610.90 \\
603.83 \\
610.32 \\
610.16\end{array}$ & $\begin{array}{l}2.690 \\
2.775 \\
2.854 \\
2.962 \\
3.003\end{array}$ & $\begin{array}{l}1.789 \\
1.910 \\
2.097 \\
2.292 \\
2.391\end{array}$ \\
\hline $\begin{array}{l}47.958 \\
47.953 \\
47.949 \\
47.946 \\
47.938\end{array}$ & $\begin{array}{l}-102.150 \\
-102.151 \\
-102.150 \\
-102.150 \\
-102.151\end{array}$ & $\begin{array}{l}602.34 \\
585.50 \\
583.97 \\
587.42 \\
608.44\end{array}$ & $\begin{array}{l}3.143 \\
3.585 \\
3.635 \\
3.662 \\
4.067\end{array}$ & $\begin{array}{l}2.711 \\
3.538 \\
3.726 \\
3.803 \\
4.611\end{array}$ \\
\hline $\begin{array}{l}47.935 \\
47.931 \\
47.927 \\
47.924 \\
47.920\end{array}$ & $\begin{array}{l}-102.151 \\
-102.150 \\
-102.150 \\
-102.150 \\
-102.151\end{array}$ & $\begin{array}{l}612.71 \\
614.84 \\
617.64 \\
618.81 \\
622.51\end{array}$ & $\begin{array}{l}3.944 \\
4.219 \\
4.234 \\
4.373 \\
4.262\end{array}$ & $\begin{array}{l}4.348 \\
4.995 \\
5.005 \\
5.333 \\
5.119\end{array}$ \\
\hline
\end{tabular}


Table 8. Latitude, longitude, altitude, Bouguer gravity, and residual gravity values--Continued

[Latitude and longitude values are in decimal degrees; the negative sign of the longitude is the convention referencing longitudi: west of the prime meridian; altinde is in meters above sea level; the Bouguer gravity values and residual gravity values are in the umits of milligals]

\begin{tabular}{|c|c|c|c|c|}
\hline Latitude & Longltude & Altitude & Bouguer gravlty & Residual gravity \\
\hline $\begin{array}{l}47.917 \\
47.913 \\
47.909 \\
47.906 \\
47.902\end{array}$ & $\begin{array}{l}-102.151 \\
-102.151 \\
-102.151 \\
-102.151 \\
-102.151\end{array}$ & $\begin{array}{l}626.87 \\
633.57 \\
639.53 \\
640.09 \\
643.22\end{array}$ & $\begin{array}{l}4.173 \\
4.218 \\
4.275 \\
4.274 \\
4.221\end{array}$ & $\begin{array}{l}4.967 \\
5.047 \\
5.209 \\
5.235 \\
5.128\end{array}$ \\
\hline $\begin{array}{l}47.898 \\
47.894 \\
47.891 \\
47.887 \\
47.884\end{array}$ & $\begin{array}{l}-102.151 \\
-102.151 \\
-102.151 \\
-102.151 \\
-102.151\end{array}$ & $\begin{array}{l}648.57 \\
651.79 \\
659.21 \\
663.09 \\
662.95\end{array}$ & $\begin{array}{l}4.179 \\
4.199 \\
4.169 \\
4.095 \\
4.008\end{array}$ & $\begin{array}{l}5.094 \\
5.202 \\
5.186 \\
5.050 \\
4.885\end{array}$ \\
\hline $\begin{array}{l}47.880 \\
47.877 \\
47.873 \\
47.869 \\
47.866\end{array}$ & $\begin{array}{l}-102.151 \\
-102.151 \\
-102.151 \\
-102.151 \\
-102.151\end{array}$ & $\begin{array}{l}665.80 \\
666.47 \\
666.26 \\
669.93 \\
668.83\end{array}$ & $\begin{array}{l}4.001 \\
3.818 \\
4.002 \\
4.042 \\
3.937\end{array}$ & $\begin{array}{l}4.956 \\
4.632 \\
5.033 \\
5.156 \\
5.012\end{array}$ \\
\hline $\begin{array}{l}47.862 \\
47.859 \\
47.855 \\
47.852 \\
47.848\end{array}$ & $\begin{array}{l}-102.151 \\
-102.151 \\
-102.151 \\
-102.151 \\
-102.151\end{array}$ & $\begin{array}{l}668.18 \\
671.08 \\
672.79 \\
670.35 \\
665.64\end{array}$ & $\begin{array}{l}3.901 \\
3.831 \\
4.193 \\
4.243 \\
4.190\end{array}$ & $\begin{array}{l}4.954 \\
4.863 \\
5.658 \\
5.748 \\
5.758\end{array}$ \\
\hline $\begin{array}{l}47.841 \\
47.838 \\
47.830 \\
47.826 \\
47.823\end{array}$ & $\begin{array}{l}-102.151 \\
-102.151 \\
-102.151 \\
-102.151 \\
-102.151\end{array}$ & $\begin{array}{l}666.48 \\
662.01 \\
663.92 \\
658.16 \\
657.79\end{array}$ & $\begin{array}{l}4.149 \\
3.834 \\
3.897 \\
3.858 \\
3.796\end{array}$ & $\begin{array}{l}5.725 \\
5.140 \\
5.436 \\
5.385 \\
5.329\end{array}$ \\
\hline $\begin{array}{l}47.819 \\
47.815 \\
47.812 \\
47.808 \\
47.804\end{array}$ & $\begin{array}{l}-102.151 \\
-102.151 \\
-102.151 \\
-102.150 \\
-102.151\end{array}$ & $\begin{array}{l}661.73 \\
650.90 \\
645.54 \\
637.56 \\
634.07\end{array}$ & $\begin{array}{l}3.628 \\
3.672 \\
3.526 \\
3.257 \\
2.979\end{array}$ & $\begin{array}{l}5.046 \\
5.203 \\
4.979 \\
4.515 \\
4.038\end{array}$ \\
\hline $\begin{array}{l}47.801 \\
47.797 \\
47.794 \\
47.790 \\
48.000\end{array}$ & $\begin{array}{l}-102.151 \\
-102.151 \\
-102.151 \\
-102.151 \\
-102.172\end{array}$ & $\begin{array}{l}629.15 \\
631.19 \\
622.75 \\
625.77 \\
630.20\end{array}$ & $\begin{array}{l}2.822 \\
2.696 \\
2.629 \\
2.574 \\
2.256\end{array}$ & $\begin{array}{r}3.765 \\
3.614 \\
3.549 \\
3508 \\
.862\end{array}$ \\
\hline $\begin{array}{l}47.996 \\
47.978 \\
47.963 \\
47.949 \\
47.945\end{array}$ & $\begin{array}{l}-102.172 \\
-102.172 \\
-102.172 \\
-102.172 \\
-102.172\end{array}$ & $\begin{array}{l}629.52 \\
608.43 \\
595.60 \\
582.70 \\
593.43\end{array}$ & $\begin{array}{l}2.384 \\
2.408 \\
2.953 \\
3.222 \\
3.292\end{array}$ & $\begin{array}{l}1.127 \\
1.143 \\
2.252 \\
2.800 \\
2.939\end{array}$ \\
\hline $\begin{array}{l}47.942 \\
47.938 \\
47.934 \\
47.928 \\
47.924\end{array}$ & $\begin{array}{l}-102.172 \\
-102.172 \\
-102.172 \\
-102.172 \\
-102.172\end{array}$ & $\begin{array}{l}601.08 \\
603.71 \\
605.50 \\
617.66 \\
621.56\end{array}$ & $\begin{array}{l}3.411 \\
3.478 \\
3.483 \\
3.663 \\
3.710\end{array}$ & $\begin{array}{l}3.205 \\
3.322 \\
3.368 \\
3.788 \\
3.849\end{array}$ \\
\hline $\begin{array}{l}47.920 \\
47.857 \\
47.853 \\
47.848 \\
47.837\end{array}$ & $\begin{array}{l}-102.172 \\
-102.172 \\
-102.172 \\
-102.172 \\
-102.172\end{array}$ & $\begin{array}{l}627.03 \\
680.44 \\
671.16 \\
671.38 \\
659.98\end{array}$ & $\begin{array}{l}3.728 \\
4.523 \\
4.866 \\
4.075 \\
2.140\end{array}$ & $\begin{array}{l}3.967 \\
6122 \\
6816 \\
5304 \\
1.616\end{array}$ \\
\hline
\end{tabular}


Table 8. Latitude, longitude, altitude, Bouguer gravity, and residual gravity values--Continued

[Latitude and longinde values are in decimal degrees; the negative sign of the longinde is the convention referencing longitude west of the prime meridian; altitude is in meters above sea level; the Bouguer gravity values and residual gravity values are in the units of millig ?ls]

\begin{tabular}{|c|c|c|c|c|}
\hline Latitude & Longltude & Altltude & Bouguer gravity & Realdual gravity \\
\hline $\begin{array}{l}47.830 \\
47.826 \\
47.820 \\
47.819 \\
47.812\end{array}$ & $\begin{array}{l}-102.172 \\
-102.172 \\
-102.172 \\
-102.172 \\
-102.172\end{array}$ & $\begin{array}{l}654.04 \\
650.30 \\
649.91 \\
651.68 \\
642.21\end{array}$ & $\begin{array}{l}2.858 \\
3.939 \\
2.756 \\
3.843 \\
2.587\end{array}$ & $\begin{array}{l}3.133 \\
5.400 \\
3.071 \\
5.278 \\
2.875\end{array}$ \\
\hline $\begin{array}{l}47.807 \\
47.804 \\
47.800 \\
47.797 \\
47.793\end{array}$ & $\begin{array}{l}-102.172 \\
-102.172 \\
-102.172 \\
-102.172 \\
-102.172\end{array}$ & $\begin{array}{l}644.05 \\
641.64 \\
636.55 \\
635.71 \\
633.49\end{array}$ & $\begin{array}{l}3.526 \\
2.249 \\
3.947 \\
2.661 \\
2.656\end{array}$ & $\begin{array}{l}4.862 \\
2.341 \\
5.817 \\
3.347 \\
3.349\end{array}$ \\
\hline $\begin{array}{l}47.786 \\
47.782 \\
47.779 \\
47.993 \\
47.989\end{array}$ & $\begin{array}{l}-102.172 \\
-102.172 \\
-102.172 \\
-102.193 \\
-102.193\end{array}$ & $\begin{array}{l}623.68 \\
621.54 \\
619.76 \\
606.21 \\
610.93\end{array}$ & $\begin{array}{l}2.635 \\
2.493 \\
3.273 \\
2.575 \\
2.581\end{array}$ & $\begin{array}{l}3.462 \\
3.248 \\
4.915 \\
1.457 \\
1.480\end{array}$ \\
\hline $\begin{array}{l}47.985 \\
47.981 \\
47.978 \\
47.974 \\
47.971\end{array}$ & $\begin{array}{l}-102.193 \\
-102.193 \\
-102.193 \\
-102.193 \\
-102.193\end{array}$ & $\begin{array}{l}604.36 \\
599.87 \\
599.07 \\
600.34 \\
598.62\end{array}$ & $\begin{array}{l}2.618 \\
2.606 \\
3.079 \\
2.783 \\
2.809\end{array}$ & $\begin{array}{l}1.543 \\
1.510 \\
2.459 \\
1.897 \\
1.951\end{array}$ \\
\hline $\begin{array}{l}47.967 \\
47.963 \\
47.960 \\
47.957 \\
47.952\end{array}$ & $\begin{array}{l}-102.193 \\
-102.194 \\
-102.193 \\
-102.193 \\
-102.193\end{array}$ & $\begin{array}{l}603.35 \\
586.09 \\
586.89 \\
595.39 \\
580.11\end{array}$ & $\begin{array}{l}2.817 \\
2.833 \\
2.840 \\
2.815 \\
3.018\end{array}$ & $\begin{array}{l}1.911 \\
1.970 \\
2.005 \\
1.926 \\
2.367\end{array}$ \\
\hline $\begin{array}{l}47.949 \\
47.946 \\
47.943 \\
47.939 \\
47.935\end{array}$ & $\begin{array}{l}-102.190 \\
-102.193 \\
-102.193 \\
-102.193 \\
-102.194\end{array}$ & $\begin{array}{l}582.43 \\
587.56 \\
592.78 \\
596.89 \\
605.95\end{array}$ & $\begin{array}{l}3.129 \\
3.034 \\
3.194 \\
3.164 \\
3.213\end{array}$ & $\begin{array}{l}2.609 \\
2.423 \\
2.694 \\
2.698 \\
2.788\end{array}$ \\
\hline $\begin{array}{l}47.932 \\
47.928 \\
47.924 \\
47.920 \\
47.916\end{array}$ & $\begin{array}{l}-102.193 \\
-102.193 \\
-102.193 \\
-102.193 \\
-102.194\end{array}$ & $\begin{array}{l}610.61 \\
610.84 \\
617.74 \\
622.37 \\
621.48\end{array}$ & $\begin{array}{l}3.243 \\
3.397 \\
3.301 \\
3.374 \\
3.570\end{array}$ & $\begin{array}{l}2.834 \\
3.165 \\
3.022 \\
3.167 \\
3.583\end{array}$ \\
\hline $\begin{array}{l}47.913 \\
47.909 \\
47.906 \\
47.903 \\
47.898\end{array}$ & $\begin{array}{l}-102.194 \\
-102.194 \\
-102.193 \\
-102.194 \\
-102.194\end{array}$ & $\begin{array}{l}626.04 \\
635.27 \\
647.65 \\
651.62 \\
653.80\end{array}$ & $\begin{array}{l}3.656 \\
3.636 \\
3.705 \\
3.647 \\
3.710\end{array}$ & $\begin{array}{l}3.789 \\
3.754 \\
3.884 \\
3.827 \\
3.975\end{array}$ \\
\hline $\begin{array}{l}47.895 \\
47.891 \\
47.887 \\
47.883 \\
47.880\end{array}$ & $\begin{array}{l}-102.194 \\
-102.193 \\
-102.194 \\
-102.194 \\
-102.194\end{array}$ & $\begin{array}{l}653.29 \\
663.41 \\
665.17 \\
663.80 \\
670.48\end{array}$ & $\begin{array}{l}3.760 \\
3.562 \\
3.524 \\
3.607 \\
3.856\end{array}$ & $\begin{array}{l}4.111 \\
3.746 \\
3.655 \\
3.882 \\
4.381\end{array}$ \\
\hline $\begin{array}{l}47.877 \\
47.870 \\
47.866 \\
47.862 \\
47.858\end{array}$ & $\begin{array}{l}-102.194 \\
-102.194 \\
-102.194 \\
-102.194 \\
-102.193\end{array}$ & $\begin{array}{l}672.30 \\
669.91 \\
675.54 \\
674.12 \\
678.57\end{array}$ & $\begin{array}{l}3.589 \\
3.669 \\
3.670 \\
3.636 \\
3.643\end{array}$ & $\begin{array}{l}3.883 \\
4.151 \\
4.152 \\
4.155 \\
4.230\end{array}$ \\
\hline
\end{tabular}


Table 8. Latitude, longitude, altitude, Bouguer gravity, and residual gravity values--Continued

[Latitude and longinde values are in decimal degrees; the negative sign of the longitude is the convention referencing longitude west of the prime meridian; altitude is in meters above sea level; the Bouguer gravity values and residual gravity values are in the units of milligals]

\begin{tabular}{|c|c|c|c|c|}
\hline Latltude & Longltude & Altitude & Bouguer gravity & Reoldua' gravity \\
\hline $\begin{array}{l}47.855 \\
47.851 \\
47.848 \\
47.823 \\
47.819\end{array}$ & $\begin{array}{l}-102.194 \\
-102.193 \\
-102.193 \\
-102.194 \\
-102.194\end{array}$ & $\begin{array}{l}668.40 \\
669.21 \\
651.49 \\
640.59 \\
643.50\end{array}$ & $\begin{array}{l}3.663 \\
3.757 \\
3.828 \\
3.756 \\
3.510\end{array}$ & $\begin{array}{l}4.298 \\
4.531 \\
4.700 \\
4.908 \\
4.475\end{array}$ \\
\hline $\begin{array}{l}47.815 \\
47.812 \\
47.808 \\
47.999 \\
47.995\end{array}$ & $\begin{array}{l}-102.194 \\
-102.193 \\
-102.193 \\
-102.215 \\
-102.215\end{array}$ & $\begin{array}{l}639.11 \\
630.56 \\
630.59 \\
576.22 \\
580.89\end{array}$ & $\begin{array}{l}4.042 \\
3.619 \\
3.733 \\
2.374 \\
2.216\end{array}$ & $\begin{array}{r}5.557 \\
4.803 \\
5.057 \\
1.147 \\
.842\end{array}$ \\
\hline $\begin{array}{l}47.992 \\
47.988 \\
47.985 \\
47.981 \\
47.974\end{array}$ & $\begin{array}{l}-102.215 \\
-102.215 \\
-102.215 \\
-102.215 \\
-102.215\end{array}$ & $\begin{array}{l}595.59 \\
593.53 \\
590.65 \\
588.12 \\
586.44\end{array}$ & $\begin{array}{l}2.355 \\
2.354 \\
2.317 \\
2.401 \\
2.511\end{array}$ & $\begin{array}{r}1.084 \\
1.054 \\
.980 \\
1.180 \\
1.326\end{array}$ \\
\hline $\begin{array}{l}47.970 \\
47.967 \\
47.959 \\
47.956 \\
47.953\end{array}$ & $\begin{array}{l}-102.215 \\
-102.215 \\
-102.215 \\
-102.215 \\
-102.215\end{array}$ & $\begin{array}{l}579.00 \\
578.49 \\
591.03 \\
594.54 \\
590.66\end{array}$ & $\begin{array}{l}2.416 \\
2.460 \\
2.482 \\
2.597 \\
2.585\end{array}$ & $\begin{array}{l}1.175 \\
1.223 \\
1.283 \\
1.512 \\
1.493\end{array}$ \\
\hline $\begin{array}{l}47.949 \\
47.945 \\
47.942 \\
47.938 \\
47.934\end{array}$ & $\begin{array}{l}-102.215 \\
-102.215 \\
-102.215 \\
-102.215 \\
-102.215\end{array}$ & $\begin{array}{l}578.07 \\
581.43 \\
590.39 \\
597.34 \\
608.12\end{array}$ & $\begin{array}{l}2.576 \\
2.709 \\
2.669 \\
2.876 \\
2.733\end{array}$ & $\begin{array}{l}1.471 \\
1.770 \\
1.698 \\
2.103 \\
1.792\end{array}$ \\
\hline $\begin{array}{l}47.930 \\
47.927 \\
47.924 \\
47.916 \\
47.913\end{array}$ & $\begin{array}{l}-102.215 \\
-102.215 \\
-102.215 \\
-102.215 \\
-102.215\end{array}$ & $\begin{array}{l}616.21 \\
610.33 \\
613.26 \\
624.30 \\
623.09\end{array}$ & $\begin{array}{l}2.621 \\
2.689 \\
2.753 \\
2.933 \\
2.887\end{array}$ & $\begin{array}{l}1.620 \\
1.749 \\
1.911 \\
2.282 \\
2.192\end{array}$ \\
\hline $\begin{array}{l}47.909 \\
47.905 \\
47.902 \\
47.898 \\
47.894\end{array}$ & $\begin{array}{l}-102.215 \\
-102.215 \\
-102.215 \\
-102.215 \\
-102.215\end{array}$ & $\begin{array}{l}617.35 \\
627.08 \\
644.55 \\
645.68 \\
653.11\end{array}$ & $\begin{array}{l}3.113 \\
3.110 \\
3.264 \\
3.201 \\
3.182\end{array}$ & $\begin{array}{l}2.672 \\
2.660 \\
3.020 \\
2.885 \\
2.877\end{array}$ \\
\hline $\begin{array}{l}47.891 \\
47.887 \\
47.883 \\
47.880 \\
47.873\end{array}$ & $\begin{array}{l}-102.215 \\
-102.215 \\
-102.215 \\
-102.215 \\
-102.215\end{array}$ & $\begin{array}{l}655.13 \\
660.36 \\
661.18 \\
661.83 \\
672.54\end{array}$ & $\begin{array}{l}3.197 \\
3.315 \\
3.415 \\
3.489 \\
3.442\end{array}$ & $\begin{array}{l}2.953 \\
3.185 \\
3.444 \\
3.600 \\
3.563\end{array}$ \\
\hline $\begin{array}{l}47.870 \\
47.866 \\
47.862 \\
47.862 \\
47.858\end{array}$ & $\begin{array}{l}-102.215 \\
-102.215 \\
-102.215 \\
-102.215 \\
-102.215\end{array}$ & $\begin{array}{l}669.70 \\
671.40 \\
673.72 \\
673.72 \\
662.89\end{array}$ & $\begin{array}{l}3.526 \\
3.714 \\
3.733 \\
4.154 \\
3.867\end{array}$ & $\begin{array}{l}3.783 \\
4.182 \\
4.217 \\
5.059 \\
4.559\end{array}$ \\
\hline $\begin{array}{l}47.854 \\
47.850 \\
47.848 \\
47.830 \\
47.826\end{array}$ & $\begin{array}{l}-102.215 \\
-102.215 \\
-102.215 \\
-102.215 \\
-102.215\end{array}$ & $\begin{array}{l}661.92 \\
658.36 \\
644.29 \\
640.14 \\
635.37\end{array}$ & $\begin{array}{l}3.721 \\
3.787 \\
3.830 \\
3.675 \\
3.678\end{array}$ & $\begin{array}{l}4.293 \\
4.501 \\
4.605 \\
4.473 \\
4.545\end{array}$ \\
\hline
\end{tabular}


Table 8. Latitude, longitude, altitude, Bouguer gravity, and residual gravity values--Continued

[Latitude and longinde values are in decimal degrees; the negative sign of the longitude is the convention referencing longitude west of the prime meridian; altiude is in meters above sea level; the Bouguer gravity values and residual gravity values are in the units of milliga's]

\begin{tabular}{|c|c|c|c|c|}
\hline Latltude & Longitude & Altitude & Bouguer gravity & Residuai gravl " \\
\hline $\begin{array}{l}47.822 \\
47.819 \\
47.815 \\
47.811 \\
47.804\end{array}$ & $\begin{array}{l}-102.215 \\
-102.215 \\
-102.215 \\
-102.215 \\
-102.215\end{array}$ & $\begin{array}{l}630.30 \\
626.12 \\
624.53 \\
623.62 \\
621.19\end{array}$ & $\begin{array}{l}3.490 \\
3.508 \\
3.332 \\
3.364 \\
3.255\end{array}$ & $\begin{array}{l}4.256 \\
4.336 \\
4.022 \\
4.155 \\
4.026\end{array}$ \\
\hline $\begin{array}{l}47.603 \\
47.603 \\
47.603 \\
47.603 \\
47.603\end{array}$ & $\begin{array}{l}-101.849 \\
-101.853 \\
-101.860 \\
-101.865 \\
-101.870\end{array}$ & $\begin{array}{l}630.83 \\
632.14 \\
636.05 \\
641.48 \\
652.47\end{array}$ & $\begin{array}{l}-12.063 \\
-11.949 \\
-10.864 \\
-11.977 \\
-11.741\end{array}$ & $\begin{array}{r}-10.498 \\
-10.426 \\
-8.544 \\
-10.977 \\
-10.702\end{array}$ \\
\hline $\begin{array}{l}47.603 \\
47.603 \\
47.603 \\
47.603 \\
47.603\end{array}$ & $\begin{array}{l}-101.875 \\
-101.878 \\
-101.882 \\
-101.913 \\
-101.918\end{array}$ & $\begin{array}{l}664.04 \\
651.90 \\
646.22 \\
644.86 \\
640.18\end{array}$ & $\begin{array}{l}-11.871 \\
-11.867 \\
-12.596 \\
-10.958 \\
-10.608\end{array}$ & $\begin{array}{l}-11.190 \\
-11.273 \\
-12.882 \\
-10.871 \\
-10.358\end{array}$ \\
\hline $\begin{array}{l}47.603 \\
47.603 \\
47.603 \\
47.603 \\
47.603\end{array}$ & $\begin{array}{l}-101.924 \\
-101.929 \\
-101.936 \\
-101.936 \\
-101.941\end{array}$ & $\begin{array}{l}628.92 \\
636.51 \\
626.45 \\
626.46 \\
621.66\end{array}$ & $\begin{array}{r}-10.643 \\
-3.668 \\
-3.103 \\
-2.060 \\
-2.209\end{array}$ & $\begin{array}{r}-10.614 \\
3.146 \\
4.001 \\
6.087 \\
5.609\end{array}$ \\
\hline $\begin{array}{l}47.603 \\
47.603 \\
47.603 \\
47.603 \\
47.603\end{array}$ & $\begin{array}{l}-101.945 \\
-101.950 \\
-101.954 \\
-101.959 \\
-101.966\end{array}$ & $\begin{array}{l}627.85 \\
630.69 \\
623.72 \\
611.99 \\
604.67\end{array}$ & $\begin{array}{l}-4.473 \\
-4.541 \\
-4.638 \\
-4.239 \\
-.871\end{array}$ & $\begin{array}{l}.925 \\
.679 \\
.282 \\
.898 \\
7.417\end{array}$ \\
\hline $\begin{array}{l}47.603 \\
47.603 \\
47.603 \\
47.603 \\
47.603\end{array}$ & $\begin{array}{l}-101.972 \\
-101.983 \\
-101.988 \\
-101.993 \\
-101.999\end{array}$ & $\begin{array}{l}600.12 \\
617.14 \\
616.83 \\
606.79 \\
601.64\end{array}$ & $\begin{array}{l}-3.325 \\
-6.644 \\
-6.724 \\
-6.650 \\
-6.642\end{array}$ & $\begin{array}{r}2.283 \\
-4.691 \\
-5.001 \\
-5.032 \\
-5.212\end{array}$ \\
\hline $\begin{array}{l}47.603 \\
47.603 \\
47.603 \\
47.603 \\
47.603\end{array}$ & $\begin{array}{l}-102.004 \\
-102.009 \\
-102.014 \\
-102.019 \\
-102.024\end{array}$ & $\begin{array}{l}595.66 \\
597.62 \\
596.81 \\
593.77 \\
595.57\end{array}$ & $\begin{array}{l}-6.427 \\
-6.831 \\
-6.557 \\
-6.566 \\
-8.726\end{array}$ & $\begin{array}{r}-4.922 \\
-5.927 \\
-5.543 \\
-5.662 \\
-10.155\end{array}$ \\
\hline $\begin{array}{l}47.603 \\
47.603 \\
47.603 \\
47.603 \\
47.646\end{array}$ & $\begin{array}{l}-102.030 \\
-102.037 \\
-102.044 \\
-102.048 \\
-101.822\end{array}$ & $\begin{array}{l}600.18 \\
612.50 \\
615.92 \\
618.17 \\
603.76\end{array}$ & $\begin{array}{r}-8.262 \\
-8.161 \\
-7.610 \\
-6.997 \\
-11.368\end{array}$ & $\begin{array}{r}-9.408 \\
-9.400 \\
-8.524 \\
-7.418 \\
-10.294\end{array}$ \\
\hline $\begin{array}{l}47.646 \\
47.646 \\
47.646 \\
47.646 \\
47.646\end{array}$ & $\begin{array}{l}-101.832 \\
-101.838 \\
-101.843 \\
-101.849 \\
-101.854\end{array}$ & $\begin{array}{l}617.14 \\
614.00 \\
617.82 \\
622.38 \\
624.94\end{array}$ & $\begin{array}{l}-10.642 \\
-10.544 \\
-10.936 \\
-10.251 \\
-10.224\end{array}$ & $\begin{array}{r}-9.200 \\
-9.272 \\
-10.246 \\
-9.163 \\
-9.300\end{array}$ \\
\hline $\begin{array}{l}47.646 \\
47.646 \\
47.646 \\
47.646 \\
47.646\end{array}$ & $\begin{array}{l}-101.860 \\
-101.865 \\
-101.874 \\
-101.880 \\
-101.886\end{array}$ & $\begin{array}{l}624.54 \\
619.98 \\
611.22 \\
611.80 \\
614.26\end{array}$ & $\begin{array}{r}-10.316 \\
-10.302 \\
-10.102 \\
-10.149 \\
-9.375\end{array}$ & $\begin{array}{r}-9.742 \\
-9.926 \\
-9.815 \\
-10.145 \\
-8.850\end{array}$ \\
\hline
\end{tabular}


Table 8. Latitude, longitude, altitude, Bouguer gravity, and residual gravity values--Continued

[Latitude and longitude values are in decimal degrees; the negative sign of the longinade is the convention referencing longitude west of the prime meridian; altitude is in meters above sea level; the Bouguer gravity values and residual gravity values are in the units of milligals]

\begin{tabular}{|c|c|c|c|c|}
\hline Letltude & Longltude & Altitudo & Bouguer gravlty & Residual gravity \\
\hline $\begin{array}{l}47.646 \\
47.646 \\
47.646 \\
47.646 \\
47.646\end{array}$ & $\begin{array}{l}-101.893 \\
-101.899 \\
-101.903 \\
-101.908 \\
-101.913\end{array}$ & $\begin{array}{l}613.94 \\
626.35 \\
632.73 \\
630.82 \\
634.65\end{array}$ & $\begin{array}{r}-9.345 \\
-9.254 \\
-9.296 \\
-10.823 \\
-10.740\end{array}$ & $\begin{array}{r}-9.046 \\
-9.083 \\
-9.310 \\
-12.552 \\
-12.567\end{array}$ \\
\hline $\begin{array}{l}47.646 \\
47.646 \\
47.646 \\
47.646 \\
47.646\end{array}$ & $\begin{array}{l}-101.918 \\
-101.924 \\
-101.929 \\
-101.935 \\
-101.940\end{array}$ & $\begin{array}{l}639.82 \\
645.10 \\
641.08 \\
643.81 \\
650.11\end{array}$ & $\begin{array}{r}-5.596 \\
-5.202 \\
-4.876 \\
-4.864 \\
-5.042\end{array}$ & $\begin{array}{l}-2.481 \\
-1.906 \\
-1.379 \\
-1.597 \\
-2.104\end{array}$ \\
\hline $\begin{array}{l}47.646 \\
47.646 \\
47.646 \\
47.646 \\
47.646\end{array}$ & $\begin{array}{l}-101.945 \\
-101.950 \\
-101.961 \\
-101.967 \\
-101.972\end{array}$ & $\begin{array}{l}652.44 \\
651.53 \\
650.73 \\
654.13 \\
653.92\end{array}$ & $\begin{array}{l}-5.020 \\
-5.058 \\
-7.961 \\
-7.748 \\
-7.537\end{array}$ & $\begin{array}{l}-2.248 \\
-2.481 \\
-8.630 \\
-8386 \\
-8151\end{array}$ \\
\hline $\begin{array}{l}47.646 \\
47.646 \\
47.646 \\
47.646 \\
47.646\end{array}$ & $\begin{array}{l}-101.977 \\
-101.982 \\
-101.987 \\
-101.993 \\
-101.999\end{array}$ & $\begin{array}{l}649.33 \\
653.92 \\
663.11 \\
661.42 \\
663.94\end{array}$ & $\begin{array}{l}-7.706 \\
-7.585 \\
-7.726 \\
-7.593 \\
-8.126\end{array}$ & $\begin{array}{r}-8638 \\
-8560 \\
-9.016 \\
-8867 \\
-10129\end{array}$ \\
\hline $\begin{array}{l}47.646 \\
47.646 \\
47.646 \\
47.646 \\
47.646\end{array}$ & $\begin{array}{l}-102.004 \\
-102.009 \\
-102.015 \\
-102.021 \\
-102.025\end{array}$ & $\begin{array}{l}666.14 \\
661.36 \\
652.46 \\
651.57 \\
647.80\end{array}$ & $\begin{array}{l}-7.676 \\
-7.619 \\
-7.594 \\
-7.355 \\
-7.390\end{array}$ & $\begin{array}{l}-9.416 \\
-9.435 \\
-9.591 \\
-9.220 \\
-9.415\end{array}$ \\
\hline $\begin{array}{l}47.646 \\
47.646 \\
47.646 \\
47.646 \\
47.646\end{array}$ & $\begin{array}{l}-102.031 \\
-102.036 \\
-102.041 \\
-102.048 \\
-102.052\end{array}$ & $\begin{array}{l}654.89 \\
656.18 \\
651.99 \\
643.48 \\
638.79\end{array}$ & $\begin{array}{l}-7.457 \\
-6.630 \\
-6.396 \\
-5.779 \\
-5.893\end{array}$ & $\begin{array}{l}-9.735 \\
-8239 \\
-7.902 \\
-6833 \\
-7.146\end{array}$ \\
\hline $\begin{array}{l}47.646 \\
47.646 \\
47.646 \\
47.646 \\
47.646\end{array}$ & $\begin{array}{l}-102.057 \\
-102.063 \\
-102.068 \\
-102.073 \\
-102.078\end{array}$ & $\begin{array}{l}640.52 \\
628.35 \\
634.68 \\
633.55 \\
628.30\end{array}$ & $\begin{array}{r}-5.663 \\
-4.771 \\
-4.638 \\
-4.847 \\
-5.049\end{array}$ & $\begin{array}{l}-6828 \\
-5.214 \\
-5.091 \\
-5.563 \\
-6149\end{array}$ \\
\hline $\begin{array}{l}47.646 \\
47.646 \\
47.646 \\
47.646 \\
47.646\end{array}$ & $\begin{array}{l}-102.083 \\
-102.089 \\
-102.094 \\
-102.099 \\
-102.106\end{array}$ & $\begin{array}{l}627.08 \\
626.35 \\
629.20 \\
632.05 \\
635.35\end{array}$ & $\begin{array}{l}-4.438 \\
-4.532 \\
-4.449 \\
-5.095 \\
-3.119\end{array}$ & $\begin{array}{l}-4.995 \\
-5371 \\
-5312 \\
-6733 \\
-2.888\end{array}$ \\
\hline $\begin{array}{l}47.646 \\
47.646 \\
47.674 \\
47.674 \\
47.674\end{array}$ & $\begin{array}{l}-102.111 \\
-102.115 \\
-101.843 \\
-101.853 \\
-101.857\end{array}$ & $\begin{array}{l}631.82 \\
627.66 \\
603.10 \\
607.79 \\
607.38\end{array}$ & $\begin{array}{r}-5.203 \\
-5.347 \\
-10.057 \\
-10.291 \\
-10.199\end{array}$ & $\begin{array}{r}-7.173 \\
-7.555 \\
-9.846 \\
-10715 \\
-10701\end{array}$ \\
\hline $\begin{array}{l}47.674 \\
47.674 \\
47.674 \\
47.674 \\
47.674\end{array}$ & $\begin{array}{l}-101.862 \\
-101.877 \\
-101.882 \\
-101.887 \\
-101.898\end{array}$ & $\begin{array}{l}608.02 \\
611.44 \\
611.53 \\
612.39 \\
619.58\end{array}$ & $\begin{array}{r}-10.319 \\
-9.911 \\
-9.874 \\
-9.755 \\
-9.633\end{array}$ & $\begin{array}{l}-11.152 \\
-10892 \\
-11.011 \\
-10939 \\
-11.062\end{array}$ \\
\hline
\end{tabular}


Table 8. Latitude, longitude, altitude, Bouguer gravity, and residual gravity values--Continued

[Latitude and longinde values are in decimal degrees; the negative sign of the longitude is the convention referencing longitude west of the prime meridian; altitude is in meters above sea level; the Bouguer gravity values and residual gravily values are in the units of milliga's]

\begin{tabular}{|c|c|c|c|c|}
\hline Latitude & Longitude & Altitude & Bouguer gravity & Residual gravity \\
\hline $\begin{array}{l}47.674 \\
47.674 \\
47.674 \\
47.674 \\
47.674\end{array}$ & $\begin{array}{l}-101.904 \\
-101.909 \\
-101.913 \\
-101.919 \\
-101.925\end{array}$ & $\begin{array}{l}618.54 \\
618.07 \\
620.74 \\
620.30 \\
622.36\end{array}$ & $\begin{array}{l}-9.626 \\
-9.390 \\
-9.430 \\
-9.118 \\
-8.912\end{array}$ & $\begin{array}{l}-11.288 \\
-11.014 \\
-11.241 \\
-10.757 \\
-10.542\end{array}$ \\
\hline $\begin{array}{l}47.674 \\
47.674 \\
47.674 \\
47.674 \\
47.674\end{array}$ & $\begin{array}{l}-101.930 \\
-101.936 \\
-101.994 \\
-101.998 \\
-102.005\end{array}$ & $\begin{array}{l}622.33 \\
623.00 \\
634.60 \\
633.32 \\
641.01\end{array}$ & $\begin{array}{l}-8.676 \\
-8.890 \\
-7.603 \\
-7.541 \\
-7.572\end{array}$ & $\begin{array}{l}-10.269 \\
-10.918 \\
-10.108 \\
-10.121 \\
-10.355\end{array}$ \\
\hline $\begin{array}{l}47.674 \\
47.674 \\
47.674 \\
47.674 \\
47.674\end{array}$ & $\begin{array}{l}-102.012 \\
-102.017 \\
-102.022 \\
-102.029 \\
-102.054\end{array}$ & $\begin{array}{l}638.72 \\
631.55 \\
629.82 \\
630.31 \\
624.37\end{array}$ & $\begin{array}{l}-7.864 \\
-7.112 \\
-7.002 \\
-7.085 \\
-6.511\end{array}$ & $\begin{array}{r}-11.140 \\
-9.812 \\
-9.698 \\
-10.050 \\
-9.493\end{array}$ \\
\hline $\begin{array}{l}47.674 \\
47.674 \\
47.674 \\
47.674 \\
47.674\end{array}$ & $\begin{array}{l}-102.059 \\
-102.063 \\
-102.068 \\
-102.074 \\
-102.079\end{array}$ & $\begin{array}{l}618.57 \\
616.57 \\
613.37 \\
615.28 \\
621.45\end{array}$ & $\begin{array}{l}-6.429 \\
-6.831 \\
-9.679 \\
-7.211 \\
-6.828\end{array}$ & $\begin{array}{r}-9.468 \\
-10.354 \\
-16.199 \\
-11.416 \\
-10.752\end{array}$ \\
\hline $\begin{array}{l}47.674 \\
47.674 \\
47.674 \\
47.674 \\
47.674\end{array}$ & $\begin{array}{l}-102.084 \\
-102.090 \\
-102.094 \\
-102.099 \\
-102.103\end{array}$ & $\begin{array}{l}625.52 \\
624.82 \\
628.52 \\
637.49 \\
635.78\end{array}$ & $\begin{array}{l}-4.889 \\
-3.886 \\
-4.469 \\
-4.438 \\
-4.291\end{array}$ & $\begin{array}{l}-7.014 \\
-5.143 \\
-6.377 \\
-6.398 \\
-6.159\end{array}$ \\
\hline $\begin{array}{l}47.688 \\
47.688 \\
47.688 \\
47.688 \\
47.688\end{array}$ & $\begin{array}{l}-101.824 \\
-101.829 \\
-101.834 \\
-101.840 \\
-101.846\end{array}$ & $\begin{array}{l}610.19 \\
608.45 \\
604.70 \\
608.38 \\
606.07\end{array}$ & $\begin{array}{r}-10.579 \\
-9.810 \\
-9.459 \\
-10.120 \\
-9.827\end{array}$ & $\begin{array}{r}-10.854 \\
-9.521 \\
-9.036 \\
-10.561 \\
-10.203\end{array}$ \\
\hline $\begin{array}{l}47.688 \\
47.688 \\
47.688 \\
47.688 \\
47.688\end{array}$ & $\begin{array}{l}-101.851 \\
-101.860 \\
-101.865 \\
-101.899 \\
-101.904\end{array}$ & $\begin{array}{l}605.63 \\
604.70 \\
604.90 \\
613.39 \\
618.87\end{array}$ & $\begin{array}{l}-9.873 \\
-9.942 \\
-9.604 \\
-9.122 \\
-8.996\end{array}$ & $\begin{array}{l}-10.507 \\
-10.970 \\
-10.491 \\
-10.727 \\
-10.641\end{array}$ \\
\hline $\begin{array}{l}47.688 \\
47.688 \\
47.688 \\
47.688 \\
47.688\end{array}$ & $\begin{array}{l}-101.915 \\
-101.921 \\
-101.979 \\
-101.990 \\
-101.996\end{array}$ & $\begin{array}{l}616.44 \\
613.81 \\
615.73 \\
620.98 \\
620.24\end{array}$ & $\begin{array}{l}-8.638 \\
-8.846 \\
-6.092 \\
-5.346 \\
-5.376\end{array}$ & $\begin{array}{r}-10.339 \\
-10.918 \\
-7.246 \\
-6.048 \\
-6.288\end{array}$ \\
\hline $\begin{array}{l}47.688 \\
47.688 \\
47.688 \\
47.688 \\
47.688\end{array}$ & $\begin{array}{l}-102.001 \\
-102.007 \\
-102.011 \\
-102.017 \\
-102.022\end{array}$ & $\begin{array}{l}618.68 \\
615.70 \\
616.23 \\
620.51 \\
619.48\end{array}$ & $\begin{array}{l}-5.206 \\
-4.955 \\
-4.798 \\
-4.745 \\
-4.666\end{array}$ & $\begin{array}{l}-6.040 \\
-5.703 \\
-5.512 \\
-5.596 \\
-5.563\end{array}$ \\
\hline $\begin{array}{l}47.688 \\
47.688 \\
47.688 \\
47.688 \\
47.703\end{array}$ & $\begin{array}{l}-102.027 \\
-102.033 \\
-102.054 \\
-102.060 \\
-101.856\end{array}$ & $\begin{array}{l}613.86 \\
610.35 \\
606.41 \\
606.74 \\
611.52\end{array}$ & $\begin{array}{l}-4.252 \\
-4.185 \\
-5.353 \\
-5.374 \\
-8.201\end{array}$ & $\begin{array}{l}-4.889 \\
-4.857 \\
-7.758 \\
-7.890 \\
-7.980\end{array}$ \\
\hline
\end{tabular}


Table 8. Latitude, longitude, attitude, Bouguer gravity, and residual gravity values--Continued

[Latitude and longitude values are in decimal degrees; the negative sign of the longitude is the convention referencing longitude west of the prime meridian; altitude is in meters above sea level; the Bouguer gravity values and residual gravity values are in the units of milligals]

\begin{tabular}{|c|c|c|c|c|}
\hline Lalitude & Longlitude & Altltude & Bouguer gravity & Residurl gravlty \\
\hline $\begin{array}{l}47.703 \\
47.703 \\
47.703 \\
47.703 \\
47.703\end{array}$ & $\begin{array}{l}-101.861 \\
-101.867 \\
-101.878 \\
-101.883 \\
-101.888\end{array}$ & $\begin{array}{l}612.86 \\
611.40 \\
610.72 \\
608.24 \\
607.74\end{array}$ & $\begin{array}{l}-8.213 \\
-8.033 \\
-7.823 \\
-7.805 \\
-7.649\end{array}$ & $\begin{array}{l}-8.185 \\
-8.051 \\
-8.034 \\
-8.164 \\
-8.024\end{array}$ \\
\hline $\begin{array}{l}47.703 \\
47.703 \\
47.703 \\
47.703 \\
47.703\end{array}$ & $\begin{array}{l}-101.899 \\
-101.904 \\
-101.910 \\
-101.915 \\
-101.921\end{array}$ & $\begin{array}{l}606.15 \\
603.71 \\
604.28 \\
605.26 \\
598.40\end{array}$ & $\begin{array}{l}-7.617 \\
-7.482 \\
-7.267 \\
-7.197 \\
-6.972\end{array}$ & $\begin{array}{l}-8.365 \\
-8.259 \\
-8.009 \\
-8.047 \\
-7.824\end{array}$ \\
\hline $\begin{array}{l}47.703 \\
47.703 \\
47.703 \\
47.703 \\
47.703\end{array}$ & $\begin{array}{l}-101.926 \\
-101.931 \\
-101.936 \\
-101.947 \\
-101.952\end{array}$ & $\begin{array}{l}603.05 \\
598.09 \\
603.71 \\
607.51 \\
603.95\end{array}$ & $\begin{array}{l}-5.720 \\
-6.455 \\
-6.301 \\
-5.781 \\
-5.514\end{array}$ & $\begin{array}{l}-5.468 \\
-7.052 \\
-6.960 \\
-6.238 \\
-5.866\end{array}$ \\
\hline $\begin{array}{l}47.703 \\
47.703 \\
47.703 \\
47.703 \\
47.703\end{array}$ & $\begin{array}{l}-101.958 \\
-101.964 \\
-101.968 \\
-101.974 \\
-101.985\end{array}$ & $\begin{array}{l}605.36 \\
606.69 \\
605.47 \\
606.58 \\
602.11\end{array}$ & $\begin{array}{l}-5.292 \\
-5.157 \\
-5.082 \\
-4.813 \\
-4.302\end{array}$ & $\begin{array}{l}-5.549 \\
-5.461 \\
-5.498 \\
-5.099 \\
-4.372\end{array}$ \\
\hline $\begin{array}{l}47.703 \\
47.703 \\
47.703 \\
47.703 \\
47.703\end{array}$ & $\begin{array}{l}-101.989 \\
-101.995 \\
-102.001 \\
-102.006 \\
-102.011\end{array}$ & $\begin{array}{l}601.69 \\
604.22 \\
603.37 \\
602.96 \\
603.51\end{array}$ & $\begin{array}{l}-4.060 \\
-3.759 \\
-3.478 \\
-3.362 \\
-3.202\end{array}$ & $\begin{array}{l}-4.046 \\
-3.615 \\
-3.163 \\
-3.109 \\
-2.892\end{array}$ \\
\hline $\begin{array}{l}47.703 \\
47.703 \\
47.703 \\
47.703 \\
47.703\end{array}$ & $\begin{array}{l}-102.017 \\
-102.022 \\
-102.027 \\
-102.033 \\
-102.038\end{array}$ & $\begin{array}{l}603.36 \\
602.15 \\
599.31 \\
605.93 \\
611.56\end{array}$ & $\begin{array}{l}-3.221 \\
-3.148 \\
-2.907 \\
-2.975 \\
-2.834\end{array}$ & $\begin{array}{l}-3.125 \\
-3.104 \\
-2.692 \\
-2.998 \\
-2.827\end{array}$ \\
\hline $\begin{array}{l}47.703 \\
47.703 \\
47.703 \\
47.703 \\
47.703\end{array}$ & $\begin{array}{l}-102.049 \\
-102.054 \\
-102.060 \\
-102.069 \\
-102.081\end{array}$ & $\begin{array}{l}617.98 \\
620.13 \\
626.14 \\
621.49 \\
607.75\end{array}$ & $\begin{array}{l}-2.869 \\
-2.714 \\
-2.524 \\
-2.354 \\
-1.781\end{array}$ & $\begin{array}{l}-3.179 \\
-2.961 \\
-2.731 \\
-2.586 \\
-1.691\end{array}$ \\
\hline $\begin{array}{l}47.703 \\
47.703 \\
47.703 \\
47.717 \\
47.717\end{array}$ & $\begin{array}{l}-102.086 \\
-102.092 \\
-102.097 \\
-101.942 \\
-101.947\end{array}$ & $\begin{array}{l}598.59 \\
606.06 \\
593.68 \\
595.84 \\
598.27\end{array}$ & $\begin{array}{l}-1.658 \\
-1.608 \\
-1.434 \\
-8.217 \\
-8.074\end{array}$ & $\begin{array}{r}-1.551 \\
-1.601 \\
-1.370 \\
-11.495 \\
-11.367\end{array}$ \\
\hline $\begin{array}{l}47.717 \\
47.717 \\
47.717 \\
47.717 \\
47.717\end{array}$ & $\begin{array}{l}-101.953 \\
-101.958 \\
-101.963 \\
-101.969 \\
-101.974\end{array}$ & $\begin{array}{l}600.23 \\
601.37 \\
603.37 \\
603.90 \\
604.41\end{array}$ & $\begin{array}{r}-2.561 \\
-2.213 \\
4.178 \\
2.149 \\
-.778\end{array}$ & $\begin{array}{r}-.504 \\
.005 \\
4.074 \\
8.408 \\
2.446\end{array}$ \\
\hline $\begin{array}{l}47.717 \\
47.717 \\
47.717 \\
47.717 \\
47.717\end{array}$ & $\begin{array}{l}-101.985 \\
-101.990 \\
-102.001 \\
-102.006 \\
-102.011\end{array}$ & $\begin{array}{l}603.36 \\
601.47 \\
597.56 \\
599.53 \\
594.25\end{array}$ & $\begin{array}{l}-3.621 \\
-3.546 \\
-3.391 \\
-3.163 \\
-2.881\end{array}$ & $\begin{array}{l}-3.576 \\
-3.552 \\
-3.484 \\
-3.198 \\
-2.751\end{array}$ \\
\hline
\end{tabular}


Table 8. Latitude, longitude, altitude, Bouguer gravity, and residual gravity values--Continued

[Latirude and longitude values are in decimal degrees; the negative sign of the longitude is the convention referencing longitude west of the prime meridian; altitude is in meters above sea level; the Bouguer gravity values and residual gravity values are in the units of milligals]

\begin{tabular}{|c|c|c|c|c|}
\hline Latifude & Longltude & Altitude & Bouguer gravlty & Resldual gravity \\
\hline $\begin{array}{l}47.717 \\
47.717 \\
47.717 \\
47.717 \\
47.717\end{array}$ & $\begin{array}{l}-102.016 \\
-102.022 \\
-102.027 \\
-102.033 \\
-102.038\end{array}$ & $\begin{array}{l}592.87 \\
590.38 \\
591.01 \\
591.85 \\
591.83\end{array}$ & $\begin{array}{l}-2.846 \\
-2.840 \\
-2.643 \\
-1.533 \\
-1.468\end{array}$ & $\begin{array}{r}-2.814 \\
-2.987 \\
-2.664 \\
-.600 \\
-.574\end{array}$ \\
\hline $\begin{array}{l}47.717 \\
47.717 \\
47.717 \\
47.717 \\
47.717\end{array}$ & $\begin{array}{l}-102.049 \\
-102.055 \\
-102.060 \\
-102.065 \\
-102.071\end{array}$ & $\begin{array}{l}595.87 \\
598.13 \\
599.76 \\
602.28 \\
604.01\end{array}$ & $\begin{array}{r}-1.618 \\
-1.465 \\
-1.301 \\
-1.249 \\
-.880\end{array}$ & $\begin{array}{r}-1.155 \\
-.943 \\
-.747 \\
-.747 \\
-.178\end{array}$ \\
\hline $\begin{array}{l}47.717 \\
47.717 \\
47.717 \\
47.717 \\
47.717\end{array}$ & $\begin{array}{l}-102.076 \\
-102.081 \\
-102.086 \\
-102.093 \\
-102.098\end{array}$ & $\begin{array}{l}607.75 \\
613.80 \\
617.87 \\
615.29 \\
611.10\end{array}$ & $\begin{array}{l}-1.929 \\
-1.890 \\
-1.711 \\
-1.782 \\
-1.636\end{array}$ & $\begin{array}{l}-2.321 \\
-2.360 \\
-2.104 \\
-2.418 \\
-2.219\end{array}$ \\
\hline $\begin{array}{l}47.717 \\
47.717 \\
47.717 \\
47.717 \\
47.732\end{array}$ & $\begin{array}{l}-102.103 \\
-102.115 \\
-102.126 \\
-102.130 \\
-101.823\end{array}$ & $\begin{array}{l}603.96 \\
598.83 \\
591.84 \\
578.10 \\
635.98\end{array}$ & $\begin{array}{l}-1.515 \\
-2.280 \\
-1.275 \\
-1.154 \\
-6.189\end{array}$ & $\begin{array}{l}-2.072 \\
-3.820 \\
-2.015 \\
-1.852 \\
-3.979\end{array}$ \\
\hline $\begin{array}{l}47.732 \\
47.732 \\
47.732 \\
47.732 \\
47.732\end{array}$ & $\begin{array}{l}-101.835 \\
-101.840 \\
-101.845 \\
-101.861 \\
-101.866\end{array}$ & $\begin{array}{l}634.61 \\
635.68 \\
636.33 \\
638.12 \\
641.01\end{array}$ & $\begin{array}{l}-5.985 \\
-9.838 \\
-9.844 \\
-7.385 \\
-7.515\end{array}$ & $\begin{array}{r}-4.073 \\
-11.913 \\
-12.097 \\
-7.802 \\
-8.243\end{array}$ \\
\hline $\begin{array}{l}47.732 \\
47.732 \\
47.732 \\
47.732 \\
47.732\end{array}$ & $\begin{array}{l}-101.877 \\
-101.882 \\
-101.887 \\
-101.899 \\
-101.904\end{array}$ & $\begin{array}{l}630.91 \\
628.15 \\
617.21 \\
612.96 \\
610.93\end{array}$ & $\begin{array}{l}-7.177 \\
-7.210 \\
-6.537 \\
-6.350 \\
-6.334\end{array}$ & $\begin{array}{l}-7.909 \\
-8.147 \\
-6.951 \\
-6.973 \\
-7.092\end{array}$ \\
\hline $\begin{array}{l}47.732 \\
47.732 \\
47.732 \\
47.732 \\
47.732\end{array}$ & $\begin{array}{l}-101.920 \\
-101.926 \\
-101.931 \\
-101.936 \\
-101.942\end{array}$ & $\begin{array}{l}607.02 \\
604.43 \\
605.49 \\
602.72 \\
601.03\end{array}$ & $\begin{array}{l}-6.102 \\
-6.072 \\
-6.199 \\
-1.635 \\
-1.614\end{array}$ & $\begin{array}{r}-7.188 \\
-7.269 \\
-7.673 \\
1.280 \\
1.138\end{array}$ \\
\hline $\begin{array}{l}47.732 \\
47.732 \\
47.732 \\
47.732 \\
47.732\end{array}$ & $\begin{array}{l}-101.946 \\
-101.950 \\
-101.958 \\
-101.985 \\
-101.990\end{array}$ & $\begin{array}{l}598.46 \\
594.81 \\
591.72 \\
598.51 \\
600.25\end{array}$ & $\begin{array}{l}-1.478 \\
-2.184 \\
-1.854 \\
-4.057 \\
-3.963\end{array}$ & $\begin{array}{r}1.303 \\
-.219 \\
.222 \\
-4.941 \\
-4.892\end{array}$ \\
\hline $\begin{array}{l}47.732 \\
47.732 \\
47.732 \\
47.732 \\
47.732\end{array}$ & $\begin{array}{l}-101.995 \\
-102.001 \\
-102.008 \\
-102.012 \\
-102.017\end{array}$ & $\begin{array}{l}600.04 \\
598.90 \\
597.47 \\
595.60 \\
589.96\end{array}$ & $\begin{array}{l}-3.618 \\
-3.686 \\
-3.455 \\
-3.266 \\
-3.085\end{array}$ & $\begin{array}{l}-4.328 \\
-4.629 \\
-4.337 \\
-4.029 \\
-3.826\end{array}$ \\
\hline $\begin{array}{l}47.732 \\
47.732 \\
47.732 \\
47.732 \\
47.746\end{array}$ & $\begin{array}{l}-102.022 \\
-102.028 \\
-102.033 \\
-102.038 \\
-101.834\end{array}$ & $\begin{array}{l}591.95 \\
591.14 \\
587.45 \\
582.59 \\
638.36\end{array}$ & $\begin{array}{l}-2.912 \\
-2.937 \\
-2.621 \\
-2.485 \\
-8.775\end{array}$ & $\begin{array}{r}-3.571 \\
-3.790 \\
-3.235 \\
-3.072 \\
-10.158\end{array}$ \\
\hline
\end{tabular}


Table 8. Latitude, longitude, altitude, Bouguer gravity, and residual gravity values--Continuec

[Latitude and longitude values are in decimal degrees; the negative sign of the longitude is the convention referencing longitud: west of the prime meridian; altitude is in meters above sea level: the Bouguer gravity values and residual gravity values are in the units of milligal s]

\begin{tabular}{|c|c|c|c|c|}
\hline Latitude & Longltude & Altitude & Bouguer gravity & Residu al gravity \\
\hline $\begin{array}{l}47.746 \\
47.746 \\
47.746 \\
47.746 \\
47.746\end{array}$ & $\begin{array}{l}-101.845 \\
-101.860 \\
-101.866 \\
-101.878 \\
-101.884\end{array}$ & $\begin{array}{l}640.18 \\
636.32 \\
636.15 \\
630.11 \\
630.94\end{array}$ & $\begin{array}{l}-8.780 \\
-8.493 \\
-8.166 \\
-7.996 \\
-8.110\end{array}$ & $\begin{array}{l}-10582 \\
-10512 \\
-10094 \\
-10143 \\
-10566\end{array}$ \\
\hline $\begin{array}{l}47.746 \\
47.746 \\
47.746 \\
47.746 \\
47.746\end{array}$ & $\begin{array}{l}-101.899 \\
-101.904 \\
-101.909 \\
-101.919 \\
-101.924\end{array}$ & $\begin{array}{l}628.89 \\
622.09 \\
619.77 \\
609.82 \\
611.01\end{array}$ & $\begin{array}{l}-7.328 \\
-5.044 \\
-4.091 \\
-7.340 \\
-7.136\end{array}$ & $\begin{array}{r}-9.517 \\
-5.105 \\
-3.311 \\
-10.119 \\
-9.883\end{array}$ \\
\hline $\begin{array}{l}47.746 \\
47.746 \\
47.746 \\
47.746 \\
47.746\end{array}$ & $\begin{array}{l}-101.929 \\
-101.941 \\
-101.947 \\
-101.952 \\
-101.958\end{array}$ & $\begin{array}{l}614.08 \\
602.25 \\
604.83 \\
604.83 \\
600.62\end{array}$ & $\begin{array}{l}-6.526 \\
-5.934 \\
-5.684 \\
-2.396 \\
-2.024\end{array}$ & $\begin{array}{r}-8819 \\
-7.962 \\
-7.659 \\
-1.237 \\
-.610\end{array}$ \\
\hline $\begin{array}{l}47.746 \\
47.746 \\
47.746 \\
47.746 \\
47.746\end{array}$ & $\begin{array}{l}-101.966 \\
-101.970 \\
-101.974 \\
-101.979 \\
-101.987\end{array}$ & $\begin{array}{l}599.14 \\
597.52 \\
597.04 \\
594.87 \\
588.09\end{array}$ & $\begin{array}{r}-1.682 \\
-1.170 \\
-1.165 \\
-.871 \\
-1.037\end{array}$ & $\begin{array}{r}-.193 \\
.723 \\
.646 \\
1.109 \\
.543\end{array}$ \\
\hline $\begin{array}{l}47.746 \\
47.746 \\
47.746 \\
47.746 \\
47.746\end{array}$ & $\begin{array}{l}-101.996 \\
-102.001 \\
-102.011 \\
-102.036 \\
-102.049\end{array}$ & $\begin{array}{l}585.90 \\
589.14 \\
589.43 \\
583.10 \\
576.41\end{array}$ & $\begin{array}{r}-.396 \\
-.451 \\
-.023 \\
.725 \\
-1.265\end{array}$ & $\begin{array}{r}1.629 \\
1.394 \\
1.970 \\
2.903 \\
-1.333\end{array}$ \\
\hline $\begin{array}{l}47.746 \\
47.746 \\
47.746 \\
47.746 \\
47.746\end{array}$ & $\begin{array}{l}-102.054 \\
-102.073 \\
-102.077 \\
-102.081 \\
-102.092\end{array}$ & $\begin{array}{l}576.75 \\
576.25 \\
577.63 \\
580.13 \\
590.41\end{array}$ & $\begin{array}{r}-1.097 \\
-.411 \\
-.115 \\
-.057 \\
-.531\end{array}$ & $\begin{array}{r}-1.122 \\
-.134 \\
.366 \\
.426 \\
-.763\end{array}$ \\
\hline $\begin{array}{l}47.746 \\
47.746 \\
47.746 \\
47.746 \\
47.746\end{array}$ & $\begin{array}{l}-102.097 \\
-102.108 \\
-102.113 \\
-102.119 \\
-102.125\end{array}$ & $\begin{array}{l}594.36 \\
596.87 \\
590.31 \\
602.41 \\
608.44\end{array}$ & $\begin{array}{l}.328 \\
.548 \\
.810 \\
.598 \\
.881\end{array}$ & $\begin{array}{r}.861 \\
1.144 \\
1.573 \\
1.039 \\
1.550\end{array}$ \\
\hline $\begin{array}{l}47.761 \\
47.761 \\
47.761 \\
47.761 \\
47.761\end{array}$ & $\begin{array}{l}-101.942 \\
-101.950 \\
-101.955 \\
-101.960 \\
-101.965\end{array}$ & $\begin{array}{l}612.77 \\
607.93 \\
607.32 \\
600.49 \\
595.57\end{array}$ & $\begin{array}{l}-3.464 \\
-3.259 \\
-3.178 \\
-3.059 \\
-2.910\end{array}$ & $\begin{array}{l}-3.608 \\
-3.383 \\
-3.404 \\
-3.273 \\
-3.088\end{array}$ \\
\hline $\begin{array}{l}47.761 \\
47.761 \\
47.761 \\
47.761 \\
47.775\end{array}$ & $\begin{array}{l}-101.996 \\
-102.022 \\
-102.027 \\
-102.033 \\
-101.958\end{array}$ & $\begin{array}{l}589.91 \\
581.93 \\
586.64 \\
587.24 \\
598.67\end{array}$ & $\begin{array}{l}-2.256 \\
-1.594 \\
-1.252 \\
-1.114 \\
-1.915\end{array}$ & $\begin{array}{l}-2.603 \\
-1.871 \\
-1.304 \\
-1.114 \\
-1.355\end{array}$ \\
\hline $\begin{array}{l}47.775 \\
47.775 \\
47.775 \\
47.775 \\
47.775\end{array}$ & $\begin{array}{l}-102.055 \\
-102.060 \\
-102.065 \\
-102.071 \\
-102.076\end{array}$ & $\begin{array}{l}590.74 \\
594.05 \\
595.75 \\
599.18 \\
601.26\end{array}$ & $\begin{array}{r}.618 \\
.877 \\
1.045 \\
1.442 \\
1.711\end{array}$ & $\begin{array}{l}1.453 \\
1.868 \\
2.156 \\
2.810 \\
3.276\end{array}$ \\
\hline
\end{tabular}


Table 8. Latitude, longitude, altitude, Bouguer gravity, and residual gravity values--Continued

[Latitude and longitude values are in decimal degrees; the negative sign of the longitude is the convention referencing longitude west of the prime meridian; altitude is in meters above sea level; the Bouguer gravity values and residual gravity values are im the units of milligals]

\begin{tabular}{|c|c|c|c|c|}
\hline Latltude & Longltude & Altitude & Bouguer gravlty & Residusl grsvit, \\
\hline $\begin{array}{l}47.775 \\
47.775 \\
47.775 \\
47.790 \\
47.790\end{array}$ & $\begin{array}{l}-102.081 \\
-102.089 \\
-102.177 \\
-101.836 \\
-101.840\end{array}$ & $\begin{array}{l}604.51 \\
602.67 \\
616.36 \\
653.58 \\
652.94\end{array}$ & $\begin{array}{r}1.659 \\
2.424 \\
5.900 \\
-2.697 \\
-2.498\end{array}$ & $\begin{array}{r}3.056 \\
4.461 \\
10.166 \\
.203 \\
.476\end{array}$ \\
\hline $\begin{array}{l}47.790 \\
47.790 \\
47.790 \\
47.790 \\
47.790\end{array}$ & $\begin{array}{l}-101.846 \\
-101.855 \\
-101.861 \\
-101.867 \\
-101.878\end{array}$ & $\begin{array}{l}654.63 \\
650.39 \\
650.03 \\
647.77 \\
640.79\end{array}$ & $\begin{array}{l}-2.239 \\
-1.830 \\
-1.482 \\
-1.392 \\
-1.17\end{array}$ & $\begin{array}{r}.784 \\
1.326 \\
1.858 \\
1.835 \\
1.888\end{array}$ \\
\hline $\begin{array}{l}47.790 \\
47.790 \\
47.790 \\
47.790 \\
47.790\end{array}$ & $\begin{array}{l}-101.883 \\
-101.966 \\
-101.970 \\
-101.975 \\
-101.985\end{array}$ & $\begin{array}{l}638.96 \\
615.38 \\
606.66 \\
609.32 \\
615.48\end{array}$ & $\begin{array}{l}-.788 \\
1.130 \\
1.411 \\
1.506 \\
2.037\end{array}$ & $\begin{array}{l}2.488 \\
4.059 \\
4.531 \\
4.605 \\
5.370\end{array}$ \\
\hline $\begin{array}{l}47.790 \\
47.790 \\
47.790 \\
47.790 \\
47.790\end{array}$ & $\begin{array}{l}-101.990 \\
-101.996 \\
-102.006 \\
-102.011 \\
-102.017\end{array}$ & $\begin{array}{l}610.47 \\
609.23 \\
602.90 \\
607.93 \\
602.61\end{array}$ & $\begin{array}{r}2.422 \\
-3.249 \\
-4.824 \\
-4.567 \\
-4.185\end{array}$ & $\begin{array}{r}6.045 \\
-5.405 \\
-8.812 \\
-8.386 \\
-7.800\end{array}$ \\
\hline $\begin{array}{l}47.790 \\
47.790 \\
47.790 \\
47.790 \\
47.790\end{array}$ & $\begin{array}{l}-102.022 \\
-102.027 \\
-102.038 \\
-102.043 \\
-102.052\end{array}$ & $\begin{array}{l}599.36 \\
596.74 \\
592.90 \\
597.42 \\
609.16\end{array}$ & $\begin{array}{l}-4.174 \\
-3.627 \\
-3.357 \\
-2.622 \\
-2.386\end{array}$ & $\begin{array}{l}-7.880 \\
-6.833 \\
-6.527 \\
-5.161 \\
-4.872\end{array}$ \\
\hline $\begin{array}{l}47.790 \\
47.790 \\
47.790 \\
47.790 \\
47.790\end{array}$ & $\begin{array}{l}-102.071 \\
-102.076 \\
-102.093 \\
-102.096 \\
-102.099\end{array}$ & $\begin{array}{l}609.14 \\
604.93 \\
616.47 \\
617.49 \\
617.48\end{array}$ & $\begin{array}{r}-.904 \\
-.526 \\
.047 \\
.446 \\
.651\end{array}$ & $\begin{array}{r}-2.286 \\
-1.540 \\
-.728 \\
.046 \\
.402\end{array}$ \\
\hline $\begin{array}{l}47.790 \\
47.790 \\
47.790 \\
47.790 \\
47.790\end{array}$ & $\begin{array}{l}-102.108 \\
-102.115 \\
-102.119 \\
-102.125 \\
-102.133\end{array}$ & $\begin{array}{l}614.19 \\
618.93 \\
625.18 \\
621.98 \\
616.34\end{array}$ & $\begin{array}{r}.627 \\
.761 \\
1.059 \\
1.258 \\
5.305\end{array}$ & $\begin{array}{r}.181 \\
.379 \\
.921 \\
1.224 \\
9.193\end{array}$ \\
\hline $\begin{array}{l}47.790 \\
47.790 \\
47.790 \\
47.790 \\
47.804\end{array}$ & $\begin{array}{l}-102.138 \\
-102.142 \\
-102.161 \\
-102.166 \\
-101.829\end{array}$ & $\begin{array}{l}616.01 \\
619.61 \\
623.32 \\
629.69 \\
650.42\end{array}$ & $\begin{array}{l}5.729 \\
5.628 \\
5.532 \\
5.912 \\
-4.200\end{array}$ & $\begin{array}{r}9.960 \\
9.732 \\
9.351 \\
10.021 \\
-3.075\end{array}$ \\
\hline $\begin{array}{l}47.804 \\
47.804 \\
47.804 \\
47.804 \\
47.804\end{array}$ & $\begin{array}{l}-101.850 \\
-101.915 \\
-101.979 \\
-101.984 \\
-101.990\end{array}$ & $\begin{array}{l}651.18 \\
631.24 \\
617.06 \\
613.30 \\
610.92\end{array}$ & $\begin{array}{l}-4.077 \\
-3.690 \\
-2.434 \\
-2.720 \\
-3.040\end{array}$ & $\begin{array}{l}-3.493 \\
-4.645 \\
-3.765 \\
-4.457 \\
-5.266\end{array}$ \\
\hline $\begin{array}{l}47.804 \\
47.804 \\
47.804 \\
47.804 \\
47.804\end{array}$ & $\begin{array}{l}-102.000 \\
-102.065 \\
-102.076 \\
-102.080 \\
-102.087\end{array}$ & $\begin{array}{l}614.22 \\
628.93 \\
624.99 \\
623.34 \\
623.72\end{array}$ & $\begin{array}{r}-2.022 \\
-.396 \\
.079 \\
-.146 \\
-.032\end{array}$ & $\begin{array}{r}-3.473 \\
-1.461 \\
-.722 \\
-1.236 \\
-1.120\end{array}$ \\
\hline
\end{tabular}


Table B. Latitude, longitude, altitude, Bouguer gravity, and residual gravity values--Continued

[Latitude and longinde values are in decimal degrees; the negative sign of the longinde is the convention referencing longitude west of the prime meridian; altizade is in meters above sea level; the Bouguer gravity values and residual gravity values are in the units of milligals]

\begin{tabular}{|c|c|c|c|c|}
\hline Latitude & Longitude & Altitude & Bouguer gravity & Residı lai gravity \\
\hline $\begin{array}{l}47.804 \\
47.804 \\
47.804 \\
47.804 \\
47.804\end{array}$ & $\begin{array}{l}-102.092 \\
-102.097 \\
-102.102 \\
-102.108 \\
-102.113\end{array}$ & $\begin{array}{l}627.88 \\
629.33 \\
622.59 \\
628.24 \\
630.36\end{array}$ & $\begin{array}{r}0.036 \\
.175 \\
.350 \\
.644 \\
.642\end{array}$ & $\begin{array}{r}-1.077 \\
-.823 \\
-.551 \\
-.085 \\
-.182\end{array}$ \\
\hline $\begin{array}{l}47.804 \\
47.804 \\
47.804 \\
47.804 \\
47.804\end{array}$ & $\begin{array}{l}-102.129 \\
-102.137 \\
-102.140 \\
-102.145 \\
-102.156\end{array}$ & $\begin{array}{l}633.55 \\
629.55 \\
633.94 \\
637.73 \\
631.72\end{array}$ & $\begin{array}{r}.348 \\
2.200 \\
2.262 \\
2.075 \\
2.139\end{array}$ & $\begin{array}{l}-.930 \\
2.698 \\
2.720 \\
2.268 \\
2.312\end{array}$ \\
\hline $\begin{array}{l}47.804 \\
47.804 \\
47.804 \\
47.804 \\
47.804\end{array}$ & $\begin{array}{l}-102.161 \\
-102.166 \\
-102.178 \\
-102.183 \\
-102.188\end{array}$ & $\begin{array}{l}630.84 \\
642.72 \\
634.88 \\
633.74 \\
631.59\end{array}$ & $\begin{array}{l}2.399 \\
3.301 \\
2.397 \\
2.642 \\
3.069\end{array}$ & $\begin{array}{l}2.784 \\
4.541 \\
2.636 \\
3.039 \\
3.869\end{array}$ \\
\hline $\begin{array}{l}47.804 \\
47.804 \\
47.804 \\
47.804 \\
47.804\end{array}$ & $\begin{array}{l}-102.193 \\
-102.199 \\
-102.204 \\
-102.210 \\
-102.220\end{array}$ & $\begin{array}{l}625.91 \\
624.83 \\
622.55 \\
622.06 \\
619.09\end{array}$ & $\begin{array}{l}3.306 \\
3.368 \\
3.279 \\
3.137 \\
3.169\end{array}$ & $\begin{array}{l}4.289 \\
4.395 \\
4.142 \\
3.836 \\
3.809\end{array}$ \\
\hline $\begin{array}{l}47.804 \\
47.819 \\
47.819 \\
47.819 \\
47.819\end{array}$ & $\begin{array}{l}-102.225 \\
-102.047 \\
-102.053 \\
-102.057 \\
-102.065\end{array}$ & $\begin{array}{l}614.78 \\
616.68 \\
621.24 \\
627.09 \\
637.67\end{array}$ & $\begin{array}{r}3.077 \\
.634 \\
.734 \\
1.027 \\
1.188\end{array}$ & $\begin{array}{r}3.592 \\
.557 \\
.670 \\
1.174 \\
1.345\end{array}$ \\
\hline $\begin{array}{l}47.819 \\
47.819 \\
47.819 \\
47.819 \\
47.819\end{array}$ & $\begin{array}{l}-102.070 \\
-102.075 \\
-102.080 \\
-102.092 \\
-102.098\end{array}$ & $\begin{array}{l}634.25 \\
633.02 \\
639.72 \\
651.66 \\
647.37\end{array}$ & $\begin{array}{l}1.700 \\
1.849 \\
2.012 \\
2.215 \\
2.581\end{array}$ & $\begin{array}{l}2.304 \\
2.549 \\
2.738 \\
2.971 \\
3.664\end{array}$ \\
\hline $\begin{array}{l}47.819 \\
47.819 \\
47.819 \\
47.819 \\
47.819\end{array}$ & $\begin{array}{l}-102.114 \\
-102.117 \\
-102.220 \\
-102.226 \\
-102.231\end{array}$ & $\begin{array}{l}646.82 \\
648.86 \\
628.57 \\
619.88 \\
611.59\end{array}$ & $\begin{array}{l}2.743 \\
3.195 \\
3.361 \\
3.421 \\
3.513\end{array}$ & $\begin{array}{l}3.745 \\
4.610 \\
4.028 \\
4.063 \\
4.230\end{array}$ \\
\hline $\begin{array}{l}47.833 \\
47.833 \\
47.833 \\
47.833 \\
47.833\end{array}$ & $\begin{array}{l}-101.824 \\
-101.836 \\
-101.845 \\
-101.850 \\
-101.855\end{array}$ & $\begin{array}{l}662.79 \\
662.90 \\
662.17 \\
662.60 \\
661.96\end{array}$ & $\begin{array}{l}-4.089 \\
-4.206 \\
-3.565 \\
-3.570 \\
-3.339\end{array}$ & $\begin{array}{l}-3.637 \\
-4.281 \\
-3.256 \\
-3.444 \\
-3.116\end{array}$ \\
\hline $\begin{array}{l}47.833 \\
47.833 \\
47.833 \\
47.833 \\
47.833\end{array}$ & $\begin{array}{l}-101.861 \\
-101.872 \\
-101.877 \\
-101.883 \\
-101.899\end{array}$ & $\begin{array}{l}662.53 \\
661.77 \\
660.10 \\
658.95 \\
656.23\end{array}$ & $\begin{array}{l}-3.315 \\
-3.329 \\
-3.061 \\
-3.179 \\
-2.637\end{array}$ & $\begin{array}{l}-3.233 \\
-3.597 \\
-3.225 \\
-3.664 \\
-2.985\end{array}$ \\
\hline $\begin{array}{l}47.833 \\
47.833 \\
47.833 \\
47.833 \\
47.832\end{array}$ & $\begin{array}{l}-101.904 \\
-101.915 \\
-101.919 \\
-101.925 \\
-101.936\end{array}$ & $\begin{array}{l}652.42 \\
649.97 \\
643.67 \\
644.65 \\
634.11\end{array}$ & $\begin{array}{l}-2.257 \\
-2.232 \\
-2.460 \\
-2.383 \\
-2.217\end{array}$ & $\begin{array}{l}-2.357 \\
-2.595 \\
-3.129 \\
-3.147 \\
-3.086\end{array}$ \\
\hline
\end{tabular}


Table 8. Latitude, longitude, altitude, Bouguer gravity, and residual gravity values--Continued

[Latitude and longitude values are in decimal degrees; the negative sign of the longinde is the convention referencing longitude west of the prime meridian; altitude is in meters above sea level; the Bouguer gravity values and residual gravity values are in the units of milligal ?

\begin{tabular}{|c|c|c|c|c|}
\hline Latitude & Longltude & Altitude & Bouguer gravity & Realdual gravlt" \\
\hline $\begin{array}{l}47.833 \\
47.833 \\
47.833 \\
47.833 \\
47.833\end{array}$ & $\begin{array}{l}-101.947 \\
-101.980 \\
-101.985 \\
-101.990 \\
-101.994\end{array}$ & $\begin{array}{l}627.98 \\
621.49 \\
627.53 \\
622.87 \\
622.59\end{array}$ & $\begin{array}{r}-2.175 \\
-.187 \\
.953 \\
-.250 \\
-.063\end{array}$ & $\begin{array}{r}-3.301 \\
-.083 \\
2.078 \\
-.443 \\
-.145\end{array}$ \\
\hline $\begin{array}{l}47.833 \\
47.833 \\
47.833 \\
47.833 \\
47.833\end{array}$ & $\begin{array}{l}-102.000 \\
-102.059 \\
-102.072 \\
-102.102 \\
-102.108\end{array}$ & $\begin{array}{l}619.64 \\
626.18 \\
645.91 \\
648.16 \\
656.13\end{array}$ & $\begin{array}{l}. .066 \\
1.472 \\
2.967 \\
2.844 \\
2.926\end{array}$ & $\begin{array}{l}-.244 \\
1.752 \\
4.492 \\
3.839 \\
3.894\end{array}$ \\
\hline $\begin{array}{l}47.833 \\
47.833 \\
47.833 \\
47.833 \\
47.833\end{array}$ & $\begin{array}{l}-102.118 \\
-102.129 \\
-102.135 \\
-102.145 \\
-102.151\end{array}$ & $\begin{array}{l}658.01 \\
673.18 \\
671.32 \\
669.04 \\
666.59\end{array}$ & $\begin{array}{l}3.449 \\
3.455 \\
4.193 \\
3.288 \\
3.464\end{array}$ & $\begin{array}{l}4.854 \\
4.731 \\
6.120 \\
4.232 \\
4.492\end{array}$ \\
\hline $\begin{array}{l}47.833 \\
47.833 \\
47.833 \\
47.833 \\
47.833\end{array}$ & $\begin{array}{l}-102.156 \\
-102.161 \\
-102.166 \\
-102.172 \\
-102.178\end{array}$ & $\begin{array}{l}654.89 \\
653.42 \\
654.26 \\
657.04 \\
658.08\end{array}$ & $\begin{array}{l}3.720 \\
3.668 \\
3.644 \\
3.813 \\
3.570\end{array}$ & $\begin{array}{l}4.979 \\
4.820 \\
4.711 \\
5.017 \\
4.492\end{array}$ \\
\hline $\begin{array}{l}47.833 \\
47.833 \\
47.833 \\
47.833 \\
47.833\end{array}$ & $\begin{array}{l}-102.183 \\
-102.188 \\
-102.194 \\
-102.199 \\
-102.204\end{array}$ & $\begin{array}{l}655.83 \\
654.61 \\
647.59 \\
644.08 \\
647.67\end{array}$ & $\begin{array}{l}3.657 \\
3.676 \\
3.960 \\
4.026 \\
3.944\end{array}$ & $\begin{array}{l}4.603 \\
4.612 \\
5.166 \\
5.259 \\
5.086\end{array}$ \\
\hline $\begin{array}{l}47.833 \\
47.833 \\
47.862 \\
47.862 \\
47.862\end{array}$ & $\begin{array}{l}-102.210 \\
-102.215 \\
-101.894 \\
-101.964 \\
-101.969\end{array}$ & $\begin{array}{l}643.47 \\
638.30 \\
658.00 \\
646.75 \\
644.63\end{array}$ & $\begin{array}{r}3.827 \\
3.775 \\
-1.826 \\
-.438 \\
-.314\end{array}$ & $\begin{array}{r}4.775 \\
4.651 \\
-2.031 \\
-.899 \\
-.752\end{array}$ \\
\hline $\begin{array}{l}47.862 \\
47.862 \\
47.862 \\
47.862 \\
47.862\end{array}$ & $\begin{array}{l}-101.974 \\
-101.980 \\
-101.985 \\
-101.990 \\
-101.995\end{array}$ & $\begin{array}{l}643.40 \\
641.00 \\
638.28 \\
622.75 \\
631.72\end{array}$ & $\begin{array}{l}. .136 \\
.030 \\
.136 \\
.275 \\
.071\end{array}$ & $\begin{array}{l}-.543 \\
-.317 \\
-.194 \\
-.053 \\
-.575\end{array}$ \\
\hline $\begin{array}{l}47.862 \\
47.862 \\
47.862 \\
47.862 \\
47.862\end{array}$ & $\begin{array}{l}-102.001 \\
-102.006 \\
-102.011 \\
-102.017 \\
-102.022\end{array}$ & $\begin{array}{l}637.20 \\
634.49 \\
630.54 \\
629.93 \\
632.41\end{array}$ & $\begin{array}{l}.368 \\
.450 \\
.448 \\
.577 \\
.769\end{array}$ & $\begin{array}{l}-.026 \\
-.002 \\
-.082 \\
.075 \\
.332\end{array}$ \\
\hline $\begin{array}{l}47.862 \\
47.862 \\
47.862 \\
47.862 \\
47.862\end{array}$ & $\begin{array}{l}-102.028 \\
-102.033 \\
-102.038 \\
-102.050 \\
-102.055\end{array}$ & $\begin{array}{l}632.15 \\
630.09 \\
632.47 \\
643.47 \\
652.61\end{array}$ & $\begin{array}{l}.834 \\
.967 \\
1.171 \\
1.457 \\
1.457\end{array}$ & $\begin{array}{r}.389 \\
.563 \\
.901 \\
1.281 \\
1.218\end{array}$ \\
\hline $\begin{array}{l}47.862 \\
47.862 \\
47.862 \\
47.862 \\
47.862\end{array}$ & $\begin{array}{l}-102.060 \\
-102.065 \\
-102.071 \\
-102.076 \\
-102.081\end{array}$ & $\begin{array}{l}662.36 \\
663.72 \\
660.10 \\
660.36 \\
655.41\end{array}$ & $\begin{array}{l}1.882 \\
1.908 \\
2.323 \\
2.780 \\
2.838\end{array}$ & $\begin{array}{l}1.989 \\
1.955 \\
2.724 \\
3.576 \\
3.606\end{array}$ \\
\hline
\end{tabular}


Table 8. Latitude, longitude, aititude, Bouguer gravity, and residual gravity values-Continued

[Latitude and longiude values are in decimal degrees; the negative sign of the longitude is the convention referencing longitude west of the prime meridian; altitude is in uneters above sea level; the Bouguer gravity values and residual gravity values are in the units of milligals]

\begin{tabular}{|c|c|c|c|c|}
\hline Latitude & Longltude & Altitude & Bouguer gravity & Residual gravity \\
\hline $\begin{array}{l}47.862 \\
47.862 \\
47.862 \\
47.862 \\
47.862\end{array}$ & $\begin{array}{l}-102.097 \\
-102.102 \\
-102.123 \\
-102.140 \\
-102.145\end{array}$ & $\begin{array}{l}659.38 \\
660.99 \\
669.06 \\
669.03 \\
667.55\end{array}$ & $\begin{array}{l}3.029 \\
3.428 \\
3.873 \\
3.731 \\
3.884\end{array}$ & $\begin{array}{l}3.761 \\
4.551 \\
5.173 \\
4.727 \\
4.963\end{array}$ \\
\hline $\begin{array}{l}47.862 \\
47.862 \\
47.862 \\
47.862 \\
47.862\end{array}$ & $\begin{array}{l}-102.156 \\
-102.161 \\
-102.167 \\
-102.172 \\
-102.178\end{array}$ & $\begin{array}{l}671.82 \\
676.93 \\
677.99 \\
678.81 \\
680.62\end{array}$ & $\begin{array}{l}4.091 \\
4.136 \\
4.152 \\
4.266 \\
4.222\end{array}$ & $\begin{array}{l}5.295 \\
5.338 \\
5.363 \\
5.542 \\
5.401\end{array}$ \\
\hline $\begin{array}{l}47.862 \\
47.862 \\
47.862 \\
47.862 \\
47.862\end{array}$ & $\begin{array}{l}-102.183 \\
-102.188 \\
-102.199 \\
-102.205 \\
-102.211\end{array}$ & $\begin{array}{l}681.14 \\
681.11 \\
675.35 \\
676.80 \\
678.81\end{array}$ & $\begin{array}{l}4.347 \\
4.324 \\
5.005 \\
4.767 \\
4.807\end{array}$ & $\begin{array}{l}5.651 \\
5.590 \\
6866 \\
6.351 \\
6439\end{array}$ \\
\hline $\begin{array}{l}47.877 \\
47.877 \\
47.877 \\
47.877 \\
47.877\end{array}$ & $\begin{array}{l}-101.834 \\
-101.839 \\
-101.845 \\
-101.850 \\
-101.855\end{array}$ & $\begin{array}{l}660.66 \\
655.76 \\
655.93 \\
653.85 \\
653.32\end{array}$ & $\begin{array}{l}-3.433 \\
-3.253 \\
-3.223 \\
-3.006 \\
-2.860\end{array}$ & $\begin{array}{l}-3.961 \\
-3709 \\
-3.835 \\
-3558 \\
-3412\end{array}$ \\
\hline $\begin{array}{l}47.877 \\
47.877 \\
47.877 \\
47.877 \\
47.877\end{array}$ & $\begin{array}{l}-101.861 \\
-101.866 \\
-101.872 \\
-101.878 \\
-101.883\end{array}$ & $\begin{array}{l}654.83 \\
653.25 \\
654.61 \\
652.16 \\
650.53\end{array}$ & $\begin{array}{l}-2.623 \\
-1.879 \\
-1.783 \\
-1.546 \\
-1.424\end{array}$ & $\begin{array}{l}-3.079 \\
-1.747 \\
-1.697 \\
-1.378 \\
-1.274\end{array}$ \\
\hline $\begin{array}{l}47.877 \\
47.877 \\
47.877 \\
47.877 \\
47.877\end{array}$ & $\begin{array}{l}-101.888 \\
-101.899 \\
-101.904 \\
-101.910 \\
-101.921\end{array}$ & $\begin{array}{l}653.44 \\
654.28 \\
652.20 \\
654.19 \\
649.30\end{array}$ & $\begin{array}{r}-1.246 \\
-1.120 \\
-1.023 \\
-.953 \\
-2.520\end{array}$ & $\begin{array}{l}-1.043 \\
-1.104 \\
-1.020 \\
-1.068 \\
-4.453\end{array}$ \\
\hline $\begin{array}{l}47.877 \\
47.877 \\
47.877 \\
47.877 \\
47.877\end{array}$ & $\begin{array}{l}-101.926 \\
-101.936 \\
-101.942 \\
-101.947 \\
-101.953\end{array}$ & $\begin{array}{l}644.79 \\
643.62 \\
644.33 \\
648.69 \\
652.50\end{array}$ & $\begin{array}{r}-2.222 \\
-4.681 \\
-4.468 \\
-4.626 \\
-4.507\end{array}$ & $\begin{array}{l}-3.953 \\
-9.123 \\
-8800 \\
-9.232 \\
-9.105\end{array}$ \\
\hline $\begin{array}{l}47.877 \\
47.877 \\
47.877 \\
47.877 \\
47.877\end{array}$ & $\begin{array}{l}-101.958 \\
-101.963 \\
-101.969 \\
-101.975 \\
-101.980\end{array}$ & $\begin{array}{l}651.50 \\
648.57 \\
647.99 \\
645.07 \\
643.12\end{array}$ & $\begin{array}{l}.159 \\
.346 \\
.390 \\
-.286 \\
-.687\end{array}$ & $\begin{array}{r}.093 \\
.351 \\
.349 \\
-1.129 \\
-2.027\end{array}$ \\
\hline $\begin{array}{l}47.877 \\
47.877 \\
47.877 \\
47.877 \\
47.877\end{array}$ & $\begin{array}{l}-101.985 \\
-101.990 \\
-102.000 \\
-102.006 \\
-102.011\end{array}$ & $\begin{array}{l}631.01 \\
632.75 \\
644.95 \\
637.83 \\
640.63\end{array}$ & $\begin{array}{r}.066 \\
-.014 \\
-.384 \\
.280 \\
-.337\end{array}$ & $\begin{array}{r}-.660 \\
-.900 \\
-1.852 \\
-.612 \\
-1.911\end{array}$ \\
\hline $\begin{array}{l}47.877 \\
47.877 \\
47.877 \\
47.877 \\
47.877\end{array}$ & $\begin{array}{l}-102.017 \\
-102.022 \\
-102.027 \\
-102.032 \\
-102.039\end{array}$ & $\begin{array}{l}641.16 \\
636.73 \\
637.75 \\
638.79 \\
635.85\end{array}$ & $\begin{array}{r}.283 \\
.677 \\
-.049 \\
.787 \\
.917\end{array}$ & $\begin{array}{r}-.806 \\
-.115 \\
-1.647 \\
-.006 \\
.114\end{array}$ \\
\hline
\end{tabular}


Table 8. Latitude, longitude, aititude, Bouguer gravity, and residual gravity values--Continued

[Latitude and longitude values are in decimal degrees; the negative sign of the longitude is the convention referencing longitude west of the prime meridian; altitude is in meters above sea level; the Bouguer gravity values and residual gravity values are in the units of milligals]

\begin{tabular}{|c|c|c|c|c|}
\hline Lattiude & Longitude & Aititude & Bouguer gravity & Reeldual grav'ty \\
\hline $\begin{array}{l}47.877 \\
47.877 \\
47.877 \\
47.877 \\
47.877\end{array}$ & $\begin{array}{l}-102.043 \\
-102.049 \\
-102.054 \\
-102.061 \\
-102.065\end{array}$ & $\begin{array}{l}640.63 \\
640.63 \\
649.72 \\
661.60 \\
667.41\end{array}$ & $\begin{array}{l}1.030 \\
1.118 \\
1.008 \\
1.102 \\
1.131\end{array}$ & $\begin{array}{r}0.288 \\
.374 \\
.109 \\
.179 \\
.177\end{array}$ \\
\hline $\begin{array}{l}47.877 \\
47.877 \\
47.877 \\
47.877 \\
47.877\end{array}$ & $\begin{array}{l}-102.070 \\
-102.075 \\
-102.082 \\
-102.086 \\
-102.091\end{array}$ & $\begin{array}{l}661.71 \\
656.69 \\
652.10 \\
655.87 \\
659.88\end{array}$ & $\begin{array}{l}1.401 \\
1.574 \\
2.592 \\
1.786 \\
2.639\end{array}$ & $\begin{array}{r}.645 \\
.911 \\
2.887 \\
1.180 \\
2.820\end{array}$ \\
\hline $\begin{array}{l}47.877 \\
47.877 \\
47.877 \\
47.877 \\
47.877\end{array}$ & $\begin{array}{l}-102.097 \\
-102.104 \\
-102.113 \\
-102.119 \\
-102.124\end{array}$ & $\begin{array}{l}658.95 \\
659.83 \\
660.35 \\
658.02 \\
657.55\end{array}$ & $\begin{array}{l}2.398 \\
3.229 \\
3.573 \\
4.475 \\
4.551\end{array}$ & $\begin{array}{l}2.310 \\
3.910 \\
4.436 \\
6.240 \\
6.335\end{array}$ \\
\hline $\begin{array}{l}47.891 \\
47.891 \\
47.891 \\
47.891 \\
47.891\end{array}$ & $\begin{array}{l}-101.834 \\
-101.839 \\
-101.845 \\
-101.850 \\
-101.856\end{array}$ & $\begin{array}{l}652.81 \\
649.65 \\
649.29 \\
650.78 \\
648.28\end{array}$ & $\begin{array}{l}-2.859 \\
-2.107 \\
-1.977 \\
-1.869 \\
-1.778\end{array}$ & $\begin{array}{l}-3.179 \\
-1.830 \\
-1.750 \\
-1.633 \\
-1.631\end{array}$ \\
\hline $\begin{array}{l}47.891 \\
47.891 \\
47.891 \\
47.891 \\
47.891\end{array}$ & $\begin{array}{l}-101.861 \\
-101.872 \\
-101.877 \\
-101.883 \\
-101.888\end{array}$ & $\begin{array}{l}649.06 \\
656.02 \\
651.94 \\
651.23 \\
649.05\end{array}$ & $\begin{array}{r}-1.504 \\
-1.186 \\
-.928 \\
-.842 \\
-.733\end{array}$ & $\begin{array}{r}-1.225 \\
-.898 \\
-.471 \\
-.479 \\
-.378\end{array}$ \\
\hline $\begin{array}{l}47.891 \\
47.891 \\
47.891 \\
47.891 \\
47.891\end{array}$ & $\begin{array}{l}-101.894 \\
-101.899 \\
-101.904 \\
-101.910 \\
-101.920\end{array}$ & $\begin{array}{l}648.91 \\
649.49 \\
649.15 \\
650.56 \\
644.67\end{array}$ & $\begin{array}{l}-.628 \\
-.517 \\
-.493 \\
-.389 \\
-.194\end{array}$ & $\begin{array}{l}-.353 \\
-.264 \\
-.284 \\
-.264 \\
-.102\end{array}$ \\
\hline $\begin{array}{l}47.891 \\
47.891 \\
47.891 \\
47.891 \\
47.891\end{array}$ & $\begin{array}{l}-101.926 \\
-101.931 \\
-101.937 \\
-101.942 \\
-101.953\end{array}$ & $\begin{array}{l}645.64 \\
650.60 \\
651.38 \\
650.66 \\
649.92\end{array}$ & $\begin{array}{l}-.062 \\
.016 \\
.053 \\
.451 \\
.630\end{array}$ & $\begin{array}{l}.014 \\
.102 \\
.004 \\
.698 \\
.877\end{array}$ \\
\hline $\begin{array}{l}47.891 \\
47.891 \\
47.891 \\
47.891 \\
47.891\end{array}$ & $\begin{array}{l}-102.134 \\
-102.141 \\
-102.146 \\
-102.156 \\
-102.161\end{array}$ & $\begin{array}{l}654.06 \\
654.97 \\
655.65 \\
657.47 \\
658.15\end{array}$ & $\begin{array}{l}5.388 \\
5.082 \\
5.445 \\
5.166 \\
5.185\end{array}$ & $\begin{array}{l}7.752 \\
7.046 \\
7.733 \\
7.152 \\
7.151\end{array}$ \\
\hline $\begin{array}{l}47.891 \\
47.891 \\
47.891 \\
47.891 \\
47.891\end{array}$ & $\begin{array}{l}-102.166 \\
-102.171 \\
-102.177 \\
-102.182 \\
-102.188\end{array}$ & $\begin{array}{l}663.49 \\
664.13 \\
663.34 \\
661.74 \\
657.24\end{array}$ & $\begin{array}{l}5.115 \\
5.144 \\
5.074 \\
5.104 \\
4.960\end{array}$ & $\begin{array}{l}6.993 \\
6.983 \\
6.825 \\
6.854 \\
6.574\end{array}$ \\
\hline $\begin{array}{l}47.891 \\
47.891 \\
47.891 \\
47.891 \\
47.891\end{array}$ & $\begin{array}{l}-102.199 \\
-102.205 \\
-102.210 \\
-102.221 \\
-102.226\end{array}$ & $\begin{array}{l}660.27 \\
654.65 \\
658.17 \\
648.22 \\
649.80\end{array}$ & $\begin{array}{l}4.630 \\
4.588 \\
4.422 \\
4.177 \\
3.778\end{array}$ & $\begin{array}{l}5.821 \\
5.719 \\
5.426 \\
4.868 \\
4.051\end{array}$ \\
\hline
\end{tabular}


Table 8. Latitude, longitude, altitude, Bouguer gravity, and residual gravity values--Continued

[Latitude and longiude values are in decimal degrees; the negative sign of the longinde is the convention referencing longituie west of the prime meridian; altitude is in meters above sea level; the Bouguer gravity values and residual graviry values are in the units of milligals]

\begin{tabular}{|c|c|c|c|c|}
\hline Latitude & Longltude & Altitude & Bouguer gravity & Residıal gravity \\
\hline $\begin{array}{l}47.891 \\
47.891 \\
47.891 \\
47.891 \\
47.906\end{array}$ & $\begin{array}{l}-102.232 \\
-102.242 \\
-102.247 \\
-102.252 \\
-101.834\end{array}$ & $\begin{array}{l}642.62 \\
643.95 \\
643.03 \\
642.42 \\
645.69\end{array}$ & $\begin{array}{r}3.482 \\
3.199 \\
3.250 \\
3.089 \\
-2.312\end{array}$ & $\begin{array}{r}3.442 \\
2.900 \\
3.004 \\
2.687 \\
-2.414\end{array}$ \\
\hline $\begin{array}{l}47.906 \\
47.906 \\
47.906 \\
47.906 \\
47.906\end{array}$ & $\begin{array}{l}-101.839 \\
-101.845 \\
-101.850 \\
-101.856 \\
-101.861\end{array}$ & $\begin{array}{l}643.23 \\
644.77 \\
648.52 \\
645.76 \\
649.15\end{array}$ & $\begin{array}{l}-2.453 \\
-2.336 \\
-2.292 \\
-1.900 \\
-1.861\end{array}$ & $\begin{array}{l}-2.858 \\
-2.803 \\
-2.864 \\
-2.197 \\
-2.268\end{array}$ \\
\hline $\begin{array}{l}47.906 \\
47.906 \\
47.906 \\
47.906 \\
47.905\end{array}$ & $\begin{array}{l}-101.867 \\
-101.872 \\
-101.877 \\
-101.883 \\
-101.889\end{array}$ & $\begin{array}{l}649.95 \\
649.09 \\
648.68 \\
645.04 \\
641.16\end{array}$ & $\begin{array}{l}-1.767 \\
-1.502 \\
-1.543 \\
-1.156 \\
-1.075\end{array}$ & $\begin{array}{l}-2.244 \\
-1.833 \\
-2.020 \\
-1.411 \\
-1.431\end{array}$ \\
\hline $\begin{array}{l}47.905 \\
47.905 \\
47.906 \\
47.906 \\
47.906\end{array}$ & $\begin{array}{l}-101.942 \\
-101.947 \\
-101.953 \\
-101.969 \\
-101.974\end{array}$ & $\begin{array}{l}643.41 \\
642.51 \\
643.04 \\
648.64 \\
646.95\end{array}$ & $\begin{array}{r}.179 \\
.428 \\
.682 \\
-.270 \\
-.028\end{array}$ & $\begin{array}{r}-.103 \\
.278 \\
.670 \\
-1.572 \\
-1.156\end{array}$ \\
\hline $\begin{array}{l}47.906 \\
47.906 \\
47.906 \\
47.906 \\
47.906\end{array}$ & $\begin{array}{l}-101.980 \\
-101.985 \\
-101.990 \\
-102.044 \\
-102.097\end{array}$ & $\begin{array}{l}647.07 \\
645.87 \\
645.99 \\
648.51 \\
641.74\end{array}$ & $\begin{array}{r}-.308 \\
.352 \\
.692 \\
1.132 \\
3.421\end{array}$ & $\begin{array}{r}-1.833 \\
-.574 \\
-.036 \\
.015 \\
3.963\end{array}$ \\
\hline $\begin{array}{l}47.906 \\
47.906 \\
47.906 \\
47.920 \\
47.920\end{array}$ & $\begin{array}{l}-102.114 \\
-102.119 \\
-102.125 \\
-101.947 \\
-101.958\end{array}$ & $\begin{array}{l}640.20 \\
634.10 \\
643.09 \\
645.56 \\
647.34\end{array}$ & $\begin{array}{l}3.405 \\
3.672 \\
3.703 \\
1.309 \\
1.982\end{array}$ & $\begin{array}{l}3.782 \\
4.277 \\
4.282 \\
1.749 \\
2.918\end{array}$ \\
\hline $\begin{array}{l}47.934 \\
47.934 \\
47.934 \\
47.934 \\
47.934\end{array}$ & $\begin{array}{l}-101.829 \\
-101.850 \\
-101.872 \\
-101.878 \\
-101.884\end{array}$ & $\begin{array}{l}642.09 \\
642.83 \\
636.70 \\
636.81 \\
636.85\end{array}$ & $\begin{array}{r}-1.505 \\
-1.178 \\
-.627 \\
-.231 \\
-.356\end{array}$ & $\begin{array}{r}-1.357 \\
-1.221 \\
-.717 \\
-.059 \\
-.435\end{array}$ \\
\hline $\begin{array}{l}47.934 \\
47.934 \\
47.934 \\
47.934 \\
47.934\end{array}$ & $\begin{array}{l}-101.889 \\
-101.899 \\
-101.904 \\
-101.910 \\
-101.931\end{array}$ & $\begin{array}{l}631.56 \\
640.50 \\
641.25 \\
641.49 \\
642.05\end{array}$ & $\begin{array}{r}-.097 \\
.416 \\
.434 \\
.337 \\
1.435\end{array}$ & $\begin{array}{r}-.058 \\
.734 \\
.723 \\
.357 \\
2.093\end{array}$ \\
\hline $\begin{array}{l}47.934 \\
47.949 \\
47.949 \\
47.949 \\
47.949\end{array}$ & $\begin{array}{l}-101.936 \\
-101.824 \\
-101.829 \\
-101.834 \\
-101.839\end{array}$ & $\begin{array}{l}641.89 \\
640.59 \\
639.16 \\
637.73 \\
639.03\end{array}$ & $\begin{array}{r}1.473 \\
-1.236 \\
-1.203 \\
-1.205 \\
-1.197\end{array}$ & $\begin{array}{r}2.113 \\
-.998 \\
-1.080 \\
-1.162 \\
-1.279\end{array}$ \\
\hline $\begin{array}{l}47.949 \\
47.949 \\
47.949 \\
47.949 \\
47.949\end{array}$ & $\begin{array}{l}-101.845 \\
-101.850 \\
-101.857 \\
-101.863 \\
-101.877\end{array}$ & $\begin{array}{l}639.37 \\
638.96 \\
639.32 \\
639.10 \\
632.75\end{array}$ & $\begin{array}{r}-1.129 \\
-1.435 \\
-1.243 \\
-.683 \\
-.378\end{array}$ & $\begin{array}{r}-1.320 \\
-2.060 \\
-1.838 \\
-.851 \\
-.608\end{array}$ \\
\hline
\end{tabular}


Table 8. Latitude, longitude, altitude, Bouguer gravity, and residual gravity values--Continued

[Latitude and longitude values are in decimal degrees; the negative sign of the longitude is the convention referencing longitude west of the prime meridian; altinde is in meters above sea level; the Bouguer gravity values and residual gravity values are in the units of milligals]

\begin{tabular}{|c|c|c|c|c|}
\hline Latitude & Longltude & Aititude & Bouguer gravity & Residual gra \\
\hline $\begin{array}{l}47.949 \\
47.949 \\
47.949 \\
47.949 \\
47.949\end{array}$ & $\begin{array}{l}-101.883 \\
-101.888 \\
-101.893 \\
-101.898 \\
-101.904\end{array}$ & $\begin{array}{l}629.92 \\
630.97 \\
637.14 \\
640.68 \\
640.78\end{array}$ & $\begin{array}{r}-0.203 \\
.031 \\
.176 \\
.263 \\
.435\end{array}$ & $\begin{array}{r}-0.407 \\
.014 \\
.163 \\
.238 \\
.434\end{array}$ \\
\hline $\begin{array}{l}47.949 \\
47.949 \\
47.949 \\
47.949 \\
47.949\end{array}$ & $\begin{array}{l}-101.910 \\
-101.915 \\
-101.920 \\
-101.926 \\
-101.931\end{array}$ & $\begin{array}{l}640.89 \\
640.98 \\
641.51 \\
641.34 \\
640.78\end{array}$ & $\begin{array}{l}.672 \\
.916 \\
1.235 \\
1.585 \\
1.955\end{array}$ & $\begin{array}{l}.758 \\
1.185 \\
1.709 \\
2.276 \\
2.920\end{array}$ \\
\hline $\begin{array}{l}47.949 \\
47.949 \\
47.949 \\
47.949 \\
47.949\end{array}$ & $\begin{array}{l}-101.937 \\
-101.941 \\
-101.947 \\
-101.952 \\
-101.958\end{array}$ & $\begin{array}{l}641.98 \\
641.61 \\
643.38 \\
643.14 \\
642.88\end{array}$ & $\begin{array}{l}2.082 \\
2.128 \\
2.185 \\
2.387 \\
2.597\end{array}$ & $\begin{array}{l}3.018 \\
3.071 \\
3.085 \\
3.396 \\
3.694\end{array}$ \\
\hline $\begin{array}{l}47.949 \\
47.949 \\
47.949 \\
47.949 \\
47.949\end{array}$ & $\begin{array}{l}-101.980 \\
-102.038 \\
-102.044 \\
-102.050 \\
-102.055\end{array}$ & $\begin{array}{l}641.78 \\
630.40 \\
625.21 \\
625.40 \\
620.07\end{array}$ & $\begin{array}{l}2.693 \\
4.494 \\
3.756 \\
4.140 \\
4.053\end{array}$ & $\begin{array}{l}3.531 \\
6.337 \\
4.768 \\
5.440 \\
5.275\end{array}$ \\
\hline $\begin{array}{l}47.949 \\
47.949 \\
47.949 \\
47.949 \\
47.949\end{array}$ & $\begin{array}{l}-102.060 \\
-102.065 \\
-102.076 \\
-102.087 \\
-102.092\end{array}$ & $\begin{array}{l}606.41 \\
608.42 \\
603.21 \\
605.99 \\
594.68\end{array}$ & $\begin{array}{l}4.019 \\
4.036 \\
3.709 \\
3.653 \\
3.555\end{array}$ & $\begin{array}{l}5.143 \\
5.122 \\
4.335 \\
4.154 \\
3.910\end{array}$ \\
\hline $\begin{array}{l}47.949 \\
47.949 \\
47.949 \\
47.949 \\
47.949\end{array}$ & $\begin{array}{l}-102.097 \\
-102.102 \\
-102.108 \\
-102.113 \\
-102.118\end{array}$ & $\begin{array}{l}594.83 \\
608.39 \\
600.03 \\
592.50 \\
595.68\end{array}$ & $\begin{array}{l}2.985 \\
2.877 \\
3.062 \\
3.388 \\
3.382\end{array}$ & $\begin{array}{l}2.731 \\
2.468 \\
2.768 \\
3.421 \\
3.370\end{array}$ \\
\hline $\begin{array}{l}47.949 \\
47.949 \\
47.949 \\
47.949 \\
47.949\end{array}$ & $\begin{array}{l}-102.140 \\
-102.146 \\
-102.156 \\
-102.161 \\
-102.167\end{array}$ & $\begin{array}{l}585.01 \\
584.46 \\
584.75 \\
583.34 \\
583.39\end{array}$ & $\begin{array}{l}4.564 \\
5.260 \\
5.282 \\
2.089 \\
2.127\end{array}$ & $\begin{array}{r}5.617 \\
6.970 \\
6.966 \\
.556 \\
.657\end{array}$ \\
\hline $\begin{array}{l}47.949 \\
47.948 \\
47.963 \\
47.963 \\
47.963\end{array}$ & $\begin{array}{l}-102.183 \\
-102.193 \\
-101.868 \\
-101.872 \\
-101.885\end{array}$ & $\begin{array}{l}583.74 \\
587.91 \\
632.97 \\
635.27 \\
630.97\end{array}$ & $\begin{array}{r}3.281 \\
2.312 \\
-.466 \\
-.648 \\
.147\end{array}$ & $\begin{array}{r}2.877 \\
.966 \\
-.794 \\
-1.229 \\
.072\end{array}$ \\
\hline $\begin{array}{l}47.963 \\
47.963 \\
47.963 \\
47.963 \\
47.963\end{array}$ & $\begin{array}{l}-101.893 \\
-101.899 \\
-101.904 \\
-101.910 \\
-101.920\end{array}$ & $\begin{array}{l}635.88 \\
638.03 \\
640.94 \\
641.72 \\
643.08\end{array}$ & $\begin{array}{r}.519 \\
.564 \\
.966 \\
.780 \\
1.510\end{array}$ & $\begin{array}{r}.561 \\
.603 \\
1.292 \\
.769 \\
2.013\end{array}$ \\
\hline $\begin{array}{l}47.963 \\
47.963 \\
47.963 \\
47.963 \\
47.963\end{array}$ & $\begin{array}{l}-101.926 \\
-101.931 \\
-101.937 \\
-101.942 \\
-101.947\end{array}$ & $\begin{array}{l}641.15 \\
640.09 \\
639.06 \\
639.12 \\
637.51\end{array}$ & $\begin{array}{l}1.698 \\
1.996 \\
2.297 \\
2.443 \\
2.757\end{array}$ & $\begin{array}{l}2.318 \\
2.813 \\
3.262 \\
3.467 \\
3.994\end{array}$ \\
\hline
\end{tabular}


Table 8. Latitude, longitude, altitude, Bouguer gravity, and residual gravity values--Continued

[Latitude and longitude values are in decimal degrees; the negative sign of the longitude is the convention referencing longitude west of the prime meridian; altime is in meters above sea level; the Bouguer gravity values and residual gravity values are in the units of milligals]

\begin{tabular}{|c|c|c|c|c|}
\hline Letitude & Longltude & Altitude & Bouguer gravity & Residuri gravity \\
\hline $\begin{array}{l}47.963 \\
47.963 \\
47.963 \\
47.963 \\
47.963\end{array}$ & $\begin{array}{l}-101.953 \\
-101.964 \\
-101.969 \\
-101.974 \\
-101.980\end{array}$ & $\begin{array}{l}638.39 \\
638.30 \\
637.40 \\
637.63 \\
635.68\end{array}$ & $\begin{array}{l}3.203 \\
3.094 \\
3.829 \\
3.770 \\
3.910\end{array}$ & $\begin{array}{l}4.861 \\
4.416 \\
5.808 \\
5.579 \\
5.810\end{array}$ \\
\hline $\begin{array}{l}47.964 \\
47.963 \\
47.963 \\
47.963 \\
47.963\end{array}$ & $\begin{array}{l}-101.985 \\
-101.990 \\
-101.996 \\
-102.166 \\
-102.176\end{array}$ & $\begin{array}{l}635.63 \\
633.75 \\
630.73 \\
606.93 \\
598.69\end{array}$ & $\begin{array}{l}3.944 \\
3.833 \\
3.894 \\
3.710 \\
3.548\end{array}$ & $\begin{array}{l}5.778 \\
5.491 \\
5.515 \\
3.772 \\
3.430\end{array}$ \\
\hline $\begin{array}{l}47.963 \\
47.963 \\
47.963 \\
47.963 \\
47.978\end{array}$ & $\begin{array}{l}-102.182 \\
-102.188 \\
-102.197 \\
-102.203 \\
-101.872\end{array}$ & $\begin{array}{l}596.92 \\
594.37 \\
584.87 \\
582.29 \\
632.42\end{array}$ & $\begin{array}{l}3.440 \\
3.170 \\
3.369 \\
3.568 \\
-.014\end{array}$ & $\begin{array}{l}3.190 \\
2.673 \\
3.062 \\
3.446 \\
.230\end{array}$ \\
\hline $\begin{array}{l}47.978 \\
47.978 \\
47.978 \\
47.978 \\
47.978\end{array}$ & $\begin{array}{l}-101.878 \\
-101.889 \\
-101.893 \\
-101.899 \\
-101.905\end{array}$ & $\begin{array}{l}637.51 \\
638.83 \\
639.77 \\
639.01 \\
638.19\end{array}$ & $\begin{array}{r}.135 \\
.524 \\
.641 \\
.894 \\
3.476\end{array}$ & $\begin{array}{r}.036 \\
.485 \\
.627 \\
1.008 \\
6.086\end{array}$ \\
\hline $\begin{array}{l}47.978 \\
47.978 \\
47.978 \\
47.978 \\
47.978\end{array}$ & $\begin{array}{l}-101.911 \\
-101.916 \\
-101.921 \\
-101.927 \\
-101.932\end{array}$ & $\begin{array}{l}637.18 \\
636.75 \\
624.69 \\
627.25 \\
627.00\end{array}$ & $\begin{array}{l}1.392 \\
1.545 \\
1.809 \\
1.978 \\
2.103\end{array}$ & $\begin{array}{l}1.789 \\
1.991 \\
2.444 \\
2.657 \\
2.784\end{array}$ \\
\hline $\begin{array}{l}47.980 \\
47.981 \\
47.981 \\
47.979 \\
47.978\end{array}$ & $\begin{array}{l}-101.936 \\
-101.942 \\
-101.947 \\
-101.953 \\
-101.963\end{array}$ & $\begin{array}{l}621.77 \\
622.35 \\
630.68 \\
631.88 \\
634.36\end{array}$ & $\begin{array}{l}2.309 \\
1.638 \\
1.950 \\
2.603 \\
3.961\end{array}$ & $\begin{array}{l}3.104 \\
1.690 \\
2.236 \\
3.425 \\
6.019\end{array}$ \\
\hline $\begin{array}{l}47.978 \\
47.978 \\
47.978 \\
47.978 \\
47.978\end{array}$ & $\begin{array}{l}-101.969 \\
-101.979 \\
-101.985 \\
-101.990 \\
-101.996\end{array}$ & $\begin{array}{l}634.32 \\
633.99 \\
625.66 \\
630.12 \\
632.42\end{array}$ & $\begin{array}{l}4.172 \\
2.990 \\
5.053 \\
5.236 \\
1.565\end{array}$ & $\begin{array}{r}6.353 \\
3.812 \\
7.875 \\
8.171 \\
.735\end{array}$ \\
\hline $\begin{array}{l}47.978 \\
47.978 \\
47.978 \\
47.978 \\
47.978\end{array}$ & $\begin{array}{l}-102.006 \\
-102.011 \\
-102.016 \\
-102.022 \\
-102.027\end{array}$ & $\begin{array}{l}626.11 \\
627.78 \\
628.26 \\
611.81 \\
615.84\end{array}$ & $\begin{array}{l}1.815 \\
1.977 \\
1.966 \\
2.111 \\
1.894\end{array}$ & $\begin{array}{l}1.071 \\
1.340 \\
1.261 \\
1.516 \\
1.016\end{array}$ \\
\hline $\begin{array}{l}47.978 \\
47.978 \\
47.978 \\
47.978 \\
47.978\end{array}$ & $\begin{array}{l}-102.033 \\
-102.038 \\
-102.049 \\
-102.054 \\
-102.059\end{array}$ & $\begin{array}{l}628.61 \\
629.67 \\
627.61 \\
623.48 \\
619.76\end{array}$ & $\begin{array}{l}1.774 \\
1.792 \\
1.994 \\
2.914 \\
2.938\end{array}$ & $\begin{array}{r}.743 \\
.692 \\
.964 \\
2.777 \\
2.768\end{array}$ \\
\hline $\begin{array}{l}47.978 \\
47.978 \\
47.978 \\
47.978 \\
47.978\end{array}$ & $\begin{array}{l}-102.065 \\
-102.070 \\
-102.076 \\
-102.081 \\
-102.183\end{array}$ & $\begin{array}{l}618.33 \\
618.28 \\
617.98 \\
620.52 \\
605.14\end{array}$ & $\begin{array}{l}3.179 \\
1.918 \\
1.848 \\
1.925 \\
4.261\end{array}$ & $\begin{array}{r}3.232 \\
.621 \\
.471 \\
.570 \\
4.850\end{array}$ \\
\hline
\end{tabular}


Table 8. Latitude, longitude, aititude, Bouguer gravity, and residual gravity values--Continued

Thatiude and longitude values are in decimal degrees; the negative sign of the longitude is the convention referencing longitude west of the prime meridian; altínde is in meters above sea level; the Bouguer gravity values and residual gravity values are in the units of milligals'.

\begin{tabular}{|c|c|c|c|c|}
\hline Letltude & Longltude & Altltude & Bouguer gravlty & Resldual gravity \\
\hline $\begin{array}{l}47.978 \\
47.978 \\
47.978 \\
47.978 \\
47.978\end{array}$ & $\begin{array}{l}-102.188 \\
-102.199 \\
-102.204 \\
-102.210 \\
-102.221\end{array}$ & $\begin{array}{l}603.24 \\
594.46 \\
597.64 \\
594.91 \\
579.34\end{array}$ & $\begin{array}{l}3.420 \\
4.336 \\
5.796 \\
5.095 \\
2.780\end{array}$ & $\begin{array}{l}3.184 \\
4.998 \\
7.919 \\
6.569 \\
1.932\end{array}$ \\
\hline $\begin{array}{l}47.978 \\
47.978 \\
47.978 \\
47.978 \\
47.978\end{array}$ & $\begin{array}{l}-102.226 \\
-102.231 \\
-102.237 \\
-102.242 \\
-102.247\end{array}$ & $\begin{array}{l}573.24 \\
576.18 \\
572.96 \\
572.98 \\
573.09\end{array}$ & $\begin{array}{r}1.666 \\
1.724 \\
1.057 \\
.987 \\
.857\end{array}$ & $\begin{array}{r}-.305 \\
-.183 \\
-1.527 \\
-1.581 \\
-1.878\end{array}$ \\
\hline $\begin{array}{l}47.978 \\
47.978 \\
47.978 \\
47.978 \\
47.978\end{array}$ & $\begin{array}{l}-102.263 \\
-102.268 \\
-102.274 \\
-102.279 \\
-102.284\end{array}$ & $\begin{array}{l}570.22 \\
568.25 \\
567.27 \\
567.35 \\
567.51\end{array}$ & $\begin{array}{l}2.207 \\
2.071 \\
2.028 \\
1.856 \\
1.696\end{array}$ & $\begin{array}{l}.922 \\
.636 \\
.650 \\
.323 \\
.027\end{array}$ \\
\hline $\begin{array}{l}47.978 \\
47.978 \\
47.978 \\
47.978 \\
47.978\end{array}$ & $\begin{array}{l}-102.290 \\
-102.295 \\
-102.300 \\
-102.311 \\
-102.316\end{array}$ & $\begin{array}{l}583.35 \\
587.31 \\
587.26 \\
594.99 \\
604.45\end{array}$ & $\begin{array}{r}1.462 \\
1.295 \\
1.370 \\
1.125 \\
.802\end{array}$ & $\begin{array}{r}-.401 \\
-.711 \\
-.509 \\
-.895 \\
-1.551\end{array}$ \\
\hline $\begin{array}{l}47.978 \\
47.978 \\
47.978 \\
47.642 \\
47.639\end{array}$ & $\begin{array}{l}-102.322 \\
-102.328 \\
-102.332 \\
-101.844 \\
-101.844\end{array}$ & $\begin{array}{l}608.49 \\
610.70 \\
614.13 \\
618.39 \\
620.04\end{array}$ & $\begin{array}{r}.608 \\
.354 \\
.333 \\
-11.465 \\
-10.526\end{array}$ & $\begin{array}{r}-1.856 \\
-2.270 \\
-2.273 \\
-11.167 \\
-9.120\end{array}$ \\
\hline $\begin{array}{l}47.635 \\
47.632 \\
47.629 \\
47.625 \\
47.622\end{array}$ & $\begin{array}{l}-101.844 \\
-101.844 \\
-101.844 \\
-101.844 \\
-101.844\end{array}$ & $\begin{array}{l}614.87 \\
613.91 \\
616.13 \\
615.88 \\
627.58\end{array}$ & $\begin{array}{r}-9.875 \\
-10.061 \\
-10.393 \\
-13.100 \\
-9.588\end{array}$ & $\begin{array}{r}-7.663 \\
-7.850 \\
-8.341 \\
-13.569 \\
-6.321\end{array}$ \\
\hline $\begin{array}{l}47.617 \\
47.614 \\
47.610 \\
47.607 \\
47.603\end{array}$ & $\begin{array}{l}-101.844 \\
-101.844 \\
-101.844 \\
-101.844 \\
-101.844\end{array}$ & $\begin{array}{l}625.78 \\
629.85 \\
641.78 \\
633.52 \\
627.52\end{array}$ & $\begin{array}{l}-12.861 \\
-12.964 \\
-12.963 \\
-12.078 \\
-12.176\end{array}$ & $\begin{array}{l}-12.634 \\
-12.685 \\
-12.452 \\
-10.510 \\
-10.506\end{array}$ \\
\hline $\begin{array}{l}47.643 \\
47.639 \\
47.636 \\
47.632 \\
47.891 \\
47.891\end{array}$ & $\begin{array}{l}-101.886 \\
-101.886 \\
-101.887 \\
-101.886 \\
-102.097 \\
-102.103\end{array}$ & $\begin{array}{l}619.60 \\
615.07 \\
628.38 \\
628.51 \\
649.35 \\
650.09\end{array}$ & $\begin{array}{r}-7.805 \\
-7.661 \\
-7.656 \\
-7.764 \\
7.813 \\
3.354\end{array}$ & $\begin{array}{r}-5.510 \\
-5.088 \\
-4.933 \\
-4.899 \\
12.962 \\
3.960\end{array}$ \\
\hline
\end{tabular}


Supplement 1. Local numbers and site-identification numbers of wells, test holes, and springs

\begin{tabular}{|c|c|c|c|}
\hline Local number & Site-identification number & Local number & Sito-identiflcation number \\
\hline $\begin{array}{l}146-086-32 \mathrm{AA} \\
146-088-09 \mathrm{CZCD} \\
146-088-10 \mathrm{CBA} \\
146-088-20 \mathrm{CCD} \\
146-088-29 \mathrm{BCA}\end{array}$ & $\begin{array}{l}472526101392201 \\
472825101541801 \\
472844101530201 \\
472641101553401 \\
472621101553401\end{array}$ & $\begin{array}{l}146-091-01 \mathrm{DDC} \\
146-091-05 \mathrm{ACB} \\
146-091-05 \mathrm{CBB} \\
146-091-08 \mathrm{CAA} \\
146-091-09 \mathrm{BCCC}\end{array}$ & $\begin{array}{l}472918102123401 \\
472951102175901 \\
472938102183701 \\
472846102180801 \\
472849102172401\end{array}$ \\
\hline $\begin{array}{l}146-088-30 D A C \\
146-088-30 D D D \\
146-089-06 \mathrm{BDB} \\
146-089-08 \mathrm{AAB} \\
146-089-09 \mathrm{CCB}\end{array}$ & $\begin{array}{l}472601101560301 \\
472548101555301 \\
472951102041901 \\
472911102022501 \\
472832102020601\end{array}$ & $\begin{array}{l}146-091-11 C B \\
146-091-12 B B D \\
146-091-12 B D B \\
146-091-13 B C A 1 \\
146-091-13 B C A 2\end{array}$ & $\begin{array}{l}472843102144301 \\
472904102131601 \\
472858102131301 \\
472807102132201 \\
472807102132202\end{array}$ \\
\hline $\begin{array}{l}146-089-09 D A C \\
146-089-10 \mathrm{CBD} \\
146-089-15 \mathrm{CDC} \\
146-089-15 \mathrm{DCB} \\
146-089-17 \mathrm{BDC}\end{array}$ & $\begin{array}{l}472839102010801 \\
472838102004001 \\
472733102003001 \\
472740102001102 \\
472800102030301\end{array}$ & $\begin{array}{l}146-091-14 A D C \\
146-091-14 D D B \\
146-091-17 C D C \\
146-091-20 A B A \\
146-091-20 A C A\end{array}$ & $\begin{array}{l}472800102135101 \\
472740102135101 \\
472735102181801 \\
472728102174501 \\
472715102174901\end{array}$ \\
\hline $\begin{array}{l}146-089-20 \mathrm{BBB} \\
146-089-22 \mathrm{DCB} 1 \\
146-089-22 \mathrm{DCB} 2 \\
146-089-24 \mathrm{CBC} \\
146-089-25 \mathrm{AAA}\end{array}$ & $\begin{array}{l}472727102032201 \\
472648102001101 \\
472648102001102 \\
472654101581701 \\
472634101571001\end{array}$ & $\begin{array}{l}\text { 146-091-20DDD1 } \\
\text { 146-091-20DDD2 } \\
\text { 146-091-21CDD1 } \\
\text { 146-091-21CDD2 } \\
\text { 146-091-21DCD }\end{array}$ & $\begin{array}{l}472642102: 73001 \\
472641102.172802 \\
472642102165201 \\
472642104: 65202 \\
472642102163301\end{array}$ \\
\hline $\begin{array}{l}146-089-28 \mathrm{CDB} \\
146-089-30 \mathrm{AAA} \\
146-089-34 \mathrm{BBA} 1 \\
146-089-34 \mathrm{BBA} 2 \\
146-089-35 \mathrm{BBA} 1\end{array}$ & $\begin{array}{l}472556102014601 \\
472635102033101 \\
472542102004001 \\
472542102004002 \\
472542101592301\end{array}$ & $\begin{array}{l}146-091-21 D D C \\
146-091-22 \mathrm{BBA} \\
146-091-22 \mathrm{CBA} \\
146-091-24 \mathrm{BDB} 1 \\
146-091-24 \mathrm{BDB} 2\end{array}$ & $\begin{array}{l}47264210262301 \\
472728102155501 \\
47270210 \approx 155501 \\
47271410 \approx 131201 \\
47271410 \approx 131202\end{array}$ \\
\hline $\begin{array}{l}146-089-35 \mathrm{BBA} 2 \\
146-089-36 \mathrm{BDA} \\
146-090-05 \mathrm{DAA} \\
146-090-07 \mathrm{CAB} \\
146-090-08 \mathrm{BBC}\end{array}$ & $\begin{array}{l}472542101592302 \\
472529101574801 \\
472938102095201 \\
472845102115601 \\
472905102105901\end{array}$ & $\begin{array}{l}146-091-25 A C C \\
146-091-25 D C \\
146-091-26 A A B 1 \\
146-091-26 A A B 2 \\
146-091-26 A A B 3\end{array}$ & $\begin{array}{l}47261310 \AA 125401 \\
472556102124401 \\
472635102135101 \\
472635102135102 \\
47263510 \approx 135103\end{array}$ \\
\hline $\begin{array}{l}146-090-08 C A A \\
146-090-09 \mathrm{CDD} \\
146-090-13 \mathrm{DCA} \\
146-090-13 \mathrm{DCC} 1 \\
146-090-13 \mathrm{DCC} 2\end{array}$ & $\begin{array}{l}472845102103101 \\
472826102091401 \\
472740102050701 \\
472733102051601 \\
472733102051602\end{array}$ & $\begin{array}{l}146-091-28 A B A \\
146-091-28 B B B \\
146-091-30 B C D \\
146-091-31 B A D \\
146-091-31 B D A 1\end{array}$ & $\begin{array}{l}47263610 \AA 163301 \\
47263610 \_172101 \\
47261610 \approx 194401 \\
472537102192501 \\
47253010 \_192601\end{array}$ \\
\hline $\begin{array}{l}146-090-15 \mathrm{BCC} \\
146-090-15 \mathrm{DAA} 1 \\
146-090-15 \mathrm{DAA} 2 \\
146-090-18 \mathrm{CDD} 1 \\
146-090-18 \mathrm{CDD} 2\end{array}$ & $\begin{array}{l}472759102082701 \\
472753102072001 \\
472753102072002 \\
472733102114701 \\
472733102114702\end{array}$ & $\begin{array}{l}146-091-31 B D A 2 \\
146-091-32 C A A \\
146-091-34 C B A \\
146-091-35 B B C \\
146-091-36 B C B\end{array}$ & $\begin{array}{l}472527102192902 \\
472518102.180801 \\
472517102155501 \\
472537102.144801 \\
472530102133201\end{array}$ \\
\hline $\begin{array}{l}146-090-19 \mathrm{CBA} \\
146-090-20 \mathrm{BDB} 1 \\
146-090-20 \mathrm{BDB} 2 \\
146-090-20 \mathrm{CCC} \\
146-090-21 \mathrm{ACC}\end{array}$ & $\begin{array}{l}472701102120601 \\
472714102104001 \\
472714102104002 \\
472641102105901 \\
472707102090501\end{array}$ & $\begin{array}{l}146-092-02 D C A \\
146-092-14 B B \\
146-092-14 C D D \\
146-092-15 B B B \\
146-092-15 D D D\end{array}$ & $\begin{array}{l}472927102.213801 \\
472822102.221401 \\
472735102215801 \\
472820102234101 \\
472735102223601\end{array}$ \\
\hline $\begin{array}{l}146-090-21 \mathrm{BD} \\
146-090-22 \mathrm{ACD} 1 \\
146-090-22 \mathrm{ACD} 2 \\
146-090-25 \\
146-090-25 \mathrm{DAD} 1\end{array}$ & $\begin{array}{l}472714102091601 \\
472707102073901 \\
472707102073902 \\
472548102050601 \\
472602102044801\end{array}$ & $\begin{array}{l}146-092-19 \mathrm{DBC} \\
146-092-22 \mathrm{ABB} \\
146-092-27 \mathrm{CBB} \\
146-092-27 \mathrm{DDD} \\
146-092-28 \mathrm{CCC}\end{array}$ & $\begin{array}{l}472656102265401 \\
472729102230401 \\
472611102234301 \\
472551102223601 \\
472551102245901\end{array}$ \\
\hline $\begin{array}{l}146-090-25 \mathrm{DAD} 2 \\
146-090-25 \mathrm{DCCA} \\
146-090-30 \mathrm{BAA} \\
\text { 146-090-30DDD1 } \\
146-090-30 \mathrm{DDD} 2\end{array}$ & $\begin{array}{l}472602102044802 \\
472551102051201 \\
472634102114701 \\
472549102110901 \\
472549102110902\end{array}$ & $\begin{array}{l}\text { 146-092-29DDC1 } \\
146-092-29 D D C 2 \\
146-092-30 D A A \\
146-092-32 C D D 1 \\
146-092-32 C D D 2\end{array}$ & $\begin{array}{l}472551102251801 \\
472551102251802 \\
472611102262501 \\
472459102254701 \\
472455102254502\end{array}$ \\
\hline
\end{tabular}


Supplement 1. Local numbers and site-identification numbers of wells, test holes, and springs--Continued

\begin{tabular}{|c|c|c|c|}
\hline Local number & Site-identification number & Local number & Site-identification numher \\
\hline $\begin{array}{l}146-092-34 \mathrm{ABB} \\
146-092-35 \mathrm{DAD} 1 \\
146-092-35 \mathrm{DAD} 2 \\
146-093-03 \mathrm{CDD} \\
146-093-14 \mathrm{DDBD}\end{array}$ & $\begin{array}{l}472545102230401 \\
472512102211901 \\
472512102211902 \\
472919102305301 \\
472738102290501\end{array}$ & $\begin{array}{l}147-087-12 \mathrm{BAB} \\
147-087-13 \mathrm{BCB} \\
147-088-01 \mathrm{ABD} \\
147-088-01 \mathrm{ACB} \\
147-088-01 \mathrm{BDD}\end{array}$ & $\begin{array}{l}473423101423401 \\
473318101425202 \\
473509101494201 \\
473503101495201 \\
473456101500101\end{array}$ \\
\hline $\begin{array}{l}146-093-15 D D D \\
146-093-17 \mathrm{CBB} \\
146-093-19 \mathrm{BDD} \\
146-093-20 \mathrm{ADD} \\
146-093-20 \mathrm{CBC}\end{array}$ & $\begin{array}{l}472735102301501 \\
472755102335601 \\
472709102344301 \\
472709102324801 \\
472656102335601\end{array}$ & $\begin{array}{l}147-088-01 C C D \\
147-088-01 D C C \\
147-088-03 A A A \\
147-088-03 A B A 1 \\
147-088-03 A B A 2\end{array}$ & $\begin{array}{l}473430101502001 \\
473430101495201 \\
473516101515601 \\
473516101521601 \\
473516101521602\end{array}$ \\
\hline $\begin{array}{l}146-093-20 C C A \\
146-093-22 A D D \\
146-093-22 C C C \\
146-093-24 C C A B \\
146-093-24 D C C 1\end{array}$ & $\begin{array}{l}472650102334601 \\
472709102301501 \\
472643102312201 \\
472650102284201 \\
472643102281101\end{array}$ & $\begin{array}{l}147-088-03 \mathrm{ABC} \\
147-088-03 \mathrm{ADB} \\
147-088-07 \mathrm{BDD} \\
147-088-11 \mathrm{BAA} 1 \\
147-088-11 \mathrm{BAA} 2\end{array}$ & $\begin{array}{l}473509101522501 \\
473503101520601 \\
473404101562501 \\
473424101511801 \\
473424101511802\end{array}$ \\
\hline $\begin{array}{l}146-093-24 D C C 2 \\
146-093-25 A B B \\
146-093-26 C B A \\
146-093-26 C B B \\
146-093-27 C C C\end{array}$ & $\begin{array}{l}472643102281102 \\
472637102281101 \\
472611102295601 \\
472611102300601 \\
472551102312201\end{array}$ & $\begin{array}{l}147-088-11 \mathrm{BAB} \\
147-088-11 \mathrm{BDCl} \\
147-088-11 \mathrm{BDC} 2 \\
147-088-12 \mathrm{BAD} \\
147-088-12 \mathrm{CAB}\end{array}$ & $\begin{array}{l}473424101512801 \\
473404101512801 \\
473404101512802 \\
473417101500101 \\
473357101501101\end{array}$ \\
\hline $\begin{array}{l}146-093-27 \mathrm{CDD} \\
146-093-27 \mathrm{DAA} \\
146-093-28 \mathrm{AAA} 1 \\
146-093-28 \mathrm{AAA} 2 \\
146-093-28 \mathrm{ADD}\end{array}$ & $\begin{array}{l}472551102305301 \\
472611102301501 \\
472637102313201 \\
472637102313202 \\
472617102313201\end{array}$ & $\begin{array}{l}147-088-12 \mathrm{CBB} \\
147-088-16 \mathrm{ADA} \\
147-089-03 \mathrm{DA} \\
147-089-03 \mathrm{DBA} \\
147-089-11 \mathrm{DAD}\end{array}$ & $\begin{array}{l}473357101503001 \\
473318101531301 \\
473446101594201 \\
473450101595601 \\
473351101582001\end{array}$ \\
\hline $\begin{array}{l}146-093-28 C \mathrm{CA} \\
146-093-28 \mathrm{DDB} 1 \\
146-093-28 D \mathrm{DD} 2 \\
146-093-28 \mathrm{DDB} 3 \\
146-094-04 \mathrm{BBC}\end{array}$ & $\begin{array}{l}472558102322901 \\
472558102314101 \\
472558102314102 \\
472558102314103 \\
472958102401801\end{array}$ & $\begin{array}{l}\text { 147-089-31DDD } \\
147-089-33 \mathrm{ADA} \\
147-089-33 \mathrm{DAD} 1 \\
147-089-33 \mathrm{DAD} 2 \\
147-089-33 \mathrm{DDA}\end{array}$ & $\begin{array}{l}473009102032701 \\
473042102005401 \\
473022102005401 \\
473022102005402 \\
473016102005401\end{array}$ \\
\hline $\begin{array}{l}146-094-05 C B D \\
146-094-05 D C C \\
146-094-08 D A C 1 \\
146-094-08 D A C 2 \\
146-094-08 D A D 1\end{array}$ & $\begin{array}{l}472932102412401 \\
472917102390001 \\
472840102403701 \\
472840102403702 \\
472840102402701\end{array}$ & $\begin{array}{l}\text { 147-089-34DCB1 } \\
147-089-34 D C B 2 \\
147-089-34 D D C \\
147-090-19 C D C \\
147-090-20 D D B\end{array}$ & $\begin{array}{l}473016102000601 \\
473016102000602 \\
473009101594701 \\
473155102115401 \\
473201102095901\end{array}$ \\
\hline $\begin{array}{l}\text { 146-094-08DAD2 } \\
146-094-13 \mathrm{CBB} \\
146-094-15 \mathrm{ACC} 1 \\
146-094-15 \mathrm{ACC} 2 \\
146-094-23 \mathrm{AAD}\end{array}$ & $\begin{array}{l}472840102402702 \\
472755102362901 \\
472801102382301 \\
472801102382302 \\
472722102363801\end{array}$ & $\begin{array}{l}147-090-20 D D C C \\
147-090-22 C C C \\
147-090-25 A B C \\
147-090-31 A C D \\
147-090-35 A D B D\end{array}$ & $\begin{array}{l}473151102100401 \\
473155102082401 \\
473141102051201 \\
473037102112501 \\
473039102060901\end{array}$ \\
\hline $\begin{array}{l}146-094-24 \mathrm{BDD} \\
146-094-24 \mathrm{CAA} \\
146-094-24 \mathrm{CAB} 1 \\
146-094-24 \mathrm{CAB2} \\
146-094-24 \mathrm{DDD} 1\end{array}$ & $\begin{array}{l}472709102360001 \\
472703102360001 \\
472703102360901 \\
472703102360902 \\
472643102352201\end{array}$ & $\begin{array}{l}147-090-36 \mathrm{DAD} \\
147-091-14 \mathrm{BDD} \\
147-091-15 \mathrm{CCD} \\
147-091-15 \mathrm{DCC} \\
147-091-17 \mathrm{AAD}\end{array}$ & $\begin{array}{l}473023102044401 \\
473314102141701 \\
473248102155201 \\
473248102152401 \\
473327102172701\end{array}$ \\
\hline $\begin{array}{l}146-094-24 \mathrm{DDD} 2 \\
146-094-35 \mathrm{AAB} \\
146-095-15 \mathrm{ABCD} \\
146-095-35 \mathrm{DDC} \\
147-087-03 \mathrm{CCA}\end{array}$ & $\begin{array}{l}472643102352202 \\
472545102364801 \\
472812102455701 \\
472459102442601 \\
473436101451501\end{array}$ & $\begin{array}{l}147-091-21 D C A \\
147-091-22 \mathrm{AAD} \\
147-091-25 \mathrm{BBD} \\
147-091-25 \mathrm{CCA} \\
147-091-25 \mathrm{DAA}\end{array}$ & $\begin{array}{l}473202102163001 \\
473235102145501 \\
473139102132001 \\
473105102132201 \\
473124102122301\end{array}$ \\
\hline $\begin{array}{l}147-087-03 \mathrm{CDB} \\
147-087-04 \mathrm{ABA} \\
147-087-04 \mathrm{ABC} \\
147-087-09 \mathrm{BAD} \\
147-087-12 \mathrm{BAA}\end{array}$ & $\begin{array}{l}473436101450501 \\
473516101455301 \\
473509101460201 \\
473422101461501 \\
473423101422301\end{array}$ & $\begin{array}{l}147-091-25 D C C \\
147-091-26 \mathrm{BDB} \\
147-091-26 \mathrm{CCD} \\
147-091-26 \mathrm{CDB} \\
147-091-27 \mathrm{BBD}\end{array}$ & $\begin{array}{l}473058102130001 \\
473136102142701 \\
473104102143601 \\
473111102142701 \\
473143102155201\end{array}$ \\
\hline
\end{tabular}


Supplement 1. Local numbers and site-identification numbers of wells, test holes, and springs--Continued

\begin{tabular}{|c|c|c|c|}
\hline Local number & Slto-identiflcation number & Local number & Slte-Identifioat'on number \\
\hline $\begin{array}{l}\text { 147-091-28ACC } \\
147-091-28 D D D 1 \\
147-091-28 D D D 2 \\
147-091-28 D D D 3 \\
147-091-29 B C A\end{array}$ & $\begin{array}{l}473130102164101 \\
473104102161101 \\
473104102161102 \\
473104102161103 \\
473136102182501\end{array}$ & $\begin{array}{l}147-095-18 \mathrm{DDA} \\
147-095-19 \mathrm{BBAC} \\
147-095-22 \mathrm{BBB} \\
147-095-23 \mathrm{CCA} \\
147-095-23 \mathrm{DBDB}\end{array}$ & $\begin{array}{l}473257102192601 \\
473241102 \leq 12301 \\
473240102163701 \\
473205102151300 \\
473211102143501\end{array}$ \\
\hline $\begin{array}{l}\text { 147-091-30AAA } \\
147-091-31 \mathrm{CDB} 1 \\
147-091-31 \mathrm{CDB} 2 \\
147-091-33 \mathrm{ADD} \\
147-091-35 \mathrm{BDA}\end{array}$ & $\begin{array}{l}473149102184401 \\
473019102193101 \\
473019102193102 \\
473038102161101 \\
473045102141701\end{array}$ & $\begin{array}{l}147-095-24 \mathrm{AAC} \\
147-095-26 \mathrm{BBB} 1 \\
147-095-26 \mathrm{BBB} 2 \\
147-095-29 \mathrm{DBBD} \\
147-095-32 \mathrm{BDC}\end{array}$ & $\begin{array}{l}473237102130801 \\
473152102152301 \\
473152102152302 \\
473120102183001 \\
473042102185601\end{array}$ \\
\hline $\begin{array}{l}147-091-36 A A C \\
147-091-36 \mathrm{BBD} \\
147-091-36 \mathrm{CBD} \\
147-092-03 \mathrm{CDC} 1 \\
147-092-03 \mathrm{CDC} 2\end{array}$ & $\begin{array}{l}473051102123201 \\
473048102132101 \\
473020102132101 \\
473431102232001 \\
473428102232402\end{array}$ & $\begin{array}{l}\text { 147-095-33BDBD } \\
148-086-20 D A A \\
148-086-29 A A A 2 \\
148-087-01 C C C \\
148-087-02 C D C\end{array}$ & $\begin{array}{l}473041102173401 \\
473724101391301 \\
473658101391302 \\
473939101425201 \\
473941101434901\end{array}$ \\
\hline $\begin{array}{l}147-092-10 \mathrm{AABD} \\
147-092-15 \mathrm{ADD} \\
147-092-21 \mathrm{DA} \\
147-092-21 \mathrm{DDB} \\
147-092-36 \mathrm{BC}\end{array}$ & $\begin{array}{l}473419102224201 \\
473310102223201 \\
473211102235401 \\
473202102235801 \\
473040102210201\end{array}$ & $\begin{array}{l}148-087-03 D D D \\
148-087-04 C D D \\
148-087-06 D C A \\
148-087-06 D C B \\
148-087-06 D C C\end{array}$ & $\begin{array}{l}473943101441801 \\
473939101461201 \\
473945101482601 \\
473950101483301 \\
473939101483501\end{array}$ \\
\hline $\begin{array}{l}147-093-03 D B B \\
147-093-05 C D D \\
147-093-07 A C D D \\
147-093-07 C B C A \\
147-093-08 B B C A\end{array}$ & $\begin{array}{l}473451102304001 \\
473431102332401 \\
473403102342201 \\
473352102351001 \\
473418102335001\end{array}$ & $\begin{array}{l}\text { 148-087-07AAA1 } \\
148-087-07 \mathrm{AAA} 2 \\
148-087-07 \mathrm{DDD} \\
148-087-08 \mathrm{BBC} \\
148-087-10 \mathrm{CCC}\end{array}$ & $\begin{array}{l}473932101480701 \\
473932101480702 \\
473848101480701 \\
473915101480301 \\
473848101452501\end{array}$ \\
\hline $\begin{array}{l}147-093-08 \mathrm{CAAC} \\
147-093-09 \mathrm{ABCA} \\
147-093-15 \mathrm{BCD} \\
147-093-29 \mathrm{DCA} \\
147-093-33 \mathrm{DAC}\end{array}$ & $\begin{array}{l}473354102332801 \\
473419102315901 \\
473314102310901 \\
473111102330401 \\
473024102314001\end{array}$ & $\begin{array}{l}148-087-11 D D D \\
148-087-13 \mathrm{BBB} \\
148-087-13 \mathrm{DDD} \\
148-087-14 \mathrm{BAA} \\
148-087-14 \mathrm{BAB}\end{array}$ & $\begin{array}{l}473848101430201 \\
473841101425201 \\
473756101414601 \\
473847101433501 \\
473846101435301\end{array}$ \\
\hline $\begin{array}{l}147-093-34 \mathrm{DBB} \\
147-093-35 \mathrm{CBC1} \\
147-093-35 \mathrm{CBC} 2 \\
147-093-35 \mathrm{CBC} 3 \\
147-094-01 \mathrm{DAA}\end{array}$ & $\begin{array}{l}473028102304601 \\
473025102300201 \\
473024102300302 \\
473027102300303 \\
473451102351901\end{array}$ & $\begin{array}{l}\text { 148-087-14DAA } \\
148-087-15 \mathrm{AAA} \\
148-087-15 \mathrm{DCC} \\
148-087-15 \mathrm{DCD} \\
148-087-16 \mathrm{AAA}\end{array}$ & $\begin{array}{l}473820101425801 \\
473846101441601 \\
473756101444701 \\
473800101443701 \\
473841101453401\end{array}$ \\
\hline $\begin{array}{l}147-094-02 \mathrm{AD} \\
147-094-03 \mathrm{CDBD} \\
147-094-04 \mathrm{DDA} \\
147-094-26 \mathrm{BCB} \\
147-094-33 \mathrm{DB}\end{array}$ & $\begin{array}{l}473501102364001 \\
473433102383901 \\
473438102390801 \\
473139102374201 \\
473031102393201\end{array}$ & $\begin{array}{l}148-087-19 D D D \\
148-087-20 A B \\
148-087-24 B C D \\
148-087-24 C C C \\
148-087-27 A D A\end{array}$ & $\begin{array}{l}473705101480701 \\
473747101471701 \\
473731101424301 \\
473705101425201 \\
473646101441801\end{array}$ \\
\hline $\begin{array}{l}147-094-34 \mathrm{BAD} \\
147-09435 \mathrm{CAA} \\
147-09435 \mathrm{CBB} \\
147-09435 \mathrm{DBDC} \\
147-094-36 \mathrm{BAD}\end{array}$ & $\begin{array}{l}473054102383001 \\
473032102371501 \\
473034102452301 \\
473022102370101 \\
473053102360001\end{array}$ & $\begin{array}{l}148-087-27 B B D \\
148-087-27 C C C \\
148-087-27 D B D \\
148-087-27 D D A \\
148-087-31 B A A\end{array}$ & $\begin{array}{l}473652101451501 \\
473614101452501 \\
473626101443701 \\
473620101441801 \\
473607101484501\end{array}$ \\
\hline $\begin{array}{l}147-095-12 B C D \\
147-095-12 C A D \\
147-095-13 C C C 1 \\
147-095-13 C C C 2 \\
147-095-13 C C C 3\end{array}$ & $\begin{array}{l}473406102435601 \\
473354102433701 \\
473250102440601 \\
473250102440602 \\
473246102440403\end{array}$ & $\begin{array}{l}148-087-33 B B B \\
148-087-34 A A D \\
148-087-35 B B C \\
148-088-01 A A A \\
148-088-01 B B B\end{array}$ & $\begin{array}{l}473607101464201 \\
473601101441801 \\
473601101440901 \\
474024101.792301 \\
474024101503001\end{array}$ \\
\hline $\begin{array}{l}147-095-14 A A A \\
147-095-14 C A C \\
147-095-14 C B B 1 \\
147-095-14 C B B 2 \\
147-095-14 C B B 3\end{array}$ & $\begin{array}{l}473334102441501 \\
473302102450401 \\
473309102452301 \\
473309102452302 \\
473309102452303\end{array}$ & $\begin{array}{l}148-088-01 C B \\
148-088-02 D D A \\
148-088-02 D D B \\
148-088-05 A B A \\
148-088-07 D C C\end{array}$ & $\begin{array}{l}473955101502501 \\
473945101504001 \\
473945101504901 \\
474024101544901 \\
473848101561601\end{array}$ \\
\hline
\end{tabular}


Supplement 1. Local numbers and site-identification numbers of wells, test holes, and springs--Continued

\begin{tabular}{|c|c|c|c|}
\hline Local number & Slto-Identiflcatlon number & Local number & Sito-Identificatlon number \\
\hline $\begin{array}{l}148-088-07 D D D \\
148-088-08 \mathrm{CAC} \\
148-088-08 \mathrm{DDC} \\
148-088-10 \mathrm{AAA} \\
148-088-10 \mathrm{CDD}\end{array}$ & $\begin{array}{l}473848101554701 \\
473900101551801 \\
473848101544001 \\
473932101515601 \\
473848101523501\end{array}$ & $\begin{array}{l}148-089-36 \mathrm{AAA} \\
148-089-36 \mathrm{CAA} 1 \\
148-089-36 \mathrm{CAA} 2 \\
148-089-36 \mathrm{CAA} 3 \\
148-090-01 \mathrm{ABA}\end{array}$ & $\begin{array}{l}473607101570401 \\
473541101574201 \\
473541101574202 \\
473541101574203 \\
474025102050301\end{array}$ \\
\hline $\begin{array}{l}148-088-10 \mathrm{DDD} \\
148-088-11 \mathrm{AAA} \\
148-088-11 \mathrm{CCC} \\
148-088-11 \mathrm{DBB} \\
148-088-12 \mathrm{CCD} 1\end{array}$ & $\begin{array}{l}473848101515601 \\
473932101504001 \\
473848101514701 \\
473907101510801 \\
473848101502001\end{array}$ & $\begin{array}{l}148-090-01 \mathrm{BAD} \\
148-090-01 \mathrm{CAC} \\
148-090-02 \mathrm{DB} \\
148-090-03 \mathrm{ABB} 1 \\
148-090-03 \mathrm{ABB} 2\end{array}$ & $\begin{array}{l}474016102052101 \\
473951102053101 \\
473954102062301 \\
474023102074101 \\
474023102074102\end{array}$ \\
\hline $\begin{array}{l}148-088-12 C C D 2 \\
148-088-12 C D C 1 \\
148-088-12 C D C 2 \\
148-088-12 C D D \\
148-088-13 B C B\end{array}$ & $\begin{array}{l}473848101502002 \\
473848101501101 \\
473848101501102 \\
473848101500101 \\
473828101503001\end{array}$ & $\begin{array}{l}148-090-05 A A D \\
148-090-06 \mathrm{DDD} \\
148-090-07 D C C \\
148-090-07 D C D \\
148-090-08 \mathrm{BB}\end{array}$ & $\begin{array}{l}474016102094901 \\
473938102110601 \\
473849102113201 \\
473849102112601 \\
473928102105001\end{array}$ \\
\hline $\begin{array}{l}148-088-15 C \mathrm{CB} \\
148-088-16 \mathrm{DAA} \\
148-088-18 \mathrm{AAA} \\
148-088-18 \mathrm{CBA} \\
148-088-21 \mathrm{DBC} 1\end{array}$ & $\begin{array}{l}473803101530401 \\
473815101531301 \\
473845101554601 \\
473815101564501 \\
473718101534201\end{array}$ & $\begin{array}{l}148-090-09 \mathrm{DBA} \\
148-090-10 \mathrm{CDA} \\
148-090-12 \mathrm{ABAC} \\
148-090-12 \mathrm{DACA} \\
148-090-12 \mathrm{DDB}\end{array}$ & $\begin{array}{l}473906102085201 \\
473853102075401 \\
473932102050801 \\
473905102045101 \\
473853102045201\end{array}$ \\
\hline $\begin{array}{l}148-088-21 \mathrm{DBC} 2 \\
148-088-21 \mathrm{DBD} \\
148-088-26 \mathrm{BAD} \\
148-088-28 \mathrm{DD} \\
148-088-30 \mathrm{AAA}\end{array}$ & $\begin{array}{l}473718101534702 \\
473718101533701 \\
473652101511801 \\
473617101531801 \\
473658101554701\end{array}$ & $\begin{array}{l}148-090-13 \mathrm{BBC} \\
148-090-13 \mathrm{DDC} \\
148-090-15 \mathrm{AAA} \\
148-090-16 \mathrm{ABC} \\
148-090-22 \mathrm{BCC}\end{array}$ & $\begin{array}{l}473834102055001 \\
473755102045201 \\
473839102071601 \\
473834102090001 \\
473730102082301\end{array}$ \\
\hline $\begin{array}{l}148-088-35 \mathrm{ABD} \\
148-088-35 \mathrm{ACA} \\
148-088-35 \mathrm{DDD} 1 \\
148-088-35 \mathrm{DDD} 2 \\
148-088-36 \mathrm{CC}\end{array}$ & $\begin{array}{l}473601101505901 \\
473554101505901 \\
473522101504001 \\
473522101504002 \\
473522101503001\end{array}$ & $\begin{array}{l}148-090-23 A A A \\
148-090-23 A B C \\
148-090-23 D D C \\
148-090-24 D C C \\
148-090-25 B C\end{array}$ & $\begin{array}{l}473749102055901 \\
473742102062801 \\
473704102060901 \\
473704102051201 \\
473641102054501\end{array}$ \\
\hline $\begin{array}{l}148-089-04 C D D \\
148-089-06 C A D 1 \\
148-089-06 C A D 2 \\
148-089-07 A C \\
148-089-07 D D D\end{array}$ & $\begin{array}{l}473938102013201 \\
473951102040501 \\
473951102040502 \\
473919102035301 \\
473847102032601\end{array}$ & $\begin{array}{l}148-090-26 \mathrm{ABB} 1 \\
148-090-26 \mathrm{ABB} 2 \\
148-092-03 \mathrm{ABA} \\
148-092-03 \mathrm{DBA} \\
148-092-04 \mathrm{ACBA}\end{array}$ & $\begin{array}{l}473657102062801 \\
473657102062802 \\
474023102225301 \\
473957102225301 \\
474011102241701\end{array}$ \\
\hline $\begin{array}{l}148-089-09 \mathrm{AAB} \\
148-089-10 \mathrm{BBB} \\
148-089-11 \mathrm{AA} \\
148-089-12 \mathrm{BDD} \\
148-089-12 \mathrm{DB}\end{array}$ & $\begin{array}{l}473932102010301 \\
473932102004401 \\
473929101582501 \\
473913101574201 \\
473904101572801\end{array}$ & $\begin{array}{l}148-092-04 \mathrm{CBD} \\
148-092-05 \\
148-092-06 \mathrm{AAD} \\
148-092-06 \mathrm{BAD} \\
148-092-06 \mathrm{BCA}\end{array}$ & $\begin{array}{l}473951102244801 \\
474002102253801 \\
474012102262501 \\
474016102270201 \\
474010102272101\end{array}$ \\
\hline $\begin{array}{l}148-089-12 \mathrm{DCC} \\
148-089-13 \mathrm{BCC} \\
148-089-13 \mathrm{BCC} 2 \\
148-089-18 \mathrm{BCD} \\
148-089-20 \mathrm{BAC}\end{array}$ & $\begin{array}{l}473847101573201 \\
473822101581101 \\
473822101581102 \\
473821102042401 \\
473743102025801\end{array}$ & $\begin{array}{l}148-092-06 \mathrm{BDB} \\
148-092-11 \mathrm{AAC} \\
148-092-11 \mathrm{ACA} \\
148-092-11 \mathrm{CCB} \\
148-092-14 \mathrm{ABBB}\end{array}$ & $\begin{array}{l}474010102271101 \\
473925102212701 \\
473919102213601 \\
473854102222401 \\
473844102215201\end{array}$ \\
\hline $\begin{array}{l}148-089-20 B A D \\
148-089-20 C B B \\
148-089-22 C D A \\
148-089-22 D A B \\
148-089-27 C D C\end{array}$ & $\begin{array}{l}473743102024801 \\
473723102031701 \\
473711102001501 \\
473724101594601 \\
473613102002501\end{array}$ & $\begin{array}{l}148-092-23 \mathrm{ABB} \\
148-092-23 \mathrm{CCA} \\
148-092-24 \mathrm{CCCA} \\
148-092-24 \mathrm{CCCB} \\
148-092-26 \mathrm{ACA}\end{array}$ & $\begin{array}{l}473750102214601 \\
473712102221501 \\
473704102211301 \\
473704102211201 \\
473646102213601\end{array}$ \\
\hline $\begin{array}{l}148-089-27 D C C \\
148-089-28 A C B \\
148-089-30 A D A \\
148-089-30 B D C A \\
148-089-33 C C A\end{array}$ & $\begin{array}{l}473611102000801 \\
473645102012201 \\
473645102032601 \\
473642102041401 \\
473526102015201\end{array}$ & $\begin{array}{l}148-092-26 C C D \\
148-092-35 B D A \\
148-093-01 D D C \\
148-093-04 C A B 1 \\
148-093-04 C A B 2\end{array}$ & $\begin{array}{l}473614102221501 \\
473555102215601 \\
473938102274901 \\
473957102321701 \\
473957102321702\end{array}$ \\
\hline
\end{tabular}


Supplement 1. Local numbers and site-jdentification numbers of wells, test holes, and springs--Continued

\begin{tabular}{|c|c|c|c|}
\hline Local number & Site-identification number & Local number & Site-identification number \\
\hline $\begin{array}{l}148-093-04 C B D \\
148-093-05 C C A 1 \\
148-093-05 C C A 2 \\
148-093-09 B B C \\
148-093-10 C C C\end{array}$ & $\begin{array}{l}473951102322701 \\
473944102334301 \\
473944102334302 \\
473925102323601 \\
473847102312001\end{array}$ & $\begin{array}{l}149-087-11 B C C \\
149-087-15 A A D \\
149-087-17 D C D \\
149-087-20 B B B \\
149-087-21 C C D\end{array}$ & $\begin{array}{l}474425101470501 \\
474346101471401 \\
474307101500801 \\
474300101505601 \\
474215101492901\end{array}$ \\
\hline $\begin{array}{l}148-093-14 C D C \\
148-093-15 A C B \\
148-093-17 B B D 1 \\
148-093-17 B B D 2 \\
148-093-19 A B A C\end{array}$ & $\begin{array}{l}473755102294401 \\
473827102304101 \\
473834102334301 \\
473821101322401 \\
473749102342701\end{array}$ & $\begin{array}{l}149-087-25 \mathrm{CAB} \\
149-087-26 \mathrm{BCB} \\
149-087-27 \mathrm{AAB} \\
149-087-27 \mathrm{CBB} \\
149-087-28 \mathrm{ADB}\end{array}$ & $\begin{array}{l}474142101452801 \\
474153101470401 \\
474208101472401 \\
474142101482201 \\
474155101484101\end{array}$ \\
\hline $\begin{array}{l}148-093-20 B C A \\
148-093-23 B A D B \\
148-093-31 D B D \\
148-093-32 C D B \\
148-093-34 D B C C\end{array}$ & $\begin{array}{l}473736102334301 \\
473744102293701 \\
473534102342101 \\
473528102333401 \\
473533102304601\end{array}$ & $\begin{array}{l}149-087-28 D A A \\
149-087-29 D D D \\
149-087-30 A D D \\
149-087-32 C C C \\
149-087-34 A B B\end{array}$ & $\begin{array}{l}474141101482901 \\
474122101494801 \\
474149101 \leq 10601 \\
474030101505601 \\
474116101474301\end{array}$ \\
\hline $\begin{array}{l}\text { 148-094-01DDD } \\
148-094-03 A B B \\
148-094-03 A D A D \\
148-094-13 A A D \\
148-094-13 B B D\end{array}$ & $\begin{array}{l}473938102351901 \\
474023102382101 \\
474011102375201 \\
473834102351901 \\
473834102361601\end{array}$ & $\begin{array}{l}\text { 149-087-35DCB } \\
149-088-01 C D D \\
149-088-02 C D C \\
149-088-04 D A D \\
149-088-04 D C D\end{array}$ & $\begin{array}{l}474037101462601 \\
474451101 \leq 30101 \\
474451101542801 \\
474503101561301 \\
474451101563401\end{array}$ \\
\hline $\begin{array}{l}148-094-14 A A B \\
148-094-14 A A C A \\
148-094-14 D A C \\
148-094-15 C A D \\
148-094-20 A A A B\end{array}$ & $\begin{array}{l}473840102364501 \\
473839102363201 \\
473808102364501 \\
473808102383001 \\
473753102403101\end{array}$ & $\begin{array}{l}\text { 149-088-11CDC } \\
\text { 149-088-11DAA1 } \\
149-088-11 D A A 2 \\
149-088-12 \mathrm{BAB} \\
149-088-19 \mathrm{BCC}\end{array}$ & $\begin{array}{l}474359101 \leq 42801 \\
474418101 \leq 34001 \\
474416101 \leqslant 33802 \\
474442101 \leq 31501 \\
474241101 \leq 95601\end{array}$ \\
\hline $\begin{array}{l}148-094-20 D D D \\
148-094-23 C B D \\
148-094-25 C C C \\
148-094-26 D C A \\
148-094-30 B A A D\end{array}$ & $\begin{array}{l}473705102402501 \\
473717102373301 \\
473613102362601 \\
473619102365501 \\
473658102422201\end{array}$ & $\begin{array}{l}149-088-20 \mathrm{CBC} \\
149-088-21 \mathrm{BBB} \\
149-088-23 \mathrm{BBB} \\
149-088-23 \mathrm{DAA} \\
149-088-25 \mathrm{CAA}\end{array}$ & $\begin{array}{l}474228101583901 \\
474300101572201 \\
474300101544801 \\
474233101 \leq 34201 \\
474142101530101\end{array}$ \\
\hline $\begin{array}{l}148-094-33 A C D \\
148-094-36 A C A A \\
148-095-01 D B B \\
148-095-02 B B B \\
148-095-03 A A A\end{array}$ & $\begin{array}{l}473547102392801 \\
473537102353601 \\
473958102432801 \\
474025102452601 \\
474026102453301\end{array}$ & $\begin{array}{l}149-088-26 \mathrm{BAB} \\
149-088-27 \mathrm{BBB} \\
149-088-27 \mathrm{CCC} \\
149-088-30 \mathrm{BAA} \\
149-088-32 \mathrm{AAC}\end{array}$ & $\begin{array}{l}474208101542801 \\
474208101560501 \\
474122101560501 \\
474208101592701 \\
474109101574101\end{array}$ \\
\hline $\begin{array}{l}148-095-08 C A B D \\
148-095-12 D C C 1 \\
148-095-12 D C C 2 \\
148-095-13 A D C \\
148-095-18 B D\end{array}$ & $\begin{array}{l}473908102485101 \\
473847102432801 \\
473847102432802 \\
473821102430801 \\
473829102500601\end{array}$ & $\begin{array}{l}149-088-35 \mathrm{AAA} \\
149-088-35 \mathrm{ABB} \\
149-088-35 \mathrm{BAA} \\
149-088-36 \mathrm{AAA} \\
149-089-01 \mathrm{ACB} 1\end{array}$ & $\begin{array}{l}474116101534001 \\
474116101510901 \\
474116101511901 \\
474116101522301 \\
474524102 C 03501\end{array}$ \\
\hline $\begin{array}{l}148-095-22 C C A \\
148-095-35 B D D \\
149-086-16 C A \\
149-087-02 D D C 1 \\
149-087-02 D D C 2\end{array}$ & $\begin{array}{l}473711102463101 \\
473547102445501 \\
474322101413101 \\
474451101460701 \\
474451101460702\end{array}$ & $\begin{array}{l}149-089-01 \mathrm{ACB} 2 \\
149-089-01 \mathrm{BDA} \\
149-089-02 \mathrm{ADA} \\
149-089-02 \mathrm{BBB} \\
149-089-02 \mathrm{DAD}\end{array}$ & $\begin{array}{l}474524102 C 03502 \\
474521102 C 04101 \\
474524102 C 12301 \\
474537102 C 23101 \\
474504102 C 12301\end{array}$ \\
\hline $\begin{array}{l}149-087-03 A D D \\
149-087-05 C D C \\
149-087-05 D B D \\
149-087-05 D C C \\
149-087-06 A A A\end{array}$ & $\begin{array}{l}474517101471401 \\
474451101503701 \\
474504101500801 \\
474451101501701 \\
474537101510601\end{array}$ & $\begin{array}{l}149-089-03 \mathrm{BBC} \\
149-089-03 \mathrm{BBD} \\
149-089-03 \mathrm{DAA} \\
149-089-04 \mathrm{CDC} \\
149-089-07 \mathrm{BAB}\end{array}$ & $\begin{array}{l}474530102 C 34801 \\
474529102 C 33801 \\
474512102 C 23701 \\
474451102044601 \\
474445102072001\end{array}$ \\
\hline $\begin{array}{l}149-087-06 \mathrm{DCC} \\
149-087-06 \mathrm{DDA} \\
149-087-08 \mathrm{ABB} 1 \\
149-087-08 \mathrm{ABB} 2 \\
149-087-09 \mathrm{DAD}\end{array}$ & $\begin{array}{l}474451101513501 \\
474456101510201 \\
474445101501701 \\
474445101501902 \\
474412101483101\end{array}$ & $\begin{array}{l}149-089-08 \mathrm{CBC} \\
149-089-09 \mathrm{BAB} 1 \\
149-089-09 \mathrm{BAB} 2 \\
149-089-10 \mathrm{AAA} \\
149-089-10 \mathrm{AAD}\end{array}$ & $\begin{array}{l}474412102 C 62201 \\
474445102044601 \\
474445102024702 \\
474445102024001 \\
474438102023601\end{array}$ \\
\hline
\end{tabular}


Supplement 1. Local numbers and site-identification numbers of wells, test holes, and springs--Continued

\begin{tabular}{|c|c|c|c|}
\hline Local number & Slto-identificatlon number & Local number & Sito-Identification nurzber \\
\hline $\begin{array}{l}149-089-10 \mathrm{BBC} \\
149-089-10 \mathrm{CBB} 1 \\
149-089-10 \mathrm{CBB} 2 \\
149-089-10 \mathrm{CBB3} \\
149-089-11 \mathrm{BBB} 1\end{array}$ & $\begin{array}{l}474438102034801 \\
474419102034801 \\
474417102034401 \\
474418102034802 \\
474445102023101\end{array}$ & $\begin{array}{l}149-092-10 D C B B \\
149-092-22 C D C \\
149-092-27 \mathrm{BBB} \\
149-092-29 \mathrm{DCC} \\
149-092-30 \mathrm{CAB}\end{array}$ & $\begin{array}{l}474406102261601 \\
474214102263601 \\
474207102265601 \\
474121102285101 \\
474141102302701\end{array}$ \\
\hline $\begin{array}{l}149-089-11 B B B 2 \\
149-089-11 \mathrm{CBB} 1 \\
149-089-11 \mathrm{CBB} 2 \\
149-089-13 \mathrm{AAA} \\
149-089-13 \mathrm{CDC}\end{array}$ & $\begin{array}{l}474445102023102 \\
474419102023101 \\
474420102023102 \\
474353102000601 \\
474307102005401\end{array}$ & $\begin{array}{l}\text { 149-092-33DDAC } \\
149-092-34 \mathrm{BBAC} \\
149-092-35 \mathrm{BDA} \\
149-092-36 \mathrm{DACD} \\
149-093-02 \mathrm{ACB}\end{array}$ & $\begin{array}{l}474033102270801 \\
474114102264701 \\
474102102251001 \\
474041102232101 \\
474523102324101\end{array}$ \\
\hline $\begin{array}{l}149-089-13 D A A \\
149-089-14 C B B \\
149-089-15 A A A \\
149-089-15 D D C \\
149-089-15 D D D\end{array}$ & $\begin{array}{l}474327102000601 \\
474326102022501 \\
474353102024001 \\
474307102025001 \\
474307102024001\end{array}$ & $\begin{array}{l}\text { 149-093-05ACAD } \\
149-093-05 C D C \\
149-093-08 D C C \\
149-093-09 A C D A \\
149-093-09 C C C\end{array}$ & $\begin{array}{l}474520102362501 \\
474450102365001 \\
474358102363101 \\
474426102330201 \\
474359102355201\end{array}$ \\
\hline $\begin{array}{l}\text { 149-089-17BAD } \\
149-089-18 \mathrm{ADB} 1 \\
149-089-18 \mathrm{ADB} 2 \\
149-089-18 \mathrm{BDA} \\
149-089-19 \mathrm{ADA}\end{array}$ & $\begin{array}{l}474344102055101 \\
474340102064101 \\
474338102063902 \\
474340102071001 \\
474248102063201\end{array}$ & $\begin{array}{l}149-093-09 \mathrm{CCD} \\
149-093-10 \mathrm{AAA} \\
149-093-11 \mathrm{ABBA} \\
149-093-12 \mathrm{ACC} \\
149-093-12 \mathrm{BBB}\end{array}$ & $\begin{array}{l}474358102354301 \\
474444102332901 \\
474444102323801 \\
474424102312501 \\
474444102320301\end{array}$ \\
\hline $\begin{array}{l}149-089-20 C C B \\
149-089-23 C \mathrm{CC} 1 \\
149-089-23 \mathrm{CCC} 2 \\
149-089-24 \mathrm{AAA} \\
149-089-25 \mathrm{AAA}\end{array}$ & $\begin{array}{l}474222102062201 \\
474217102023001 \\
474217102023002 \\
474301102000601 \\
474209102000601\end{array}$ & $\begin{array}{l}\text { 149-093-14CCC } \\
149-093-16 \mathrm{BDDD} \\
\text { 149-093-18DDB } \\
\text { 149-093-21DCA } \\
149-093-21 D C C\end{array}$ & $\begin{array}{l}474306102332001 \\
474330102352101 \\
474313102372901 \\
474221102350501 \\
474214102351501\end{array}$ \\
\hline $\begin{array}{l}149-089-25 \mathrm{ADD} \\
149-089-27 \mathrm{DBB} \\
149-089-28 \mathrm{ADA} \\
149-089-36 \mathrm{BBB} 1 \\
149-089-36 \mathrm{BBB} 2\end{array}$ & $\begin{array}{l}474149102000601 \\
474143102030901 \\
474156102035701 \\
474117102011301 \\
474117102011302\end{array}$ & $\begin{array}{l}\text { 149-093-23ACD } \\
149-093-23 A C \\
149-093-24 C C D B \\
149-093-25 D D D \\
149-093-26 A D B\end{array}$ & $\begin{array}{l}474240102323201 \\
474243102312001 \\
474215102320601 \\
474122102305601 \\
474155102322201\end{array}$ \\
\hline $\begin{array}{l}149-090-01 \mathrm{AAA} \\
149-090-01 \mathrm{AAB} \\
149-090-04 \mathrm{DDD} \\
149-090-05 \mathrm{AB} \\
149-090-05 \mathrm{DCC}\end{array}$ & $\begin{array}{l}474537102074901 \\
474537102075801 \\
474453102114501 \\
474534102132901 \\
474452102132001\end{array}$ & $\begin{array}{l}149-093-27 \mathrm{ABA} \\
149-093-34 \mathrm{ACA} \\
149-094-07 \mathrm{CAD} \\
149-094-09 \mathrm{ABA} \\
149-094-09 \mathrm{ABCA}\end{array}$ & $\begin{array}{l}474208102334801 \\
474103102334801 \\
474412102453801 \\
474444102424601 \\
474438102425501\end{array}$ \\
\hline $\begin{array}{l}149-090-11 \mathrm{ADA} 1 \\
149-090-11 \mathrm{ADA} 2 \\
149-090-11 \mathrm{DBC} \\
149-090-12 \mathrm{DAD} \\
149-090-12 \mathrm{DDD}\end{array}$ & $\begin{array}{l}474432102090601 \\
474432102090602 \\
474407102094401 \\
474411102074801 \\
474402102074701\end{array}$ & $\begin{array}{l}\text { 149-094-09DDDD } \\
\text { 149-094-12DCCD } \\
\text { 149-094-14AAA } \\
\text { 149-094-14BA } \\
149-094-15 \mathrm{ADAB}\end{array}$ & $\begin{array}{l}474356102434001 \\
474357102390601 \\
474352102395301 \\
474349102403601 \\
474341102411201\end{array}$ \\
\hline $\begin{array}{l}149-090-24 \mathrm{BDA} \\
149-090-24 \mathrm{CDA} \\
149-090-28 \mathrm{DDD} \\
149-090-34 \mathrm{CCC} \\
149-090-35 \mathrm{ABC}\end{array}$ & $\begin{array}{l}474248102082701 \\
474222102082701 \\
474123102114001 \\
474031102113101 \\
474106102093301\end{array}$ & $\begin{array}{l}\text { 149-094-16BDAC } \\
149-094-21 \mathrm{AAD} \\
149-094-21 \mathrm{DD} \\
149-094-22 \mathrm{BBB} \\
149-094-22 \mathrm{BCB}\end{array}$ & $\begin{array}{l}474336102431001 \\
474254102422601 \\
474219102423301 \\
474300102421701 \\
474247102421701\end{array}$ \\
\hline $\begin{array}{l}\text { 149-091-08AAA } \\
\text { 149-091-17BAB } \\
\text { 149-091-18DBCD } \\
149-091-22 \mathrm{BDCA} \\
149-091-30 \mathrm{CCD}\end{array}$ & $\begin{array}{l}474441102204001 \\
474351102212901 \\
474317102222001 \\
474243102185001 \\
474121102225601\end{array}$ & $\begin{array}{l}\text { 149-094-25ABC } \\
149-094-27 \mathrm{CB} \\
149-094-27 \mathrm{DAA} \\
149-094-28 \mathrm{AAA} 1 \\
149-094-28 \mathrm{AAA} 2\end{array}$ & $\begin{array}{l}474201102390501 \\
474139102421201 \\
474142102410901 \\
474208102422601 \\
474208102422602\end{array}$ \\
\hline $\begin{array}{l}\text { 149-091-31BAA } \\
149-091-33 B C C \\
149-092-08 B A A A \\
149-092-10 A C A A \\
149-092-10 D A B C\end{array}$ & $\begin{array}{l}474115102223601 \\
474055102203101 \\
474446102285701 \\
474432102260401 \\
474417102260201\end{array}$ & $\begin{array}{l}\text { 149-094-28AACC } \\
149-094-28 \mathrm{CDAB} \\
149-094-29 \mathrm{ABB} \\
149-095-03 \mathrm{DBDA} \\
149-095-04 \mathrm{ADCC}\end{array}$ & $\begin{array}{l}474200102423801 \\
474130102430901 \\
474208102441201 \\
474502102490801 \\
474513102502101\end{array}$ \\
\hline
\end{tabular}


Supplement 1. Local numbers and site-identification numbers of wells, test holes, and springs--Continued

\begin{tabular}{|c|c|c|c|}
\hline Local number & Site-identification number & Local number & Slte-Identiflcat'sn number \\
\hline $\begin{array}{l}\text { 149-095-04CCB } \\
149-095-05 D C D \\
149-095-06 A C C \\
149-095-06 A D D B \\
149-095-06 D A A\end{array}$ & $\begin{array}{l}474458102511401 \\
474451102514301 \\
474517102530901 \\
474516102524401 \\
474511102524001\end{array}$ & $\begin{array}{l}150-089-13 C B C \\
150-089-13 C D D \\
150-089-14 A D D \\
150-089-15 A D A \\
150-089-19 C D D\end{array}$ & $\begin{array}{l}474833102 ? 11301 \\
474820102\urcorner \cap 4401 \\
474843102 ? 12201 \\
474852102 ? 24001 \\
474727102 ? 71001\end{array}$ \\
\hline $\begin{array}{l}149-095-08 \mathrm{AAC} \\
149-095-08 \mathrm{ADA} \\
149-095-09 \mathrm{CDD} \\
149-095-15 \mathrm{CBB} \\
149-095-16 \mathrm{AA}\end{array}$ & $\begin{array}{l}474435102513301 \\
474432102512301 \\
474400102504501 \\
474327102495701 \\
474350102501201\end{array}$ & $\begin{array}{l}150-089-20 D C C \\
150-089-22 D D A \\
150-089-23 D C B 1 \\
150-089-23 D C B 2 \\
150-089-25 B D D B\end{array}$ & $\begin{array}{l}474727102 ? 54301 \\
474734102 ? 24001 \\
474734102715201 \\
474734102715202 \\
474703102 ?, 4501\end{array}$ \\
\hline $\begin{array}{l}149-095-16 \mathrm{DAD} \\
149-095-32 \mathrm{ACAC} \\
149-095-36 \mathrm{DBD} \\
150-087-03 \mathrm{BAB} \\
150-087-16 \mathrm{DDA}\end{array}$ & $\begin{array}{l}474321102500701 \\
474101102514801 \\
474046102463601 \\
475050101480201 \\
474827101483101\end{array}$ & $\begin{array}{l}150-089-25 C B B \\
150-089-26 A A A \\
150-089-26 B C C \\
150-089-31 B C C \\
150-089-31 D A A\end{array}$ & $\begin{array}{l}474655102711301 \\
474721102712301 \\
474701102723101 \\
474608102773901 \\
474602102763201\end{array}$ \\
\hline $\begin{array}{l}150-087-20 \mathrm{CBC} \\
150-087-21 \mathrm{AAA} \\
150-087-22 \mathrm{DAA} \\
150-087-27 \mathrm{BBB} \\
150-087-31 \mathrm{DCD}\end{array}$ & $\begin{array}{l}474741101505601 \\
474814101483101 \\
474748101471301 \\
474722101482101 \\
474544101512501\end{array}$ & $\begin{array}{l}150-089-32 \mathrm{DAA} \\
150-089-33 \mathrm{BCC} \\
150-089-34 \mathrm{AAA} \\
150-089-34 \mathrm{DDD} \\
150-090-01 \mathrm{BCBD}\end{array}$ & $\begin{array}{l}474602102751401 \\
474609102750501 \\
474629102724001 \\
474543102724001 \\
475034102785301\end{array}$ \\
\hline $\begin{array}{l}150-087-32 \mathrm{CBB} \\
150-087-32 \mathrm{CCD} \\
150-087-33 \mathrm{BAA} \\
150-087-34 \mathrm{AAD} \\
150-088-01 \mathrm{DDD}\end{array}$ & $\begin{array}{l}474604101505601 \\
474544101504601 \\
474630101490901 \\
474623101471301 \\
475004101522301\end{array}$ & $\begin{array}{l}150-090-03 \mathrm{CDD} \\
150-090-12 \mathrm{BBB} 1 \\
150-090-12 \mathrm{BBB} 2 \\
150-090-12 \mathrm{DAA} \\
150-090-13 \mathrm{ACA}\end{array}$ & $\begin{array}{l}475003102110201 \\
474957102785601 \\
474957102785602 \\
474930102774901 \\
474851102780801\end{array}$ \\
\hline $\begin{array}{l}150-088-02 C B C \\
150-088-03 C D D \\
150-088-05 D A A \\
150-088-07 D B B \\
150-088-08 B C B\end{array}$ & $\begin{array}{l}475017101544801 \\
475004101553601 \\
475024101573101 \\
474931101591801 \\
474945101583901\end{array}$ & $\begin{array}{l}150-090-13 A D A \\
150-090-13 A D D \\
150-090-16 C B B \\
150-090-16 C C C \\
150-090-17 \mathrm{CBA}\end{array}$ & $\begin{array}{l}474851102774901 \\
474845102774901 \\
474838102124801 \\
474819102124801 \\
474838102135501\end{array}$ \\
\hline $\begin{array}{l}150-088-09 \mathrm{BBBD} \\
150-088-13 \mathrm{CBC} \\
150-088-15 \mathrm{CBB} \\
150-088-16 \mathrm{CCD} \\
150-088-18 \mathrm{ADD} 1\end{array}$ & $\begin{array}{l}474953101571701 \\
474833101533001 \\
474839101560501 \\
474820101571201 \\
474846101584901\end{array}$ & $\begin{array}{l}150-090-17 \mathrm{CCC} \\
150-090-19 \mathrm{AAC} \\
150-090-19 \mathrm{ADB} \\
150-090-20 \mathrm{BDB} \\
150-090-21 \mathrm{BC}\end{array}$ & $\begin{array}{l}474819102140501 \\
474808102142201 \\
474802102142701 \\
474759102134601 \\
474756102124301\end{array}$ \\
\hline $\begin{array}{l}150-088-18 A D D 2 \\
150-088-18 A D D 3 \\
150-088-24 C C C \\
150-088-25 B A A \\
150-088-27 D A A\end{array}$ & $\begin{array}{l}474846101584902 \\
474847101584603 \\
474728101533001 \\
474721101530101 \\
474655101545701\end{array}$ & $\begin{array}{l}150-090-21 \mathrm{CB} \\
150-090-21 \mathrm{CBB} \\
150-090-22 \mathrm{CCC} \\
150-090-24 \mathrm{AAAB} \\
150-090-24 \mathrm{DDD}\end{array}$ & $\begin{array}{l}474743102124301 \\
474746102124801 \\
474727102113101 \\
474814102775101 \\
474727102774901\end{array}$ \\
\hline $\begin{array}{l}150-088-28 D D D \\
150-088-29 C C D \\
150-088-29 C D C \\
150-088-29 D A D \\
150-088-33 A D D\end{array}$ & $\begin{array}{l}474635101561401 \\
474635101582901 \\
474635101582001 \\
474645101573001 \\
474606101561001\end{array}$ & $\begin{array}{l}150-090-25 \mathrm{DAA} 1 \\
150-090-25 \mathrm{DAA} 2 \\
150-090-25 \mathrm{DAA3} \\
150-090-25 \mathrm{DAD} \\
150-090-28 \mathrm{DDC}\end{array}$ & $\begin{array}{l}474654102774901 \\
474654102774902 \\
474654102774903 \\
474647102774901 \\
474634102115001\end{array}$ \\
\hline $\begin{array}{l}150-088-34 A B A \\
150-088-34 C C C \\
150-088-35 B A B \\
150-089-01 B C B \\
150-089-04 D C A\end{array}$ & $\begin{array}{l}474629101551501 \\
474542101560201 \\
474629101542801 \\
475037102011301 \\
475010102041701\end{array}$ & $\begin{array}{l}150-090-29 A D A \\
150-090-32 A C B 1 \\
150-090-32 A C B 2 \\
150-090-32 C D C \\
150-090-32 C D D\end{array}$ & $\begin{array}{l}474707102125701 \\
474616102130501 \\
474616102130502 \\
474543102134801 \\
474542102133601\end{array}$ \\
\hline $\begin{array}{l}150-089-06 \mathrm{ADA} \\
150-089-06 \mathrm{BBC} \\
150-089-08 \mathrm{DDD} \\
150-089-09 \mathrm{CCC} \\
150-089-12 \mathrm{BBCA}\end{array}$ & $\begin{array}{l}475036102063201 \\
475044102073001 \\
474911102051401 \\
474911102050501 \\
474952102010901\end{array}$ & $\begin{array}{l}150-090-32 D C \\
150-090-33 B D C \\
150-090-33 D C A \\
150-090-36 A A A \\
150-090-36 A D D\end{array}$ & $\begin{array}{l}474546102132201 \\
474608102122901 \\
474549102120001 \\
474628102774901 \\
474608102774901\end{array}$ \\
\hline
\end{tabular}


Supplement 1. Local numbers and site-identification numbers of wells, test holes, and springs--Continued

\begin{tabular}{|c|c|c|c|}
\hline Local number & Site-identiflcation number & Local number & Slte-ldentfication numter \\
\hline $\begin{array}{l}150-091-35 C C A \\
150-092-02 A B A \\
150-092-04 A A D C \\
150-092-08 D D C A \\
150-092-12 B B D A\end{array}$ & $\begin{array}{l}474551102174701 \\
475048102245301 \\
475041102270701 \\
474913102282901 \\
474952102240801\end{array}$ & $\begin{array}{l}151-088-09 \mathrm{AAB} \\
151-088-09 \mathrm{ABB} \\
151-088-11 \mathrm{AAA} \\
151-088-12 \mathrm{ABB} \\
151-088-12 \mathrm{BBA} 1\end{array}$ & $\begin{array}{l}475510101562301 \\
475510101564301 \\
475510101534001 \\
475510101525201 \\
475510101532101\end{array}$ \\
\hline $\begin{array}{l}150-092-12 \mathrm{CAB} \\
150-092-14 \mathrm{ABD} \\
150-092-20 \mathrm{ABAC} \\
150-093-01 \mathrm{DDA} \\
150-093-02 \mathrm{ADC}\end{array}$ & $\begin{array}{l}474930102240301 \\
474900102245201 \\
474809102284401 \\
475008102310201 \\
475028102322801\end{array}$ & $\begin{array}{l}\text { 151-088-12BBA2 } \\
151-088-14 \mathrm{BAD} \\
151-088-18 \mathrm{ADAC} \\
151-088-18 \mathrm{DAD} \\
151-088-23 \mathrm{DDA}\end{array}$ & $\begin{array}{l}475510101532102 \\
475411101541801 \\
475401101591001 \\
475345101584801 \\
475246101534001\end{array}$ \\
\hline $\begin{array}{l}150-093-02 C B B \\
150-093-04 B D \\
150-093-11 B A A \\
150-093-31 A D D \\
150-093-33 C A A\end{array}$ & $\begin{array}{l}475022102332801 \\
475031102353001 \\
474954102322501 \\
474609102372101 \\
474603102352501\end{array}$ & $\begin{array}{l}151-088-24 C C C \\
151-088-24 D A A \\
151-088-25 B B A \\
151-088-25 B B B 1 \\
151-088-25 B B B 2\end{array}$ & $\begin{array}{l}475240101533101 \\
475259101522301 \\
475233101532101 \\
475233101533001 \\
475233101533002\end{array}$ \\
\hline $\begin{array}{l}150-094-15 A B C \\
150-094-16 A C C 1 \\
150-094-16 A C C 2 \\
150-094-19 D D D A \\
150-094-21 A B A\end{array}$ & $\begin{array}{l}474859102414001 \\
474846102425701 \\
474846102425702 \\
474728102450101 \\
474813102424701\end{array}$ & $\begin{array}{l}151-088-25 C C C \\
151-088-25 C C D \\
151-088-27 D D D 1 \\
151-088-27 D D D 2 \\
151-088-28 D A A\end{array}$ & $\begin{array}{l}475146101533101 \\
475147101532101 \\
475147101545701 \\
475147101545702 \\
475207101561401\end{array}$ \\
\hline $\begin{array}{l}150-094-22 \mathrm{CBA} \\
150-094-23 \mathrm{DBAC} \\
150-094-28 \mathrm{ADA} \\
150-094-32 \mathrm{CCB} \\
150-094-33 \mathrm{ACC}\end{array}$ & $\begin{array}{l}474747102420901 \\
474743102401801 \\
474708102422801 \\
474551102445201 \\
474610102425701\end{array}$ & $\begin{array}{l}151-088-29 A A A \\
151-088-29 A D A \\
151-088-29 B B B \\
151-088-31 B B C \\
151-088-33 B B A\end{array}$ & $\begin{array}{l}475236101573101 \\
475220101573101 \\
475233101583801 \\
475134101595501 \\
475141101571201\end{array}$ \\
\hline $\begin{array}{l}150-094-33 \mathrm{CB} \\
150-094-35 \mathrm{ACB} \\
150-095-05 \mathrm{BBA} 1 \\
150-095-05 \mathrm{BBA} 2 \\
150-095-08 \mathrm{BDBD}\end{array}$ & $\begin{array}{l}474600102433001 \\
474617102402401 \\
475048102522501 \\
475049102522102 \\
474942102520901\end{array}$ & $\begin{array}{l}151-088-34 \mathrm{AAA} \\
151-089-01 \mathrm{DAA} \\
151-089-04 \mathrm{ABA} \\
151-089-04 \mathrm{ABD} \\
151-089-04 \mathrm{BBA}\end{array}$ & $\begin{array}{l}475141101545701 \\
475536102000501 \\
475602102041601 \\
475555102041601 \\
475602102045501\end{array}$ \\
\hline $\begin{array}{l}150-095-09 \mathrm{BAAB} \\
150-095-09 \mathrm{DBDC} \\
150-095-10 \mathrm{DCBD} \\
150-095-13 \mathrm{CBCD} \\
150-095-13 \mathrm{DCC}\end{array}$ & $\begin{array}{l}474959102504801 \\
474920102502701 \\
474927102491401 \\
474831102472201 \\
474820102464601\end{array}$ & $\begin{array}{l}\text { 151-089-05DCC1 } \\
151-089-05 D C C 2 \\
151-089-07 \mathrm{BDB} \\
151-089-07 \mathrm{DCD} \\
151-089-10 \mathrm{CDC1}\end{array}$ & $\begin{array}{l}475516102054301 \\
475516102054302 \\
475457102072001 \\
475424102065101 \\
475424102032801\end{array}$ \\
\hline $\begin{array}{l}150-095-14 \mathrm{DCB} \\
150-095-16 \mathrm{CC} \\
150-095-17 \mathrm{CACA} \\
150-095-18 \mathrm{DCD} \\
150-095-21 \mathrm{CCAC}\end{array}$ & $\begin{array}{l}474826102480301 \\
474823102510901 \\
474832102520701 \\
474820102525901 \\
474730102511001\end{array}$ & $\begin{array}{l}151-089-10 \mathrm{CDC} 2 \\
151-089-11 \mathrm{CCC} \\
151-089-12 \mathrm{ADD} \\
151-089-13 \mathrm{DAA} \\
151-089-14 \mathrm{DDC}\end{array}$ & $\begin{array}{l}475424102032802 \\
475424102023001 \\
475450102000501 \\
475352102000501 \\
475332102013701\end{array}$ \\
\hline $\begin{array}{l}150-095-22 A A C \\
150-095-29 C A C \\
150-095-32 A A C D \\
151-087-03 A D D \\
151-087-08 B B\end{array}$ & $\begin{array}{l}474804102485701 \\
474649102521201 \\
474621102513101 \\
475546101471301 \\
475514101504601\end{array}$ & $\begin{array}{l}151-089-18 B B A \\
151-089-19 \mathrm{CCC} \\
151-089-24 \mathrm{BBA} \\
151-089-25 \mathrm{BBCA} \\
151-089-25 \mathrm{DAA}\end{array}$ & $\begin{array}{l}475418102072901 \\
475240102073901 \\
475326102010301 \\
475230102010901 \\
475208102000501\end{array}$ \\
\hline $\begin{array}{l}151-087-15 B A A \\
151-087-15 C D D \\
151-087-15 D C C \\
151-087-17 D D C \\
151-087-20 A A C\end{array}$ & $\begin{array}{l}475421101475201 \\
475336101475201 \\
475336101474201 \\
475336101495801 \\
475323101495801\end{array}$ & $\begin{array}{l}\text { 151-089-30BBB1 } \\
151-089-30 \mathrm{BBB} 2 \\
151-089-30 \mathrm{DDD} \\
151-089-31 \mathrm{DCA} \\
151-089-33 \mathrm{DDC}\end{array}$ & $\begin{array}{l}475234102073901 \\
475234102073902 \\
475148102063101 \\
475103102065101 \\
475056102040601\end{array}$ \\
\hline $\begin{array}{l}151-087-33 \mathrm{DAA} \\
151-088-01 \mathrm{ABA} 1 \\
151-088-01 \mathrm{ABA} 2 \\
151-088-08 \mathrm{AAA} \\
151-088-08 \mathrm{DAA}\end{array}$ & $\begin{array}{l}475119101483101 \\
475602101524301 \\
475600101524602 \\
475510101573101 \\
475443101573101\end{array}$ & $\begin{array}{l}151-089-34 \mathrm{ABBD} \\
151-089-34 \mathrm{ADD} \\
151-089-34 \mathrm{DAA} \\
151-089-36 \mathrm{DDD} \\
151-090-03 \mathrm{ABB}\end{array}$ & $\begin{array}{l}475138102030401 \\
475122102023901 \\
475116102023901 \\
475056102000501 \\
475602102105201\end{array}$ \\
\hline
\end{tabular}


Supplement 1. Local numbers and site-identification numbers of wells, test holes, and springs--Continued

\begin{tabular}{|c|c|c|c|}
\hline Local number & Site-identification number & Local number & Site-identification number \\
\hline $\begin{array}{l}151-090-03 \mathrm{BAA} \\
151-090-03 \mathrm{CCC} \\
151-090-05 \mathrm{BBB} \\
151-090-05 \mathrm{CBB} \\
151-090-06 \mathrm{DAD}\end{array}$ & $\begin{array}{l}475602102110201 \\
475513102113401 \\
475602102140501 \\
475536102140501 \\
475529102141101\end{array}$ & $\begin{array}{l}\text { 151-092-31AAA } \\
151-092-31 \mathrm{BDD} \\
151-092-33 \mathrm{CDC} \\
151-092-34 \mathrm{DAA} \\
151-093-02 A D C A\end{array}$ & $\begin{array}{l}475141102294001 \\
475121102301801 \\
475055102275401 \\
475115102254901 \\
475542102321701\end{array}$ \\
\hline $\begin{array}{l}151-090-08 \mathrm{DAD} 1 \\
151-090-08 \mathrm{DAD} 2 \\
151-090-09 \mathrm{BBB} \\
151-090-11 \mathrm{AAB} \\
151-090-13 \mathrm{BA}\end{array}$ & $\begin{array}{l}475437102125701 \\
475437102125702 \\
475511102125201 \\
475510102091301 \\
475418102082801\end{array}$ & $\begin{array}{l}151-093-03 D A D \\
151-093-03 D B D \\
151-093-09 A C B \\
151-093-09 D B A \\
151-093-10 A A A B\end{array}$ & $\begin{array}{l}475527102333201 \\
475527102335101 \\
475455102351801 \\
475442102350901 \\
475510102333201\end{array}$ \\
\hline $\begin{array}{l}151-090-14 A B D D \\
151-090-14 A C A 1 \\
151-090-14 A C A 2 \\
151-090-16 \mathrm{BAB} \\
151-090-19 \mathrm{BAA}\end{array}$ & $\begin{array}{l}475408102092301 \\
475405102092501 \\
475405102092502 \\
475418102122901 \\
475327102145001\end{array}$ & $\begin{array}{l}151-093-10 \mathrm{BAB} \\
151-093-14 \mathrm{DAB} \\
151-093-14 \mathrm{DBAD} \\
151-093-15 \mathrm{CDA} \\
151-093-16 \mathrm{BCD}\end{array}$ & $\begin{array}{l}475505102341801 \\
475350102^{2} 22401 \\
475847102^{2} 22701 \\
475337102341101 \\
47535610 \div 354701\end{array}$ \\
\hline $\begin{array}{l}151-090-20 \mathrm{DAD} 1 \\
151-090-20 \mathrm{DAD} 2 \\
151-090-25 \mathrm{BAA} \\
151-090-25 \mathrm{DDA} \\
151-090-26 \mathrm{DDD}\end{array}$ & $\begin{array}{l}475253102125701 \\
475253102125702 \\
475235102082201 \\
475155102074901 \\
475148102090601\end{array}$ & $\begin{array}{l}151-093-16 \mathrm{BDCC} \\
151-093-21 \mathrm{ADD} \\
151-093-21 \mathrm{BBA} \\
151-093-22 \mathrm{DDD} \\
151-093-23 \mathrm{BCC}\end{array}$ & $\begin{array}{l}47535510 \approx 353601 \\
47530510 \approx 344801 \\
47532410 \approx 354701 \\
47523810 \approx 333201 \\
47530410 \simeq 332201\end{array}$ \\
\hline $\begin{array}{l}151-090-29 B B C \\
151-090-30 A A \\
151-090-31 A A A \\
151-090-32 B A C \\
151-090-32 D D A\end{array}$ & $\begin{array}{l}475227102140801 \\
475230102141901 \\
475140102141401 \\
475135102134601 \\
475103102125701\end{array}$ & $\begin{array}{l}151-093-24 D C C \\
151-093-27 \mathrm{BBB} \\
151-093-28 D C D \\
151-093-28 D D D 1 \\
151-093-28 D D D 2\end{array}$ & $\begin{array}{l}47523810 \div 312501 \\
47523210 \simeq 343801 \\
47514610 \approx 350901 \\
47514610 \div 344901 \\
47514510 \div 344802\end{array}$ \\
\hline $\begin{array}{l}151-090-33 \mathrm{DBD} \\
151-090-35 \mathrm{BAA} \\
151-090-36 \mathrm{ADD} \\
151-090-36 \mathrm{BAD} \\
151-090-36 \mathrm{DDA}\end{array}$ & $\begin{array}{l}475114102120101 \\
475142102094501 \\
475124102075201 \\
475135102082701 \\
475103102074901\end{array}$ & $\begin{array}{l}151-093-29 \mathrm{ADD} \\
151-093-33 \mathrm{CBB} \\
151-093-34 \mathrm{AAC} \\
151-093-34 \mathrm{ABDA} \\
151-093-35 \mathrm{BBB} 1\end{array}$ & $\begin{array}{l}47521210 \approx 360701 \\
475114102355701 \\
475120102340101 \\
475135102334501 \\
47514010-332201\end{array}$ \\
\hline $\begin{array}{l}151-091-01 \mathrm{BAA} \\
151-091-01 \mathrm{BBC} \\
151-091-02 \mathrm{BDC} 1 \\
151-091-02 \mathrm{BDC} 2 \\
151-091-02 \mathrm{CDC}\end{array}$ & $\begin{array}{l}475603102160601 \\
475555102163901 \\
475542102173701 \\
475542102173702 \\
475515102173901\end{array}$ & $\begin{array}{l}151-093-35 \mathrm{BBB} 2 \\
151-094-06 \mathrm{AAB} 1 \\
151-094-06 \mathrm{AAB} 2 \\
151-094-09 \mathrm{ADD} \\
151-094-10 \mathrm{AD}\end{array}$ & $\begin{array}{l}47514010=332202 \\
475601102451301 \\
475601102451302 \\
47544910 \approx 423001 \\
475452102411801\end{array}$ \\
\hline $\begin{array}{l}151-091-11 \mathrm{BAA} 1 \\
151-091-11 \mathrm{BAA} 2 \\
151-091-11 \mathrm{BBB} 1 \\
151-091-11 \mathrm{BBB} 2 \\
151-091-11 \mathrm{BBC}\end{array}$ & $\begin{array}{l}475510102172301 \\
475510102172302 \\
475510102175701 \\
475506102175701 \\
475504102175601\end{array}$ & $\begin{array}{l}151-094-10 \mathrm{BB} \\
151-094-10 \mathrm{CA} \\
151-094-17 \mathrm{CC} \\
151-094-19 \mathrm{ABDB} \\
151-094-28 \mathrm{DAA}\end{array}$ & $\begin{array}{l}475505102421501 \\
475439102415601 \\
475334102444901 \\
475320102452301 \\
475207102423001\end{array}$ \\
\hline $\begin{array}{l}151-091-11 C D D \\
151-091-12 B B A 1 \\
151-091-12 B B A 2 \\
151-091-26 C A A \\
151-092-03 C C C\end{array}$ & $\begin{array}{l}475421102172201 \\
475510102162501 \\
475510102162502 \\
475209102172801 \\
475514102265601\end{array}$ & $\begin{array}{l}\text { 151-094-29CC } \\
151-094-33 \mathrm{BCA} \\
\text { 151-095-04DBD1 } \\
\text { 151-095-04DBD2 } \\
151-095-04 \mathrm{DCCA}\end{array}$ & $\begin{array}{l}475149102444901 \\
475128102432701 \\
475529102502701 \\
475529102502702 \\
475517102503001\end{array}$ \\
\hline $\begin{array}{l}151-092-04 \mathrm{BAB} \\
151-092-06 \mathrm{AAD} \\
151-092-08 \mathrm{BBB} \\
151-092-15 \mathrm{ADD} \\
151-092-15 \mathrm{BBB}\end{array}$ & $\begin{array}{l}475600102275401 \\
475553102294001 \\
475508102293001 \\
475357102254901 \\
475416102265601\end{array}$ & $\begin{array}{l}\text { 151-095-05BDAC } \\
151-095-06 \mathrm{DDAC} \\
151-095-08 \mathrm{CACA} \\
151-095-09 \mathrm{CD} \\
151-095-16 \mathrm{BDBD}\end{array}$ & $\begin{array}{l}475545102520401 \\
475518102524501 \\
475438102521101 \\
475427102505101 \\
475359102504901\end{array}$ \\
\hline $\begin{array}{l}151-092-22 D D D \\
151-092-23 C C A \\
151-092-28 A B A B \\
151-092-30 A B C \\
151-092-30 A D D\end{array}$ & $\begin{array}{l}475239102254901 \\
475245102253001 \\
475233102272901 \\
475226102300901 \\
475213102293901\end{array}$ & $\begin{array}{l}151-095-20 \mathrm{BDDB} \\
151-095-21 \mathrm{DBBD} \\
151-095-24 \mathrm{ACD} \\
151-095-29 \mathrm{ABB} \\
151-095-29 \mathrm{BCB}\end{array}$ & $\begin{array}{l}475305102520601 \\
475256102503101 \\
475305102463901 \\
475233102515301 \\
475220102523101\end{array}$ \\
\hline
\end{tabular}


Supplement 1. Local numbers and site-identification numbers of wells, test holes, and springs--Continued

\begin{tabular}{|c|c|c|c|}
\hline Local number & Site-Identification number & Local number & Site-Identification number \\
\hline $\begin{array}{l}151-095-30 \mathrm{ABD} \\
151-095-30 \mathrm{ACA} \\
151-095-30 \mathrm{BBA} \\
151-095-30 \mathrm{CDAC} \\
151-095-36 \mathrm{ABA}\end{array}$ & $\begin{array}{l}475226102530001 \\
475220102530001 \\
475231102533601 \\
475151102532401 \\
475140102463901\end{array}$ & $\begin{array}{l}152-089-04 \mathrm{ABA} \\
152-089-05 \mathrm{BAC} \\
152-089-05 \mathrm{BACB} \\
152-089-06 \mathrm{AAD} \\
152-089-06 \mathrm{DAD}\end{array}$ & $\begin{array}{l}480119102041501 \\
480110102060401 \\
480115102060601 \\
480112102063001 \\
480045102063001\end{array}$ \\
\hline $\begin{array}{l}151-095-36 A C B \\
151-095-36 \mathrm{BBA} \\
151-096-36 \mathrm{AAA} \\
152-086-06 \mathrm{DBDA} \\
152-087-15 \mathrm{BCD}\end{array}$ & $\begin{array}{l}475127102464801 \\
475140102471701 \\
475141102535701 \\
480045101434501 \\
475915101481101\end{array}$ & $\begin{array}{l}152-089-08 C C C 1 \\
152-089-08 C C C 2 \\
152-089-13 C D C \\
152-089-15 C B B \\
152-089-19 A D C\end{array}$ & $\begin{array}{l}475939102062001 \\
475939102062002 \\
475846102005201 \\
475906102034601 \\
475819102063901\end{array}$ \\
\hline $\begin{array}{l}152-087-16 A A A \\
152-087-17 C C C \\
152-087-18 A D D \\
152-087-18 D D D \\
152-087-19 A D D\end{array}$ & $\begin{array}{l}475934101483101 \\
475849101505601 \\
475915101510501 \\
475847101510401 \\
475823101510501\end{array}$ & $\begin{array}{l}152-089-19 B C C \\
152-089-19 B C C C \\
152-089-22 B B C 1 \\
152-089-22 B B C 2 \\
152-089-23 C C C\end{array}$ & $\begin{array}{l}475807102074001 \\
475815102073801 \\
475833102034601 \\
475833102034602 \\
475753102022901\end{array}$ \\
\hline $\begin{array}{l}152-087-19 B C \\
152-087-22 B C B \\
152-087-22 D C D \\
152-087-27 B B C \\
152-087-27 B C B\end{array}$ & $\begin{array}{l}475825101595101 \\
475829101482101 \\
475757101473301 \\
475744101482101 \\
475729101482301\end{array}$ & $\begin{array}{l}152-089-23 \mathrm{CDB} 1 \\
152-089-23 \mathrm{CDB} 2 \\
152-089-23 \mathrm{CDB} 3 \\
152-089-25 \mathrm{DAA} \\
152-089-27 \mathrm{ABB}\end{array}$ & $\begin{array}{l}475759102020901 \\
475759102020902 \\
475759102020903 \\
475719102000401 \\
475622102040001\end{array}$ \\
\hline $\begin{array}{l}152-087-27 \mathrm{CBB} \\
152-087-28 \mathrm{DAA} \\
152-087-29 \mathrm{BAA} \\
152-087-34 \mathrm{CCC} \\
152-088-02 \mathrm{ADCl}\end{array}$ & $\begin{array}{l}475724101482101 \\
475729101483401 \\
475750101502701 \\
475612101482101 \\
480059101534901\end{array}$ & $\begin{array}{l}152-089-27 C B D \\
152-089-28 D C D \\
152-089-29 C C C 1 \\
152-089-29 C C C 2 \\
152-089-29 C C C 3\end{array}$ & $\begin{array}{l}475713102033601 \\
475700102041401 \\
475659102062001 \\
475659102062002 \\
475700102062503\end{array}$ \\
\hline $\begin{array}{l}152-088-02 \mathrm{ADC} 2 \\
152-088-03 \mathrm{DDCB} \\
152-088-04 \mathrm{BBAB} \\
152-088-04 \mathrm{BBB} \\
152-088-04 \mathrm{BBBD} 1\end{array}$ & $\begin{array}{l}480059101534902 \\
480031101550601 \\
480120101571301 \\
480117101572201 \\
480120101571901\end{array}$ & $\begin{array}{l}152-089-29 \mathrm{CCC} 4 \\
152-089-29 \mathrm{CCC} \\
152-089-29 D A D \\
152-089-30 A C A \\
152-089-30 \mathrm{BCC}\end{array}$ & $\begin{array}{l}475700102062604 \\
475701102062105 \\
475713102051201 \\
475733102064901 \\
475726102073701\end{array}$ \\
\hline $\begin{array}{l}152-088-04 \mathrm{BBBD} 2 \\
152-088-04 \mathrm{BDA} \\
152-088-05 \mathrm{DAD} 1 \\
152-088-05 \mathrm{DAD} 2 \\
152-088-06 \mathrm{AAC} 1\end{array}$ & $\begin{array}{l}480120101571902 \\
480121101571701 \\
480046101573001 \\
480043101572802 \\
480112101585701\end{array}$ & $\begin{array}{l}152-089-30 \mathrm{CBC} \\
152-089-30 \mathrm{DBA} \\
152-089-30 \mathrm{DDB} \\
152-089-30 D D D \\
152-089-31 \mathrm{AAA}\end{array}$ & $\begin{array}{l}475713102073701 \\
475719102064901 \\
475706102063901 \\
475659102063001 \\
475653102063001\end{array}$ \\
\hline $\begin{array}{l}152-088-06 A A C 2 \\
152-088-10 D D D \\
152-088-11 \mathrm{BBB} \\
152-088-13 \mathrm{DCD} \\
152-088-21 \mathrm{ACCA}\end{array}$ & $\begin{array}{l}480112101585702 \\
475940101545601 \\
480026101544701 \\
475847101524201 \\
475821101564201\end{array}$ & $\begin{array}{l}152-089-31 \mathrm{ABA} \\
152-089-31 \mathrm{BAB} 1 \\
152-089-31 \mathrm{BAB} 2 \\
152-089-31 \mathrm{BBB} \\
152-089-34 \mathrm{ABB}\end{array}$ & $\begin{array}{l}475653102064901 \\
475653102071801 \\
475653102071802 \\
475653102073701 \\
475655102031001\end{array}$ \\
\hline $\begin{array}{l}152-088-22 A A A \\
152-088-23 A D A 1 \\
152-088-23 A D A 2 \\
152-088-23 A D A 3 \\
152-088-24 A B A\end{array}$ & $\begin{array}{l}475840101545601 \\
475827101534001 \\
475827101534002 \\
475827101534003 \\
475840101524201\end{array}$ & $\begin{array}{l}152-089-34 \mathrm{BBA} \\
152-089-35 \mathrm{DDC} \\
152-089-35 \mathrm{DDD} \\
152-089-01 \mathrm{CDD} \\
152-090-02 \mathrm{CDD}\end{array}$ & $\begin{array}{l}475653102033601 \\
475606102013101 \\
475606102012101 \\
480032102082501 \\
480032102094301\end{array}$ \\
\hline $\begin{array}{l}152-088-28 B B B 1 \\
152-088-28 B B B 2 \\
152-088-32 B A A \\
152-088-33 B C A A \\
152-088-34 B B B\end{array}$ & $\begin{array}{l}475747101572101 \\
475744101572301 \\
475655101580901 \\
475642101571001 \\
475654101560701\end{array}$ & $\begin{array}{l}152-090-02 \mathrm{CDDA} \\
152-090-03 \mathrm{ABA} \\
152-090-08 \mathrm{ACD} \\
152-090-09 \mathrm{BCC} \\
152-090-11 \mathrm{DDD} 1\end{array}$ & $\begin{array}{l}480031102094001 \\
480119102104001 \\
480006102131501 \\
480006102124601 \\
475938102090501\end{array}$ \\
\hline $\begin{array}{l}152-088-35 \mathrm{AAA} 1 \\
152-088-35 \mathrm{AAA} 2 \\
152-089-01 \mathrm{BBB} \\
152-089-02 \mathrm{BBB} 1 \\
152-089-02 \mathrm{BBB} 2\end{array}$ & $\begin{array}{l}475655101534001 \\
475655101534002 \\
480119102011101 \\
480119102022901 \\
480119102022902\end{array}$ & $\begin{array}{l}152-090-11 D D D 2 \\
152-090-11 D D D 3 \\
152-090-12 A B B \\
152-090-13 B B C \\
152-090-13 C C C 1\end{array}$ & $\begin{array}{l}474538102090502 \\
475938102090901 \\
480026102081601 \\
475926102085401 \\
475846102085401\end{array}$ \\
\hline
\end{tabular}


Supplement 1. Local numbers and site-identification numbers of wells, test holes, and springs--Continued

\begin{tabular}{|c|c|c|c|}
\hline Local number & Site-identification number & Local number & Sito-identlifcation number \\
\hline $\begin{array}{l}152-090-13 C C C 2 \\
152-090-13 D A A 1 \\
152-090-13 D A A 2 \\
152-090-14 C D C \\
152-090-14 D D D\end{array}$ & $\begin{array}{l}475846102085402 \\
475906102074701 \\
475903102074702 \\
475846102095201 \\
475846102090401\end{array}$ & $\begin{array}{l}152-090-36 \mathrm{ABB} 2 \\
152-090-36 \mathrm{ABB} 3 \\
152-090-36 \mathrm{ABC} \\
152-090-36 \mathrm{ADD} \\
152-090-36 \mathrm{DDD}\end{array}$ & $\begin{array}{l}475655102081602 \\
475654102081703 \\
475647102081601 \\
475634102074701 \\
475607102074701\end{array}$ \\
\hline $\begin{array}{l}152-090-15 B A A \\
152-090-15 B A D \\
152-090-17 C D C \\
152-090-17 \mathrm{CDD} \\
152-090-17 \mathrm{DDD}\end{array}$ & $\begin{array}{l}475933102110001 \\
475925102110101 \\
475843102135101 \\
475846102133401 \\
475846102125501\end{array}$ & $\begin{array}{l}152-091-04 \mathrm{BBB} 1 \\
152-091-04 \mathrm{BBB} 2 \\
152-091-05 \mathrm{ADD} \\
152-091-05 \mathrm{DBB} 1 \\
152-091-05 \mathrm{DBB} 2\end{array}$ & $\begin{array}{l}480119102202901 \\
480119102202902 \\
480059102203901 \\
480052102210801 \\
480052102210802\end{array}$ \\
\hline $\begin{array}{l}152-090-18 C C C \\
152-090-18 D D D \\
152-090-19 D D D \\
152-090-20 A D C \\
152-090-20 A D D\end{array}$ & $\begin{array}{l}475846102152001 \\
475846102141301 \\
475753102141301 \\
475820102130501 \\
475820102125501\end{array}$ & $\begin{array}{l}152-091-05 D B B 3 \\
152-091-08 D D D \\
152-091-09 C D C \\
152-091-09 D D D 1 \\
152-091-09 D D D 2\end{array}$ & $\begin{array}{l}480049102210503 \\
475939102203901 \\
475939102201001 \\
475940102192201 \\
475939102192102\end{array}$ \\
\hline $\begin{array}{l}152-090-20 \mathrm{CDD} \\
152-090-21 \mathrm{CBC} \\
152-090-22 \mathrm{DAD} \\
152-090-23 \mathrm{AAD} \\
152-090-24 \mathrm{BCCA}\end{array}$ & $\begin{array}{l}475753102133401 \\
475807102124601 \\
475807102102101 \\
475833102090401 \\
475822102085201\end{array}$ & $\begin{array}{l}152-091-10 B B B \\
152-091-13 C C D \\
152-091-15 B C C \\
152-091-15 B C C C \\
152-091-15 D D A\end{array}$ & $\begin{array}{l}480026102191201 \\
475846102162801 \\
475912102191201 \\
475909102191401 \\
475852102180401\end{array}$ \\
\hline $\begin{array}{l}152-090-24 \mathrm{CDD} \\
152-090-24 \mathrm{DDD} \\
152-090-25 \mathrm{ABD} \\
152-090-25 \mathrm{CBB} \\
152-090-25 \mathrm{CCC}\end{array}$ & $\begin{array}{l}475753102082501 \\
475753102074701 \\
475740102080601 \\
475717102085901 \\
475700102085401\end{array}$ & $\begin{array}{l}152-091-17 A D C \\
152-091-18 B D C \\
152-091-18 C D A \\
152-091-19 D C C \\
152-091-21 D D D\end{array}$ & $\begin{array}{l}475912102204901 \\
475912102224501 \\
475850102223601 \\
475753102222501 \\
475753102192201\end{array}$ \\
\hline $\begin{array}{l}152-090-25 D B C 1 \\
152-090-25 D B C 2 \\
152-090-25 D D C 1 \\
152-090-25 D D C 2 \\
152-090-26 C D D\end{array}$ & $\begin{array}{l}475714102081601 \\
475714102081602 \\
475700102075601 \\
475700102075602 \\
475700102094301\end{array}$ & $\begin{array}{l}152-091-24 C D D \\
152-091-24 D C C \\
152-091-25 B B D \\
152-091-25 D B B \\
152-091-26 A D D 1\end{array}$ & $\begin{array}{l}475753102160801 \\
475753102155901 \\
475739102162801 \\
475719102151901 \\
475726102164701\end{array}$ \\
\hline $\begin{array}{l}152-090-26 \mathrm{DAA} \\
152-090-26 \mathrm{DAD} \\
152-090-26 \mathrm{DDA} \\
152-090-26 \mathrm{DDC} \\
152-090-27 \mathrm{ABB} 1\end{array}$ & $\begin{array}{l}475720102090401 \\
475711102090501 \\
475707102090401 \\
475700102091401 \\
475747102105001\end{array}$ & $\begin{array}{l}152-091-26 A D D 2 \\
152-091-29 A A A \\
152-091-29 \mathrm{CCC} \\
152-091-32 \mathrm{ABB} \\
152-091-32 \mathrm{BBA}\end{array}$ & $\begin{array}{l}475726102164702 \\
475746102203901 \\
475659102214701 \\
475653102211301 \\
475655102214401\end{array}$ \\
\hline $\begin{array}{l}152-090-27 \mathrm{ABB} 2 \\
152-090-27 \mathrm{ABB} 3 \\
152-090-27 \mathrm{CAA} \\
152-090-27 \mathrm{DDD} \\
152-090-29 \mathrm{ADD}\end{array}$ & $\begin{array}{l}475747102105002 \\
475746102105003 \\
475720102110001 \\
475700102102101 \\
475727102125601\end{array}$ & $\begin{array}{l}152-091-33 A B D \\
152-092-01 D C C \\
152-092-02 A C C \\
152-092-02 B C C \\
152-092-02 D D\end{array}$ & $\begin{array}{l}475646102194101 \\
480033102234401 \\
480100102250101 \\
480100102254001 \\
480036102243701\end{array}$ \\
\hline $\begin{array}{l}152-090-29 B C C \\
152-090-29 D C D \\
152-090-30 B B \\
152-090-31 D C B \\
152-090-33 A A D\end{array}$ & $\begin{array}{l}475727102140301 \\
475700102131501 \\
475741102151701 \\
475614102144201 \\
475647102113801\end{array}$ & $\begin{array}{l}152-092-07 \mathrm{AAA} \\
152-092-07 \mathrm{AABB} \\
152-092-11 \mathrm{AAA} \\
152-092-11 \mathrm{BDCC} \\
152-092-12 \mathrm{DDD}\end{array}$ & $\begin{array}{l}480024102293701 \\
480024102295401 \\
480026102243201 \\
480005102252201 \\
475933102230901\end{array}$ \\
\hline $\begin{array}{l}152-090-33 \mathrm{BBC} \\
152-090-34 \mathrm{BAA} 1 \\
152-090-34 \mathrm{BAA} 2 \\
152-090-34 \mathrm{BAB} \\
152-090-35 \mathrm{AAD}\end{array}$ & $\begin{array}{l}475647102124601 \\
475654102110001 \\
475654102110002 \\
475654102110901 \\
475647102090401\end{array}$ & $\begin{array}{l}152-092-14 \mathrm{DDD} \\
152-092-15 \mathrm{DCC} \\
152-092-16 \mathrm{CDBD} \\
152-092-16 \mathrm{CDDC} \\
152-092-17 \mathrm{BBB}\end{array}$ & $\begin{array}{l}475846102243201 \\
475846102261801 \\
475847102275301 \\
475841102274501 \\
475933102293101\end{array}$ \\
\hline $\begin{array}{l}152-090-35 \mathrm{BAC} \\
152-090-35 \mathrm{BBD} \\
152-090-36 \mathrm{AAA} \\
152-090-36 \mathrm{ABA} \\
152-090-36 \mathrm{ABB} 1\end{array}$ & $\begin{array}{l}475647102095201 \\
475647102100201 \\
475654102074701 \\
475654102080601 \\
475654102081601\end{array}$ & $\begin{array}{l}152-092-17 \mathrm{BDCB} \\
152-092-17 \mathrm{DDDA} \\
152-092-18 \mathrm{AADD} \\
152-092-18 \mathrm{ABBB} \\
152-092-18 \mathrm{DABB}\end{array}$ & $\begin{array}{l}475911102291301 \\
475846102281901 \\
475921102293701 \\
475931102301101 \\
475903102295101\end{array}$ \\
\hline
\end{tabular}


Suppiement 1. Local numbers and site-identification numbers of wells, test holes, and springs--Continued

\begin{tabular}{|c|c|c|c|}
\hline Local number & Sito-Identlification number & Local number & Site-Identiflcatlon number \\
\hline $\begin{array}{l}\text { 152-092-19AAA1 } \\
\text { 152-092-19AAA2 } \\
152-092-19 A A A 3 \\
152-092-19 A A A 4 \\
152-092-19 A A B\end{array}$ & $\begin{array}{l}475840102294101 \\
475840102294102 \\
475840102294103 \\
475839102293604 \\
475840102295001\end{array}$ & $\begin{array}{l}152-094-20 D D A \\
152-094-21 B C C \\
152-094-21 C A D \\
152-094-21 D A A \\
152-094-21 D B C\end{array}$ & $\begin{array}{l}475800102434701 \\
475820102433701 \\
475807102430801 \\
475813102423001 \\
475807102425901\end{array}$ \\
\hline $\begin{array}{l}152-092-19 \mathrm{ABB} \\
152-092-19 \mathrm{ABBD} \\
152-092-20 \mathrm{ADD} \\
152-092-20 \mathrm{BBA} \\
152-092-20 \mathrm{BBB} 1\end{array}$ & $\begin{array}{l}475840102301001 \\
475833102300601 \\
475820102282301 \\
475840102292101 \\
475840102293101\end{array}$ & $\begin{array}{l}152-094-21 D C \\
152-094-21 D D B \\
152-094-24 B B B \\
152-094-25 C C C \\
152-094-25 D A A\end{array}$ & $\begin{array}{l}475757102425401 \\
475800102423901 \\
475840102394601 \\
475700102394601 \\
475720102383901\end{array}$ \\
\hline $\begin{array}{l}\text { 152-092-20BBB2 } \\
152-092-21 \mathrm{ADAA} \\
152-092-22 \mathrm{ADCD} \\
152-092-28 \mathrm{DDD} \\
152-092-29 \mathrm{AAA}\end{array}$ & $\begin{array}{l}475840102293102 \\
475826102270301 \\
475816102255201 \\
475700102270601 \\
475746102282301\end{array}$ & $\begin{array}{l}152-094-27 \mathrm{AAB} \\
152-094-27 \mathrm{BBB} \\
152-094-27 \mathrm{DDD} \\
152-094-28 \mathrm{ABA} \\
152-094-28 \mathrm{BAB}\end{array}$ & $\begin{array}{l}475747102412201 \\
475747102422001 \\
475700102411301 \\
475747102424901 \\
475747102431801\end{array}$ \\
\hline $\begin{array}{l}152-092-29 D D D \\
152-092-30 A A B \\
152-092-31 C C C \\
152-092-31 D A A \\
152-093-01 C C D A\end{array}$ & $\begin{array}{l}475700102282301 \\
475746102295001 \\
475606102304801 \\
475626102294101 \\
480031102315301\end{array}$ & $\begin{array}{l}152-094-28 B B C \\
152-094-29 A A B \\
152-094-29 A C C \\
152-094-29 C C C \\
152-094-29 D C A\end{array}$ & $\begin{array}{l}475740102433701 \\
475747102435601 \\
475740102435601 \\
475700102445401 \\
475707102440601\end{array}$ \\
\hline $\begin{array}{l}152-093-01 C C D C \\
152-093-01 D A A \\
152-093-12 D D D \\
152-093-13 C A C A \\
152-093-13 C D B D\end{array}$ & $\begin{array}{l}480029102315701 \\
480050102305901 \\
475940102305801 \\
475858102314001 \\
475851102314301\end{array}$ & $\begin{array}{l}152-094-30 A C D \\
152-094-30 A D D \\
152-094-30 C C D \\
152-094-31 A C A \\
152-094-31 B C D\end{array}$ & $\begin{array}{l}475727102452301 \\
475727102450401 \\
475700102460201 \\
475640102452301 \\
475633102460201\end{array}$ \\
\hline $\begin{array}{l}152-093-16 \mathrm{BB} \\
152-093-18 \mathrm{DCB} \\
152-093-20 \mathrm{BAA} \\
152-093-20 \mathrm{BAC} \\
152-093-23 \mathrm{BDDC}\end{array}$ & $\begin{array}{l}475928102354801 \\
475854102375101 \\
475840102364301 \\
475834102365301 \\
475816102325101\end{array}$ & $\begin{array}{l}152-094-31 \mathrm{DBD} \\
152-094-32 \mathrm{BBB} \\
152-094-32 \mathrm{CCB} \\
152-094-32 \mathrm{DBC} \\
152-094-33 \mathrm{AD}\end{array}$ & $\begin{array}{l}475620102452301 \\
475653102445401 \\
475613102445401 \\
475620102441601 \\
475635102423101\end{array}$ \\
\hline $\begin{array}{l}\text { 152-093-24AADA } \\
152-093-25 D C D \\
152-093-25 D D B \\
152-093-26 \mathrm{BCC} \\
152-093-34 \mathrm{DAA} 1\end{array}$ & $\begin{array}{l}475835102305401 \\
475700102311701 \\
475706102310701 \\
475727102331501 \\
475626102333101\end{array}$ & $\begin{array}{l}152-094-33 \mathrm{BBB} \\
152-094-33 \mathrm{CAB} \\
152-094-33 \mathrm{DBA} \\
152-094-34 \mathrm{ADC} \\
152-094-34 \mathrm{BCAA}\end{array}$ & $\begin{array}{l}475653102433701 \\
475626102431801 \\
475626102424901 \\
475633102412201 \\
475641102420701\end{array}$ \\
\hline $\begin{array}{l}152-093-34 \mathrm{DAA} 2 \\
152-093-35 \mathrm{CCD} \\
152-093-35 \mathrm{DDD} \\
152-094-01 \mathrm{CCB} \\
152-094-06 \mathrm{DC}\end{array}$ & $\begin{array}{l}475625102332902 \\
475606102331201 \\
475606102321501 \\
480040102394501 \\
480037102452801\end{array}$ & $\begin{array}{l}152-094-32 \mathrm{CAA} \\
152-094-35 \mathrm{DCA} \\
152-095-02 \mathrm{BD} \\
152-095-02 \mathrm{BDCD} \\
152-095-06 \mathrm{BAC}\end{array}$ & $\begin{array}{l}475626102415101 \\
475613102401501 \\
480104102481901 \\
480056102481301 \\
480115102532701\end{array}$ \\
\hline $\begin{array}{l}152-094-07 \mathrm{BB} \\
152-094-10 \mathrm{ABC} \\
152-094-10 \mathrm{ABD} \\
152-094-11 \mathrm{DAC} \\
152-094-16 \mathrm{CCA}\end{array}$ & $\begin{array}{l}480024102460601 \\
480020102414201 \\
480020102413201 \\
475954102400501 \\
475854102432801\end{array}$ & $\begin{array}{l}152-095-07 \mathrm{CB} \\
152-095-08 \mathrm{CB} \\
152-095-16 \mathrm{ADD} \\
152-095-19 \mathrm{DD} 1 \\
152-095-19 \mathrm{DD} 2\end{array}$ & $\begin{array}{l}475958102534201 \\
475958102522601 \\
475914102500801 \\
475758102524501 \\
475758102524502\end{array}$ \\
\hline $\begin{array}{l}152-094-19 A C C \\
152-094-19 C \mathrm{CBA} \\
152-094-19 \mathrm{CBBC} \\
152-094-19 \mathrm{CCAB} 1 \\
152-094-19 \mathrm{CCAB} 2\end{array}$ & $\begin{array}{l}475820102453301 \\
475815102455901 \\
475812102461401 \\
475802102460401 \\
475802102460402\end{array}$ & $\begin{array}{l}152-095-20 \mathrm{BDAC} \\
152-095-32 \mathrm{CBC} \\
152-096-12 \mathrm{AD} \\
153-088-36 \mathrm{ADAC} \\
153-092-25 \mathrm{AB}\end{array}$ & $\begin{array}{l}475820102520401 \\
475621102523001 \\
480012102540101 \\
480156101552701 \\
480301102264901\end{array}$ \\
\hline $\begin{array}{l}152-094-19 C C C C \\
152-094-19 C C D D 1 \\
152-094-19 C C D D 2 \\
152-094-19 D B C \\
152-094-20 A C C\end{array}$ & $\begin{array}{l}475752102461401 \\
475752102455901 \\
475752102455902 \\
475807102453301 \\
475820102441601\end{array}$ & $\begin{array}{l}\text { 153-094-18DCDA } \\
153-094-19 C D D \\
153-094-23 C C C 1 \\
153-094-23 C C C 2 \\
153-094-23 C C C 3\end{array}$ & $\begin{array}{l}480408102484601 \\
480311102490701 \\
480311102442501 \\
480311102442502 \\
480311102442503\end{array}$ \\
\hline
\end{tabular}


Suppiement 1. Local numbers and site-identification numbers of wells, test holes, and springs--Contined

\begin{tabular}{cc||cc}
\hline Local number & Slto-ldentification number & Local number & Sito-identificatior number \\
\hline 153-094-29DDAC & 480224102471401 & $153-094-32 \mathrm{CDBD}$ & 480132102475301 \\
$153-094-30 \mathrm{DD}$ & 480222102483301 & $153-094-33 \mathrm{CBAC}$ & 480145102465501 \\
$153-094-32 \mathrm{BDCA}$ & 480144102473601 & & \\
\hline
\end{tabular}

